Yann Basset

Malik Tahar-Chaouch

Martín Aguilar Sánchez

(coordinadores)

\title{
Procesos democráticos en contextos de violencia: México y Colombia
}






\section{PROCESOS DEMOCRÁTICOS EN CONTEXTOS DE VIOLENCIA: MÉXICO Y COLOMBIA}





\title{
PROCESOS DEMOCRÁTICOS EN CONTEXTOS DE VIOLENCIA: MÉXICO Y COLOMBIA
}

\author{
Coordinadores
}

YANN BASSET, MALIK TAHAR-CHAOUCH

Y MARTÍN AGUILAR SÁNCHEZ
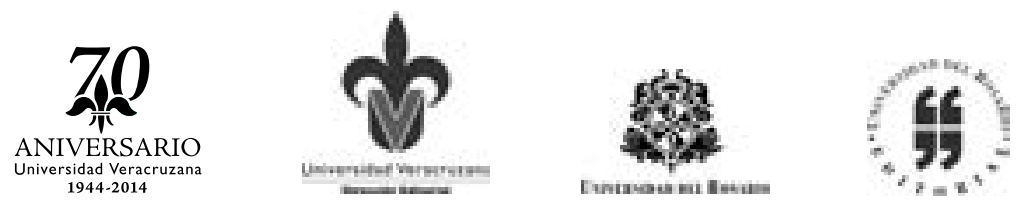
Maquetación de forros: Enriqueta del Rosario López Andrade, con collage digital de Miguel Gerardo Ramírez / Kilka Diseño Gráfico

Procesos democráticos en contextos de violencia: México y Colombia / coordinadores Yann Basset, Malik Tahar-Chaouch y Martín Aguilar Sánchez. - Bogotá: Editorial Universidad del Rosario, Facultades de Ciencia Política y Gobierno, y de Relaciones Internacionales; Universidad de Veracruz, dirección editorial, 2015.

434 páginas. - (Colección Biblioteca)

Incluye referencias bibliográficas

ISBN: 978-958-738-557-1

Democracia - México / Democracia - Colombia / Violencia - México / Violencia Colombia / Indígenas de Colombia - Actividad política / América Latina - Historia política / I. Título / II. Serie.

$320.9720861 \quad$ SCDD 20

Catalogación en la fuente - Universidad del Rosario. Biblioteca

La publicación de este libro se financió con recursos del PIFI 2013.

Primera edición: Bogotá, D.C., abril de 2015

D.R. (C) Universidad Veracruzana

Dirección Editorial

Hidalgo núm. 9, Centro, CP 91000

Xalapa, Veracruz, México

Apartado postal 97

diredit@uv.mx

Tel./fax (01228) 8185980; 8181388

D.R. (c) 2015 Universidad del Rosario, Facultades de Ciencia Política y Gobierno, y de Relaciones Internacionales

D.R. (c) 2015 Editorial Universidad del Rosario

Carrera 7 núm. 12B-41, oficina 501

Bogotá, Colombia

Tel. 2970200, ext. 7721

editorial.urosario.edu.co

ISBN: 978-958-738-557-1

Impreso en Colombia

Printed in Colombia 


\title{
INTRODUCCIÓN
}

\author{
YANN BASSET Y MALIK TAHAR-ChaOUCH
}

LA OLA DE ESPERANZAS que acompañó la transición democrática en la mayoría de los países de América Latina, durante los años ochenta, se transformó a la postre en unos discursos más escépticos, cuando no francamente pesimistas. Los mismos autores que se inscribieron en este enfoque terminaron en no pocos casos revisando sus postulados. ${ }^{1} \mathrm{Se}$ había asumido en forma demasiado rápida que los regímenes políticos de la región tenían que evolucionar necesariamente hacia formas parecidas a las democracias liberales de Estados Unidos y Europa sin tomar en cuenta las particularidades de las sociedades locales. Estas expectativas, cargadas por lo demás de elementos normativos, estaban sin duda condenadas a generar decepción.

Además de buscar superar cierto sesgo culturalista y evolucionista presente en los análisis de la transición, la reorientación posterior permitió explorar con mayor cuidado la complejidad de la idea de democracia. Lejos de presentarse como un modelo institucional acabado, la democracia como régimen tiene una larga historia de tensiones internas entre principios esenciales que solo se articulan entre sí mediante compromisos cambiantes, frágiles y siempre susceptibles de negociación y revisión. Esto se vislumbra en los ejemplos supuestamente más acabados de democracia, como lo ha mostrado Pierre Rosanvallon en el caso

1 El caso más ilustrativo es probablemente el de Guillermo O’Donnell, que pasó del estudio de la transición democrática al de la "democracia delegativa" o la "inefectividad de la ley". El libro Contrapuntos (1998) hace un recorrido comentado de su obra a través de una compilación de artículos de varias épocas que da muy bien cuenta de la evolución de su pensamiento, por lo menos hasta la fecha de publicación. 
francés a través de su historia conceptual de lo político, ${ }^{2}$ ¿cómo no se iba a vislumbrar en sociedades tan complejas como las latinoamericanas, sobre un período histórico a veces mucho más limitado? La toma de consciencia de esta complejidad ha llevado hoy día a poner sobre la agenda el tema de las variedades de las democracias, ${ }^{3}$ lo que permite dar cuenta de múltiples formas que se desarrollan en América Latina.

Colombia y México habían sido considerados países aparte en la perspectiva de la transición. Ellos no habían conocido dictaduras militares análogas a las de sus vecinos y, en general, se mantuvo la continuidad en la organización de elecciones periódicas a lo largo de la segunda mitad del siglo xx. Sin embargo, ambos regímenes limitaban considerablemente el alcance del pluralismo político, a través del acuerdo consociacional del Frente Nacional, en el caso colombiano, y de la hegemonía del Partido de la Revolución Institucional, en el caso mexicano.

Esas singularidades tuvieron implicaciones distintas en cada país y en el desarrollo de la investigación referente a ellos. Si bien el régimen colombiano no respondía a los cánones de una democracia-modelo y presentaba rasgos autoritarios, tampoco podía ser definido tan fácilmente como una dictadura, ni siquiera como un caso típico de autoritarismo. Por lo tanto, Colombia fue olvidada como caso de estudio de la transición. Algunos problemas ligados con esos procesos de transición fueron abordados, como en particular el tema de la reforma del Estado y/o constitucional, así como los retos del pluralismo político y de la competitividad electoral, pero no se consideró nunca a Colombia como un caso relevante de transición a la democracia. En cambio, si bien el régimen mexicano presentaba características distintas a otros regímenes autoritarios de la región, no dejaba de ser definido precisamente

2 Rosanvallon, Pierre. (2006). Por una historia conceptual de lo político. México: Fondo de Cultura Económica.

3 Coppedge, Michael, Gerring, John y Lindberg, Staffan. (2012). "Variedades de democracia: un enfoque histórico, multidimensional y desagregado". Revista Española de Ciencia Política 30. 
como un régimen autoritario, un régimen de "partido hegemónico" en el cual las elecciones eran meras simulaciones. Por ello, la pluralización partidista, la instauración de regulaciones electorales "negociadas" entre elites políticas y luego el cambio político del año 2000 (el fin del gobierno PRI nacional) fueron analizados desde el enfoque de la transición. Este último dominó tan ampliamente que impidió, o restringió, otros tipos posibles de análisis y perspectivas acerca de la realidad política del país. ${ }^{4}$

Finalmente, con los desencantos de la llamada "post-transición", se generó una crítica a la interpretación ortodoxa del cambio político (como iniciador de un proceso de consolidación democrática), en la cual no se negaba la realidad del proceso mexicano de transición, sino que se subrayaba su carácter sui generis e inacabado, debido precisamente a las características del régimen autoritario que la había precedido y a la forma como determinó el proceso de transición, reduciéndolo así sus pactos a la dimensión electoral (el paso de la simulación a la competitividad electoral) en detrimento de una refundación del régimen (y de sus rezagos autoritarios). ${ }^{5}$ Hoy, ese cuestionamiento empieza incluso a rebasar el enfoque de la transición hasta generar autocríticas entre sus más destacados ponentes. ${ }^{6}$

Es por esta razón que consideramos que los varios giros hacia miradas más complejas sobre el tema de la democracia en América Latina constituyen una buena ocasión para volver a estudiar estos dos países atípicos, más allá de la barrera que el enfoque artificial de la tran-

4 En el caso de México, varios trabajos adoptaron el enfoque de la transición y consolidación. No obstante, el gradual desmonte del autoritarismo priísta tiene muchos rasgos sui generis si lo comparamos con la salida de las dictaduras militares de América del Sur o la caída de los regímenes "sultánicos" de América Central. Véase: Becerra, Salazar y Woldenberg. (2000). La mecánica del cambio político en México. México: Cal y Arena; Cansino, C. (2000). La transición mexicana, 1977-2002. Centro de Estudios de Política Comparada: México: Fondo de Cultura Económica.

5 Merino, M. (2003). La transición votada: crítica a la interpretación del cambio político en México. México: Fondo de Cultura Económica.

6 Cansino, C. (2008). La muerte de la ciencia política. Buenos Aires: Sudamericana. 
sición había puesto entre los analistas respectivos de sus dinámicas políticas. Como lo acabamos de mencionar, en ambos casos hubo una larga y compleja evolución hacia la aceptación de un mayor pluralismo político. Estos macroprocesos son muy conocidos y recibieron mucha atención por parte de la academia. No obstante, las diversas miradas a la democracia que se han desarrollado entre tanto nos invitan a ir más allá. Por ello en este libro nos fijamos el objetivo de operar un triple desplazamiento de la mirada sobre la democracia.

El primer desplazamiento es espacial. Quisimos tomar distancia de los conocidos fenómenos nacionales para enfocarnos en la esfera regional y local. Si se ha debatido mucho de lo que significó la democratización en el primer ámbito, nuestros conocimientos están todavía muy limitados en cuanto al segundo. Varios análisis mostraron que un proceso de democratización a nivel nacional puede perfectamente convivir con la persistencia de diversos tipos de autoritarismos a nivel regional o local. ${ }^{7}$ De este modo, dirigimos la mirada hacia el ámbito local para averiguar qué significó la democratización en unos espacios que por distintas razones se mantuvieron alejados de las dinámicas políticas nacionales. En el caso mexicano, la mayor parte de los estudios compilados acá se centran sobre el estado de Veracruz, que no conoció la alternancia que se manifestó en el ámbito nacional, y que sigue siendo aparentemente un bastión inexpugnable del PRI. En el caso colombiano, los factores que tienden a preservar espacios de autoritarismos subnacionales no tienen que ver con la persistencia de unas estructuras político-partidarias hegemónicas, sino más bien con la violencia política cruzada de las guerrillas y de las milicias paramilitares, que limitan las posibilidades de expresión de la ciudadanía. Los casos de estudios que se desarrollan en este libro se caracterizan todos por ubicarse en espacios particularmente afectados por la violencia, y que, por otra parte,

7 Véase al respecto: Gibson, Edward. (2006). Autoritarismo sub-nacional: estrategias territoriales de control político en regímenes democráticos. Revista Desafíos 14. Bogotá: Universidad del Rosario. 
sufren de graves carencias en materia de desarrollo, infraestructura y cubrimiento por parte de las instituciones estatales.

En segundo lugar, buscamos comprender dichos procesos de democratización desplazando la mirada desde la esfera institucional hacia la esfera social. Esto significa observar el comportamiento de distintos actores sociales. La distancia existente entre la ley y la realidad, el país legal y el país real, es un tópico en América Latina y hacia ahí apuntaron varias críticas a los estudios clásicos de la democratización. La democratización en la esfera política no afecta en forma directa y automática las prácticas sociales. Por esta razón, centramos la mirada sobre las acciones colectivas emprendidas por actores que, anclados en un ámbito local, aspiran a formular y a hacer valer demandas o reivindicaciones específicas. Se trata de prestar atención a prácticas ${ }^{8}$ que, a priori, no entran en lo que se entiende convencionalmente como política. No obstante, nos interesa observar cómo las acciones colectivas de los actores analizados logran (o no) traducirse en demandas que puedan expresarse bajo la forma de demandas democráticas. Por otra parte, nos interesa igualmente observar las elites políticas locales ${ }^{9}$ que intervienen sobre los terrenos en los cuales se realizan dichas acciones colectivas. Idealmente, se supondría que los “procesos de democratización” al nivel local nacen del encuentro entre las demandas expresadas por los actores

8 Incluimos como "prácticas" de la acción colectiva los discursos que producen los actores involucrados. Estos discursos son, por su naturaleza, uno de los elementos que estudiamos con particular atención.

9 Para nuestro análisis, abarcamos en el término "elites políticas" a los actores que ocupan cualquier puesto electivo, o que están involucrados directamente en la competencia por los mismos. Nos interesan particularmente los puestos electivos locales que corresponden a las circunscripciones en las cuales se desarrollan los procesos objetos de nuestro análisis, como los ediles, concejales y alcaldes, y sus relaciones con elites políticas de mayor trascendencia como los diputados y gobernadores de departamentos, o los representantes y senadores nacionales. Incluimos los dirigentes de los partidos políticos al nivel local, que suelen ser los mismos elegidos o candidatos. De esta manera, las elites políticas se distinguen de las elites militantes que se destacan en el seno de los procesos de acción colectiva; no obstante, como lo veremos en muchos casos, esto no excluye que éstas últimas lleguen a incursionar en lo político. 
sociales y las elites políticas que las transmiten sobre la agenda política. No obstante, en la realidad, tales interacciones son mucho más complejas y pueden ser fuente de insatisfacción tanto por parte de los participantes a la acción colectiva como por las elites políticas implicadas. A veces, por distintas razones, ni siquiera se da el encuentro. Esto no excluye que procesos de democratización aparezcan de otra manera, a través de las mismas dinámicas suscitadas por la acción colectiva, o de iniciativas unilaterales de las elites políticas, e incluso a menudo como resultado no buscado de tensiones entre ambas. De cualquier manera, buscamos estudiar las dinámicas suscitadas por los actores sociales que en dichas regiones intentan formular demandas en la esfera política, y también los obstáculos a los cuales se enfrentan para que la movilización social, bajo formas diversas, pueda desembocar sobre la constitución de reivindicaciones políticas que, como tal, sean susceptibles de articularse con los actores que hacen parte de la arena política formal.

En tercer y último lugar, buscamos estudiar los procesos de democratización de una manera fundamentalmente comprensiva. Esto significa que en lugar de partir de una concepción predeterminada de lo que son o deben ser los procesos de democratización, hemos buscado comprender el significado que los mismos actores estudiados (tanto los participantes de la acción colectiva como las elites políticas) otorgan a la categoría de "democracia", la noción que manejan de "Estado", y el contenido que ellos mismos confieren a la noción de "derechos". Como ya lo hemos señalado, las dinámicas sociales que estudiamos no se expresan siempre espontánea e inicialmente a través de los conceptos de Estado, derechos o democracia. Sin embargo, al confrontarse a la esfera política ellos son implícitamente invitados a expresarse a través de esas categorías. Tal "invitación” deriva de la forma en la cual la política asume idealmente en un régimen democrático. Como es obvio, este proceso de politización de las demandas supone que los actores dominan un lenguaje y unos discursos propios del campo político. En realidad, muchas veces existe un desfase profundo entre las prácticas de 
acciones colectivas de los actores que estudiamos y las formas que se esperaría que adquieran para que sus demandas puedan ser procesadas eficazmente dentro de la esfera política. Nos interesa en particular estudiar estos grados de desfase, observando las dinámicas que permiten superarlo en algunos casos, y los obstáculos que, al contrario, los perpetúan en otros, y si las elites políticas asumen un papel al respecto.

Hechos estos apuntes, y no obstante la perspectiva comprensiva acá reseñada, es preciso explicar nuestra elección de utilizar la categoría de "procesos de democratización”. Para poder llevar a cabo la tarea propuesta no podemos partir de una noción preconcebida de democracia. Esa es probablemente la mayor lección que nos han dado las revisiones del enfoque de la transición democrática. Así que nos apoyamos en una concepción amplia y abierta de la misma. La perspectiva de Claude Lefort nos parece particularmente adecuada para nuestro propósito. ${ }^{10}$ Contrastándola con el totalitarismo moderno y la sociedad monárquica tradicional, Lefort buscó los fundamentos de la democracia más allá de la esfera institucional a la cual la Ciencia Política pretende relegarla. En una democracia, las esferas del poder, del saber y del derecho adquieren una autonomía recíproca irreductible y, por otra parte, cada una de ellas se desenvuelve bajo el signo de una indeterminación esencial. Ninguna de ellas encuentra un principio de legitimación definitivo e incontestable por fuera de ella misma. De este modo, la democracia se vuelve "la sociedad histórica por excelencia". ${ }^{11}$

Lo esencial, a mi modo de ver, es que la democracia se instituye y se mantiene por la disolución de los referentes de certeza. Inaugura una historia en la que los hombres experimentan una indeterminación última respecto al fundamento del poder, de la ley, y del saber, y respecto al funda-

10 Véase: Lefort, Claude. (1990). La invención democrática. Buenos Aires: Nueva Visión. Igualmente, del mismo autor: Lefort, Claude. (1994). La incertidumbre democrática. Barcelona: Anthropos.

11 Lefort, 1994, p. 45. 
mento de la relación del uno con el otro en todos los registros de la vida social...12

Tal concepción implica que la democracia, lejos de institucionalizarse en unas formas y unos contenidos definitivos e incontestables, supone adelantar un debate permanente, a la vez imprescindible y propiamente inacabable, sobre sus propios fundamentos. No existe un criterio definitivo sobre quién detenta el poder y cómo tiene que ejercerse, sobre el contenido de los derechos y la forma en que se implementan, y finalmente, sobre lo que es verdad y lo que es erróneo. De ahí se deduce la importancia de adoptar una perspectiva comprensiva amplia, como la que hemos señalado más arriba. La democracia supone que los mismos actores sociales, individuos o grupos de toda índole, sean los que le dan sentido a lo político a través de unos debates, unas reivindicaciones, unas luchas que les permitan integrar y transformar sus demandas en sus propias concepciones acerca del poder, de la ley y de la verdad. Este proceso de integración y de transformación es lo que estudiamos en este libro, y su importancia radica en el hecho de que es precisamente ahí que la democracia adquiere todo su substrato social y su pleno sentido. Tal perspectiva es la que justifica nuestra utilización de la noción de “procesos de democratización” en el sentido explicado más arriba. De una manera muy general, podemos decir en resumen que apunta en realidad a la construcción de lo político desde lo social.

Para lograr comprender plenamente estos procesos de democratización, el proyecto quiso desplegar y complementar dos líneas de análisis. La primera línea, que denominamos “acción colectiva”, parte del análisis de los actores y de los procesos de movilización social. En este sentido, se trata de identificar y caracterizar, bajo la perspectiva comprensiva arriba mencionada, los repertorios de acción colectiva de los actores sociales, y muy particularmente las prácticas a través de las cuales adquieren formas

12 Ibid., p. 50, subrayado en el texto. 
políticas. Se estudió con especial cuidado los obstáculos que encuentran los procesos de politización de las demandas. Es importante señalar para el caso colombiano que, por su marginalidad, los casos que estudiamos carecen en general de antecedentes, lo que explica la necesidad de proceder al análisis a través de esta perspectiva comprensiva. El caso de México es distinto, aunque existan ciertas rupturas que también justifican la utilización de este enfoque. A finales de la década de los años ochenta se dio un cambio en el modelo clásico de acción colectiva en México. Se transitó del modelo clásico autoritario de partido hegemónico, que caracterizó al PRI de 1940 a 1980, a uno de rasgos sectorizados y democráticos. Las características del nuevo modelo de acción colectiva responden, en primer lugar, a los procesos de liberalización que se dieron en México a partir de la década de los ochenta y, en segundo lugar, al cambio de modelo económico que trajo como consecuencia la llegada del neoliberalismo. El cambio del modelo clásico de acción colectiva en México evidentemente repercutió en la forma y en los fines que perseguían los clásicos movimientos sociales. Al parecer, lo que la evidencia nos muestra es que transitamos de grandes movimientos sociales con ideologías marxistasnacionalistas, a lo que Touraine ha llamado los nuevos movimientos sociales que responden a lógicas regionales, sectoriales y democráticas.

La segunda línea, que denominamos "elites políticas", vuelve a centrarse en la arena política convencional, pero con el objetivo de encontrar en qué medida las prácticas estudiadas en la primera línea se relacionan con ésta. Idealmente, las elites políticas son llamadas a jugar un papel de intermediarios entre las demandas de los actores sociales y las instituciones políticas en los procesos de democratización. Observaremos entonces los procesos de democratización que efectivamente resultan de estas relaciones. Al respecto, los procesos electorales son sin duda unos momentos de importancia fundamental que estudiamos con particular atención. ${ }^{13}$

13 Aunque no son los únicos, nos interesaremos también, por ejemplo, en la coproducción de políticas públicas con la participación de líderes sociales al lado de las elites políticas. 
Sin embargo, esta situación ideal que constituye supuestamente la regla es en realidad la excepción. Estuvimos atentos a la forma en que se realizan estas articulaciones y a los obstáculos que encuentran cuando, por diversos motivos, no se concretan. Son casos que no resultan en procesos de democratización o que se traducen en procesos de democratización que por múltiples factores no pasan por las elites políticas y buscan conectarse a las instituciones del Estado por otros medios (por ejemplo, en el caso de la judicialización de las demandas sociales, o de la producción de planes culturales alternativos a la categoría de desarrollo). Vale la pena precisar que aun cuando nacen procesos de democratización de las articulaciones entre acciones colectivas y elites políticas, pueden realizarse tanto en forma positiva (cuando las elites políticas de todos los niveles buscan de alguna forma dar respuestas a las demandas consideradas), como negativa (cuando las relaciones con las mismas se caracterizan más bien por el conflicto).

Por otra parte, se buscará caracterizar la actitud de estas elites políticas con respecto a los actores e instituciones políticas centrales. En el caso de Colombia, este segundo aspecto adquiere un particular interés en el contexto de la reforma política de 2003, que se da en el marco de una reconfiguración del sistema partidario desde una situación de fragmentación extrema. La manera como las elites políticas locales se articulan a estas dinámicas "desde arriba” de la escena política puede también ser susceptible de crear procesos de democratización. En el caso de México, el análisis se enfoca en particular al estudio de las dinámicas de las redes de poder político en los estados de Veracruz e Hidalgo bajo el impacto del proceso nacional de democratización y en contextos estatales de conservación de la hegemonía del PRI. Se trata de entender los elementos de discontinuidad y continuidad de la conformación de esas elites a través de la pluralización partidista y de la competencia electoral. Se pretende también explicar el porqué de la conservación del poder por el PRI, combinando las variables contextuales con los elementos explicativos más propios del campo político local. 
Cada artículo presente en este libro privilegia una de estas dos líneas pero, de una manera u otra, busca cierto acercamiento para entender los procesos de democratización. Por lo tanto, la apuesta fue ofrecer al lector, combinando las diversas contribuciones al libro, una mirada amplia y compleja sobre los mismos.

Para el caso de Colombia, Mónica Acosta, Ángela Santamaría y Yeshica Serrano estudian el tema de la integración de los pueblos indígenas a la dinámica de la democratización. Las distintas estrategias utilizadas y los varios pueblos estudiados permiten una lectura comparada que nos muestra, en forma ilustrativa, la complejidad y riqueza que adquieren estos procesos de democratización a nivel local. Muestran todo el potencial que tienen para inscribir las demandas en la agenda nacional en el caso arhuaco, hasta para cambiar la vida cotidiana, como lo demuestra el caso de las mujeres kankuamas. No obstante, el caso de los wounaan nos recuerda también las enormes dificultades que hay que sobrellevar en un contexto de violencia.

Karen Cerón, Juan Carlos Guerrero, Pedro Rojas y Luisa Trujillo se enfocan precisamente sobre una de las regiones más afectadas por la violencia, con fenómenos de desplazamientos masivos, de violaciones sistemáticas a los derechos humanos y despojos de tierra a gran escala. Muestran que aun en estas situaciones extremas, diversas formas de resistencia existen y se adaptan con éxitos variados al contexto cambiante. Se realizan a través de un amplio espectro de repertorios, desde el arte hacia acercamientos inventivos hacia la Iglesia o las instituciones municipales, desde el discurso de la neutralidad frente al conflicto hacia las reivindicaciones étnicas.

Armando Durán se interesa igualmente por esta transformación y porosidad de los repertorios de resistencia en otro terreno: la costa pacífica del suroccidente del país. Ahí también las reivindicaciones étnicoculturales han ganado un espacio creciente, acompañando el proceso de reconocimiento de los territorios colectivos para las poblaciones afrocolombianas que se gestionó desde la esfera política. No obstante, lo 
que podría constituir un ejemplo exitoso de proceso de democratización es obstaculizado por la violencia y por el auge de grandes proyectos agroindustriales en la región que llevan a poner en debate el modelo de desarrollo desde el ámbito local y las prácticas de las poblaciones.

Para el caso de México, Martín Aguilar Sánchez analiza las transformaciones y tendencias de la acción colectiva en el contexto de las políticas neoliberales y del proceso de democratización, enfatizando en la problemática de la relación entre movimientos sociales y sistema político, en particular en el estado de Veracruz. Se observa, en este sentido, una fragmentación de dichos movimientos donde surgen nuevas luchas sectoriales, al mismo tiempo que una pugna para abrir el campo de la política institucional a reivindicaciones ubicadas en la perspectiva de una democracia ampliada.

Efraín Quiñonez León se centra en la dimensión local de la relación entre participación ciudadana y elites políticas, basándose principalmente en el caso del municipio de Santiago Tuxtla del estado de Veracruz. Su análisis muestra cómo las pugnas por la autonomía y el rechazo a la imposición electoral han provocado discontinuidades en el control político local a través de la alternancia, sin implicar una ruptura en las prácticas políticas y formas tomadas por ese control político.

Finalmente, Manuel Hernández Pérez analiza cómo dos organizaciones cafetaleras en la región de la Huatusco, Veracruz, la Unión Regional de Pequeños Productores de Café de Huatusco (URPPC) y la Red Nacional de Cafetaleras Sustentables A.C. (Redcafés), se afrentan con la reestructuración económica y el reto de la sustentabilidad. En el contexto del proceso incipiente de democratización esos actores sociales generan nuevas formas de organización e identidades políticas, al mismo tiempo que siguen confrontados con el contexto corporativo y el control político que aún opera en el Estado.

Desde la segunda línea, Yann Basset retoma varios de los terrenos anteriores en Colombia, buscando evidencias de cómo estos distintos procesos de democratización se traducen en la esfera político-electoral 
formal. Las evidencias empíricas que da la participación electoral muestran que los dos ámbitos están lejos de ser separados y que existen casi siempre tentativas de llevar a la arena electoral estos fenómenos (y cuando no, resistencias explícitas a las mismas). No obstante, el éxito de las mismas depende en buena parte de la existencia de una escala apropiada de las circunscripciones electorales. La participación electoral puede contribuir a reforzar estos movimientos cuando se da a una escala apropiada, como puede comportar el riesgo de sus divisiones en el caso contrario.

Para el caso de México, Leopoldo Alafita Méndez abre con una investigación basada en encuestas de valores sobre el estado general de la cultura política en el estado de Veracruz. Al subrayar el pasado corporativo-autoritario del sistema político, se interesa por la posibilidad del desarrollo de una cultura cívica entre los ciudadanos que pueda lograr romper con esas herencias y las prácticas políticas que conllevan. Su análisis muestra que, al mismo tiempo que el sistema político conserva amplios rasgos corporativos-autoritarios, la cultura política de una ciudadanía de por sí heterogénea contiene rasgos contradictorios que apuntan hacia una mayor exigencia de democracia y favorecen la reproducción del sistema político que la conforma, aunque sea en medio de una crisis de confianza en los actores e instituciones políticas.

Finalmente, los trabajos de Daniel Carrasco Brihuega y Malik Tahar-Chaouch se interesan por las dinámicas de las elites políticas en dos estados de la república mexicana donde no hubo alternancia política: Hidalgo y Veracruz. Carrasco enfoca su análisis de las elites políticas locales desde la perspectiva de redes sociales para contestar a una serie de preguntas que describen una dinámica de multiplicación de redes y una mayor intensidad de interacción entre ellas en medio de una mayor competitividad electoral, cuyos efectos políticos esa misma dinámica logra neutralizar relativamente bien. En el mismo sentido, Tahar-Chaouch articula tres niveles de análisis -características del personal político, redes de poder político y campo político- para entender 
cómo las dinámicas de las elites políticas logran adaptarse al contexto de la pluralización política en beneficio de la hegemonía del PRI y, en todo caso, de la reproducción de un sistema político que conserva rasgos autoritarios muy notorios.

En síntesis, a pesar de las discontinuidades introducidas por el mayor pluralismo y la nueva exigencia democrática en los sistemas políticos colombiano y mexicano, así como en las dinámicas y relaciones de los actores sociales y políticos, se observa en ambos casos y en contextos locales las dificultades concretas para generar una nueva realidad política con pactos democráticos y sociales más sólidos. El énfasis mayor de los trabajos colombianos sobre la dimensión de la acción colectiva es sintomático de un proceso más antiguo de crisis de la esfera formal de la política y de violencia, paradójicamente en un sistema político cuyo carácter democrático, si bien limitado, había sido menos cuestionado que en México. En México, la pregnancia de las herencias corporativas y la mayor consolidación histórica del Estado pueden explicar la atención mayor para los procesos formales de la política nacional y local. Los “avances" de la democratización, lejos de desembocar en una consolidación de las instituciones y del propio Estado, parecen implicar un escepticismo cada vez mayor con respeto a ellos. Esto puede ser considerado como un efecto positivo de la democratización, en particular de la autonomización de los actores sociales y de la ciudadanía. Es también ya el síntoma de un desencanto democrático donde el binomio "liberalización/corporativismo", lejos de generar la autonomía soñada, desata una fragmentación social y una crisis institucional cuya mejor ilustración es la violencia creciente en el país. 
PRIMERA PARTE:

ACCIÓN COLECTIVA 



\title{
ENTRE MOCHILAS, CESTERÍA Y POPOROS: EXPERIENCIAS CRUZADAS ENTRE LAS ELITES, LA ACCIÓN COLECTIVA INDÍGENA Y LOS PROCESOS DE DEMOCRATIZACIÓN
}

\author{
Mónica Acosta García ${ }^{*}$, Norey Maku Quigua ${ }^{*}$, \\ Ángela Santamaría ${ }^{* * *}$ Y Yeshica Serrano ${ }^{* * * *}$
}

\section{INTRODUCCIÓN}

EL CONCEPTO DE “DEMOCRACIA” ha sido deconstruido y reconstruido en el contexto latinoamericano, a partir del estudio de prácticas políticas y culturales que implican a sujetos muy diversos que históricamente no fueron considerados como ciudadanos (como los pueblos indígenas, los afroamericanos y las mujeres), y para quienes existían históricamente fuertes "derechos de entrada" al campo político (Bourdieu, 1984). Retomando los términos de Lefort, la "democracia" supone que los mismos actores sociales, individuos o grupos, sean los que le dan sentido a "lo político" a través de debates, reivindicaciones y luchas que

Joven investigadora del Centro de Estudios Políticos e Internacionales (CEPI) de las Facultades de Ciencia Política y Gobierno, y de Relaciones Internacionales. Abogada e internacionalista de la Universidad del Rosario. Doctorante del programa de Derecho de la misma universidad.

** Miembro del pueblo indígena arhuaco. Asistente de investigación del Centro de Estudios Políticos e Internacionales (CEPI) de las Facultades de Ciencia Política y Gobierno, y de Relaciones Internacionales. Becario del programa de Ciencia Política de la Universidad del Rosario.

*** Investigadora del CEPI, Facultad de Ciencia Política y Gobierno, y de Relaciones Internacionales; investigadora del Observatorio en Redes y Acción Colectiva (ORAC); Doctora en Sociología de la École des Hautes Études en Sciences Sociales de París.

**** Antropóloga de la Universidad Externado de Colombia. Actualmente cursa una maestría en Estudios Políticos e Internacionales y está vinculada a la misma universidad como Joven Investigadora del CEPI en la línea de investigación de Movimiento Sociales y Acción Colectiva. Doctorante del programa de Derecho de la Universidad del Rosario. 
les permitan integrar y transformar sus demandas en sus concepciones propias acerca del poder, de la ley y de la verdad. Aquí es importante detenernos en la categoría de "democracia" y, retomando algunas ideas de Norberto Bobbio, Nicola Matteucci y Gianfranco Pasquino, recordar cómo la teorización de este concepto ha estado atravesada por la teoría clásica aristotélica, la teoría medieval romana de la "soberanía popular" y la teoría que emerge con el Estado moderno. Es importante resaltar también la relación entre democracia y socialismo, la cual además del derecho al voto, introduce la necesidad de la profundización del proceso de democratización a través de la crítica de la democracia representativa y la reflexión sobre la democracia directa, la participación popular, el control del poder popular "desde abajo" y la expansión de la toma de decisiones políticas, económicas; la autogestión; el autogobierno y los órganos de control desde la sociedad civil.

Este artículo presenta tres estudios de caso sobre acción colectiva indígena en tres escenarios y culturas diversas en Colombia. Nuestro objetivo en este trabajo consiste en mostrar algunas equivalencias y diferencias entre los tres procesos. No buscamos, de ninguna manera, presentar un universo irreductible de prácticas de acción colectiva indígena y de prácticas de democratización. Presentamos una articulación de tipo "provisional”, es decir que pretendemos que sea posible una permanente "deconstrucción” para evitar la dimensión normativa y excluyente de las "definiciones" de la "democracia” para los pueblos indígenas. Por ello nos centraremos aquí en el análisis de diversas prácticas jurídicas, políticas y culturales observadas y analizadas en los tres contextos como expresión de procesos de profundización de concepciones indígenas de la "democracia”.

1 Autores de la red modernidad/colonialidad como A. Quijano han hablado de modernidades alternativas. Igualmente, en otros confines del sur, en la India, desde el análisis de estas modernidades alternativas, autores como Upendra Baxi y Rajagopal han conceptualizado la producción de una política y de un derecho internacional “desde abajo". Desde allí buscamos presentar estas experiencias. 
La investigación de los tres casos de prácticas de acción colectiva, sus procesos de democratización y su relación con las elites políticas indígenas giró en torno a la siguiente pregunta: ¿cuáles son las prácticas de acción colectiva emergentes en los casos estudiados, los procesos de democratización que se derivan de ellas, y el papel que juegan las elites políticas en ellos?

\section{ITINERARIO DE LA INVESTIGACIÓN Y PLAN DEL ARTÍCULO}

Este capítulo se sitúa en el cruce de diferentes disciplinas y problemáticas, y nos ha exigido como autores el desplazamiento del universo político (nacional y local) al jurídico y del jurídico al cultural. La complejidad del objeto implicó también optar por una aproximación multidisciplinaria, buscando articular elementos de la acción colectiva, la antropología y la Ciencia Política. De esta manera, damos elementos sobre dinámicas individuales y colectivas de manera comparada a través de la reconstrucción de tres casos: el kankuamo, el arhuaco y el wounaan, dando cuenta de las semejanzas y de las diferencias que pueden existir entre estos. De hecho, los casos que hemos abordado dan cuenta de realidades políticas y sociales muy distintas entre sí, siendo este un ejercicio mucho más complejo en el diálogo que hemos elaborado con cada uno de los casos.

La lectura de los trabajos de P. Bourdieu nos ofreció herramientas teóricas y metodológicas pertinentes para analizar las distintas problemáticas introducidas anteriormente. La noción de campo es para nosotros muy fecunda. Se trata de "un espacio relativamente autónomo", "un microcosmos dotado de sus propias leyes" (Bourdieu, 1997, 14). Esta noción, esencialmente la de campo simbólico (derecho, político, del conocimiento, del Estado, étnico) es fundamental para nuestro análisis pues nos permite situarnos en el cruce de diferentes disciplinas y objetos de estudio. El concepto de campo(s) y las interacciones entre sus diversas expresiones permite no reducir "la causa indígena" a lo mera- 
mente cultural, o a lo jurídico o político. De la mano del capital étnico que exploraremos en este artículo, en nuestras realidades sociales ha emergido una suerte de campo étnico que debe ser caracterizado en trabajos posteriores y a través de un trabajo colaborativo.

Como ya lo afirmamos, aportaremos desde este estudio elementos para la caracterización de un campo étnico, a partir del trabajo que ya hemos realizado desde el estudio del subcampo de los derechos indígenas reconocidos en 1991 (Dezalay, Garth, 2002; Santamaría, 2007, p. 16). Actualmente, a nivel latinoamericano y con las experiencias de Bolivia y Ecuador, ya existen las bases estructurales para hablar de un campo étnico.

\section{HEREJES Y PROFESIONALES DE LA POLÍTICA: IDENTIDADES Y CLASIFICACIÓN SOCIAL FUNDADA EN LA RAZA²}

La categoría de espacio social es utilizada por Bourdieu para designar una construcción multidimensional en donde se oponen diversas clases según la estructura y volumen de capital (económico, político, jurídico, militante, social o étnico) (Bourdieu, 1979). El espacio social objeto de nuestro estudio, el campo político, es terriblemente complejo y posee intrínsecamente múltiples subcampos como el subcampo del militantismo. Este se encuentra compuesto por agentes políticos que poseen una posición dominada en el campo político. Igualmente, como lo mostramos en otros trabajos, nos interesa analizar la relación entre el militantismo indígena y el subcampo de los derechos indígenas. Para Poupeau, hablar de capital militante es insistir en la dimensión del compromiso. El capital político da cuenta de manera insuficiente de

2 Como lo afirma A. Quijano, la idea de raza no tiene antecedentes antes de América. Lo anterior implicó la producción de nuevas identidades sociales subalternizadas como: indios, negros, mestizos. Igualmente, a estas razas fueron asociadas posiciones, recursos y capitales a través del patrón de dominación colonial impuesto (Quijano, 2000, p. 202). 
este tipo de compromiso pues, "en efecto, el capital militante designa, más allá del tipo de compromiso político, los saberes adquiridos en particular gracias a las propiedades sociales que permiten jugar con más o menos éxito, en un espacio que está lejos de ser homogéneo" (Poupeau, 2004 , p. 11). Más allá de la manera en la que los agentes sociales adquieren y luego usan este tipo de capital, queda por comprender la lógica de transferencias a través de las cuales el capital militante (por lo menos una parte de este) puede ser utilizado en otros espacios, y la forma como ciertas propiedades eficientes en otros dominios pueden ser transferidas en estas instancias. En otro de sus textos Poupeau caracteriza el capital militante y los agentes que lo detentan, como aquellos que obtienen legitimidad del lazo con "el terreno", por la posesión de un saberhacer organizacional, en la toma de la palabra en las asambleas, la capacidad de organizar reuniones, concentraciones (Poupeau, 2007, p. 49).

Es importante resaltar que el militantismo indígena está atravesado por una división social del trabajo contestatario, que ha generado a su interior una jerarquía de objetos y causas sociales. Al interior de este existe para nosotros una lucha por la acumulación del capital etnojurídico.

Después de haber trabajado sobre varios casos de movilización indígena en Colombia y en la región, hemos propuesto la noción de capital étnico como una subespecie del capital militante. Por ejemplo, cuando se trata de analizar las características necesarias para que un líder o lideresa indígena sea elegido como representante de su pueblo, el capital escolar no juega siempre un papel fundamental, como podremos observarlo en el análisis de los casos (Santamaría, 2007).

La conceptualización del capital étnico no ha sido muy desarrollada por los sociólogos bourdosianos distintos a Poupeau, por ello proponemos en este artículo algunos elementos de caracterización de este capital. Para detentar el capital étnico se requiere pertenecer a un grupo étnico. Esta pertenencia está relacionada con elementos subjetivos como: la autoidentificación del agente (la conciencia individual de la identidad 
indígena, introducida por el Convenio 169 de 1989 de la OIT) y la voluntad de preservar su cultura. Igualmente, convergen elementos objetivos como: poseer como grupo elementos culturales que los distinguen de la colectividad nacional, descendencia histórica, determinación de preservar de acuerdo con sus prácticas tradicionales y por un derecho propio. Igualmente, se consideran indígenas por el hecho de ser originarios y descender de culturas ancestrales con instituciones sociales, económicas, políticas y culturales propias. Estos grupos son además reconocidos por la sociedad y sus instituciones y poseen una relación especial con la tierra (OIT, 1989). Sin embargo, hay que aclarar que la cuestión de la pertenencia étnica es muy compleja. Después de la Constitución de 1991, algunos grupos han iniciado procesos de reetnización para resignificar su identidad a partir de procesos de reconstrucción identitaria (es el caso, por ejemplo, de los pueblos kankuamo o muisca, entre otros).

Es importante resaltar que entre los 102 pueblos reconocidos por la Organización Indígena de Colombia (ONIC) existen diferencias muy marcadas y jerarquías culturales, económicas, políticas y sociales establecidas desde el proceso de colonización y potenciadas justamente por la entrada en los procesos electorales, y la profesionalización o no de sus dirigentes. Dichas diferencias han permeado en casi todos los casos sus cosmovisiones (salvo tal vez en el caso de los pueblos no contactados), y han producido discursos híbridos, producidos y reconstruidos con autoridades y expertos que han reforzado y reproducido las diferencias y especificidades de cada pueblo. Para comprender la sociogénesis de este tipo de capital es necesario plantear algunas reflexiones preliminares sobre las características del campo en el que emerge (jurídico y político) y que ha genera actualmente un campo étnico con la experiencia boliviana y ecuatoriana. ${ }^{3}$

3 Este concepto está en construcción. Sin embargo, la hipótesis que hemos venido manejando en trabajos anteriores es que es a partir de un capital específico como el étnico que los líderes indígenas y sus movimientos abrieron espacios de autonomía en ciertos países e instancias, que han establecido las bases para un campo étnico 


\section{CAPITALES POLÍTICOS Y JURÍDICOS DUALES: LA BASE PARA LA EMERGENCIA DE UN CAPITAL ÉTNICO (POSITIVO)}

Estamos convencidos que el apoyo y los privilegios reconocidos a los indígenas no son suficientes para hacerlos salir de su situación miserable. Es necesario sacarlos de su condición de brutalidad, de inactividad y de pereza. Esta situación es la fuente de todos los vicios. Por esta razón, estamos convencidos que todas las castas indígenas deben ser abolidas. Los indios deben tener la misma condición jurídica que los zambos y mulatos. Para aumentar nuestra producción agrícola debemos iniciar un proceso de hispanización de los indígenas. Hay que acabar con su indolencia y estupidez. Podemos repetir la misma experiencia que con los animales, el cruce de razas. Los indígenas pueden desaparecer a través de la mezcla con los blancos, a través de matrimonios mixtos entre blancos y mujeres indígenas”. Pedro Vargas, corregidor de Zipaquirá, 1781 (Stafford, 1991, p. 7)

En el marco de la Constituyente, y ya desde los años 1980, el capital étnico (positivo) se vuelve muy importante en el campo político de acuerdo con el marco de los derechos especiales reconocidos a los pueblos indígenas por el Convenio 169 de 1989 de la Organización Internacional del Trabajo (огт). Este Convenio se erige como el primer instrumento jurídico internacional que reconoce a los pueblos indígenas como sujetos del derecho a la libre determinación (art. 2); es decir que pueden hablar por sí mismos y que tienen el derecho de determinar libremente su condición política y de perseguir libremente su desarrollo económico, social y cultural. Así, el Convenio reconoce la defensa de la identidad cultural y el derecho a la propia cultura, el derecho a la tierra y al territorio, el derecho a la participación y el deber de los gobiernos a

que debe ser caracterizado en el marco justamente del tema del Dossier sobre los cambios constitucionales en las últimas décadas. Por esta razón en este trabajo nos centraremos en el capital étnico. 
la consulta previa (arts. 6, 7), el derecho a la salud y educación propias y al derecho propio (arts. 9, 10, 11, 12), entre otros. Respecto al tema de nuestro análisis, dicho convenio promueve la construcción de un proceso democrático en países multiétnicos, pluriculturales y plurilingües. Igualmente, este instrumento consagra obligaciones para los Estados ratificantes frente a la garantía de los derechos de los pueblos indígenas.

En este contexto, para que el agente indígena sea considerado como líder o lideresa, debe tener un reconocimiento al interior de su pueblo o comunidad. Debe haber desarrollado trabajo comunitario y por lo general debe ser hablante de su lengua nativa o tener equivalentes estructurales que representen simbólicamente lo anterior en términos de pertenencia cultural. Igualmente, por lo general es originario de una familia o clan que le ha permitido heredar capital social y militante. Un punto importante también es el relacionamiento que este agente debe tener con las autoridades políticas tradicionales de su pueblo y con las autoridades espirituales. Igualmente, debe poseer capitales sociales y políticos que le permitan tejer alianzas estratégicas con representantes de otros sectores sociales.

Adicional a lo anterior, consideramos importante describir brevemente las diversas problemáticas sociales (violencia, pobreza, etc.) transversales a los tres casos y que en muchas ocasiones alejan a los actores sociales de las dinámicas políticas centrales e inciden en los procesos de democratización y prácticas de acción colectiva locales (la Sierra Nevada de Santa Marta y el departamento del Chocó).

\section{DINÁMICA DEL CONFLICTO ARMADO Y PROBLEMÁTICAS SOCIALES EN TERRITORIOS INDÍGENAS}

En el año 2004, con relación al análisis sobre la situación de derechos humanos de los pueblos indígenas de Colombia, el relator especial de la ONU Rodolfo Stavenhagen concluyó que "la situación de los derechos humanos de los indígenas de Colombia es grave, crítica y profunda- 
mente preocupante" (ONU-ECOSOC, 2004, p. 5). Stavenhagen constató que, como consecuencia del conflicto interno, los grupos armados ilegales y la explotación de recursos naturales, los pueblos indígenas han sido sometidos a graves violaciones de derechos humanos y han tenido que soportar "las devastadoras consecuencias del conflicto", como asesinatos, torturas, desplazamientos masivos, desapariciones forzadas, reclutamiento, entre muchas otras. En este punto, destacó la "amenaza a la supervivencia física y cultural" de algunas comunidades indígenas especialmente vulnerables. ${ }^{4}$

Además de reportar la difícil situación de los pueblos indígenas, en especial de las mujeres y los niños, como resultado del conflicto armado, la violencia y el narcotráfico, evidenció los “efectos negativos" del impacto ambiental y cultural generado por actividades económicas como la extracción de petróleo, la explotación forestal, las operaciones mineras y la construcción de megaproyectos hidroeléctricos sobre las condiciones de vida de las comunidades indígenas ${ }^{5}$ (ONU-ECOsoc, 2004, p. 15). Según el informe del alto comisionado de las Naciones Unidas para los Derechos Humanos sobre la Situación de los Derechos Humanos y del Derecho Internacional Humanitario (OACNUDH) en Colombia, desde ese mismo año aumentan los enfrentamientos en varios de los territorios de los grupos étnicos, al igual que los bombardeos, los homicidios selectivos de líderes y lideresas, reclutamientos forzosos, confinamientos y bloqueos de alimentos. Las comunidades más afectadas por el conflicto han sido "las de la Sierra Nevada de Santa Marta (SNSM), las del Eje Cafetero, las del Chocó, y las de zonas donde se desarrolla el Plan

4 Para esa época por lo menos 12 pueblos en la Amazonía se encontraban en peligro de exterminio: awá, kofán, siona, páez, coreguaje, carijona, guayabero, muinanebora, pastos, embera y witoto (onIC, "Palabra dulce, aire de vida", 2010).

5 De acuerdo con el informe de la OACNUDH, "en zonas de interés económico, en ocasiones no se tiene en cuenta la presencia de comunidades afrocolombianas o pueblos indígenas, o no se titula su territorio ancestral como colectivo o resguardo, para evitar el deber de consulta. En otras ocasiones, las consultas son realizadas con quienes no representan legítimamente a la comunidad afectada, o no se respetan los procesos internos de los pueblos y comunidades de toma de decisiones" (2010, p. 14). 
Patriota" (OACNUdH, 2004, p. 64). Esta situación llevó a que muchas de las comunidades fueran protegidas por medidas cautelares (pueblos embera chamí, embera katío, pijao, paez del Alto Naya, lideresas wayuu, wiwa y wounaan) o provisionales (pueblo kankuamo) por la Comisión y la Corte Interamericana de Derechos Humanos, respectivamente.

Sin embargo, continuó la situación de vulneración de derechos humanos de los pueblos indígenas. ${ }^{6}$ En el año 2010, James Anaya, relator especial para pueblos indígenas, en el contexto de su visita de seguimiento a las recomendaciones hechas en el año 2004, determinó que "la situación de los Pueblos Indígenas no ha sido afrontada con la urgencia que la gravedad de la situación merece"; particularmente, los programas, políticas y leyes "no permiten una efectiva protección y satisfacción de los derechos de los pueblos indígenas"7 (ONU-Ecosoc, 2010). Retomando los términos de la Corte Constitucional, el relator afirmó que el conflicto armado tiene un impacto desproporcionado sobre los pueblos indígenas, los cuales "sufren alarmantes patrones de desplazamiento forzado, homicidio, falta de alimentación y otros problemas

6 Durante 2004 y 2010, los enfrentamientos en territorios indígenas permanecieron. En el transcurso de dicho período las diferentes entidades (OACNUDH, Acción Social hoy Departamento para la Prosperidad Social, coDHes y Amnistía Internacional, para dar algunos ejemplos) registraron bombardeos, homicidios selectivos de líderes tradicionales y políticos indígenas, reclutamientos forzosos, desplazamientos y despojos de tierras, confinamientos, bloqueos de alimentos, amenazas, tomas de rehenes por parte de las AUC y de las Farc. Igualmente, algunos homicidios, capturas masivas y arbitrarias de líderes de los grupos étnicos fueron atribuidos a miembros de la fuerza pública. En 2004 "las comunidades más afectadas por homicidios selectivos de grupos paramilitares fueron las Embera Chamí (Caldas), Wayuu (La Guajira), Wiwa (snsm/La Guajira), y Kankuama (Cesar)" (OACNudH, 2004, p. 64). Según cifras de Acción Social, entre 2006 y 2007 el desplazamiento total de la población creció en un $16,8 \%$, mientras que el desplazamiento de la población indígena creció en un $23,1 \%$. Asimismo, algunas comunidades se encuentran en situación de confinamiento y carecen de atención humanitaria (ONU-ECOsoc, 2010, p. 15).

7 Esto obedece, retomando las palabras del Relator Especial anterior, al "desfase entre una legislación nacional avanzada y la poca efectividad real de las instituciones encargadas de su protección, en el marco de un conflicto armado interno en el cual participan numerosos contendientes cuya acción incide en las posibilidades de supervivencia de las comunidades" (ONU-ECOsoc, 2010, p. 7). 
graves a causa del conflicto armado en el país y distintos factores subyacentes" (oNU-ECOSOC, 2010, p. 9).

Adicional a lo anterior, durante los últimos años se han sumado los efectos negativos del desarrollo de los proyectos económicos en territorios indígenas, como veremos a continuación. La OACNUDH llama la atención sobre el "impacto negativo que tiene en la estructura social de las comunidades, el cambio en el uso del suelo provocado por las industrias extractivas. Dicho cambio contribuye a la pérdida de los conocimientos tradicionales y a un deterioro sustancial de sus capacidades de organización, toma de decisiones y autogobierno. Si esta situación persiste, el conflicto social exacerbado tenderá a extenderse y será aún más difícil de resolver" (OACNUDH, 2012, p. 19).

\section{Sierra Nevada de Santa Marta}

Es importante dar algunos elementos de contexto sobre la situación de derechos humanos enfrentada por los pueblos indígenas de la (SNSM) durante la década del 2000, a causa de la dinámica del conflicto armado en la región y de la construcción de megaproyectos.

Según la OIK y la ONIC, durante la primera década de los años 2000 el pueblo kankuamo vivió un verdadero proceso de "etnocidio" y riesgo de exterminio físico y cultural. En la época más crítica se dieron aproximadamente 300 asesinatos, procesos de desplazamiento forzado indígena masivo (más de 400 familias kankuamas, es decir aproximadamente 1500 personas), y algunos casos de refugio político en Venezuela y Canadá. Aunque fue protegido por la Corte Interamericana de Derechos Humanos con medidas provisionales, en el año 2011, luego de cinco resoluciones, "la Corte consideró que ya no existían condiciones necesarias para mantener la vigencia de las medidas provisionales, por lo que ordenó levantarlas" (Corte IDH, 2011).

Según el diagnóstico para el Auto 004 del pueblo arhuaco, en el ámbito de los derechos humanos, los hechos de mayor gravedad han 
sido los siguientes: despojo del territorio tradicional por los grupos armados ilegales; presencia de grupos armados en su territorio, y control basado en la intimidación; restricción alimentaria, apropiación de los alimentos, productos agrícolas y ganado de los indígenas por parte de los grupos armados, lo cual genera inseguridad alimentaria, mayor recurso a la cacería y afectación del medio ambiente; irrespeto a las autoridades indígenas e imposición de pautas de comportamiento o restricción de las prácticas propias; asesinatos selectivos de autoridades arhuacas; asesinatos de indígenas arhuacos por señalamiento; reclutamiento forzado y voluntario de indígenas por parte de los grupos armados ilegales; restricción de la movilidad e intimidación de población por presencia de actores armados; bombardeos; bloqueo por parte de los actores armados al desarrollo de sus economías; exigencia de las Fuerzas Armadas de que los indígenas porten una certificación de indígenas. Con respecto a este último punto, la militarización y presencia de las Fuerzas Armadas en sus territorios y en la vida comunitaria ha generado un fuerte impacto cultural y violaciones de derechos humanos.

El pueblo kogui se ha visto afectado, además de las situaciones antes mencionadas, en temas relacionados con restricción a la movilidad de alimentos, robo de alimentos, cultivos y ganado; crisis alimentaria; restricciones de movilidad y afectación de sitios sagrados, lo que rompe la dinámica de pagamentos y afecta la integridad cultural. Esto mismo ocurre con el pueblo wiwa. Aunque desde el año 2005 ha sido beneficiario de medidas cautelares por parte de la Comisión Interamericana de Derechos Humanos, la presencia de grupos armados, cultivos ilícitos, ejecuciones extrajudiciales, asesinatos selectivos de líderes, amenazas, desplazamientos y despojo de tierras, no son asuntos desconocidos en su territorio.

Todo lo anterior, ha generado un impacto cultural individual y colectivo de los pueblos indígenas de la SNSM, en un contexto en el cual el Estado colombiano no garantiza su identidad cultural y no protege la especial relación que estos tienen con su territorio. Adicionalmente, 


\begin{tabular}{|c|c|}
\hline Situación de DH & Megaproyectos \\
\hline 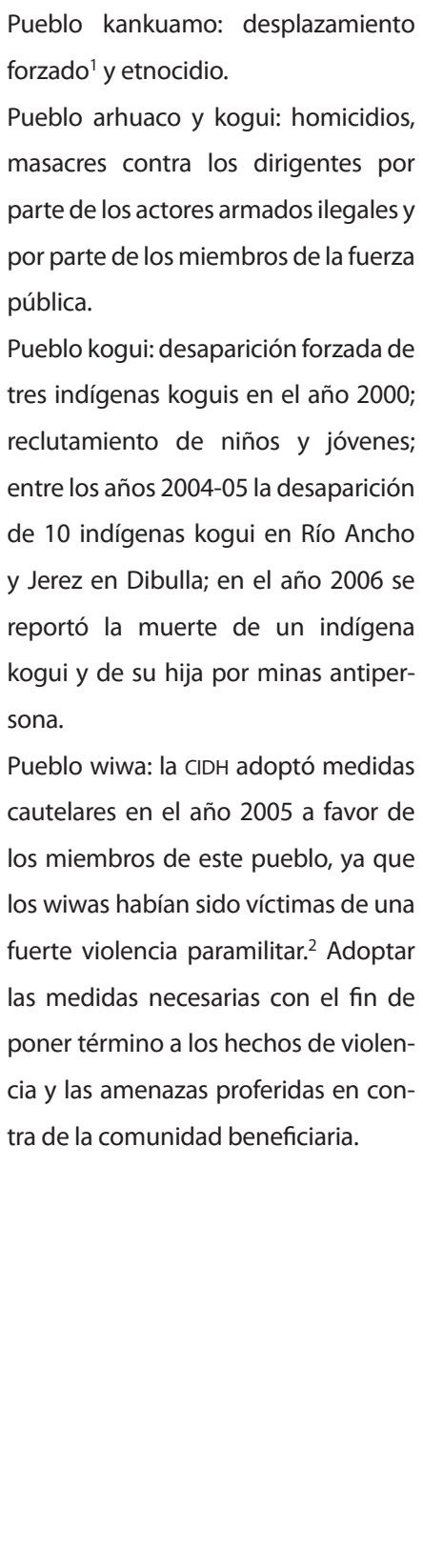 & 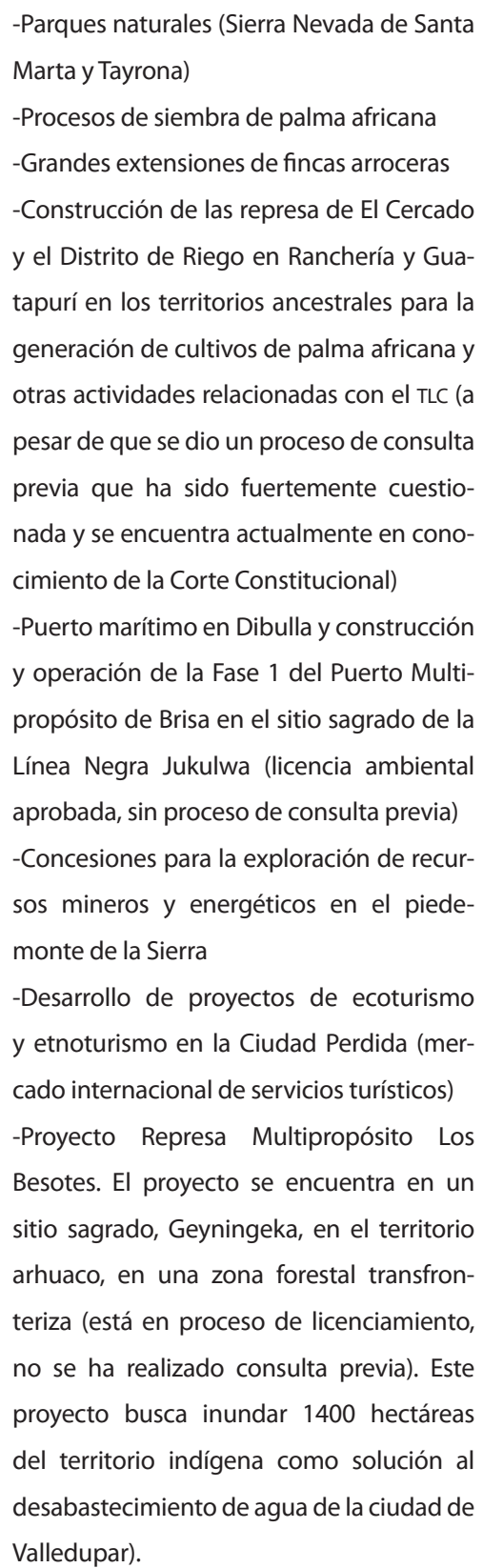 \\
\hline
\end{tabular}

FUENTE: elaboración propia 
existe una relación entre la implementación de megaproyectos económicos y la violación de derechos humanos. Según el Auto 004 del 2009 proferido por la Corte Constitucional colombiana, los pueblos indígenas han tenido un impacto desproporcionado del conflicto armado en sus territorios.

\section{Departamento del Chocó: región del bajo San Juan}

El Departamento del Chocó no es ajeno a dicha problemática. Desde mediados de la década de 1970 este departamento se ha constituido para los grupos armados (Farc, ELN, EPL, AUC) en una zona estratégica "para el repliegue de sus tropas y para el tráfico de armas y pertrechos" (Defensoría del Pueblo, 2013).

La dinámica del conflicto armado en el departamento,

aunque se concentra en términos de indicadores de violencia fundamentalmente alrededor de la cuenca del Atrato, cubre las subregiones que se configuran alrededor del San Juan y del Baudó y que permiten en primer lugar, configurar corredores de movilidad, abastecimiento, tráfico de armas y de drogas desde Antioquia, el Eje Cafetero y el Valle del Cauca hasta el mar Pacífico (usando como puntos de llegada los municipios que conforman la subregión del litoral); en segundo lugar, consolidar zonas de captación de recursos para el financiamiento de sus estructuras armadas provenientes de la agroindustria, la explotación minera y la explotación maderera; y en tercer lugar, preservar el dominio sobre las zonas de cultivos ilícitos y las actividades ligadas a la economía cocalera. (Defensoría del Pueblo, 2013)

Lo anterior ha llevado a que las comunidades (88\% de afrodescendientes y $4,68 \%$ de indígenas) vivan con las consecuencias del conflicto: masacres, bloqueos económicos, confinamientos, enfrentamientos, grandes desplazamientos masivos, algunos individuales y silenciosos. 


\begin{tabular}{|c|c|}
\hline Situación de DH & Megaproyectos \\
\hline 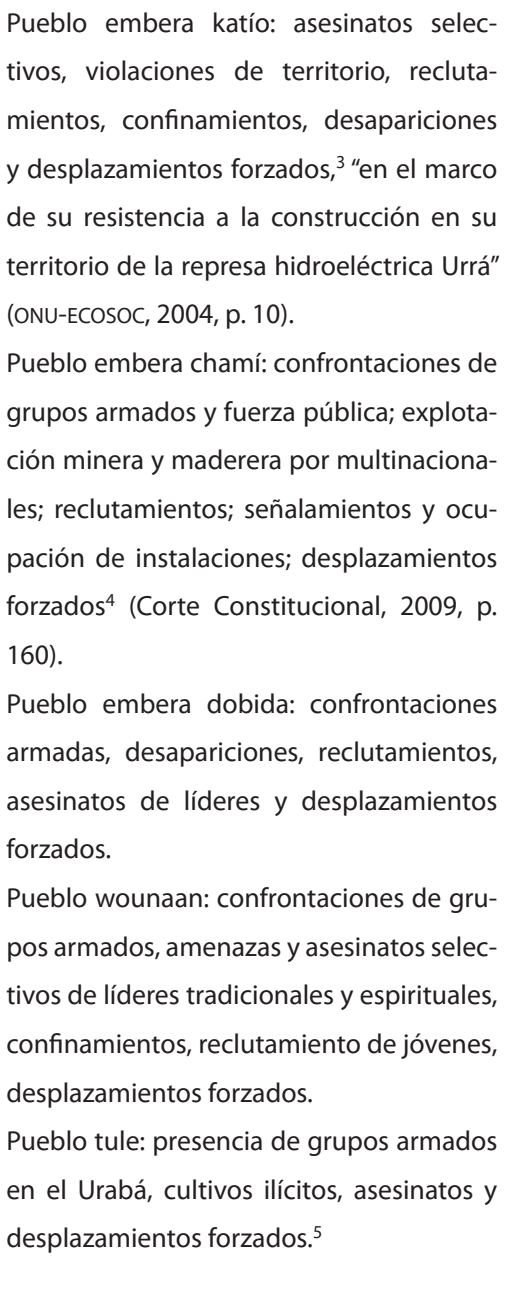 & 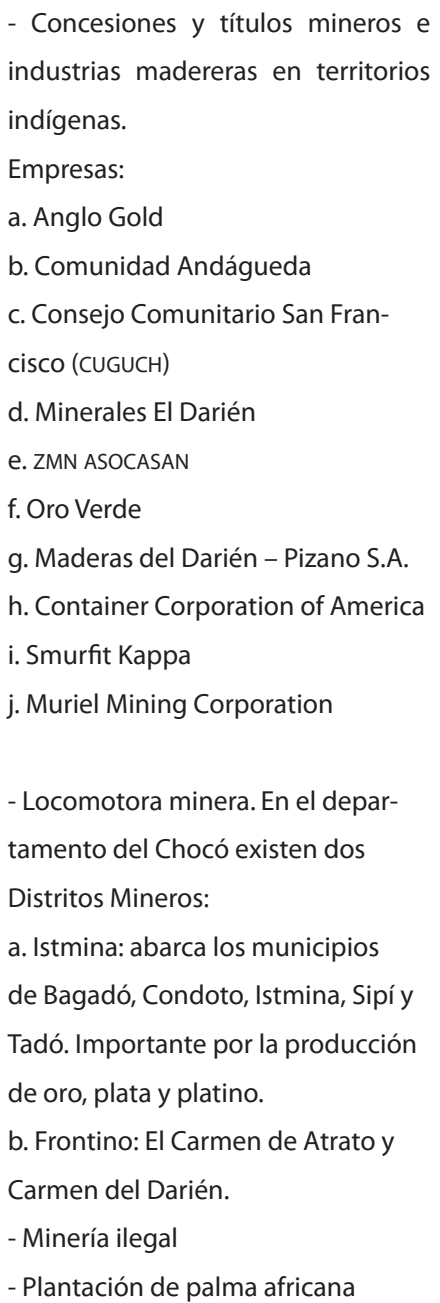 \\
\hline
\end{tabular}

FUENTE: elaboración propia con base en "Pacífico. Territorio de etnias"

De acuerdo con el informe de la Asociación de Cabildos Indígenas del Chocó (OREwA), “desde 1999 se han desplazado más de 7.545 indígenas, a causa del Ejército Nacional, tropas adscritas al Batallón Alfonso Mansalva Flores, Brigada 4, DAs, Farc, ELN, Paramilitares Gaitanistas y Los 
Rastrojos" (orewA, 2010, p. 3). Para marzo de 2012, coDHEs registró un total de 73 desplazamientos masivos, de los cuales 6 ocurrieron en Chocó (994 personas), como consecuencia del conflicto armado entre las Farc y la fuerza pública, sin desconocer "otras dinámicas que rompen con las estructuras sociales, tales como las economías extractivas no tradicionales y megaproyectos" (Codhes, 2012, p. 5).

Finalmente, no podemos perder de vista que el departamento cuenta con los indicadores sociales más críticos del país. Para el año 2003, tiene el Índice de Desarrollo Humano (IDH) más bajo y el de mayor distancia con respecto al promedio nacional (0,68 sobre 0,78$)$ (Defensoría del Pueblo, 2013). Para el año 2010, presenta las tasas más altas de mortalidad materna, "mientras que el promedio nacional es de 73,1 muertes por cada 100.000 nacidos vivos, en Chocó es 250,9"; y de mortalidad infantil, "mientras que el promedio nacional es de 15,6 muertes por cada 1.000 nacidos vivos, en Chocó es 32,8” (onU-ECOsoc, 2010, p. 23).

\section{TEJIENDO REDES ENTRE MOCHILAS KANKUAMAS}

Las mujeres tejen mochilas en tamaños que toman nombre propio, son cargueras o mochilones, terceras o susagaos. Se ocupan de la preparación de los alimentos. A las tres y media de la mañana ya el fogón está echando candela o la estufa está prendida. Se descansa y se conversa hilando o corchando lana y fique en una carrumba en plena tarde. Se camina metiendo la aguja una y otra vez. También se ocupan atendiendo a los hijos y más niños que hay en el pueblo, en hogares de Bienestar Familiar como madres comunitarias. ${ }^{8}$

El proceso organizativo de las mujeres kankuamas permite hacer nuevas reflexiones sobre la acción colectiva de los movimientos indígenas

8 Fragmento del trabajo etnográfico La recuperación de la memoria histórica de los kankuamos: un llamado de los antiguos. Siglo XX-XVIII de los antropólogos Adriana Pumarejo y Patrick Morales. 
en Colombia. Este proceso ha logrado articular las demandas individuales y colectivas de las mujeres y de sus familias, incidiendo desde la base social y política para la participación en la toma de decisiones de la organización indígena.

El resurgimiento del pueblo kankuamo surge de la añoranza y los recuerdos de los más viejos, de las luchas por el territorio y de las ganas de seguir existiendo como pueblo. "Desde afuera" ven a los kankuamos en un proceso lleno de trabas, trampas y oportunismo, para otros son campesinos, para los arhuacos su despertar como pueblo indígena se dio después de los derechos alcanzados en la Constitución Política de 1991. Antes, para muchos, estos no se reconocían como tales, pero "hacia adentro" y gracias a la tradición conservada por los otros tres pueblos los kankuamos recuerdan que vienen de la madre tierra y hacen parte de los cuatro hijos de esta para ocupar la Sierra Nevada de Santa Marta.

Las mujeres kankuamas han hecho parte del proceso de reetnización contribuyendo, en distintos escenarios, al fortalecimiento político y cultural desde la defensa de los derechos individuales y colectivos, derechos que provienen de una lógica cultural, política y jurídica ajena, y que se hibridan a las prácticas culturales propias (creencias y valores) para darle una nueva lectura al mundo del cual hacen parte (Merry, 2010).

En este sentido, por medio del proceso de las mujeres kankuamas buscaremos comprender cuáles han sido las prácticas de acción colectiva emergentes y los procesos de democratización que se han generado a partir de estas. Así mismo, analizaremos las dificultades de los actores frente a dichos procesos de democratización, como también de la emergencia de nuevas elites políticas kankuamas.

\section{ORGANIZACIÓN POLITICA Y SOCIAL DEL PUEBLO KANKUAMO}

La Sierra Nevada de Santa Marta es un territorio tradicional y ancestral de los pueblos indígenas kogui, arhuaco, wiwa y kankuamo. Esta región abarca los departamentos de Magdalena, Guajira y Cesar al norte de 
Colombia, lo que permite encontrar en esta una gran diversidad de ecosistemas y culturas. El pueblo kankuamo se encuentra en la parte norte del departamento del Cesar, cerca de la ciudad de Valledupar, en las comunidades de Río Seco y Murillo en la parte baja del territorio; La Mina, Ramalito, Los Haticos, Rancho La Goya, Mojao, Pontón y Atánquez en la parte media; y Guatapurí y Chemesquemena en las partes más altas del territorio (Morales, 2011, p. 30). En esta última zona se encuentra una de las reservas de agua más importantes de la región, brindando particularidades de un clima húmedo, contrario a la parte sur, donde el clima es mucho más seco (Morales, 2011, 31).

De acuerdo con el censo realizado por el DANE en el año 2005, se informó que la población estimada se encontraba cerca de 6924 habitantes. Pero para el año 2011, según un estudio realizado por la Organización Indígena Kankuama (OIK) en el año 2008 la población kankuama se estimó en 15.000 individuos, de los cuales el 65\% habita en el resguardo y el 35\% corresponde a población desplazada y/o migrante a la ciudad de Valledupar u otras ciudades del país. De esta población se estima que el $43 \%$ de la población son mujeres y el 52\% son hombres (oIK, 2008, 7; Montero, 2011, 14-15).

En la cabeza de la organización se reconoce como máxima autoridad al mamo, figura que, contrario al caso arhuaco, se encuentra en proceso de recuperación cultural, pues ya no existen mamos kankuamos vivos. Esta persona tiene en sus manos la gobernabilidad, el ejercicio de la justicia propia y la responsabilidad de establecer vínculos entre la comunidad y el mundo espiritual. Junto al mamo, el Consejo de Mayores apoya al gobierno propio, y se les reconoce como autoridad por su estatus social y conocimiento. El mamo tiene incidencia en las decisiones que se toman dentro de la Organización Indígena Kankuama (оIK). En el organigrama de la oIK se encuentra el pueblo como centro de la organización social, del cual se deriva el Congreso Kankuamo, las Comisiones de Apoyo y los Grupos de Apoyo. En el Congreso se proyecta el gobierno propio de la oık, el cual está conformado por Cabildos 
Menores y por el Cabildo Gobernador. Este tiene una estructura administrativa conformada por el secretario general, el tesorero general y el fiscal general. Como cabeza de toda esta estructura de gobierno se encuentra el Consejo de Mayores.

\section{DE INDIOS A CAMPESINOS Y DE CAMPESINOS A INDIOS.}

\section{LA RECUPERACIÓN DEL PUEBLO KANKUAMO}

Durante muchos años el pueblo indígena kankuamo no hizo parte de los registros demográficos de los pueblos indígenas en Colombia. Este pueblo era considerado como una población campesina-mestiza, e incluso era referida por otros pueblos de la SNSM como una población "civilizada" o como "hermanos menores" alejados de la Ley de Origen, que ocupaban la parte norte del departamento del Cesar en las faldas de la Sierra Nevada de Santa Marta (Pumarejo y Morales, 2003: 22-25).

El proceso organizativo del pueblo kankuamo inicia en los años ochenta a partir de la reivindicación y el reconocimiento por parte de miembros de las comunidades como propietarios de algunos terrenos, así como también a partir de la incorporación y el fortalecimiento de ciertas prácticas culturales como los pagamentos al territorio (Morales, 2011: 103-104). Esto les permite acumular su propio capital étnico. No obstante, solo hasta el año 1993, luego de la constitución de la Organización Nacional Indígena de Colombia (ONIC), se certifica y reconoce a la OIK, a partir de la evaluación de algunos expertos institucionales como la División de Asuntos indígenas (DAI), quienes elaboraron un concepto a partir de las reivindicaciones indígenas kankuamas (Morales, 2011, p. 108). Con este fin, se realiza el Primer Congreso de la oIK en la comunidad de Atánquez, en él se da el reconocimiento legal por parte del Estado colombiano a esta organización indígena, la cual se afilia directamente a la ONIC como su organización de base nacional (OIK, 2008: 8). Dentro de los principios de lucha de esta naciente organización se destacan temas como: identidad (la forma de sentir, pensar y actuar 
de los kankuamos), unidad (cohesión y convivencia colectiva del pueblo kankuamo y de los otros pueblos de la SNSM), territorialidad (como uno de los pilares fundamentales de la vida indígena), autonomía (por el derecho a gobernarse con sus propias autoridades), interculturalidad (por su relación con los demás pueblos de la SNSM) y participación en el fortalecimiento de los procesos colectivos de toma de decisiones (ork, 2006: 19-20).

Como expresamos en la primera parte del capítulo, la oık reseña que desde 1985 hasta el 2008 su territorio se convirtió en un escenario de guerra donde se violaron los derechos humanos de todos los pueblos indígenas de la SNSM. Así, durante este período se asesinó de forma selectiva a líderes, hombres, mujeres y niños; se reclutó a jóvenes en los distintos grupos armados ilegales de forma involuntaria, se estigmatizó a la población y se debilitó la organización interna del pueblo indígena. "En fin, ha puesto en grave riesgo la permanencia física y cultural del pueblo indígena kankuamo" (oIK, 2009, 12). Frente a la situación de exterminio del pueblo kankuamo, la Corte Interamericana de Derechos Humanos solicitó, en el año 2003, otorgar medidas provisionales de protección para los pueblos indígenas de la SNSM (CIDH, 2003). Este último ciclo de violencia desembocó en múltiples procesos políticos y jurídicos que buscaban la resistencia del pueblo kankuamo como una unidad social, cultural y política.

Frente a las problemáticas generadas por causa del conflicto armado, en el año 2004 se radicó la Sentencia T-025 en la cual se demandó al Estado por la falta de respuesta al fenómeno del desplazamiento forzado en Colombia y por otra serie de violaciones sistemáticas de los derechos humanos. No obstante, frente al silencio y la ausencia de respuesta del Estado para la atención a las víctimas del conflicto armado en Colombia, la Corte Constitucional colombiana expidió los Autos 092 de 2008 y 004 de 2009. Estos obligan al Estado colombiano, por medio de cada una de las instituciones que lo conforman, a crear programas de protección a las víctimas del conflicto 
armado como mujeres, niños y niñas y grupos étnicos. Estas problemáticas impulsaron nuevos mecanismos de protección de los derechos humanos, en los cuales la onic y delegados de las organizaciones regionales afiliadas a esta, como la огк, introdujeron en sus repertorios los discursos de las víctimas de la violencia e incorporaron elementos propios de las afectaciones colectivas y culturales de los pueblos indígenas.

De la mano con estos procesos, las organizaciones indígenas de Colombia participaron en la producción y posterior adopción de la Declaración de las Naciones Unidas sobre los Derechos de los Pueblos Indígenas en el año 2007. Por medio de la Resolución 005 de 2007 de la ONIC, el nuevo gobierno indígena decide adoptar de manera íntegra la Declaración de las Naciones Unidas (Declaración de la Naciones Unidas sobre los Derechos de los Pueblos Indígenas, 2007), y se abstiene de aplicar toda medida administrativa, legislativa o judicial que la viole.

Complementariamente, rechaza las explicaciones y argumentos del gobierno colombiano utilizados para no acoger tal Declaración, ya que estos violan y atentan contra los derechos a la autonomía, territorio y cultura, y desconocen los derechos individuales y colectivos de los pueblos indígenas de Colombia (Santamaría, 2010, 193).

Como consecuencia de la violencia en los territorios indígenas surgió la preocupación de la situación de las mujeres, quienes se habían convertido en objetivo militar. Dora Tavera, líder indígena del pueblo Pijao, Consejera Mayor de la onic y excoordinadora del área de Familia, Mujer y Generación de esta organización, exponía que las mujeres víctimas del conflicto armado en Colombia eran afectadas de múltiples formas. "A ellas se violan y acosan sexualmente, se asesinan con sus hijos en el vientre, se reclutan y se les enamora como estrategia militar; quedan viudas y huérfanas afectando de forma integral las garantías de la pervivencia de sus pueblos" (entrevista a Dora Tavera, en Bogotá, en agosto de 2011). 


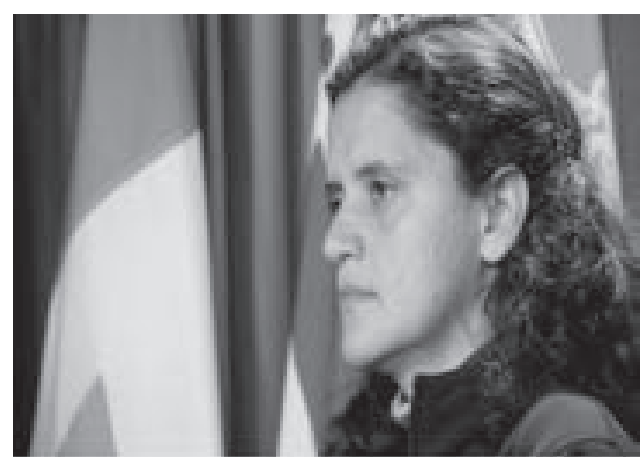

Mujeres indígenas en Colombia: tejiendo vida y pensamiento en las diferentes regiones del país. Disponible en: Indigenous Portal

Como respuesta a esta problemática se creó la Consejería de la Mujer, Familia y Generación en la onIC, durante el VII Congreso Indígena de Colombia en el año 2007 (onic e inipu, 2010). Reconociendo que muchas de las lógicas de la vida íntima-privada de los pueblos indígenas se generan dentro de la familia, y que esta tiene como base fundamental la mujer y el rol que ella desempeña en la vida reproductiva, económica y sociocultural, la Consejería tuvo que extender su radio de acción a otros grupos etáreos como los adultos mayores, niños y jóvenes.

A través de la Consejería se han recogido las inquietudes, necesidades y problemáticas de las mujeres con el fin de brindarles apoyo a sus demandas individuales. Entre las necesidades captadas, aparece el interés de muchas mujeres por acceder a espacios de participación política, donde se les escuche y reconozca como actores fundamentales en el sostenimiento del movimiento y de la organización indígena. Así, desde la Consejería se ha brindado capacitación a las mujeres indígenas en temas que les proveen herramientas discursivas de defensa de los derechos humanos y de liderazgo político para que puedan acceder a los distintos escenarios de toma de decisiones. 


\section{PROCESO ORGANIZATIVO DE LAS MUJERES KANKUAMAS}

El proceso de las mujeres indígenas kankuamas, muy distinto del caso arhuaco y wounaan, debe entenderse no solo como un proceso reciente, en el cual las mujeres comenzaron a ocupar los espacios de incidencia política. En este caso, consideramos fundamental identificar, a lo largo del tiempo, la resistencia social de las mujeres por medio de sus hogares, en los lugares más íntimos de la familia, en la cotidianidad de los quehaceres diarios para recordarles a sus hijos y nietos quiénes son y de dónde vienen. Es así como al interior de la comunidad se ha dado una suerte de división social del trabajo militante que ha ubicado tradicionalmente a la mujer en el ámbito de lo privado.

La líder indígena del pueblo kankuamo Mildred Montero recordaba en Bogotá que su madre la aconsejaba mientras se encontraban alrededor del fogón. Mildred había venido a Bogotá para representar a las mujeres de la Macroregional Norte en un encuentro de mujeres pertenecientes a distintos grupos étnicos, para hablar de las problemáticas que les acontecen. Las palabras que ella expone son recuerdos de las enseñanzas de su mamá sobre algunos roles de las mujeres kankuamas en la familia y el sostenimiento del hogar.

...Por ejemplo yo no me crié con mi papá, pero yo sentí el apoyo de mi mamá. En el fogón era donde ella nos inculcaba y nos decía: hijas ustedes son indígenas, ustedes son kankuamas porque ustedes son indias. Ella nos explicaba " $i$ ustedes no pueden dejar sus costumbres, porque entonces van a dejar de ser indias!". Yo me acuerdo que yo tenía un hermanito, el que me sigue a mí, a él le daba rabia que le dijeran indio. Él decía: "Yo no soy indio", mi mamá lo cogía y le decía: “Usted sí es indio”, porque yo soy indio y ustedes son indios, y le explicaba; y los hombres son trabajadores, tienen que cortar la leña. Y, por ejemplo, las mujeres solamente es para tejer, para cuidar a los hijos, para lavar la loza, ahora decimos loza pero antes decían chisme, para lavar los chismes. Los mamos, usted debe 
creer mucho, si usted no cree en sus mamos entonces no hay autoridades propias, entonces el pueblo va a desaparecer. (Entrevista a Mildred Montero, en Bogotá en abril de 2012)

El proceso de Mildred Montero viene desde la base del pueblo kankuamo en la comunidad de La Mina. Gracias a su participación en la Comisión de Derechos Humanos de la ork en la comunidad de La Mina y a su formación como enfermera, pudo acceder a espacios mucho más privados de las familias kankuamas. Esto garantizó que con el tiempo fuera reconocida como una de las líderes más importantes del pueblo. En este sentido, ella, como otras líderes, son reconocidas por los múltiples roles que desarrollan tanto en los procesos políticos y organizativos como en la vida familiar y en la cotidianidad.

No obstante, hacemos la salvedad de que no todos los procesos de mujeres están encaminados a ocupar lugares de incidencia política, como por ejemplo los cabildos o las gobernaciones. Otras mujeres, de quienes hablaremos más adelante, han concentrado sus esfuerzos para incorporarse en áreas que son de vital importancia en la vida comunitaria y que garantizan la pervivencia de las prácticas culturales como la educación, la salud, las artesanías y el acceso a los derechos.

Para esto, retomando los términos de Dumoulin, se han llevado a cabo "alianzas estratégicas solidarias" entre el pueblo y "organizaciones transnacionales" como el Consejo Noruego para los Refugiados y la Cooperación Suiza, que desde el año 2010 han estado acompañando a través de talleres de formación y capacitación a mujeres que fueron afectadas por la violencia entre los años 1998 y 2008. Este tipo de solidaridad de organizaciones internacionales con el movimiento indígena en Colombia ha generado la fuerte apropiación del discurso de los derechos humanos y formas alternativas de desarrollo por parte de la organización (Dumoulin, Kervan, 2010).

Si bien los megaproyectos es uno de los principales problemas de las organizaciones indígenas en el marco de la implementación de un 
modelo económico extractivista, las organizaciones transnacionales poseen una agenda enfocada en las problemáticas particulares de las mujeres kankuamas. En este sentido, han apoyado a la Organización de Mujeres Indígenas Kankuamas (омІк) para construir con ellas marcos de defensa jurídica internacional y nacional. La омıк fue creada en el año 1995 pero no contó con los recursos económicos y humanos suficientes, por lo cual permaneció ausente en todos los procesos de las mujeres indígenas hasta hace dos años. Esta organización fue creada a partir del II Congreso de la oIK, y reconocida por el Cabildo Mayor debido al trabajo constante de mujeres kankuamas que se habían vinculado en este proceso (Montero, 2011, p. 10), como por ejemplo Paulina Villazón y Carolina Montero, quienes son en la actualidad miembros del Consejo de Mayores del pueblo kankuamo.

Esta organización retomó su fuerza en el año 2007 cuando se creó la Consejería de Mujer Familia y Generación de la onic. A través de esta, se canalizó el apoyo internacional para la protección de las mujeres indígenas afectadas por la violencia del conflicto armado. En este proceso, las mujeres han ganado reconocimiento al interior de las comunidades, permitiendo a su vez la transformación de lógicas internas de las estructuras organizativas tradicionales e incorporando el enfoque de género. Esto ha obligado a que en las agendas de los proyectos locales de las organizaciones indígenas se contemple la inserción de las mujeres en los escenarios políticos. Si bien la estructura de oportunidad política, expuesta desde los estudios de la acción colectiva por Tarrow, se enfoca en el acceso a los recursos institucionales para dar lugar a la acción política colectiva (Tarrow, 1998: 109-110), este enfoque no da cuenta de las transformaciones que se dan al interior de las comunidades locales, desde las estructuras culturales tradicionales. Como ejemplo, el caso del acceso de las mujeres a los cabildos indígenas, siendo estas instituciones tradicionalmente masculinas. Así mismo, la permisibilidad de los esposos de las mujeres líderes para asumir nuevos roles en la familia, o el cuidado y la crianza de los hijos mientras las mujeres se ausentan 
para incorporarse en los espacios políticos. Es decir, la división social y sexual del trabajo militante sufre transformaciones profundas en términos de roles de género con la entrada de las mujeres kankuamas en los espacios de incidencia.

Otro espacio que fomentó la participación de las mujeres es la Asociación de Artesanas Kankuamas (ASOARKA). Esta asociación se fundó en el año 2006 como parte del proceso de recuperación del antiguo proyecto productivo de artesanas Chimbuchike. Es así que durante este año lograron reunir a 200 mujeres artesanas con el fin de promover el fortalecimiento cultural y económico mediante la producción de mochilas kankuamas. Para el año 2010 se promovió la participación política de las mujeres vinculadas a ASOARKA a través de capacitaciones brindadas por la омıк y el apoyo de organizaciones internacionales como el Consejo Noruego para Refugiados. Esta alianza gestionó los espacios y los apoyos internacionales para brindar los talleres de formación a las mujeres vinculadas a los procesos productivos desde las artesanías.

Mildred Montero exponía durante nuestro encuentro cuáles fueron las principales dificultades durante el proceso de acceso a la participación dentro de los cabildos, ya que en ese entonces se consideraba problemático que las mujeres tuvieran voz dentro de estos espacios:

...y lo que pasa es que yo veía que pasaban muchas situaciones con las mujeres de discriminación y nadie decía nada. Entonces, cuando yo comencé a salir a las capacitaciones ya era otra cosa porque empecé a aprender que no se debe maltratar a la mujer, que teníamos unos derechos y deberes. Cuando yo llegaba a trasmitir eso a mi comunidad, a los hombres no les gustaba. Entonces fue ahí que empecé a tener problemas, porque ellos decían que yo les daba casquillo a las mujeres porque estaba despertándolas, y por eso las mujeres no tenían que meterse en comisiones, y se formó el problema. Pero entonces el Cabildo nos apoyó mucho. Él decía que había que dar la oportunidad a las mujeres, que nos dejaran, 
porque íbamos avanzando. Y así, yo iba al Cabildo y fui haciendo el papel de secretaría con el coordinador. (Entrevista a Mildred Montero, en Bogotá en abril de 2012)

\section{Sede de ASOARKA en la comunidad del Mojao}

En ella se encuentra Rosa Manuela Montero, gerente de AsOARKA y una de las mujeres artesanas

Rosa Manuela Montero fue quien fomentó este proyecto a través de la experiencia recibida en el diplomado internacional sobre mujeres indígenas líderes en el año 2010. Rosa Manuela, quien era la gerente de ASOARKA desde el año 2006, coordinó junto con Delviz Estrada, coordinadora de la омıк, para articular a las mujeres artesanas en los procesos organizativos sobre la lucha de las mujeres indígenas. La propuesta fue la capacitación de cincuenta mujeres en derechos de las mujeres y derechos de los pueblos indígenas y liderazgo político. El propósito era brindarles herramientas jurídicas y políticas que les permitiera acceder a la toma de decisiones tanto en los espacios privados-familiares como en los públicos-políticos.

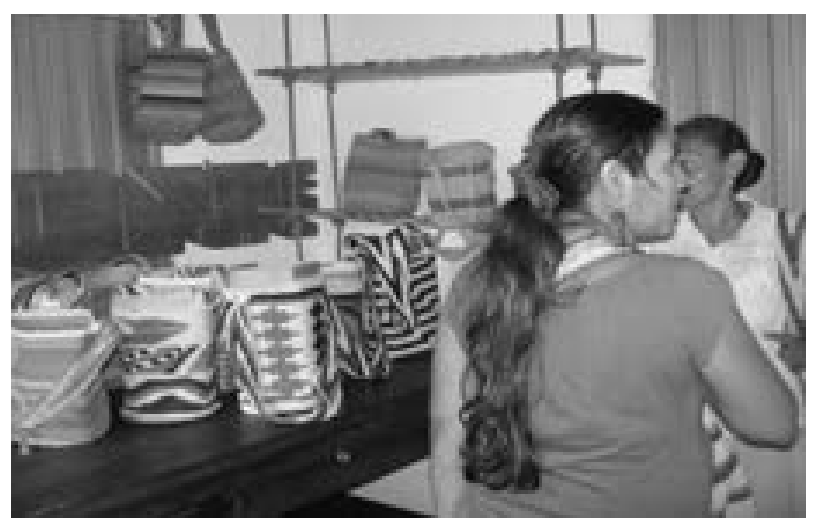

Yeshica Serrano Riobó, febrero de 2012 


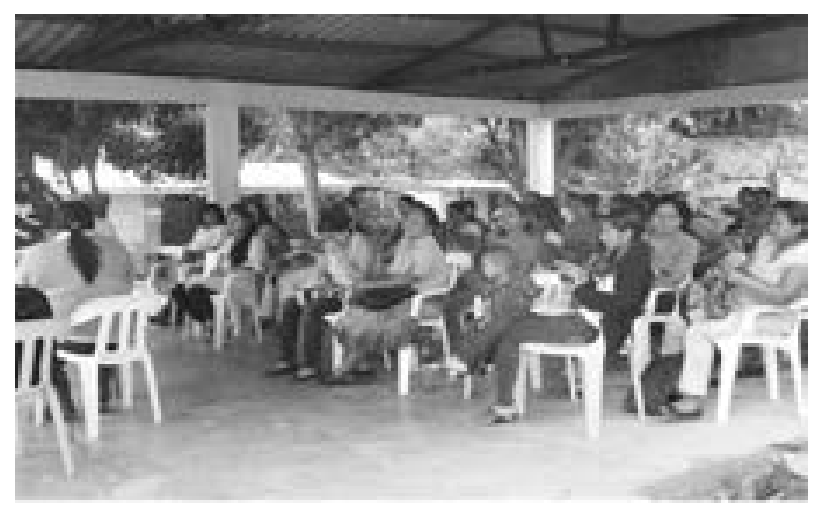

Encuentro de mujeres de la omIK (Organización de mujeres indígenas kankuama. (Foto: Yeshica Serrano)

Rosa Manuela es una de las líderes más importantes del pueblo kankuamo. Es esposa del Cabildo Gobernador de la oIK y representa una autoridad y una elite sobre los procesos políticos y sociales en materia de mujeres. El papel que ha desempeñado como gerente de ASOARKA y gestora de los talleres de formación le ha dado un reconocimiento importante dentro del pueblo indígena.

Con respecto a su trayectoria en los procesos organizativos a través de las artesanías, Rosa Manuela contaba que ASOARKA surgió como una necesidad de las mujeres artesanas para tener mayor autonomía en los procesos productivos, ya que era costumbre la centralización del poder adquirido por el Cabildo Mayor:

Fue entonces en el 2009 que vieron la necesidad de que nos dieran autonomía en el manejo de las artesanías como una asociación independiente; que no fuera la organización la que estuviera direccionada al tema de artesanías, y las artesanas pidieron eso a las autoridades [...] y bueno, las autoridades vieron con buenos ojos que se organizará el tema de las artesanías. Dieron las directrices para su funcionamiento, pero hemos tenido autonomía en el manejo como tal de la asociación, y pues 
articulado siempre al direccionamiento general, dándoles informes a las mismas autoridades de cómo vamos y qué estamos haciendo. (Entrevista a Rosa Manuela Montero en Valledupar e marzo de 2012)

El espacio que se ha generado en ASOARKA para los talleres de formación ha sido fundamental en el fortalecimiento de la омıк, la cual se ha proyectado como una organización que atiende asuntos particulares de las mujeres indígenas de este pueblo. Esta organización debe rendir informes a su organización de base, la oIK, pero genera a través de las artesanas y del apoyo de las organizaciones de cooperación, como también de las instituciones del Estado, formas de autogestión para el fortalecimiento en la respuesta a sus demandas. Un ejemplo de esto son las exigencias que le hacen a los programas institucionales como el Instituto Colombiano de Bienestar Familiar (ICBF) sobre la capacitación de las madres comunitarias o la generación de programas de atención diferencial como minutas alimentarias y programas de educación a primera infancia y a las necesidades de las familias kankuamas.

En lo que va corrido del proceso, desde la constitución de la омIк, se han realizado dos talleres de formación en los cuales se han capacitado alrededor de 200 mujeres kankuamas. A estos talleres han llegado mujeres con múltiples dificultades familiares, psicosociales, económicas, entre otras, buscando alternativas para "salir adelante" y mejorar su calidad de vida. Los procesos de acción colectiva se han encaminado, en un principio, a encontrar opciones que les permitan transformar situaciones de pobreza y vulnerabilidad tanto de ellas como de sus familias, afectadas por el desplazamiento forzado, el conflicto armado, la violencia intrafamiliar y la inequidad del acceso a los programas del Estado. Así mismo, logran acceder a espacios de los gobiernos propios como una forma de posicionar en dos esferas (lo público y lo privado) las problemáticas de las mujeres, para generar mayor presión a los cambios institucionales y en las lógicas tradicionales de exclusión de género. Así, a través de los talleres de formación encuentran un lugar propicio para 
el fortalecimiento de su rol como mujeres, y también el espacio para asumir el poder de la palabra en la toma de decisiones políticas y sociales. Así mismo, se ha motivado a que las mujeres se sientan vinculadas en los procesos políticos de la organización indígena. Aquí vemos cómo la acumulación de un capital escolar (no universitario) ha sido fundamental en la emergencia de acciones colectivas para la participación de las mujeres kankuamas en varios escenarios locales y nacionales.

Por medio de la vinculación en los procesos de acción colectiva a través de ASOARKA y OMIK las mujeres se han motivado a participar en los procesos locales a través de las Consejerías en las comunidades. Esto ha contribuido en la construcción de trayectorias políticas de mujeres kankuamas dentro de las organizaciones a partir del acceso a capitales escolares (universitarios y no universitarios) y políticos.

\section{ESCOLARIZACIÓN Y MIGRACIÓN DE LAS MUJERES KANKUAMAS}

Como exponíamos en la introducción, el capital étnico como subespecie del capital militante de los líderes y las lideresas apoya la construcción de referentes de representación dentro de los pueblos kankuamo, arhuaco y wounaan. No obstante, en el caso de las mujeres kankuamas el acceso escolar no indígena marcó una diferencia tajante en el proceso organizativo de este pueblo, que dista de los otros casos que aquí mencionaremos puesto que su construcción de capital étnico se dio como un ejercicio reflexivo externo a partir de su reconocimiento como indígenas desde las universidades y no como parte de una reafirmación constante interna del pueblo kankuamo.

Aunque buena parte de las migraciones hacia Valledupar y otras ciudades fueron provocadas por las amenazas generadas por la violencia durante el conflicto armado, también se dieron migraciones con el propósito de mejorar las condiciones de vida. El acceso a la educación para las mujeres kankuamas en las ciudades implicó la transformación y ruptura de esquemas repetitivos de exclusión social y pobreza en el territorio. 
Parte de las luchas feministas emprendidas desde los años setenta han respondido a las demandas por la equidad de género de las mujeres trabajadoras (Colazo, 2009), pero muy poco se ha mencionado sobre las luchas de las mujeres indígenas. No obstante, a partir del trabajo realizado por Francesca Gargallo (2012) es posible reconocer que desde el mundo indígena se han construido distintas formas de lucha desde los feminismos. Algunos de ellos se han apoyado en el reconocimiento de derechos propios colectivos y derechos humanos. Así, la comprensión de lo político y la percepción de lo público y lo doméstico se han transformado a lo largo de tiempo, ya que dentro del movimiento indígena ha germinado una idea renovada sobre el rol femenino en la lucha por el territorio y los derechos individuales y colectivos (ONIC-EFIN, 2006). Estos nuevos roles femeninos son la construcción de las mujeres indígenas y madres, reconocidas como actores políticos, quienes son poseedoras de un conocimiento ancestral que estrecha su relación con la madre tierra, siendo esta la base de la vida familiar y organizacional de los pueblos indígenas.

No obstante, aunque se han abierto espacios para la incorporación de las mujeres en los procesos políticos, aún persisten obstáculos que limitan la participación de las mujeres, pues algunas lógicas tradicionales y algunas percepciones nacionales y globales ponen en duda sus capacidades políticas. Por lo mismo, ellas se apoyan desde sus historias de origen para reafirmar que la mujer y el hombre son una integralidad que proporciona equilibro y armonía para la vida.

En este sentido, aunque las mujeres no han accedido a cargos de poder dentro de las comunidades, han logrado conquistar otros espacios que inciden en las estructuras de base de la organización indígena, como: la salud, la educación, lo jurídico, lo productivo y lo administrativo. Estos espacios también han sido fruto del acceso escolar universitario y de la formación brindada por el apoyo de la cooperación internacional. Astrid Ulloa afirma que los logros de las mujeres indígenas no deben entenderse solo desde la lucha de los movimientos, sino como el 
resultado de diversos procesos que permitieron a las mujeres exponer sus necesidades. Entre los factores que empujaron el acceso a la participación política, Ulloa destaca los siguientes aspectos:

a. La consolidación en las organizaciones de base indígenas de políticas, programas y espacios de participación de las mujeres.

b. La formación política y académica de las mujeres indígenas.

c. La conformación de organizaciones de base de mujeres indígenas.

d. La presencia activa de las organizaciones no gubernamentales.

e. Los cambios en las políticas gubernamentales.

f. El replanteamiento del papel de las mujeres indígenas desde la academia.

g. La relación mujeres-naturaleza (Ulloa, 2007).

Los procesos de acción colectiva de las mujeres kankuamas tienen su firmeza en la reetnización de este pueblo. Aunque durante muchas décadas consideraron que para mejorar su calidad de vida y "superarse en la vida" era necesario salir de las comunidades, solo a través de este proceso comienzan a repensarse como parte de un grupo étnico con derechos individuales y colectivos. Los trabajos que estas mujeres desarrollaron en las casas de familias garantizaron una educación de mejor nivel.

Durante estos procesos comenzó a gestarse la idea de una pertenencia étnica en las instituciones educativas universitarias, lo que generó procesos híbridos en los que las mujeres adquirieron capital étnico emergente del proceso de reetnización kankuama, capital económico y educativo. Según Axel Rojas, los procesos de educación multicultural son otras formas de marcar la alteridad, de seguir hablando del otro para gobernarlo y definen cómo deben ser pensados en el proyecto nacional (Rojas, 2011). Pero en nuestro concepto, las mujeres que han logrado cierto capital escolar han influido en la percepción del liderazgo que ellas ejercen sobre las mujeres kankuamas artesanas. Los 
casos más representativos han sido los de Rosa Manuela Montero, Mildred Montero, Ana Manuela Ochoa, quienes han jalonado los procesos organizativos de estas mujeres, impulsando y promocionando su formación en derechos humanos y derechos de las mujeres para el fortalecimiento del liderazgo político de las mismas. En estos procesos ellas tienen como compromiso replicar estos conocimientos con las otras mujeres de las comunidades que no tienen acceso a ellos. De esta manera, han logrado que la mayoría de mujeres kankuamas se hayan motivado a participar en los talleres de formación que brinda la омıк, encontrando en estos espacios posibilidades de superar formas de violencia estructural, simbólica y física (Bourgois, 2009). En medio de estos procesos se han sumado otras mujeres que han ganado un importante lugar en las Comisiones de Trabajo para el reconocimiento de los derechos de las mujeres tanto en lo tradicional como de derechos individuales. Aunque el acceso a la educación sigue siendo limitado, lo que refleja otras formas de exclusión, las mujeres que presentaremos a continuación han contribuido en los procesos de acción colectiva.

\section{Ana Manuela Ochoa}

Ana Manuela Ochoa es una de las líderes más importantes del pueblo kankuamo y es originaria de la comunidad de Chemesquemena. Es abogada de la Universidad de los Andes y se ha destacado como litigante ante la Corte Interamericana de Derechos Humanos. Es la hija mayor de Carolina Montero, miembro del Consejo de Mayores, y, como muchas mujeres de este pueblo, llegó a la ciudad de Bogotá con el fin de estudiar en una de las universidades más prestigiosas de Colombia.

Ana Manuela se vinculó a la oık desde sus inicios, pero a través de la beca de estudios brindada por la Universidad de los Andes para personas pertenecientes a grupos étnicos, ella buscaba fortalecer conocimientos y experiencias en áreas específicas de la defensa de los pueblos indígenas. 
...Ya en el proceso de formación como tal fue de las cosas más difíciles de mi vida, porque yo tenía una beca por medio del programa de oportunidades, por eso debía ser una excelente estudiante. Ese era uno de los requisitos, porque podían entrar líderes y buenos estudiantes; pues yo ya había sido líder, no solo había liderado en la Organización Indígena Kankuama, sino también en la organización nacional de mujeres indígenas de la ONIC, pues había participado en congresos y con una participación siempre muy activa. (Entrevista a Ana Manuela Ochoa en Bogotá en junio de 2009)

Ana Manuela acompañó el proceso de reetnización kankuamo a través de la socialización del proceso de la oık en un momento donde los jóvenes no se consideraban parte del proceso. Solo los mayores tenían claridad sobre la "campesinización" del pueblo y su herencia indígena. Así mismo, durante este período Ana Manuela fue Consejera de Mujer en la Consejería de la oıк.

A través de esta experiencia identificamos que los procesos de las mujeres indígenas en las universidades suelen ser complejos debido a la multiplicidad de situaciones que deben enfrentar. No obstante, estos espacios permitieron en algunos casos la revitalización cultural de algunas mujeres y, por supuesto, su inserción en los procesos políticos de las organizaciones indígenas de base. Como veremos más adelante, el acceso a la universidad fue un espacio que le permitió reencontrarse con la herencia que se había resistido aceptar.

\section{Rosa Manuela Montero}

Rosa Manuela Montero es una mujer de 34 años, lideresa y exgerente de ASOARKA. Es la esposa del Cabildo Gobernador Jaime Enrique Arias, con quien tiene un niño de ocho años y una niña de diez meses. Al igual que su prima, es originaria de Chemesquemena, y al igual que ella heredó el nombre de Manuela en honor a su bisabuelo el mamo Manuel, 
quien fue reconocido como una autoridad dentro del pueblo. Desde muy joven se fue a la ciudad de Valledupar pues su familia no contaba con recursos para brindarle los estudios secundarios. Desde muy pequeña se fue con su hermana y una tía a trabajar en "casa de familia”. De esta forma ella logró garantizar sus estudios secundarios en un colegio técnico-comercial, y luego los estudios universitarios de contaduría en la Universidad Popular del Cesar. Ingresó a la universidad por medio de unos programas de apoyo que brindaba la oık. Durante el primer año participó activamente en las muestras culturales del pueblo kankuamo. En este espacio, dejó de sentir que sus rasgos fenotípicos fueran un factor más de discriminación y se reafirmó como mujer indígena.

...Y bueno cuando ya estaba en la universidad fue cuando yo comencé a meterme en ese proceso de la organización y empezó a gustarme esa dinámica. Me parecía interesante ese proceso de reorganización y el reconocimiento. [...] Yo creo que en la universidad me sentí mucho mejor que en el colegio. La verdad es que yo no sentí esa discriminación, porque allá, en la universidad, ya comencé a identificarme y a presentarme como indígena de un pueblo, incluso dando a conocer también nuestra cultura, porque mucha gente desconocía el pueblo kankuamo, entonces aprovechaba para darlo a conocer en esos espacios de la universidad. (Entrevista con Rosa Manuela Montero en Valledupar en marzo de 2012).

A través de estos espacios Rosa se vinculó en los procesos productivos de las artesanas kankuamas, lo que en el año 2006 le permitiría ocupar el cargo de gerente, cargo durante el cual recibió la beca del Fondo Indígena para un diplomado internacional de liderazgo de mujeres indígenas. A partir de esta experiencia surgió la iniciativa de recoger las demandas individuales de las mujeres y de desarrollar con ellas los talleres de formación en liderazgo político. Con este proceso comenzó la revitalización de la omıк, vinculado al proceso de las mujeres artesa- 
nas de la asociación ASOARKA, a través de la apropiación de discursos como mujeres víctimas de la violencia y sujetos de derechos, por lo cual los talleres hacen énfasis en el fortalecimiento de conocimiento de derechos humanos y derechos de las mujeres, pues se considera que a partir de estas herramientas jurídicas las mujeres pueden tener mayor empoderamiento de los procesos jurídicos y políticos.

\section{Mildred Montero}

Mildred Montero tiene un proceso particular. Retomando los términos de Rajagopal, Rosa y Ana Manuela vienen de procesos que se han construido "desde abajo". Estas mujeres han logrado construir un estatus social distinto lejos de las comunidades de las que provienen. La relación que ellas sostienen con su territorio y demás mujeres está mediada por los proyectos y programas que desarrollan. Por el contrario, Mildred habita en la comunidad de La Mina junto a su esposo y sus dos hijos. Cuando inició la violencia migró sin éxito con su familia materna a la ciudad de Valledupar, buscando un lugar donde reconstruir su vida. Los costos de sostenimiento eran mucho mayores y "pasaban trabajos", así que resolvieron regresan a La Mina. Estando allá, a los 17 años se casó con su novio mientras se acaloraba nuevamente la violencia en esta comunidad. Su familia salió de la región y ella se quedó.

Mildred se vinculó al proceso organizativo de la oIK como secretaria del líder indígena Fredy Arias, quien fue asesinado posteriormente por grupos paramilitares en Valledupar. A partir de esto, ella y otros líderes de la zona organizan movilizaciones para llamar la atención nacional e internacional sobre lo que está sucediendo con su pueblo. Actualmente, dirige un hogar infantil del Bienestar Familiar y es enfermera de profesión, lo cual le dio cierto reconocimiento dentro de la comunidad para el trabajo con las mujeres víctimas de la violencia familiar y del conflicto armado. Ahora mismo se encuentra estudiando psicología en la Universidad Nacional Abierta y a Distancia (UNAD). Se 
ha desempeñado como delegada de la Consejería de Mujer, Familia y Generación de La Mina, como también de la oIK, en la onIC y actualmente es la coordinadora de Derechos Humanos delegada de la Macro Norte.

Mildred exponía durante nuestro encuentro cómo a través de los procesos de formación desde las primeras Escuelas de Derechos Humanos se logró fortalecer otros procesos de la Organización Indígena Kankuama:

La primera fue la Escuela Propia de Derechos Humanos, y luego fue la de Fredy. Yo participaba en las dos Escuelas. Nosotros duramos casi seis meses en esa Escuela y fueron pocos los que terminamos. Los ciclos eran por módulos así que tocaba exponer, hacer tareas, trabajos en las comunidades; también teníamos que socializar y hacer encuestas. Ahí aprendimos muchas cosas que estaban pasando en el pueblo y nosotros no hacíamos nada desde la defensa de los derechos humanos. Entonces eso me permitió a mí fortalecer mucho más la comunidad porque yo empecé a trabajar el tema de los derechos con las mujeres, los hombres, incluso en los colegios. Ahí me di a conocer. Por ejemplo, yo les explicaba a ellos en el caso de las mujeres, muchos asuntos sobre maltrato. Antes ellas mentían y encubrían al hombre; en cambio, ahora no. Ya se ve poco maltrato a la mujer, ya ellas saben que tienen unos derechos y reclaman. (Entrevista realizada a Mildred Montero en La Mina, Cesar, en marzo de 2012 y en Bogotá en abril de 2012)

\section{Presencia y Ausencia del Estado}

A partir de la promulgación de los Autos de la Corte Constitucional en 2009 y de la participación de este grupo de mujeres, la OMIK en asociación con ASOARKA han logrado avanzar en el apoyo de los programas que permiten su fortalecimiento en los espacios políticos indígenas. El Estado ha promovido el fortalecimiento de las mujeres a través de los programas, 
como por ejemplo, hogares infantiles y madres comunitarias del Instituto Colombiano de Bienestar Familiar (ICBF). Estos programas vinculan a las mujeres a talleres en los cuales se capacitan sobre la protección a la primera infancia, apoyo familiar e identificación de situaciones de riesgo y violencia familiar. Algunos de estos programas se han propuesto desde la омıк como punto de soporte para el fortalecimiento de los procesos que se están adelantando desde esta organización.

Otra institución es la desaparecida Acción Social, ahora el Departamento para la Prosperidad Social, a través del cual se gestionaron proyectos productivos para las mujeres afectadas por el conflicto armado. Así mismo, la presencia de algunas compañías de extracción de hidrocarburos y minerales como Ecopetrol y Carboandes, están acompañando la gestión de "Mujeres Rurales Productivas”, el cual cuenta con la participación de las mujeres de ASOARKA. En algunos casos estos apoyos han sido leídos como una forma de "legalizar" el daño social y ambiental que generan las empresas extractoras de recursos naturales en territorios indígenas. No obstante, frente a las condiciones de pobreza y falta de acceso de alimentos en varias de las zonas del territorio kankuamo, estos apoyos resuelven parte de las necesidades diarias de las comunidades. Cada programa que se propone en las comunidades debe pasar por el aval de las autoridades indígenas:

...y más que todo porque esto tiene un conducto regular, entonces estos deben ser avalados por la organización o debe ser de conocimiento de nuestro Cabildo Gobernador. Él es el que da el aval, si puede o no. Entonces, son poquitos los aportes que el Estado ha hecho [...] más que todo, hay que decir, que el Estado es así, o sea, dice que sí pero siempre juega con dos caras y eso, en esas dos caras uno no sabe cuál es la que le toca. (Entrevista a Sibelys Villazón en Guatapurí, Cesar, en enero de 2013)

Como mencionábamos, hay programas que se piensan en el fortalecimiento de los procesos familiares y de género, pero ninguno de ellos 
está diseñado para dar respuestas a las demandas de las mujeres y de las familias indígenas. Por lo mismo, el diálogo con el Estado suele ser ausente, lleno de conflictos donde los apoyos son gestionados desde las bases de las comunidades indígenas, y donde ellos plantean sus necesidades y las proyectan a través de las organizaciones regionales y nacionales. Quienes dan cuenta de estos procesos son aquellos líderes y lideresas indígenas que entran y salen de los contextos locales a los nacionales y trasnacionales, que sostienen diálogos de doble vía entre las comunidades y los delegados de las instituciones estatales, donde estos se constituyen como una elite indígena.

\section{LAS NUEVAS ELITES KANKUAMAS}

Las lógicas migratorias desencadenadas por la violencia, así como las perspectivas frente a la calidad de vida de las mujeres indígenas, motivaron el desplazamiento de muchas de ellas, con lo cual ganaron, en medio de este proceso, nuevos capitales económicos, políticos, sociales y culturales. En este sentido, las mujeres que lideran estos procesos políticos mencionadas anteriormente se han ido constituyendo como una nueva elite indígena kankuama.

Mientras algunos pueblos indígenas de Colombia se resisten a integrarse al Estado política y culturalmente, por medio del aislamiento voluntario o del fortalecimiento de prácticas tradicionales como sus autoridades o jurisdicción propia, otros ven en el Estado una institución que les brinda oportunidades de mejorar "su calidad de vida" por medio de la educación, la tecnología y la economía.

El pueblo kankuamo ha incorporado a sus creencias tradicionales otras prácticas propias de la sociedad moderna no indígena. Algunos reemplazan sus trajes tradicionales en la ciudad y los retoman en los espacios de reunión con las autoridades; así mismo, estas lógicas se repiten en las prácticas culturales como las ceremonias, rituales, músicas y el idioma. 
Los líderes indígenas, entre ellos las mujeres, han asumido buena parte de estas dinámicas de los mestizajes culturales (García, 1989). Esto se expresa a través de la apropiación de todos los recursos discursivos desde la reetnización del pueblo, así como de la defensa del territorio y la madre tierra.

Pero, para sostener el diálogo con el Estado y el movimiento en redes trasnacionales que apoyan los procesos locales de defensa, deben poseer otra clase de recursos culturales propios de las sociedades modernas no indígenas, adquiridos por medio de la educación, la economía de mercado y la tecnología.

Así, en este espacio se plantea la idea sobre el surgimiento de una elite política indígena que convive y desarrolla su cotidianidad en medio de las prácticas sociales, políticas y culturales de un mundo moderno y cosmopolita.

En ese sentido, pueden acceder fácilmente a los procesos locales y globales de democratización incorporando en estas prácticas culturales tradicionales kankuamas en proceso de recuperación. En el caso de las mujeres indígenas, logramos identificar a Rosa Manuela Montero y a Ana Manuela Ochoa como poseedoras de recursos económicos, educativos, sociales y políticos que las ubican dentro de las elites indígenas kankuamas.

Las familias de estas líderes indígenas no se asientan en las comunidades del resguardo indígena, ni desarrollan su cotidianidad en el mundo indígena; se mueven por distintos escenarios nacionales e internacionales y replican estos conocimientos en contextos más locales de la organización indígena.

Para concluir, estos procesos de acción colectiva no pueden leerse como un fenómeno lineal y homogéneo. Este proceso está lleno de matices donde se traslapan tipologías culturales, económicas, jurídicas, políticas e históricas que marcan las características de la acción política colectiva de las mujeres kankuamas. 


\section{DE LA "LEY DE SE"9 A LOS PROCESOS ELECTORALES: LOS ARHUACOS Y SU "ENTRADA EN LA POLÍTICA MUNICIPAL"}

En el marco de esta reflexión sobre la "democracia y la acción colectiva indígena”, el análisis a partir de la experiencia del pueblo arhuaco ${ }^{10}$ en la SNSM permitirá aportar algunos elementos de comprensión sobre la “entrada en política” de líderes y dirigentes arhuacos en las elecciones para Alcaldía y Concejo del municipio de Pueblo Bello, desde su creación en el año 1998. El trabajo de campo ${ }^{11}$ permitió entender las formas de acción colectiva del pueblo arhuaco, fundadas discursiva y culturalmente en categorías “extrañas” a nuestra tradición democrática, como: Ley de Origen,

9 La Ley de Se es la ley del conocimiento y del cumplimiento en pensamiento de las leyes que mantienen en orden el universo; es la Ley de origen, principio y orden de todos los seres. Es la ley dejada a los hermanos mayores (arhuacos, koguis, wiwas, kankuamos) al momento de la creación del universo, y que aún conservan "escrita” en la geografía de su territorio. Según su cultura, en el momento de la creación fueron creados primero por el padre Serankwa junto con la Sierra Nevada de Santa Marta, por esto ellos son los hermanos mayores y la Sierra Nevada de Santa Marta el corazón del mundo Jwawika Umunukunu, y les fue dada la Ley de origen con la responsabilidad de vivir de acuerdo a ella en el territorio delimitado por la Línea Negra y de esta forma mantener el equilibrio de la Sierra Nevada y, por consiguiente, el equilibrio del Universo. Después el padre Serankwa creó los demás pueblos: "los hermanos menores".

10 Según la Confederación Indígena Tayrona (СІт) el pueblo arhuaco tiene una población aproximada de 40.000 personas. El censo del DANE de 2005 registró una población de 13.450 personas en el municipio de Pueblo Bello, de los cuales 9754 son arhuacos (72,5\% de los habitantes). Entre los 102 pueblos indígenas reconocidos por la ONIC en el país, los arhuacos poseen una de las organizaciones políticas indígenas más fuertes. Gracias a las condiciones geográficas, culturales y jurídicas en las que se encuentran aún pueden convivir bajo el mandato ancestral dictado por la Ley de Origen ( $\mathrm{Se}$ ), la cual se concreta en sus autoridades "propias" (como los mamus, el Cabildo Gobernador, la Directiva Central y las autoridades menores de cada asentamiento de la Sierra Nevada de Santa Marta) y la CIT.

11 A continuación citamos las principales actividades con el pueblo arhuaco realizadas en el marco del proyecto: realización de un diplomado sobre Diplomacia Indígena con la participación de los profesores de la Universidad del Rosario y 55 estudiantes arhuacos entre agosto y diciembre del 2011; realización de entrevistas: una con Nayarith Hernández Villazón, candidata liberal a la Alcaldía de Pueblo Bello, y otras con los miembros de la lista indígena inscrita por el movimiento AICO al Concejo durante el período postelectoral en febrero del 2012; participación en un taller de 10 días sobre liderazgo arhuaco en Simonorwa, del 10 de julio al 20 de julio del 2012; participación en el encuentro con profesionales arhuacos, en Simonorwa, agosto de 2010; presentación y participación en la Asamblea General del Pueblo Arhuaco, el 21 de agosto del 2012, Nabusimake. 
mamu, ${ }^{12}$ Gobierno Propio, ${ }^{13}$ Territorio, Autonomía (Torres, 1996, 2004). Estos son los principales elementos que definen el capital étnico del arhuaco. De la vitalidad de estos elementos depende lo que podríamos llamar un proceso de "democratización” arhuaco.

Igualmente, pudimos ubicar las dificultades de la acción colectiva en esta región para la concreción de sus demandas debido a la presencia de actores armados legales e ilegales y de actores económicos estatales y multinacionales (Mora, Naranjo, Rodríguez \& Santamaría, 2009). Así, pudimos definir las características principales de las acciones colectivas arhuacas y su relación, o desencuentro, con las elites políticas locales. Estas características hacen referencia a cuestiones "propias" que deben ser entendidas en el marco del dinamismo propio de las culturas.

\title{
FORMAS DE GOBIERNOS ANCESTRALES: LA ESPIRITUALIDAD COMO PRINCIPIO DE ORGANIZACIÓN, ACCIÓN, PODER Y DEMOCRATIZACIÓN
}

\author{
El mundo espiritual transforma el material. \\ Conducir el pensamiento hacia Se, \\ pues la Ley de Se legisla todo en armonía, \\ desde el principio hasta el fin.
}

Mamu Wiwa Ramón Gil Barros

El trabajo de campo realizado en las regiones de Pueblo Bello, Nabusimake y Simunurwa nos permitió avanzar en la comprensión de las

12 Máximo líder del pueblo arhuaco tanto en la dimensión espiritual como política, guardián e intérprete de la Ley de Sé. En el atlas Iku, el pueblo arhuaco lo define como encarnación del saber; es el encargado de orientar, guiar, aconsejar, pagar y adivinar para que el Iku permanezca dentro de la Sierra guardando La ley de Origen.

13 Entre los distintos gobernadores arhuacos después de la expulsión de los misioneros capuchinos en 1982, están: José Rufino Crespo Zalabata (1971), Liberato Crespo (1974-1978); Pastor Niño (1971); Sebastián Zalabata (1971); Luis Napoleón (19781988); Bienvenido Arroyo (1987-2000); Julio Alberto Torres (2000-2009); Rogelio Mejía (2010-2012). Igualmente, aparecen 4 lideresas muy importantes como Dionisia Alfaro, Benerexa Márquez, Leonor Zalabata y Salomé Torres. 
prácticas de acción colectiva emergentes. Para comprenderlas es importante realizar un breve ejercicio de contextualización de los principios en los que se fundamenta el gobierno y las acciones del pueblo arhuaco.

Para el pueblo arhuaco la vida del $\mathrm{Iku}^{14}$ gira alrededor del mamu, al nacer, durante la vida, en la muerte y después de esta, al igual que en la toma de decisiones económicas, sociales, culturales y políticas. El mamu encarna la Ley de Origen, es el encargado de cuidar la tierra, salvar la vida, cuidar el mundo, "su poder" reside en el "saber", conoce, conserva y transmite la ley tradicional. La convivencia y la supervivencia del Iku están determinadas por esta. El mamu vela por la adaptación de todos al medio ecológico, para que aprendan a trabajar, se apropien de las costumbres de la Ley Tradicional y también para que aprendan a ser "mayores" y a cuidar la Madre. Con su saber, el mamu "trabaja” para "mantener el equilibrio con la naturaleza y con los seres sobrenaturales para mantener la salud social” (Pueblo arhuaco, 2001). Así, la figura del mamu es importante e imprescindible para el ejercicio de gobierno "propio" del pueblo arhuaco y de los demás pueblos de la Sierra (koguis, wiwas y kankuamos).

De lo anterior se desprende una diferencia de capitales entre el pueblo arhuaco y el pueblo kankuamo. Mientras que para los primeros el conocimiento del mamu y su presencia en las dinámicas comunitarias son hoy en día una realidad, para los segundos son un recuerdo que están intentando recuperar a través de las enseñanzas de los mamus koguis y arhuacos. Los kankuamos también sufrieron la pérdida de su lengua, de su vestido y del manejo ancestral de su territorio, por lo que más que un capital étnico poseen un vasto capital militante producto de su proceso de reetnización, como lo pudimos observar en los perfiles analizados anteriormente. En contraste, el accionar del pueblo arhuaco está orientado a fortalecer las instituciones propias de gobierno, como la figura del mamu, que garanticen las condiciones del ser arhuaco, por

14 Nombre tradicional de los arhuacos; así se llaman a sí mismos. 
lo cual en este caso nos referiremos a un proceso de "democratización" que conduce al fortalecimiento de la cultura y se convierte en un eje fundamental de la acción colectiva "propia".

En los discursos analizados de los arhuacos (tanto en textos como en escenarios de debate), pudimos observar que su actuación implica repertorios de acción muy complejos que se manifiestan en las estrategias implementadas para la defensa de la cultura y el territorio, construidas desde su cosmovisión. El discurso se centra en elementos cercanos al ecologismo global, vehiculando conceptos como equilibrio, protección de la naturaleza, etc. Sin embargo, a pesar de que los arhuacos comparten ese ideario con otros pueblos de la Sierra, en el momento del análisis comparativo es evidente que sus discursos y prácticas políticas han sido poco permeadas por la teoría de la democracia liberal, radical, etc., caso contrario al del pueblo kankuamo. Para explicarlo no podemos caer en esencialismos, y en este contexto no hay que olvidar que durante el período colonial y durante la República no existieron colegios de abogados para los indígenas. Solo hasta el final de los años setenta del siglo xx comenzaron a ingresar los primeros estudiantes indígenas a universidades colombianas.

Los centros de formación de los abogados eran conventos o seminarios de órdenes religiosas en donde había que probar la pureza de la sangre. En el siglo xIx, el ejercicio del oficio de abogado estaba muy regulado y reservado a personas muy bien posicionadas en la sociedad, ya que los costos de los procesos y de la formación eran muy elevados (Ruíz, 1916). Es importante mencionar que, de cierta forma, la educación profesional ha permitido que algunos indígenas adquieran cierto estatus social, como es el caso de las mujeres kankuamas quienes se integraron al Estado como sociedades campesinas mestizas. En el caso arhuaco ha existido históricamente una resistencia a las múltiples formas de integración, lo que limitó el acceso a la educación superior. Aquí se debe tener en cuenta que la identidad no es una esencia, es algo que se construye en medio de procesos de hibridación cultural. Así, el pue- 
blo arhuaco habla de un desarrollo propio orientado a la "permanencia" cultural y de una educación, salud y justicia "propias"15 que gravitan alrededor de elementos que pertenecen a su legado ancestral y elementos nuevos apropiados del movimiento indígena o de otros movimientos sociales.

Los resultados aquí presentados buscan aportar elementos de comprensión sobre un proceso organizativo sobreviviente con respecto a una situación colonial tan fuerte como la de la presencia de los Capuchinos por más de setenta años en el territorio. En este sentido, es importante resaltar que este proceso se consolida como una forma de acción colectiva política no violenta. Ante la amenaza física y cultural a la que han sido sometidos los arhuacos, una de sus estrategias de resistencia ha sido reinventar algunas de sus instituciones políticas a través de una articulación entre "lo ancestral" y "lo nuevo", entendido como un fenómeno propio de los procesos culturales. La manifestación más clara de ello es que, si bien el mamu es la máxima autoridad de todo orden, el ejercicio del poder político ha sido delegado a la figura del Cabildo Gobernador, cabeza de la Directiva Central. A pesar de que estas últimas figuras fueron instituciones "introducidas" por los españoles, “fueron adaptadas y asumidas por la mayoría de los pueblos indígenas de Colombia como las autoridades legítimas para ejercer jurisdicción dentro del territorio que se les reconocía como propiedad colectiva” (Pueblo arhuaco, 2001; Ruíz, Duque). Para el pueblo arhuaco "el poder político, la toma de decisiones y la autoridad civil, responden a unas normas y leyes tradicionales (gobierno nacional, departamental, municipal o entidades) de una manera directa y firme, asimilando lo que favorece su identidad y le da sentido de pertenencia” (Pueblo arhuaco, 2001). Por lo tanto, se construyen y se redefinen permanentemente.

15 Es importante resaltar que el pueblo arhuaco retoma el control político de su territorio en los años ochenta tras la expulsión de los misioneros capuchinos, quienes se habían asentado en el territorio desde 1914 (Rodríguez, Rojas, Santamaría, 2012). 


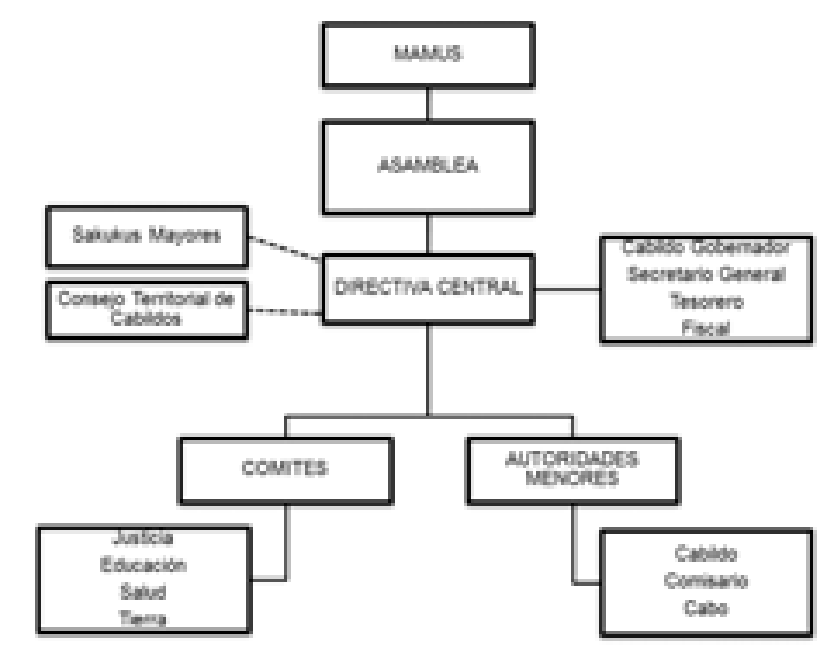

FUENTE: elaboración propia

El diagrama aquí presentado muestra las principales figuras de autoridad para el pueblo arhuaco. El desarrollo del gobierno arhuaco tiene lugar en su territorio ancestral, compuesto por 52 asentamientos y dividido en 4 zonas geopolíticas: Central, Occidental, Suroccidental, Oriental. Las decisiones políticas se debaten en el seno de la Asamblea General que es convocada por la Directiva Central. Si bien todo tiene que estar articulado y en armonía con las leyes tradicionales, se presentan "tensiones" producidas por la forma como esas leyes tradicionales tienen que articularse con lo no tradicional, lo que viene de afuera, lo que no es propio. Existe un firme consenso al interior del pueblo arhuaco frente a la necesidad de fortalecer y conservar sus tradiciones con el objetivo de seguir existiendo como cultura. Las lógicas de las tensiones internas obedecen a formas presentes de gobierno, donde se reclama a las autoridades un profundo conocimiento de la cultura y el territorio, ya que el poder dentro del pueblo arhuaco emana del conocimiento y cumplimento de la Ley de Origen. Son los mamus quienes tienen un conocimiento profundo de esta, de ahí que sean ellos quienes poseen mayor conocimiento de la cultura y el territorio; en consecuencia, están revestidos de una autoridad 
que legitima las instituciones políticas del pueblo arhuaco. Al respecto, cabe agregar que los mamus, más que creaciones individuales, son procesos colectivos toda vez que es la interacción entre mamu y comunidad, el reconocimiento de esta, lo que dota al mamu de relevancia y legitimidad. Las autoridades políticas del pueblo arhuaco tanto en la máxima instancia -Cabildo Gobernador-, como en las instancias locales -Cabildos Menores-, deben contar en todo momento con la aprobación de la comunidad y de los mamus. Las principales decisiones del pueblo arhuaco se deben debatir y aprobar en Asambleas Comunitarias del orden general o local según el caso, y deben ser refrendadas por los mamus.

Cada una de las regiones en la que está dividido el territorio arhuaco posee dinámicas particulares en términos de la geografía humana, física y económica; esto determina el ejercicio de poder al interior de las zonas y en las dinámicas colectivas del pueblo arhuaco. La zona Oriental es reconocida por el vigor cultural, allí se asientan las comunidades arhuacas más tradicionales; en consecuencia, son sus originarios quienes poseen un mayor volumen de capital étnico. La zona Suroccidental es reconocida por la fertilidad de sus suelos, allí se encuentran los tres programas de café orgánico del territorio arhuaco; esto tiene que ver con el hecho de que el clima es más apto para los cultivos, posee carreteras y se encuentra más próxima a una cabecera municipal. Lo anterior ha acarreado una mayor interacción con las dinámicas del municipio de Pueblo Bello, en particular las relaciones comerciales que se tejen en la cotidianidad y que determinan en gran medida dinámicas clientelistas de la población arhuaca.

La dimensión espacial y simbólica es fundamental para el ejercicio del Gobierno del pueblo arhuaco. Así lo reconoció el Estado colombiano según resolución 837 del 28 de agosto de 1995, en la que reconoce 54 sitios sagrados presentes en la Línea Negra. ${ }^{16}$ Por lo tanto, las autoridades tradi-

16 Frontera que delimita el territorio ancestral de los cuatro pueblos de la Sierra Nevada de Santa Marta, fue reconocida por el Estado colombiano en la resolución No. 000002 del 4 de enero. 
cionales están estrechamente relacionadas con la conservación y funcionamiento de los sitios sagrados (los cuales están a lo largo y ancho de todo el territorio ancestral delimitados por la Línea Negra). En particular son importantes para el gobierno propio arhuaco las cuatro kankurwas ${ }^{17}$ mayores (Numaka, Seykwinkuta, Seykumuke y Seynimin).

Esta forma de gobierno ha sido construida y preservada desde las márgenes del campo político, y presenta algunas características como no poseer un régimen representativo $y$, por lo tanto, no hay división, ni distinción de los poderes legislativo, judicial y ejecutivo. "Entre los Iku, el cabildo está conformado sólo por una persona que se designa para ejercer este cargo. El Cabildo es adivinado por el Mamu, entre personas de la comunidad que tengan buen criterio, que sean ejemplo de vida, conocedoras de la tradición, con buena palabra para dar consejo; junto con el Comisario, ejerce su función de consejero, guía y orientador, en la administración de justicia. No hay un tiempo fijo para ejercer el cargo, éste solo se pierde cuando su conducta no corresponde a los patrones morales de la comunidad" (Pueblo arhuaco, 2001). El poder político se descentraliza a través de los cabildos menores y comisarios quienes son "autoridad tradicional" en cada uno de los asentamientos arhuacos, y son elegidos de forma autónoma y por consenso por sus habitantes con el visto bueno de los mamus de la región.

Como lo hemos observado, desde el año 2006 los arhuacos han liderado movilizaciones pacíficas o, como afirma Alexandra Mora, "concentraciones espirituales en sitios sagrados como el cerro sagrado Jukulwa". Según la investigadora Liliana Múnera, ${ }^{18}$ frente al hecho de que la empresa partió en dos el cerro los mamus trataron de visitar el sitio, lo cual no les fue permitido. En abril de 2007 hubo una gran movilización de los cuatro pueblos de la SNSM que fue apoyada por periodistas de CNN y de otros lugares del mundo, así como por diferentes oNG. En el 2009 se moviliza-

17 Templos ceremoniales definidos desde la Ley de Origen.

18 Antropóloga de la Universidad Nacional de Colombia. Investigadora del Programa por la Paz del Centro de Investigación y Educación Popular (CINEP). 


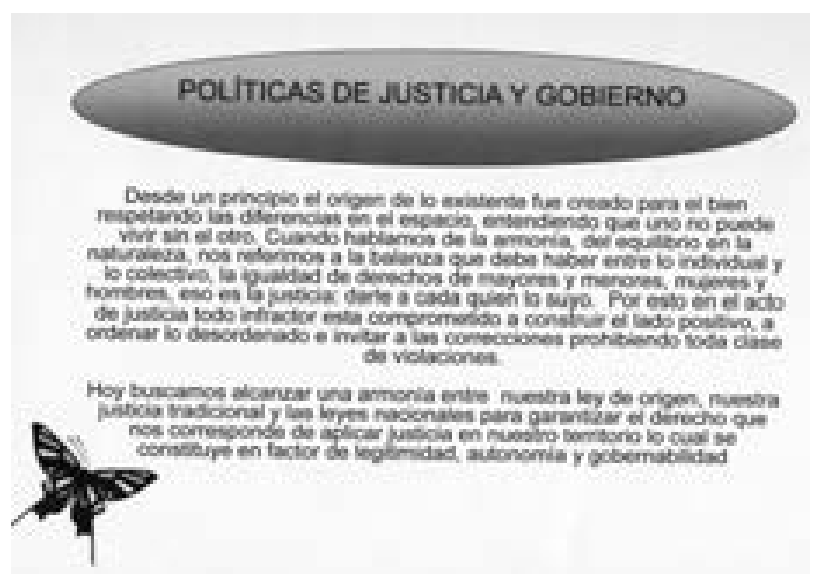

FUENTE: Archivo Plan de Vida del Pueblo Arhuaco

ron 300 indígenas. La marcha pacífica fue dispersada por Agentes Antimotines, quienes ante la presión de los indígenas lanzaron gases lacrimógenos, según advirtió en su momento José de los Santos Sauna Limaco, gobernador de la Organización Gonawindua Tayrona (El Tiempo, 2009). Se dio igualmente un fuerte proceso de judicialización del conflicto ante varios actores de nivel nacional (autoridades locales, Tribunal del Departamento de la Guajira y la Corte Constitucional, Consejo de Estado). En este escenario, como lo afirma Mora, la no participación y el silencio como forma de resistencia civil ha sido también una forma de protesta. Es posible entonces visibilizar un tipo de estrategia y de acción: el trabajo en red para la defensa de los derechos de los pueblos indígenas, retomando la estructura de movilización descrita por Keck y Sikkink. Este tipo de acciones de denuncia han tenido lugar con el apoyo de diferentes oNG de derechos humanos como ILSA, CODHES Y CINEP.

Desde el punto de vista del relacionamiento con el Estado y las elites políticas de nivel nacional, estos pueblos han establecido un trabajo de incidencia en política pública en torno a la defensa de la integralidad ambiental y de la diversidad cultural del territorio. Los mamus de la SNSM 


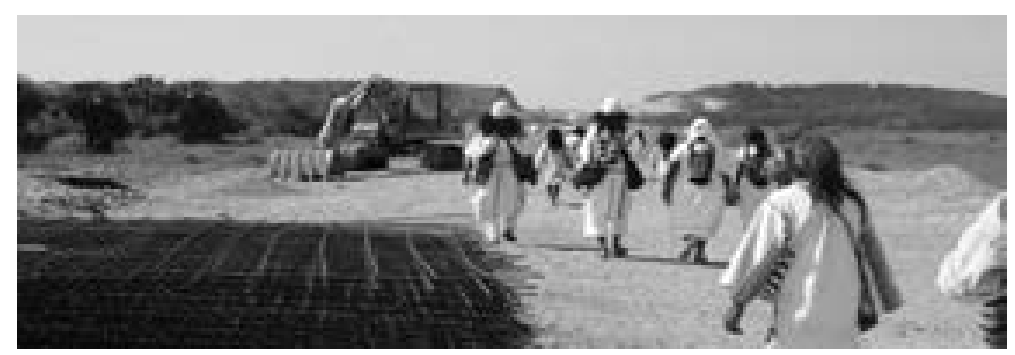

Al fondo el cerro sagrado Jukulwa partido en dos para construir el puerto multipropósito Brisa. (Foto de Danilo Villafañe)

han convocado a senadores y representantes de la República, medios de prensa y organizaciones estatales y ambientales con el fin de dar a conocer esta problemática y proponer soluciones a través de un diálogo intercultural que tenga en cuenta los derechos económicos, sociales, culturales y ambientales de pueblos indígenas (Consejo Territorial de Cabildos de la SNSM, Organización Gonawindua Tayrona, 2007).

\section{PERFILES DE LÍDERES ARHUACOS Y SU EXPERIENCIA}

\section{EN LA POLÍTICA LOCAL}

Puesto que una de las preguntas que busca responder este libro se refiere al encuentro entre los líderes indígenas y las elites políticas locales, así como la generación de interacciones que idealmente resultarán en lo que designaríamos como "procesos de democratización”, el caso arhuaco nos ha mostrado que en la práctica estas interacciones son muy complejas. Como lo mencionamos anteriormente, el pueblo arhuaco ha tenido históricamente un fuerte rechazo frente a "la participación en la política local". Este rechazo se ha dado sobre todo por parte de los mamus toda vez que estos espacios no corresponden a la estructura del gobierno ancestral definido en la Ley de Origen o al que actualmente ha "adaptado" como propio el pueblo arhuaco. Por otro lado, las interacciones han sido permeadas por el conflicto armado. 
Después de realizar varias entrevistas con los líderes arhuacos que han participado en política local, en efecto el encuentro con las elites sociales y políticas locales del municipio de Pueblo Bello ha existido. Para estos líderes, la participación en espacios de política local es una experiencia nueva, desconocida y traumática. Por una parte, los temas prioritarios del municipio son "extraños” al pueblo arhuaco. Por otra, la forma de deliberación temática de las corporaciones públicas y sus tiempos son diferentes a las deliberaciones asamblearias de los arhuacos, que no tienen restricción. Finalmente, las dinámicas de alianzas y negociación propias de los procesos electorales también aparecen como ajenas a las prácticas internas de la comunidad.

\section{ITINERARIOS ARHUACOS EN LA POLÍTICA TRADICIONAL}

Los mamus y las autoridades indígenas no han comulgado hasta el momento con la entrada en política a nivel municipal o departamental o nacional. Sin embargo, han existido múltiples intentos individuales de miembros del pueblo arhuaco para llegar a las corporaciones públicas desde la promulgación de la Constitución de 1991. En 1992, Rubiel Zalabata Torres aspiró al Concejo de Bogotá; en 1994 Álvaro Torres aspiró el Concejo de Valledupar; en 1999 Vicente Villafañe y Geremías Torres aspiraron al Concejo de Valledupar avalados por el Partido Liberal. En las elecciones del 2002 Moisés Villafañe intentó llegar a la Cámara de Representantes por la circunscripción especial indígena con el aval de la Organización Gonawindwa Tayrona y obtuvo en esa oportunidad 44.000 votos. Posteriormente, aspiró al Senado en las elecciones de 2006 con el aval del Partido Liberal, obtuvo 4000 votos. En estas mismas elecciones, la arhuaca Belkis Izquierdo aspiró a la Cámara de Representantes por Bogotá con el aval del Partido Cambio Radical y obtuvo 5000 votos. En el 2011 la lideresa Leonor Zalabata Torres aspiró a la Asamblea Departamental del Cesar avalada por el Movimiento Mio. Es de resaltar que además de los concejales arhuacos electos en Pueblo Bello, la única aspiración exitosa a una corporación pública fuera de este municipio ha sido la curul obtenida 
en dos elecciones por Ati Quigua en el Concejo de Bogotá durante los períodos 2004-2007 y 2008-2011. En las elecciones municipales de 2011, los líderes y autoridades de Simonorwa encabezadas por el líder Geremías Torres deciden respaldar una lista propia de 10 jóvenes sin trayectoria política para que aspiraran al Concejo de Pueblo Bello con el aval del partido político AICo. Una gran mayoría de la población de Nabusimake decide apoyar a un joven politólogo arhuaco como candidato al Concejo de Pueblo Bello por el Partido Liberal, ambas listas respaldaban a la candidata a la alcaldía Nayarith Hernández Villazón. (Elaboración propia)

\section{Sakuku Mayor: Camilo Niño}

La experiencia de unos de los líderes más antiguos, Camilo Niño, desde la oposición en el Concejo de Pueblo Bello, muestra la complejidad de participar en política cuando se ha sido formado en otra tradición política y la dificultad de traducir las concepciones de la cultura al lenguaje político local. Igualmente, los repertorios de acción y la estructura de movilización para retomar los términos de Tarrow son muy distintos y casi incompatibles.

Yo hablaba desde un discurso de conservación de la Sierra, el agua, y ese discurso a ellos no les sonaba, no les interesaba. Por ejemplo, en Solera hay trece nacederos, y están dañando todo eso. Yo les decía que si seguían así en diez años se iban a secar esos nacederos. Yo insistía en que se reubicara a esa gente. Nadie me puso atención. Uno le enseña a la gente que quiere aprender, a la que no es imposible. La gente decía: eso es chochería. En el Concejo no les interesaba nada de democracia, derechos humanos. Yo trataba de hablar de esos temas, pero lo único que les importaba era el dinero. Como en el pueblo saben que el arhuaco tiene reconocimiento, entonces en el Concejo decían aquí tenemos el Sakuku Mayor como de palabra, pero en la práctica no me tenían en cuenta. En un encuentro de Concejales, vi como desde afuera, hay más reconocimiento. 
La politiquería es eso: venga nos tomamos un tinto, compadre, pero nada más. Nos utilizan es para mostrarnos. Hablan del poporo pero no hay políticas para ayudar al pueblo indígena y menos cuando se dice que estábamos en contra del municipio. (Entrevista a Camilo Niño en la Región del Pantano, Nabusimake, en febrero de 2012)

La experiencia de Niño nos muestra cómo la participación política de los arhuacos se estrella con las dinámicas propias de la politiquería y con intereses diferentes a los suyos, con lo cual se presenta una fuerte dificultad para reconvertir las demandas arhuacas con la de otros sectores sociales. Un punto de tensión importante es la constitución del municipio, que debió ser concertada con los arhuacos, ya que gran parte del territorio del municipio pertenece al resguardo reconocido en el año 1983. Sin embargo, este fue aprobado sin el consentimiento de los indígenas. La aprobación del municipio fue el resultado de la unión entre las elites políticas de Valledupar, que veían en la constitución del municipio un fortín político. La iniciativa fue de los políticos Hugo Rudas Villazón y Crispín Villazón de Armas. El pueblo arhuaco decidió votar “NO” a la constitución del municipio en la consulta popular, sin embargo ganó el "sí". Esto dejó en evidencia la falta de experiencia en los ejercicios políticos electorales del pueblo arhuaco y anunció las dificultades que se presentarían en el futuro para la participación de los arhuacos en las dinámicas del municipio. Hubo una gran abstención del voto indígena y la gran mayoría de los que lo hicieron fueron cooptados por prácticas clientelistas a favor del "sí". A pesar de que se acudió a la acción de tutela, el Consejo de Estado falló favorablemente frente a la constitución del municipio. Distintos líderes arhuacos denunciaron frente a este caso problemas de corrupción en el Alto Tribunal. En palabras del líder: "Nosotros no estábamos de acuerdo con el municipio, ese municipio debería tener una vocación ambiental, un enfoque desde el desarrollo propio y desde la permanencia cultural" (entrevista a Camilo Niño en febrero de 2012). 
Como se observa con respecto a las primeras alianzas entre los dos tipos de líderes, existen tensiones fuertes frente al tema del municipio, y una directriz de los mamus para no participar en política local. Sin embargo, los líderes entrevistados obtuvieron suficiente votación para entrar en el Concejo, en una posición minoritaria y de oposición.

\section{Germán Hernández, ${ }^{19}$ Cabildo Businchama: ${ }^{20}$ represión paramilitar en el Concejo de Pueblo Bello}

Germán Hernández, hijo de Dionisia Alfaro, ${ }^{21}$ una de las grandes lideresas del pueblo arhuaco (Torres Márquez, 1978), nació en Pueblo Bello en 1957. Realizó sus estudios de primaria en Simonorwa con las españolas de la Misión Capuchina y luego, en convenio con el Comité de Cafeteros, en el bachillerato agrícola Cenicafé. Es el séptimo hijo de diez hermanos y quedó huérfano a los siete años.

Mi mamá pasó como 20 años en la lucha indígena. Nació en 1937 en Nabusimake y murió como de 75 años. Ella fue egresada de la Misión, fue una de las primeras estudiantes. Allá se casó con un wayúu, Bernavé. A él le regalaron el apellido, un arriero de apellido Hernández. Éramos muchos, y como mi mamá estuvo en la lucha, salía mucho y a nosotros nos criaron otras señoras. Me acuerdo mucho que por ejemplo la viruela me tocó pasarla sólo, me dio mucho trabajo. Cuando ya podía transmitirme la historia sobre la lucha, ya estaba muy enferma, entonces yo aprendí por otras personas, pues ella no pudo contarme mucho.

Sé que mi mamá se asesoraba mucho de los mamus. Ella no tenía plata, la gente le aportaba, para viajar, para caminar, la comida, para

19 Aproximadamente 40-45 años, originario de la región de Simonorwa. Cabildo del Resguardo de Ampliación de Businchama.

20 Este cabildo de ampliación fue constituido en 1995, cuenta con 600 hectáreas aproximadamente y, más o menos, con 1000 habitantes.

21 Fue parte del grupo fundador de la Liga Indígena de la Sierra Nevada de Santa Marta. 
hacer el bastimento. (Entrevista a Germán Hernández en Nabusimake en febrero de 2012)

Como podemos ver en el caso de Germán H., este posee un importante capital militante y étnico heredado de su madre. Sin embargo, su escolarización y formación inicial tuvo muchos tropiezos, pues tuvo que trabajar para ganarse la vida durante gran parte de su infancia y juventud. Fue hacia los 18 años cuando Germán $H$. se casa y comienza realmente su trabajo con la comunidad. Durante los años siguientes será nombrado secretario en Simonorwa, además tendrá 6 hijos con su esposa. En 1997, con la creación del municipio se lanza al Concejo de Pueblo Bello: “Saqué 700 votos. Creo que ha sido la mejor votación hasta hoy”.

Estábamos en un problema muy complicado en el marco del conflicto armado. Una presencia muy fuerte de paramilitares en la región. Tenían mucha incidencia. Conmigo no se metieron. Durante esa época yo me aseguré mucho con los mamus. El alcalde era Hugo Rudas Villazón. Durante un año no hice ningún tipo de incidencia, pues uno va aprendiendo en el camino y a uno lo utilizan mucho cuando no sabe. Después de un año le cogí el ritmo a la cuestión. En el último año me delegaron para talleres, seminarios en nombre del Concejo. Los últimos presidentes del Concejo me tenían en cuenta, pero había mucha envidia. (Entrevista a Germán Hernández en Nabusimake en febrero de 2012)

Germán H. narra cómo el último día antes de las elecciones llegó el líder de los paramilitares, alias “38”, quien tenía mucha incidencia en la región. Hizo que varios candidatos se retirarán de la lista. A Germán le dijo que se inscribiera. Por el pueblo arhuaco había una lista encabezada por el líder Clodomiro Arroyo.

Los cuatro años que estuve en el Concejo fue una época muy dura. Se hacía todo lo que los paramilitares querían. Del presupuesto, había 
recursos que iban derecho para ellos, como 35 millones. Los paras tenían incidencia directa en el Plan de Desarrollo. En esa época hasta los contratos venían arreglados. En términos de servicios públicos nos hicieron por ejemplo pagar una tarifa superior, se le subió un $4 \%$ en un año. No había posibilidad de hablar. El tema de reservas naturales que era fundamental para nosotros, no era posible discutirlo. (Entrevista a Germán Hernández en Nabusimake en febrero de 2012)

Germán afirma que desde esa época no ha querido participar en política local, pues para el siguiente representante en el Concejo fue aún más difícil. Sin embargo, desde su experiencia, es posible decir que tuvo un margen de maniobra para trabajar sobre las cuestiones sanitarias, las vías y las plantas solares. Es decir, temas ambientales marginales. Todo lo anterior tuvo lugar en medio de una situación muy complicada de orden público.

Durante esa época se hicieron muchos pagamentos. De esa forma se logró que el pueblo arhuaco tuviera menos víctimas que otros pueblos. Yo me quedé quieto por un tiempo, y en el 2004 me llamaron para ayudar al Cabildo saliente de Businchama en el tema de las escrituras, pues querían comprar una casa oficina y nos metimos en eso como unos dos años. La gente no le caminó mucho. Entonces yo seguí con un proyecto de fortalecimiento de kankurwas en Sabanita. En el 2006 me llamaron en una Asamblea para que acompañara a José Riveira. Luego, la comunidad me llamó para ser Secretario General del Cabildo entre 2006-2009. Se comenzó a pensar en la ampliación del resguardo arhuaco, a través del Resguardo de Businchama. El total de la población del resguardo de Businchama es de 800 habitantes en más o menos 127 hectáreas. Queda como a dos horas a pie de Pueblo Bello. En ese proceso ya llevamos como seis años. (Entrevista a Germán Hernández en Nabusimake en febrero del 2012)

Con la experiencia de Germán Hernández vemos claramente cómo la presencia de actores armados ilegales en el contexto de una escalada de 
violencia en la región hace optar a los arhuacos por el repliegue sobre sí mismos y por el fortalecimiento y la resistencia cultural no violenta desde los trabajos tradicionales con los mamus.

\section{La experiencia de un docente bilingüe}

Según nuestros entrevistados, los asentamientos que han participado en elecciones locales son: Simonorwa y Jewrwa en la zona suroccidental y Gunnarun en la zona oriental. Con la creación del municipio de Pueblo Bello y la aparición de las dinámicas políticas electorales propias de los municipios llegó a la Sierra el tema político, con el Partido Liberal, la U y el Partido Verde, según lo vimos en las últimas elecciones, cargado de politiquería y clientelismo. Al respecto, en palabras de Gregorio, antes "eran grupitos y eso no es comunidad, antes eran azules y rojos. Los indígenas eran liberales”. Antes de la constitución del municipio empezaron los Castro $^{22}$ de Valledupar a hacer política, y ellos "tenían muchos votos de los indígenas". Esta alianza tiene raíces históricas: desde la época en que, como lo narra el historiador Friede y el literato Baute, los arhuacos bajaban de la Sierra y pernoctaban en la casa de los Castro en Valledupar (Friede, 1963, 1973).

Era una familia reconocida. Cuando uno llegaba a Valledupar tenía en dónde hospedarse. Entre las familias políticas importantes estaban los Mestre, los Villazón, los Pavajeau. Durante las elecciones de Hugo Álvarez para la alcaldía de Pueblo Bello, por el partido liberal, se le acusó de peculado, por la desviación del acueducto y lo pusieron preso. Entonces dejaron de encargado a Adolfo Mestre. Posteriormente vino la disputa entre Martiniano con el apoyo de los indígenas desde el Cabildo mismo, quien se enfrentaba a Pepe Pianeta. Este último de la

22 Familia de una amplia tradición política en el Cesar, reconocida por sus grandes posesiones de tierra. Tuvo una popular relación con el pueblo arhuaco debido a la proximidad de sus fincas con el resguardo arhuaco. 
línea de Landazabal, quien estaba a cargo de la cooperativa de café, y, por lo tanto, tenía un vínculo comercial con los indígenas. Luego vino la contienda política entre Nayarith y Landazabal. Este último un comerciante cercano a la gente pues le fiaba el mercado, le prestaba plata. (Entrevista a Gregorio Izquierdo en Región del Pantano, Nabusimake, en febrero del 2012)

Las últimas elecciones, como lo afirmaron nuestros entrevistados y fue consignado por la MOE, estuvieron atravesadas por la corrupción y el clientelismo. "Dos días antes de la campaña, subieron a Nabusimake camiones enteros con mercados. Javier Landazabal, le prometía a la gente que iba a hacer cinco puentes en cemento, que iba a poner tubos de metal. Fue una campaña muy costosa, una campaña de miles y miles de millones de pesos, pero no se conoce el proceder de ese dinero... tal vez... dineros ilícitos".

También se observó el proceso de traslado de votos de indígenas de Atánquez, de habitantes de Aguas Blancas, y fuerte presencia de la policía. Este proceso electoral se dio en el contexto del nuevo reposicionamiento de las autodefensas en Pueblo Bello, "para restablecer el orden". Durante la alcaldía de Javier Landazabal era tan fuerte la connivencia entre el gobierno local y los paramilitares que "llegó como directora del hospital la esposa de ' 38 '”:

Durante esa época había mucho temor en la región. No podíamos subir mercados por más de 200.000 pesos. Durante esa época, el señor Camilo Niño entró al Concejo. Pero en esa situación, afirmaba Gregorio, no se podía hacer gran cosa. Cualquier proyecto que él proponía tenía a toda la oposición encima. Pudo hacer algunas cosas pequeñas, "que una manguera por aquí, otra por allá". El poder de ejecutar lo tenía el alcalde. (Entrevista a Gregorio Izquierdo en Región del Pantano, Nabusimake, en febrero del 2012) 


\section{Álvaro Antonio Torres}

Su nombre, dado por los mamus, es Geyarubin (significa fuego sagrado). Se trata de un mayor arhuaco de 58 años, nacido y criado en Nabusímake. Estuvo internado de 1961 a 1967 en el orfelinato Las Tres Avemarías de Nabusímake bajo la educación de los misioneros capuchinos, sin embargo esto no fue impedimento para que años más tarde se convirtiera en un fuerte opositor de la presencia de la misión Capuchina en la Sierra. Desde muy joven se vinculó con los procesos organizativos de su comunidad acumulando así una amplia trayectoria de liderazgo en procesos políticos, de educación y salud.

Para las elecciones municipales de 2011, el mayor Álvaro, con un amplio capital militante acumulado, se convirtió en uno de los principales promotores de la candidatura al Concejo de Pueblo Bello del joven arhuaco Seyningumu Torres quien, por fraude en el proceso de registro de los votos, no alcanzó la curul; sin embargo, permitió en Nabusímake hacer un ejercicio de oposición a la forma tradicional de hacer política. Uno de los propósitos de esta candidatura era hacer un ejercicio comunitario de la región de Nabusímake, es decir que fuera una candidatura surgida de un consenso y no de una aspiración personal, una intención de trasladar el carácter colectivo del gobierno arhuaco a las instituciones políticas "externas". Por otro lado, este proceso de participación tuvo la intención de realizar una contracampaña a las aspiraciones del candidato a la alcaldía de Pueblo Bello Javier Landazabal Gómez.

En palabras del mayor Álvaro "estábamos retados en Nabusímake, decíamos vamos a ver si nos ganan los mercados, el cemento y las mangueras o si por el contrario podemos tener un posición política crítica". Si bien no se alcanzó el objetivo de obtener un espacio en el Concejo, uno de los mayores logros de este proceso fue derrotar en Nabusímake al candidato Javier Landazabal Gómez, quien a pesar del esfuerzo clientelista no pudo obtener la mayoría de votos. Para el mayor Álvaro, el hecho de que se hubieran presentado fraudes en el conteo de votos del 
candidato indígena obedece a una clara intención de impedir que este indígena llegara al Concejo, toda vez que ya eran de conocimiento público las altas cualidades técnicas del candidato y su posición crítica frente al proceso del municipio de Pueblo Bello. Es de resaltar que este arhuaco es politólogo de la Universidad Nacional e hijo de Sebastián Torres, un reconocido líder del pueblo arhuaco; en consecuencia, marcaba una diferencia con otros arhuacos que habían alcanzado una curul en el Concejo de Pueblo Bello.

En este proceso se ve la confrontación entre una elite local de Pueblo Bello, que cuenta con las estructuras de gobierno y un vasto capital económico, y una elite indígena del pueblo arhuaco, que planteó un debate centrado en las propuestas políticas y que logró un triunfo parcial en el espacio propio: Nabusímake. Pero que fue derrotada de manera irregular en las dinámicas locales externas: proceso de conteo y registro de votos en el municipio de Pueblo Bello.

\section{LA EXPERIENCIA DE LA LISTA INDÍGENA: ¿CASO FALLIDO?}

En el 2011, desde la región de Simonorwa, un grupo de jóvenes bajo la coordinación del líder arhuaco Geremías Torres lanza una lista indígena para tener participación fuera de los partidos tradicionales en el Concejo de Pueblo Bello que, a su vez, respaldó la candidatura de Nayarith Hernández Villazón, quien aspiraba a la Alcaldía por segunda vez por el Partido Liberal. Esta candidata propone un discurso basado en los derechos de las mujeres, los pequeños productores y los pueblos indígenas, además establece una alianza con los arhuacos de Simonorwa y Nabusímake, dos de las principales regiones de la SNSm. Nayarith, al igual que buena parte de la familia Villazón, tiene vínculos familiares con algunas familias del pueblo arhuaco como los Izquierdo. Por ello, para muchos electores era la candidata de "los indios". 


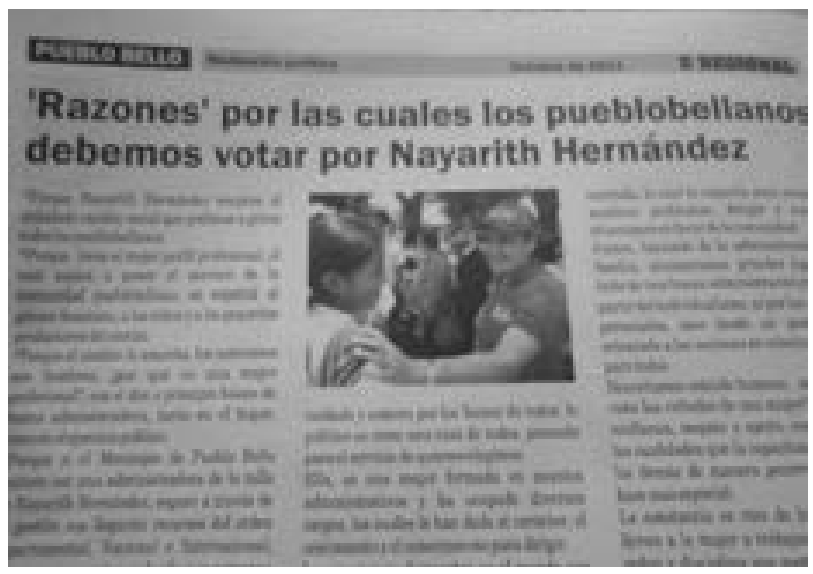

Informativo El Regional, octubre de 2011

Es importante resaltar que el pueblo arhuaco representa aproximadamente el 72\% de la población del municipio de Pueblo Bello por lo cual, en términos ideales, la lista que apoyaba la candidatura de Nayarith tenía, cuantitativamente, altas posibilidades de conseguir por lo menos una curul. Sin embargo, no hay que olvidar que este grupo se constituyó en medio de la negativa de los mamus a la política, pues habían identi-

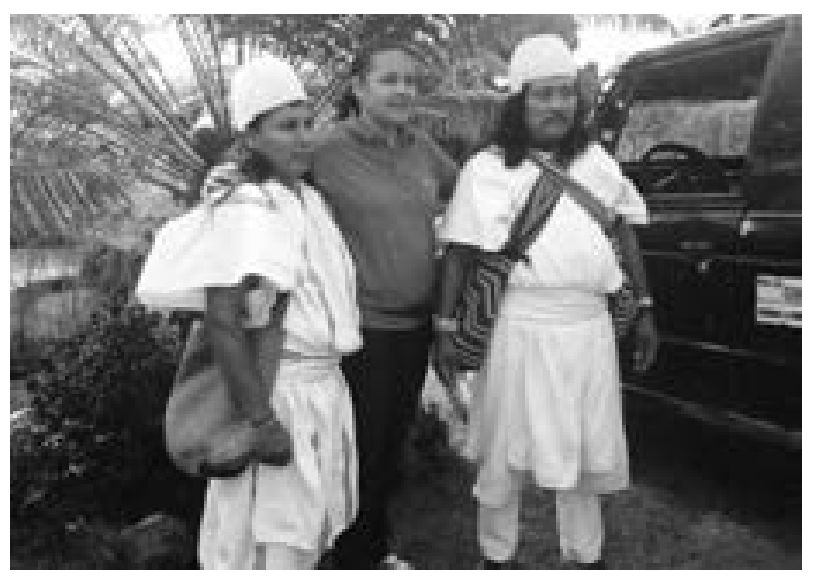

Freddy Izquierdo, Nayarith Hernández y Geremías Torres, octubre de 2011 
ficado la necesidad de hacer una reflexión interna. Se denunciaron posibles irregularidades como traslados de mesas, constreñimiento al elector, parcialización de jurados de votación, pérdida de votos de la lista indígena en Jewrwa y Nabusímake.

A diferencia de los casos anteriores, en los que encontramos la participación emergente de las mujeres kankuamas y la experiencia del pueblo arhuaco en las elecciones municipales, a continuación describiremos el caso límite del pueblo wounaan y algunos procesos y prácticas de acción colectiva que han emergido aun en situación de desplazamiento forzado y pobreza.

\section{ENTRE CONDICIONES DE SOBREVIVENCIA Y PRÁCTICAS DE ACCIÓN COLECTIVA: EL PUEBLO WOUNAAN EN MADRID, CUNDINAMARCA}

Con el objetivo de analizar y comparar las prácticas de acción colectiva indígenas, en esta parte del capítulo nos referiremos a la situación crítica que ha tenido que afrontar el pueblo wounaan a causa del conflicto armado, y cómo aun en una situación tan extrema y dramática han emergido algunas prácticas de acción colectiva y procesos de democratización a partir de "lo social". ${ }^{23}$ Nos centraremos en los repertorios de acción de los actores involucrados y en el proceso de acumulación del capital étnico y político de algunos de los líderes, lo que ha permitido un acercamiento con las elites políticas locales.

Como en los casos anteriores, en primer lugar haremos una breve aproximación a la organización política y social del pueblo wounaan, para luego comprender a través de los perfiles de algunos líderes cómo en las familias desplazadas ha emergido un pequeño proceso organiza-

23 La democracia supone que los mismos actores sociales dan sentido a lo político a través de unos debates, unas reivindicaciones y unas luchas que les permitan integrar y transformar sus demandas en sus propias concepciones acerca del poder, de la ley y de la verdad (Lefort). 
tivo y cuál ha sido su relación o desencuentro con las elites políticas locales, sin olvidar las dificultades de la acción colectiva para la concreción de sus demandas debido a las diversas problemáticas a las que este grupo de familias se enfrenta día a día (pobreza, violencia, etc.). En este caso, el trabajo de campo se dio en el marco del proyecto "Escuela Intercultural de Diplomacia Indígena (EIDI)” con miembros del pueblo wounaan, desplazados en el municipio de Madrid, Cundinamarca, durante los años 2011 y 2012.

\section{APROXIMACIÓN AL PROCESO ORGANIZATIVO DEL PUEBLO WOUNAAN}

El pueblo indígena wounaan se encuentra en las zonas centrales de la región del Pacífico de Colombia, en las cuencas baja y media del río San Juan (municipio Litoral del San Juan, de Istmina y Pizarro), en el río Curiche, municipio de Juradó y en el río Docampado, hasta la Serranía Wounaan al norte y Bahía Málaga al sur (municipio de Buenaventura, Valle del Cauca). Igualmente en la región del Darién en Panamá (Observatorio DDHH y DIH, 2010, p. 2). Son alrededor de 8000 personas, organizadas en 18 resguardos $^{24}$ en el departamento del Chocó y 6 en el municipio de Buenaventura, Valle del Cauca. En el ejercicio del derecho a la autonomía y gobierno propio, la población se ha organizado de la siguiente manera:

En la base de cada resguardo, como en los casos anteriores, se encuentran las “Autoridades Locales", el Cabildo Gobernador, elegido por la Asamblea (reunión de toda la comunidad) por período de un año, y la Junta Directiva. Los Cabildos Gobernadores de cada comunidad a su vez conforman los “Cabildos Mayores”, los cuales están divididos por zonas: Bajo San Juan, Medio San Juan y Serranía Wounaan. A nivel

24 El resguardo indígena es una "división territorial de carácter legal que, por medio de un título, garantiza a determinado grupo indígena la propiedad sobre un territorio poseído en común y tradicionalmente habitado por él” (OEA, 2012). 


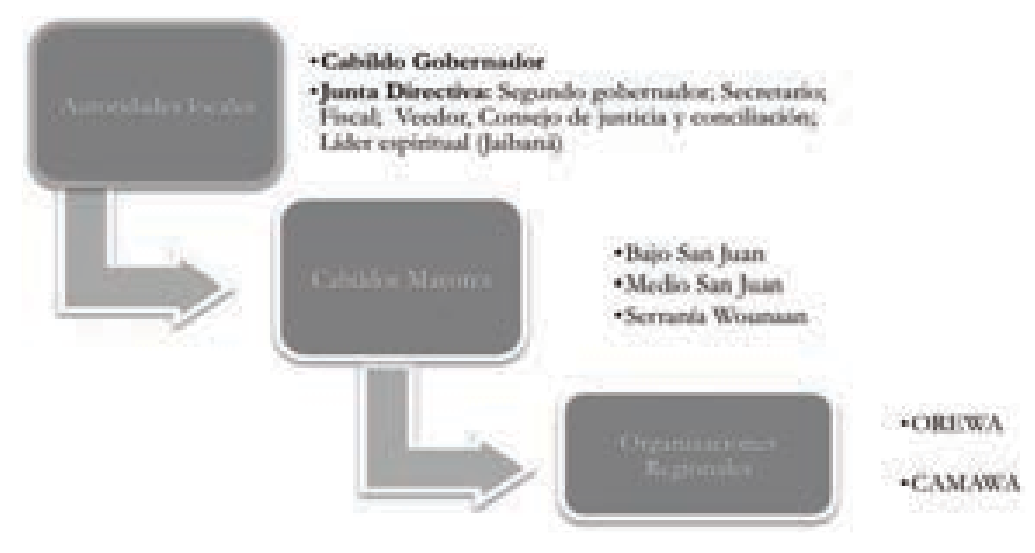

regional, el pueblo wounaan se encuentra bajo la Organización Regional Embera Wounaan (OREWA), organización que viene desde la década de los años setenta, la cual, como consecuencia de una crisis organizativa en 2005, cambió a Asociación de Cabildos Indígenas Wounaan, Embera Dobida, Katío, Chamí y Tule del Departamento del Chocó (OREWA). Representa 247 cabildos indígenas del departamento; y la Asociación de Autoridades Wounaan del Pacífico (CAmawa), encargada de orientar el accionar del gobierno de los Cabildos Locales y otras organizaciones comunitarias.

Aunque los pueblos indígenas gozan de los derechos colectivos al territorio, a la autonomía y a la identidad cultural, como expresamos respecto a los otros casos el conflicto armado, la explotación de recursos naturales (minerales, maderas, palma aceitera), la construcción de megaproyectos, la presencia de cultivos ilícitos y los corredores estratégicos para su movilización y distribución, las fumigaciones aéreas de cultivos (CCJ, 2009, p. 12) han generado un impacto negativo en estas poblaciones ${ }^{25}$ y las han obligado a cambiar sus formas de gobierno pro-

25 De acuerdo con la OACNUDH en Colombia, "los indígenas constituyen el 7 por ciento de toda la población desplazada de Colombia, a pesar de que sólo representan en torno al 3,4\% de la población" (Amnistía Internacional, 2010). Las principales causas del desplazamiento indígena son: el conflicto armado, los diversos crímenes 
pio y estructuras organizativas (la esfera social se entrelaza con la esfera política). Aquí lo "propio" como en los casos anteriores debe entenderse como resultado de procesos de hibridación cultural, como se hace evidente en la estructura organizativa en la cual se combinan formas de organización sindical con la figura del líder espiritual. Es esta la situación de la región del Chocó, afectada por estas problemáticas, y de los miembros del pueblo wounaan, desplazados actualmente en el municipio de Madrid.

\section{DESDE El LITORAL DEL SAN JUAN AL MUNICIPIO DE MADRID}

En el caso que nos ocupa, la población ha sido víctima de múltiples desplazamientos ${ }^{26}$ debido al conflicto armado de la región del Pacífico. En particular, algunos miembros expresan que dicha dinámica se ha generado por: el tránsito y la permanencia de los actores armados, al ser una ruta clave del narcotráfico guerrilla, paramilitares y Ejército se disputan el territorio; el temor y las repercusiones del conflicto (no podían salir a pescar ni a cazar porque los mataban); ${ }^{27}$ el reclutamiento de los más jóvenes; la violencia hacia las mujeres, niños y niñas; y, la más grave, la amenaza a los líderes por su actividad política o espiritual. En el desarrollo de los talleres de la EIDI, uno de los líderes, aunque con un español muy básico, nos narra la situación por la que atraviesa diariamente su comunidad:

perpetuados por los grupos armados (masacres, asesinatos selectivos de líderes, reclutamientos, secuestros, etc.), explotación de recursos, ocupación de territorios y destrucción de bienes.

26 El desplazamiento de esta población desde su territorio se ha dado en diversas etapas en busca de estabilidad socioeconómica. La ruta de desplazamiento de la población: en lancha desde el Litoral del San Juan a Bajo Calima (departamento del Chocó), en bus hasta Buenaventura (departamento del Valle del Cauca), en bus hasta Zipacón (departamento de Cundinamarca), La Mesa (departamento de Cundinamarca) o Bogotá (departamento de Cundinamarca) y, finalmente, Madrid (departamento de Cundinamarca).

27 Esta información hace parte del diario de campo del trabajo desarrollado con la comunidad en el marco de la EIDI. 
Nosotros fuimos amenazados por los paracos. Como uno tiene muchas amistades, uno escucha de ellas que vienen por tal persona, entonces le dicen que vaya acumulando cualquier centavo y así puede irse. Eso me ocurrió... Mi trabajo era de carpintería, hacer lanchas en la etnia negra. ${ }^{28}$ Pero yo tenía mi casa en la comunidad indígena, y debía subir a trabajar. Eso no le gustó a los paracos (ellos estaban allá donde estaba trabajando). Como yo siempre subía de mi casa, decían que yo estaba en la guerrilla, y por eso vinieron las amenazas.

Cuando eso ocurrió pasamos mucho trabajo. Salimos a las 8 de la noche hacia el mar, con un amigo que venía saliendo a Buenaventura. Fuimos a Buenaventura al otro día. Yo le dije a la señora que los otros indígenas desplazados nos podían decir por qué no los llamamos. Yo le dije a un amigo que se desplazó y estaba viviendo en Zipacón, yo tenía el número y le timbré; me dijo que yo podía conseguir trabajo. Inmediatamente salimos a Bogotá en bus y de Bogotá a una vereda en Zipacón. Llegando ahí no pude declarar, porque no teníamos plata para pagar el pasaje, no trajimos nada de ollas, nada de servicios, por esa razón paramos un tiempo. En cierta parte nos ayudaron, pero la dificultad vino: no conseguíamos trabajo, por esa razón nos vinimos a Madrid. (Entrevista a uno de los líderes en el marco de la EIDI, septiembre de 2012)

Sin embargo, aunque la comunidad actualmente está lejos de las amenazas y de las consecuencias directas del conflicto armado, la situación no es muy alentadora. La población que habita en Madrid (en total son 84 personas, 16 núcleos familiares ${ }^{29}$ tiene problemas de salud, no pueden acudir a su medicina tradicional y en las Entidades Prestadoras de

28 El territorio de los wounaan colinda con los territorios tradicionales de las "comunidades negras" o "afrodescendientes" que han sido objeto de un proceso de titulación colectiva liderado por sus Concejos Comunitarios y organizaciones de base: aCADESAn en el Bajo y Medio San Juan, oncaproteca en el río Calima y los Consejos Comunitarios de Bahía Málaga (CAmawa, 2000, p. 4).

29 La mayoría de la población proviene del municipio Litoral del San Juan (creado en 1993, cabecera municipal: Docordó, población: 45\% indígenas), de los resguardos Quebrada de Pichima, Taparal y Docordó Balsalito. 
Salud no son atendidos; la alimentación no es la más adecuada debido a la falta de dinero y a que no consiguen los alimentos tradicionales; además, viven en condiciones extremas, en hacinamiento y con escasos servicios públicos. Los niños, niñas y adolescentes, además de no contar con educación propia, no pueden acceder fácilmente a la educación del municipio por inconvenientes con el idioma y con los documentos de identificación; la situación económica y laboral no es estable: son los hombres los que deben trabajan bajo extremas condiciones (largas jornadas, sin salario, etc.), mientras las mujeres deben cuidar sus hijos. En este punto es oportuno indicar que la situación acá descrita no solo se presenta en la comunidad wounaan, sino en general en los pueblos indígenas desplazados. Al respecto, la onIC ha determinado:

Si [el desplazamiento] es a centros urbanos se complica un poco más, ya que la mayoría de nuestras compañeras no saben muy bien el español, se asustan ante la inmensidad de la ciudad, el anonimato y la falta de solidaridad de sus habitantes, nos mata el recuerdo de nuestros montes y selvas y de sus sonidos. Nos enfrentamos a nuevos problemas para criar a nuestros hijos y relacionarnos con nuestros compañeros, por no ser la ciudad nuestro medio habitual. [...] A las mujeres indígenas nos toca pelear para que nos reconozcan como desplazadas, pelear para acceder a la salud y a la educación que no es propia, preparar alimentos con comida ajena a nuestra cultura y cuerpo; luchar para que nuestras familias no se desintegren y los hijos no pierdan nuestra cultura. (ONIC, citado en Amnistía Internacional, 2010. Las cursivas son añadidas)

Dichas situaciones, tan ajenas y distantes de la realidad de los centros de poder, conllevan a que los actores más marginales aspiren a formular y a hacer valer sus demandas, en muchos casos sin prestar atención a si sus reivindicaciones logran (o no) traducirse en demandas democráticas. Como lo mencionamos en el primer caso de las mujeres kankuamas, y según algunos matices que sobre el caso wounaan daremos a continua- 
ción, la dinámica de violencia sufrida durante más de dos décadas por el pueblo kankuamo ha impulsado la participación de las mujeres, quienes han hecho parte del proceso de reetnización, de fortalecimiento político y cultural, y de la defensa de sus derechos individuales y colectivos, en asuntos tan básicos como el acceso a la salud, la educación propia, etcétera.

\section{LOS PROCESOS ORGANIZATIVOS EMERGEN: ¿PRÁCTICAS}

DE ACCIÓN COLECTIVA?, ¿PROCESOS DE DEMOCRATIZACIÓN?

A pesar de la situación límite en la que se encuentra la comunidad desplazada en Madrid (pobreza extrema, desplazamiento forzado, etc.), algunos líderes de la comunidad han adquirido legitimidad en el subcampo militante a causa de la posesión de un saber-hacer organizacional, de la capacidad de organizar reuniones y de tomar el liderazgo en las asambleas que se desarrollan lejos de sus territorios y prácticas tradicionales, aunque su capital escolar es escaso (los líderes no tuvieron acceso a educación secundaria ni universitaria). No obstante, ¿cómo los procesos de acción colectiva de los actores analizados logran (o no) traducirse en demandas que pueden expresarse como demandas democráticas?, ¿cuáles son esas prácticas de acción colectiva emergentes, los procesos de democratización que se derivan de ellas, y el papel que juegan las elites políticas en ellos? En este sentido, centraremos esta parte del capítulo en la trayectoria de algunos líderes de la comunidad y de su capital étnico: Mistrico Carpio, Licanio Piraza y su esposa Erta Carpio, antes y después del desplazamiento.

\section{Mistrico Carpio}

Mistrico Carpio, hijo de Míster Carpio y Cernelia Chiripua, nació en 1969 en la comunidad de Pichima Quebrada. Es el tercer hijo de siete hermanos y cursó hasta quinto de primaria. Siendo muy joven se casó con Floripa Chamapuro y tiene cuatro hijos: María (de 24 años, desplazada con su 
esposo y sus dos hijos menores), Adán (22 años), José (17 años) y Paola (16 años) también desplazados. Durante su permanencia en el territorio se dedicó a la carpintería y a las labores del campo. En los últimos años, antes de su desplazamiento, participó en asuntos de gobierno propio.

En un tiempo estuve en esas. La comunidad me eligió como segundo gobernador, una vez. Eso dura por un año y lo cambian; la comunidad lo vuelve a elegir. Pero eso es importante cuando uno está viviendo bien, pero cuando no, ¡no! Cuando uno está en su gobernación uno manda a lo local, que es su comunidad, pero por el conflicto armado ya es diferente. Son ellos los que mandan, se hace lo que ellos digan, esa gente lo obliga a uno. Por esa razón si un compañero escucha una amenaza, o al gobernador lo amenazan, uno no se mete en eso. El gobernador no se mete en esas para evitar el problema. (Entrevista a Mistrico Carpio en septiembre de 2012)

Mistrico cuenta con un importante capital étnico. Tuvo reconocimiento de la comunidad en su territorio al participar en el ejercicio del gobierno propio. Por ser uno de los primeros miembros del pueblo en desplazarse, actualmente dirige la comunidad desplazada en Madrid y lidera algunos procesos relacionados con la situación de desplazamiento (solicitud de ayudas humanitarias y del acceso a la educación de los menores y de los adultos, derechos de petición, acciones de tutela, presentación de proyectos productivos). Su lengua nativa es el wounmeu, y aunque se le dificulta hablar bien en español su capital social y militante le ha permitido tejer incipientes alianzas con representantes de otros sectores sociales (organizaciones de víctimas, colectivos de abogados, autoridades del municipio -alcalde y personero).

\section{Erta Carpio y Licanio Piraza: entre artesanías y política}

Erta Carpio, originaria del municipio del Litoral de San Juan, hija de Míster y de la señora Cernelia, hermana de Mistrico Carpio, nació en la 
comunidad de Pichima. Durante su infancia se dedicó a las labores de la casa y a la artesanía, y no acudió a la escuela. A la edad de 15 años, se casó con Licanio Piraza, líder político y espiritual, a quien conoció durante una reunión de capacitación en la comunidad de Pichima. La joven pareja se desplazó por el río San Juan hasta Taparralito, más precisamente la quebrada de Taparralito. Fue entonces cuando llegó su primer hijo Wilmer. En esa época, Licanio era líder político muy activo en la comunidad. Siempre estuvo relacionado con el Cabildo, y en una ocasión se desempeñó como tal. Sin embargo, su actividad política le trajo riesgosas consecuencias.

Años después, empezaron a llegar las águilas negras, y empezaron a amenazar a mucha gente. La gente comenzó a decir que estaban buscando a mi esposo para "matarlo". Mi hermano, a quien ya habían amenazado y estaba en La Mesa (Cundinamarca), nos dijo que nos fuéramos para allá. Entonces decidimos irnos en enero del 2011. El primero en salir fue Licanio, por su actividad política y por ser hermano de un Jaibaná, estaba en peligro. Licanio estaba siendo formado para ser líder espiritual (Notas de Observación Mónica Acosta, octubre de 2011).

Allí Licanio encontró un trabajo en construcción, gracias a contactos de sus familiares que se desempeñaban en lo mismo. Fue en La Mesa en donde Licanio declaró la situación de desplazamiento ante las autoridades locales y obtuvo una carta de declaración de la situación de desplazamiento, la cual conserva hasta el día de hoy. Erta, aunque no estuvo escolarizada (a diferencia de algunas mujeres kankuamas), siguió trabajando en artesanías, contribuyendo desde su espacio tradicional y capital étnico (conserva la lengua y prácticas culturales como la danza, el tejido y la pintura en el cuerpo) alejado de la esfera política, al fortalecimiento político y cultural de su pueblo, aún en situación de desplazamiento. El capital étnico de Licanio, quien proviene de una familia con trayectoria política y espiritual que le permitió heredar capital 
social y militante, relacionarse con las autoridades políticas y espirituales tradicionales de su territorio, y conservar su lengua nativa, le ha posibilitado también liderar algunos procesos sobre su situación actual.

\section{RELACIÓN CON LAS ELITES POLÍTICAS EN EL TERRITORIO}

\section{Antes del desplazamiento}

La relación Mistrico y de otros hombres de la comunidad con sus autoridades locales era estrecha. Algunos de ellos tenían trayectoria política local, capital militante (Mistrico y Licanio) y otros la estaban construyendo, como Wilmer, hijo de Licanio, quien nos habló de sus aspiraciones por ser Cabildo. Sin embargo, las relaciones con las autoridades del municipio (Litoral del San Juan) no se dieron de la misma forma. La participación política de la comunidad en las instituciones municipales (Alcaldía, Concejo, Personería, Despacho del Alcalde, Secretaría General, Tesorería, Planeación y Obras Públicas, Secretaría de Asuntos Indígenas, Educación, Salud, Desarrollo Institucional) no fue muy representativa. Aunque la participación se dio en procesos electorales municipales y nacionales, estos procesos fueron poco transparentes.

Eso por allá todo es político. Si usted había votado por él, usted recibía una ayuda, mientras que no, le decía: como usted no me ayudó así mismo no le ayudaré. Acá en la ciudad uno lo ve diferente, en el campo lo que monta el alcalde no sé de dónde sacan la plata, pero lo compran directamente a uno. El día de política eso botaban la plata. O ayudaban en alimentación, y se comprometen en algunas cosas. Y si no votan amenazan a la comunidad.

La ayuda del alcalde o del personero, jeso depende! Para que aprobaran un proyecto era votando. En el Concejo, si no había un concejal del pueblo, era igual, no recibía ayudas, porque no había quién lo aprobara, o que hablara allá. 
En el campo más que todo lo que monta el alcalde son que buscan a la gente que tiene plata, como los paracos. Por eso viene el problema. El alcalde no les dice nada porque son de la misma gallada. (Entrevista a uno de los líderes en el marco de la EIDI, septiembre de 2012)

Adicionalmente, verificamos que las entidades del municipio del Litoral del San Juan tienen poca relación con los wounaan en territorio. Por ejemplo, la Secretaría de Asuntos Indígenas de la Alcaldía ha estado desarticulada en muchas ocasiones de la dinámica organizativa y de gestión de los Cabildos Locales y el Cabildo Mayor Wounaan del bajo San Juan; en palabras de Erta: la "presencia del Estado era casi inexistente en el territorio".

Existían muy pocos proyectos y obras, planes de inversión, aunque participaron de algunos proyectos relacionados con los hogares infantiles y las escuelas. Esto ocurre igualmente con las organizaciones indígenas regionales, quienes solo "aparecían en épocas de elecciones", expresa Wilmer, joven wounaan.

\section{Después del desplazamiento}

Si en su territorio había un desencuentro con las elites políticas, las relaciones eran escasas, en el municipio de Madrid son inexistentes. En Madrid las autoridades municipales poco saben de su presencia, ni siquiera las autoridades locales o las organizaciones regionales como la OREWA o Camawa reconocen su situación. Aunque el líder de la comunidad ha intentado entablar contacto con el alcalde municipal, la situación no ha mejorado.

Esto obedece en buena medida a la barrera de lenguaje entre los wounaan y las autoridades municipales: como no hablan bien español no pueden expresar bien sus demandas. Así, como en el caso arhuaco, en la comunidad existe una gran dificultad en la concreción de las demandas sociales. 
Pues yo solamente tengo el contacto del alcalde nuevo. Con él sí he hablado. Casualmente por eso quiero ir en estos días a hablar a la alcaldía. Cuando estaba en su campaña él me decía que le entregara el proyecto y que lo esperara a cuando llegara al puesto. Con el personero no sé. Cuando estaba en una asamblea de desplazados acá en Madrid, yo le ayudé, por eso de pronto él me quiere colaborar. (Entrevista a Mistrico Carpio, septiembre de 2012)

En los primeros años de la situación de desplazamiento, los mayores de la comunidad Licanio y Mistrico, y sus hijos que seguirían el mismo camino de ellos en territorio, vieron truncada su trayectoria política en los municipios receptores. Sin embargo, la situación en la que viven y el afán por sobrevivir los llevó a iniciar un proceso organizativo como desplazados en Madrid. Esto se ha favorecido por el apoyo brindado por el cabildo indígena wounaan de Bogotá, José Lelu, desplazado también desde hace más de una década en la ciudad de Bogotá. En palabras de Mistrico:

Mi preocupación es la salud y la educación de los niños y las mujeres. ¿En dónde vamos a vivir?, si decidimos quedarnos acá. Estamos comenzando con la ayuda del Cabildo. Estamos en eso. Para organizarnos necesitamos que alguien nos ayude, cambiar las ideas. La idea es conformar una directiva porque nuestros hijos lo van a necesitar, para que los hijos puedan levantarse. Tenemos muchas necesidades y nos falta conocimiento. Ya tenemos el censo, somos hartos. Ya tenemos la organización, yo el representante, el segundo representante, Wilmer García, el secretario Jaime Piraza, el tesorero Emir Piraza, y el fiscal Juan Chiripua. Primero necesito conocimiento de la organización y cómo se puede conformar desde el inicio. Luego posicionarnos en la Alcaldía. (Notas de campo de Mónica Acosta, octubre de 2012)

Aunque este proceso de acción colectiva no ha logrado traducirse en demandas democráticas, los líderes de la comunidad han dado pasos 
gigantes en el marco de una situación de crisis humanitaria. Hasta el momento lograron el registro de la "Asociación Wounaan de Madrid. Wounaan Maach aba Naag" ante la Cámara de Comercio en un municipio cercano, y la inscripción de la asociación como una organización de víctimas del desplazamiento forzado. Igualmente, debido a un contacto reciente con la Secretaría de Educación del municipio, la mayoría de los adultos (hombres y mujeres) tomaron un curso de sistemas brindado por el Servicio Nacional de Aprendizaje (SENA); sin embargo, poco les interesa acceder a la educación para mejorar su calidad de vida y "superarse en la vida".

A diferencia de los anteriores casos (arhuacos y mujeres kankuamas), los procesos de acción colectiva y procesos de democratización del pueblo wounaan en Madrid apenas están emergiendo. No obstante, algunos poseen un alto capital étnico y militante al pertenecer a la clase dirigente de la comunidad (Cabildo gobernador-local, curandera, etc.), y la problemática social los ha alejado de las dinámicas políticas (en el territorio y en el municipio receptor). Su situación de desplazamiento y de pobreza ha sido la mayor dificultad que han encontrado para concretar procesos de democratización y dar un sentido político a sus demandas.

Las estrategias, discursos y repertorios de acción de estos actores se traducen en la "solución de las necesidades inmediatas". Las categorías "Derechos", "Estado", "Democracia”, no son manejadas en los discursos de estos líderes, a diferencia de los otros casos vistos anteriormente. Además, observamos una gran desarticulación con la estructura del Estado (municipio, departamento) y su gobierno propio. No hay articulación clara entre las organizaciones, las autoridades principales de sus resguardos y las autoridades tradicionales locales. La población desconoce las autoridades con representación ante el Estado (Asociación de Cabildos Mayores CAMAWA, OREWA) y las vías para acceder a cosas básicas como el sistema de salud, educación, programas sociales, etcétera.

Los líderes (Mistrico Carpio, Licanio Piraza) y otros hombres de la comunidad han iniciado un proceso organizativo (la asociación, con 
una estructura similar a una ONG), con apoyo del cabildo wounaan de Bogotá, que les permita un acercamiento con las autoridades del municipio y reconvertir así sus demandas sociales. Sin embargo, este proceso ha sido lento, por lo cual tenemos grandes expectativas de los resultados e impactos que genere, pues no ha tenido respuestas más efectivas. Los wounaan de Madrid buscan ser autónomos, pero la asociación solo les permitirá cierta autonomía en la gestión de proyectos para la consecución de recursos a manera de ONG, mas no en el ejercicio del gobierno propio que le otorga el reconocimiento de la Dirección de Asuntos Indígenas. Los únicos que tienen tal capacidad en las ciudades son los llamados "cabildos urbanos", reconocidos por el Ministerio del Interior. ${ }^{30}$

\section{PARA CONCLUIR}

Al inicio del capítulo explicamos cómo el capital étnico era un factor constitutivo de los tres casos que aquí hemos mencionado. Sin embargo, el capital étnico no está per se en pueblos que se han identificado como poseedores de características culturales que los diferencia de otros. Este capital es el resultado de lo que cada uno de los pueblos ha construido a partir de sus propias dinámicas sociales, políticas e historias. En el caso de las mujeres kankuamas, este capital ha sido el producto del proceso de reinvención y reetnización del pueblo a partir de todos los elementos externos, ajenos a lo que fue "originalmente" el pueblo kankuamo, para repensarse ahora como heredero de una sabiduría ancestral extinta de

30 En Bogotá existen los siguientes cabildos urbanos: Inga, Muisca de Bosa, Muisca de Suba, Kichwa y Pijao. El reconocimiento de las autoridades de estos cabildos tiene la particularidad de que fue un indígena quien, como Director de Asuntos Indígenas, expidió el administrativo. La Dirección de Asuntos Indígenas lleva un registro de Autoridades Indígenas, quien se encuentre allí posee personería jurídica de entidad pública de carácter especial, lo que le permite contraer convenios interadministrativos con el Estado, gozando de cierta autonomía administrativa y un enfoque diferencial en la ejecución de proyectos. Actualmente existe un vacío jurídico para el tema de los cabildos urbanos pues el reconocimiento de sus autoridades depende más de voluntad política que de una reglamentación al respecto. 
la Sierra Nevada de Santa Marta, sabiduría que antiguamente compartió con los otros pueblos de esta zona, por lo que en este caso "el ser" indígena se convierte más en una causa que en una condición que propicia un capital militante indígena.

Por el contrario, el pueblo arhuaco ha nutrido desde adentro, desde las estructuras sociales más tradicionales de su pueblo, los elementos sociales, culturales y políticos que les permiten visibilizar en contextos nacionales e internacionales sus demandas, una acción colectiva desde el capital étnico que poseen. No obstante, este capital étnico poco funciona en contextos locales, como por ejemplo la participación de algunos líderes en el Concejo de Pueblo Bello; la fortaleza cultural de este pueblo se ve avasallada por las prácticas politiqueras y clientelistas de la política de contextos municipales.

En el caso wounaan, aunque el capital étnico es alto, no tienen ningún valor en el campo político y social. Las fortalezas en las prácticas propias de su cultura, como la lengua, las prácticas culturales, las relaciones espirituales con el territorio, entre otros elementos, son anuladas frente a la dramática situación del desplazamiento forzoso. Esto genera dificultades en la traducción de sus exigencias y de sus necesidades en demandas democráticas, y los lleva a expresar discursos y estrategias relacionados solo con la "solución de las necesidades inmediatas".

Frente al trabajo realizado por nuestro colega Yann Basset en el primer capítulo, de la construcción y análisis de estos casos emerge una diferencia entre la política y lo político. Esta frontera porosa ha sido trabajada en varios escenarios pero, en este caso, retomamos las ideas de David Slater. En sus términos, lo político no se restringe al ámbito tradicional del ejercicio institucional del poder político: la política. En el marco de los nuevos movimientos sociales, lo político trasciende la frontera moderna de lo público y lo privado, y pone en el centro del análisis a los líderes que se han ubicado históricamente en los confines del campo político.

En este sentido, identificamos que las mismas dinámicas sociales y políticas han cambiado algunas estructuras tradicionales de los pueblos 
indígenas que aquí hemos mencionado. Por ejemplo, en el caso de las mujeres kankuamas es importante distinguir la dinámica que han logrado dentro de la oIk, con el fin de transformar estructuras tradicionales de poder y de abrir espacios para la incorporación de las mujeres en los diversos escenarios de participación política. No ha sido un proceso sencillo por las complejas situaciones de violencia a causa del conflicto armado que se vive en la región. Las mujeres kankuamas nos muestran perfiles, acciones y repertorios no tradicionales del campo político. Lo anterior implica dificultades, como la violencia y la victimización, que actores como los kankuamos han subvertido, con lo cual se ha logrado la visibilización nacional e internacional de su causa en múltiples escenarios. Por tal razón, mujeres como Ana Manuela, Rosa Manuela, Mildred, entre otras, logran hacer parte de los procesos de democratización dentro del pueblo kankuamo a través de la réplica de conocimiento a otras mujeres sobre los derechos fundamentales de las indígenas y el acceso a los distintos espacios de participación política. La respuesta estatal frente a los procesos locales organizativos no es ausente pero deja un mal sabor puesto que sigue siendo un Estado manejado desde las lógicas masculinas y racistas. Esto no ha permitido fortalecer alianzas estratégicas entre el pueblo kankuamo y las elites políticas de la región. Por supuesto, las mujeres se encuentran mucho más lejos de este tipo de relacionamiento.

Como pudimos observar aquí en los confines del campo político, estos procesos, en algunos casos como el kankuamo están relacionados con un fuerte recurso a los derechos humanos, y más precisamente con los derechos de los pueblos indígenas y de las mujeres. Sin embargo, se trata de un recurso no retórico, sino encarnado en la vida cotidiana, en el hilar vivencial de las mujeres. Es muy importante resaltar la emergencia de nuevas elites políticas indígenas. Estas elites hacen parte de un proceso híbrido en el que "se entra" y "se sale" de los contextos modernos-globales y los tradicionales-locales, generando al interior del pueblo kankuamo otras lógicas de división de “clases” entre los líderes que 
viven en Valledupar y los que lideran procesos locales y habitan en las comunidades del resguardo indígena.

El segundo caso muestra, por el contrario, una relación entre elites políticas y líderes arhuacos que, sin embargo, no ha generado procesos de democratización "hacia afuera" sino "hacia adentro". En el contexto político regional, por el contrario, ha implicado represión y hostigamiento por parte de los grupos paramilitares, ya que los gobiernos locales están permeados por los actores armados ilegales. En este contexto, para los líderes indígenas existe una desconfianza sobre el modelo de la democracia representativa a nivel local. En los últimos años, la respuesta de la comunidad ha sido un "no" a la entrada en política formal para generar, eso sí, procesos de profundización del gobierno propio y procesos internos de fortalecimiento cultural. Han emergido experiencias nuevas, desde generaciones más jóvenes, pero siempre en el contexto de fortalecimiento de la política interna.

Así, es posible afirmar que para el caso arhuaco el discurso democrático ha permeado muy débilmente las estructuras organizativas y sus repertorios de acción. En el caso específico del derecho, hemos observado un uso social del derecho constitucional por parte de los arhuacos como forma de movilización legal y algunas expresiones de movilización social (Mora, Naranjo, Rodríguez y Santamaría, 2009).

Los arhuacos no le "apuestan" a la democracia representativa. Para ellos lo fundamental es la "territorialidad y el sistema del territorio colectivo" y el tema de "identidad y permanencia cultural”. Desconocen el tema democrático y en muchos casos sus principios son incompatibles con su cosmovisión. Para ellos los temas de educación y salud son fundamentales para proteger lo "cultural". Por eso otro pilar es la identidad cultural. Retomando las palabras de uno de los líderes: "Nosotros antes que ciudadanos somos Ika, miembros de la comunidad, y nuestras obligaciones consisten en cumplir nuestros deberes con la Madre Tierra". Sin embargo, reconocen que existen lógicas políticas no indígenas a las cuales plantean estrategias alterna- 
tivas de participación para garantizar la permanencia cultural del pueblo.

A diferencia del caso del pueblo arhuaco y de las mujeres kankuamas, en el pueblo wounaan desplazado en Madrid-Cundinamarca apenas están emergiendo los procesos de acción colectiva. En el caso estudiado observamos la dificultad de la comunidad para dar sentido político a sus demandas. Las limitaciones comunicativas generan muchas dificultades en la apropiación de discursos y de repertorios de acción que incluyan categorías como "Derechos", "Estado", "Democracia”, siendo estas prácticamente inexistentes en las demandas planteadas por los líderes de esta comunidad desplazada. Sin embargo, rescatamos el capital étnico de algunos de los líderes de la comunidad, originado por el reconocimiento que tuvieron en su comunidad antes del desplazamiento (y que actualmente tienen), la conservación de la lengua materna, la herencia de capital social y militante, y las buenas relaciones que han mantenido con las autoridades tradicionales y espirituales en el territorio.

Es precisamente la situación límite en la que se encuentran (desplazamiento forzado, violencia, pobreza, etc.) y el capital étnico de algunos de los líderes, lo que los ha llevado a generar procesos organizativos emergentes, a tomar el liderazgo en algunos asuntos de su interés en el municipio y a tejer alianzas con representantes de otros sectores sociales. Este es un caso que está naciendo en términos organizativos, por lo cual es de nuestro interés seguir de cerca este proceso de acción colectiva emergente.

\section{BIBLIOGRAFÍA}

CoDHes. (2012). Boletín de la Consultoría para los Derechos Humanos y el Desplazamiento, 79. Bogotá, Quito.

Corte Interamericana de Derechos Humanos. (2011). Levantamiento de medidas provisionales en el Asunto Pueblo Indígena Kankuamo vs. 
Colombia. Disponible en http://corteidhblog.blogspot.com/2011/12/ levantamiento-de-medidas-provisionales.html

Defensoría del Pueblo. (2013). El mapa del conflicto armado en el Chocó.

Sistema de Alertas Tempranas. Disponible en http://www.defensoria. org.co/red/anexos/pdf/03/pc/conflicto_en_el_choco.pdf

República de Colombia. Corte Constitucional. (2009). Auto 004 de 2009. Disponible en: http://www.corteconstitucional.gov.co/relatoria/autos/ 2009/a004-09.htm

Observatorio de Derechos Humanos y Derecho Internacional HumaNitario (oddhi) \& Programa Presidencial para los Derechos Humanos y DIH (2010). Diagnóstico de la situación del pueblo indígena Embera Katío. oDDHH, Bogotá.

odDhH. (2010). Diagnóstico de la situación del pueblo indígena emberá chamí. ODDHH, Bogotá.

Organización de Naciones Unidas (onu) y Consejo Económico y Social (ECOSOC). (2004). Informe del Relator Especial sobre la situación de los derechos humanos y las libertades fundamentales de los pueblos indígenas, sr. Rodolfo Stavenhagen. Adición: Misión a Colombia (E/CN.4/2005/88/ Add.2). Ecosoc, Bogotá.

ONU-ECOSOC (2010). Informe del Relator Especial sobre la situación de los derechos humanos y las libertades fundamentales de los indígenas, James Anaya. La situación de los pueblos indígenas en Colombia: seguimiento a las recomendaciones hechas por el Relator Especial anterior. (A/ HRC/15/34/). ONU-ECosoc, Bogotá.

Oficina del Alto Comisionado de las Naciones Unidas para los DereChos Humanos (OACNudh). (2004). Informe Anual de la Alta Comisionada de las Naciones Unidas para los Derechos Humanos sobre la situación de derechos humanos y derecho internacional humanitario en Colombia, año 2004. OACNUdH, Bogotá.

OACNUDH. (2012). Informe Anual de la Alta Comisionada de las Naciones Unidas para los Derechos Humanos sobre la situación de derechos humanos y derecho internacional humanitario en Colombia, año 2012. OACNUDH, Bogotá. 
Organización Regional Embera WounaAn (orewa). (2010). Informe sobre la situación de los pueblos indígenas del Chocó ante la visita de los miembros del Foro Permanente sobre Cuestiones Indígenas de Naciones Unidas. OREWA, Bogotá.

\section{CASO ARHUACO}

Friede, Juan. (1963). Problemas sociales de los arhuacos. Tierras, gobierno, misiones. Monografías sociológicas, 16. . (1973). La explotación indígena en Colombia bajo el Gobierno de las Misiones. El caso de los arhuacos de la Sierra Nevada de Santa Marta. Punta de Lanza, Bogotá.

Mora, Alexandra. (2009). Multinacionales en la Sierra Nevada de Santa Marta. Caso: Puerto Multipropósito Brisa. En Judicialización de los conflictos en la Sierra Nevada de Santa Marta. Editorial del Rosario, Bogotá.

Ortiz Pérez, Luisa. El silencio como forma de resistencia civil. Análisis del discurso del ezlN, 1997-2001. Revista Venezolana de Economía y Ciencias Sociales, 10(001), 109-127.

Torres Márquez, Vicencio. (1978). Los indígenas arhuacos y "la vida de la civilización”. Editorial América Latina, Bogotá.

\section{CASO WOUNAAN}

Amnistía Internacional. (2010). La lucha por la supervivencia y la dignidad. Abusos contra los derechos humanos de los pueblos indígenas en Colombia. Disponible en: http://www.amnesty.org/en/library/asset/AMR23/ 001/2010/en/810b60b9-88db-437c-941f-8555e2327607/amr230012010es. pdf

Asociación de Autoridades Wouna an del Pacífico (camawa) y Organización Regional Embera Wounaan (orewA). (2000). Plan de vida del pueblo wounaan y siepien del Bajo San Juan. Comunidad de Papayo, Bajo San Juan. 
Comisión Colombiana de Juristas (CCJ). (2009). Informe de seguimiento a la aplicación de las recomendaciones del Relator Especial de las Naciones Unidas sobre los derechos humanos y libertades fundamentales de los pueblos indigenas (2005-2008). Disponible en: http://www.coljuristas. org/documentos/libros_e_informes/inf_2009_n2.pdf

ObServatorio DDHh y DiH. (2010). Diagnóstico de la situación del pueblo indígena Wounaan. Disponible en: http://www.derechoshumanos.gov.co/ Observatorio/documents/2010/DiagnosticoIndigenas/Diagnostico_ WOUNAAN.pdf

\section{CASO KANKUAMO}

Achila Neira, Mauricio. (2008). Idas y venidas, vuelas y revueltas. Protestas sociales en Colombia. 1958-1990. Instituto Colombiano de Antropología e Historia, Bogotá.

BARRING, Maruja. (2001). El mundo al revés: imágenes de la mujer indígena. Clacso, Bueno Aires.

Bourgois, Phillipe. (2009). Treinta años de retrospectiva etnográfica sobre la violencia en la América. En: Guatemala: Violencias desbordadas. Universidad de Córdoba, Córdoba.

Bolos, Silvia. (2008). Mujeres y espacio público. Construcción y ejercicio de la ciudadanía. Universidad Iberoamericana, México.

Donato, Luz Marina et al. (2007). Mujeres indígenas, territorialidad y biodiversidad en el contexto latinoamericano. Editorial Universidad Nacional de Colombia, Fundación Natura y Unión Mundial para la Naturaleza - unODC, Bogotá.

Dumoulin-Kervran, David. (2010). Transformaciones de las solidaridades transnacionales: de las redes militantes hacia los campos globalizados. El caso de la defensa de las poblaciones indígenas. En: Jano y las caras opuestas de los derechos humanos de los pueblos indígenas. Editorial Universidad del Rosario, CEPI, Bogotá. 
García CANClini, Néstor. (1989). Culturas híbridas. Estrategias para entrar y salir de la modernidad. Grijalbo, México.

LAURENT, Virginie. (2005). Comunidades indígenas, espacios políticos y movilizaciones electorales en Colombia 1990-1998. Motivaciones, campos de acción e impactos. EFEA e ICANH, Bogotá.

Martínez-Novo, Carmen. (2011). Multiculturalismo oficial en América Latina: ¿democratización o consolidación de la desigualdad?. En La multiculturalidad estatalizada. Indígenas, afrodescendientes y configuraciones de estado. ICANH, Bogotá

Merry, Sally. (2010). Derechos humanos, violencia de género: el derecho internacional en el mundo de la justicia local. Siglo xxi y Universidad de los Andes, Bogotá.

Ministerio de Gobierno. (1970). Legislación Nacional sobre Indígenas. Dirección General de Integración y Desarrollo de la Comunidad, Bogotá.

Montero, Rosa Manuela. (2011). Participación de las mujeres en el gobierno del pueblo indígena kankuamo, municipio de Valledupar, departamento del Cesar - Colombia. Trabajo final para el Diplomado para el fortalecimiento del liderazgo de las mujeres indígenas (modalidad mixta). CIESAs, Fondo Indígena y Agencia Española de Cooperación Internacional para el Desarrollo. Cartagena.

Morales, Patrick. (2011). Los idiomas de la reetnización. Corpus christi y pagamentos entre los indígenas kankuamos en la Sierra Nevada de Santa Marta. Universidad Nacional de Colombia, Bogotá.

NARANJo, Édgar Ricardo. (2009). La concepción cultural y política del territorio en el pensamiento indígena del Cauca, visto desde el discurso del Quintín Lame. Monografía de grado para optar al título de Politólogo de la Universidad del Rosario. s.p., Bogotá.

. (2012). De la lucha por la tierra al conocimiento de los Derechos Humanos: genealogía discursiva del Consejo Regional Indígena del Cauca. En: Identidades políticas porosas. Estudios sobre las reivindicaciones sociales nacionales y transnacionales. Universidad del Rosario, CEPI, Bogotá. 
оІк. (2009). Hoja de cruz. Memoria histórica de los impactos de conflicto armado en el pueblo indígena kankuamo. Kuino, Valledupar.

Organización Nacional Indígena de Colombia (onic). (2007). Derechos de los pueblos indígenas y sistemas de jurisdicción propia. Bochica, Bogotá.

. (2008). Mujeres indígenas sabias y resistentes. Voces y vivencias. Documento Especial INIPU. Bochica, Bogotá.

. (2010). Consejo Mayor de la autoridad nacional del gobierno indígena ONIC. Caminos recorridos: experiencias de la consejería de la mujer, familia y generación. ONIC, Bogotá.

Peñaranda, Daniel Ricardo. (2009). Organizaciones indígenas y participación política en Colombia. El acceso a los espacios de representación 19902002. La Carreta Política, Medellín.

Reichel Dolmatoff, Gerardo \& Dussán de Reichel, Alicia. (2011). La gente de Aritama. La personalidad cultural de una aldea mestiza de Colombia. Editorial Universidad Javeriana, Bogotá. 


\title{
PROCESOS DE DEMOCRATIZACIÓN EN EL BAJO ATRATO COLOMBIANO: UNA MIRADA DESDE LOS INTERSTICIOS ENTRE LO SOCIAL Y LO POLÍTICO
}

\author{
Karen Nathalia Cerón Steevens ${ }^{*}$, Juan Carlos Guerrero \\ Bernal $^{* *}$, Pedro Rojas Oliveros ${ }^{* * *}$ y Luisa Trujillo Paredes ${ }^{* * *}$ \\ Permite que esta novena nos una como un pueblo negro que edifica su \\ identidad a partir del fortalecimiento de los procesos organizativos y \\ la defensa del territorio. Anima nuestra fe y haz que nazca en nuestros \\ corazones la llama de tu Evangelio que dignifica la condición humana. \\ Fragmento de LA Oración PARA TODOS LOS DíAS \\ de la Novena de Navidad de La Diócesis de Quibdó \\ Queremos biche, queremos borojó; \\ Multinacionales, ¡fuera del Chocó! \\ CONSIGNA RECURRENTE EN MANIFESTACIONES \\ DE ORGANIZACIONES SOCIALES CHOCOANAS
}

ESTE CAPÍTUlO SE PROPONE describir y analizar los “procesos de democratización" que han tenido lugar en el bajo Atrato colombiano, especialmente desde el comienzo de los años ochenta, aunque sin dejar de

Internacionalista y magíster en Estudios Políticos e Internacionales. Docente e investigadora del Observatorio de Redes y Acción Colectiva (or AC) de la Universidad del Rosario.

** Doctor en Sociología y magíster en Relaciones Internacionales. Profesor, investigador y coordinador del Observatorio de Redes y Acción Colectiva (orAC) de la Universidad del Rosario.

*** Politólogo e investigador del Centro de Estudios Políticos e Internacionales (CEPI) y profesor auxiliar de la Facultad de Ciencia Política y Relaciones Internacionales de la Universidad del Rosario.

**** Politóloga de la Universidad del Rosario. Investigadora del Centro de Estudios Políticos e Internacionales (CEPI). 
hacer miradas retrospectivas sobre rasgos particulares de la historia de esta subregión. El lector ya habrá advertido que acabamos de escribir entre comillas la expresión "procesos de democratización”. En efecto, la duda puede surgir sobre la factibilidad de estos procesos en una subregión del territorio colombiano que ha carecido secularmente de una presencia significativa del Estado, cuyos habitantes han vivido en la marginalidad y en la pobreza, y en donde la violencia se convirtió en un fenómeno omnipresente y generalizado, sobre todo desde mediados de los años noventa. Por eso, antes que nada, es preciso aclarar cómo entendemos aquí los "procesos de democratización”.

Primero que todo, hablamos de "procesos" y de "democratización" -en lugar de "democracia"- porque consideramos, retomando a Claude Lefort (2004), que la característica esencial de una sociedad democrática es la indeterminación. Esto quiere decir que en la democracia existe una incertidumbre constante en cuanto al fundamento del poder, de la ley y del saber. ${ }^{1}$ Según esto, la democracia no es un régimen político estático sino dinámico, a través del cual lo político toma una cierta forma, pero sin que esta pueda ser fijada en lo absoluto y de una vez por todas; sencillamente porque el rasgo de la democracia es el de ser siempre un proceso inacabado, el de ser una aspiración siempre en movi-

1 Jesús Silva-Herzog Márquez afirma, en su síntesis del pensamiento de Lefort, que "la revolución democrática no es el asalto del poder", sino "el fin de un poder adherido a un cuerpo" o a un solo sujeto, bien sea éste individual o colectivo. Dicho de otro modo, "quienes ejercen el poder en democracia no son sus propietarios", pues en una democracia el poder es visto como "una sustancia resbaladiza, inasible". Ahora bien, "cuando el poder aparece como un 'lugar vacío', la sociedad [se convierte] en el teatro de una aventura, [puesto que] 'lo que se ve instituido no está nunca establecido, lo conocido está minado por lo desconocido, el presente se muestra innombrable y cubre tiempos sociales múltiples' [...]". Es por esto que la ley no queda nunca fija en una democracia: "Sus enunciados son siempre debatibles, su significado se vuelve impreciso y disputable". Y, del mismo modo, "el conocimiento tampoco encuentra vocero", al menos no un vocero único capaz de detentar absolutamente "la verdad". En suma, en todos los frentes (el poder, la ley y el saber), la democracia exige una "indeterminación radical” (Silva-Herzog Márquez, 2011). O, diría Lefort, lo esencial de la democracia es que nada puede ser fijado por esencia, porque "la democracia se instituye y se mantiene por la disolución de los referentes de certeza” (Lefort, 2004, p. 50). 
miento, como en una especie de perfeccionamiento sin límites, aunque con regresiones posibles (como sucede, según Lefort, cuando se transita de la democracia al totalitarismo). Y es que todo depende, en últimas, de cómo en una sociedad los actores llenan de significado o, mejor aún, de significados múltiples (en plural), aquello llamado democracia. Desde luego, tales significados no son estáticos sino cambiantes a lo largo del tiempo.

También debemos resaltar que nos estamos refiriendo a "procesos de democratización" (en plural y no en singular), porque las acciones y dinámicas constitutivas de la democracia transcurren no solo dentro de los canales institucionales, sino igualmente fuera de ellos, es decir en el seno de la sociedad. Diría Jesús Silva-Herzog Márquez (2011), inspirándose en Lefort, que "la democracia no altera solamente las coordenadas de la institucionalidad política, [...] la mutación democrática [también] transforma la carne de lo social”. Y esto es así, porque para Lefort es imposible reducir la democracia a un sistema de instituciones: ella es igualmente una forma de sociedad (Lefort 2004, 43). Así, pues, los procesos de democratización no deben situarse única y exclusivamente en arenas institucionales, sino también en espacios de aparición de varios actores sociales que tienen un cierto grado de independencia relativa frente a las elites políticas instituidas.

En consonancia con lo anterior, hemos considerado que los procesos de democratización deben describirse y analizarse considerando dos dimensiones esenciales. Por un lado, hay una dimensión que se refiere a la profundización de la democracia tal y como ella se ha instituido, es decir, a partir de la forma que ella ha llegado a tomar en un momento y un lugar dados; o podríamos decir, mejor, con base en la forma como la democracia se ha constituido históricamente en una sociedad específica. Por otro lado, hay una dimensión que tiene que ver con la reconfiguración de la democracia ya instituida; esta faceta se refiere a las críticas que pueden formularse a una democracia, tal y como ella se ha constituido en un momento y un lugar dados. Para acla- 
rar ambas dimensiones vamos a especificar algunos de los procesos que podrían estar contenidos en ellas.

La profundización de la democracia ya instituida puede tener diferentes componentes. Uno de ellos sería el relevo de las elites a través del ejercicio electoral. Tal relevo resulta ser más o menos profundo, dependiendo de si él se limita a un simple cambio de los sujetos que temporalmente detentan el poder, o si implica además una ruptura con respecto a las lógicas clientelistas que suelen prevalecer donde amplios sectores de la población viven a diario afrontando un sinnúmero de necesidades básicas insatisfechas y donde los políticos profesionales se dedican a intercambiar votos por favores. Otro elemento tendría que ver con la exigibilidad de derechos ya instituidos, pero no siempre efectivos. Se trata, pues, de acciones emprendidas por individuos o colectivos para hacer valer derechos que ya han sido conquistados y reconocidos a nivel institucional, pero que en la práctica son desconocidos y, por lo tanto, su existencia es meramente formal. Y por último, otro componente se referiría a las acciones que, a través de canales institucionales de deliberación establecidos, buscan cuestionar "verdades" asentadas en el imaginario colectivo de una sociedad, con el objeto de visibilizar y proponer "nuevas verdades". ${ }^{2}$

La reconfiguración de la democracia ya instituida comprendería otros procesos. Uno de ellos sería la posibilidad de ensanche de las elites

2 Conviene explicar con mayor detalle este último componente de la profundización de la democracia. Como ya se mencionó anteriormente, en la perspectiva de Lefort, en una sociedad democrática no pueden existir verdades definitivamente establecidas. Por ejemplo, no hay verdades definitivas sobre la historia o la situación presente de un país. Entonces, en una sociedad democrática, la historia puede ser siempre objeto de una reescritura, la cual puede tener como objetivo visibilizar y reconocer la existencia de actores sociales que han sido ignorados en una "historia oficial" (como ocurre, a veces, con algunas poblaciones minoritarias al interior de una nación). Igualmente, en una sociedad democrática, el presente puede ser objeto siempre de múltiples interpretaciones. Desde nuestra perspectiva, el hecho de que ese tipo de verdades establecidas durante un tiempo en los imaginarios colectivos pueda ser objeto de discusión a través de canales institucionales establecidos que hacen posible ese cuestionamiento constituye un camino más de profundización de la democracia. 
o de "deselitización" de una sociedad, a través de reformas a las instituciones establecidas que permitan a más personas y más sectores de la población acceder al círculo minoritario con medios de acceso al poder, al goce de los derechos y al conocimiento; dicho de otra manera, se trata de reformas tendientes a hacer más igualitaria una sociedad. Otro componente tendría que ver con el reconocimiento de nuevos derechos y nuevas libertades, bien sea por la vía de iniciativas tomadas por parte de elites políticas reformistas, o bien por la vía de acciones reivindicativas realizadas por actores sociales que emprenden acciones colectivas. Claro está que este componente implica también el reconocimiento de nuevos sujetos políticos que por lo general emergen cuando se exigen nuevos derechos y libertades. Por último, podría considerarse otro elemento relacionado con exigencias de autonomía y de instauración de formas propias de gobierno, justificadas en diferencias culturales y/o identitarias que pueden ser reivindicadas por actores específicos.

Para concluir este planteamiento inicial frente a los procesos de democratización, es importante aclarar un par de cuestiones más. Primero, la profundización de la democracia se lleva a cabo tanto a través de las formas de democracia representativa, como a través de las formas de democracia participativa instituidas en un momento dado. Y segundo, la reconfiguración de la democracia supone una aspiración a instituir tanto nuevas formas de democracia representativa, como de democracia participativa. Es por esta razón que en este capítulo analizamos los procesos de democratización atendiendo a las dinámicas generadas no solo por la acción de elites políticas instituidas, sino también por la acción de sujetos políticos que emergen en el seno mismo de la sociedad a través de acciones colectivas. Y nos interesa, por supuesto, observar las interacciones de doble vía más relevantes que se dan entre lo institucional y lo social.

En este capítulo intentaremos dar respuesta a dos preguntas generales que están relacionadas con los actores, las dinámicas y los alcances de los procesos de democratización que han tenido lugar en el bajo 
Atrato colombiano: ¿cómo los pobladores de esta subregión han sido considerados y reconocidos a lo largo del tiempo por el Estado y las elites políticas dominantes?, ¿cómo y con qué grado de éxito dichos pobladores han intentado constituirse en sujetos políticos y qué tipo de relación han entablado con el Estado al realizar esos esfuerzos?

Las respuestas a estas preguntas no aparecerán a lo largo del capítulo de forma separada, sino más bien simultánea, aunque cada parte pueda concentrarse un poco más en una pregunta que en la otra. Al plantear estas preguntas, no pretendemos hacer un análisis completo de los procesos de democratización en el bajo Atrato, sino realizar tan solo una primera aproximación al tema. Además, como ya lo mencionamos, esta investigación hará un énfasis particular en el análisis de los procesos de democratización que se desencadenaron al inicio de los años ochenta, aunque a veces tengamos que remontarnos en el tiempo para comprenderlos mejor.

Este capítulo se organiza de la siguiente forma. Comenzamos con una caracterización general de la subregión del bajo Atrato, para permitirle al lector comprender de qué subregión vamos a hablar. Luego realizamos una reflexión sobre qué son "las comunidades" que se han asentado en el bajo Atrato y cómo estas se han ido constituyendo a lo largo del tiempo, en buena parte gracias a la intervención de agentes externos. Enseguida nos concentraremos en el entendimiento de la manera en que la Iglesia ha intervenido en la zona, sobre todo intentando comprender el sentido de la acción eclesial. Después, describimos y analizamos cómo ciertas organizaciones sociales que surgieron en los años ochenta se fracturaron debido a la generalización de la violencia, y también cómo se recompusieron un poco más adelante, dando lugar a organizaciones sociales que hoy reivindican derechos étnico-territoriales. Posteriormente, profundizamos en ese proceso de etnización, mostrando sus fases, sus dinámicas y también sus obstáculos. Y, finalmente, efectuamos una reflexión sobre la manera como las organizaciones sociales de afrodescendientes se han articulado con las elites políticas locales. 
Para desarrollar esta investigación realizamos entrevistas y diálogos informales con miembros de las comunidades y con líderes sociales y acompañantes de los procesos organizativos del bajo Atrato. El trabajo de campo se realizó en diferentes visitas y estadías en Quibdó (diciembre de 2012) y en los municipios de Riosucio (octubre de 2002, de marzo a octubre de 2011 y enero de 2013), de Curbaradó (octubre de 2002), y de Carmen del Darién (de marzo a octubre de 2011). Durante el trabajo de campo tomamos contacto con varias organizaciones sociales del Chocó: la Asociación de Consejos Comunitarios y Organizaciones del Bajo Atrato (Ascoba), el Consejo Comunitario Mayor de la Asociación Campesina Integral del Atrato (Cocomacia), el Consejo Comunitario Mayor de la Opoca (Cocomopaca), la Unión de Desplazados del Chocó-Quibdó (UDCH) y el Fondo Interétnico de Solidaridad del Chocó (FISCH). Igualmente, algunos líderes comunitarios que tuvieron que desplazarse nos concedieron entrevistas en Bogotá, en octubre de 2002.

El acercamiento con representantes de la Iglesia católica que hacen presencia permanente en los territorios también fue fundamental para este trabajo. A través de entrevistas a profundidad con miembros de la Diócesis de Quibdó, la Fundación Universitaria Claretiana y con el director de la Pastoral Social de la Parroquia Nuestra Señora del Carmen en Riosucio, nos fue posible captar hasta cierto punto la relación estrecha entre las comunidades, las organizaciones sociales y las religiosas. En Bogotá, en abril de 2003, pudimos además entrevistar a miembros del equipo del Centro de Investigaciones para la Educación Popular (CINEP), una ONG jesuita que desde 1997 vienen acompañando a las comunidades del bajo Atrato.

El trabajo de campo fue complementado con una revisión de fuentes documentales que pueden clasificarse en cinco grupos: primero, una literatura académica sobre estudios afrocolombianos; segundo, un conjunto de documentos producidos por organizaciones gubernamentales y no gubernamentales donde se analizan las condiciones económicas y ambientales del bajo Atrato, así como el conflicto armado que ha tenido 
lugar allí; tercero, una serie de documentos elaborados por ONG acompañantes de diversos procesos organizativos que surgieron en la subregión; cuarto, diferentes textos producidos por la Iglesia católica, en particular por la Diócesis de Quibdó, que nos ayudaron a entender la acción de la Iglesia católica en el Chocó; por último, algunas fuentes audiovisuales, principalmente documentales, fotografías y documentos curatoriales, obtenidos a través del Archivo Fílmico del Chocó y del grupo de investigación de la Corporación Oraloteca de la Universidad Tecnológica del Chocó, piezas estas que nos permitieron seguir pistas históricas encontradas a lo largo de la investigación.

\section{UNA CARACTERIZACIÓN GENERAL DEL BAJO ATRATO}

La subregión del bajo Atrato se ubica al norte del departamento de Chocó, en aquella esquina noroccidental de Colombia que se encuentra cerca de la frontera con Panamá. El eje alrededor del cual se constituye la subregión es el río Atrato, cuando este se aproxima a su desembocadura, es decir, desde el corregimiento de Belén de Bajirá hasta el Golfo de Urabá, en otro corregimiento llamado Bocas del Atrato. La geografía se caracteriza por la predominancia de terrenos planos e inundables, con algunas colinas medias que no superan los 600 metros de altura. Se trata de una zona selvática húmeda que registra una alta pluviosidad y que, por lo tanto, conoce extensos periodos de inundación durante el año, en particular desde febrero hasta noviembre. Sin embargo, las comunidades de pobladores asentadas en el bajo Atrato se han habituado a la agresividad del clima y han establecido una fuerte relación con la naturaleza, particularmente con el río Atrato y sus múltiples afluentes. De hecho, los nombres asignados a esas comunidades coinciden con los de las cuencas de los ríos y riachuelos que por allí transitan y que desembocan en el río Curvaradó o en el Atrato, las dos principales arterias fluviales. No hay comunidad en esta zona que no esté identificada con una cuenca fluvial. 
El bajo Atrato abarca cuatro municipios del norte del departamento del Chocó (Riosucio, Carmen del Darién, Acandí y Ungía), junto con el corregimiento de Bocas del Atrato. Los municipios que conforman la subregión no están todavía densamente poblados. De acuerdo con las estadísticas, allí solo habitan 58.722 habitantes: 28.556 en Riosucio, 5.290 en Carmen del Darién, 14.862 en Ungía y 10.014 en Acandí (DANE, 2008). Y demo-gráficamente hablando, vale la pena subrayar que la población de las cabeceras municipales es en su mayoría flotante. En efecto, allí residen grupos de personas que se vieron obligadas a salir de zonas rurales y a ubicarse en dichas cabeceras, debido a dos oleadas de violencia que produjeron desplazamientos forzados significativos en 1995 y 2003. Estos desplazados no se han asentado de forma definitiva en las cabeceras municipales; con regularidad, van y vienen de sus comunidades rurales en búsqueda de sustento y con el propósito de intentar no perder del todo sus tierras.

En el bajo Atrato existen varios territorios colectivos que han sido adjudicados a "comunidades negras" o "de afrodescendientes", de acuerdo con lo planteado en la Ley 70 de 1993 (más adelante, nos referiremos con mayor profundidad a esta ley). Según las cifras oficiales, la totalidad de esos territorios colectivos en el bajo Atrato asciende a 69: 47 situados en Riosucio, 21 en Acandí y 1 en Carmen del Darién, en Unguía no aparece registrado ningún territorio colectivo adjudicado a las comunidades negras (Ministerio del Interior y de Justicia, 2011). Adicionalmente, en el bajo Atrato se asientan varios resguardos indígenas, particularmente en los municipios de Riosucio y Carmen del Darién. En la actualidad, las comunidades que pertenecen a estos resguardos son en su mayoría embera, con variaciones de wounaan y catío y tule (derivada de los cuna). El número total de resguardos que hacen parte de la subregión asciende por ahora a $16 .^{3}$

3 Con relación a los resguardos indígenas del bajo Atrato, vale la pena subrayar lo siguiente: "Desde la década de los setentas se vienen constituyendo resguardos indígenas, proceso que indujo a la conformación de cabildos como forma de autoridad 
Las estadísticas nacionales muestran además que la población asentada en el bajo Atrato conoce un alto nivel necesidades básicas insatisfechas, entre las cuales se encuentran el acceso a la vivienda, a los servicios sanitarios y a la educación. En la mayoría de los casos, más del $50 \%$ de la población tiene necesidades básicas insatisfechas: Riosucio (85,21\%), Carmen del Darién (90,67\%), Ungía (60,63\%) y Acandí $(49,25 \%)$ (DANE, 2008). Las condiciones de pobreza son evidentes tanto en las zonas rurales como en las urbanas; sin embargo, la situación es quizás más grave en las cabeceras municipales, toda vez que el incremento acelerado de la población ha hecho más difícil la cobertura de necesidades básicas, y que las limitadas actividades económicas no han permitido una generación creciente de empleo.

Tradicionalmente, las zonas altas del bajo Atrato han sido utilizadas por las comunidades para la siembra de cultivos, mientras que las bajas e inundables se han empleado para la pesca. En el bajo Atrato existe una economía campesina y una actividad pesquera artesanal, orientada sobre todo hacia la autosubsistencia, que se desarrolló a medida que varios grupos poblacionales colonizaron el territorio a partir de la segunda mitad del siglo xıx (más adelante mencionaremos con mayor detalle esos procesos de colonización). Pero esa economía de autosubsistencia se encontró con el acelerado proceso de explotación agrícola industrializada que empezó a tener lugar en el Urabá antioqueño ${ }^{4}$ desde las primeras décadas del siglo xx, así como con otros intereses económicos foráneos. Así, a lo largo del siglo pasado fueron desarrollándose diversas actividades económicas que son más bien incompatibles con la economía tradicional de autosubsistencia: la pro-

y representación reconocida desde fuera, sin tradición entre los indígenas del Chocó, como influencia de las formas organizativas del suroccidente del país, y las presiones de las instituciones oficiales que los adoptaron como patrón deseable. En cada cabildo habitan varias comunidades compuestas por dos o más parentelas asentadas alrededor de una micro cuenca o quebrada, conformando caseríos, cuyo jefe es denominado gobernador" (Navarrete Serna, 2009, p. 25).

4 El Urabá antioqueño colinda con el bajo Atrato que, dicho sea de paso, es también llamado el "Urabá chocoano". 
ducción agroindustrial de azúcar, ${ }^{5}$ la explotación forestal y maderera, la ganadería extensiva, los cultivos ilícitos y el tráfico de drogas, los monocultivos de banano y de palma de aceite, la extracción del arracacho, ${ }^{6}$ la explotación de minerales y de hidrocarburos.

La dinámica entre todos estos tipos de actividades económicas es compleja. Por ejemplo, con la proliferación de explotación maderera desde los años ochenta, la selva empezó a ser utilizada con propósitos agrícolas, extendiendo las fronteras de cultivo. Sin embargo, las condiciones del suelo selvático, que se caracteriza por ser pobre, hacen necesario el uso de agroquímicos en grandes cantidades para garantizar la eficiencia de los monocultivos (particularmente el del banano y la palma de aceite). El uso de agroquímicos, provistos por grandes compañías multinacionales, genera una dependencia permanente, y hace cada vez más difícil para los pobladores de la subregión mantener las semillas tradicionales o cultivar de manera independiente.

Ahora bien, los diversos intereses políticos y económicos que se ciernen sobre el bajo Atrato no están relacionados únicamente con la diversidad en recursos naturales y el potencial económico de su explotación. También hay que considerar aquellos derivados de la posición geográfica de la subregión (la cercanía a zonas de frontera y a aguas internacionales con Panamá) que la convierten en un nodo estratégico de una red de rutas comerciales de narcóticos y de contrabando, y en una zona donde se proyectan grandes proyectos de infraestructura que terminarían de conectar a Suramérica con Centroamérica. Al mismo tiempo, la diversidad topográfica que hace difícil el acceso a la subre-

5 Esta producción se llevó a cabo entre 1923 y 1941 en el ingenio azucarero de Sautatá, cuyos propietarios fueron una familia de comerciantes sirios de apellido Abuchara que se asociaron con industriales puertorriqueños. Ese ingenio de 5000 hectáreas de extensión, donde trabajaron unas 400 personas, fue durante mucho tiempo el "símbolo de empuje y progreso" del bajo Atrato.

6 Esta actividad pone en riesgo la seguridad alimentaria de las poblaciones del bajo Atrato, en tanto el arracacho constituye la fuente de alimento y hábitat del bocachico, insumo básico de los pescadores. 
gión, facilita la ubicación y el resguardo de actores armados ilegales de diversa índole.

Sin duda alguna, al igual que el resto del territorio chocoano, el bajo Atrato ha sido sobre todo representado como una despensa inagotable de recursos, mano de obra barata y minas para la "prosperidad". Desde los centros de poder, la subregión ha sido vista como un territorio de frontera donde prima la ausencia del Estado, lo natural-premoderno, lo primitivo (Escobar y Pedrosa, 1996; Restrepo, 2012). Sin embargo, los imaginarios de las elites sobre el Chocó no terminan allí, pues paradójicamente esta visión negativa, "esta idea de lo inhóspito y lo malsano", coexiste con "la imagen de la enorme riqueza de la región", en particular debido a la asociación que se realiza entre los ríos chocoanos y los yacimientos de oro (Restrepo, 2012, p. 240).

En los siguientes apartes del capítulo vamos a describir y a analizar cómo los pobladores de una subregión, con las características y dinámicas que acabamos de señalar, se han ido constituyendo, no sin dificultades, a lo largo del tiempo en sujetos políticos con identidades particulares. Lo relevante es que estas identidades son alternativas, e incluso antagónicas al modelo económico y a los imaginarios dominantes durante mucho tiempo. Precisamente como lo señalan Escobar y Pedrosa, la salvaguarda de las riquezas biodiversas, culturales y sociales de la región "requiere que pensemos en actores sociales capaces de crear vías alternas para la región” (1996, p. 18).

\section{LOS ACTORES Y LOS PROCESOS CONSTITUTIVOS DE LAS “COMUNIDADES" DEL BAJO ATRATO}

Para comprender los procesos de movilización social y de acción colectiva contenciosa en el bajo Atrato, es preciso, antes que nada, aclarar qué son las "comunidades" que hoy se encuentran dispersas en las cuencas de diversos ríos que confluyen hacia el Atrato, cuando este se aproxima a su desembocadura. Estas "comunidades" no son cuerpos 
sociales uniformes, si se tiene en cuenta su composición social y cultural; son más bien un conjunto de pequeñas sociedades, heterogéneas en su estructura poblacional, que se han desperdigado en numerosos caseríos rurales (la excepción es el puerto fluvial de Riosucio que constituye la principal cabecera municipal de la región). Todos estos caseríos, situados en las riberas del Atrato y de los múltiples ríos que confluyen hacia él, surgieron de un largo proceso de colonización que podría caracterizarse como multiétnico, ${ }^{7}$ pluriregional $^{8}$ y pluritemporal $;^{9}$ lo

7 Aunque los afrodescendientes son mayoritarios en el bajo Atrato, la estructura poblacional de esta subregión es en realidad heterogénea y mezclada. Como lo señala Eduardo Restrepo, allí "los negros se han encontrado estrechamente relacionados desde hace varias generaciones con varios grupos poblacionales [...] Al lado de los negros, en zonas rurales y urbanas se encuentran chilapos, paisas, costeños y cholos" (2011, p. 49). Los llamados chilapos son mestizos provenientes de las sabanas de Córdoba y de Sucre, mientras que el término cholos se aplica a las poblaciones indígenas de la región. Y los paisas no son únicamente las personas provenientes de Antioquía, sino en general cualquier blanco "del interior" o de la costa.

8 Las personas que colonizaron el bajo Atrato provienen, en primer lugar, del sur del Chocó, de donde partió una de las primeras corrientes migratorias, pero también de varios departamentos de Colombia, en particular de Antioquia, Atlántico, Bolívar, Córdoba y Sucre.

9 De acuerdo con varios autores (Vargas Sarmiento, 1999; Osorio Gómez, 2006; Restrepo, 2011;Villa, 2013), la colonización del bajo Atrato fue bastante tardía y se ha realizado en diferentes oleadas de migrantes. Una primera oleada de pobladores negros comenzó a instalarse allí desde mediados del siglo XIX, provenientes del medio y el alto Atrato, y de las cuencas de los ríos San Juan y Baudó. Esos pioneros eran antiguos esclavos que obtuvieron su libertad con la ley de abolición de la esclavitud de 1851 y que decidieron abandonar las zonas de explotación aurífera, y su profesión "forzada" de mineros, para instalarse con sus familias en el bajo Atrato y vivir allí de la agricultura y la pesca. Esta corriente migratoria fue descendiendo por el Atrato fundando a su paso múltiples caseríos. Algunos de estos pobladores negros llegaron acompañados de indígenas emberas que habían también habitado en las riberas del Baudó. Casi en forma paralela a esa migración de negros libertos, se dio otra corriente migratoria de criollos y mulatos provenientes de Cartagena, ciudad con la cual se establecieron importantes relaciones comerciales durante el siglo xIX y principios del xx. Varios de estos migrantes se vieron atraídos por las nacientes actividades extractivas del caucho, la tagua y la raicilla que eran recogidas en la región y exportadas desde Turbo hacia Cartagena, pero igualmente muchos de ellos llegaron simplemente en búsqueda de terrenos libres para dedicarse a la agricultura. En el siglo xx, a partir de los años cincuenta y hasta los setenta, se produjo la llegada de los chilapos que habían sido desplazados por latifundistas de Córdoba y Sucre, y que también deseaban encontrar tierras disponibles para el cultivo. En los años cincuenta llegaron además los paisas, en una especie de prolongación de la colonización del Urabá antioqueño que tomó mucho auge con la construcción de la 
que quiere decir que la proveniencia de colonizadores era diversa y el momento de colonización correspondía primordialmente a necesidades de acceso a la tierra y fortalecimiento de actividades económicas. Quizás el único rasgo compartido por todos los habitantes del bajo Atrato sea el de haber sido inmigrantes que llegaron a la región para desligarse de un pasado penoso o para aspirar a una ascensión social; ${ }^{10}$ es decir, al igual que en el Urabá antioqueño, los colonizadores del "Urabá chocoano" (otra forma de designar el bajo Atrato) fueron individuos que se alejaron de sus lugares de origen con la intención de construir un nuevo proyecto de vida (Ortiz Sarmiento, 1999).

Los relatos de los habitantes del bajo Atrato sugieren que antes de los años setenta el nivel de cohesión e integración de las "comunidades" por ellos conformadas era bastante limitado. Desde luego, allí siempre han existido formas de solidaridad, como la hospitalidad y la generosidad que se hace a veces manifiesta entre colonos. Pero no hay que sobreestimar el alcance de esas formas elementales de solidaridad que siempre han tenido lugar más bien a una escala social reducida, es decir, hacia la gente próxima (los familiares, los vecinos o las personas provenientes de una misma región de origen) y solo eventualmente hacia algunos colonos solitarios. Los límites de esas expresiones de solidaridad también son evidentes en su carácter efímero, pues los colonos han tendido a ayudar a aquel que tiene necesidad, pero solo mientras el recién llegado a la subregión puede volverse autosuficiente. Además, las narraciones de los colonos sobre los viejos tiempos dejan claro que la gente de aquel entonces vivía

carretera al mar (Medellín-Turbo) y el desarrollo de la explotación comercial del banano.

10 Tampoco los indígenas embera que hoy viven en el bajo Atrato, y que despectivamente son llamados cholos, son aborígenes de la zona. Los señores ancestrales de esos territorios, que vivieron allí durante toda la Colonia, fueron los tules (llamados por los españoles como cunas o cunas-cunas). Restrepo recuerda que "los tules, que ahora habitan en Panamá, ofrecieron una exitosa resistencia a las pretensiones de dominación española. Se aliaron con ingleses, franceses y holandeses para hacer del bajo Atrato un lugar vedado y temido, hasta tal punto que, bajo pena de muerte, fue prohibida la navegación por este río [el Atrato] por cerca de un siglo" (Restrepo, 2011, p. 47). 
en las comunidades al mismo tiempo "alejada y junta” (Comisión Intereclecial de Justicia y Paz, 2005, p. 30). Eso significa que cada uno tenía su pedazo de tierra, distinto al de los otros, y cada uno lo cultivaba y lo trabajaba de manera independiente; esto no impedía que los fines de semana las personas se reunieran para hacer una fiesta o una olla comunitaria, en las que podían tomar parte personas de comunidades próximas. En ese sentido, el “juntos” se refiere a espacios de socialización mínimos y no a procesos de conformación de comunidades fuertemente integradas, o con un sentido comunitario fuerte, y mucho menos a organizaciones sociales con carácter reivindicativo.

Las "comunidades" del bajo Atrato deben ser entonces comprendidas sobre todo como una pluralidad de sociedades heterogéneas, configuradas en un contexto que les ha impedido estructurarse fácilmente, debido a la débil presencia del Estado y a la precariedad del enmarcamiento institucional de la vida social en la región. En esas sociedades rurales campesinas, tradicionalmente poco homogéneas y cohesionadas, las comunidades se han ido conformando, siempre con cierta precariedad, a través de un proceso largo, frágil y lleno de obstáculos. En ese proceso ha sido crucial la acción de actores ajenos a las comunidades mismas que, de una u otra manera, y no siempre con plena consciencia, les han ido dando forma. A continuación vamos a centrarnos en el rol de tres actores esenciales: los partidos políticos, la guerrilla y la Iglesia católica.

La débil presencia del Estado colombiano en el bajo Atrato no requiere mayor demostración. Las instituciones nacionales siempre han hecho muy poca presencia en esta región, y las instituciones regionales y locales han carecido de recursos para intervenir con eficiencia. Por supuesto, esto no significa que el bajo Atrato haya permanecido absolutamente desconectado de la vida política nacional, pues, del mismo modo que en el resto del Chocó, los partidos políticos se hicieron presentes allí a través de un proceso prolongado de construcción de redes políticas clientelistas. Los llamados "caciques" o "gamonales" han sido 
la figura fundamental para la fabricación de estas redes. ${ }^{11}$ A través de ellos, los partidos políticos fueron asegurando su presencia en el bajo Atrato, estableciendo relaciones de clientelismo, de padrinazgo y de compadrazgo que se convirtieron en la principal "solución” a las necesidades de una población "por el Estado.

El clientelismo ha contribuido por mucho tiempo a la cooptación y a la adhesión de los habitantes del bajo Atrato a los proyectos de los partidos políticos tradicionales (e incluso a los de la izquierda), inhibiendo en cierta medida el desarrollo de organizaciones sociales autónomas y de acciones colectivas contenciosas. Pero el clientelismo ha servido también para impulsar y promover, en particular desde mediados del siglo $\mathrm{xx}$, “acciones comunales" que progresivamente le dieron una cierta forma a las comunidades del bajo Atrato. Esto se llevó a cabo a través de las Juntas de Acción Comunal (JAC) que, pese a haber sido concebidas en un inicio por el Estado colombiano como un instrumento para incorporar a sectores marginados y rurales en los planes nacionales de modernización, se fueron igualmente transformando en un espacio que hizo viable el clientelismo local.

En efecto, las JAC han servido como mecanismos mediante los cuales se distribuyen, en el seno de poblaciones que deben organizarse, tanto los recursos propios de los caciques, como los fondos del Estado. Es esa obligación a organizarse la que ha contribuido a constituir las

11 Carlos Miguel Ortíz define al "cacique" o "gamonal" como un jefe municipal del directorio de un partido político. Según él, este dirigente político local actúa como un intermediario de una red que pone en contacto a las elites políticas citadinas con la realidad local de un territorio nacional marginado. Su función consiste en agenciar proyectos económicos y sociales que pretenden solucionar necesidades básicas de la población allí asentada. A través de ese "mecanismo de distribución de favores", los caciques compiten entre sí por los votos, gracias a los cuales legitiman su poder político (Ortiz Sarmiento, 1999, 63-70). Carlos Agudelo sostiene que los gamonales existen en el Pacífico colombiano desde el siglo XIX, cuando predominaba la política de los caudillos. A finales del siglo xIX y principios del xx, a medida que los caudillos regionales fueron despareciendo y que el bipartidismo se fortaleció sobre la base de "jefes naturales" a nivel nacional, los gamonales fueron adquiriendo un mayor margen de autonomía frente a la clientela local o regional (Agudelo 2004, p. 71). 
"comunidades". Las JAC son una modalidad de enmarcamiento y de integración de la sociedad, en la que se mezcla la vía privada (la ayuda de los compadres y los padrinos) con la vía pública (la distribución de los fondos del Estado). Ahora bien, lo que deseamos subrayar, en términos del análisis de los procesos de organización social, es que el Estado contribuyó a engendrar a las comunidades, porque la promoción de las JAC fue un factor decisivo para generalizar el uso del término "comunidades" en lugares remotos donde existían sociedades que no siempre conocían de antemano un alto nivel de cohesión e integración, como es el caso del bajo Atrato. Como lo señala Carlos Agudelo, ese término de “comunidades" acabó siendo asimilado y de uso corriente entre pobladores de territorios con esas características (Agudelo, 2004, 30).

Paralela a la forma de enmarcamiento precario que el Estado ha ejercido sobre los habitantes del bajo Atrato a través de las JAC, surgió otra forma de moldeamiento de la vida social comunitaria que responde a la acción de las guerrillas (en particular, las Farc). ${ }^{12}$ Sobre todo, desde el inicio de los años ochenta, los guerrilleros llenaron vacíos dejados por el Estado, ofreciendo un poco de seguridad y de orden a los habitantes del bajo Atrato, actuando contra algunas manifestaciones de delincuencia, interviniendo de vez en cuando para resolver conflictos en torno a la tierra, intentando imponer ciertas normas de convivencia e impulsando, a veces, trabajos colectivos y solicitudes de servicios al Estado a través de las JAC, tal como lo recuerdan algunos miembros de Ascoba que fueron entrevistados.

12 La presencia sostenida de distintos frentes de las Farc en el bajo Atrato fue más bien tardía y se hizo más fuerte y notoria con la creación en 1982 del Frente 34 de las Farc, el cual surgió a partir del Frente 5 que había sido instaurado una década antes en el eje bananero del Urabá antioqueño. A partir de ese momento, la guerrilla comenzó a realizar un "trabajo político" más intenso y regular en el bajo Atrato, convocando a reuniones en las que se buscaba explicar justificar lucha armada y persuadir a los habitantes de adherir a ella. Un poco más tarde, hacia el final de la década de los ochenta y el principio de los noventa, apareció el Frente 57. En ese momento, las Farc entraron en una fase de ofensiva militar mucho más agresiva, intentando tomar el control de los territorios por vías más expeditas y violentas. 
En particular, al promover las acciones comunales -en ocasiones presionando e intimidando- la guerrilla también procuró generar el sentido comunitario en los caseríos del bajo Atrato. Solo que sus habitantes nunca se plegaron del todo a las iniciativas y coacciones guerrilleras, inicialmente porque la guerrilla no siempre estuvo presente y no fue muy coercitiva, y luego porque la gente de la región se molestó, cada vez más, frente a ciertas acciones guerrilleras que empezaron a ser consideradas como abusos (los reclutamientos forzados de jóvenes, la imposición de leyes destinadas a "administrar justicia”, las obligaciones a participar en "trabajos comunitarios", la injerencia en organizaciones sociales que surgieron a comienzos de los años ochenta por fuera de las vías ofrecidas por los partidos políticos, etc.). Cierto, a fin de cuentas, los pobladores del bajo Atrato tuvieron que acomodarse sutilmente a la influencia ejercida por la guerrilla en sus territorios, pero también dejaron aflorar esporádicamente pequeñas expresiones de oposición mediante las cuales se pretendía preservar un mínimo de autonomía y de desobediencia

En ese sentido, no puede concluirse que las comunidades hayan sido totalmente permeadas y moldeadas por la guerrilla. Podríamos decir, incluso, que el término connivencia no es el más apropiado para describir las relaciones que se tejen en zonas abandonadas por el Estado entre los habitantes y los guerrilleros. En realidad, se trata de relaciones mucho más complejas que tienen un carácter pragmático, pues a través de ellas se establece una especie de modus vivendi obligatorio entre actores armados y poblaciones civiles, sin que esto anule del todo las posibilidades o las aspiraciones de estos últimos a conservar un mínimo de autonomía. Claro está, muchas veces esa autonomía tiene que ser buscada de manera subrepticia y disimulada.

Queda por mencionar el papel de la Iglesia católica que ha sido el gestor de las acciones colectivas más duraderas y trascendentes en el bajo Atrato, fortaleciendo así las redes comunitarias. Dichas formas florecieron en los años ochenta gracias al trabajo realizado, al menos un 
decenio antes, por misioneros claretianos sensibles a la teología de la liberación. Estos padres de la Iglesia católica se encargaron de promover la economía solidaria, la consciencia por el derecho a la tierra y la lucha por la dignidad de todas las personas "marginadas". El trabajo de la Iglesia, y más precisamente el de la parroquia de Riosucio y el de la Diócesis de Quibdó, consistió en persuadir a los colonos-campesinos que ellos eran, al mismo tiempo, "hijos de las tierras de la región”, “hijos de Dios” y "personas poseedoras de derechos”, mostrándoles asimismo que "un nuevo mundo" podía nacer de la "organización colectiva” (en este caso, las “comunidades" eclesiales de base).

Varios habitantes actuales del bajo Atrato conservan un recuerdo del trabajo realizado con los padres claretianos. Según ellos, ese trabajo les hizo ver que "Dios no ama la injusticia" y les ayudó a solucionar necesidades básicas, como la construcción de escuelas y la creación de redes de comercialización para sus productos (Comisión Intereclecial de Justicia y Paz, 2005, 30). Pero es aún más importante el hecho de que los contactos con los misioneros anclaron con mucha más fuerza el espíritu comunitario entre los habitantes del bajo Atrato.

En efecto, desde el inicio de los años ochenta un número creciente de individuos comenzó a colaborar con la Iglesia en calidad de laicos, después de recibir una formación para poder catequizar, animar reuniones colectivas y ser delegados de la palabra de Dios. Para la Iglesia, esas personas debían consagrar su trabajo "al servicio y al desarrollo de sus comunidades". No fueron pocos los líderes comunitarios que brotaron de esos procesos de formación. Y eso tuvo un impacto en los caseríos, donde la gente empezó a tomar cada vez más decisiones con respecto a asuntos que les concernían de manera colectiva y a poner en marcha nuevas formas de trabajo colectivo (como por ejemplo las mingas). Incluso entre los diferentes poblados que están esparcidos y separados a lo largo de las cuencas de los ríos se generaron dinámicas colectivas, como cuando surgió, a principios de los años ochenta, Asocomunales, una asociación que reunió a varias JAC con la intención de resolver mancomunadamente problemá- 
ticas comunes (CINEP y CORDAID, 2000, p. 24). Y, por último, la contribución sin duda más trascendente de la Iglesia católica fue el apoyo al nacimiento de las primeras organizaciones sociales que se dedicaron a la reivindicación de la propiedad sobre la tierra (Agudelo, 2004: 118-120): una de ellas la Organización de Campesinos del Bajo Atrato (OCABA), que reunió a campesinos mestizos y negros y fue fundada entre 1983 y 1985; la otra, Cabildos Mayores Indígenas de la Zona del Bajo Atrato (CAMIZBA), que congregó a los indígenas y apareció en 1986 (más adelante volveremos sobre estas primeras organizaciones sociales que dieron origen a su vez a las organizaciones en las que lo étnico comenzó a ser una reivindicación central).

Hasta aquí, hemos visto cómo los partidos políticos, la guerrilla y la Iglesia católica contribuyeron a dar forma a las comunidades del bajo Atrato de distintas maneras. Allí mismo están los gérmenes de las organizaciones sociales con carácter reivindicativo que van a emerger tardíamente (a partir de los años ochenta), y que van a ser esenciales en los procesos de democratización, ya que conllevan a la afirmación de sujetos y de identidades colectivas, así como la exigencia de derechos. Esas organizaciones no surgieron de un proceso autónomo por parte de los pobladores del bajo Atrato, sino sobre todo como resultado de procesos potencializados inicialmente por agentes externos, como los que hemos señalado a lo largo de este aparte.

\section{LA IGLESIA CATÓLICA EN EL CHOCÓ COMO MOTOR DE PROCESOS SOCIALES COMUNITARIOS}

Entre los tres agentes externos que han potencializado procesos de organización social en el bajo Atrato, la Iglesia ocupa un lugar importante frente a los demás debido a que los procesos sociales y las acciones colectivas que ha acompañado han sido aquellos que a la postre han tenido una mayor trascendencia. Esto se explica en parte por la conti- 
nuidad en la presencia de la Iglesia desde hace varios siglos en la región, ${ }^{13}$ lo cual ha impedido que sea percibida como un agente totalmente externo por las comunidades. Pero también se explica por el hecho de que la labor de la Iglesia no se ha limitado a la evangelización de los pobladores del bajo Atrato, sino que se ha caracterizado por un acompañamiento frecuente a las comunidades, cada vez que ellas han tenido que sortear circunstancias difíciles. De esa forma, la Iglesia ha logrado convertirse en un actor que goza de legitimidad, respeto y aceptación entre los habitantes del bajo Atrato. Ni el Estado (a través de las instituciones) ni la guerrilla han llegado a estar tan cerca de las comunidades y a contar con igual grado de aceptación.

Debido a la importancia que tiene la acción de la Iglesia católica en el bajo Atrato (y en todo el Chocó), este apartado busca caracterizarla. Desde la perspectiva de una sociología comprensiva, se entenderá la acción eclesial a través de las categorías que sirven para justificar y dar sentido a la acción de sus representantes. Lo que se busca es comprender las justificaciones teológicas que han sustentado y enmarcado "el Plan Pastoral" de la Iglesia en el bajo Atrato y en el Chocó. Sin ignorar, por supuesto, que detrás de todas estas razones de orden teológico existe un claro interés evangelizador que en ciertos momentos ha ocasionado algunas fricciones temporales. Aquí no se pretende pues idealizar la acción de la iglesia católica.

Antes de hacer el análisis del sentido de la acción eclesial, es preciso aclarar que a lo largo de este apartado se hará una alusión recurrente a la Diócesis de Quibdó, ${ }^{14}$ dado que esta ha brindado un apoyo sustancial a los procesos comunitarios del bajo Atrato. Así ha sido desde hace un tiempo, a pesar de que los municipios de esta subregión, al igual

13 La presencia de la Iglesia católica en el Chocó data del siglo xviI, cuando comunidades de jesuitas, franciscanos, carmelitas, dominicos, capuchinos y claretianos empezaron a cristianizar el territorio.

14 De acuerdo con el Diccionario de la Real Academia Española, una diócesis es un distrito o territorio en donde un prelado (como pueden serlo un arzobispo, un obispo, etc.) tiene y ejerce jurisdicción espiritual. 
que la parroquia de Riosucio, ${ }^{15}$ hacen parte de la jurisdicción de la Diócesis de Apartadó debido a su cercanía geográfica al Urabá antioqueño. En realidad, desde que los claretianos asumieron la administración de la parroquia de Riosucio, en 1958, los vínculos de las comunidades del bajo Atrato con la Diócesis de Quibdó no han cesado de fortalecerse, sobre todo gracias a una constante actividad de los claretianos, lo cual les ha permitido estar presentes en zonas recónditas.

Subrayemos de entrada que el objetivo de entablar relaciones armoniosas con poblaciones que, como las del Chocó, han tenido tradiciones culturales distintas al cristianismo, siempre ha sido un reto esencial para los representantes de la Iglesia en el Chocó. Así lo han expresado ellos mismos al sostener que su labor de misioneros exige "creatividad pastoral", es decir, estar dispuestos a entrar en un proceso de "inculturación". ${ }^{16}$ Para ellos, esto equivale a reconocer la riqueza cultural de los pueblos y etnias propias del territorio donde se lleva a cabo la misión. Dicho de otro modo, esto exige algo esencial: que "la Iglesia [encarne] el Evangelio en las diversas culturas y, al mismo tiempo, [introduzca] a los pueblos con sus culturas en su misma comunidad [la comunidad cristiana]". El testimonio de Jorge Iván Castaño Rubio, antiguo obispo de la Diócesis de Quibdó que, como lo veremos enseguida, jugó un rol muy importante en el trazado de los derroteros de la

15 La parroquia de Riosucio, Nuestra Señora del Carmen, fue fundada en 1920 por los carmelitas. Desde entonces, la parroquia surgió como el epicentro de la acción de la Iglesia en el bajo Atrato. Los carmelitas atendieron la capilla hasta 1958, año en el que comenzó la administración de los claretianos.

16 Para aclarar lo que significa la "inculturación” para la Iglesia católica, podemos retomar la definición que el padre Pedro Arrupe (quien fue Superior General de los jesuitas) propuso en 1978. Según él, “inculturación significa encarnación de la vida y del mensaje cristiano en una concreta área cultural, de manera que tal experiencia no solamente consiga expresarse con elementos propios de la cultura en cuestión -lo que sería una simple adaptación superficial- sino que llegue a ser el principio inspirador, normativo y unificante que transforma y vuelve a formular esta cultura, dando origen a una nueva creación". Esta definición de inculturación fue retomada por monseñor Castaño Rubio en 1991(Floréz López, 2012, p. 594). 
labor evangelizadora del departamento, ilustra cómo ese proceso de “inculturación” ha sido vivido por los misioneros del Chocó:

En el camino emprendido pude vivir la gran hospitalidad y bondad que brinda el pueblo pobre, pues al recibir de ellos el agua de coco o el vaso del jugo de piña o de borojó, estábamos recibiendo todo lo que el pueblo podía o tenía para dar. Cuando en el año 1983 fui nombrado obispo puse en mi escudo episcopal el texto de Isaías, asumido por Jesús, según nos cuenta el evangelista Lucas: "Evangelizare pauperibus misit me". El Señor me envío a evangelizar a los pobres. Hoy tendría que escribir: el Señor me envío a ser evangelizado por los pobres. (Flórez López, 2012: 442-443).

Este testimonio ayuda también a entender en parte por qué la labor evangelizadora de la Iglesia en el Chocó ha sido exitosa, en particular entre las comunidades de afrodescendientes (cuando se visita el departamento es difícil no sorprenderse con el fervor y la piedad con los que esas comunidades han asimilado la fe católica). En buena medida, dicho éxito tiene que ver con una actitud de cierta apertura y diálogo de la Iglesia con la cultura y las tradiciones afro, lo que ha generado un evidente sincretismo cultural. Esto puede observarse en la celebración de las fiestas de San Pacho, sobrenombre del patrono de los chocoanos, San Francisco de Asís, a quien cada año se honra mediante la tradicional chirimía chocoana, música con ritmos animados compuesta por platillos, clarinete, tambores y saxofón. Varios sacerdotes reconocen que en esa fiesta la Iglesia ha perdido protagonismo, pues se convirtió en una “fiesta popular", símbolo de la identidad del pueblo chocoano. Por esto, los sacerdotes consideran que en el Chocó se llevó a cabo una "etnización de lo religioso". ${ }^{17}$ En otras palabras, allí se dio "una conquista

17 Sin temor a abusos, puede decirse también que "lo étnico se tomó al santo" (San Pacho) o que ha habido un proceso de "etnización del santo", porque San Francisco de Asís ha adquirido en las representaciones iconográficas hechas en el Chocó una 
étnica de las fiestas", lo que modificó el sentido que inicialmente la Iglesia quería darle a este tipo de celebraciones, convirtiéndolas en espacios "para que la gente se reconozca". ${ }^{18}$

Para comprender el trabajo de los claretianos en el Chocó también es importante subrayar que, desde inicios de los años ochenta, el sentido de su acción eclesial se ha venido retroalimentando constantemente con los postulados de la Doctrina Social de la Iglesia y con las conclusiones de la II y la III Conferencias Generales del Episcopado Latinoamericano correspondientes a la teología de la liberación. ${ }^{19}$ A partir de ese momento se produjo una renovación de la Iglesia en el Chocó. Esto se expresó en un viraje pronunciado del "plan pastoral" hacia una "evangelización liberadora" fundada en el fortalecimiento de las "comunidades de base" (también llamadas "comunidades eclesiales de base"). Desde entonces, la Iglesia católica en el Chocó asumió un rol mucho más activo en los procesos de promoción de organizaciones sociales, en la implementación de estrategias de seguridad alimentaria y en la protección y defensa de los derechos humanos. El artífice y principal promotor de este cam-

tez más oscura. Los sacerdotes dicen entonces que el santo adquirió las características propias del pueblo.

18 Palabras del sacerdote José Oscar Córdoba Lizcano, que también es el actual Secretario de Educación de la Alcaldía de Quibdó, pronunciadas durante el Primer Encuentro Nacional del Cuerpo Sonoro", realizado en Quibdó entre el 11 y 15 de septiembre de 2012.

19 La II Conferencia General del Episcopado Latinoamericano, también conocida como la Conferencia de Medellín, se llevó a cabo en esta ciudad de Colombia en 1968. Esta conferencia pretendía analizar el rol que debía asumir la Iglesia en América Latina para poder ser "un instrumento de salvación" y convertirse en un soporte a los diferentes procesos de cambio social vividos en el continente. La III Conferencia General del Episcopado latinoamericano se efectuó en Puebla (México) en 1979 y fue presidida personalmente por el papa Juan Pablo II. En ella, se prolongó la reflexión sobre la acción de la Iglesia en el continente que ya se había iniciado en la conferencia anterior. La llamada "teología de la liberación" es una corriente teológica que nace en el seno de la Iglesia luego del Concilio Vaticano II (1962-1965) y de la Conferencia Episcopal de Medellín. Esta perspectiva se plantea preguntas que se enmarcan en el papel de la fe en medio de un contexto de opresión como lo es el Latinoamericano, dicha creencia entonces debería ser liberadora antes que alienadora. Su cercanía con la ideología marxista ha hecho que algunos sectores de la Iglesia católica la rechacen debido a las incompatibilidades que supuestamente plantea con el Evangelio. 
bio fue Jorge Iván Castaño Rubio, obispo de la Diócesis de Quibdó desde 1983 hasta 2001 (18 años en total).

De acuerdo con toda una serie de documentos de este obispo (Floréz López, 2012), es claro que el trabajo de la Iglesia en el Chocó y su fuerte apoyo a la acción colectiva de algunas organizaciones sociales está justificado y sustentado sobre todo en la Doctrina Social de la Iglesia y en unas razones teológicas tomadas en su gran mayoría de la teología de la liberación. Podría decirse que los principios orientadores de la acción eclesial en el Chocó son: la defensa de la vida, la opción por el pobre, la defensa del territorio y el énfasis en lo comunitario.

El primer principio establece que la Iglesia en la zona asume una defensa irrevocable por la vida. Este esfuerzo eclesial, explicitado por sus líderes a través de una Carta Pastoral del año 2000, responde a que los misioneros "deben ser fieles a la voluntad de Jesús” que vino "para que tengamos vida y vida en abundancia” (Jn. 10,10). Además, porque tal y como esos líderes lo expresan: "Nosotros tenemos una inmensa deuda con la nube de mártires que nos han precedido (Hb. 12,1), por ende se hace necesario alzar nuestra voz para compartir la realidad y la esperanza del pueblo chocoano que sufre".

El segundo principio se refiere al servicio al pobre, que tomó mucha fuerza desde las Conferencias Episcopales Latinoamericanas de Medellín (en 1968) y de Puebla (en 1979). De acuerdo con este principio, la evangelización no solo debe permitir una conversión personal, sino también una transformación social desde las estructuras. Para monseñor Castaño Rubio, este fue un "mensaje esperanzador” que debía traducirse en un compromiso evangelizador concreto: "Contribuir a una nueva sociedad, más justa y fraterna”. Además, el mismo obispo sostuvo que la preferencia por los pobres está justificada por una razón teológica fundamental que podría sintetizarse así: "En el pobre hay una especial presencia de Dios". En ese sentido, y dada su condición de pobreza, el Chocó ha sido presentado siempre como un escenario propicio para materializar ese propósito transformador. 
TABLA 1. Parangones de la realidad chocoana con los mensajes bíblicos

\begin{tabular}{|c|c|}
\hline $\begin{array}{c}\text { Síntomas de la realidad } \\
\text { chocoana }\end{array}$ & Relación con elementos de la Biblia \\
\hline $\begin{array}{l}\text { Dificultades que se viven } \\
\text { por la problemática de la } \\
\text { tierra en el departamento } \\
\text { del Chocó }\end{array}$ & $\begin{array}{l}\text { Los líderes religiosos del Chocó traen a colación } \\
\text { con frecuencia la experiencia del pueblo de Dios y, } \\
\text { ante todo, las peripecias que tuvieron que atrave- } \\
\text { sar los judíos en búsqueda de la tierra prometida, } \\
\text { lo que es semejable a las dificultades que se viven } \\
\text { a diario por la tierra en el departamento del Chocó. } \\
\text { Luis Carlos Hinojosa, lo comenta así: "Desde } 586 \text { se } \\
\text { presenta el destierro hacia Babilonia, cayó la ciudad } \\
\text { de Jerusalén y el templo fue destruido. Evidente- } \\
\text { mente este acontecimiento representa un duro golpe } \\
\text { para los judíos pues se quedaron sin reino, perdieron } \\
\text { su independencia y ante todo su propia tierra. De una } \\
\text { u otra manera, pasaron a ser extranjeros fuera de su } \\
\text { patria y aun sin ser esclavizados vivían bajo el mando } \\
\text { de otras autoridades que ejercían su poder sobre ellos } \\
\text { y a las cuales debían pagar tributos". }\end{array}$ \\
\hline $\begin{array}{l}\text { La pobreza del pueblo } \\
\text { chocoano }\end{array}$ & $\begin{array}{l}\text { La correlación de experiencias la hizo Luis Carlos } \\
\text { Hinojosa al referirse a la situación de pobreza que, } \\
\text { al igual que los pobladores del Chocó, vivía el pue- } \\
\text { blo de Israel, luego de haber perdido a sus reyes y } \\
\text { a su tierra. }\end{array}$ \\
\hline $\begin{array}{l}\text { Dolencias materiales y } \\
\text { espirituales del pueblo } \\
\text { chocoano }\end{array}$ & $\begin{array}{l}\text { Ante una serie de necesidades de tipo espiritual } \\
\text { y material en los tiempos previos a la llegada de } \\
\text { Jesús, el padre Hinojosa aclara que el anhelo de la } \\
\text { llegada de un mesías que trajera la salvación estaba } \\
\text { muy presente entre los judíos, aunque estos espe- } \\
\text { raban que fuera un guerrero. } \\
\text { No obstante, agrega Hinojosa, la figura de Jesu- } \\
\text { cristo, que rompe con ese parámetro, debido a su } \\
\text { mesianismo pacífico, adquiere una significancia } \\
\text { liberadora a muchas dolencias. }\end{array}$ \\
\hline
\end{tabular}




\begin{tabular}{|c|c|}
\hline $\begin{array}{l}\text { Síntomas de la realidad } \\
\text { chocoana }\end{array}$ & Relación con elementos de la Biblia \\
\hline $\begin{array}{l}\text { El racismo experimentado } \\
\text { por las comunidades afro } \\
\text { del Pacífico colombiano }\end{array}$ & 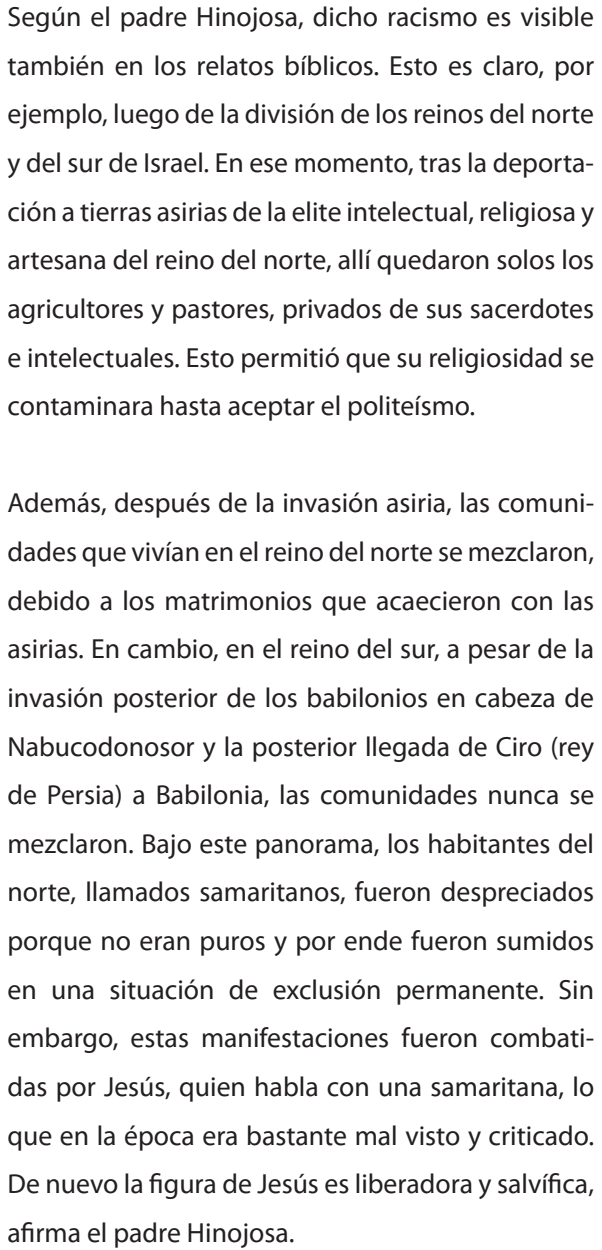 \\
\hline
\end{tabular}

FUENTE: elaboración propia a partir de lo relatado por el padre Luis Carlos Hinojosa, director de la Pastoral Social de la Diócesis de Quibdó, durante una entrevista realizada el 14 de diciembre de 2012 
El tercer principio del ejercicio religioso en el Chocó tiene que ver con la defensa del territorio. Y, como podrá verse enseguida, la defensa del territorio está también vinculada con la defensa y el cuidado del medio ambiente. ${ }^{20}$ Según monseñor Castaño Rubio, el plan evangelizador de la Iglesia debía expresar con claridad una opción "por la vida del pueblo negro". Esta opción quedó formulada de la manera siguiente: “Optamos por la defensa y preservación del territorio y medioambiente, por el aprovechamiento racional de los recursos naturales, fundamentales para la vida, y demás bienes codiciados por intereses económicos nacionales e internacionales, frente a lo cual debemos tener criterios y posición siempre clara a favor del pueblo"21 (Floréz López, 2012, p. 561).

Finalmente, el cuarto principio es el énfasis en lo comunitario. Como lo recuerdan los obispos en su Carta Pastoral de 2010, aquí estamos frente a un elemento que se sustenta en la identidad cristiana misma, "caracterizada por la vivencia en comunidad como signo de la creencia en Jesucristo resucitado". 22 Es a partir de esta idea fundamental que la Iglesia insiste en que los pueblos afrodescendientes deben fortalecer sus procesos organizativos étnico-territoriales y crear organizaciones donde estas aún no existan, para que "en comunidad” se defienda

20 Aunque los representantes de la Iglesia en el Chocó no lo dicen explícitamente, la cuestión ambiental aparece como objeto de preocupación en algunas encíclicas. Este es el caso de la encíclica promulgada para el 80 aniversario de la Renun Novarum. Allí se alude a las consecuencias "dramáticas de la actividad humana" generadas por "una explotación inconsiderada de la naturaleza" (Pablo VI, 1971).

21 Extracto tomado del documento escrito por monseñor Castaño Rubio, titulado La tierra que soñamos. Es interesante observar también cómo la defensa del territorio ha sido justificada como una prioridad para la Iglesia, a partir de la interpretación de ciertos pasajes bíblicos. Esto queda claro en una Carta Pastoral de Adviento emitida por los obispos de Tumaco, Guapi, Buenaventura, Istmina-Tadó, Quibdó y Apartadó. En dicho documento, los obispos evocaron pasajes de la Biblia en los cuales, según ellos, se muestra que la tierra no tiene un fin acumulativo, ni mucho menos está destinada al enriquecimiento de unos pocos, en detrimento de muchos (Alvarado Solano et al., 2010).

22 Varios pasajes de la Biblia aluden a ese sentido comunitario. Por ejemplo, esta perspectiva es fácilmente visible en el libro de los Hechos de los Apóstoles (4, 32-33), donde se afirma "que nadie consideraba sus bienes como propios, sino que todo lo tenían ellos en común”. 
la propiedad y el uso colectivo del territorio. Desde la perspectiva de la Iglesia, el fomento del sentido comunitario es esencial, dado que los afrodescendientes se encuentran siempre confrontados a un riesgo: el de las divisiones propiciadas entre ellos por los actores armados y por los agentes del modelo de economía extractiva. Los obispos de varias diócesis del Chocó han sido claros en que el robustecimiento de los pobladores del Chocó solo puede lograrse "haciendo primar los intereses comunitarios sobre los particulares” (Alvarado Solano et al., 2010).

Ahora bien, sumado a los anteriores principios teológicos, cabe resaltar que la Iglesia ha realizado un ejercicio permanente de lectura de la realidad chocoana a la luz la Biblia. Este esfuerzo que lideran los religiosos de la zona para sustentar su plan evangelizador, es además producto de una actividad interpretativa de la Iglesia que permite trasmitir no solo un mensaje religioso para las comunidades sino también orientar la acción colectiva de las organizaciones sociales. En la tabla 1 se ejemplifican los parangones realizados por Luis Carlos Hinojosa, director de la Pastoral Social de la Diócesis de Quibdó, obtenidos durante el trabajo de terreno realizado en diciembre de 2012.

\section{FRACTURAS Y RECOMPOSICIONES DE LA ACCIÓN COLECTIVA EN UN CONTEXTO DE VIOLENCIA}

Después de haber hecho un análisis sobre la acción eclesial en el Chocó intentando mostrar cuál es el sentido dado a dicha acción por los representantes de la Iglesia, vamos a volver sobre los procesos de acción colectiva contenciosa en el bajo Atrato, en una época en la que tales procesos se vieron truncados. Vamos a describir y analizar cómo esos procesos se fracturaron y cómo se recompusieron de nuevo, pero bajo formas novedosas, deteniéndonos igualmente en el papel que juega la Iglesia durante este periodo.

A mediados de los años noventa, el bajo Atrato entró en un proceso acelerado de generalización de la violencia, como resultado de la incur- 
sión de los grupos paramilitares en la región, quienes, después de haber iniciado una ofensiva en el Urabá antioqueño, descendieron hacia el Chocó con el objeto de desalojar a la guerrilla de los territorios que se encontraban bajo su influencia y de bloquear los avances de las organizaciones sociales de las comunidades del bajo Atrato que, después de la proclamación de la Constitución de 1991, comenzaron a obtener títulos legales de carácter colectivo sobre las tierras que habían ocupado "ancestralmente". Lo que hizo posible esa titulación de tierras fue la promulgación de la Ley 70 de 1993, que reconoció a las “comunidades negras" como una minoría étnica con derechos territoriales (más adelante volveremos sobre esa ley para subrayar su importancia). Para poder reclamar dichos derechos, las comunidades tuvieron que crear "Consejos Comunitarios"23 que rápidamente surgieron en todo el Chocó a lo largo de los años noventa.

La llamada -o mejor mal llamada- "connivencia" de estos procesos organizativos del bajo Atrato con las guerrillas (Farc), significó que las luchas antisubversivas del Ejército y los grupos paramilitares de Antioquia posaran sus ojos sobre la subregión. Así también, la recurrencia de las organizaciones negras a la autonomía a través de la colectivización de la tierra (Ley 70) constituía una peligrosa posición antagónica ante los intereses económicos y geoestratégicos de los actores armados ilegales, del Estado y de las empresas de extracción nacionales e internacionales. De esta forma, al mismo tiempo que la constitución y la Ley permitían a las comunidades negras gozar de ciertos derechos, hechos como las operaciones militares denominadas "Octubre Negro"

23 En la Ley 70, los Consejos Comunitarios son considerados como una instancia necesaria para poder asignar títulos colectivos de tierras a las comunidades de afrocolombianos. Esos Consejos Comunitarios comenzaron a crearse lentamente en el bajo Atrato durante la década de los noventa, aunque inscritos en el marco de las movilizaciones por la tierra que oсABA venía promoviendo desde los ochenta. Los Consejos Comunitarios son los entes encargados de administrar los territorios reconocidos por el Estado como propiedad colectiva de las comunidades negras (en el último aparte del capítulo haremos referencia a las funciones específicas que le han sido asignadas a estos consejos de acuerdo con la ley colombiana). 
(1996) y “Génesis" (1997) y la ofensiva paramilitar sumergieron los habitantes del bajo Atrato en las dinámicas de la violencia territorial.

La irrupción paramilitar no se llevó a cabo simplemente enfrentando de frente a la guerrilla, sino sobre todo ejerciendo la violencia sobre la población civil, en particular sobre aquellas personas tildadas de ser "bases sociales" de los subversivos. Las repercusiones de esta nueva fase del conflicto fueron agudas, no solo para varios habitantes de las comunidades de las diferentes cuencas de los ríos que no tuvieron más alternativa que desplazarse forzadamente hacia distintas direcciones (unos hacia Panamá, otros hacia Turbo y otros más hacia Mutatá); los efectos también fueron significativos sobre los procesos organizativos que se estaban consolidando en la región desde los años ochenta y que habían adquirido un tono cada vez más reivindicativo, en particular con respecto a los derechos territoriales.

En efecto, las JAC, Ocaba y Camizba (esta última en una menor medida) se vieron fuertemente golpeadas con la incursión paramilitar y entraron en un proceso de descomposición y pérdida de dinamismo que puede explicarse a través de varios factores: el asesinato o las amenazas dirigidas a varios líderes comunitarios; la generalización del miedo y la desconfianza entre las personas activas en esas organizaciones sociales; las condiciones precarias de vida de las personas desplazadas que terminaron confinadas en campamentos improvisados y que se vieron obligadas a concentrarse en su sobrevivencia. ${ }^{24}$ Allí, en esos campamentos de desplazados, los habitantes de las comunidades vivieron por un tiempo en medio del desarraigo y de la desesperanza, atravesando por un proceso de desubjetivación o de pérdida de su identidad

24 No entramos aquí en los detalles de las condiciones de vida de las personas que fueron desplazadas en el bajo Atrato. Existen informes donde son recogidos los testimonios de esas víctimas con suficiente detalle, especialmente aquellas que, al no poder llegar a Mutatá, terminaron confinadas en un campamento de desplazados improvisado en el poblado de Pavarandó (CINEP y CORDAID, 2000; Comisión Intereclecial de Justicia y Paz, 2005). 
como sujetos. Bajo esas circunstancias, claro está, la acción colectiva se hizo muy difícil. ${ }^{25}$

Pese a todo, y siguiendo con la idea de acompañamiento y guía de la acción colectiva que asume la Iglesia católica, los fundamentos de la acción cambiaron, en particular en uno de los campamentos (el de Pavarandó, donde se instalaron los desplazados que iban en dirección a Mutatá). Es preciso subrayar que la labor de acompañamiento de la Iglesia allí26 no se limitó a servir de canalizador de ayudas humanitarias y de intermediario entre los desplazados y las autoridades estatales, con el objeto de buscar soluciones a la problemática de las personas que tuvieron que abandonar sus tierras. Todo lo contrario, la Iglesia (y sobre todo el CINEP, de origen jesuita) participó activamente en la invención de una estrategia de sobrevivencia en medio del conflicto y de un mecanismo de protección de los miembros de las comunidades del bajo Atrato, que debía, al mismo tiempo, permitirles regresar a sus tierras. Lo que se moldeó en ese momento fue una acción colectiva fundada en la idea de "neutralidad".

Bajo el principio de neutralidad se lanzó en el campamento de Pavarandó, en el marco de una serie de talleres de formación en derechos del hombre. ${ }^{27}$ Se trataba de asumir un compromiso colectivo de respeto a unas consignas de "neutralidad" que debían aplicarse en medio de las confrontaciones armadas y que eran, según los representantes de la Iglesia, la única garantía para que los desplazados pudieran retornar en segu-

25 Con el desplazamiento forzado incluso los Consejos Comunitarios, creados bajo el marco de la Ley 70 de 1993, perdieron mucha fuerza.

26 Varios actores eclesiales fueron acompañantes de los desplazados en Pavarandó: la Diócesis de Apartado, la Parroquia de Riosucio, la Comisión Intereclecial de Justicia y Paz (CIjP) y el Centro de Investigación para la Educación Popular (CINEP). Este último fue el que más contribuyó a revivir la acción colectiva de las comunidades del Bajo Atrato, cuando estas se vieron desplazadas en Pavarandó.

27 Un representante de cada comunidad del bajo Atrato asistió a esos talleres de formación que abordaron un amplio abanico de temas como: la Constitución de 1991, la Ley 70 de negritudes, los derechos del hombre, el Derecho Internacional Humanitario. El representante de cada comunidad que participó en estos talleres debía enseguida informar a su propia comunidad sobre la formación recibida. 
ridad a sus tierras. La Iglesia postulaba que, creando esas "zonas neutras con relación al conflicto armado", los desplazados iban a poder aislarse de la violencia y vivir en seguridad en sus lugares de habitación originales. Mediante las consignas de neutralidad se fundó lo que de ahí en adelante se llamarían "las Comunidades de Paz". ${ }^{28}$

Estas nuevas comunidades fueron, por lo tanto, un invento producto de una estrategia concebida para substraer a una población y a su espacio de habitación de las lógicas guerreras de los actores armados. En ese sentido, las comunidades de paz no pueden ser consideradas como un modo de asociación fundado en una comunidad original y preexistente, sino como un colectivo que emergió de la adhesión común a una serie de normas que buscaban sobre todo restablecer la distinción entre civiles y combatientes, creando un espacio autónomo y al abrigo de la violencia de los actores armados (Rolland, 2003: 40-43). Este sería el verdadero principio fundador de las comunidades.

El restablecimiento de la distinción entre civiles y combatientes suponía la aceptación, por parte de los habitantes del bajo Atrato, de un compromiso a "no colaborar" con los actores armados (no portar armas, no dar información, no aportar ayudas logísticas). Es evidente

28 La iniciativa de las "Comunidades de Paz" no se inventó en Pavarandó, sino en San José de Apartadó, un municipio del Urabá antioqueño cercano a la zona bananera. Allí, otros desplazados, acompañados por la Diócesis de Apartado, el cineP y la cijP, crearon, el 23 de marzo de 1997, la "Comunidad de Paz de San José de Apartadó". Más o menos en ese momento, varios de los habitantes del bajo Atrato estaban apenas instalándose en el campamento de desplazados de Pavarandó. Así que la idea fue trasplantada más tarde por la Iglesia católica de un lugar al otro. Hay un excelente trabajo académico (Uribe de Hincapié, 2004) dedicado al análisis de la experiencia de las Comunidades de Paz de San José de Apartadó, la cual ha gozado de un reconocimiento significativo a nivel de las redes de militancia transnacional. Esta iniciativa estuvo mucho más dirigida por la CIJP, mientras que la de Pavarandó estuvo más en manos del cinep. Además, la experiencia de San José de Apartadó se caracterizó por una fuerte determinación de sus miembros a resistir a la penetración de los grupos armados. Esto se debió no solo a una cierta radicalidad en la conducción por parte de la CIJP, sino también a una tradición de resistencia popular de los habitantes de San José de Apartadó, quienes, en el momento de colonizar sus tierras, realizaron invasiones y luchas frente a los grandes hacendados, con el apoyo de la Asociación Nacional de Usuarios Campesinos (ANUC). 
que, en buena medida, ese modo de acción colectiva retomaba unas categorías del lenguaje jurídico (más precisamente del Derecho Internacional Humanitario), ${ }^{29}$ hasta entonces desconocidas por las comunidades del bajo Atrato. Se trata de categorías que fueron llevadas y transmitidas en el seno del campamento de desplazados por la Iglesia y por las oNG acompañantes. Ahora bien, el principio de neutralidad, sobre la base del cual se configuraron las Comunidades de Paz en 1997, poco a poco dejó de ser el eje esencial de la acción colectiva de los desplazados en el bajo Atrato. Esto ocurrió porque para muchos desplazados resultó difícil adherir sin reticencias y sin cierto escepticismo a dicho principio, debido a tres razones esenciales. Primero, la neutralidad en medio del conflicto armado fue percibida como una idea que no surgió del seno mismo de las comunidades. En efecto, como se explicó anteriormente, la idea fue promovida por la Iglesia entre los desplazados del bajo Atrato, en un intento por aplicar categorías propias del derecho internacional humanitario al conflicto armado de la subregión. Pero varios desplazados creyeron, casi desde el momento mismo en el que se lanzó la iniciativa de las Comunidades de Paz, que la neutralidad era inaplicable en el contexto de violencia de la zona, pues la mayor parte del tiempo los civiles no podían resistir a las exigencias y a las presiones ejercidas por los actores armados ${ }^{30}$ y porque de alguna manera las familias podrían estar vinculadas al conflicto, donde la militancia en uno u otro bando suele ser común debido a la carencia de oportunidades laborales. Claro está, mientras las Comunidades de Paz existieron y permitieron la canalización de recursos externos hacia los desplazados, esa opinión no se manifestó

29 De hecho, el principal acompañante de las Comunidades de Paz (el CINEP) promovió esta iniciativa a nivel internacional, ante otros Estados y ante la opinión pública internacional, como una "modalidad de aplicación del DIH".

30 Es más o menos obvio que resistir sin armas a la presión de los actores armados es un objetivo muy arriesgado, en contextos donde la violencia proveniente de múltiples actores armados es omnipresente y donde la presencia estatal tendía a manifestarse también a través del uso de la fuerza en su afán de "retomar el control territorial". 
casi nunca abierta y públicamente, sino tan solo en algunas circunstancias excepcionales.

Segundo, el principio de neutralidad no fue aceptado con facilidad por algunos desplazados porque, para ellos, este poseía una connotación de pasividad frente a las injusticias y a la realidad violenta de la región. Esto explica, en parte, por qué el término "neutralidad" no siempre era utilizado en el bajo Atrato, ni siquiera por los líderes de las Comunidades de Paz. Más bien, muchas veces, dentro de la subregión se prefería evocar otra palabra que parecía sintetizar mucho mejor las aspiraciones de los habitantes de la región: la "autonomía”. En cambio, fuera del bajo Atrato y de cara a los interlocutores externos, en particular frente a las ONG extranjeras que apoyaban a las Comunidades de Paz, el uso del término "neutralidad" era casi un imperativo. Sobre todo porque, para movilizar apoyos externos, las oNG acompañantes de esta iniciativa (sobre todo el CINEP) insistieron en presentar a las comunidades como una forma de "resistencia civil" frente al conflicto armado fundada en el principio de la neutralidad. No obstante, dado que los voceros de los desplazados no querían que los miembros de sus comunidades aparecieran como sujetos pasivos, es decir, como simples víctimas de la violencia sin posición alguna frente al conflicto armado, en varias ocasiones frente a interlocutores externos prefirieron utilizar el término "neutralidad activa". Este reacomodamiento de los términos es interesante pues muestra cómo los desplazados, y en particular sus líderes, intentaron apropiarse de una idea que en principio les parecía ajena y susceptible de múltiples críticas, pero que también servía para movilizar apoyos externos, especialmente a nivel internacional.

Tercero, lo que se acaba de señalar demuestra en qué medida la neutralidad no tuvo nunca un significado unívoco y absolutamente compartido para todos los desplazados que tomaron parte en las Comunidades de Paz. Más bien es preciso subrayar que la neutralidad adquirió múltiples significados entre dichos desplazados, significados que no siempre fueron compatibles entre sí, ni totalmente claros. Algunos 
comprendieron la neutralidad de la misma forma en que la Iglesia había querido promover la idea inicialmente, esto es, como un compromiso colectivo de negarse a colaborar con los actores armados. Pero otros desplazados entendieron la neutralidad como "un modo de aislarse" que consistía en adoptar una conducta de "sospecha hacia todo el mundo"; aunque no siempre fue claro hacia quién exactamente debía desarrollarse ese tipo de actitud, dado que en ocasiones los desplazados no solo parecían sospechar de los actores armados, sino también de los agentes del Estado y de otros actores ajenos a la subregión. Por último, ciertos desplazados llegaron a concebir la neutralidad de formas que eran difíciles de comprender -al menos para un observador externo-, tal y como se evidencia en algunas distinciones realizadas por los desplazados entre la "neutralidad directa" y la "neutralidad indirecta". No es fácil saber si esa distinción tenía alguna relación con el hecho de que la cooperación frente a los actores armados podía ser directa o indirecta, y de que quizás una de esas dos formas de cooperación resultaba condenable para los desplazados y la otra no, de manera que abstenerse de una de esas dos formas de cooperar resultaba ser más sencillo que la otra; o incluso, quizás la diferencia entre ambos tipos de neutralidad tampoco era totalmente clara ni siquiera para los mismos desplazados.

Hemos resaltado las dificultades que conocieron los miembros de las Comunidades de Paz para aplicar el principio de neutralidad, con el propósito de mostrar que la adhesión a los compromisos que exigía esa iniciativa colectiva no fue total. De hecho, esta adhesión se hizo cada vez más frágil y la iniciativa se fue reorientando y redefiniendo con el tiempo, dejando paulatinamente a un lado la neutralidad como principio esencial de la movilización colectiva.

Uno de los primeros signos de esta recomposición gradual tuvo lugar en mayo del año 2000, cuando los miembros de las comunidades tuvieron que designar a un representante de cada cuenca para conformar una "Comisión humanitaria” que en adelante debía encargarse de dialogar con los actores armados. Puede decirse que la creación de esta 
comisión puso en entredicho -aunque no de manera abierta y quizás ni siquiera consciente- la idea original de las Comunidades de Paz, ya que la Iglesia católica había propuesto al inicio que ella misma debía asumir ese tipo de diálogos con el objeto de "preservar" a las comunidades de cualquier tipo de contacto con los actores armados. La creación de la comisión fue un signo de que los contactos y las negociaciones entre los habitantes del bajo Atrato y los actores armados se seguían realizando de manera cotidiana, pero informal. Se llegó, pues, a un punto en el que el principal acompañante de las Comunidades de Paz, el CineP, prefirió institucionalizar ese tipo de diálogos, intentando así controlarlos y dirigirlos mejor. Pero esos intentos por establecer una especie de modus vivendi con los actores armados no funcionaron. ${ }^{31}$ En diciembre de 2002, la situación de las Comunidades de Paz era realmente difícil y delicada debido a un declive y a una desorganización evidentes en la movilización colectiva. Por ejemplo, unos meses antes la participación de los habitantes del bajo Atrato en la Asamblea General anual de las comunidades fue muy débil, ${ }^{32}$ al mismo tiempo que las instancias

31 Esto fue evidente en las reflexiones conclusivas que hizo un padre del CINEP en una reunión plenaria realizada durante la celebración del quinto aniversario de las Comunidades de Paz en octubre de 2002. En ese momento, él sostuvo frente a los miembros de las comunidades que no era posible "vivir por fuera del conflicto", que aquello era "una utopía irrealizable”. Más bien, era preciso admitir que el conflicto armado era una realidad y que las comunidades debían "vivir en medio de él”. Y habiendo reconocido esa realidad, dicho padre concluyó: “Quizás en algún momento podamos substraernos al conflicto. Pero, por ahora, lo más importante es pedir un respeto por la vida de las personas".

32 Nosotros constatamos esa baja notable de la participación en la Asamblea General anual de las comunidades, cuando asistimos al quinto aniversario de existencia de las Comunidades de Paz, celebrado en Curbaradó en octubre de 2002. Pocas personas de la región asistieron a ese evento y a los talleres organizados por el CINEP durante la celebración. Los temas mismos de discusión durante los talleres daban cuenta de una defección más o menos generalizada frente a la iniciativa. Preguntas del estilo de “¿qué hacemos con las personas de las comunidades que no están realmente comprometidas en el proceso?" surgieron con frecuencia entre las pocas personas que sí asistieron a los ejercicios. La respuesta de los acompañantes del CiNEP ante ese tipo de preguntas también revela cuán difícil era lograr una adhesión de las personas a la iniciativa: "Ahí hay que hacer un trabajo de concientización; hay que mostrarle a las personas para qué sirven las Comunidades de Paz y ayudarles a comprender que su ausencia de compromiso pone en peligro a los otros miembros de las 
comunitarias, las cuales debían organizar y dirigir la iniciativa, parecían diluirse. ${ }^{33}$

El cuestionamiento de la neutralidad, como principio de base de las Comunidades de Paz, condujo al surgimiento de una nueva forma de acción colectiva que se concretó con la creación de la Asociación de los Consejos Comunitarios y de las Organizaciones del Bajo Atrato (Ascoba). Esta asociación se consolidó a partir del trabajo de los Consejos Comunitarios ${ }^{34}$ de diferentes cuencas de la región, los cuales celebraron una primera Asamblea General en octubre de 2003. No es anodino, ni es una mera coincidencia que esta asociación haya sido creada cuando las Comunidades de Paz se reunieron para festejar una vez más su aniversario, pues la apuesta de los líderes comunitarios del bajo Atrato era la de darle vida a una organización que tuviera más autonomía frente a los acompañantes locales e internacionales. Esta voluntad fue evidente cuando, al iniciar la asamblea de las comunidades, los líde-

comunidades". Sin embargo, hay que subrayar que la débil participación en la celebración del quinto aniversario de las Comunidades de Paz se debió sobre todo a las presiones e intimidaciones ejercidas por los actores armados sobre la población civil. Por ejemplo, por un lado, la guerrilla impidió la asistencia al evento de los habitantes y líderes de la cuenca del Jiguamiandó, que en su gran mayoría no pudieron desplazarse hasta Curbaradó. Por otro lado, los paramilitares habían ocupado Curbaradó y vigilaban lo que ocurría durante la celebración del aniversario, aunque su presencia no era completamente visible, pues estaban allí vestidos de civiles (notas de trabajo de campo tomadas el 20 de octubre de 2002).

33 Una instancia importante de las Comunidades de Paz, la "Comisión Central”, compuesta de dieciocho individuos, debía recomponerse justo después del quinto aniversario de las comunidades realizado en octubre de 2002. En diciembre de 2002 esta comisión aún no se había constituido, dado que solamente seis personas habían sido nombradas para conformarla. Esto ocurrió porque la mayoría de las comunidades no había de hecho designado a sus representantes.

34 Hay que aclarar que los Consejos Comunitarios nunca dejaron de existir durante el tiempo que pervivió la iniciativa de las Comunidades de Paz. Aunque esos consejos se vieron debilitados con el desplazamiento de los habitantes del bajo Atrato, los desplazados intentaron en varias oportunidades devolverles su dinamismo. Incluso en el seno del campamento de Pavarandó, los desplazados consideraron que dichos consejos debían ser una instancia fundamental en el proceso de búsqueda de una solución a su problemática, puesto que, sin ellos, los habitantes del bajo Atrato no podrían nunca tener un acceso legítimo a la tierra. Por esta razón, los Consejos Comunitarios hicieron parte del conjunto de instancias de regulación de la vida en las cuencas, creadas en el marco de la iniciativa de las Comunidades de Paz. 
res de la región decidieron deliberar solos, sin la presencia de las instituciones que normalmente los acompañaban y la de otros observadores externos. ${ }^{35}$ Sin duda alguna, Ascoba traduce la intención de los habitantes del bajo Atrato de distanciarse de la tutela de la Iglesia, pero sin romper del todo los lazos establecidos con ella. Esto es evidente en la manera como la Asociación presenta incluso hoy en día el objetivo de su organización en su página web:

Asociación de Consejos Comunitarios y Organizaciones del Bajo Atrato que busca para todas las Comunidades y sus habitantes una mejor calidad de vida integral, teniendo en cuenta la construcción e implementación de planes de etnodesarrollo que respondan a las necesidades económicas, sociales, culturales y políticas de la población, para obtener una mejor armonía con la naturaleza, basados en los valores cristianos y de justicia social.

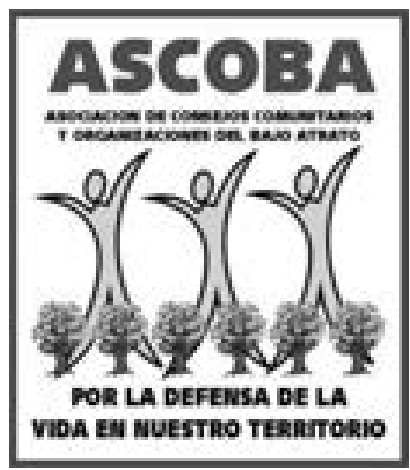

FUENTE: página web de ASCOBA

35 Por lo general, varios diplomáticos, junto con funcionarios de ONG y de organizaciones internacionales, asistían a los aniversarios de las Comunidades de Paz para expresar su "apoyo moral" a la iniciativa. El sexto aniversario de las comunidades no fue la excepción, de tal suerte que para los invitados externos fue una sorpresa ver emerger allí una nueva organización: Ascoba. La decisión que en esa ocasión tomaron los líderes comunitarios del bajo Atrato de deliberar solos, sin la presencia de observadores externos, incomodó un poco a sus principales acompañantes (los miembros del equipo Urabá del CINEP), puesto que normalmente estos últimos eran los que siempre se encargaban de organizar y dirigir los debates en las asambleas de las comunidades (notas de trabajo de campo tomadas el 20 de octubre de 2002). 
Ahora bien, la creación de Ascoba expresa en todo caso el desgaste del concepto de neutralidad sobre el cual se fundaron las Comunidades de Paz, puesto que este no apareció abiertamente como un objetivo, ni como un principio de base de la nueva organización, cuyas reivindicaciones fundamentales en ese momento fueron "la autonomía” y "los derechos sobre el territorio". Este último objetivo estaba además relacionado con la necesidad -identificada ya por actores eclesiales- de hacer de la tierra un espacio de interacción caracterizado por un acceso y distribución justos.

Con frecuencia, los líderes de Ascoba sintetizaron esas dos reivindicaciones en una fórmula que presentaba de la manera siguiente el objetivo general de la organización: "el desarrollo étnico-cultural”. En efecto, se trataba de una búsqueda de la autonomía a través del despliegue de una identidad étnica y cultural. Esta identidad era considerada como una condición necesaria para acceder a la tierra y para darle a su vez un substrato material a esa autonomía anhelada. Aquí sería preciso subrayar que lo que se buscaba era "desarrollar", y no "reforzar", unas identidades étnicas preexistentes y bien delimitadas. La etnicidad interviene aquí a posteriori, como un recurso que haría más factible la recuperación de una autonomía perdida por los habitantes de la región a lo largo del tiempo. ${ }^{36}$

Con toda razón, Stellio Rolland califica la movilización de Ascoba como "etno-política", dado que lo que está en juego es transformar una población víctima en un sujeto político, por medio de un discurso étnico-cultural. En otras palabras, Ascoba pretende construir una causa sobre la idea de que los habitantes del bajo Atrato deben pasar del estatus de "desplazado" al de "campesinos sin tierra", al de "miembro de

36 Cabe recordar que la cuestión étnica no intervino nunca como un elemento central del conflicto armado en el bajo Atrato. Ese conflicto nunca fue una guerra étnica. Las identidades étnicas eran de hecho más bien débiles entre la población afrocolombiana antes de que se llevaran a cabo los primeros desplazamientos a mediados de los años noventa. 
una comunidad afrocolombiana", al de "propietario de un territorio ancestral" y al de "detentor de una identidad y de una cultura" (Rolland, 2006, p. 3). En ese sentido, el nacimiento de Ascoba debe ser comprendido como un intento de una población marginalizada, y víctima de toda suerte de violencias, para incorporarse y erguirse. Esta tentativa suponía una toma de distancia con relación a nociones como las de "neutralidad" y "sociedad civil", muy evocadas desde el momento en el que fueron creadas las Comunidades de Paz. La distancia frente al concepto de neutralidad se expresó sobre todo en la idea de que no debía confundirse el hecho de declararse neutro frente al conflicto armado, con una actitud que consistiría en no interesarse en los problemas de la región ("ellos no quieren saber de nada, porque todo les es igual”). ${ }^{37} \mathrm{En}$ cuanto al concepto de sociedad civil, es claro que las comunidades deseaban aparecer como algo más, es decir, como propietarios de una tierra que ellos han decidido ocupar y defender de manera pacífica. ${ }^{38} \mathrm{~A}$ partir del momento en el que Ascoba apareció como un actor de peso en la escena local, las comunidades del bajo Atrato dejaron un poco de lado la idea de constituir un espacio humanitario fundado en los principios del Derecho Internacional Humanitario y substraído a las lógicas de los actores armados. La intención pasó a ser más bien la de construir un espacio para la realización de una territorialidad nueva que pudiera legitimar realmente la autoridad de los consejos comunitarios.

Puede considerarse entonces a Ascoba como la cristalización de la aspiración de los líderes del bajo Atrato por tomar en sus manos la movilización de los habitantes de su región. Una prueba de ello sería la participación elevada de estos líderes en su primera Asamblea General:

37 Esta frase fue utilizada por una monja de la Diócesis de Apartadó para sintetizar así las críticas que normalmente se le hacían a la idea de neutralidad en la región. El comentario fue recogido por los miembros de un comité de solidaridad francés con las Comunidades de Paz en un reporte de una misión hecha sobre el terreno entre el 8 y el 22 de diciembre de 2002.

38 De esa manera fueron interpretadas las nuevas reivindicaciones de los habitantes del bajo Atrato por la misma monja de la Diócesis de Apartado que fue mencionada en la anterior nota de pie a página. 
cada consejo comunitario envió allí tres delegados. Esta situación contrasta con la débil participación, un año antes, de los mismos líderes en las reuniones de las Comunidades de Paz. Es cierto que desde su nacimiento Ascoba tomó la delantera sobre la antigua iniciativa de acción colectiva promovida por la Iglesia católica.

El éxito inicial de Ascoba también está relacionado con el hecho de que la nueva asociación buscaba romper con el aislamiento en el cual se encontraban las comunidades que se habían comprometido en las Comunidades de Paz. En efecto, Ascoba deseaba inscribir a esas comunidades en una movilización más amplia que cubría a todo el departamento del Chocó. Esta movilización era promovida por la Asociación Campesina Integral del Atrato (ACIA), ${ }^{39}$ una organización muy activa desde mediados de los ochenta en la región del medio Atrato, que, más o menos hacia el año 2002, comenzó a impulsar la idea de una federación de consejos comunitarios en el Chocó. Fue bajo la perspectiva de la creación de esa federación que los consejos comunitarios del bajo Atrato erigieron su asociación, ya que para tener el derecho al voto en ella, era preciso crear una organización única que no existía bajo la figura de las Comunidades de Paz. Además, ACIA, por su dinamismo y su capacidad para perdurar en el tiempo, se había convertido en un verdadero modelo para los campesinos del bajo Atrato. Por esos motivos, los líderes del bajo Atrato se propusieron alinear a las antiguas Comunidades de Paz bajo este nuevo modelo de acción colectiva, más anclado en el desarrollo étnico-cultural. ${ }^{40}$

Hay que subrayar, sin embargo, que la rectificación de la acción colectiva en el bajo Atrato no implicó el abandono total de los térmi-

39 ACIA nació de un largo proceso de organización de los campesinos afrocolombianos del medio Atrato (una subregión del Chocó situada al sur del bajo Atrato). Dicho proceso comenzó hacia 1982 con el trabajo de los padres claretianos que constituyeron allí comunidades eclesiales de base.

40 La fuerza de ACiA como modelo de organización fue evidente a través de la presencia de sus representantes en la primera asamblea general de los consejos comunitarios del bajo Atrato. Un padre de la parroquia de Riosucio también asistió a ese evento. 
nos bajo los cuales esta se había llevado a cabo desde el nacimiento de las Comunidades de Paz. Lo que en realidad se produjo fue una cohabitación de términos y de reivindicaciones heterogéneas, con el objeto de no socavar los apoyos externos que se recibían de ong extranjeras. Así, los principios de base de la acción colectiva de Ascoba se forjaron alrededor de un núcleo duro (la etnicidad, la cultura y el territorio), y al mismo tiempo de toda una serie de elementos periféricos, algunos de ellos relativamente nuevos (como el medio ambiente), y otros relacionados con los pivotes de la iniciativa de las Comunidades de Paz (el sentido comunitario, la solidaridad y la no violencia). Para ser más precisos, aunque el deseo de los líderes del bajo Atrato era crear una nueva organización, ellos no abandonaron del todo las referencias y los registros discursivos de la antigua iniciativa. Los líderes de Ascoba han utilizado y combinado estos registros múltiples de distintas formas, de acuerdo con los interlocutores y con los contextos en los cuales ellos han tenido que actuar. Por eso, Stellio Rolland habla de una plasticidad en el uso dado por Ascoba a las categorías, las identidades y los sentidos de pertenencia colectiva (Rolland, 2006). Esto se expresa, por ejemplo, en el hecho de que los líderes de Ascoba, al igual que los antiguos acompañantes de las Comunidades de Paz -que de todos modos siguieron acompañando el nuevo proceso-, han afirmado en ocasiones, frente a las oNG extranjeras, que los principios y los objetivos de las Comunidades de Paz no han sido abandonados sino integrados a la nueva organización, la cual reúne a esas y también a otras que nunca habían adherido a la neutralidad.

Subrayar esta plasticidad en el uso de registros discursivos no conlleva a poner en duda la aspiración a resistir de las comunidades. En la movilización de Ascoba, y en su discurso étnico-cultural, hay una resistencia que llegó a tomar formas concretas, como por ejemplo la estrategia de "avanzadas en las zonas rurales ocupadas". Para comprender este modo de acción, es preciso saber que cuando surgió Ascoba una gran mayoría de los habitantes del bajo Atrato, que ya 
había regresado a sus tierras, se vio obligada de nuevo a abandonar sus asentamientos y a desplazarse en el año 2003. Varios de ellos se instalaron en las cabeceras municipales de la región, especialmente en Riosucio, donde Ascoba instaló su sede. Esto quiere decir que las zonas rurales del bajo Atrato habían sido casi completamente desalojadas, después de las incursiones y las presiones ejercidas por los actores armados, incluyendo las del general Rito Alejo del Río y la operación militar del batallón 13 que facilitó la expansión paramilitar en el Urabá antioqueño y chocoano.

En ese momento, Ascoba lanzó la idea de resistir de una nueva forma: circulando en permanencia en los territorios rurales, que legalmente le pertenecían a las comunidades, pero que se encontraban de hecho en las manos de los actores armados. Se trataba pues de intentar repoblar las zonas rurales, yendo allí a trabajar la tierra de manera itinerante y temporal. Estas "avanzadas" fueron concebidas como una estrategia de los consejos comunitarios para disputarles sutilmente la autoridad a los actores armados y a las empresas agroindustriales que se estaban instalando en la región (Rolland, 2006, p. 16).

Estas estrategias desplegadas por Ascoba, así como el uso flexible de los registros discursivos, dan cuenta en realidad del contexto de fluidez y de transacciones permanentes que caracterizan el universo social en el cual se encuentran los habitantes del bajo Atrato.

La fluidez se manifiesta en el hecho de que esos habitantes ya no son campesinos que lograron regresar a sus tierras, sino unos desplazados casi eternos de la violencia. Sus desplazamientos se han vuelto poco más o menos incesantes: ellos regresan y dejan de nuevo sus tierras, bien sea para buscar formas de subsistencia, o bien para huir de las agresiones de los actores armados.

Y una forma efectiva que tienen los campesinos para hacerle frente a esta condición precaria es situándose sucesivamente en varios registros discursivos al momento de presentarse frente a un público exterior. Stellio Rolland observó, por ejemplo, que los campesinos 
pueden, en un momento dado, privilegiar su identidad de "desplazado" para mantener un vínculo con las agencias humanitarias, e incluso para emprender una carrera política (algunos "desplazados notables" tuvieron éxito y accedieron a puestos administrativos a nivel local o regional).

$\mathrm{Y}$ en otro momento, ellos pueden presentar sus estrategias individuales de sobrevivencia, como aquella que consiste a ir a la parcela durante un periodo corto de tiempo para llevar a cabo una agricultura de subsistencia, como una acción de "campesinos en resistencia" que intentan organizarse (Rolland, 2006, p. 18). Claro está, ninguna de esas formas de presentarse es completamente falsa. Más bien, en el contexto de fluidez de las condiciones en las cuales se vive en el bajo Atrato, todas ellas son, al mismo tiempo, válidas.

\section{LA FORMACIÓN DE UN SUJETO POLÍTICO AFROCOLOMBIANO: COMO POR ARTE DE ETNIZACIÓN}

A continuación vamos a analizar la formación del sujeto político afrocolombiano a partir del momento en el que se produce el proceso de etnización de la acción colectiva en el bajo Atrato. Queremos mostrar cómo ese proceso supone una apropiación particular del territorio y un ejercicio colectivo alternativo al institucional, aunque en permanente interacción con los actores políticos locales. Para el culturalista español Raúl Minchinela, "la corrección política es un juego de eufemismos que pretende evitar conflictos a base de rehuir ciertos tópicos. Lo notable es -explica- que el tópico se da por sobre entendido; sin el prejuicio, no existe la corrección porque no habría nada que evitar. Así que cada vez que aparece algo que es políticamente correcto, es como si anunciara con un letrero de neón que hay un tabú justo detrás" (2007). De manera reducida, lo que esta idea plantea es la tendencia a renombrar y (re)imaginar hechos y sujetos que históricamente han sido excluidos de las sociedades organizadas, negados como constitución histórica y reducidos a la particularidad de la diferencia. 
Así, en el caso de las personas afrodescendientes en Colombia, un proceso social reciente ha llevado a la constitución de un sujeto político novedoso, difícil de pensar hace tres décadas, que busca radicalizar su diferencia como eje de su propuesta de mundo alternativa (Segato, 2007, p. 18). Este proceso, en el que las comunidades afrocolombianas transitaron por la ruta de la invisibilidad a la visibilidad, ha sido nombrado por algunos autores como etnización (Wade, 1997; Restrepo, 2005b). Materializada en la Constitución de 1991 y en la Ley 70 de 1993 (en donde las "comunidades negras" al fin surgen en el imaginario jurídico), la etnización de las comunidades afrodescendientes en Colombia ha contribuido a la dislocación del proyecto de una sola nación, una sola lengua y una sola religión. Este proyecto fue concebido y desarrollado por las elites colombianas blanco-mestizas y quedó incorporado por mucho tiempo en la Constitución de 1886.

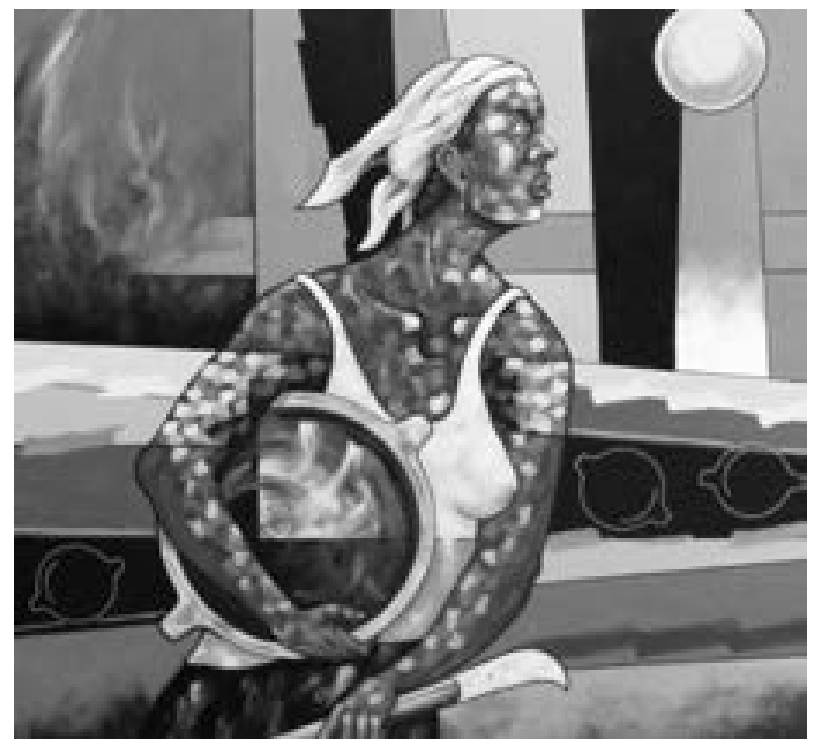

Representación de la afrocolombianidad en Oro, del artista antioqueño Rubén Crespo 
Podemos entender por etnización aquel proceso mediante el cual una o varias poblaciones son imaginadas como una comunidad étnica. Se trata de un proceso constante y complejo que supone la configuración de un campo discursivo y de visibilidades desde los cuales se constituye el sujeto de la etnicidad. Igualmente, el proceso demanda una serie de mediaciones desde las cuales se hace posible no solo el campo discursivo y de visibilidades, sino también las modalidades organizativas que se instauran en nombre de la comunidad étnica. Y, por último, pero no menos relevante, este proceso se asocia con la destilación del conjunto de subjetividades correspondientes (Restrepo, 2005a, p. 143).

En el apartado anterior vimos cómo, en medio de un contexto de generalización de la violencia, un proceso incipiente de constitución del sujeto étnico se rompió en el bajo Atrato (nos referimos a las movilizaciones reivindicativas de derechos territoriales que se cristalizaron en Ocaba durante los años ochenta), y cómo, después de una fase en la que se renunció a las reivindicaciones étnicas para darle prioridad a la constitución de unas Comunidades de Paz basadas en la idea de neutralidad, lo étnico volvió a emerger con fuerza (es lo que sucede con la creación de Ascoba). A continuación, vamos a profundizar en este último proceso de etnización que fue descrito y analizado en el apartado anterior, sobre todo a partir de las dinámicas "internas" a las comunidades y a partir del papel que la Iglesia desempeñó en ese proceso. Aquí, ampliaremos el contexto del surgimiento y del desarrollo de las organizaciones étnico-territoriales del bajo Atrato chocoano, mostrando que el proceso cultural y político en el que ellas han estado inmersas se ha construido no solo "desde adentro y hacia afuera", sino también "desde afuera y hacia adentro".

Este proceso, mediante el cual un nuevo sujeto de derechos se constituye y se visibiliza, dentro y fuera de la subregión, es lo que designamos como un "desde adentro y hacia afuera". Pero es preciso subrayar también que dicho sujeto no ha surgido a partir de una dinámica exclusivamente endógena, como tampoco sus espacios de organización social y los de participación política (esto es evidente, por ejemplo, en la 
forma como fueron creadas las JAC y las organizaciones de campesinos creadas con la ayuda de la Iglesia en los ochenta). Así que aquí deseamos mostrar cómo los procesos más recientes de etnización también se nutren de dinámicas y de agentes que rebasan lo local o lo subregional (como cuando ciertos discursos que vienen "desde afuera” tienen una influencia e impactan sobre los de “adentro”). Estas dinámicas son igualmente constitutivas de eso que las comunidades protagonistas del proceso de etnización suelen llamar "identidades propias”, “identidades autóctonas", o "identidades ancestrales".

Para el antropólogo colombiano Eduardo Restrepo (2005a), el proceso de etnización se compone de cuatro fases, de las cuales nosotros hemos escogido las dos primeras para recrear una especie de precuela de Ascoba, en donde buscamos captar la manera como, en los procesos organizativos de las comunidades afrocolombianas del bajo Atrato, se corresponden los contextos locales con los nacionales y viceversa.

En primer lugar, volvamos sobre la génesis del proceso, pero con un enfoque nuevo. Hacia la mitad de los años ochenta, ciertas condiciones específicas se dieron en el medio Atrato para hacer posible la génesis de la estrategia organizativa de las poblaciones campesinas negras. Una de esas condiciones está relacionada con una coyuntura específica. En aquella época, la amenaza de despojo de las tierras habitadas por estas poblaciones durante varias generaciones se hizo creciente, dado que el Estado desconocía su presencia desde que declaró una gran parte de la región del Pacífico como "zonas baldías". Esto facilitó el otorgamiento de concesiones o permisos de explotación de los recursos forestales y mineros a compañías foráneas. ${ }^{41}$

41 Esta ecuación no solo describe las concesiones para explotación de minas, caucho y madera de los sesenta hasta ahora. Nos referimos también a una característica histórica de la región y a su desdén por parte del Estado. El documental Chocó en blanco y negro cuenta cómo, en el amanecer del siglo xx, el presidente Rafael Reyes entregó como premio al general Arriaga por sus servicios prestados durante la Guerra de los Mil Días, gran parte de las tierras que tiempo después el mismo general vendería a la Empresa Chocó Pacífico hacia 1906. 
En esta génesis del proceso organizativo de las "comunidades negras" 42 del bajo Atrato, se aprecia la influencia que sobre los "campesinos negros” tuvo el movimiento indígena de la región, que logró a través de diversas estrategias la titulación de importantes extensiones de tierra a través de la figura de resguardo. Y aquí es importante destacar la relación que se estableció entre las comunidades afrodescendientes y la Asociación de Cabildos Indígenas Embera, Wounaan, Katío, Chamí y Tule (OREWA). ${ }^{43}$ Dicha relación no surgió espontáneamente sino que se dio mediada por la acción de la Iglesia católica, cuyos misioneros consideraron que los negros también debían poder tener una figura muy parecida a la del resguardo e inspirarse del modelo de movilización de las comunidades indígenas. Ahora bien, en este momento, para las órdenes religiosas foráneas, principalmente los claretianos, lo más importante era la reivindicación de derechos territoriales y lo étnico no constituía una reivindicación en sí misma, puesto que estaba atado a las exigencias planteadas sobre los territorios. Es decir, que se partía de la idea de que para poder reivindicar derechos sobre los territorios era preciso demostrar que existía una especie de comunidad étnica. Esa demostración no era fácil en aquella época, porque los negros, a diferencia de los indígenas, no habían sido tradicionalmente considerados como una etnia. Por eso, para argumentar que una cierta comunidad étnica existía, se hizo énfasis en las formas "tradicionales" de explotación de la tierra por parte de las "culturas negras". Lo que puede apreciarse entonces es el surgimiento de un "discurso étnico", pero en filigrana, y lo que prima es más bien un "discurso de reivindicaciones territoriales" que se acompaña de un "discurso ecologista” (Restrepo, 2011). En efecto, en ese entonces quienes reivindi-

42 Es preciso colocar aquí la expresión “comunidades negras” entre comillas, dado que en aquel momento los negros que habitaban el bajo Atrato, junto con personas de "otras etnias", no se autocalificaban de esa forma. Más bien, ellos se veían a sí mismos como "campesinos".

43 La OREWA nace durante los años setenta a través de la articulación entre algunos estudiantes indígenas y el Centro Pastoral Indígena. Aunque en sus inicios basaba su lucha en la reivindicación de derechos educativos, hoy se erige como una organización más amplia donde los discursos étnico-territoriales tienen mayor resonancia. 
caban se presentaban ante todo como "campesinos" y no como individuos pertenecientes a una etnia específica; es más ni siquiera se presentaban como "campesinos negros" (Ruiz Serna, 2006: 235-236; Restrepo, 2011: 55). El antecedente de Ascoba, es decir Ocaba, expresa esta fase bastante bien.

Además de lo anterior, es necesario destacar la influencia que tuvo, sobre el discurso organizativo de los habitantes del bajo Atrato, la presencia de una variedad de "expertos" (antropólogos, ecónomos agrícolas, agrónomos, ingenieros, etc.) que trabajaron en la zona durante los años ochenta en un proyecto de desarrollo rural resultante de la cooperación técnica internacional entre el Gobierno holandés y el colombiano. A través de las investigaciones y los trabajos realizados por estos "expertos", fue posible deconstruir una serie de prejuicios respecto a los campesinos negros, activando una nueva representación de estas personas: "Portadores de complejos modelos productivos que aprovechan diferencialmente los disímiles nichos del ecosistema, lo cual demanda un detallado conocimiento del mismo y una exitosa adaptación, sin destruirlo" (Restrepo, 2005a, p. 145). Y desde luego, deconstruir significa también construir un nuevo imaginario, del cual se fueron apropiando a su vez las poblaciones negras.

Luego del período de génesis, que se extiende a lo largo de los años ochenta, viene otra etapa del proceso de etnización que podría llamarse "Los negros existimos". ${ }^{44}$ Durante esta fase del proceso, las organizaciones locales creadas durante los años ochenta hicieron un intento por articularse en un proyecto de índole nacional, encarnado, sin mucho éxito, en el Proceso de Comunidades Negras (PCN). ${ }^{45}$ Trasladar las demandas de las orga-

44 Este fue el mensaje enviado por los negros del Chocó a los asambleístas de la Constituyente que redactaron el texto de 1991, en una petición llamada el Telegrama Negro. Esto hizo parte de todo un repertorio de acciones colectivas (tomas pacíficas a instituciones oficiales, plantones, intervenciones culturales, marchas) realizadas en el Chocó entre 1990 y 1991 que buscaban visibilizar a las comunidades negras y la necesidad de su reconocimiento cultural y político.

45 "El Proceso de Comunidades Negras (PCN) está conformado por 120 organizaciones étnico-territoriales, entre consejos comunitarios y organizaciones de base que están 
nizaciones del escenario local al nacional suponía articular múltiples iniciativas alrededor de un objetivo común: incluir a las comunidades negras en las discusiones públicas sobre la nueva Constitución nacional y visibilizar así los elementos diversos de la nacionalidad colombiana. Al igual que en la fase anterior, las alianzas con otros sectores como los pueblos indígenas y las órdenes religiosas fueron fundamentales, mucho más teniendo en cuenta que ningún representante negro fue elegido para hacer parte de la Asamblea Nacional Constituyente. Es decir que en esta fase las alianzas se intentaron tejer a nivel nacional, y ya no simplemente en el ámbito local o subregional. A través de la constitución de estas alianzas, y ya sobre el cierre de las sesiones de la Asamblea Nacional Constituyente, se logró redactar el artículo transitorio 55(AT-55) y se puso en marcha el funcionamiento de una Comisión Especial para Comunidades Negras (CECN) que precisamente reunió a líderes comunitarios de todo el país con la intención de reglamentar y precisar el contenido del AT-55. De allí surgió la Ley 70 de 1993, también llamada "Ley de Negritudes", gracias a la cual "las comunidades negras" comenzaron a existir en el imaginario jurídico nacional. ${ }^{46}$

dividas en palenques regionales. Su máxima autoridad es la Asamblea seguida del Consejo Nacional de Palenques que reúne a delegados de todos los palenques regionales. También cuentan con un Equipo de Coordinación Regional, en donde hay representantes de las mujeres, de los jóvenes y de los “mayores”. Sus principales demandas giran en torno a la defensa de los derechos humanos de las comunidades negras, el reconocimiento de los derechos étnicos, culturales, territoriales, sociales, económicos y políticos. Igualmente, se busca el fortalecimiento de los procesos organizativos autónomos (Alto Comisionado de Naciones para los Derechos Humanos, 2011).

46 El AT-55 ordenó la expedición de una ley que regulara la administración y destinación de los territorios que por tradición pertenecían a las poblaciones afrodescendientes. Como resultado de dicha medida, en el año 1993 se expidió la Ley 70 "por la cual se desarrolla el artículo transitorio 55 de la Constitución Política”, y cuyo objeto es "reconocer a las comunidades negras que han venido ocupando tierras baldías en las zonas rurales ribereñas de los ríos de la Cuenca Pacífico, de acuerdo a sus prácticas tradicionales de producción, el derecho a la propiedad colectiva" (Ley 70 de 1993). No está demás subrayar que el AT-55 y la Ley 70 no fueron simplemente una concesión del Estado a las comunidades negras. Ambos fueron el producto de una insistente labor de cabildeo tanto del movimiento Cimarrón, como de la Asociación Campesina Integral del Atrato (ACIA). Tras la obstinada evasión de los asambleístas de la Constituyente, el movimiento se manifestó con varias tomas pacíficas que tenían como objetivo hacer presión para el reconocimiento de las comunidades negras. Las tomas más famosas fueron la de la Catedral y la sede del InCORA de 
La Ley desarrolló temas fundamentales como el uso del suelo y el subsuelo, la extracción de recursos mineros y la educación. Los principios que rigen esta Ley son:

[El] reconocimiento y protección de la diversidad étnica y cultural y el derecho a la igualdad de todas las culturas que conforman la nacionalidad colombiana [...] la participación de las comunidades negras y sus organizaciones sin detrimento de su autonomía, en las decisiones que las afectan y en las de toda la nación en pie de igualdad, de conformidad con la ley. (Ley 70 de 1993)

Y tanto el objeto como los principios conllevan a la definición de ciertos canales de participación, a través de los cuales las comunidades negras asentadas en el litoral Pacífico pueden ejercer su autonomía y hacer realidad su reivindicación étnico-territorial, así:

Artículo 4. El Estado adjudicará a las comunidades negras de que trata esta ley la propiedad colectiva sobre las áreas que, de conformidad con las definiciones contenidas en el artículo segundo, comprenden las tierras baldías de las zonas rurales ribereñas de los ríos de la Cuenca del Pacífico y aquellas ubicadas en las áreas de que trata el inciso segundo del artículo 1o. de la presente ley que vienen ocupando de acuerdo con sus prácticas tradicionales de producción. (Ley 70 de 1993).

Artículo 5. Para recibir en propiedad colectiva las tierras adjudicables, cada comunidad formará un Consejo Comunitario como forma de administración interna, cuyos requisitos determinará el reglamento que expida el Gobierno Nacional. (Ley 70 de 1993)

Quibdó, en mayo de 1991 y, en el mismo año, la toma a la Embajada de Haití (Centro de Pastoral Afrocolombiana, 2003). 
Además de las que prevea el reglamento, son funciones de los Consejos Comunitarios:

Delimitar y asignar áreas al interior de las tierras adjudicadas; velar por la conservación y protección de los derechos de la propiedad colectiva, la preservación de la identidad cultural, el aprovechamiento y la conservación de los recursos naturales; escoger al representante legal de la respectiva comunidad en cuanto persona jurídica, y hacer de amigables componedores en los conflictos internos factibles de conciliación. (Ley 70 de 1993)

Es claro, pues, que el fortalecimiento político y de reconocimiento de las organizaciones afro se enmarca formalmente bajo los lineamientos normativos producto de la Constitución Política de 1991 y de la Ley 70 de 1993. Ahora bien, para finalizar es preciso identificar a continuación algunos de los elementos de la ley que se consideran problemáticos a la hora de analizar el ejercicio de la autonomía territorial por parte de las comunidades negras del bajo Atrato. Estos elementos son, además, altamente influyentes en el proceso de consolidación de autoridades locales (tanto las electas, como las designadas en los Consejos Comunitarios), así como en la toma de decisiones respecto al uso que se da al territorio y la interacción con, por ejemplo, empresas extractivas o agrícolas foráneas de gran envergadura.

El reconocimiento de la propiedad colectiva propende por la protección de los territorios y de las prácticas tradicionales de las comunidades afro. La propiedad colectiva implica pues la titulación colectiva de los predios, obligando a las comunidades a estrechar sus vínculos de manera que se eviten posibles conflictos y se garantice el uso de la tierra, procurando el bienestar general. Sin embargo, la propiedad colectiva desconoce la realidad previa a 1993, cuando muchas familias provenientes del norte del país y de Antioquia tuvieron, en su momento, acceso a títulos de compraventa que les otorgaban derechos de propiedad privada sobre los predios. Las familias que aún conservan dichos títulos se confrontan ahora con la obligatoriedad de someterse a la colectivización de la propiedad, 
sin que siquiera se sientan identificados con las comunidades a las que “pertenecen”. Así, varios estudios, entrevistas y seguimientos a la implementación de la Ley 70 de 1993 demuestran que inicialmente "el camino de la reivindicación de los pueblos indígenas, cuyo reconocimiento se centró en la adjudicación de territorios, se mostró como itinerario que debían seguir los [demás] grupos étnicos" (Zambrano, 2003). Pero el problema es que el itinerario trazado al inicio desconoció una diversidad étnica adicional, cuyo comportamiento endógeno difiere del indígena.

El reconocimiento de propiedad colectiva a las comunidades negras ha sido entonces complicado. Si bien algunos de los habitantes de los baldíos adjudicables eran afro, otros habitantes eran colonos llegados al territorio desde la década de los años ochenta. ${ }^{47}$ Así, debido a una regulación indistinta, la forzada homogenización étnica da como resultado una débil identidad colectiva. Se configura así una noción de pertenencia en donde algunos -dada su etnia- "no pertenecen" al grupo étnico beneficiario directo de la Ley 70. Esto deriva entonces en conflictos y en competencias internas entre individuos, e incluso a veces familias, que buscan asegurar el mismo acceso a la tierra. Lo anterior se evidencia cuando las familias manifiestan su deseo de tener las parcelas delimitadas, acción contraria a la norma que tan solo permite la delimitación de linderos sobre la totalidad del territorio colectivo.

Entonces, si la Ley 70 tenía por objetivo propender por la constitución de una administración autónoma del territorio, a través de autoridades comunitarias que, entre otras cosas, protegen la tradición étnica y las prácticas que de ella se derivan; la diversidad interna de los habitantes del territorio dificulta de hecho la consolidación del ejercicio autónomo de la ciudadanía individual y, en ese orden, de la acción ciudadana organizada de manera colectiva. De tal forma, tal como señalan Gustavo Montañés y Ovidio Delgado, el supuesto sobre el que se basa

47 Esta información corresponde a la narrativa de miembros de Ascoba, que no son afrodescendientes. 
dicha autonomía hace que "el sentido de pertenencia e identidad, el de conciencia regional, al igual que el ejercicio de la ciudadanía y de acción ciudadana, solo adquieran existencia real a partir de la expresión territorial" (Delgado, 1998, xx), lo que implica de antemano una inestable validez. El territorio per se no garantiza el ejercicio de la ciudadanía a menos que esté antecedido por un sentido compartido de pertenencia que garantice la reivindicación y exigibilidad de intereses y derechos comunes, derechos que, en su materialización, se entrelacen con el uso y disfrute de territorio mismo.

La conformación de Consejos Comunitarios como unidad administrativa interna es quizá otro de los factores que carece de comprensión y apropiación por parte de las comunidades. Durante el trabajo de campo realizado en el año 2011, fue posible observar cómo una de las necesidades constantes en las comunidades - caso Costa de Oro y cuenca de La Larga- seguía siendo la capacitación y conocimiento de la Ley 70, tras nueve años de su expedición. Los Consejos Comunitarios suelen confundirse con las anteriores juntas administradoras comunales (JAC), y la reglamentación de estos a través del Decreto Reglamentario 1745 de 1995 alimenta la confusión, dado que establece que "una comunidad negra podrá constituirse en Consejo Comunitario, que como persona jurídica ejerce la máxima autoridad de administración interna dentro de las Tierras de las Comunidades Negras". En otras palabras, de acuerdo con la Ley 70 y con dicho decreto, el Consejo es a la vez la unidad territorial y el órgano administrativo interno. Posteriormente, se aclara que al Consejo Comunitario lo componen la Asamblea General y la Junta del Consejo. Y aunque todo esto pareciera sencillo, para los habitantes de la mayoría de comunidades del bajo Atrato es difícil comprender cuál es su rol como miembros de la comunidad. Dado que no todos pertenecen a la Asamblea o a la Junta del Consejo, en recurrentes ocasiones pueden llegar a presentarse dinámicas de exclusión -deliberadas o no, e incluso cargadas de un resentimiento histórico por los procesos de colonización y migración forzada. 
Adicionalmente, tal como lo reglamenta el Decreto 1745, la toma de decisiones de la Asamblea se dará preferiblemente por consenso. Sin embargo, de no lograrse, se procederá a decidir por mayoría de asistentes. Cabe señalar que, en términos prácticos, las viviendas de los consejos comunitarios se encuentran dispersas en el territorio y en muchas ocasiones las grandes distancias dificultan la cobertura administrativa del territorio en su totalidad y el llamado a la participación en las asambleas. Aunque también se trata de un problema de percepción: dado que las decisiones que se toman al interior de la Asamblea difícilmente han sido escuchadas por actores políticos estratégicos y la presencia de actores armados persiste, ${ }^{48}$ algunos miembros de la comunidad pueden considerar infructuosa y peligrosa su participación en estos espacios de deliberación y decisión.

\section{LAS ARTICULACIONES DE LAS ORGANIZACIONES AFRO CON LA ESFERA POLÍTICA INSTITUCIONAL A NIVEL LOCAL}

Con respecto a la clase política, los miembros de las organizaciones de Consejos Comunitarios en el Chocó sienten que existe una especie de "rivalidad", sobre todo porque los políticos tradicionales no parecen querer fortalecer a las organizaciones, sino más bien debilitarlas. Durante los periodos electorales incluso algunos políticos han intentado ponerse en contra de las organizaciones pese a que estas han convocado con frecuencia a los candidatos para exponerles sus puntos de vista y tratar de dialogar con ellos (en ocasiones incluso se llegaron a realizar foros con los políticos, con el apoyo de ONG internacionales). En síntesis, el principal reclamo de las organizaciones sociales frente a los políticos (o frente a "la clase política", como ellos los llaman) ha sido el

48 Durante las reuniones del Consejo Comunitario es evidente la presencia de personas que no sus miembros y que son señalados por la comunidad como miembros de grupos armados. Pero esto no les impide escuchar atentamente las discusiones comunitarias. Además, se presentan casos en los que las listas de asistencia a los consejos son observadas y a veces retenidas temporalmente por estos "observadores”, ejerciendo así un control sobre la participación. 
siguiente: "A los mandatarios de turno se les pide que cumplan con el deber de representar y de llegar a las comunidades, cosa que realmente no hacen o muy pocas veces hacen". En efecto, desafortunadamente, durante mucho tiempo los políticos han menospreciado el valor de los Consejos Comunitarios, así que "el posicionamiento" de estas organizaciones en el campo de la política y en el campo político ha sido lento.

Aquí es importante aclarar que los Consejos Comunitarios del Chocó han venido elaborando planes de desarrollo a partir de una identificación de necesidades básicas que incluyen la educación, la salud, la vivienda y los servicios públicos. Esos planes -llamados "planes de vida" o también "planes de etno-desarrollo"- buscan esencialmente hacer propuestas que les permitan a las familias "vivir dignamente". Varios de esos planes les han sido entregados a las administraciones locales para que "cumplan" con ellos. Así, puede verse cómo los Consejos Comunitarios han ido adquiriendo por sí mismos unas competencias que van mucho más allá del simple reclamo de derechos colectivos sobre las tierras. Aunque esto no significa, claro está, que la lucha por el territorio haya dejado de ser uno de los fundamentos de la organización. De acuerdo con lo anterior, las funciones de los Consejos Comunitarios se han ido ampliando y de allí proviene esa rivalidad implícita con las autoridades locales, que los perciben como una especie de "contrapoder".

Para entender mejor esta rivalidad política es importante contrastar las funciones que, según la ley, le corresponden a los Consejos Comunitarios, con aquellas que normalmente le son asignadas a los Consejos Municipales y a las alcaldías. Las funciones del Consejo Comunitario, a través de sus órganos administrativos internos (a saber, la Asamblea y la Junta del Consejo Comunitario), se especificaron en el Decreto 1745 de 1995. Para la comparación nos vamos a centrar en algunas funciones que son de mayor complejidad para las comunidades ya que definen su rol político como autoridades territoriales autónomas, y hacen equiparable -y casi duplican- las funciones de las autoridades locales. Veamos dichas funciones en las siguientes tablas. 
TABLA 2. Articulación de funciones concernientes a los planes de vida y planes de desarrollo

\begin{tabular}{|c|c|}
\hline Asamblea & Junta del Consejo Comunitario \\
\hline $\begin{array}{l}\text { 5. Aprobar o improbar los planes de } \\
\text { desarrollo económico, social y cultu- } \\
\text { ral que formule la Junta del Consejo } \\
\text { Comunitario. }\end{array}$ & $\begin{array}{l}\text { 5. Ejercer el gobierno económico de las } \\
\text { tierras de las comunidades negras según } \\
\text { sus sistemas de derecho propio y la legis- } \\
\text { lación vigente. } \\
\text { 6. Delimitar y asignar en usufructo áreas de } \\
\text { uso y aprovechamiento individual, familiar } \\
\text { y comunitario en el territorio titulado en } \\
\text { colectivo, reconociendo las que han venido } \\
\text { ocupando tradicionalmente y con base } \\
\text { en el reglamento que expida la Asamblea } \\
\text { General del Consejo Comunitario. } \\
\text { 7. Presentar y gestionar planes de desa- } \\
\text { rrollo para su comunidad, previa autoriza- } \\
\text { ción de la Asamblea General del Consejo } \\
\text { Comunitario. } \\
\text { 11. Presentar, concertar, ejecutar y hacer } \\
\text { seguimiento a proyectos y programas con } \\
\text { entidades públicas y privadas para el desa- } \\
\text { rrollo económico, social y cultural de su } \\
\text { comunidad. }\end{array}$ \\
\hline \multicolumn{2}{|c|}{$\begin{array}{l}\text { Funciones relacionadas con el Consejo Municipal (Art. 313, Constitución 1991): } \\
\text { Adoptar los correspondientes planes y programas de desarrollo económico y social } \\
\text { y de obras públicas. } \\
\text { Reglamentar los usos del suelo y, dentro de los límites que fije la ley, vigilar y contro- } \\
\text { lar las actividades relacionadas como la construcción y enajenación de inmuebles } \\
\text { destinados a vivienda. } \\
\text { Funciones relacionadas con la Alcaldía Municipal: } \\
\text { Presentar oportunamente los proyectos de acuerdo sobre planes programas y pro- } \\
\text { yectos que le permitan impulsar el desarrollo económico, social, ambiental y de } \\
\text { obras públicas del municipio. }\end{array}$} \\
\hline \multicolumn{2}{|c|}{$\begin{array}{l}\text { Observación } \\
\text { Aunque el cumplimiento del Plan de Gobierno de las autoridades locales electas } \\
\text {-Consejo Municipal y alcalde- está condicionado por el contexto en el que se ins- } \\
\text { criben, la formulación de las funciones no contempla la necesidad de incluir los } \\
\text { "planes de desarrollo" elaborados por la Junta del Consejo Comunitario. La única } \\
\text { interacción expresa en el Decreto Reglamentario se refiere a la obligatoria notifica- } \\
\text { ción de la lista de miembros que debe realizar la Junta toda vez que sea designada. } \\
\text { El Decreto reglamentario no especifica estrategias ni mecanismos de acceso a recur- } \\
\text { sos que en efecto permitan dar cumplimiento a los planes de desarrollo comunitario, } \\
\text { lo que implica tácitamente una ardua labor de cabildeo que, en la mayoría de los } \\
\text { casos, supera las habilidades y la formación política con la que cuentan sus miembros. }\end{array}$} \\
\hline
\end{tabular}


TABLA 3. Transferencia de responsabilidades administrativas territoriales y limitaciones en la capacidad técnica

\begin{tabular}{|c|c|}
\hline Asamblea & Junta del Consejo Comunitario \\
\hline $\begin{array}{l}\text { 7. Aprobar la delimitación de las } \\
\text { tierras de las comunidades negras } \\
\text { que serán solicitadas en propiedad } \\
\text { colectiva, con base en la propuesta } \\
\text { formulada por la Junta del Consejo } \\
\text { Comunitario. }\end{array}$ & $\begin{array}{l}\text { 1. Elaborar el informe que debe acompa- } \\
\text { ñar la solicitud de titulación, según lo dis- } \\
\text { puesto en los artículos } 8 \text { y } 9 \text { de la Ley } 70 \\
\text { de } 1993 . \\
\text { 2. Presentar a la Asamblea General del } \\
\text { Consejo Comunitario, para su aprobación, } \\
\text { la propuesta de delimitación del territorio } \\
\text { que será solicitado en titulación colectiva. } \\
\text { 3. Diligenciar ante el Incora -actualmente } \\
\text { Incoder- la titulación colectiva de las tie- } \\
\text { rras de la comunidad negra respectiva. }\end{array}$ \\
\hline \multicolumn{2}{|c|}{$\begin{array}{l}\text { Observación } \\
\text { No se encuentran funciones especíicas que guarden alguna relación directa entre } \\
\text { las autoridades locales y los Consejos Comunitarios. Como se ve, la delimitación de } \\
\text { las tierras de comunidades negras es un proceso autónomo que depende directa- } \\
\text { mente de la capacidad técnica y organizativa de los consejos comunitarios. En el } \\
\text { trabajo de campo de } 2011 \text { se pudo observar que la delimitación de linderos entre } \\
\text { los consejos sigue siendo uno de los temas críticos recurrentes que impiden el ejer- } \\
\text { cicio administrativo autónomo y, por esa vía, el cumplimiento de la Ley. }\end{array}$} \\
\hline \multicolumn{2}{|c|}{$\begin{array}{l}\text { La presencia de actores armados dificulta la delimitación territorial, la definición de } \\
\text { linderos y la apropiación comunitaria del territorio; sus acciones armadas tienden a } \\
\text { sobrepasar la autoridad de fuerzas de policía y militar dejando a las comunidades } \\
\text { en una forzosa situación de autoprotección. El desplazamiento y el despojo die- } \\
\text { ron lugar al asentamiento de megaproyectos agrícolas -palma de aceite, ganadería } \\
\text { extensiva y cultivo de banano- que dificultan más la enorme labor de delimitación } \\
\text { y exigibilidad de tierras para las comunidades y que fueron facilitados por viciados } \\
\text { procesos de titulación de tierras por parte de la autoridad responsable, Incoder. }\end{array}$} \\
\hline
\end{tabular}


TABLA 4. Transferencia de administración de recursos naturales y limitaciones en la capacidad técnica

\begin{tabular}{|c|c|}
\hline Asamblea & Junta del Consejo Comunitario \\
\hline $\begin{array}{l}\text { 11. Velar por el aprovechamiento y } \\
\text { conservación de los recursos natu- } \\
\text { rales de conformidad con la legis- } \\
\text { lación ambiental y las prácticas tra- } \\
\text { dicionales de producción y demás } \\
\text { que garanticen el manejo sustenta- } \\
\text { ble de los recursos naturales. }\end{array}$ & $\begin{array}{l}\text { 9. Presentar a consideración de la Asamblea } \\
\text { General del Consejo Comunitario, para su } \\
\text { aprobación, el reglamento de administra- } \\
\text { ción territorial y manejo de los recursos } \\
\text { naturales, y velar por su cumplimiento. } \\
\text { 10. Administrar, con base en el reglamento } \\
\text { y las normas vigentes, el uso, aprovecha- } \\
\text { miento y conservación de los recursos natu- } \\
\text { rales, y concertar la investigación en las Tie- } \\
\text { rras de las Comunidades Negras. }\end{array}$ \\
\hline \multirow{2}{*}{\multicolumn{2}{|c|}{$\begin{array}{l}\text { Funciones relacionadas a la Alcaldía Municipal (Art. } 315 \text { CPC 1991) } \\
\text { Fijar políticas que conlleven a la conservación de los recursos naturales. }\end{array}$}} \\
\hline & \\
\hline \multicolumn{2}{|l|}{ Observación } \\
\hline \multicolumn{2}{|c|}{$\begin{array}{l}\text { Una vez más, aunque la ley define las funciones, no se establecen mecanismos de } \\
\text { evaluación y capacitación técnica que les garanticen a las comunidades acceder al } \\
\text { conocimiento técnico y jurídico necesario para elaborar y sancionar el reglamento } \\
\text { de administración territorial y manejo de los recursos naturales. }\end{array}$} \\
\hline \multicolumn{2}{|c|}{$\begin{array}{l}\text { En repetidas ocasiones se ha evidenciado que la comunidad desconoce el potencial } \\
\text { de los recursos naturales existentes en su territorio, sobre los que se cierne la ambi- } \\
\text { ción explícita de actores privados externos en busca de su extracción. }\end{array}$} \\
\hline \multicolumn{2}{|c|}{$\begin{array}{l}\text { Esto representa a su vez un impedimento para la formulación de planes de aprove- } \\
\text { chamiento y conservación de los mismos. }\end{array}$} \\
\hline
\end{tabular}


Tal y como se observa, las funciones asignadas tanto a la Asamblea como a la Junta del Consejo Comunitario son muchas veces equiparables con las correspondientes al Consejo Municipal y la misma Alcaldía, y en el marco normativo no se mencionan mecanismos de articulación que permitan a las autoridades territoriales comunitarias coordinar sus labores con las de las autoridades municipales. Así, las necesidades, propuestas y exigencias de las comunidades difícilmente quedan plasmadas en los planes de gobierno local y en los planes de desarrollo. Semejante ausencia de canales explícitos de comunicación mantiene ausentes las demandas y la identificación de necesidades comunitarias en el proceso de formulación de los programas de gobierno, desde el mismo momento en que inician las candidaturas para elegir autoridades locales. Los Consejos Comunitarios se ven entonces obligados a asumir responsabilidades sin que exista una preparación preliminar, siquiera técnica, que garantice efectivamente el cumplimiento de dichas funciones. La ley desconoce además la grave situación de seguridad y riesgo que deben afrontar estas comunidades en su cotidianidad, dado que interactúan con actores armados paramilitares -Rastrojos, Urabeños y Águilas Negras- y guerrilleros -frentes 57 y 34 de las Farc y compañía Aurelio Rodríguez de las Farc.

Cabe agregar también que las dinámicas organizativas social y territorial que se desprenden de la Ley 70 y su Decreto Reglamentario, aunque otorgan autonomía y delegan responsabilidades a los Consejos Comunitarios también requerirían mejor acompañamiento por parte de las autoridades locales. En un proceso de verificación y diagnóstico de los planes de desarrollo pudo observarse cómo, a pesar del esfuerzo hecho por los consejos comunitarios, ocurren dos cosas: o bien sus solicitudes, exigencias y propuestas para los planes de desarrollo -formuladas a través de sus planes de vida- no son tenidos en cuenta; o bien, no existe una política pública de acompañamiento al cumplimiento de la Ley 70, donde se establezca que hace parte de las funciones de las autoridades locales el prestar servicio de formación y fortalecimiento a los Consejos Comunitarios. 
Tal y como lo hemos demostrado, existe una rivalidad entre las organizaciones sociales de los afros y las autoridades municipales, puesto que hay una superposición de funciones entre ambos que no puede resolverse ni a través de la ley, ni a través de las prácticas políticas tradicionales. Sin embargo, esa relación de rivalidad se ha comenzado a modificar puesto que algunas personas que han sido parte del proceso de movilización de los afros también han logrado entrar recientemente en la política (como, por ejemplo, la actual alcaldesa de Quibdó).

En el caso específico del bajo Atrato, aunque Ascoba ha intentado, desde hace mucho tiempo, sensibilizar a los políticos locales frente a la lucha que ellos llevan, en realidad poco ha sido la atención que normalmente dichos políticos le han prestado. Las relaciones han sido muy distantes, sobre todo al inicio. Solo a medida que Ascoba fue adquiriendo un cierto reconocimiento, los políticos -como por ejemplo el alcaldecomenzaron a prestarle cierta atención, por ejemplo, atendiendo a invitaciones de los líderes para sentarse a discutir temas que interesan a los habitantes de la subregión.

Ahora, pese a este acercamiento relativo, o quizás gracias a él, los líderes actuales de Ascoba consideran que es necesario revaluar una postura defendida por la organización desde su creación: aquella que pretende evitar que la organización social "se politice". En efecto, al crearse las organizaciones sociales de las comunidades negras se aspiraba a que estas fueran "apolíticas", lo cual significaba mantenerla lejos de la política. Hoy, en cambio, los líderes estiman que para poder alcanzar muchos objetivos es necesario tener un acceso al mundo de la política. Y ya hay precisamente una experiencia de acceso de un líder social al campo político: el del alcalde de Carmen del Darién, Antonio Ospina Serna, quien, después de haber sido concejal, ${ }^{49}$ logró elegirse como alcalde tras realizar una campaña política inédita. Su campaña electo-

49 Justamente, en un intento por lograr tener un impacto político, algunos líderes en los Consejos Comunitarios de Carmen del Darién y de Riosucio llegaron a ser consejeros municipales. Antonio Ospina Serna fue concejal del municipio del Carmen 
ral, contraria a la tradición de prometer satisfacción a las necesidades básicas de las comunidades a través de la provisión de insumos y recursos -al mejor estilo clientelista-, consistió en el acercamiento a la gente a través de la recolección y construcción colectiva de propuestas para el mejoramiento de sus condiciones de vida. Siguiendo un trabajo comunitario, los recorridos por las comunidades -similares a las comisiones que realiza Ascoba- le permitieron al candidato identificar las problemáticas particulares de cada una. ${ }^{50}$ Como resultado, los habitantes del municipio en zonas rurales y urbanas, reconocen su gestión como inédita y eficiente, y se sienten mejor representados. Sin duda, este estilo de hacer política tiene que ver con la experiencia previa como líder activo de Ascoba que se había acostumbrado a recorrer y a conocer los diferentes Consejos Comunitarios de la subregión.

Para Ascoba, la elección de Ospina Serna constituye un logro político significativo, puesto que al posicionar a un líder propio como autoridad local se ha facilitado la comunicación entre las organizaciones sociales y las instituciones locales. Esto a su vez ha tenido un efecto en los planes de desarrollo municipales del Carmen del Darién, cuyos contenidos están siendo elaborados a partir de un diagnóstico más fiel de la realidad de la población puesto que los líderes comunitarios intervienen y participan más directamente en ellos.

Sin embargo, la formación de nuevos liderazgos conoce algunos obstáculos como resultado de la historia reciente de violencia que se suma al clientelismo y la apatía política. Una lectura sociológica del clientelismo en Chocó durante los años ochenta (Echevarría Córdoba y Halaby Córdoba, 1995, p. 26) afirmaba que las relaciones de poder en

del Darién entre el 2008 y el 2011. Renunció a su cargo de concejal un año antes de que se terminara su mandato para lanzarse a la candidatura por la Alcaldía.

50 La campaña se hizo con poco dinero y en lugar de hacer reuniones comunitarias para repartir almuerzos, el candidato se reunió con la gente, les proponía a cada uno poner algo para la comida con el objeto de reunirse y presentarles su propuesta. Ante quienes le decían que otros políticos estaban ofreciendo dinero y cosas a la gente, el candidato les dijo que podían perfectamente aceptar esas ofertas pero que eso no los obligaba a votar por ellos. 
los municipios chocoanos se configuran alrededor de las actividades económicas más productivas. De acuerdo con esa perspectiva, el clientelismo surge de "la relación patrocinador (financiador de campañas)patrón (político)-clientes, [estos últimos] estableciendo nuevas relaciones de adaptación: empresarios madereros y políticos; empresarios pescadores-políticos, transportadores-políticos, mineros-políticos". ${ }^{51}$

El clientelismo no solo está relacionado con actividades económicas legales sino también con el posicionamiento de actividades ilícitas como el cultivo y transporte de coca, el contrabando, la minería ilegal y la presencia de grupos armados ilegales. En Riosucio, los últimos alcaldes (Jorge Isaac Mosquera Caicedo, Ricardo Azael Victoria Martínez y Eulalio Lemos Mosquera) fueron detenidos en el año 2010, junto con los exconcejales Manuel Padilla Córdoba y Libardo José Ferro, por concierto para delinquir y por sus presuntas relaciones con el bloque Elmer Cárdenas de las autodefensas, al mando de Freddy Rendón Herrera, alias "el Alemán". 52

Adicionalmente, según algunos miembros de Ascoba entrevistados, el desplazamiento forzado y la intensa violencia relacionada con intereses económicos que se produjo en la subregión desde el inicio de los años noventa, son percibos como el producto de la acción u omisión estatal a través de las autoridades y fuerzas militares. Este proceso, sumado a la tendencia politiquera (de promesas y dádivas que no se cumplían), incrementó la desconfianza hacia las autoridades locales y

51 Este fenómeno se evidencia en el manejo de recursos que viabilizan proyectos productivos de menor escala (maquinaria para la extracción de minerales y para el procesamiento y empaque de productos agropecuarios); de manera que el acceso y uso de dichos recursos es un beneficio que depende del valor político (votos) que la comunidad esté dispuesta a pagar. Justamente la compra de maquinaria por parte de los Consejos Comunitarios ha sido una manera de independizar su producción de los intereses particulares de los políticos de turno.

52 “Por presuntos vínculos con el 'Alemán’ Fiscalía profirió acusación contra el alcalde de Riosucio", El Tiempo, 26 de marzo de 2010; "Capturan a alcalde de Riosucio, Chocó, Jorge Mosquera”, El Espectador, 26 de marzo de 2010; "Fiscalía llama a juicio a 5 funcionarios de Riosucio (Chocó) por vínculos con ‘El Alemán””, Territorio Chocoano Noticias, 9 de septiembre de 2010. 
las instituciones de gobierno y aumentó la apatía electoral. Así, el desinterés de los habitantes en las cabeceras municipales obedece al hecho de que muchos de ellos llegaron por el desplazamiento desde 1995. Según el Registro Único de Población Desplazada, al menos 61.190 personas tuvieron que salir de sus viviendas y territorios por amenazas de grupos armados desde 1997 (Acción Social, 2010) y los municipios receptores fueron principalmente el Carmen del Darién y Riosucio. Al ser desplazados y despojados, gran parte de los habitantes de los municipios carecen de un vínculo con la dinámica política local.

Sin embargo, el desinterés y la apatía política registrada parecen contradecirse con los resultados electorales. Como se ve en las siguientes tablas, durante los dos últimos periodos electorales la participación alcanzó el 54,23\% en el caso de Riosucio y el 67,47\% en el caso de Carmen del Darién para el año 2011. Cifras similares a las del 2007, cuando el 53,9\% del potencial electoral ejerció el voto en Riosucio y el 65,19\% en Carmen del Darién. En ambos periodos, el porcentaje nacional de participación se situó alrededor del 51\%, de manera que el comportamiento electoral local no distó significativamente del nacional y se considera representativo.

Si bien los electores de estos municipios votan, el desinterés se manifiesta en el desconocimiento de los candidatos y sus partidos. Las filiaciones partidistas varían mucho de año a año, lo cual hace difícil para los electores la identificación de las posturas y diferencias esenciales entre los partidos políticos. Excepto por el Partido Liberal, Cambio Radical o el Partido Social de Unidad Nacional (Partido de la U), el reconocimiento político tiende a posarse más sobre el candidato y sus antecedentes que sobre el partido.

Al observar cambios en el número de mesas de votación, el incremento en Carmen del Darién fue de 4 mesas entre 2007 y 2011, por su parte en Riosucio se instalaron 13 mesas más en el año 2011. En las vísperas de elecciones ya se tenía conocimiento del significativo incremento de mesas en Riosucio, el cual se justificaba por la necesidad de acceder a las 
CERÓN STEEVENS ETAL.

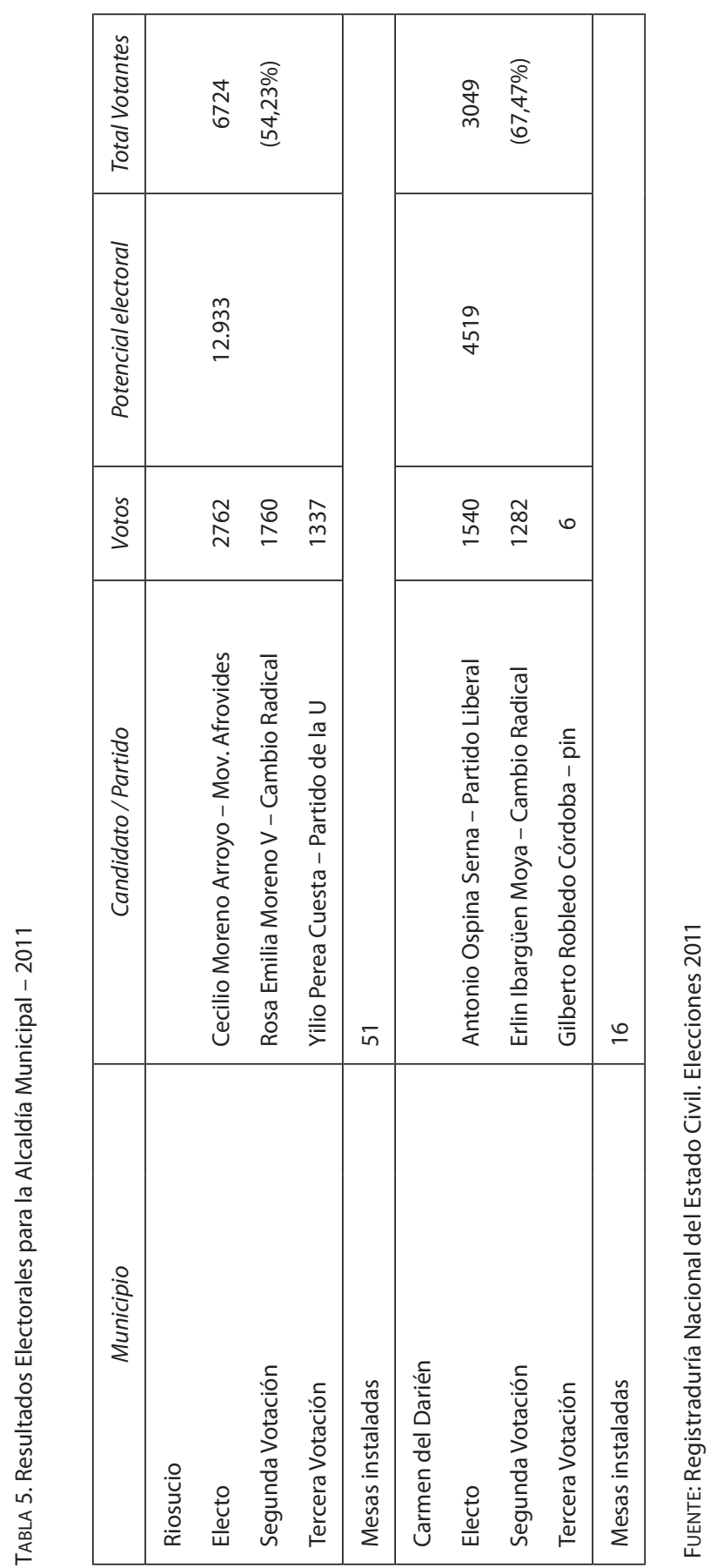


PROCESOS DE DEMOCRATIZACIÓN...

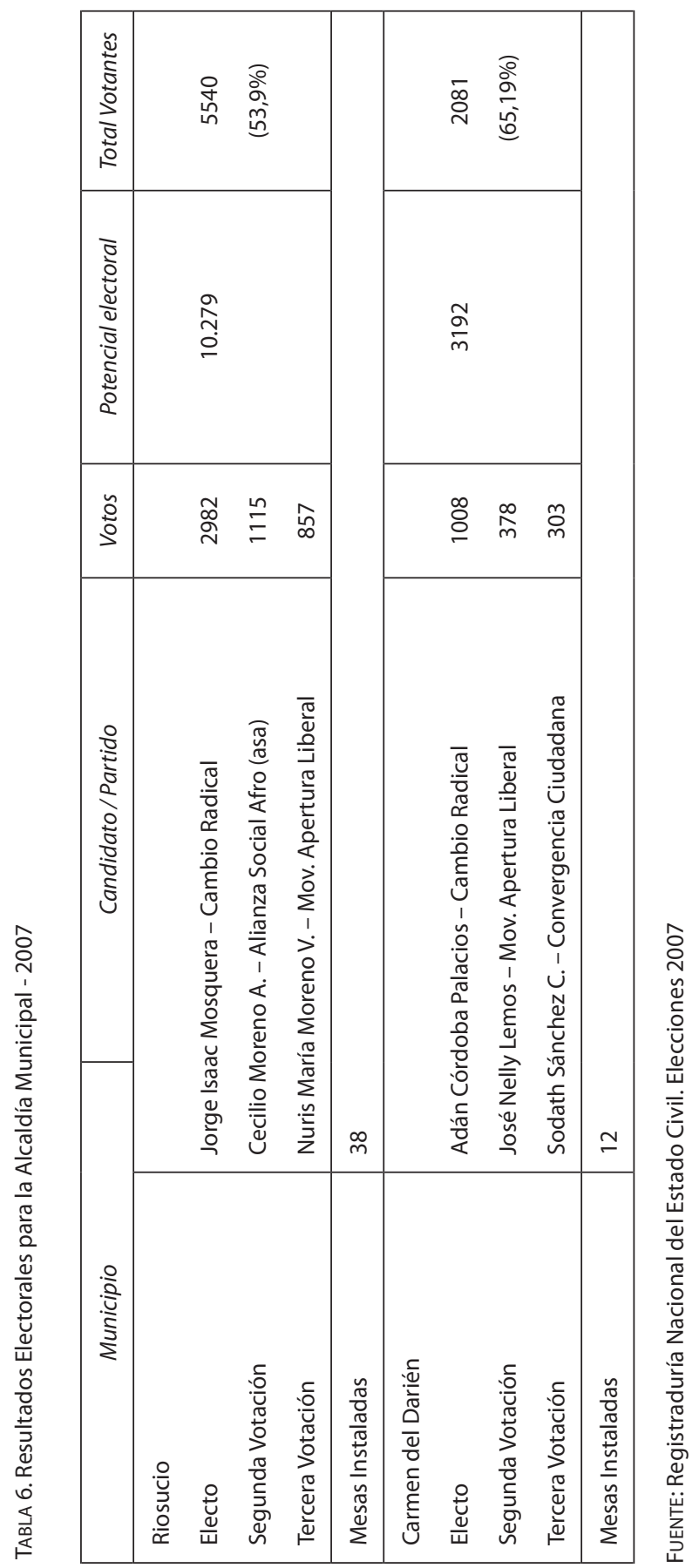


comunidades ubicadas en zonas rurales apartadas de los cascos urbanos. Algunos miembros de Ascoba explicaron que esta situación se debe también a que los cascos urbanos son lugares donde toman fuerza los fortines políticos, partidos cuyos intereses económicos prevalecen sobre las necesidades de la población. Así, según su propio análisis, la ruralidad de los electores de Carmen del Darién fue lo que permitió que la campaña y la elección fuera más limpia, obedeciendo más al diálogo y a la construcción mancomunada de propuestas de gobierno, en vez de la satisfacción inmediata de necesidades a través de pagos y prebendas.

\section{CONCLUSIONES}

Con base en lo expuesto a lo largo del capítulo, realizaremos una reflexión final sobre los procesos de democratización en el bajo Atrato. Primero que todo, es preciso subrayar el doble efecto que tiene la precaria presencia estatal en esta subregión sobre los procesos de democratización. Por un lado, ella representa un obstáculo, en la medida en que la débil presencia de instituciones estatales -y en ciertos casos, incluso su ausencia casi total- ha colocado a la subregión en una posición periférica y marginal crónica, haciendo difícil la estructuración de la sociedad. Esto se evidenció en este trabajo cuando se caracterizaron las "comunidades" que surgieron paulatinamente en las zonas de colonización remotas del bajo Atrato; como pudo verse, esas comunidades constituyen ante todo conjuntos dispersos de asentamientos de colonos, diversos en su composición y no muy bien integrados, en cuyo seno los sujetos políticos no emergen con facilidad. Por otro lado, la lejanía frente a los centros de poder político a nivel nacional conllevó, al mismo tiempo, a que los procesos de democratización locales en el bajo Atrato se hayan realizado, muy a menudo, a través de dinámicas que tienen lugar por fuera de los canales institucionales y de la esfera política formal. Esto significa que los procesos de democratización de mayor importancia no se han dado bajo el impulso de los partidos políticos y 
sus respectivas redes de clientela. Esos procesos han sido más bien dinamizados por actores no estatales bien diversos: la guerrilla a través de algunas acciones de tipo comunal, la Iglesia mediante su labor misional, las organizaciones no gubernamentales con su trabajo de acompañamiento a las poblaciones desplazadas y víctimas del conflicto armado, y hasta algunos académicos a través de sus reflexiones sobre la afrocolombianidad.

No cabe duda de que, entre estos actores no estatales que han tenido una incidencia en los procesos de democratización a nivel local, la Iglesia católica ha jugado un papel protagónico y esencial que no se ha limitado al acompañamiento sino a la generación constante de acciones colectivas y de procesos sociales que han perdurado en el tiempo. En efecto, la misión evangelizadora de la Iglesia en el bajo Atrato se ha caracterizado por una forma particular de acción eclesial que no se restringe a la transmisión del mensaje cristiano a través de las liturgias, sino que supone una labor comprometida con la defensa de la vida y del territorio, la opción preferencial por el pobre y el énfasis en lo comunitario. Esto podría asemejase a un proyecto político cuya visibilidad parecería incluso hasta evidente en el lema mismo de la Diócesis de Quibdó: "Por la defensa de la vida, el territorio y la soberanía de los pueblos". Pero los líderes de la Iglesia a nivel local sostienen que su acción no tiene una naturaleza política, ya que si así lo fuera, su proyecto pastoral sería netamente terrenal, temporal y no trascendente, y se convertiría con facilidad en un objeto de manipulación por parte de los sistemas ideológicos o los partidos políticos. ${ }^{53}$

Ahora bien, aun así la acción de la Iglesia en el bajo Atrato ha tenido fuertes implicaciones en la esfera política, no solo por la diver-

53 Los líderes de la Iglesia católica en el Chocó han sostenido que es imposible no asociar una evangelización profunda con una fuerte preocupación por lo social. Lo cual no significa que la evangelización tenga un contenido político. Un plan pastoral así concebido tiene inevitables consecuencias políticas, pero no puede ser entendido como un proyecto político, jamás como una plataforma política, como un medio para llegar al poder o tumbar gobiernos (Castaño Rubio, 2001). 
sidad de población que atiende y los múltiples ejes que abarca, sino sobre todo por los procesos de exigencia y de reconocimiento de derechos que ha ayudado a desencadenar. En una subregión como el bajo Atrato muchas veces la Iglesia ha sido crucial en la construcción de una relación de los habitantes de esos territorios marginados con el Estado y, por ende, en la constitución de sujetos políticos en medio de una sociedad un tanto desestructurada. Esto le ha conferido a la Iglesia un poder simbólico manifiesto tanto en el grado de aceptabilidad que tienen sus acciones entre la población local, como en el hecho de que los espacios ocupados por ella -por ejemplo, las parroquias- terminan siendo uno de los pocos lugares seguros en medio de un contexto de violencia que se fue generalizando a partir de mediados de los años noventa. ${ }^{54}$

Dejemos ahora a un lado a los actores que han impulsado los procesos de democratización en el bajo Atrato y entremos a evaluar el alcance de tales procesos. Desde luego, en ese contexto local que hemos estudiado los procesos de democratización han sido lentos y prolongados, máxime cuando los obstáculos a superar en el camino no han sido menores (más adelante, volveremos sobre esas trabas y en particular sobre una de ellas: la violencia). Pero esto no significa que las dinámicas de profundización y reconfiguración de la democracia que evocamos en la introducción hayan estado del todo ausentes en la subregión. Eso sí, hay que subrayar que la profundización fue bastante incipiente hasta tanto no hubo un momento de reconfiguración de la democracia. Dicho de otro modo, y para ser más precisos, hasta 1991 la profundización de la democracia se limitó al surgimiento de algunas formas organizativas -en particular las JAC- que buscaban más que todo solucionar una serie de necesidades básicas insatisfechas. Solo hacia mediados de los años ochenta, con el auspicio y apoyo de la Iglesia, comenzaron a emerger

$54 \mathrm{Al}$ respecto, no deja de ser diciente el que los habitantes de Riosucio se sientan más seguros frente a la parroquia de ese pequeño burgo, que frente a la alcaldía del mismo. 
actores sociales (como Ocaba) que buscaron una reconfiguración de la democracia, basada en la exigencia de derechos territoriales que hasta ese momento no habían sido reconocidos. Y a esos reclamos se añadieron enseguida otros relacionados con el reconocimiento de la afrocolombianidad.

Con la Constitución de 1991 y la promulgación de la Ley 170 de 1993, se llegó finalmente a un momento de reconfiguración democrática que engendró a su vez unos procesos de profundización democrática de mayor alcance. En efecto, ese nuevo marco legal estableció no solo unos derechos étnico-territoriales novedosos, sino también un canal por medio del cual las colectividades de afrodescendientes (los Consejos Comunitarios) entraron en permanente y directa interlocución con el poder local. Al ser responsables de identificar necesidades y de diseñar planes de vida, y pese a no contar con todos los recursos indispensables para hacerlo, esas colectividades de carácter étnico tomaron un control mayor sobre sus territorios y se afirmaron como un poder político singular. Sobre todo, dado que la ejecución de los planes de vida concebidos por los Consejos Comunitarios es susceptible de ser exigida a las Alcaldías y los Consejos Municipales de la subregión.

El proceso de afirmación de los Consejos Comunitarios como figura territorial y cuna de poder político ha generado otros procesos de profundización de la democracia, como aquel relacionado con el surgimiento de líderes de organizaciones sociales que pretenden llegar a representar a sus comunidades en las instituciones locales. Esta ambición ha resultado tan desafiante para las elites políticas tradicionales que las relaciones de rivalidad entre las autoridades locales bajo su control y las nuevas colectividades de afrodescendientes han sido inevitables. Por considerarse mejores conocedores de los territorios y sus necesidades, los líderes de las organizaciones sociales afro calculan que si llegaran a tener una oportunidad de acceso a la arena política contarían con una mayor legitimidad. Por esto la acción de organizaciones como 
Ascoba, que históricamente han representado el interés colectivo de las comunidades -ahora consejos comunitarios-, se vuelve fundamental para comprender la interacción entre los actores políticos comunitarios y los actores políticos institucionales a nivel local. Esa interacción tiende a ser más intensa y el reconocimiento mutuo entre estas dos esferas políticas de naturaleza distinta tiende a crecer.

Ahora, el proceso de democratización local permanece aún cargado de obstáculos. Especialmente porque las políticas de reconocimiento a las comunidades afrocolombianas han funcionado de manera contradictoria. Si bien se erigen, principalmente a partir de la Constitución de 1991 y la Ley 70 de 1993, como posibilidad de reparación histórica, visibilización y participación política tanto a nivel local como nacional, las relaciones clientelares consiguen todavía poner camino de herradura a los diferentes procesos organizativos y a las iniciativas de representación política de las comunidades. Además, mientras organizaciones como Ascoba se conforman para hacer pervivir las comunidades y proteger tanto el territorio como los lazos sociales tejidos en él, diversos actores armados, movidos por intereses económicos y políticos, imponen y/o dan continuidad a contextos de violencia cuyo impacto negativo sobre la vida democrática es considerable.

Esta es precisamente la situación dicotómica que señala César Rodríguez: pese a que en la década del noventa del siglo anterior Colombia se sentó sobre una extensa lista de derechos y garantías sociales, también en ese entonces las tecnologías de la violencia sobre poblaciones vulnerables llegaron a extremos sin precedentes (2009). Y este escenario persiste, pues los territorios de las comunidades continúan siendo campos de disputa entre diversos actores que, además del combate bilateral, someten a la población a las lógicas de la desconfianza, la amenaza, el matoneo. ${ }^{55}$ Las relaciones sociales cimentadas en la mayoría de

55 Con respecto a mediados de los años noventa, el panorama de los actores armados que operan en la subregión del bajo Atrato se ha transformado, dado el desmembramiento de los grupos paramilitares en grupos más pequeños y mucho más focaliza- 
los casos por el parentesco son, así, fragmentadas, lo cual hace difícil la construcción de lazos basados en la solidaridad étnica o en la pertenencia política. Esto ocurre a medida que sobrevivir tiende a convertirse en el interés primario.

\section{BIBLIOGRAFÍA}

Agudelo, Carlos. (2004). Politique et populations noires en Colombie: enjeux du multiculturalisme. L'Harmattan, Paris.

Alto Comisionado de Naciones para los Derechos Humanos, Oficina en Colombia. (2011). ¿Qué es el Proceso de Comunidades Negras - PCN? Disponible en: http://www.hchr.org.co/afrodescendientes/index.php/ portada/ique-es-el-proceso-de-comunidades-negras-pcn.html.

Alvarado Solano, Hernán et al. (2010). Carta Pastoral de Adviento de los obispos de Guapi, Quibdó, Buenaventura, Tumaco, Itsmina- Tadó y Apartadó. S.c.: s.p.

Centro de Pastoral Afrocolombiana (cepac). (2003). Historia del pueblo afrocolombiano. Perspectiva pastoral. Popayán: Tecnigráficas. Disponible en: http://axe-cali.tripod.com/cepac/hispafrocol/.

CINeP y CORDAID. (2000). Comunidades de Paz del Urabá. Una historia que merece ser contada. CINEP \& CORDAID, Bogotá.

Comisión Intereclecial de Justicia y Paz. (2005). La tramoya. Derechos humanos y palma aceitera. Curvaradó y Jiguamiandó. Justicia y Paz \& Banco de datos del cinep, Bogotá.

DANE. (2008). Censo general 2005. Perfiles censo general del departamento del Chocó. Disponible en http://www.dane.gov.co/index.php/poblacion-ydemografia/censos.

dos en el control de las rutas de producción, procesamiento y transporte de la coca (las llamadas Bandas Criminales o Bacrim). Estos grupos se disputan entre sí el control territorial, tejiendo a veces alianzas esporádicas e inestables con los grupos de guerrilla, y otras veces en franca oposición a estos últimos. Los mismos grupos armados ejercen una tutela y control sobre las labores de extracción minera ilegal que cada vez se intensifican más. 
Delgado, O. (1998). Espacio, territorio y región: conceptos básicos para un proyecto nacional. Cuadernos de Geografía, 1 (1-2), 121-133.

Echevarría Córdoba, Jaime, \& Halaby Córdoba, Julio César. (1995). Chocó: sociología del comportamiento político. Universidad Tecnologíca del Chocó Diego Luis Córdoba, Quibdó.

Escobar, Arturo \& Pedrosa, Álvaro. (1996). Introducción: Modernidad y desarrollo en el Pacífico colombiano. En: Pacífico: ¿desarrollo o diversidad? CEREC, Bogotá.

Floréz López, Jesús (ed.). (2012). Un obispo en una epoca de cambios. La iglesia del Vaticano II en Quibdó. Editorial Fundación Universitaria Claretiana (FUCLA), Quibdó.

LEForT, Claude. (2004). La incertidumbre democrática. Ensayos sobre lo político. Anthropos, Barcelona.

Minchinela, Raúl. (2007). Capítulo 5: Reflexiones de Repronto. En: El comesandías. FantaVisión, Zaragoza.

Ministerio del Interior y de Justicia, Dirección de Asuntos para Comunidades Negras, Afrocolombianas, Raizales y Palenqueras. (2011). Relación de Consejos Comunitarios. Disponible en http://www.mij.gov.co/ econtent/library/documents/DocNewsNo1784DocumentNo6012.PDF.

Navarrete Serna, María Patricia. (2009). Departamento del Chocó. Diagnóstico Regional. NuffiC-SEnA, Bogotá.

Ortiz Sarmiento, Carlos Miguel. (1999). Urabá: tras las huellas de los inmigrantes 1955-1990. ICFES, Bogotá.

Osorio Gómez, Jairo. (2006). Pueblos itinerantes de Urabá. La historia de las exclusiones. Universidad Internacional de Andalucía, España.

Pablo VI. (1971). Octogésima Adveniens. Encíclica Papal con ocasión del LXXX aniversario de la encíclica Rerum Novarum. Disponible en http://www. vatican.va/holy_father/paul_vi/apost_letters/documents/hf_p-vi_ apl_19710514_octogesima-adveniens_sp.html.

Restrepo, Eduardo. (2005a). Biopolítica y alteridad: dilemas de la etnización de las Colombias negras. En: Políticas de la teoría y dilemas en los estudios de las colombias negras. Universidad del Cauca, Popayán. 
PROCESOS DE DEMOCRATIZACIÓN...

(2005b). Escencialismo étnico y movilización política: tensiones en las relaciones entre saber y poder. En: Políticas de la teoría y dilemas en los estudios de las Colombias negras. Universidad del Cauca, Popayán. . (2011). Etnización y multiculturalismo en el Bajo Atrato. Revista Colombiana de Antropología, 47(2), 37-68.

. (2012). El Pacífico: región de fronteras. En: Anuario Fundación Universitaria Claretiana. FUCLA, Quibdó.

Rolland, Stellio. (2003). Les "communautés de paix” de Colombie. Une stratégie d'action collective: du processus organisationnel des déplacés à la constitution de la cause humanitaire. Centre d'études des mouvements sociaux (CEMs), Ecole des Hautes Etudes en Sciences Sociales (eHEss), Paris.

Rolland, Stellio. (2006). Les déplacés du bourg colombien de Riosucio: entre regroupements communautaires et production de nouvelles térritorialités (1997-2006). s.e, Paris.

Ruiz Serna, Daniel. (2006). Nuevas formas de ser negro. Consideraciones sobre las identidades entre la gente chilapa y negra del Bajo Atrato chocoano. En: Identidades culturales y formación del Estado en Colombia. Universidad de los Andes, Bogotá.

Segato, Rita Laura. (2007). Políticas de la identidad, diferencia y formaciones nacionales de alteridad. En: La nación y sus otros. Prometeo Libros, Buenos Aires.

Silva-Herzog Márquez, Jesús. (2011). La democracia de Lefort. Disponible en: http://www.nexos.com.mx/?P=leerarticulo\&Article=2047018.

Uribe de Hincapié, María Teresa. (2004). Emancipación social en un contexto de guerra prolongada. El caso de la comunidad de paz de San José de Apartadó. En: Emancipación social y violencia en Colombia. Norma, Bogotá.

Vargas Sarmiento, Patricia (ed.). (1999). Construcción territorial en el Chocó. Historias locales. Vol. 2. Ministerio de Cultura, Bogotá.

Villa, William. (2013). Colonización y conflicto territorial en el bajo Atrato. El poblamiento de las cuencas de la margen oriental. Revista de Estudios del Pacífico Colombiano (1), 9-56. 
CERÓN STEEVENS ETAL.

WAdE, Peter. (1997). Gente negra, nación mestiza. Dinámicas de las identidades raciales en Colombia. Uniandes, Bogotá.

Zambrano, C. (2003). Nación y pueblos indígenas en transición. En: Etnopolíticas y racismo. Conflictividad y desafíos interculturales. Universidad Nacional de Colombia, Bogotá. 


\title{
ACCIÓN COLECTIVA EN EL PACÍFICO SUR COLOMBIANO: EXPERIENCIA DEL PROCESO DE COMUNIDADES NEGRAS (PCN)
}

\author{
Armando Durán Durán ${ }^{*}$
}

\section{INTRODUCCIÓN}

EN EL PRESENTE ESCRITO se realiza una primera aproximación, a manera de incursión tentativa, exploratoria y reflexiva, a algunos relatos, vivencias y acontecimientos que pueden estar configurando el presente del Pacífico sur colombiano. Esta incursión sin duda amerita mayores niveles de profundización y perspicacia, teniendo en cuenta que estas páginas son producto de un naciente proceso investigativo. ${ }^{1}$ El texto se estructura siguiendo un camino de indagación e interpretación tributario de la siguiente tesis central: comprender los discursos contemporáneos que subyacen en las historias recientes del Pacífico sur colombiano pasa por indagar procesos de acción colectiva de los pobladores de la región.

Los discursos contemporáneos son entendidos como conjuntos de percepciones y conocimientos que los diferentes sujetos sociales usan y producen al explicar un hecho presente o una situación de la vida cotidiana. Comúnmente, en su cotidianidad, los actores sociales legitiman prácticas y sentidos con respecto a la vida social, que pueden ser identi-

\footnotetext{
Profesor del programa de Gestión y Desarrollo Urbanos - Ekística, de las facultades de Ciencia Política y Gobierno y de Relaciones Internacionales de la Universidad del Rosario.

1 Este documento se elabora en el marco del proyecto de investigación: Acción colectiva y elites políticas en el ámbito local, el cual fue financiado por el Fondo de Investigación de la Universidad del Rosario. De igual forma hace parte de una iniciativa de investigación mayor liderada desde el proyecto de tesis doctoral del autor.
} 
ficados y analizados a partir de las opiniones expresadas de manera individual o desde las creencias que se van gestando al colectivizarse una determinada visión sobre un hecho particular. Dicho de otra manera, además de la cognición individual, el discurso implica esencialmente una cognición sociocultural. Esto, porque los agentes sociales comparten con otros miembros de su grupo, comunidad o cultura, normas, valores, creencias, reglas de comunicación y representaciones sociales que se traducen en actos y orientaciones de la vida personal y social (Van Dijk, 2000). Desde este ángulo de mirada, el documento pretende hilar algunas historias sobre los sentidos y prácticas que constituyen y caracterizan la acción colectiva anudada al Proceso de Comunidades Negras (PCN) en los últimos tiempos. De manera particular se aborda el PCN desde la experiencia de tres Consejos Comunitarios ${ }^{2}$ de la región.

La pesquisa privilegia una metodología de corte cualitativo e intenta urdir tramas entre relatos, vivencias y acontecimientos, principalmente. Como afirma Barthes (1977), innumerables son los relatos existentes. Más que pretender dar cuenta de todos ellos, lo que interesa aquí es el relato experto, aquel "texto" que se produce a partir del detallado conocimiento de un hecho específico. Este tipo de relato casi siempre se sustenta en un lenguaje escrito articulado, y procura cierta sistematicidad a la hora de interpretar un fenómeno particular. En el presente estudio, las investigaciones de académicos, de instituciones gubernamentales y del sector privado, entre otras, son consideradas dentro de este tipo de "fuente" documental. Esta perspectiva sobre el relato se considera pertinente dado que la actividad investigativa, más allá de desencadenar otros procesos, genera relatos expertos porque la

2 En el marco del reconocimiento del derecho a la propiedad colectiva de los territorios habitados por poblaciones negras (Ley 70 de 1993), los Consejos Comunitarios son la instancia jurídica que "ejerce la máxima autoridad de administración interna dentro de las Tierras de las Comunidades Negras, de acuerdo con los mandatos constitucionales y legales que lo rigen y los demás que le asigne el sistema de derecho propio de cada comunidad" (Art. 1, Decreto 1745). 
investigación experta, antes que elaborar descripciones y conocimientos de la realidad, que reproducen y equivalen a la realidad, auspicia interpretaciones activas construidas sobre esta (Guber, 2006).

Una segunda apuesta metodológica del estudio consiste en intentar "escuchar la voz" de la región desde las vivencias de los habitantes del lugar. Lo anterior, con el fin de entender algunos rasgos del proceso de acción colectiva del Pacífico sur colombiano desde la posición de las vivencias de los sujetos que habitan esta parte del país. Vivencias que son comprendidas como experiencias de vida situadas, como subjetividades que son desplegadas por los pobladores de la zona de estudio en sus trayectorias de vida cotidiana. Por último, el tercer componente metodológico de la investigación alude a los acontecimientos. Son entendidos como los hechos o sucesos locales-globales de gran relevancia para la región. Los acontecimientos son hechos que sin lugar a dudas "irrumpen" la vida social instituida y que, por esa vía, se erigen como nuevos ámbitos instituyentes de la vida social, esto es, se erigen como fundadores de nuevas situaciones históricas. En palabras de Alain Badiou, "sólo hay acontecimiento en relación con una situación histórica, aún cuando una situación histórica no produzca necesariamente un acontecimiento" (Badiou, 1999, p. 202).

En síntesis, la apuesta metodológica de la presente indagación se sustenta en la superposición de las tres "lentes" anteriormente descritas: los relatos expertos, las vivencias y los acontecimientos. "Lentes" de indagación que manera operativa se traducen en: la selección y revisión de investigaciones consideradas relevantes sobre y para la región; la elaboración, realización y análisis de entrevistas no estructuradas y de conversatorios grupales in situ con actores locales; y la visibilización y estudio de los relatos y vivencias, descritos en los dos procesos anteriores, en contextos situados y reconstruidos por ciertos acontecimientos (Durán, 2012). En los registros investigativos primarios participaron algunos pobladores locales y representantes de los Consejos Comunitarios: del río Patía Grande, sus brazos y la ensenada de Tumaco-Acapa, 
de la Cuenca baja del río Calima, y Mayor del río Anchicayá. A todos ellos gracias por compartir sus memorias, infortunios y esperanzas. ${ }^{3}$

Este artículo contiene cuatro apartados. En el primero se presentan algunos antecedentes de la acción colectiva en el Pacífico sur colombiano antes de la década de los años noventa del siglo anterior. En el siguiente, se describe lo que pudo haber significado, para los embrionarios procesos organizativos de la gente negra, la redacción y puesta en marcha de la Constitución Política de Colombia del 1991, particularmente desde la experiencia del Proceso de Comunidades Negras (PCN) y en el contexto de algunos Consejos Comunitarios de la región. El tercer apartado introduce una lectura sobre la ruptura que sufren los procesos de acción colectiva que la población negra venía liderando con la puesta en funcionamiento de la Ley 70 de 1993, ruptura que se da con el acelerado recrudecimiento del conflicto armado en esta parte del país. Por último, se establecen algunas reflexiones que suscita el caso analizado a manera de apertura del proceso investigativo iniciado.

\section{ANTECEDENTES DE LA ACCIÓN COLECTIVA EN EL PACÍFICO SUR COLOMBIANO}

A continuación, se exponen algunos antecedentes de la acción colectiva desplegada por la población asentada en el Pacífico sur colombiano. Para ello, se parte por explicitar ciertos rasgos que definen el Pacífico sur colombiano, zona donde se realiza la investigación. De igual forma, se plantean algunos tópicos de lo que podría significar la "nueva" visibilidad de la región Pacífica a nivel global y local. Posteriormente se presenta cómo se asume la noción de acción colectiva en la investigación, para luego describir lo que se consideran "atisbos" de la acción colectiva en el Pacífico sur colombiano a finales del siglo pasado.

3 Un especial agradecimiento al líder afrocolombiano Luis Armando Ortiz por la oportunidad de recorrer en su compañía algunos lugares del Pacífico sur colombiano. 


\section{PACÍFICO SUR COLOMBIANO}

La región del Pacífico ${ }^{4}$ abarca los territorios de cuatro departamentos de Colombia: Chocó, Valle del Cauca (Buenaventura), ${ }^{5}$ Cauca $^{6}$ y Nariño. ${ }^{7}$ Se caracteriza por tener una vegetación selvática con precipitaciones de las más altas del mundo (llega a los $10.000 \mathrm{~mm}^{8}$ en el área del río Atrato, al norte); numerosas cuencas hidrográficas recorren su geografía de valles amplios e inundables (Romero, 2009). El Pacífico colombiano se encuentra ubicado al oeste de la cordillera Occidental de los Andes y se extiende por cerca de 1300 kilómetros, desde el Ecuador, en

4 Siguiendo a Jacques Aprile-Gniset (1993) la conquista del Pacífico colombiano por parte de los ibéricos solo se evidencia hasta finales del siglo xvi. Las cuencas hidrográficas del Magdalena y el Cauca resultaron más favorables para la conquista y colonización euroamericana que la cuenca del Atrato. La cuenca del Atrato se resistió a la conquista euroamericana por lo dificultoso de sus terrenos y la fiereza de sus gentes (Pedrosa, 1996). Aprile-Gniset expone dos ciclos históricos en el poblamiento de la vertiente del Pacífico colombiano. El primero refiere al indoamericano o amerindio -por ejemplo, la cultura de la Tola localizada en la actual área de Tumaco, y que vivió en estas tierras hace más de dos mil años (500 a.C. a 300 d.C.) (Bouchard, 2003)-, cuyo decaimiento se precipitó a finales del siglo XVI con la colonización española. Y el segundo tiene que ver con el afroamericano, que empieza con la llegada de los hispanos en el siglo xviI, crece en el siglo xvin con la llegada de los africanos esclavizados y se consolida y adquiere su máxima expresión a finales del siglo XIX (Rivas, 1999).

5 Buenaventura, único municipio del departamento de Valle del Cauca que hace parte de la región, tuvo sus orígenes como asentamiento temporal y no propiamente como una población a finales del siglo XIX, y antes de convertirse en puerto marítimo "no era más que un precario caserío en las bocas del río Anchicayá” (Pedrosa, 1996, p. 69). Algunas de las razones fueron: a) resistencia de los nativos, b) espesa selva, c) alta humedad, d) alta temperatura y d) condiciones geográficas en conjunto (Romero, 2009).

6 Popayán mantuvo el dominio del Pacífico colombiano por medio de caminos reales que le permitieron la administración de los centros mineros de Barbacoas, Raposo y Nóvita, principalmente (Pedrosa, 1996).

7 Durante el período colonial se establecieron haciendas ganaderas en la región del Patía y se intensificó la explotación de oro en Barbacoas con destino a la Casa de la Moneda de Popayán. Las duras condiciones de los esclavos llevó a que muchos de ellos se fugaran de las minas de Barbacoas e Iscuandé. Así se dio inicio al cimarronaje y se construyeron los palenques en sitios de difícil acceso (Viloria, 2007). Tumaco emergió como centro de población a finales del siglo xviII y comienzos del XIX, por esa época es doblemente marginada: por albergar poco oro y por poseer ríos cortos, lo cual dificultaba la comunicación hacia el interior (Hoffmann, 1997).

$81 \mathrm{~mm}$ de precipitación equivale a un litro de agua por metro cuadrado. 
el sur, hasta Panamá, en el norte. Cubre un área de casi diez millones de hectáreas de selva húmeda tropical (Oslender, 2008). Resguarda a una población estimada 4.000.000 de personas, lo que representa el 9\% de la población colombiana9 ${ }^{9}$ (Dane, 2005). En esta investigación se comprende por Pacífico sur el área del litoral que va desde el municipio de Buenaventura hasta el departamento de Nariño. ${ }^{10}$

En las últimas décadas tres acontecimientos han promovido una "nueva" visibilidad de la región, no solo a nivel nacional sino también en la esfera mundial. El primero es el proceso de la Asamblea Nacional Constituyente que dio origen a la promulgación de la nueva Constitución Política de Colombia en el año 1991 y que permitió, entre otros aspectos, que numerosas organizaciones sociales del litoral Pacífico emprendieran acciones colectivas de reivindicación, a nivel nacional, de los derechos sobre los territorios y la cultura que tradicionalmente los había venido identificando como pobladores del Pacífico colombiano, y que a la postre se tradujo, inicialmente en 1991, en el artículo transitorio $55^{11}$ de la nueva Constitución Política de Colombia y, posteriormente, en la Ley 70 de 1993. Esta Ley tiene por objeto:

9 Para el año 2013, según las proyecciones estimadas por el Departamento Administrativo Nacional de Estadística (DANE), la población del Chocó es de 490.327 personas, de Cauca 1.354.733, de Nariño 1.701.782, y la del municipio de Buenaventura de 384.504 personas.

10 Esta área de la costa sur del Pacífico comprende 7 municipios del departamento de Nariño (Tumaco, Francisco Pizarro, La Tola, El Charco, Olaya Herrera, Mosquera y Santa Bárbara-Iscuandé), tres del Cauca (Guapi, López de Micay y Timbiquí) y uno del Valle del Cauca (Buenaventura).

11 El artículo transitorio 55 consagrado en la Constitución Política de Colombia de 1991, refiere a que: "Dentro de los dos años siguientes a la entrada en vigencia de la Constitución, el Congreso expedirá, previo estudio por parte de una comisión especial que el gobierno creará para tal efecto, una ley que reconozca a las comunidades negras que han venido ocupando tierras baldías en las zonas rurales ribereñas de los ríos de la Cuenca del Pacífico, de acuerdo con sus prácticas tradicionales de producción, el derecho a la propiedad colectiva sobre áreas que habrá de demarcar la misma ley. En la comisión especial de que trata el inciso anterior tendrán participación en cada caso representantes elegidos por las comunidades involucradas. La propiedad así reconocida sólo será enajenable en los términos que señale la ley. La misma ley establecerá mecanismos para la protección de la identidad cultural y los derechos de 
Reconocer a las comunidades negras que han venido ocupando tierras baldías $^{12}$ en las zonas rurales ribereñas de los ríos de la Cuenca del Pacífico, de acuerdo con sus prácticas tradicionales de producción, el derecho a la propiedad colectiva [...] Así mismo, tiene como propósito establecer mecanismos para la protección de la identidad cultural y de los derechos de las comunidades negras en Colombia como grupo étnico, y el fomento de su desarrollo económico y social, con el fin de garantizar que estas comunidades obtengan condiciones reales de igualdad de oportunidades frente al resto de la sociedad colombiana. (Art. 1)

El segundo hito histórico lo marcó el advenimiento del discurso transnacional de la conservación y la biodiversidad, que define a la región del Pacífico como un ecosistema estratégico de bosque tropical húmedo con gran riqueza en especies. Los antecedentes que producen la irrupción global de la conservación de la biodiversidad como principio y objetivo de política transnacional devienen, de manera particular durante las dos últimas décadas, de la Reunión de Río de Janeiro (1992) y del convenio sobre Diversidad Biológica (1992). Posteriormente, en el año 2002, en Cancún, México, se reunieron representantes gubernamentales de los países con más alta biodiversidad ${ }^{13}$ del

estas comunidades, y para el fomento de su desarrollo económico y social” (Constitución Política de Colombia, 1991, art. transitorio 55).

12 En la misma Ley se indica que las tierras baldías "son terrenos situados dentro de los límites del territorio nacional que pertenecen al Estado y que carecen de otro dueño, y los que, habiendo sido adjudicados con ese carácter, deban volver a dominio del Estado, de acuerdo con lo que dispone el artículo de la ley 110 de 1913, y las normas que lo adicionen o reformen" (artículo 2). Como antecedente es importante mencionar que es en el gobierno de Alberto Lleras Camargo (1958-1962) en donde se promulgan las leyes que desconocen el poblamiento que tanto indígenas como negros han establecido en el Pacífico declarando las tierras de la región como baldías o de colonización (Botero, 2008).

13 El concepto de biodiversidad o diversidad biológica refiere a la variedad en el interior del mundo viviente, y presenta diferentes grados de complejidad (variabilidad genética de poblaciones, multiplicidad de especies, diversidad de ecosistemas y paisajes). Estos niveles, interrelacionados entre sí espacial y funcionalmente, se estudian desde el nivel de los genes, especies, comunidades, hasta los ecosistemas y paisajes (IAvH, 2000, en Romero et al., 2004). 
mundo y pactaron la "Declaración de Cancún", la cual establece el Grupo de Países Megadiversos Afines, entre ellos Colombia, como un mecanismo de consulta y cooperación para promover intereses y prioridades relacionados con la conservación y el uso sostenible de la diversidad biológica.

Y el tercer acontecimiento da cuenta de la exacerbación del conflicto armado en la región. Sin duda, el conflicto armado es una dinámica reciente en el Pacífico sur colombiano y, como se mostrará más adelante, se constituye en el hecho más contemporáneo de transformación de la acción colectiva en la zona de estudio. El conflicto armado, un fenómeno que tuvo unos inicios ideológicos a mediados del siglo xx, se ha convertido cada vez más en irregular y tiene un carácter prolongado. En este conflicto intervienen y confluyen diversos actores legales e ilegales: Estado, ${ }^{14}$ Farc,${ }^{15}$ ELN $^{16}$ y AUC,${ }^{17}$ entre los más significativos. El conflicto armado interno tiene como combustible primordial las drogas de uso ilícito y deja como principal víctima a la población local (Pizarro, 2004). Para el Pacífico sur colombiano la escalada del conflicto armado ha significado, entre otros aspectos, el desplazamiento forzado de

14 Específicamente hacen presencia en la zona: Escuadrones Móviles de Carabineros (Emcar), la Brigada XXIX del Ejército, Fuerza Naval Pacífico, Batallón de Infantería de Marina (Baflim) No. 10; la Brigada Móvil No. 19 (Observatorio del Programa Presidencial de DDHн y DIH, 2009).

15 Fuerzas Armadas Revolucionarias de Colombia. Particularmente los Frentes 2, 6, 29, 30, 48 y 60. En los últimos años están operando en la zona las columnas móviles Daniel Aldana, Mariscal Antonio José de Sucre, Jacobo Arenas y Jacinto Matallana (Observatorio del Programa Presidencial de DDHн y DIH, 2009).

16 Ejército de Liberación Nacional. De manera específica, el Frente Comuneros del Sur, Frente Mártires de Barbacoas y el Frente Héroes del Sindagua. Así como la Columna Milton Hernández y la Compañía Camilo Cienfuegos (odDr, 2012).

17 Autodefensas Unidas de Colombia. En particular el Bloque Libertadores del Sur (BLs), adscrito al Bloque Central Bolívar (ВСB). Operó en Nariño a través de los Frentes Brigadas Campesinas Antonio Nariño, Lorenzo de Aldana y Héroes de Tumaco y Llorente (ODDR, 2011). Después de la desmovilización de las AUC, se evidenció la aparición de agrupaciones como la Organización Nueva Generación (ONG), Los Rastrojos (liderada por Luis Enrique Calle Serna, alias “Comba”, luego del asesinato de Wilber Varela, alias “Jabón”, antiguo jefe de la organización, en el año 2008), Los Urabeños, Las Águilas Negras, las Autodefensas Gaitanistas de Colombia y las Autodefensas Campesinas Nueva Generación (ODDR, 2011). 
poblaciones ribereñas y de costa hacia los asentamientos principales de la región sur como Tumaco y Buenaventura. De igual forma, viene generando redesplazamientos intraurbanos en estos núcleos humanos principales. De manera radical, la disputa territorial por el control de los espacios más estratégicos de esta geografía, liderada a sangre y fuego en cada uno de los ríos, playas, poblados y bosques de la región, y con una celeridad inusitada, es la que ha transformado la región sur con consecuencias nefastas para las dinámicas organizativas de los pobladores locales (Restrepo, 2005).

Al respecto, la vivencia que narra a continuación Carlos Rosero, líder y fundador del PCN, hace hincapié en dos aspectos centrales. El primero alude a que las grandes ganancias económicas que deja el negocio del narcotráfico hacen que el objetivo fundamental de los actores armados sea la influencia política y el control militar del territorio. El segundo aspecto que enfatiza Rosero tiene que ver con el régimen del terror que impera en la zona; que se traduce en muerte, desplazamiento y miedo y que, a la postre, se convierten en las secuelas que están "fracturando" los procesos organizativos locales:

Durante años, Buenaventura fue uno de los sitios más importantes en la movilización de coca, y un combustible que ha alimentado por tiempos el conflicto armado ha sido el narcotráfico. Entonces: quien controle, quien tenga influencia política, militar, en una zona como Buenaventura, pues obviamente va a devengar de esa situación grandes ingresos económicos para poder seguir haciendo la guerra como tal. Eso es lo más importante. [...] En general yo pienso que el tema del conflicto desbordó la capacidad de las organizaciones y de los líderes, la gente ha aprendido a sobrellevar ese asunto pero a costa de tener que abandonar la agenda propia y otros aspectos importantes de la lucha. Entonces se hace pero no es lo suficiente hermano para resolver eso. El impacto del conflicto armado en los liderazgos y en las organizaciones ha sido terrible, hermano. La gente tiene miedo, 
hay líderes importantes que se han tenido que desplazar o están muertos. (Rosero, 2012: 3-5) $)^{18}$

\section{ACCIÓN COLECTIVA}

Quizá una constante de las primeras referencias de los estudios sobre la acción colectiva estuvo relacionada con la llamada psicología de las masas o de las multitudes. Tales enfoques explicaban los comportamientos colectivos como tributarios de la imitación, sugestión y contagio, advirtiendo los peligros latentes de estos. Posteriores trabajos, inspirados desde una sociología funcionalista, intentan superar la mirada violenta e irracional que asignaban a la multitud tanto Gustave Le Bon como Jean Gabriel Tarde. Miradas caóticas que pertenecen a aquel filón del pensamiento conservador europeo que, hacia finales del siglo xix, se ocupó de la multitud desde una perspectiva psicológica, en un momento en que el empuje del movimiento obrero y de sus primeras organizaciones de masa se vuelve más amenazante para el orden burgués (Melucci, 1999). Para la tradición de corte más funcionalista de mitad del siglo anterior, la acción colectiva antes de ser irracional se refería más a comportamientos disfuncionales al sistema vigente, a actuaciones poco funcionales a los procesos de integración del sistema social, a conductas marginales que causaban desequilibrios y desorganización de la sociedad (Archila, 2003). Sin embargo, Robert Merton, desde el interior de esta perspectiva, introduce una distinción entre los procesos colectivos que son el resultado de la disgregación del sistema, y los procesos que tienden a una transformación de las bases estructurales del sistema mismo (Melucci, 1999). La irrupción de los llamados nuevos movimientos sociales (NMs), como el estudiantil en los años sesenta del siglo $\mathrm{xx}$, cuestiona el paradigma funcionalista y las lecturas psicológicas, debido a que estas protestas no eran comportamientos marginales a la moder-

Entrevista realizada por Juan Manuel Riascos el 4 de abril de 2012. 
nización sino más bien elementos de ella. Así surge la necesidad de indagar por las motivaciones que los individuos tienen a la hora de participar en este tipo de acciones colectivas (Archila, 2003).

A finales de los años ochenta del siglo pasado, la peculiaridad latinoamericana radicó en que nuevas formas de acción colectiva coincidieron con el cierre de los canales institucionales de expresión de las demandas sociales. Lo anterior aconteció por las dictaduras militares, especialmente en el sur de América Latina (Argentina, Uruguay, Chile y Brasil), que negaban a los partidos políticos sus funciones de mediadores de intereses sociales. En estos regímenes, que auspiciaron la represión política y afectaron a sindicatos y a otras organizaciones populares, esta situación social se profundizó por la indiferencia de las instituciones públicas frente a las demandas de la población (Jelin, 1994).

En algunos estudios sobre acción colectiva desde vertientes norteamericanas y europeas (McAdam et al., 1999) y latinoamericanas (Larangeira, 1990; Schuster et al., 2005) se propone, a la hora de estudiar la acción colectiva, dejar de lado sesgos excluyentes entre racionalidad instrumental o búsqueda simbólica, también entre el peso exclusivo de las estructuras o el de la acción humana. Se considera a la acción colectiva como generadora de la sociedad, pero constreñida por aspectos estructurales que, a su vez, son construcciones históricas modificables. Desde esta perspectiva relacional, la acción colectiva puede entenderse como el proceso en donde se articulan sujetos desde sentidos y prácticas que buscan cierto vínculo reflexivo en la interacción social (Durán, 2012). Este vínculo reflexivo es más o menos deliberado, cambiante y difuso, motivado de manera fundamental por identificaciones que pueden tener diversos niveles de complejidad y visibilidad. Y es esta perspectiva hermenéutica la que se privilegia en la presente investigación, en donde los procesos de acción colectiva de las poblaciones locales pueden rastrearse desde los vínculos, a veces contradictorios y opacos, que establecen y promueven en sus trayectorias de vida situadas en contextos espaciotemporales determinados. 


\section{AtISBOS DE ACCIÓN COLECTIVA EN LA REGIÓN DEL PACíFICO SUR}

Sin duda, el proceso de redacción de la Constitución de 1991 es un hecho fundamental que promueve y fortalece la incipiente acción colectiva de la gente negra del Pacífico colombiano, tal como se verá más adelante. En este sentido, es pertinente explorar algunos de esos antecedentes de acción colectiva en la zona sur antes de la promulgación de la Carta Magna del año 1991.

De manera particular, en el Pacífico sur colombiano existían asociaciones campesinas constituidas en las décadas de los años setenta y ochenta. Al respecto, un líder afrodescendiente nacido en la población de La Espriella, a 76 kilómetros de Tumaco, comenta: “A partir de 1973 se fueron creando organizaciones, comenzaron a bajar información los sindicatos, las organizaciones sociales y otras cooperativas" (Becerra, 2012, p. 2). En los relatos expertos construidos por algunos estudios sobre la región, se evidencia que la base de la acción colectiva en la región Pacífica sur colombiana, y que se resignifica y cualifica en la década de los años noventa, proviene de reivindicaciones y luchas, principalmente, contra la discriminación racial. Las experiencias de los movimientos negros en Estados Unidos y África, durante las décadas de los sesenta, setenta y ochenta, los cuales exigían el reconocimiento de los derechos civiles (Escobar, 1997; Rivas, 2001), inspiraron la formación de grupos locales de intelectuales y gestores de la cultura negra. El siguiente relato de la investigadora Rivas ilustra cómo la reivindicación del ser negro que se daba en ese momento no relacionaba posturas basadas en la diferencia cultural o étnica. $\mathrm{Al}$ respecto la investigadora Rivas describe:

Este discurso se fundamentaba en la lógica del marginamiento social, en donde se configura el ser negro a partir de la forma en que la esclavitud y el prejuicio que se ha desprendido de ello componen sus rasgos históricos fundamentales; es la resistencia la que adquiere el sentido político excepcional y se reivindica, entonces, la figura del cimarrón "como mito por 
excelencia de esa resistencia”. Aquí poco importa la diferencia cultural o étnica. (Rivas, 2001, p. 150)

Estas dos fuentes consultadas, una más enraizada al mundo de la vida del líder negro Porfirio Becerra, persona muy reconocida por los pobladores de los ríos y costas del Pacífico nariñense, y la otra, más arraigada con los procesos de conocimiento propios de la visión experta, particularmente sobre los estudios de la gente negra del Pacífico sur colombiano, muestran dos facetas complementarias de la emergencia y configuración de la acción colectiva en esta parte del país durante los últimos cincuenta años del siglo xx. La primera faceta reivindica el papel de las luchas campesinas y de la Asociación Nacional de Usuarios Campesinos de Colombia, ${ }^{19}$ que se gestan principalmente en los momentos de declive y ruptura del pacto político nacional conocido como Frente Nacional. ${ }^{20}$ En el caso de Tumaco se crean diversas organizaciones de campesinos que se movilizan básicamente luchando por la defensa de la tierra, aquella que les procuraba el sustento diario de sus familias, y que

19 La Asociación Nacional de Usuarios Campesinos de Colombia (ANUC) tuvo su origen legal con la expedición del Decreto 755 de 1967, el cual fue proferido por el entonces presidente de Colombia, Carlos Lleras Restrepo. Los principios políticos de la ANUC aprobados en Villa del Rosario de Cúcuta el 5 de Junio de 1971 indicaban: "La Asociación Nacional de Usuarios Campesinos de Colombia es una organización independiente del gobierno y de los partidos políticos, que agrupa en su seno a los campesinos colombianos sin distingos raciales y religiosos y que basa su acción en la siguiente plataforma mínima: 1) total respeto al derecho de los campesinos a organizarse para lograr su avance político y el continuo mejoramiento de las condiciones de vida materiales y culturales. 2) Reforma agraria integral y democrática que entregue rápidamente la tierra en forma gratuita a quienes la trabajan o quieran trabajarla; preferencialmente para adelantar programas cooperativos de producción agropecuaria o Empresas Comunitarias Campesinas que acaben radical y definitivamente el latifundio; mejoren sustancialmente la producción; eleven el nivel de vida campesino, liquiden la desocupación, la miseria, la inseguridad, la falta de atención médica y el analfabetismo en el campo [...]" (Acta de constitución de la ANUC, 1970, p. 1).

20 Refiere al pacto bipartidista, de alternancia del poder entre los partidos históricos, liberal y conservador, durante 1958 a 1974, periodo que fue posterior a la dictadura de Rojas Pinilla (1953-1957). Se caracterizó por excluir y reprimir políticamente a terceros partidos, movimientos y protestas sociales, organizaciones y agremiaciones de base (Acevedo et al., 2001). 
en ese momento era cada vez más amenazada por intereses, entre otros, de grupos de palmicultores capitalistas venidos en su mayoría de los departamentos de Cundinamarca y Valle. El líder campesino Porfirio Becerra, hombre con más de cuarenta años de experiencia en procesos organizativos, comenta al respecto:

Después de 1970 con otros compañeros, viéndonos acosados por la arremetida de los palmicultores, de la palmicultura [...], Tumaco fue declarado como uno de los mejores territorios para la siembra de palma africana. Entonces vino una arremetida de los capitalistas de Cundinamarca, del Valle y de otros sitios del país a sembrar palma africana acá. Hasta ese entonces las comunidades negras poseíamos $80 \%$ de los territorios del municipio de Tumaco. [...] Así las cosas yo me dediqué a participar en los movimientos sociales, por eso fui a la Asociación de Usuarios Campesinos, luchamos bastante. Aprendí a manejar lo que es la organización y hasta resultó el Proceso de Comunidades Negras. Algunos compañeros de la Asociación de Usuarios Campesinos no asumieron esta responsabilidad, ni quisieron aceptar el término de Comunidades Negras. Porque usted sabe tanta cucaracha que nos metieron en la cabeza, que nos llevaron a rechazar nuestra propia identidad. (Becerra, 2012, p. 2)

Antes de aludir a la segunda faceta de emergencia y configuración de la acción colectiva en la región, es pertinente abrir un pequeño paréntesis. En la experiencia de vida que narró el líder Becerra, queda señalada una cierta pauta de tensión que vincula a los actores locales en su proceso de identificación en el territorio del sur del Pacífico colombiano. Pauta de tensión que es un preámbulo de la "llegada" del discurso de lo étnico a la región en la década de los años noventa en el siglo anterior. Según lo que cuenta Porfirio Becerra, en las décadas de los setenta y ochenta se fraguó un conflicto en torno al reconocimiento de la población local. Algunos pobladores se reconocen como campesinos a "secas", otros van introduciendo una posición diferente en su identificación, campesino 
negro; ${ }^{21}$ identificación que se refuerza con los procesos organizativos que se adelantaban por aquella época en la zona.

Cruzando estas vivencias de pobladores locales con los relatos construidos desde la perspectiva de algunos estudios académicos que vienen indagando sobre la región, la lucha de campesinos negros por preservar los territorios que han habitado desde varias generaciones atrás configuró una estrategia organizativa como grupo étnico que, a la postre, hizo posible que las poblaciones locales fueran, en palabras de Restrepo, “imaginadas como una comunidad étnica”; esto es, se visibiliza "lo étnico como dispositivo para pensar y actuar sobre y desde la región”. Al respecto, el investigador comenta:

Se destiló por primera vez una noción y estrategia organizativa de las poblaciones campesinas negras como grupo étnico. Esta noción y esta estrategia organizativa respondían a la creciente amenaza de despojo de las tierras habitadas por estas poblaciones durante generaciones, a manos de un Estado que desconocía su presencia. Este desconocimiento se daba mediante la declaración de gran parte de la región del Pacífico como 'zonas baldías' (esto es, pertenecientes a la 'nación') y, por tanto, eran otorgadas concesiones o permisos de explotación de sus recursos forestales y mineros a compañías foráneas. (Restrepo, 2004, p. 272)

Cerrando el paréntesis, y retomando la segunda faceta de emergencia y configuración de la acción colectiva en la región, se evidencia de qué manera grupos no muy numerosos de intelectuales que se reconocían como negros colombianos se juntan, estableciendo así cierto vínculo

21 Algunos relatos producidos por investigaciones (Almario, 2001; Restrepo, 2001) han indicado que los pobladores locales del sur del Pacífico han tenido dificultades para retener la memoria sobre sus ancestros africanos, para dar cuenta de su etnicidad. "Antes que el despertar de una etnicidad que siempre había estado allí en silencio en la conciencia de las poblaciones locales, agazapada, esperando el momento oportuno para hacerse escuchar, asistimos a una ardua labor desplegada en múltiples niveles para la producción de dicha etnicidad" (Restrepo, 2001, p. 43). 
reflexivo en torno al ser negro. Tales posiciones comienzan a movilizar acciones e idearios, que van hasta el presente, tendientes a la reivindicación y búsqueda de caminos que materialicen una inclusión real, la inclusión del ser negro al país. Siguiendo el relato de Agudelo (1999), en la década del setenta los grupos más notorios fueron el Centro para la Investigación de la Cultura Negra (CIDCUN), creado por Amir Smith Córdoba y el Círculo de Estudios Soweto, que luego daría origen, en el año 1982, al Movimiento Nacional por los Derechos Humanos de las Comunidades Negras en Colombia (Cimarrón), dirigido por Juan de Dios Mosquera, quien, según su palabra y experiencia de vida, considera que el principal aporte de la organización Cimarrón ha sido el haber comprometido al país en la lucha contra el racismo y la discriminación:

Bueno lo primero, el haber sido el fundador, gestor e ideólogo de la construcción del proceso organizativo de base de la población afrocolombiana hoy, especialmente la construcción del movimiento nacional por los derechos humanos afrocolombianos Cimarrón. También el haber generado en el país un pensamiento y la sensibilización del pueblo afrocolombiano y de la nación en general acerca de la reivindicación de los derechos étnicos de la población afrocolombiana en la lucha contra el racismo, contra la discriminación racial. Nosotros hemos sido los que comprometimos al país con la lucha contra el racismo y la discriminación racial, también nosotros hemos contribuido a generar el liderazgo que hay en las comunidades afro del país, en mucha gente que está haciendo cosas en las comunidades, con procesos comunicativos campesinos, procesos organizativos barriales, juveniles, de mujeres. (Mosquera, 2012, p. 1$)^{22}$

Estas organizaciones y otras menos visibles, como se mencionó antes, fueron influenciadas por las luchas de gente negra de Estados Unidos y

22 Entrevista realizada por Juan Manuel Riascos el 26 de abril de 2012. 
África. Quizá este referente de acción colectiva de la población negra del litoral occidental sur emerge claramente en la famosa "Proclama de Tumaco". Esta proclama se leyó en plaza pública el 16 de septiembre de 1988, y allí se recuerda el papel que jugó Tumaco en las luchas por la independencia, en cabeza del negro liberto Vicente de la Cruz. Igualmente, en esa plaza pública se escucha la "voz fuerte" que expone: "Nosotros negros descendientes de africanos [...] estamos izando a media asta el tricolor colombiano [...] para expresar nuestro dolor de sentirnos huérfanos de patria" (Hoffmann, 1999, p. 58).

Hasta el momento se han retratado brevemente dos vínculos reflexivos significativos del proceso de comunidades negras, los cuales se consideran pertinentes a la hora de ir comprendiendo los avatares de la emergencia y la configuración de la acción colectiva en el sur del Pacífico colombiano, a saber: la defensa del territorio y la reivindicación del ser negro en el contexto del país. Frente al primero, la organización campesina, de la mano del Estado, representado en la ANUC, y de cooperativas y gremios de pobladores rurales campesinos ya existentes, "sembró", sin duda, las primeras "semillas", los primeros aprendizajes para que pobladores locales del sur del Pacífico asumieran procesos más cualificados de acción colectiva en el futuro inmediato. De igual forma, este primer atisbo visibiliza una contradicción central con respecto a los procesos, por cierto cambiantes y porosos, de identificación en que se inscribían algunos sujetos locales del sur del Pacífico en esos tiempos, y que quizás perduran, de forma actualizada, en el presente. Esta contradicción se percibe en la vivencia de algunos pobladores locales a la hora de definir su sentido de pertenencia y arraigo, en oscilaciones que van desde su identificación como campesino, como negro y como campesino negro.

Con respecto al segundo vínculo reflexivo anotado, la reivindicación del ser negro, se mostró cómo la movilización de actores intelectuales, vía expresiones artísticas y culturales, fue cualificando las demandas en cuanto miembros de una población negra que exigía y 
proclamaba el derecho a la inclusión no solo en la región sino, principalmente, en la vida política de la nación.

Ahora bien, quizá otras dos relaciones significativas que pueden ayudar a caracterizar la acción colectiva previa a la Asamblea Nacional Constituyente en el Pacífico sur colombiano tienen que ver con las órdenes religiosas ${ }^{23}$ y con las protestas urbanas. La primera, se manifiesta por medio de las prácticas que introducen en la zona algunas congregaciones religiosas foráneas a la región con la modalidad de misión, hecho que venía ocurriendo de tiempo atrás pero que se intensifica, de cierto modo, en la década del ochenta del siglo xx. Prácticas que tenían como propósito la creación de organizaciones de base y la sensibilización frente al discurso étnico emergente. La segunda relación significativa se da a partir de las protestas populares que se surten en la región como mecanismo de presión a los gobiernos de turno, con el fin de alcanzar mejoras reales en las condiciones de vida de las poblaciones asentadas en los centros urbanos principales y en sus entornos inmediatos, especialmente en términos de empleo, servicios públicos y defensa del medio natural.

Con respecto a la primera relación mencionada, y de la mano de algunos relatos elaborados por investigaciones, los agustinos hacen presencia en la región sur desde el siglo xix cuando recibieron parte del Pacífico como "tierras de misiones". En 1954 el Vicariato de Tumaco es orientado por la orden de los carmelitas. Las prácticas aprendidas durante la evangelización colonial son resignificadas y adquieren enorme fuerza en la religiosidad popular a través de cantos, representaciones, velorios y festividades. Quizá uno de los estudios más destacados entre la cultura negra y la religiosidad cristiana lo realiza el sacerdote carmelita José Miguel Garrido (Almario, 2001). Sin embargo, la

23 El papel de las órdenes religiosas es importante para la organización de la gente negra en todo el Pacífico colombiano, así existan singularidades según la subregión de que se trate. Al respecto, por ejemplo, véase el capítulo de este libro que refiere a los procesos de democratización en el bajo Atrato colombiano. 
presencia de los carmelitas en las zonas rurales de la región era esporádica y limitada. A partir de 1980 el trabajo de la iglesia en Tumaco empieza a ser importante gracias al liderazgo de Pastoral Negra que se empeña en articularse con el proceso organizativo que se desencadena con motivo de la preparación de la Ley 70 de 1993 (Hoffmann, 1999). El anterior aspecto se resalta en el trabajo de la investigadora Nelly Rivas de la siguiente manera:

La incursión de la iglesia en temas relacionados con la reivindicación territorial de la gente negra del Pacífico nariñense empieza a principios de la década del 90, cuando se está en proyecto de crear la Pastoral Afrocolombiana. Aunque la Pastoral Afrocolombiana se constituye antes del A.T. 55, ella se apoya en él para seguir su marcha y lograr su consolidación como asesora y acompañante en los procesos que se generan a partir de la aparición del artículo y luego de la ley 70. La necesidad de la conformación de la Pastoral Afro está atravesada por la preocupación que generan los megaproyectos que vienen hacia la costa Pacífica. (Rivas, 2001, p. 156)

Teniendo en cuenta el anterior relato de la investigadora Rivas, es pertinente introducir otro paréntesis de importancia que tiene que ver con el contexto emergente de una "nueva" visibilidad de la región Pacífica a nivel internacional y que repercute a escala nacional rápidamente. Desde la década de los noventa del siglo xx, la región empieza a ser vista como un lugar a "desarrollar", empieza a ser entendida como una zona a "modernizar"; esto desencadena presiones novedosas para estos territorios y para sus pobladores, por ejemplo, vía macroproyectos. ${ }^{24}$

24 A manera de ilustración, en el caso de Buenaventura, para algunos actores la forma de reconstruir esta ciudad puerto en el futuro cercano está de la mano de la buena ejecución de los macroproyectos como: TC Buen, del muelle de la Sociedad Portuaria y de la vía Alterna Interna, así como de la construcción del Puerto de Aguadulce, la zona franca Celpa y del malecón Bahía de la Cruz, entre otros. Otras visiones resaltan que estos proyectos más que auspiciar el mejoramiento de la calidad de vida de las poblaciones de Buenaventura y la preservación de sus entornos biodiversos, lo que realmente auspician es mayor desigualdad social y el desplazamiento de las per- 
Continuando con los antecedentes de la labor de la iglesia en la gestación de las acciones colectivas en la región, algunos recuerdos de las vivencias de una maestra de escuela, que nació en la parte alta del río Patía hacia el año 1927 (territorio que hoy hace parte del Consejo Comunitario Acapa), ilustran el papel esporádico de la Iglesia católica en aquellos ríos del sur del Pacífico colombiano y sus relaciones con las festividades del lugar, esto hace ya un par décadas. Esta maestra se llama Dionilia Bagüi, y al respecto comenta:

Sí, allá [Altos del río Patía] las fiestas de las imágenes y los santos eran importantes; la virgen del Carmen, la de las Lajas y la de San Antonio. En San Pedro estaba la capilla y cada año iba el cura y se celebraba la fiesta de San Pedro, en el mes de junio. [...] El cura solo llegaba a predicar y tocaba darle la comida. Estábamos todos sirviéndole al cura en las fiestas, porque se pasaban ocho días festejando. Eso era hacer el alumbrado, los castillos, hacer la procesión, al otro día la misa. La gente era bien religiosa. El cura bautizaba, casaba a los que eran de casarse. Los curas no hacían la fiesta, sino era la comunidad. La comunidad le colaboraba al cura. Si había un enfermo lo llevaban a que le hicieran el óleo y las bendiciones. (Bagüi, 2012, p. 5)

En el caso de Buenaventura, la presencia de la pastoral católica liderada por el obispo Gerardo Valencia Cano en los años sesenta exalta la necesidad de un trato no discriminatorio hacia la población del puerto. El obispo "rojo", tal como se le conocía en la región, en aquella época, se inspiró en las enseñanzas de la teología de la liberación y estimuló algunos procesos organizativos populares que se pueden considerar como antecedentes de la actual organización social en la región (Agudelo, 1999).

sonas que actualmente habitan los sitios donde se llevarán a cabo las iniciativas urbanas mencionadas. 
Siguiendo a Odilia Hoffmann, quizá la movilización popular de mayor impacto en la región Pacífica sur, en la década del setenta, tuvo que ver con el cierre de la empresa Maderas y Chapas de Nariño. Esta empresa con cierto enfoque de economía de enclave ${ }^{25}$ deja de funcionar cuando la madera empieza a escasear y, por ende, la utilidad del negocio cae. También, cuando se realiza la construcción del canal Naranjo ${ }^{26}$ en 1973, obra que orientó la oferta de madera hacia la zona del Satinga (Leal et al., 2003). El cierre de la empresa hizo que amplios sectores de población de Tumaco se movilizaran, esto por varios meses. Protestaron los obreros y sus familias, el sector educativo, los políticos locales de oposición y también estudiantes y sectores del Movimiento Obrero Independiente Revolucionario (MOIR) (Hoffmann, 1999). Según la investigadora Claudia Leal esta protesta origina una de las más destacadas experiencias sindicales del Pacífico colombiano:

En torno a este conflicto laboral se produjo una de las más interesantes experiencias sindicales del Pacífico colombiano. En este proceso se dieron acciones como la toma del aeropuerto de Tumaco el 10 de junio de 1977, con el propósito de reclamar salarios y las prestaciones sociales adeudadas por la empresa. (Leal, et al., 2003, p. 52)

Otra protesta popular que se destaca en la literatura especializada fue la ocurrida en 1982 con ocasión del derrame de crudo por parte de Ecope-

25 La economía de enclave imperante en la región desde el siglo xvir ha estado actualizándose con la idea de que las selvas húmedas deben ser despojadas de sus riquezas. Con tal fin se han establecido diferentes ciclos extractivos según la época, esto según la demanda del comercio internacional: oro, tagua, caucho, mangle, naidí, platino (Leal et al., 2003).

26 El canal Naranjo, que permitió el transvase de los ríos Patía Viejo y Patía sobre el pequeño caudal del río Santiquianga, fue el resultado de la construcción de una zanja por parte del empresario maderero Enrique Naranjo con el propósito de trasladar trozas de área del Patía hacia el Sanquianga, donde tenía un aserrío. Una zanja que al comienzo tenía metro y medio de ancho, dos de profundidad y 1800 de longitud ha generado un impacto ambiental y económico sin precedentes en la zona (Leal et al., 2003). 
trol. Hoffmann señala que es por ello que se crea la Junta Cívica de Mejoras y Defensa de los Intereses de Tumaco, liderada por miembros de clase media, elite escolarizada y algunos militantes políticos del MOIR y del Partido Comunista. En 1985, la Junta llega a Bogotá a negociar un pliego de peticiones con el presidente de entonces Belisario Betancur; en dicho pliego se incluían puntos relativos a la prestación de servicios de acueducto, electricidad, salud y educación. Otra protesta urbana que tiene recordación en la región fue la ocurrida en septiembre de 1988 y que se conoció como el Tumacazo: una protesta beligerante de la población en reclamo de mejores condiciones de vida para la gente de la ciudad y de sus entornos inmediatos. El Tumacazo se enmarcó dentro de la movilización nacional que se dio en todo el país por aquel tiempo, particularmente en el Pacífico sur se replicaron estas protestas en Guapi, Buenaventura y Quibdó (Hoffmann, 1999).

Gloria Obando, quien se define como tumaqueña con raíces campesinas, maestra de profesión e hija de un herrero liberal, recuerda el Tumacazo como el levantamiento popular más violento que se haya dado en la ciudad:

\footnotetext{
El pueblo de Tumaco luchó muchísimo por unas obras, hasta llegar a la opción del Tumacazo, un levantamiento súper violento que hubo acá, como nunca se había dado, de los que yo conozco. Fue muy doloroso. En ese momento yo era dama gris voluntaria de la Cruz Roja, mi acción social me ha gustado mucho, más por un sentimiento empático [...]. También hacía parte del Comité Cívico Tumaco Alerta que lideró el Tumacazo. (Obando, 2012, p. 1)
}

Hasta acá se han presentado algunos antecedentes, a manera de atisbos, de lo que se pudiera llamar el advenimiento de la acción colectiva en el sur del Pacífico en la coyuntura de la nueva Constitución del año 1991. Antes de pasar a este punto es importante advertir que los dos últimos antecedentes descritos introducen dos rasgos centrales. El primero es la 
presencia de actores sociales "externos" interesados en acompañar procesos de acción colectiva en la región, en este caso particular la Iglesia católica. Vínculo que alude a los procesos de acompañamiento y participación de actores que empiezan a "globalizar" ciertas prácticas locales de acción colectiva. El hecho de que la pastoral negra incursione como un actor central en la dinámica organizativa de las comunidades negras le da visibilidad a las experiencias situadas del sur del Pacífico en otros contextos internacionales, donde la pastoral negra tenía y tiene presencia. De igual forma, introduce orientaciones globales en el contexto local, una de ellas es la teología de la liberación. El segundo rasgo introduce la necesidad de indagar los intersticios, de redefinir las nominaciones que naturalizan linderos precisos entre la acción colectiva que se promueve en los ríos, las playas y los bosques, y la que se lidera en las zonas más urbanizadas de la región sur del Pacífico.

\section{AUGE DE LOS PROCESOS ORGANIZATIVOS DE LA GENTE NEGRA EN EL CONTEXTO DE LA CONSTITUCIÓN DE 1991}

En la década de los noventa ocurren algunos hechos que modifican la forma de percibir la región del Pacífico colombiano. Sin duda, uno de estos sucesos fue la irrupción de la Asamblea Nacional Constituyente con la misión principal de elaborar la nueva Carta Constitucional que dirigiría al país y que, a la postre, permitió el reconocimiento jurídico de los territorios colectivos de la gente negra del Pacífico colombiano. La siguiente experiencia de vida del líder negro Porfirio Becerra, tal como él se define, introduce algunos detalles de las circunstancias y de los actores que intervinieron para que se incluyera el artículo transitorio 55 en la Constitución Política de Colombia de 1991.

En 1991, en la Constituyente, no se acordaron de los negros en ningún momento, y, sí se acordaron, trataron de evadir la responsabilidad. Sin embargo, ya existía el convenio 169 del negro, y es a través de ese conve- 
nio que la oIT obligó a Colombia para que legislara a favor de ese convenio, resultando de eso la Ley 21. Entonces cuando se da la Constituyente, ni siquiera los negros se acordaban de qué tenían que defender. [...] Y ya fue al final de la Constituyente a través del difundo Orlando Fals Borda y Rojas Birry, el indígena, que se va quedando esto de la Ley 21 y el acuerdo 169, se van quedando ahí. (Becerra, 2012: 3-4)

En su relato, la investigadora Martha Domínguez destaca las discusiones que se dieron al interior de la Asamblea Nacional Constituyente sobre la inclusión o no de los derechos de las poblaciones negras en el texto final de la Constituyente. En definitiva, los representantes indígenas lograron que la Asamblea Nacional Constituyente aceptara el artículo transitorio 55, tal como se comentó arriba.

El reconocimiento de los derechos de propiedad colectiva para comunidades negras fue uno de los temas que polarizó las discusiones en la ANC. El sector conservador representado en el Movimiento de Salvación Nacional en un esfuerzo por bloquear esta medida se abstuvo de votar, mientras que la mayoría de miembros del Partido Liberal y de la Alianza Democrática M-19 (reinsertados del grupo revolucionario M-19) votaron a favor de la medida. La polémica llegó a tal punto que los representantes indígenas presionaron con no firmar el documento final de la ANC si se continuaba derogando el tema de los derechos territoriales de los negros. Finalmente fue aprobado el artículo transitorio 55, que disponía la creación de una comisión especial para el diseño de una ley de derechos territoriales para los pobladores negros. (Domínguez, s.f., p. 6)

La pertinencia de los procesos que se han descrito en las primeras páginas de este documento, procesos que se han presentado a manera de "preámbulo" de lo que pudo haber significado o puede estar significando la acción colectiva en el sur del Pacífico colombiano en estas dos últimas décadas, no se ponen en duda. Sin embargo, la vivencia que 
comparte el líder Porfirio Becerra, arriba mencionada, hace explícito, y habrá que seguir profundizando en este aspecto, que la acción colectiva que precedió al proceso de la Asamblea Nacional Constituyente era relativamente "débil". Esta debilidad se manifiesta en las posibilidades reales de articulación de la organización negra con los procesos de política institucional, no solo en el sur del Pacífico, sino del Pacífico como región. Lo anterior se sustenta en el hecho de que no fue elegido ninguno de los líderes de la gente negra como representante en la Asamblea Nacional Constituyente. Las diferentes organizaciones afrocolombianas no lograron ponerse de acuerdo para presentar una lista única de las negritudes a la Asamblea Nacional Constituyente.

En ese momento se lanzan varias candidaturas que a la postre no lograron los votos suficientes para obtener una curul en la Asamblea. De la mano de algunas investigaciones (Wade 1994; Agudelo, 1999), se identifica que los candidatos negros a la Asamblea Nacional Constituyente fueron: la liberal Otilia Dueñas, quien crea para la ocasión el Movimiento por un Nuevo País para las Comunidades Negras y Marginadas; Juan de Dios Mosquera, fundador de la Organización Cimarrón, quien hizo parte de una coalición de organizaciones populares y de izquierda; Justiniano Quiñones, médico de Nariño, quien con el político tradicional liberal del Chocó, Jorge Tadeo Lozano, se presentan como Liberales del Litoral Pacífico para Colombia; y Carlos Rosero dirigente de la Coordinadora de Comunidades Negras, que más tarde se convierte en el actual Proceso de Comunidades Negras (PCN), con influencia en las regiones rurales de los departamentos de Valle, Cauca, y Nariño. Hay que resaltar que en este proceso un sector de la Iglesia y un grupo de asesores del Pacífico lideran un fuerte apoyo a un candidato indígena a la constituyente, el indígena emberá Francisco Rojas Birry, desestimando los candidatos con posturas que reivindicaban las poblaciones negras (Agudelo, 1999).

La nueva Constitución del año 1991 reconoce formalmente a Colombia como un país multicultural y como una nación pluriétnica. 
Muy al contrario de la Constitución de 1886, que no reconocía tal diversidad y aseguró un concepto de nación cultural, religiosa, política y legal lo suficientemente homogénea (Wade, 2004). Tal característica de la nueva Constitución Política de Colombia permite que se activen los incipientes, y no por ello no significativos, procesos de acción colectiva que se gestaron en las décadas precedentes.

Como se ha referido, quizá el periodo más importante de acción colectiva en la región sur Pacífica se dio durante la década de los noventa $\mathrm{y}$, principalmente, en los primeros años de esta. En este periodo de tiempo se dieron tres procesos importantes, a manera de vínculos de identificación: la elaboración de la Ley 70 (entre 1991 y 1993); la aprobación de la Ley 70 (1993), y la creación de los primeros Consejos Comunitarios, vía recibo de los títulos colectivos por parte del Estado (1995 y 2000).

Posiciones de la visión experta presentan el nacimiento de la Ley 70 desde las siguientes dos lógicas. La primera es una lógica interna que buscaba solucionar los problemas de violencia por los cuales atravesaba el país y lograr un proceso de democratización y de mayor participación de la sociedad civil en las dinámicas estatales. La segunda lógica, que es global, y que se mantiene en la actualidad, buscaba que la nación respondiera al llamado de los organismos internacionales por el reclamo que se le hacía por la violación de los derechos humanos, el olvido a las minorías étnicas y la defensa del medio ambiente (Rivas, 2001). Siguiendo a la investigadora Rivas surge una pregunta que se puede enmarcar en la última lógica expuesta: ¿por qué el Estado acepta la Ley 70 ? Contrariamente a lo que se dice, refiere Rivas, la Ley 70 no necesariamente surge en el contexto de lo pluriétnico y lo multicultural, aunque se sustenta y se legitima bajo estas premisas. Es más, comenta, los "negros" no eran considerados como actores étnicos sino como parte de la sociedad colombiana "mestiza" (Rivas, 2001).

La ley se consolida en el marco de las relaciones internacionales que se encuentran vinculadas al manejo ambiental, y sobre todo en la conserva- 
ción de la biodiversidad. Así, varios autores ya han planteado que la ley 70 más que una ley para los negros es una ley para el Pacífico (Hoffmann, 1998a; Wade, 1996b). Lo anterior se presenta porque se ha caracterizado el Pacífico como una zona de alta biodiversidad. (Rivas, 2001, p. 151)

El anterior análisis introduce la necesidad de indagar por los discursos dominantes que subyacen a la hora de definir y actuar en y sobre la región del Pacífico sur, así como por aquellos discursos que se presentan como subalternos y que, por medio de manifestaciones poco visibles en los contextos de modernización de la vida social, erigen resistencia.

Ahora bien, legalizada la responsabilidad del Estado colombiano de apoyar la elaboración de la Ley 70, esto con la aprobación de la nueva Constitución Política de Colombia en el año 1991, se inicia un proceso de acción colectiva en zonas urbanas y rurales con el objetivo de elaborar un texto de ley que pudiera garantizar los derechos de la gente negra de la región. Es en ese proceso donde se establece la Coordinadora de Comunidades Negras como una red de organizaciones de nivel nacional con el mandato de articular las organizaciones de comunidades negras regionales (Palenques) y las locales (organizaciones de base).

Según el líder negro Porfirio Becerra, la Ley 70 significó el despertar de las organizaciones del sur del Pacífico. Este hombre de campo, tal como él se define, con vastos conocimientos sobre la siembra del cacao, narra aquellos momentos de su vida con las siguientes palabras:

Entonces fue el despertar de las organizaciones. Aquí en Tumaco estábamos lejos, de eso no sabíamos nada, pero acá había unos compañeros estudiantes. Uno de ellos, esas historias son las que no se le hacen saber a la gente, entonces desconoce que pasó, estaba estudiando acá, un muchacho Pedro Fermín y otro que se llama Walter García, y ellos escuchando lo que pasaba con las comunidades negras, el derecho de las comunidades negras, el artículo transitorio 55. Ellos bajaron la información a Tumaco y sindicaron las organizaciones. 
Por ejemplo, en ampaco, Organización de Pescadores Artesanales de Colombia, en ese tiempo la manejaba un compañero que lo mataron, Rafael Valencia Camacho; un hombre muy importante, muy activo, muy luchador, y por eso lo mataron. Entonces cuando llegó Pedro Fermín aquí, hicimos una reunión [...]. Rafael Valencia y yo vivíamos tan acosados económicamente, y aún sigo viviendo acosado, que no pudo ir a representar el proceso con una organización fuerte como lo era la AMPACO. [...] Nos serenamos un poco, y entonces saltó a la vista la Corporación Ecos del Pacífico, manejada por Hernán Cortes. [...] Cuando vino el proceso de análisis del artículo transitorio 55, entonces Hernán estaba empapado de las cosas y bajó la información acá y comenzamos a tejer la red. ¿Cómo lo hacemos? No podemos crear de momento una organización de comunidades negras, apoyémonos mientras en las organizaciones existentes. Entonces nos reunimos y ahí fue donde vino Asomira, 4 Pacíficos, una cooperativa de Cocoteros, vinieron cooperativas, algunas organizaciones, entre ellas la nuestra Copalmaco Ltda. [...] Fuimos creando los espacios hasta que, unidos con las organizaciones de la zona norte y centro, creamos lo que se llamó la Coordinación de Comunidades Negras. (Becerra, 2012: 4-5)

La Coordinación de Comunidades Negras fue una de las organizaciones mediadoras en el proceso de elaboración de la Ley 70, facilitó la mediación entre el Estado y las comunidades ribereñas rurales del Pacífico colombiano. En el tercer encuentro de comunidades negras del país, realizado en Puerto Tejada, en el año de 1993, pasa a denominarse Proceso de Comunidades Negras (PCN). Particularmente, para el caso del sur de la región Pacífica, y siguiendo a Carlos Agudelo, los primeros núcleos del PCN que se ubican en los cascos urbanos de Buenaventura, Guapi y Tumaco, lanzan en la coyuntura de elaboración de la Ley 70 una ofensiva organizativa hacia las áreas rurales e impulsan la "creación” de organizaciones étnico-territoriales en las zonas que deberían 
ser tituladas colectivamente. En ese proceso, se establecen los palenques $^{27}$ como instancias de coordinación regional. De esta forma se van configurando los tres niveles de la organización negra en el sur occidente del país: organizaciones de primer nivel (aglutina los territorios susceptibles a titular, lo que posteriormente, en la Ley 70 , se conoce como Consejos Comunitarios); organizaciones de segundo nivel (reúne las diferentes organizaciones que se gestan en el primer nivel, es de carácter regional; se denominan palenques); y las organizaciones de tercer nivel (que junta los diferentes palenques regionales y las organizaciones de base, y tiene una interlocución directa con el Estado). El PCN es la organización de tercer nivel con mayor liderazgo en la región sur de Pacífico colombiano. Porfirio Becerra cuenta cómo se daban los enlaces de los tres niveles principales de la organización de la población negra en la región:

La coordinación se da cuando vemos que los municipios de la costa, como somos 10, están desarticulados. Estábamos dispersos, cada uno trabajando por su lado. Entonces consideramos que era mejor una coordinación que nos agrupara y así hacer un trabajo conjunto. La coordinación era como la directiva, tenía un coordinador a nivel nacional, y bajaba la información a la región, y acá hacíamos el trabajo de base. Toda esa coordinación con todos los municipios iba a alimentar la creación de la Ley 70. (Becerra, 2012, p. 6)

Los principios que rigen el quehacer del PCN se relacionan con los derechos de reafirmación del ser negro con autonomía, el derecho al territo-

27 El Palenque Territorio Región de Nariño se constituye en 1994 en una asamblea departamental en Bocas de Satinga dentro de los parámetros y estrategia organizativa del PCN. De igual manera, se definió la estructura de coordinación del Palenque, a saber: 1) Zona Norte, que incluye las organizaciones de los municipios de la Tola, El Charco, Olaya Herrera, Iscuandé y Mosquera, con sede en Bocas de Satinga; 2) Zona Centro, que comprende los municipios de Barbacoas, Magui Payán y Roberto Payán, con sede en Barbacoas, 3) Zona Sur, conformada por las organizaciones de los municipios de Tumaco y Francisco Pizarro, con sede en Tumaco (Restrepo, 2005, p. 9). 
rio y el derecho a construir una visión propia de futuro. A continuación, Libia Grueso, fundadora del PCN, enuncia los lineamientos centrales de esta organización:

La reafirmación del Ser (del ser negros). En primer lugar: entendemos El Ser, como negros, desde el punto de vista de nuestra lógica cultural, de nuestra manera particular de ver el mundo, de nuestra visión de la vida en todas sus expresiones sociales, económicas y políticas. Una lógica que está en contradicción y lucha con la lógica de dominación, la que pretende explotarnos, avasallarnos y anularnos. Nuestra visión cultural entra en confrontación con un modelo de sociedad al que no le conviene la diversidad de visiones porque necesita la uniformidad para seguir imponiéndose; por eso el hecho de ser negros, de tener una visión distinta de las cosas, no puede ser solo para un momento especial, debe mantenerse para todos los momentos de nuestra vida. En segundo lugar: El reafirmarnos como negros implica una LUCHA HACIA ADENTRO, hacia nuestras propias conciencias, no fácilmente nos reafirmamos en nuestro SER, muchas veces y por distintos medios se nos inculca que todos somos iguales y esta es la gran mentira de la lógica de dominación. Desde este punto de vista debemos partir como primer principio del hecho de que somos negros y somos fieles a lo que somos y al orden social que concebimos desde nuestra cultura.

Derecho al territorio (un espacio para ser). El desarrollo y la recreación de nuestra visión cultural requieren como espacio vital el territorio. No podremos ser si no tenemos el espacio para vivir de acuerdo con lo que pensamos y queremos como forma de vida. De ahí que nuestra visión del territorio sea la visión del нÁBITAT, el espacio donde el hombre negro desarrolla su ser en armonía con la naturaleza.

Autonomía (derechos al ejercicio del ser). Esta autonomía se entiende en relación con la sociedad dominante y frente a otros grupos étnicos y partidos políticos, partiendo de nuestra lógica cultural, de lo que somos como pueblo negro. Entendida así, internamente somos 
autónomos en lo político y aspiramos ser autónomos en lo económico y lo social.

Construcción de una perspectiva propia de futuro. Se trata de construir una visión propia del desarrollo económico y social partiendo de nuestra visión cultural, de nuestras formas tradicionales de producción y de nuestras formas tradicionales de organización social. Consuetudinariamente esta sociedad nos ha impuesto su visión del desarrollo que corresponde a otros intereses y visiones. Tenemos derecho a aportarle a la sociedad ese mundo nuestro tal como lo queremos construir. Somos parte de la lucha que desarrolla el pueblo negro en el mundo por la conquista de sus derechos. Al mismo tiempo, desde sus particularidades étnicas, el movimiento social de comunidades negras aportará a la lucha conjunta con los sectores que propenden por la construcción de un proyecto de vida alternativo. (Grueso, 2000: 73-75)

El siguiente relato el investigador Carlos Agudelo presenta al PCN como una de las organizaciones étnico-territoriales más cualificadas, la que ha tenido más incidencia en la región sur, y la que ha sido forjadora de una base rural amplia y de una proyección política de carácter nacional:

El PCN continúa siendo el sector con más incidencia en las organizaciones étnico-territoriales del Pacífico sur. El PCN es la expresión del movimiento negro con un desarrollo discursivo más elaborado. El énfasis fundamental está en la reivindicación de la cultura negra como elemento central de su identidad y el punto de partida para el ejercicio de sus derechos al territorio, a la autonomía, a la construcción de una visión propia de desarrollo y de relación con la naturaleza. Se insiste en la afirmación de la diferencia y se cuestiona la visión de integración y asimilación a la sociedad global planteada por otros sectores del movimiento negro. Aunque su base social fundamental se encuentra en el área rural, el PCN se plantea como objetivo ser alternativa política de carácter nacional. (Agudelo, 1999, p. 20) 
Dos vivencias de actores locales de la región ilustran algunos de los procesos de acción colectiva que se dieron desde el momento de redacción de la Ley 70 de 1993 hasta la creación de los primeros Consejos Comunitarios. Al respeto, la líder Ana Granja Castillo, oriunda del municipio de Francisco Pizarro, y que pertenece al Consejo Comunitario Acapa, comenta:

Eso era una belleza, nosotros salíamos a recorrido, actualizando el censo, sistematizando las dinámicas tradicionales y productivas. Sin tener plata hicimos el diagnóstico ambiental, el fortalecimiento de la Ley 70. No permanecíamos en casa sino metidas en el río, entonces los otros no tenían espacios cómo meterse, esa fue la parte social que se trabajó. (Granja, 2012, p. 3)

Por su parte, Sebastián Moreno Murillo, oriundo del Bajo Calima, quien actualmente reside en la Colonia Especial, en Buenaventura, y que ejerce como representante del Consejo Comunitario Bajo Calima, resume lo que ha significado para su comunidad el proceso de elaboración y materialización de la Ley 70: "Este ha sido un proceso muy significativo para las comunidades, se nota el cambio que se ha llevado a cabo a través de todo este proceso, la calidad de vida ha mejorado en medio de las dificultades que tiene nuestro país” (Moreno, 2012, p. 1).

El testimonio del investigador Restrepo va más allá de lo expuesto arriba por los líderes, pues cataloga a los procesos que se desencadenaron en la región en este periodo de tiempo como una "revolución étnica":

Bien puede caracterizarse como de 'revolución étnica' lo que sucedió durante los noventa en el Pacífico sur colombiano. Una 'revolución' en el sentido de una transformación radical de las condiciones desde las cuales se articulaban los diferentes sujetos políticos. Una 'revolución' en términos de un cambio sustancial de las modalidades jurídicas desde las que se definían los derechos de propiedad sobre bastas áreas de la región. 
Finalmente, una 'revolución' en cuanto a la economía de visibilidades y las subjetividades puestas en juego con los referentes de la identidad cultural y étnica. No obstante, una 'revolución' pacífica y dentro de los límites de la institucionalidad. Una 'revolución' que involucraba transformaciones radicales, sin duda; pero unas que operaban por fuera de las lógicas de la extrema derecha o izquierda, apostándole a las tendencias hacia la democratización que se perfilaba en el país de los noventa (Restrepo, 2005, p. 6).

Las experiencias de vida presentadas anteriormente y el relato de Restrepo, hoy muy compartido por la visión experta, dan argumentos para señalar que en los primeros años de la década de años noventa se produce un acontecimiento que transforma la acción colectiva del Pacífico sur colombiano. Este es un acontecimiento sin precedente alguno en la historia de este grupo poblacional, en el cual se forjaron vínculos reflexivos en torno a los territorios, a la comunidad y a la vida misma y que otorgaron esperanzas a los pobladores locales de la región del Pacífico para agenciar "planes de bienestar" y "planes de vida” con autonomía, con respaldo jurídico y legitimidad social. Sin embargo, tal escenario rápidamente se transforma, al surgir un tercer acontecimiento central para los procesos de acción colectiva, y que emerge hacia finales de la década del noventa y principios del nuevo siglo, y que va hasta nuestros días: la exacerbación del conflicto armado en el Pacífico sur colombiano.

\section{RUPTURA Y DECLIVE DE LA ACCIÓN COLECTIVA EN EL SUR DEL PACÍFICO COLOMBIANO: LA EMERGENCIA DEL CONFLICTO ARMADO}

El Pacífico colombiano, en especial el sur, se había considerado desde los relatos de expertos hasta entrada la década de los años noventa como un "remanso de paz" (Arocha, 1993). Sin embargo, en pocos años los relatos de los investigadores sobre la región han cambiado abruptamente: de ser 
una región catalogada como "remanso de paz" ha pasado a ser representada como "pesadilla de guerra" (Restrepo, 2005), como el lugar de las "geografías del terror y desplazamiento forzado" (Oslender, 2008a).

La experiencia de vida de la líder de Salahonda, municipio de Francisco Pizarro, Ana Granja Castillo, que ha sido una mujer luchadora en los procesos de organización y movilización de las poblaciones asentadas en los territorios colectivos del Consejo Comunitario Acapa, evidencia el papel que en la región sur jugó, en la década de los noventa, la Iglesia en cabeza de la directora de Pastoral Social de la Diócesis de Tumaco, la hermana Yolanda Cerón, en especial en la definición y puesta en marcha de la Ley 70 de 1993. Ana Granja también evoca en su narración de vida uno de los hechos que han marcado la historia de la acción colectiva en el sur del Pacífico: el asesinato de la religiosa Yolanda Cerón. Para la líder Ana Granja, la muerte de la hermana Yolanda Cerón significa, entre otros aspectos, el inicio del declive del proceso organizativo del sur, como ella lo dice: desde ese momento "la tapa se afloja".

Se dice los brazos porque en la cobertura del Consejo Comunitario agarra dos esteros. [...] Entré porque me gustó. A partir de 1991 los colombianos volvieron a saber de nosotros porque estábamos en el limbo, sobre todo para garantizar nuestro derecho a la defensa del territorio. En ese entonces estaba una lideresa que se llamaba Yolanda Cerón, me gustaba mucho lo que ella hacía; hizo un trabajo social en las veredas y con la gente de los ríos. Ella aportó muchísimo al proceso de organización de la Ley 70. Siempre nos decía que nosotros teníamos que liderar los cambios, que esos no venían de afuera. Eso me gustó y me fui metiendo [...]. Cuando es asesinada Yolanda el proceso decae, la tapa se afloja. (Granja, 2012: 2-3)

En el siguiente relato del investigador Restrepo se señala cómo el asesinato de la hermana Yolanda Cerón logra transcender la lógica de un suceso esporádico (hasta ese momento los asesinatos de los líderes 
sociales de la región eran hechos no frecuentes). ${ }^{28}$ Logra trascender la lógica del "olvido" y consigue instalarse en el imaginario colectivo anclado con sentimientos de desesperanza, miedo y desazón frente a la construcción de lo que podrían llegar a ser los territorios colectivos, ahora ya "amparados" por el Estado. Dicho imaginario colectivo, que a la postre redunda en todo lo que sigue y, por supuesto, en la definición de lo que son hoy los procesos de acción colectiva en la región. Por eso, esa tarde del 19 de septiembre de 2001, los ocho "sonidos" de pistola que acabaron con la vida de Yolanda Cerón se erigieron como el punto de inflexión hasta ahora insoslayable para los procesos organizativos del sur del Pacífico colombiano.

El 19 de septiembre de 2001 en horas de la tarde, a pocos metros de la entrada de la iglesia de San Andrés de Tumaco, un sicario disparó a quemarropa ocho veces contra la hermana Yolanda Cerón. Minutos después, moría la religiosa en el hospital. Hacía exactamente un año que los paramilitares habían anunciado su llegada a la ciudad de Tumaco, en el Pacífico sur. No era la primera persona que asesinaban en aras de imponerse, pero con el asesinato de la hermana Yolanda se marcó un hito en el imaginario colectivo y un punto de quiebre en el movimiento organizativo. (Restrepo, 2005, p. 13)

Con el asesinato de la hermana Yolanda Cerón la situación de seguridad para los actores sociales, que impulsaban los procesos organizativos necesarios para hacer realidad los derechos a los títulos colectivos sobre los territorios que habitaban, tal como lo señala la Ley 70 de 1993, se tornó cada vez más preocupante pues el señalamiento, la persecución y

28 El 12 de febrero de 1997 fue asesinado Francisco Hurtado, líder del río Mira y de los procesos organizativos de la población sur, en la vereda Pital Piragua, municipio de Tumaco. Fue asesinado en el momento en el que adelantaba el censo de esta población para la titulación colectiva de las tierras de las márgenes del río Mira (Botero, 2005). 
la amenaza hicieron que muchos líderes y población local fuera objeto de desplazamiento forzado (Restrepo, 2005). Los índices de homicidios se incrementaron vertiginosamente; por ejemplo, solo en Nariño se pasó de tener 18 homicidios en 1994 a 88 en el 2006 (оDHн, 2011). La hipótesis que tiene más aceptación en la región, como se ha dicho, es que estos índices se incrementan debido a las disputas territoriales entre los diferentes actores armados, disputas que no son solo rurales sino que articulan toda la geografía de la zona desde una lógica de guerra, desde una lógica del terror (Oslender, 2008). Las Farc y el ELN otrora usaban estas zonas del país como lugares de descanso y de retaguardia. ${ }^{29}$ Con la llegada del Bloque Libertadores del Sur "comandado" por Guillermo Pérez Alzate, ${ }^{30}$ conocido como "Pablo Sevillano", se inicia una dinámica de "fuego cruzado", fundamentalmente por el control del negocio del narcotráfico. A raíz de la implementación de la política de fumigación con glifosato en el marco del Plan Colombia, el Pacífico sur empieza a ser receptor de los cultivos de coca que se desplazan hasta estas zonas por los efectos ${ }^{31}$ de las fumigaciones con glifosato en los departamentos de Putumayo y Caquetá, principalmente. Solo en Nariño se pasó de un cultivo de 4000 hectáreas de coca en 1999 a 20.000 hectáreas en 2008 (Ávila, 2011).

29 En ese momento la presencia de la guerrilla en la zona no era muy acentuada, utilizaba los territorios del sur para el descanso o el paso. Sin embargo, no dejaba de ser sustituto del Estado, en particular en la regulación de las relaciones sociales de los pobladores. Este fenómeno se presentaba, especialmente, en las zonas aledañas a los municipios de Barbacoas, Iscuandé y Ricaurte (Botero, 2005).

30 Aunque alias "Pablo Sevillano" figuraba en el papel como el principal líder de ese Bloque, el comandante a nivel regional era alias "Julio Castaño", cuyo nombre real sería Rodolfo Useda, y sobre el cual se tiene muy poca información. La comandancia política estaba al mando de alias "Diego Rivera" y la militar de alias "Juan Carlos" (Botero, 2008).

31 Efecto que en la literatura especializada se conoce como "efecto globo". Al respecto Eduardo Pizarro, anota: "La lucha contra la producción de drogas, si se mantiene intacta la demanda, se asemeja a un globo o a un colchón de aire: si se aprieta en un punto el aire se desplaza hacia el otro. Por esta razón, debido a que la demanda de coca no ha disminuido significativamente en los Estados Unidos, en la propia América Latina la reducción de su producción y elaboración conlleva simplemente su traslado a otro territorio debido a su alta rentabilidad" (Pizarro, 2004, p. 187). 
Los relatos sobre desplazamientos forzados en la región empiezan, de manera lamentable, a ser cada vez más cotidianos. Al respecto, la experiencia que vivió el Consejo Comunitario de la Cuenca Baja del río Calima retrata la situación en esta parte de la región sur. Sebastián Moreno, representante legal del Consejo, oriundo del Bajo Calima, comenta al respecto:

Hay un caso especial que nos tocó en esta Cuenca y es que en el año 2003 hubo un desplazamiento masivo [...] que una comunidad que tenía 600 y pico de familias quedaron tres o cuatro familias eso es un desplazamiento masivo, por las disputas de territorios, por el orden público, del grupo armado llámese guerrilla, paramilitares e incluyendo también al Ejército, entonces hubo un desplazamiento ojalá nunca nos vuelva a tocar. (Moreno, 2012, p. 1)

Los recuerdos del líder Mario Riascos, del sector La Gloria, en Buenaventura, hacen visibles algunos procesos que se entrecruzan con las dinámicas del conflicto armado en la región sur: desplazamientos, redesplazamientos, chantajes y resistencias.

Lo primero que ocurre en este país cuando llega una familia desplazada a una comunidad es discriminarla. Y decir este será de la guerrilla o de los paramilitares, o lo desplazaron porque era delincuencia común. Lo estigmatizan, es doloroso, porque yo fui desplazado dos veces de mi comunidad, me tocó dormir en los andenes en la ciudad de Cali. [...] Aquí llegan mestizos, llegan blancos, llegan indígenas. En el momento, en La Gloria viven 120 familias desplazadas. [...] Personas que vienen de Chocó, del río San Juan, del Baudó, de Cajambre, del Calima, de la misma zona urbana de Buenaventura. [...] Un día llegaron unos hombres armados, nosotros no sabíamos que eran paramilitares, hermano, y nos meten a un lugar y nos hacen una reunión. Nos dicen que nosotros teníamos que darle para comprar las balas, y a mí 
eso me dio rabia y le dije: Señor usted parece que es el que manda, sí nosotros le decimos que le vamos a pagar es mentira porque nosotros vivimos de la minería y nosotros lo que conseguimos es para comer pan con agua de panela por la mañana y agua de panela con pan por la tarde, entonces nosotros no le vamos a pagar. Ellos me miraron mal, y gracias a Dios y a una compañera Luz Dary y a una compañera Isaura, que hoy vive en Cali, porque hay mujeres que se amarran más los calzones que varios hombres, la mayoría de los hombres estaban temblando. Entonces, esas dos mujeres les dijeron: Ustedes no miren mal al viejo Mario porque él lo que está diciendo es verdad, mal haríamos en decirles que les vamos a pagar y al fin de mes decirles lo contrario. Entonces qué sucede, como ustedes andan armados nos matan. (Riascos, 2012: 9-10)

Además, está el fenómeno del narcotráfico asociado al conflicto armado. Numerosos estudios coinciden en afirmar que la dinámica del conflicto armado es una estrategia que busca expropiar a las comunidades negras de sus territorios, y así dar vía libre a la inversión transnacional y a la realización de macroproyectos en la región (especialmente mineros, agrícolas y de infraestructura). El relato de la investigadora Espinosa ilustra al respecto:

El argumento central de las organizaciones, que coincide con las investigaciones más recientes (Escobar, 2008; Oslender, 2008; Restrepo, 2005; Castillo, 2007), consiste en concebir el conflicto armado en esta región como una estrategia del capital transnacional, apoyado por inversionistas nacionales y por sectores económicos y políticos dominantes en Colombia, dirigida a desalojar y expropiar a las comunidades negras de sus territorios con el objetivo de utilizarlos para explotación de recursos naturales y la construcción de megaproyectos para fortalecer la capacidad portuaria y de transportes a nivel nacional y continental. (Espinosa, 2011, p. 86) 
Luego de esta breve "semblanza" sobre algunos de los impactos del conflicto armado en la región del Pacífico sur, es pertinente plantear la siguiente tesis: el conflicto armado en esta zona del país ha logrado “agujerear” el "corazón” de los procesos de organización de la gente negra en el sur, a tal punto que se percibe en la zona una desesperanza. Habrá que seguir indagando los resquicios siempre latentes de cambio. A continuación, y cerrando el apartado, es pertinente acercarse a la situación antes descrita desde la vivencia, el recuerdo y la palabra del líder Porfirio Becerra:

Entonces fueron creando tres organizaciones cuando nosotros como Palenque Regional Nariño teníamos toda una fuerza obligando al Estado a hacer cosas para respetarnos. Cuando se hacían las consultivas nosotros movilizamos al gobernador al Charco, a Satinga. Allá tenía que ir, donde nosotros decíamos. Ahora no, por allá no van, no se percatan de las cosas locales. Lo otro fue que a partir de 1997 hacia acá, que ha sido más cruel, es la vinculación del narcotráfico en serio acá y los grupos alzados en armas, se meten al centro de los territorios y los explotan comienzan a realizar la diáspora marina. (Becerra, 2012, p. 9)

\section{A MANERA DE APERTURAS}

Hasta aquí se ha tratado de presentar algunos rasgos que se consideran significativos de los procesos de acción colectiva desatados en los últimos tiempos en el Pacífico sur colombiano. Se mencionaron algunas características de los procesos de acción colectiva que se registraron como "atisbos" de la organización de los pobladores locales de la región antes de la proclamación de la nueva Constitución Política del país. El papel de la lucha campesina, la reivindicación del ser negro en el contexto nacional, la labor de la Iglesia y las protestas ciudadanas fueron algunos de los antecedentes señalados. Se presentó como hito central de la movilización negra, la década de los años noventa del siglo pasado, 
cuando las organizaciones de otrora recibieron el impulso del "discurso de la etnización" auspiciado con la nueva Carta Magna, y en particular con la elaboración y puesta en marcha de la Ley 70 de 1993. En este proceso, las poblaciones asumieron nuevas posiciones de sujeto, nuevas subjetividades a la hora de identificarse como pobladores del sur del Pacífico. Así, "surgen” y conviven diversas nominaciones y subjetividades como las de campesinos, campesinos negros, negros, entre otras, lo cual será motivo de otro trabajo. En el siguiente ámbito de descripción se mostró lo que ha significado el recrudecimiento del conflicto armado para esta zona del país. El litoral sur del Pacífico en pocos años pasó de ser catalogado como "remanso de paz" a "pesadilla de guerra", dinámica que ha implicado, entre otras cosas, la ruptura de los procesos iniciados y la desarticulación de la movilización organizativa en estos territorios. Por último, cabe señalar la necesidad de rastrear con mayor profundidad estos procesos narrados, de la mano, quizá, del enfoque triádico utilizado: los relatos, las vivencias y los acontecimientos. Un camino que se vislumbra, en este sentido, es el de indagar por los discursos dominantes que subyacen a la hora de definir y actuar en y sobre la región del Pacífico sur, así como por aquellos discursos que se presentan como subalternos, y que, por medio de manifestaciones poco visibles en contextos de modernización de la vida social, fundan resistencia y fundan otras subjetividades que quizá ancladas a la vida puedan tocar ese "corazón" de otra manera a como lo hizo el conflicto armado. Otras maneras que busquen "revivirlo", que busquen "revivir" los procesos organizativos de la población del Pacífico sur colombiano.

\section{BIBLIOGRAFÍA}

Acevedo, Á., \& Castaño, S. (2001). El Frente Nacional: una reflexión histórica de su legitimidad política. Revista de Ciencias de Ciencias Humanas, 28. Agudelo, C. (1999). Política y organización de poblaciones negras en Colombia. En: C. Agudelo, O. Hoffmann \& N. Rivas, Hacer política en el Pací- 
fico sur: algunas aproximaciones. Proyecto CIDSE-IRD, documento de trabajo número 39. Universidad del Valle, Cali.

Almario, O. (2001). Tras las huellas de los renacientes. Por el laberinto de la etnicidad e identidad de los grupos negros o 'afrocolombianos' del Pacífico sur. En: M. Pardo (ed.), Acción colectiva, estado y etnicidad. ICANH, Bogotá.

Aprile-Gniset, J. (1993). Poblamiento, hábitats y pueblos del Pacífico. Universidad del Valle, Cali.

Archila, M. (2003). Idas y venidas, vueltas y revueltas: protestas sociales en Colombia 1958-1990. CINEP e ICANH, Bogotá.

República de Colombia, Asamblea Nacional Constituyente. (1991). Constitución Política de Colombia. Legis, Bogotá.

Asociación Nacional de Usuarios Campesinos. (1970). Acta de constitución. Disponible en: http://anuc.co/dynamicdata/historia.php

Badiou, A. (2007). El ser y el acontecimiento. Manantial, Buenos Aires.

BAGÜI, D. (2012). Entrevista realizada el 16 de marzo. Tumaco, Colombia.

BARThes, R. (1977). Introducción al análisis estructural de los relatos. En: S. Niccolini (comp.), El análisis estructural. Centro Editor de América Latina, Buenos Aires.

Becerra, P. (2012). Entrevista realizada el 21 de marzo. Tumaco, Colombia.

Botero, F. (2005). De negros a Afros. Ley 70, poder e identidades negras en el Pacífico sur de Colombia. Editorial Nuevo Milenio, Medellín.

BouCHARD, J. (2003). Estudio arqueológico del sitio El Morro: un puerto prehispánico en la costa del Pacífico norecuatorial (departamento de Nariño, Colombia). Revista Española de Antropología Americana, 207-230.

Departamento Administrativo Nacional de Estadística. (2005). Censo de 2005. DANE, Bogotá.

Domínguez, M. (s.f.). Los procesos de resistencia al conflicto armado y al desplazamiento forzado por parte de pobladores rurales afrocolombianos en el municipio de Buenaventura. Disponible en: http://biblioteca.clacso. edu.ar/ar/libros/.../domínguez\%20mejía\%20artículo.doc

Durán, A. (2012). Un acercamiento metodológico al Pacífico sur colombiano. Documento inédito. 
Escobar, A. (1997). Política cultural y biodiversidad. Estado, capital y movimientos sociales en el Pacífico colombiano. En: M. Uribe \& E. Restrepo (eds.), Antropología en la modernidad: identidades, etnicidades y movimientos sociales en Colombia. ICANH, Bogotá.

Espinosa, A. (2011). Activismo global: nuevas rutas de acción colectiva del movimiento negro en Colombia. Revista Universitas Humanística, 72, 211-245.

Granja, A. (2012). Entrevista realizada el 18 de marzo. Salahonda, Colombia.

Grueso, L. (2000). El proceso organizativo de comunidades negras en el Pacífico sur colombiano. Pontificia Universidad Javeriana, Cali.

Guber, R. (2006). La etnografía. Método, campo y reflexividad. En: Enciclopedia Latinoamericana de Sociocultura y Comunicación. Grupo Editorial Norma, Bogotá.

(1997). Desencuentros en la costa: la construcción de espacios y sociedades en el litoral Pacífico. Centro de Investigaciones y Documentación Socioeconómica, Cali.

(1999). ¿La política" vs. "lo político"? La estructuración del campo político contemporáneo en el Pacífico sur colombiano. En: C. Agudelo, O. Hoffman \& N. Rivas, Hacer política en el Pacífico sur: algunas aproximaciones. Proyecto CIDSE-IRD, Documento de trabajo número 39. Universidad del Valle, Cali.

Jelin, E. (1994). ¿Ciudadanía emergente o exclusión? Movimientos sociales y oNG en los años noventa. Revista Mexicana de Sociología, 4, 91-108.

Laranjeira, S. (1990). Classes e Movimentos Sociais na América Latina. Hucitec, São Paulo.

LEAL, C., \& Restrepo, E. (2003). Unos bosques sembrados de aserríos. Historia de la extracción maderera en el Pacífico colombiano. Editorial de la Universidad de Antioquia, Medellín.

McAdam, D., McCarthy J., \& Zald, M. (1999). Movimientos sociales: perspectivas comparadas. IstMo, Madrid.

Melucci, A. (1999). Acción colectiva, vida cotidiana y democracia. Editorial del Colegio de México, Centro de Estudios Sociológicos, México: 
Moreno, S. (2012). Entrevista realizada el 29 de enero de 2012, La Colonia Especial. Buenaventura, Colombia.

Оваndo, G. (2012). Entrevista realizada el 6 de diciembre de 2012. Tumaco, Colombia.

Observatorio de Procesos de Desarme, Desmovilización y ReintegraCIón. (2012). Presencia de organizaciones guerrilleras y 'Bacrim' en territorio colombiano. Universidad Nacional de Colombia, Bogotá.

(2011). Caracterización del departamento de Nariño. Universidad Nacional de Colombia, Bogotá.

Observatorio del Programa Presidencial de Derechos Humanos y Derecho Internacional Humanitario. (2009). Dinámica reciente de la violencia en la costa Pacífica nariñense y caucana y su incidencia sobre las comunidades afrocolombianas. Abba \& Magenta Grupo Creativo, Bogotá.

Oslender, U. (2008). Comunidades negras y espacio en el Pacífico colombiano. Hacia un giro geográfico en el estudio de los movimientos sociales. Instituto Colombiano de Antropología e Historia, Universidad Colegio Mayor de Cundinamarca y Universidad del Cauca, Bogotá.

. (2008a). Geografías del terror: un marco de análisis para el estudio del terror. Revista Electrónica de Geografía y Ciencias Sociales, Scripta Nova, XII(270), 144. Disponible en: http://www.ub.es/geocrit/ sn/sn-270/sn-270-144.htm

Pedrosa, A. (1996). Paisaje y cultura. En: A. Pedrosa \& A. Escobar (eds.), Pacífico: ¿desarrollo o diversidad? Estado, capital y movimientos sociales en el Pacífico colombiano. CEReC y Ecofondo, Bogotá.

Pizarro, E. (2004). Una democracia asediada. Balance y perspectivas del conflicto armado en Colombia. Norma, Bogotá.

Restrepo, E. (2004). Biopolítica y alteridad: dilemas de la etnización de las Colombias negras. En: E. Restrepo \& A. Rojas (eds.), Conflicto e (in) visibilidad. Retos en los estudios de la gente negra en Colombia. Universidad del Cauca, Cauca.

- (2005). De 'refugio de paz' a la pesadilla de la guerra: implicaciones del conflicto armado en el proceso organizativo de 'comunidades negras' 
del Pacífico nariñense. Informe de la División de Antropología Social. ICANH, Bogotá.

Riascos, M. (2012). Entrevista realizada el 25 de enero de 2012. La Gloria, Buenaventura, Colombia.

Rivas, N. (2001). Ley 70 y medio ambiente. El caso del Consejo Comunitario Acapa, Pacífico nariñense. En: M. Pardo (ed.), Acción colectiva, estado y etnicidad. ICANH, Bogotá. (1999). Prácticas espaciales y construcción espacial en el Pacífico nariñense: el río mejicano, municipio de Tumaco. Cuadernos CIDSE-IRD, Cali.

Romero, J. (1999). Geografía económica del Pacífico colombiano. Banco de la República, Cartagena.

Romero, M., Galindo, G., Otero, J., \& Armenteras, D. (2004). Ecosistemas de la cuenca del Orinoco colombiano. Instituto de Investigación de Recursos Biológicos Alexander von Humboldt, Bogotá.

Schuster, F., Naishtat, F., Nardacchione, G., \& Pereyra, S. (2005). Tomar la palabra. Estudios sobre protesta social y acción colectiva en Argentina contemporánea. Prometeo Libros, Buenos Aires.

VAn Dijk, T. (2000). El discurso como estructura y proceso. Editorial Gedisa, Barcelona.

Viloria, J. (2007). Economía del departamento de Nariño: ruralidad y aislamiento geográfico. Banco de la República, Cartagena.

WADE, P. (2004). Los guardianes del poder: biodiversidad y multiculturalidad en Colombia. En: E. Restrepo \& A. Rojas (eds.), Conflicto e (in)visibilidad. Retos en los estudios de la gente negra en Colombia. Universidad del Cauca, Cauca. 


\title{
TRANSFORMACIONES Y TENDENCIAS DE LA ACCIÓN COLECTIVA EN EL ESTADO DE VERACRUZ: 1997-2010
}

\author{
Martin G. Aguilar SÁNChez
}

\section{TENDENCIAS DE LA ACCIÓN COLECTIVA EN MÉXICO}

La relación entre la acción colectiva y el sistema político en México tiene una larga historia. Especialmente si nos referimos al periodo en que el sistema autoritario fue predominante durante los años de 1940-2010. Como sabemos, el sistema mexicano se estructuró a partir de un partido hegemónico: el Partido Revolucionario Institucional (PRI), que subordinó a organizaciones de masas al sistema presidencialista, es decir, aquel en el que el presidente de la República ejercía un poder ilimitado sobre el Estado y la nación.

Sus raíces históricas se remontan varías décadas atrás y tuvieron su máximo desarrollo entre 1940-1982, período en el cual los movimientos sociales enarbolaron diversas reivindicaciones y donde resolverlas implicaba encontrar los canales de negociación con el partido hegemónico (PRI) e incluso adherirse a él. Es por ello que las demandas de los movimientos sociales se politizaban (Aguilar, 2009).

El proceso de liberación política se aceleró de 1982 a 1997, etapa en la que el PRI y sus organizaciones se adaptaron escasamente a los cambios que se estaban desarrollando, mientras que los movimientos sociales fueron más eficaces en la lucha por sus demandas. Los actores de los movimientos sociales de entonces tenían una concepción de la democracia no limitada a procesos electorales y de alternancia política, sino

\footnotetext{
Instituto de Investigaciones Histórico-Sociales de la Universidad Veracruzana.
} 
una perspectiva más amplia, donde los derechos de los ciudadanos representan el eje central tanto de la sociedad como de la vida económica, política y cultural (Harvey, 2000; Zermeño, 1996).

La relación entre los movimientos sociales y el sistema político es muy compleja. Para conocerla no es suficiente medir su impacto y analizar cómo los movimientos sociales entran y salen del sistema político, sino comprender cómo y por qué se origina este proceso y el tipo de transformaciones que producen. A partir de los años noventa, en la acción colectiva en México se aprecia una fragmentación de los movimientos sociales. Este fenómeno es en gran parte el producto de la consolidación del modelo neoliberal; a la par, sucedió una pérdida de identidad de algunos movimientos, como el obrero o el campesino, y emergieron movimientos sectoriales y regionales. La sociedad mexicana se diversificó y se expresaron además nuevos tipos de organizaciones como las feministas, de homosexuales, de pequeños propietarios, de ecologistas, entre muchas otras.

Se evidencia entonces la transformación del viejo esquema y la formación de otro proceso: los movimientos centrales abren paso a movimientos interclasistas y a otros movimientos fragmentados que, en apariencia, determinan poco los cambios del sistema político. La fragmentación ideológica de los movimientos tiende a construir en la sociedad civil una opinión pesimista que supone que, a falta de movimientos centrales, los cambios al interior del sistema político no pueden ser profundos y sólidos. Bajo dicha premisa, el sentido común simplifica los procesos de transformación que vive la sociedad mexicana: el aumento de población y el crecimiento urbano, la liberalización de los medios de comunicación o la permanente demanda de los ciudadanos por el respeto de los derechos ciudadanos; exigencias todas de un proceso de democratización que se refleja en los diferentes medios y sectores y que se expresa en transformaciones locales y regionales.

Esta crisis del viejo modelo coincide, por un lado, con la consolidación del modelo neoliberal, caracterizado por una desregulación econó- 
mica, la ubicación de transnacionales en los diferentes territorios y la transformación del papel del Estado nación a un Estado impactado por la globalización y por la aparición de nuevas organizaciones sociales y nuevas prácticas políticas. Por ello, en México los movimientos sociales que nacen a partir de los años ochenta se reagrupan alrededor de la defensa de los derechos humanos y se insertan en una doble dinámica: luchan por extender la apertura del sistema político y resisten los efectos de la economía neoliberal que repercuten en las condiciones de vida de los distintos actores sociales. Al mismo tiempo, lo anterior produce un complejo proceso: por una parte, la transición a la democracia abre un espacio en el que se insertan los movimientos sociales, y de manera más amplia la acción colectiva, que participan en la democratización del sistema político; por otra parte, una tendencia del sistema económico a reforzar la exclusión de las clases sociales más necesitadas.

En el estricto análisis de los movimientos sociales, durante el periodo de 1950 al año 2000 observamos profundos cambios en el modelo de la acción colectiva. Por ejemplo, en el periodo que va de 1958 a 1982, cuando todavía funcionaba el llamado modelo de sustitución de importaciones y las etapas más sólidas del sistema autoritario, encontramos intensos movimientos centrales, como el ferrocarrilero, el estudiantil de 1968, el de los electricistas de 1976, por mencionar solo algunos. Estos movimientos respondían al momento de desarrollo industrial del país y a las condiciones políticas más autoritarias. Una de las características de estos movimientos fue representar a sectores muy importantes de la sociedad mexicana e impactar amplios sectores de la misma. Las ideologías de estos movimientos se enmarcaban en una ideología marxista y nacionalista. Para este momento, la estructura de oportunidades políticas era sumamente cerrada y el Estado reprimía abiertamente a dichos movimientos.

En el periodo que va de 1982 a 1990, se inicia una transición de tales movimientos hacia los sectoriales y aparecen las llamadas Coordinadoras. Cambian también las ideologías, transitan de una ideología 
marxista-nacionalista, a otra nacionalista democrática, debido en gran parte a la crisis de los países del bloque socialista y del marxismo ortodoxo. El Estado inicia también una gradual apertura dentro de la estructura política, por ejemplo sobre el movimiento urbano-popular o el movimiento cívico popular, ya que en el Estado se generan ciertas negociaciones que incluyen a veces represión selectiva. En cambio, en el período que va de 1990-2000 encontramos, a excepción del movimiento zapatista de ideología revolucionaria, movimientos como el del Barzón, el estudiantil, el campesino, el feminista, etc., con una ideología nacionalista y democrática, siendo movimientos sectoriales por constitución y muchos de ellos de carácter regional. Ante esto, el Estado tiene una mayor apertura que se expresa en una actividad reguladora. Lo descrito anteriormente está enmarcado también en el contexto internacional, donde las olas democráticas se imponen a los Estados autoritarios en América Latina (Aguilar, 2009).

Durante el periodo 2000-2010 se multiplicaron los movimientos y las protestas regionales, como ejemplos tenemos el movimiento de la APPo en el estado de Oaxaca, "el campo no aguanta más”, que fue más intensa en algunas regiones; por su parte, el movimiento zapatista intenta articular algunas luchas indígenas y campesinas en el periodo 2000-2006, sin lograr su cometido; permanecen también los plantones y las protestas de los trabajadores electricistas despedidos de la empresa Luz y Fuerza del Centro.

Sin embargo, las protestas sociales que van formando un movimiento social de carácter nacional son aquellas que se manifiestan contra la inseguridad, especialmente de fenómenos como el secuestro y extorsión, como han sido algunas expresiones de las clases medias y altas. ${ }^{1}$

1 El periodo del gobierno presidencial de Felipe Calderón 2006-2012 se caracterizó porque el eje central fue el combate contra el narcotráfico; sin embargo, su estrategia ha sido cuestionada por falta de coherencia ya que diversificó los cárteles y debido a una constante violación a los derechos humanos de parte del ejército 
En el año 2011 se constituye el Movimiento por la Paz con Justicia y Dignidad que coordina el poeta Javier Sicilia y que ha emprendido dos caravanas, una nacional y otra en parte del territorio de los Estados Unidos, con el objetivo de visibilizar la gravedad del problema de la inseguridad y el narcotráfico en nuestro país.

\section{VERACRUZ Y EL MODELO DE ACCIÓN COLECTIVA}

En el estado de Veracruz se resintió el impacto de la reestructuración económica de los años ochenta. Transitar de un modelo agroexportador, donde los productos primarios como el café, la caña, la naranja o, la ganadería, así como la extracción del petróleo eran el centro del crecimiento económico de Veracruz, a un modelo de impulso a empresas de alta tecnología y maquiladoras generó muchos problemas. Se abandonaron prácticamente los estímulos económicos al campo y se comenzó un proceso de reestructuración industrial que implicó inversiones en sectores estratégicos: industria portuaria, petróleo y petroquímica, Tenaris Tamsa, etc., pero con severos cambios en las relaciones obrero patronales y en las condiciones de flexibilidad del trabajo.

En el ámbito rural se observan, desde 1970, movimientos independientes como la Unión Campesina Independiente en la región de Atzalan y Misantla, el Timocepanotoke Noche Altepeme Macehualme (Tinam) en la región de Zongolica, el Movimiento de 400 Pueblos, la Organización Independiente de Pueblos Unidos de las Huastecas (оIPUH) en la Huasteca. Hasta finales de los años ochenta estas organizaciones tuvieron una demanda central que fue la lucha por la tierra, y en ciertas coyunturas políticas lograron interactuar vinculadas a las coordinadoras nacionales, concretamente a la Coordinadora Plan de Ayala (Amezcua, 1990).

hacia diversos sectores. Algunas fuentes estiman que el saldo de muertos durante dicho gobierno se acerca a los 50.000 muertos, entre narcotraficantes, soldados, militares y ciudadanos. 
Por otra parte, en el sector industrial observamos, en los años ochenta, radicales transformaciones que impactaron a los trabajadores de las industrias; por ejemplo, el cierre del Instituto Mexicano del Café (Inmecafé), lo cual llevó a reorientar la política cafetalera nacional y al despido de cientos de trabajadores que laboraban atendiendo a este sector, el cierre de la azufrera Panamericana y la Compañía Exploradora del Istmo (CEDI) debido, entre otros aspectos, a los cambios de precios internacionales así como a los cambios tecnológicos, que afectaron a los trabajadores pues se cerraron sus fuentes de trabajo.

A finales de la década de los ochenta, la industria textilera veracruzana, situada en el corredor de Orizaba-Ciudad Mendoza, vivió uno de sus peores momentos al no poder competir en el mercado internacional. Esto la obligó a cerrar algunas de las fábricas e importantes fuentes de empleo y a trabajar a su mínima capacidad, por la cual se realizaron numerosos despidos. Esta década fue crítica para el sector de los trabajadores de la industria portuaria, y en Tenaris Tamsa fueron despedidos trabajadores debido a las repercusiones de la reestructuración de las relaciones laborales; tanto es así, que impactó las formas tradicionales de vinculación del sindicalismo. Algo parecido sucedió en el sur de Veracruz con la industria petrolera y la petroquímica. Por un lado, el control sindical bajo la hegemonía de Joaquín Hernández Galicia, "la Quina”, se terminó en el gobierno de Carlos Salinas de Gortari y esto llevó a una restructuración de la industria petrolera teniendo como uno de sus resultados despidos masivos en dicha industria, lo cual afectó principalmente a los trabajadores transitorios. Ligado a estos cambios, se inicia un lento proceso tendiente a la privatización de esta industria, el cual llegó a su momento más álgido en el 2008, cuando se debatió a nivel nacional el futuro de la industria petrolera y petroquímica.

A finales de los años ochenta y principios de la década de los noventa, en Veracruz se vivió un momento álgido en el movimiento urbano-popular, especialmente en las ciudades principales, como Xalapa, Veracruz y Coatzacoalcos. Organizaciones independientes como la Unión de Colo- 
nos, Inquilinos y Solicitantes de Vivienda en Veracruz (UCISver), ${ }^{2}$ la Organización de Colonos Solicitantes de Tierras de Veracruz (ocosov) o la Federación de Inquilinos de Veracruz, ${ }^{3}$ se manifiestan y demandan espacios urbanos y viviendas ante el crecimiento desordenado de estas ciudades. Xalapa, por ejemplo, impactada por la migración del interior del estado, es donde el movimiento urbano, principalmente el de la UCIsVER, logra influir en la construcción de una política ciudadana que lleva a dotar de servicios a importantes colonias populares. A diferencia de los movimientos del área rural, el movimiento urbano tiene, en distintos momentos, políticas exitosas pues consiguió diversos tipos de recursos, entre ellos financiamientos para la construcción de casas. Sin embargo, a finales de los años noventa el movimiento urbano popular se fragmenta y se debilita tanto por propias causas como por la política del Estado de dotar a ciertas colonias de servicios mínimos, con lo cual resta protagonismo a las organizaciones mencionadas. Como muestra de uno de los movimientos que anunciaba un nuevo esquema en la acción colectiva, en el periodo de los años ochenta se inicia el movimiento en contra de la planta de Laguna Verde, ${ }^{4}$ el cual movilizó a ciudadanos tanto del estado como del país; a partir de él se articula, en la siguiente década, la red de sectores ecologistas.

2 La Unión de Colonos, Inquilinos y Solicitantes de Vivienda en Veracruz (UCISVER) surge en 1984 como una organización comunitaria cuyas principales demandas eran poder acceder a la regularización del suelo, a servicios básicos y viviendas dignas. Esta organización tiene presencia en las principales ciudades del estado como Xalapa, Veracruz, Poza Rica y Coatzacoalcos.

3 Robles Guadarrama, Fidel. (2009). La UCISVER: Una experiencia urbano-popular de línea de masas en Veracruz (1984- 2000). Tesis de Licenciatura. México: Universidad Veracruzana.

4 El movimiento en contra de la Planta Nuclear Laguna Verde comenzó en 1987, aún cuando la planta estaba en proceso de construcción, promovido por ciudadanos y diversos grupos ecologistas, como el Movimiento Ecologista Antinuclear Veracruzano y el de las Madres Veracruzanas. Dichos grupos cuestionan el funcionamiento de la planta, la falta de medidas de seguridad, el peligro que representa para el medio ambiente y los pobladores y el manejo de los desechos radioactivos. Actualmente, el grupo de Madres Veracruzanas sigue manifestándose cada sábado desde hace 23 años en la Plaza Lerdo de la ciudad de Xalapa para solicitar el cierre de la planta nucleoeléctrica. 
Estos ejemplos nos sirven para reflexionar sobre cuáles fueron las principales características del modelo de la acción colectiva en Veracruz. Un modelo centrado en el área rural, en la demanda de tierras principalmente y en la vinculación con coordinadoras nacionales; en el sector industrial, una transformación radical en las relaciones laborales, lo cual llevó a una crisis de los modelos de sindicalismo, a un espacio de reconstrucción obrera y a un movimiento urbano vigoroso, que es fragmentado por las políticas estatales.

En el período 1997- 2010 encontramos algunas redes de movimientos sociales constantes, como las protestas en el sector indígena, en el sector ecologista y en el movimiento obrero; y en los últimos años, existen protestas aun incipientes por la violencia generada por la delincuencia organizada.

\section{PROTESTAS Y MOVIMIENTO INDÍGENA}

Sobre el movimiento indígena en Veracruz podemos plantear algunas características. La primera de ellas es que permanecen las organizaciones formadas en los años setenta y ochenta, cuya demanda central fue la lucha por la tierra, aunque en la actualidad la demanda de tierras ha pasado a segundo plano. Sus demandas transitan desde la regularización, la gestión de servicios y proyectos productivos hasta la defensa de los derechos humanos. Como ejemplo tenemos al tinam, la Coordinadora Regional de Organizaciones Indígenas de la Sierra de Zongolica (Croisz), el Frente Popular del Sur de Veracruz (Freposev) y la oipuH. ${ }^{5}$

5 Estas organizaciones se formaron durante los años setenta y ochenta en torno a problemáticas comunes como son la defensa de los derechos indígenas, la lucha contra la tala clandestina de árboles y aquellas relacionadas con la pobreza extrema, como el analfabetismo y el alcoholismo. En sus inicios las organizaciones fueron duramente hostigadas por el gobierno y sufrieron situaciones de represión, encarcelamientos injustificados, confrontaciones con la policía e intentos de desintegración. Actualmente las organizaciones centran su actividad en la gestión de proyectos productivos. 
En 1997, la CROIsz inició una movilización en la sierra de Zongolica para protestar contra los abusos de la Policía y las columnas volantes contra los indígenas de la región. Estos tipos de denuncias también las hizo el TINAM y la ocisz, la CROIsz movilizó cerca de mil indígenas que retuvieron a cinco policías como protesta por los abusos que estos cometían en la zona. Después de varios sucesos, entre ellos el encarcelamiento por algunos días del dirigente Julio Atenco, el gobierno de Patricio Chirinos llegó a una negociación con esta organización. En la zona norte del estado, la OIPUH emprendió un conjunto de movilizaciones en varios municipios de Hidalgo y Veracruz para protestar por la militarización de la región y por la liberación de presos que ellos consideraron políticos. Esta denuncia la hicieron en el contexto de una campaña llamada "Por una elección sin presos políticos". 6

FREPOSEV es una organización que funciona como una especie de coordinadora de algunas organizaciones en la región de Soteapan, y que se activa coyunturalmente.

En el periodo que va de 1997 al 2007 desarrolla algunas acciones para establecer vínculos de solidaridad entre organizaciones como los comités de la Defensa Popular de Zaragoza, Cosoleacaque y Oteapan y algunos ayuntamientos democráticos. En los últimos cinco años el FREPOSEv ha apoyado y promovido, en la región, la resistencia al pago de las tarifas eléctricas que hasta la fecha se mantiene en varias comunidades como Tatahuicapan, Zaragoza, Oteapan, Huazuntlan y Pajapan, principalmente.

Otra característica del periodo la podemos situar en el impulso que varias redes indígenas y campesinas han dado a la creación de nuevos municipios, como fueron los ayuntamientos en el Uxpanapa, en Sochiapan y en Tatahuicapan. En los tres casos, la demarcación del territorio y la gestión de servicios fueron una constante. Asimismo, para lograr la constitución de nuevos municipios se registran largas

$6 \quad$ La Jornada, 16 de junio de 1997. 
luchas sociales. Por ejemplo, en el caso del Uxpanapa, ${ }^{7}$ se creó el Consejo Indígena de Uxpanapa (CIUX), integrado por indígenas de diez poblados. Este consejo planteó un conjunto de necesidades de la población indígena entre los que se encontraban dos básicos: la terminación del rezago agrario y servicios como electricidad y abasto de alimentos. A estas demandas se les sumó la que detonaría una fuerte movilización de los pueblos, como fue separarse del municipio de Minatitlán y la creación de uno nuevo. La confrontación con el gobierno del estado fue permanente, pues el gobernador quería crear un nuevo municipio en uno de los poblados donde el Consejo Indígena no tenía adeptos, aprovechando las contradicciones internas que se podían dar en los trece poblados del Uxpanapa. Sus principales dirigentes fueron encarcelados en 1997 y después liberados. ${ }^{8}$

Algo parecido sucedió en Sochiapan, perteneciente anteriormente al municipio de Playa Vicente. En Sochiapan se creó el Movimiento Promunicipio Libre de Santiago Sochiapan que, en términos prácticos, se separó de Playa Vicente en el 2001 eligiendo a Andrés Cano como el primer alcalde autónomo en el periodo de gobierno de Miguel Alemán. ${ }^{9}$ El 25 de diciembre del año 2000, ante la negativa de los poderes Ejecutivo y Legislativo del gobierno del Estado de aprobar la formación de un nuevo municipio, 67 comunidades principalmente indígenas (chinantecos, zapotecos, mixes, náhualts y popolucas) se constituyeron en asamblea popular y decretaron el nuevo municipio de Sochiapa. “También formaron comisiones y direcciones administrativas en Sochiapa y una nueva policía municipal [...] y la agencia ejidal que fue habilitada como palacio municipal". ${ }^{10}$

\footnotetext{
7 La región de Uxpanapa se conforma a inicios de los años setenta con el reacomodo de grupos indígenas y campesinos de los estados de Oaxaca y Veracruz que fueran afectados por la construcción de la presa Cerro de Oro.

8 La Jornada, 12 de febrero de 1997.

9 La Jornada, 21 de julio de 2001.

10 La Jornada, 13 de enero de 2001.
} 
En este proceso de construcción de un nuevo ayuntamiento confluyen distintos elementos: las contradicciones entre nuevos actores locales, como los ganaderos indígenas en ascenso; contradicciones políticas y demandas por definición del territorio. El proceso de aprobación del nuevo ayuntamiento se dio en un ambiente de presiones y violencia que terminó con una formalización de un hecho de facto: la creación del municipio.

La creación del municipio de Tatahuicapan fue similar. La consolidación de un grupo de actores en el escenario político del lugar, indígenas formando una red autónoma del PRI, los maestros rurales con una influencia tradicional y la diferencia con los grupos políticos indígenas de Mecayapan llevaron a emprender una lucha social por la autonomía de Tatahuicapan. ${ }^{11}$ Existen varios estudios que detallan este proceso, solo diremos que la movilización indígena y la presión que ejercieron a través del agua que Tatahuicapan distribuye a otras localidades, fueron utilizados para lograr este objetivo. Lo que nos interesa resaltar en el periodo que va de 1997 al 2010 es, que la creación de nuevos municipios de ascendencia indígena generó múltiples movilizaciones y confrontaciones locales y contra el gobierno estatal por la apropiación del territorio.

Por último, una constante que encontramos en este mismo periodo es una protesta de distintas organizaciones sociales indígenas contra la militarización de las regiones con numerosa presencia indígena, lo cual ha ocasionado una permanente violación al libre tránsito. Por ejemplo, las agrupaciones MAIZ, CROISZ, OCIZ, TINAM, OIPUH y también el FREPOSEV, como registramos en el aparatado anterior, denunciaron el incremento de policías, columnas volantes y la intervención de militares en estas regiones. ${ }^{12}$

11 Entrevista con Esteban Bautista Hernández, presidente municipal de Tatahuicapan de Juárez (julio de 2009).

12 Entrevista con Maurilio Tzopil, Tequila, Ver. (junio de 2009). 
Caracterizadas estas regiones como las de mayor pobreza, ${ }^{13}$ el Estado ha argumentado para la inserción de militares, la existencia de grupos guerrilleros y de narcotráfico. A partir de la aprehensión en Guerrero de una militante del EPR, que había pertenecido a algunas organizaciones indígenas de la región, al igual que las explosiones de bombas caseras en ductos de petróleo en la zona de Orizaba, el Estado incrementó el número de militares en estas regiones, con lo cual ocasionó, por su parte, constantes violaciones a los derechos humanos. El caso más conocido fue la muerte de la indígena Ernestina Ascencio que, según reportes médicos iniciales, fue violada por los militares, versión que no fue aceptada por el gobierno estatal.

\section{LAS PROTESTAS POR EL DETERIORO DEL MEDIO AMBIENTE: EL ECOLOGISMO}

Por otra parte, uno de los sectores que se expresan en el estado de Veracruz de manera vigorosa son las redes y grupos ecologistas. Desde 995, a la fecha, ha habido numerosas protestas en contra de acciones que deterioran la ecología de la región. En Veracruz hemos observado un enorme deterioro, por ejemplo, debido a la contaminación de ríos, la tala de bosques para la ganadería, ${ }^{14}$ proyectos carreteros que alteran los ecosistemas, así como masivos derrames de petróleo producidos por una desestructurada política petrolera. Estas son algunas de las causas manifestadas a lo largo del estado, protestas a veces espontáneas y otras organizadas por grupos con interés en conservar el medio.

Después del movimiento antinuclear contra la Planta Laguna Verde, encontramos a finales del sexenio del gobernador Miguel Alemán un cre-

13 Entrevista con Julio Atenco Vidal, Orizaba, Ver. (junio de 2009).

14 Según el investigador Hipólito Rodríguez “[...] se estima que los cambios más drásticos abrían ocurrido en las llanuras de Veracruz y Tabasco, la sierra sur de Chiapas y el norte de Yucatán donde casi la totalidad de la vegetación original habría sido eliminada para dedicar el terreno a la cría de ganado o a la agricultura... ("Historia ambiental de Veracruz". Historia general de Veracruz, p. 594). 
ciente movimiento contra el segundo intento de construcción del libramiento para la zona conurbana Banderilla-Xalapa-Coatepec. ${ }^{15}$ El proyecto gubernamental estimularía principalmente el comercio de larga distancia entre el Golfo y el Pacífico y además desviaría un excesivo parque vehicular hacia Perote. La propuesta era parte del Programa Carretero Regional Gran Visión y era impulsada por empresarios jalapeños que veían en este proyecto una oportunidad de lucro.

Una red de grupos ecologistas y comunidades se opusieron al proyecto argumentando, a través de estudios hechos por especialistas y campesinos de la región, que el libramiento pondría en riesgo los sistemas ecológicos regionales como lo son el bosque de niebla, los cafetales de sombra y los manantiales que proveen de agua a miles de habitantes. La información sobre los estragos ambientales que causaría el proyecto se posicionó en la opinión pública e impactó a amplios sectores sociales de la región, con lo cual se logró un mayor nivel de movilización. El movimiento cobró tal fuerza que las autoridades estatales admitieron que la construcción del libramiento provocaría un impacto ambiental negativo, por lo que el proyecto del libramiento Trazo Sur fue cancelado y situado en la zona norte.

Esta misma red de ecologistas ha iniciado diversas protestas contra la utilización del predio La Joyita como un espacio para la construcción de supermercados, hospitales privados y un complejo habitacional. Este predio representa una importante área verde para la ciudad de Xalapa, por lo que vecinos, grupos ambientalistas, estudiantes y ciudadanos en general se manifestaron para impedir la desaparición de este pulmón forestal y denunciar la complicidad del Ayuntamiento de la ciudad. Después de varios meses de movilizaciones y plantones, en marzo de 2008 el proyecto fue cancelado.

15 El primer proyecto de libramiento, propuesto en 1991, contemplaba el trazo de una vía alterna sobre el río Pixquiac pero la oposición de diversos sectores de la población hizo que el proyecto fuera cancelado en ese mismo año. 
Otra problemática que se expresó durante el periodo 2000-2009 han sido las innumerables protestas que se han suscitado debido a la contaminación que la industria petrolera ha ocasionado. Uno de estos problemas se refiere a las explosiones de ductos debido a la falta de mantenimiento y a la falta de innovación tecnológica. Por otra parte, la actividad petrolera, que ha vuelto a presentarse en la región del paleocanal, está produciendo impactos negativos en las comunidades debido a que se están expropiando tierras, la maquinaria pesada está afectando las calles y las carreteras de los poblados y en algunos de ellos el petróleo está contaminando los mantos acuíferos. Esta situación ha generado protestas en diversas regiones del estado. En el año 2003 explotó un ducto en la región de Orizaba ${ }^{16}$ y ocasionó graves problemas a la ciudadanía; en el año 2005 hubo un derrame de petróleo que afectó a pescadores de la ciudad de Coatzacoalcos y contaminó gravemente el río del mismo nombre. ${ }^{17}$ En el norte del estado, la actividad petrolera afectó la laguna de Tamiahua y con ello hubo una mortandad de peces y una disminución de la actividad pesquera. ${ }^{18}$ Ante esta problemática generalizada, en el año 2004 se reunieron 70 presidentes municipales para llegar a un acuerdo con la industria de petróleos mexicanos para lograr el pago de indemnización y propuestas de solución a los efectos de la contaminación. ${ }^{19}$ En los límites de los estados de Puebla y Veracruz, entre Poza Rica y Venustiano Carranza, ${ }^{20}$ la explotación petrolera ha generado protestas de los ciudadanos porque el transporte petrolero y el petróleo han ocasionado contaminación sobre los mantos acuíferos.

La actividad petrolera en Veracruz se realiza bajo un esquema donde no solo Pemex participa en la explotación sino que delega actividades a empresas particulares, en su mayoría, trasnacionales.

\footnotetext{
16 Gobernantes en línea, 6 de junio de 2003.

17 Diario de Xalapa, 17 de enero de 2005.

18 Gobernantes en línea, 19 de febrero de 2005.

19 El Universal, 7 de abril de 2004.

20 Entrevista con el sacerdote José Concepción Bautista Pérez, Venustiano Carranza, Pue. (2009).
} 


\section{TRANSFORMACIONES EN EL MUNDO OBRERO}

En relación con lo que podríamos llamar el movimiento obrero, ya se mencionó la crisis que varios sectores pasaron con la reestructuración económica de los años ochenta. Ha sido uno de los sectores más castigados, y en donde las relaciones laborales, desde la perspectiva de los trabajadores, se encuentran sostenidas por el sindicato tradicional y corporativo. Por ejemplo, en el sector petrolero el sindicalismo de Petróleos Mexicanos mantenía una relación prácticamente subordinada al Ejecutivo y a las políticas de Pemex. El magisterio veracruzano responde a los tradicionales cacicazgos y a la dirigencia de Elba Esther Gordillo; en el área rural la Confederación Nacional Campesina (CNC) mantiene en sus filas a importantes capas de productores y campesinos. Así, los conflictos en el sector cañero han encontrado cobijo y protección en el gobierno estatal.

Las protestas e inconformidades de algunos sectores obreros han sido limitadas. Por ejemplo, encontramos movilizaciones en el estado de Veracruz, en las delegaciones sindicales del Seguro Social y el IsssTE, como parte de las protestas nacionales que estos sindicatos impulsaron en contra de las reformas laborales que afectarían el sistema de pensiones. En un contexto laboral donde la flexibilidad y la pérdida de derechos laborales es la constante, las luchas de estos sectores fueron presentadas por el gobierno federal como demandas de grupos obreros privilegiados.

En la región Coatzacoalcos-Minatitlán, a finales de los años noventa se formó la Coordinadora por la Defensa de Pemex, que tuvo como objetivo oponerse a la privatización de la industria petrolera y petroquímica que impulsaba el gobierno de Ernesto Zedillo. La particularidad de esta organización es que sus miembros son trabajadores técnicos y de confianza de dicha industria. A diferencia de los trabajadores sindicalizados, mantuvieron una presencia permanente a la privatización, y plantearon un proyecto de eficiencia para esta industria. De 1995 a 1998 lograron mantener un número importante de afiliados 
(4000 en su mejor momento), y tuvieron que enfrentar una serie de represalias que fueron desde la falta de promoción a trabajadores de la Coordinadora hasta el despido, principalmente de los dirigentes (Aguilar, 2009).

En el año 2002 la Coordinadora desaparece y se integra a lo que intentó ser una organización nacional llamada Unión Nacional de Trabajadores de Confianza de la Industria Petrolera (UNTCIP) conformada en Villahermosa, Tabasco. En el año 2004 esta organización decide conformarse en sindicato, lo cual no fue bien visto por la empresa que decidió despedir, en junio de ese mismo año, al Comité Directivo en su conjunto.

En este ambiente de total hostigamiento y tras varios intentos de disolución, en el año 2008 la UNTCIP se convierte en Unión Nacional de Técnicos y Profesionistas Petroleros (UNTYPP) con una nueva intención de sindicalizarse, y logran ser reconocidos a finales del año 2009. ${ }^{21}$ Este es un ejemplo de los pocos que existen en el país, en el cual una red de trabajadores puede mantenerse con una propuesta distinta a la que promueve el gobierno federal.

Por otra parte, a lo largo de la década del 2000 encontramos protestas de los trabajadores despedidos de la industria textil del corredor Ciudad Mendoza y Orizaba, región donde por el momento solo queda la huella de las luchas históricas textileras.

En el estado de Veracruz encontramos diversos esfuerzos de organizaciones no gubernamentales y grupos de mujeres que buscan mejorar sus condiciones de vida y promover sus derechos. En la región Coatzacoalcos- Minatitlán existen organizaciones como la Casa de Salud Popular "Pobladores" que promueven el empoderamiento de la mujer, sobre todo de la mujer indígena, con lo cual resaltan su papel en la preservación del patrimonio cultural, además de hacerla partícipe en la economía familiar a través de proyectos productivos.

21 Entrevistas con trabajadores petroleros, Didier Marquina Cárdenas y Moisés Flores Salmerón (julio de 2009). 
En la región Córdoba- Orizaba se han conformado organizaciones para dar orientación y acompañamiento a las mujeres que enfrentan violencia de género, como es el caso del "Centro Luz Marina\#, ubicado en el municipio de Rafael Delgado, pero que tiene incidencia en toda la región de la Sierra de Zongolica. Estas organizaciones hacen un trabajo de sensibilización y concientización sobre la violencia, la equidad de género y los derechos humanos de las mujeres, además de que promueven la cultura de la denuncia y brindan acompañamiento psicológico y jurídico a las mujeres violentadas. A través de talleres, muchos de ellos en náhuatl, se ha logrado capacitar y formar a las mujeres en temas como derechos humanos, violencia, salud, etcétera.

En la región de los tuxtlas se mantienen organizaciones que buscan la promoción de los derechos de las mujeres y la apertura de espacios para atender la violencia intrafamiliar, además de que impulsan campañas de salud en la región. Asociaciones como el Centro para la Educación y el Desarrollo Integral de la Mujer (CEDIM), promueven los derechos sexuales y reproductivos de las mujeres, así como también impulsan la recuperación de los saberes tradicionales de la región, sobre todo en materia de salud. Al mismo tiempo, el CEDIM trabaja conjuntamente con el Centro de Servicios Municipales Heriberto Jara (CESEM) para promover la democratización del ejercicio municipal en esta zona, impulsando la participación ciudadana.

En la cuestión de las mujeres ha habido logros democráticos. En el 2006 fue creado el Instituto Veracruzano de las Mujeres a partir de los Acuerdos para la Gobernabilidad en el gobierno de Fidel Herrera Beltrán. Fue a través de esta apertura que organizaciones civiles se organizaron y propusieron dos iniciativas de ley, una que crearía al Instituto Veracruzano de Acceso a la Información y otra que daría origen al Instituto Veracruzano de las Mujeres. ${ }^{22}$

22 Entrevista con Guadalupe Rebolledo, directora del Instituto municipal de las mujeres, Xalapa, Ver. (2 de julio de 2009). 
Entre los objetivos del IVM está diseñar políticas púbicas transversales con perspectiva de género, difundir información relativa a la situación de las mujeres, promover los derechos de las mujeres y una cultura fundamentada en la equidad y proponer modificaciones a la legislación vigente pata erradicar la discriminación hacia las mujeres, entre otros.

\section{EL PROBLEMA DE LA INSEGURIDAD Y LAS PROTESTAS SOCIALES}

El fenómeno de la delincuencia organizada en Veracruz ha sido poco estudiado. En el año 2004 algunas organizaciones sociales y académicos avanzamos en un diagnóstico sobre los problemas sociales en el Estado y nos sorprendimos de las expresiones de varias comunidades con respecto a que la cocaína circulaba en varias zonas rurales.

En el año 2008, a partir de los asesinatos de dos miembros de la familia Hakim, prominentes empresarios veracruzanos, quedaron a consideración varios aspectos: que el narcotráfico había penetrado a un sector del empresariado; que no hubo capacidad del Estado para esclarecer el crimen; y que el problema había llegado para quedarse. De ahí en adelante se conocieron innumerables secuestros, extorsiones a propietarios de comercios en diversas partes del Estado, la extensión del narcomenudeo y, sobre todo, la presencia del grupo de los Zetas, una banda criminal constituida por ex militares concentrados no solo en el narcotráfico sino también en la extorsión y el secuestro de comerciantes, jóvenes y migrantes.

Otros fenómenos sociales abonan en esta especie de desarticulación social, como el aumento de la pobreza en el Estado y la migración que se acrecienta desde el año 2005 aproximadamente. Como lo mencionaron algunos investigadores en Veracruz, "el registro estadístico disponible indica que la delincuencia y la violencia suelen desplegarse 
en espacios geográficos donde es mayor la desigualdad económica y el deterioro de las instituciones de justicia". ${ }^{23}$

En los últimos años las repercusiones sociales de la intervención de la delincuencia hace aparecer a la violencia como el elemento estructurador de lo social. Si bien este fenómeno no es exclusivo del estado de Veracruz, sí existen ciertas características como las mencionadas que generan un caldo de cultivo para la violencia. Si agregamos un sistema político de perfil autoritario como en el de Veracruz, entonces tenemos las condiciones óptimas para el desarrollo del crimen organizado.

Ante el problema de la inseguridad y la violencia los sectores universitarios se han movilizado y protestado ante crímenes cometidos contra un profesor de la universidad así como ante secuestros de jóvenes. Se han constituido grupos de atención a víctimas y se estructuró el Movimiento por la Paz con Justicia y Dignidad dirigido por el poeta Javier Sicilia, que ha denunciado secuestros y desapariciones, así como han sido importantes las marchas y protestas que han organizado contra estos problemas.

Una especial mención requieren los asesinatos de periodistas en el estado, los cuales han producido una serie de movilizaciones solidarias ante los agravios a ese sector: por ejemplo, en mayo del año 2012 fue asesinada la periodista Regina Martínez corresponsal de la prestigiosa revista Proceso y cuyo crimen no ha sido esclarecido. El gobierno del estado emitió un comunicado dando por cerrado el caso, y con ello es evidente la falta de rigor en la investigación.

\section{COMENTARIOS FINALES}

Este breve panorama nos da algunos elementos para reflexionar en torno a las características de la acción colectiva en el estado de Vera-

23 Rodríguez Herrero, Hipólito y Gilberto Cházaro. (2012). "Desigualdad e inseguridad en Veracruz". Diagnóstico de la violencia, la inseguridad y la justicia en Veracruz. México: UV-SESCESP. 
cruz. Primero diríamos que el modelo de movimientos sociales centrales e intensos no se ha dado; encontramos más bien, en el área rural, la emergencia y presencia de las protestas del sector indígena que ha sido históricamente marginado. En el área rural, las organizaciones se mantienen principalmente en un proceso de resistencia y han tenido algunos intentos de articularse pero sin llegar a concretar su esfuerzo. Las luchas indígenas se han profundizado en torno al respeto de los derechos humanos y al reconocimiento de su identidad.

En el sector obrero existe una transformación radical en ciertos espacios del mundo laboral, ya que esta se realizó para lograr flexibilizar la fuerza de trabajo y transformar las relaciones contractuales. En el estado observamos dos tendencias: la primera, concierne a la reestructuración productiva que llevó al despido de los trabajadores y el desconocimiento de las relaciones sindicales lo cual francamente debilita su estado. La otra tendencia corresponde al sector corporativo tradicional que sostiene las condiciones mínimas laborales a cambio de una relación clientelar, como son los casos del magisterio y de los petroleros. En este sentido, la democratización sindical es una demanda casi desaparecida en este sector; sin embargo, la resistencia obrera se centra en el reconocimiento a sus derechos contractuales y de empleo, los cuales han sido constantemente violados.

Sobre el sector ecologista, se ha generado como respuesta al deterioro del medio ambiente la conformación de una red de expertos que han logrado vincularse con diversos actores de comunidades urbanas y rurales, y que han puesto en marcha un conjunto de protestas y propuestas que han logrado detener algunas decisiones estatales que deterioran fuertemente el ambiente, como el caso de la construcción del libramiento a través del bosque de niebla. Por otra parte, el grave deterioro del medio ambiente ha producido en varias regiones del estado protestas espontáneas, sin que sean necesariamente acciones organizadas.

Podemos decir que durante la década de estudio la acción colectiva en el estado de Veracruz ha girado en torno al reconocimiento de los 
derechos sociales y ciudadanos a través, principalmente, de luchas locales. La pérdida de condiciones laborales adecuadas, la violación de derechos en las zonas indígenas y el deterioro del medio ambiente, nos hacen pensar que las condiciones democráticas son muy limitadas, lo que no permite una interlocución respetuosa entre la sociedad civil y las agencias del Estado.

Relacionado con estas redes de movimientos hemos visto la aparición de diversas organizaciones no gubernamentales que luchan por diversas demandas: redes que influyen en las políticas del sector salud para la atención a los enfermos de sida, redes y asociaciones contra la violencia a las mujeres y el respeto a la diversidad sexual, asociaciones por el respeto a los derechos indígenas, por la democratización de los ayuntamientos y asociaciones para acompañar a los migrantes, por mencionar las principales.

El fenómeno de la inseguridad y la delincuencia organizada ligada al narcotráfico ha creado un ambiente de violencia en Veracruz. El sistema político autoritario de nuestro Estado, caracterizado porque en más de setenta años no ha existido la alternancia estatal instituciones como el Instituto Electoral, el Instituto de Transparencia, la Comisión de los Derechos Humanos y los medios de comunicación a nivel estatal dependen de la voluntad del Ejecutivo, condiciones que permiten que estos grupos delincuenciales puedan estar en varias regiones y ciudades del Estado.

Ante los problemas de inseguridad, sectores de la sociedad civil han realizado protestas y formado redes que tienen como objetivo denunciar e influir en políticas públicas para disminuir la violencia y la inseguridad.

\section{SIGLAS}

CEDI: Compañía Exploradora del Istmo

Cesem: Centro de Servicios Municipales, Heriberto Jara A.C.

CIUx: Consejo Indígena de Uxpanapa 
CNC: Confederación Nacional Campesina

CROISZ: Coordinadora Regional de Organizaciones Indígenas de la Sierra de Zongolica

FReposev: Frente Popular del Sur de Veracruz

INMECAFÉ: Instituto Mexicano del Café

Issste: Instituto de Seguridad y Servicios Sociales de los Trabajadores del Estado

ociz: Organización de Campesinos Indígenas de Zongolica

ocosov: Organización de Colonos Solicitantes de Tierras de Veracruz

oIPUH: Organización Independiente de Pueblos Unidos de las Huastecas

PRI: Partido Revolucionario Institucional

TINAM: del náhuatl Timocepanotoke Noche Altepeme Macehualme que significa Unión de Todos los Pueblos Pobres

UCISver: Unión de Colonos, Inquilinos y Solicitantes de Vivienda en Veracruz

unTCIP: Unión Nacional de Trabajadores de Confianza de la Industria Petrolera

Untypp: Unión Nacional de Técnicos y Profesionistas Petroleros

\section{BIBLIOGRAFÍA}

Aguilar, Martín. (2008). Elecciones y medio de comunicación en Veracruz, 2004-2007. Revista La Palabra y el Hombre, V(5).

Aguilar, Martín (coord.) (2008). La difícil construcción democrática en Veracruz. Acceso a la justicia y actores sociales. Universidad Veracruzana, México.

Aguilar, Martín. (2009). Movimientos sociales y democracia en México 19821998. México: Porrúa, Universidad Veracruzana.

Amezcua Cardiel, Héctor. (1990). Veracruz: sociedad, economía, política y cultura. UnAm, México.

Appadurai, Arjun. (2007). El rechazo de las minorías. Ensayo sobre la geografía de la furia. Tusquets, España.

Bauman, Zygmunt. (2005). Modernidad y ambivalencia. Anthropos, España.

Carrasco Arraiza. (2012). Crimen y ¿castigo?. Revista Proceso, 1853. 
Harvey, Neil. (2000). La rebelión en Chiapas. Era, México.

LARA y Mateos Rosa María. (2006). Vivir muriendo. La estigmatización a hombres que tienen sexo con otros hombres (HSH) seropositivos del puerto de Veracruz. Colectivo Sol, conasida, México.

Olvera Rivera, Zavaleta Betancourt y Andrade Guevara (coords). (2012). Diagnóstico de la violencia, la inseguridad y la justicia en Veracruz. Uv SESCESP, México.

PARÉ, Luisa, \& Sánchez, Martha Judith (coords.). (1996). El ropaje de la tierra. Naturaleza y cultura en cinco zonas rurales. Plaza y Valdés e IIS-UnAM, México.

Ramírez Melgarejo, Ramón. (2002). La política del Estado mexicano en los procesos agrícolas y agrarios de los totonacos. Universidad Veracruzana, México.

Robles Guadarrama, Fidel. (2009). La uCISv-ver: una experiencia urbanopopular de línea de masas en Veracruz (1984- 2000). Tesis de Licenciatura. Universidad Veracruzana, México.

Rodríguez Herrero, Hipólito \& Cházaro, Gilberto. (2012). Desigualdad e inseguridad en Veracruz. En: Diagnóstico de la violencia, la inseguridad y la justicia en Veracruz. UV-SESCESP.

Rodríguez, Hipólito. (2011). Historia ambiental de Veracruz. En: Historia general de Veracruz. Universidad Veracruzana, Veracruz. . (1996). Movilidad y espacio urbano en dos ciudades del Golfo de México: Xalapa y Veracruz. Tesis de Doctorado. México: Universidad de Guadalajara-Ciesas Occidente.

Zermeño, Sergio. (1996). Una sociedad derrotada. Siglo xxi, México.

World Bank. (2002). México, Veracruz. Llave Poverty Diagnostic. World Bank, México.

\section{ENTREVISTAS}

Abelardo Márquez Morales, adherente a la Sexta Declaración de la Selva Lacandona. Mayo de 2009, Xalapa, Veracruz. 
Aciano Ramírez Morales, integrante del Consejo Regional Indígena Náhuatl (Cinotahuilt). Julio de 2009, Soteapan, Veracruz.

Alejandro Mendoza Molina, integrante de la A.C. Hacia la vida. Junio de 2009, Córdoba, Veracruz.

Antonio Guevara Espinoza, sacerdote de la localidad. Agosto 2009, Coatzintla, Veracruz.

Didier Marquina Cárdenas y Moisés Flores Salmerón, trabajadores petroleros. Julio de 2009, Minatitlán, Veracruz.

Eduardo Rivera Naser, integrante de Calisache. Agosto de 2010, Coyutla, Veracruz.

Esteban Bautista Hernández, presidente Municipal de Tatahuicapan de Juárez. Julio de 2009.

Graciela García Trejo, empleada de pemex e integrante de la Honra Campal. Agosto de 2009, Poza Rica, Veracruz.

Guadalupe Rebolledo, integrante de ACEREs. Agosto de 2009, Xalapa, Veracruz.

Hernández Vidal, presidente municipal de Pajapan. Julio 2009, Pajapan, Veracruz.

José Concepción Bautista Pérez, sacerdote de la localidad. 2009, Venustiano Carranza, Puebla.

José de Jesús Morales, integrante de CReo. Mayo de 2010, San Andrés Tuxtla, Veracruz.

Julián Martínez, profesor. Agosto de 2010, Coyutla, Veracruz.

Julio Atenco Vidal. Junio de 2009, Orizaba, Veracruz.

Luisa Paré, investigadora del Instituto de Investigaciones Sociales en la UNAM. Junio de 2009, Xalapa, Veracruz.

María López de la Rica, integrante del Centro Luz María. Julio 2009, Rafael Delgado, Veracruz.

Maurilio Tzopil, integrante de la organización tinam. Junio de 2009.

Norma Alcántara Chilma, artesana. Julio 2009, Zaragoza, Veracruz.

Patricia Ponce, investigadora del ciesAs-Golfo e integrante del Grupo Sectorial de viH sidA. Abril de 2010, Coatepec, Veracruz.

Pedro Librero Pérez, integrante de Serafín. Mayo de 2009, Papantla, Veracruz. 


\title{
CAMBIOS, CONTINUIDADES Y REACOMODOS: CONFLICTO POLÍTICO Y ALTERNANCIA EN SANTIAGO TUXTLA, VERACRUZ
}

\author{
EFrAÍn QUiÑóNEZ LEÓN*
}

\section{INTRODUCCIÓN}

EN EL PRESENTE CAPÍTULO hemos pretendido mostrar las relaciones, desplazamientos y pugnas entre las elites políticas y la participación ciudadana en contextos de alternancia. En este sentido, tomamos como eje de nuestras reflexiones los conflictos políticos experimentados a nivel local. En particular, rescatamos las disputas por el poder político en el municipio de Santiago Tuxtla, al sur del estado de Veracruz. Para tal fin, hemos adoptado una perspectiva histórica que nos permita mostrar la compleja dinámica con que operan los actores políticos y sociales en contextos locales. Como podrá observarse, esta dimensión histórica se hace evidente a lo largo del texto.

El documento está dividido en cuatro secciones principales, exceptuando la presente introducción y sus comentarios finales. En el primer apartado se exponen algunos de los ejemplos que han sido paradigmáticos para el país en la lucha por el control de los municipios, recuperando el papel desempeñado por movimientos sociales y acciones colectivas de carácter policlasistas, a menudo orilladas a la violencia con el fin de criminalizar sus acciones de protesta.

En el siguiente apartado, ofrecemos el contexto estatal de las luchas por la autonomía de los municipios, al mismo tiempo que situamos el tema de la alternancia haciendo una reflexión acerca de los cambios

\footnotetext{
Instituto de Investigaciones Histórico-Sociales, Universidad Veracruzana.
} 
ocurridos en el plano electoral de las últimas dos décadas. En este sentido, ofrecemos los datos oficiales como indicadores del cambio en la correlación de fuerzas políticas y el realineamiento de los partidos en el ámbito municipal. Una tercera parte inicia la descripción del municipio de Santiago Tuxtla, Veracruz. Ofrecemos aquí las características principales del territorio y los ejes productivos más importantes, sin perder de vista las condiciones socioeconómicas de la población del municipio, con el fin de indicar las principales características de la zona de estudio. Y en una última sección se incursiona en el tema de las pugnas entre las elites locales y cómo estas se manifiestan en el plano electoral, sin dejar de lado la relevancia que tienen los cacicazgos y la participación ciudadana que se manifiesta a través de una suerte de insurgencia electoral o bien como movimientos de protesta ante las imposiciones. Finalmente, en los comentarios finales realizamos una suerte de balance sobre algunos de los puntos que hemos considerado más relevantes del conjunto.

\section{LA DIMENSIÓN NACIONAL DE LAS DISPUTAS POR EL CONTROL DE LOS AYUNTAMIENTOS}

El estudio sobre los conflictos sociales y las luchas por el control del poder local tiene una larga historia en la academia mexicana. Desde los enfoques históricos, hasta los de carácter sociológico y politológico, la tradición discursiva en torno a la eficacia del poder municipal en la instrumentación de las políticas públicas y el nivel de su desempeño en las acciones de gobierno, los cambios institucionales y normativos, los esfuerzos democratizadores, así como las cíclicas manifestaciones de protesta social, han sido temas recurrentes en la literatura enfocada al estudio de los municipios en México.

Algunos trabajos están orientados al análisis de las costumbres, las formas de vida, las relaciones políticas y las principales actividades socioeconómicas de pequeños poblados. Otros, se interesan más por la constitución de relaciones de poder en los espacios regionales y munici- 
pales, lo que a menudo tiende a concentrarse en el estudio de los cacicazgos y las relaciones de dominación en el campo (Lomnitz, 1995; Lomnitz, 2000; Padua y Vanneph, 1998).

Más recientemente se han desarrollado investigaciones que problematizan el asunto de la administración pública y el nivel de eficiencia alcanzado, tanto en términos del manejo de los fondos públicos, como en la instrumentación de políticas para la gestión del territorio. En estos términos, las investigaciones realizadas han pretendido mostrar el tipo de relación entre los gobiernos municipales y sus contrapartes a nivel estatal y federal; mientras que, en materia de desarrollo urbano, se analizan las políticas públicas encaminadas a incidir sobre las dinámicas del espacio urbano y del territorio nacional en su conjunto (Cabrero, 2003).

Durante los años ochenta toman un nuevo impulso los debates y se estimulan estudios sobre los conflictos locales, coincidiendo justamente con un reciente arreglo institucional que otorgó mayores márgenes de autonomía a los municipios, al tiempo que se les transferían facultades en términos de la planeación del desarrollo, así como se les concedían atribuciones para el cobro de algunos impuestos y tarifas, derivados de la provisión de ciertos bienes y servicios públicos. Estas circunstancias fueron consecuencia lógica de una escalada de protestas sociales previas y de las resistencias del régimen político a la integración de diversos sectores sociales que no se sentían representados. Esto dio lugar a una suerte de espiral de protestas en el campo y en la ciudad que obligó a los actores políticos del viejo régimen a abrir espacios de interlocución con estos sectores marginados o excluidos de la representación política. Uno de estos campos de batalla fueron, precisamente, las luchas emprendidas por el control de los ayuntamientos en el norte, centro y sur del país.

Conforme ha avanzado la democratización del sistema político y las elecciones comienzan a ser creíbles y, por lo tanto, un terreno en disputa salvaguardado por un entramado institucional y un conjunto de reglas con el fin de proteger la voluntad ciudadana expresada en las urnas, no solo hemos experimentado procesos de alternancia sino que 
ello ha venido a estimular los estudios de los procesos electorales en los distintos planos de la vida política nacional. Particularmente relevante han sido los trabajos que abordan los conflictos electorales en el ámbito municipal, pues contribuyen a entender las lógicas de las disputas políticas y la alternancia a nivel local, así como la manera en que actores políticos y de la sociedad civil se articulan para acceder al poder (Rivera, 1998).

En términos de la división política del Estado mexicano, al país lo integran una capital de la República que, en este caso, es conocido como el Distrito Federal, en dónde se asientan los poderes de la nación; 32 estados, con sus propias capitales donde radican las instituciones y la autoridad estatal, y 2457 municipios, cada uno con su presidencia municipal normalmente situada en el casco urbano más antiguo. Del total de municipios, seis estados de la República concentran la mayoría de ellos, lo cual da cuenta del grado de fragmentación del territorio que obedece a determinadas condiciones históricas que han dado lugar a muy variados conflictos por la apropiación del espacio.

\begin{tabular}{|l|c|c|}
\hline \multicolumn{2}{|c|}{ Municipios en México } \\
\hline \multicolumn{1}{|c|}{ Estado } & Núm. de municipios & $\%$ \\
\hline Total nacional & 2457 & 100 \\
Oaxaca & 570 & 23,20 \\
Puebla & 217 & 8,83 \\
Veracruz & 212 & 8,63 \\
Estado de México & 125 & 5,09 \\
Jalisco & 125 & 5,09 \\
Chiapas & 118 & 4,80 \\
Subtotal & 1367 & 55,64 \\
\hline
\end{tabular}

FUENTE: López Mojardín (1986) y reconstrucción propia con base en INEGI: catálogo de entidades, municipios y localidades. (http://www3.inegi.org.mx/sistemas/mexicocifras/default.aspx?e=30) 
A nivel local, los conflictos por el poder político tienen una larga historia en México. Durante el largo ciclo de la dominación priista, los ayuntamientos no tenían mayor importancia, puesto que el centralismo y el presidencialismo otorgaban al jefe del Ejecutivo federal el papel más relevante en la toma de decisiones. Los alcaldes eran vistos no como un poder genuinamente constituido, porque sus cargos aunque eran el resultado de procesos electorales formales, era la voluntad del presidente de la República la que se imponía a través de los gobernadores en turno. Esta circunstancia fue uno de los motivos que a menudo derivó en luchas de resistencia que articularon movimientos sociales y variadas formas de protesta que originaron la creación de partidos políticos locales o regionales con el fin de oponerse al autoritarismo presidencial expresado a través de hombres fuertes, jefes políticos o caciques que contaban con el suficiente poder para imponerse. Desde luego muy pocas de estas expresiones tuvieron éxito $y$, con frecuencia, terminaron en violencia, pero es indispensable reconocerlas como las primeras manifestaciones que desafiaban las estructuras de dominación imperantes.

De acuerdo con Mojardín (1986), los movimientos de protesta a nivel local y las pugnas por el control de los ayuntamientos tienen una larga historia en México. En el norte y, como en el sur del país, existieron luchas de resistencia frente a las arbitrariedades de jefes políticos y caciques, asociados al gobierno central, con el fin de controlar el territorio e imponer autoridades.

Estos conflictos, a menudo orillados a la violencia, tuvieron un impacto al ser reconocidas las luchas autonómicas en el texto constitucional a través del artículo 115. De esta forma, quedaba "establecido el derecho de los pueblos a elegir libremente a sus gobiernos locales a través de las votaciones y se eliminó a cualquier autoridad que pudiera interponerse entre las municipalidades" y los otros niveles de gobierno (Mojardín, 1986: 32). El texto constitucional ofrecía, además, autonomía plena para que los ayuntamientos tomaran iniciativas tanto para el 
manejo de sus recursos financieros, como para organizar y proveer los servicios municipales, realizar obras públicas, emitir reglamentos y estimular la participación de la ciudadanía.

Sin embargo, de lo que se estipula en el texto constitucional a lo que pasaba en la realidad había una gran distancia, puesto que dicha autonomía era más una ficción que una realidad. En efecto, a pesar de celebrarse con cierta regularidad comicios donde los ciudadanos elegían a sus autoridades, simplemente las elecciones resultaban un acto formal porque las decisiones eran tomadas en otra parte y las elecciones no eran más que un rito de paso con el fin de simular procedimientos democráticos, con frecuencia fraudulentos. Además, los municipios tampoco eran libres por dos razones: nunca han tenido autonomía financiera plena porque la manera en que se recaban impuestos le otorga todo el poder a la federación. Por otra parte, los alcaldes pueden estar en riesgo ante el poder incontrastable de los gobernadores y ser destituidos de sus cargos mediante argucias legales de distinto tipo.

Con todo, lo que se aprecia es que hasta los años setenta del siglo pasado, el régimen había transitado casi sin sobresaltos y con una cierta estabilidad política. Además, tratándose de las pugnas por el control de los ayuntamientos, la mayoría de los movimientos disidentes se expresan todavía en los propios espacios del sistema y solamente hasta que son excluidos buscan otros mecanismos y estrategias para contrarrestar las imposiciones de que eran objeto. Esta etapa también incluye la determinación, en 1949, de desconocer al Partido Comunista y algunas expresiones partidistas de carácter regional, con el fin de combatir a los opositores. En este sentido, únicamente serían reconocidos como opciones partidarias contrarias al régimen el Partido Acción Nacional, el Partido Popular Socialista y el Partido Auténtico de la Revolución Mexicana; aunque estos dos últimos cumplían un papel subordinado al partido oficial (PRI), a menudo opciones viables para los movimientos de protesta en los planos locales, resultaban partidos opositores leales al sistema. 
Sin duda, una de las luchas más emblemáticas fue la emprendida en 1958 por Salvador Nava con el fin de conquistar el ayuntamiento de la ciudad capital de San Luis Potosí, contra la voluntad de uno de los últimos caciques del México posrevolucionario, Gonzalo N. Santos, de quien Carlos Monsiváis (2000) se expresara como un personaje pintoresco de la cultura política tradicional mexicana, un arquetipo del revolucionario que por el simple hecho de serlo podía y debía hacer valer su poder a como diera lugar, un hombre curtido en la universidad de la vida que en sus memorias hace "alarde de crímenes y fraudes". Dando la batalla al interior del PRI, Nava pierde toda oportunidad de postularse cuando en las convenciones para elegir candidatos se imponen los aspirantes e incondicionales del cacique potosino. Perpetrada la imposición, se reagrupan las organizaciones disidentes del propio partido oficial para crear la Unión Cívica Potosina, la misma que postularía a Nava como candidato a la presidencia municipal de la capital del estado. En torno a esta candidatura se unieron las fracciones priistas derrotadas en las elecciones internas y también comunistas, sinarquistas y miembros del PAN.

...el programa de los navistas poco tenía que ver con un programa partidario. Planteaban el rechazo a la imposición política y la exigencia de que las libertades democráticas garantizadas por la Constitución fueran respetadas, pedían que el gobierno se ejerciera con honestidad, en beneficio de todos y especialmente de los más pobres y marginados; querían que los ayuntamientos se democratizaran, alentando la participación de los vecinos en las juntas de mejoras... (Mojardín, 1986: 52)

En resumen, exigían ser tomados en cuenta en su calidad de ciudadanos con el fin de hacer valer sus derechos políticos, consagrados en la Constitución, de poder elegir a sus representantes. Pese a las amenazas y agresiones sufridas, Nava, la Unión Cívica Potosina y los grupos que apoyaron su candidatura resultaron victoriosos en la contienda. 
Hubo, desde luego, otras expresiones de descontento por las imposiciones y las limitaciones para hacer efectivo los derechos políticos de los ciudadanos en los espacios locales. Lo mismo en los estados del sur del país, como en municipios del norte, los espacios locales eran el escenario de movimientos de protesta por el autoritarismo estatal y por el abandono en el que se encontraban muchos poblados y ciudades. Algunas de estas expresiones de inconformidad eran enarboladas por el PAN, mientras que otras eran impulsadas por maestros normalistas disidentes o militantes de izquierda que hacían trabajo político en la clandestinidad, toda vez que el Partido Comunista había sido proscrito desde 1949.

Con la reforma política de 1977 y los procesos de descentralización administrativa iniciadas a partir de los años ochenta, se abre un nuevo ciclo en la lucha por los ayuntamientos. La primera de ellas es la obligada respuesta del gobierno de la República a las múltiples formas de descontento social contra el centralismo, el autoritarismo y la desigualdad; así como la oportunidad de incorporar a la vida política institucional a grupos y movimientos sociales que ya no se sentían representados por los viejos mecanismos e instituciones del régimen. En este sentido, la llamada apertura democrática, como se le llamó a la reforma política del 77, permitió la pluralización de las expresiones partidarias y, por lo tanto, diversificó las alternativas por las que la ciudadanía podía optar para buscar una representación más genuina de sus intereses.

La descentralización realmente practicada confirmaba que no se trataba solo de transferir mayores responsabilidades a los ayuntamientos, no al menos desde el punto de vista financiero y político, temas en que el gobierno central continuaría ejerciendo el control. Sin embargo, aunque la descentralización no implicaba necesariamente mayores recursos a los municipios, el hecho de contar con mayores atribuciones, como la de ser ejecutores de los programas diseñados por la federación, podía albergar la posibilidad de aprovechar políticamente las nuevas funciones.

En este contexto, ocurre otro de los movimientos municipalistas emblemáticos: el que desarrolla la Coordinadora Obrero Campesina 
Estudiantil del Istmo (COCEI) con el propósito de ganar la alcaldía del municipio de Juchitán, Oaxaca, cosa que finalmente se logra en marzo de 1981. El triunfo en este municipio será reivindicado como una conquista para los grupos de izquierda. Este es el momento en que se crean las grandes coordinadoras y frentes de lucha que agruparán a las organizaciones de izquierda del campo y la ciudad. Salvo la coceI, la mayoría de estas organizaciones no participan directamente en la lucha por las alcaldías, pero sí tienen como referente inmediato para la resolución de sus demandas a los gobiernos municipales. Por lo tanto, suelen ejercer algún tipo de presión sobre las autoridades locales.

Con las salvedades de cada caso, los años ochenta serán el despegue y la conquista de mayores espacios en los gobiernos locales por parte de la oposición, pero el régimen no estaba dispuesto a ceder espacios y recurre cada vez más al recurso del fraude electoral. En particular, el PAN desarrolla estrategias con el fin de ganar alcaldías, sobre todo en los municipios del norte del país, como Tijuana, Hermosillo y Chihuahua. Pero si bien al PAN no le alcanza para oponerse a la maquinaria estatal que le había propinado fraudes cada vez más escandalosos, al menos puede incorporar a sus militantes a la tarea de gobernar participando como regidores en los cabildos.

Hasta el propio Distrito Federal vivió las peores etapas del presidencialismo al ser anuladas sus autoridades locales, que han sido reconocidas muy recientemente después de largas luchas por el reconocimiento del Estado 33 o el Estado de Anahuac. En efecto, el DF ha sido el escenario del avasallamiento del gobierno central por sobre las autoridades locales que, a lo sumo, eran vistas como empleados del presidente de la República. Desde los años ochenta, ha sido sobre todo la izquierda quien más ha impulsado la necesidad de restituir y reconocer al gobierno de la ciudad de México como un poder similar al resto de los estados de la República. Así, la reforma de 1987 enviada por el presidente Miguel de la Madrid, aunque no reconoce aún una figura jurídica similar al cargo que ostentan los gobernadores del resto de las entidades federati- 
vas, lo que en la práctica significaba que la autoridad de la ciudad (el regente de la ciudad de México) aún sería designada por el presidente de la República, al menos incluyó la figura de Asamblea de Representantes del Distrito Federal, algo similar a una cámara de diputados como está reconocido en cada uno de los estados de la República.

Diez años después, el presidente Ernesto Zedillo envía una nueva reforma a la ley orgánica del Distrito Federal en la que se reconoce la figura de jefe de gobierno, el mismo que ya no sería designado por el presidente de la República, sino a través de elecciones directas mediante el voto de los ciudadanos. Así, es electo en 1997 como primer jefe de gobierno Cuauhtémoc Cárdenas, cargo en el que debió haber estado seis años pero al que renuncia en el año 2000 para buscar por tercera ocasión la presidencia de la República.

Una nueva ola democratizadora se abre justamente con el levantamiento zapatista de 1994. Si la primera ola democratizadora del sistema político en los últimos años vino del norte, un segundo impulso vino del sur y sureste del país. En efecto, aunque las elecciones de ese año no fueron descaradamente fraudulentas, como las realizadas en 1988, lo que las caracterizó fue la inequidad en la contienda y el poder incontrastable que aún conservan algunos de los poderes fácticos, como el del duopolio televisivo (Televisa / TvAzteca) con las evidentes muestras de su parcialidad en el manejo informativo favoreciendo a los actores del viejo régimen.

El movimiento zapatista estimuló de nuevo las inconformidades en los espacios locales y dio lugar a un proceso de remunicipalización en el estado de Chiapas basado en criterios étnicos y ensayando nuevos modelos en el diseño y en la forma en la que se relacionan los ayuntamientos con su población, a través de gobiernos autónomos denominados Los Caracoles.

En Veracruz la inercia desatada por el movimiento indígena en el vecino estado de Chiapas, estimulará las luchas en los espacios locales, así como la creación de nuevos municipios con un alto componente étnico. Así, se constituyen los municipios de Tatahuicapan y Santiago 
Sochiapa, ambos en la vasta zona de comunidades indígenas en el sur del estado, con una larga tradición de lucha por conseguir la autonomía plena y constituirse en municipios libres; el primero alcanza esa categoría en 1997, mientras que el segundo lo lograría en el año 2003.

Renovados impulsos de democratización se inician con la alternancia en el año 2000 cuando el panista Vicente Fox derrota al candidato oficial en las elecciones de ese año, Francisco Labastida Ochoa. Previamente, el PRI había perdido el control político de la capital del país por el candidato del PRD Cuauhtémoc Cárdenas, en la primera elección de jefe de gobierno realizada en el año de 1997. Ese mismo año se realizaron elecciones intermedias en la Cámara de Diputados, los resultados fueron adversos para el PRI, que perdió su sempiterna mayoría en la legislatura federal.

Desde el año 2006 a la fecha lo que se observa es una suerte de insatisfacción ciudadana con la democracia electoral, pues políticos de distintos signos ideológicos no han sido capaces de responder a las demandas del grueso de la población y han sido pobres aun las gestiones de gobierno que se caractericen por la transparencia en el ejercicio público y en la rendición de cuentas a los ciudadanos. Esto ha dado lugar no solo a una insatisfacción con los procesos electorales, sino también a una suerte de hartazgo que a menudo derivan en acciones o prácticas orilladas a la violencia o francamente antipolíticas.

En todo este periodo postalternancia en el plano federal, los municipios empiezan sobre todo a ser reconocidos en términos presupuestales. En efecto, los ayuntamientos comienzan a recibir cuantiosos recursos económicos que, en teoría, podrían contribuir a paliar la pobreza reinante en la mayoría de ellos, pero este no necesariamente es el caso. Lo cierto es que los ayuntamientos se han convertido en un territorio de constantes disputas entre las elites políticas locales dada la disponibilidad de mayores recursos económicos en las arcas municipales y un escenario institucional que les resulta propicio en términos de la muy pobre exigencia para que rindan cuentas de sus acciones. 
Con este apretado resumen hemos pretendido mostrar la importancia que tienen los conflictos locales, la compleja articulación que suele presentarse entre actores y movimientos sociales diversos cuando se trata de ganar las alcaldías, así como reconocer que, contra lo que el sentido común apunta, el fenómeno de la alternancia tuvo sus primeras manifestaciones en los espacios locales antes que en el plano federal cuando en el año 2000 Vicente Fox gana la presidencia de la República como candidato del PAN.

\section{LA DIMENSIÓN ESTATAL DE LA DISIDENCIA MUNICIPAL ${ }^{1}$}

La geografía veracruzana se integra mediante un conjunto muy heterogéneo de municipios con una amplia dispersión a lo largo de su vasto territorio que, de punta a punta, mide un aproximado de 1000 kilómetros. Como ya lo hemos mencionado, el estado de Veracruz está compuesto por 212 municipios con muy variadas características: desde los espacios altamente poblados que, bajo los criterios de SEDESOL, conforman distintas zonas metropolitanas (la del Puerto de Veracruz, Xalapa, Córdoba-Orizaba, Poza Rica-Tuxpan y Coatzacoalcos-Minatitlán), otros de rango medio, así como una gran cantidad de municipios rurales que se distribuyen a lo largo y ancho del territorio, con serios problemas de comunicación e integración.

Aunque no ha existido alternancia en el gobierno estatal, al menos los dos últimos procesos electorales se han visto plagados de

1 En las líneas que siguen ofrecemos un panorama general de la manera en que se ha presentado el escenario de cambios a nivel municipal en el Estado de Veracruz. En este sentido, aclaramos que no hemos hecho una reflexión sobre las transformaciones que se han venido presentando en las elecciones a diputados locales y gobernador. También, hemos dejado de lado las elecciones federales (diputados, senadores y presidente de la república) que aun cuando tienen su propia dinámica y algún impacto en los procesos políticos locales, nuestro objetivo ahora es básicamente mostrar cómo se ha venido presentando la alternancia en el contexto municipal veracruzano. En estudios previos hemos abordado aquellos temas de los que ahora prescindimos (Olvera y Quiñónez, 2001). 
irregularidades y el PRI ha encontrado dificultades para retener el poder. De hecho, los procesos electorales por la gubernatura de 2004 y 2010 han sido dirimidos en los tribunales, habida cuenta de las protestas derivadas por las supuestas evidencias de fraude manifestadas por algunos de los contendientes. Sin embargo, en los planos locales se observan cambios como el realineamiento electoral de los partidos en los municipios, así como una mayor circulación de las elites políticas transportando su escaso o amplio capital político a muy distintas formas o expresiones partidarias. A diferencia de la lucha política a nivel estatal, en los planos locales los conflictos por el poder político municipal se han venido incrementando desde por lo menos las últimas tres décadas y existen más de una experiencia de alternancia en estos espacios de la representación política. Así, el PAN se consolida como una opción viable sobre todo en contextos urbanos, mientras que el PRD lo es en ámbitos rurales y muy escasamente en algunas ciudades del territorio veracruzano.

La lógica frustración que generó en el electorado el fraude perpetrado en 1988 y los propios errores de los grupos opositores provocaron que en los comicios de 1991 la participación ciudadana descendiera sensiblemente. ${ }^{2}$ Con un padrón electoral de poco más de 3.000.000 de electores, acudieron a las urnas únicamente el $44 \%$ de los ciudadanos. Con todo, se reconoció el triunfo a la oposición en trece municipios y en otros tantos existieron movilizaciones y protestas que no prosperarían en los tribunales, salvo en dos casos en que fueron instalados sendos consejos municipales.

Sin embargo, la participación ciudadana en los procesos electorales vuelve a tomar un nuevo impulso en las elecciones locales de 1994. En efecto, no solo ocurre un salto importante en el número de electores que acuden a las urnas, también se incrementa significativamente la cantidad

2 El caso más aberrante fue el de Xalapa, pues solamente el 16\% del padrón acudió a las urnas (Olvera y Quiñónez, op. cit., pp. 449). 
de municipios que serían gobernados por la oposición. En este sentido, recordemos que el padrón electoral era de poco más de 3,5 millones de electores (3.531.761), de los cuales votó el 51,80\% (1.829.433). “Aun cuando el PRI mantuvo su hegemonía en 148 municipios, la oposición obtuvo victorias importantes en 59 municipios, de las cuales 27 correspondieron al PRD, 19 al PAN, 5 al PPS, 4 al PFCRN, 1 al PDM y 3 al PT". 3

Si las elecciones de 1994 nos permiten detectar un cambio importante en la correlación de fuerzas políticas favoreciendo a los partidos de oposición, los comicios celebrados en 1997 constituyen genuinamente un hito histórico para los procesos electorales municipales en Veracruz. Con un padrón electoral cercano a los 4.000 .000 de electores (3.969.697), casi seis de cada diez veracruzanos decidieron ejercer su derecho al voto (57\%). El PRI confirma su tendencia a la baja iniciada desde las elecciones de 1991, al perder en poco más de la mitad de los municipios y en importantes zonas urbanas del Estado. Así, únicamente gobernaría en 103 municipios, mientras que el PAN en 39 y el PRD en $59 .{ }^{4}$

En las elecciones del año 2000, con un padrón electoral de poco más de 4.000.000 de electores (4.233.156), los ciudadanos que decidieron ejercer sus derechos políticos acudiendo a las urnas fueron el 53,7\% (2.273.205). Si bien el PRI incrementa levemente el número de municipios ganados (116) con relación a la elección previa, lo cierto es que la oposición en su conjunto mantiene sus niveles de aceptación entre el

3 Olvera y Quiñónez: op. cit., pp. 449.

4 Aunque el pan gana municipios importantes en el norte (Tantoyuca, Chicontepec, etc.) y el sur (Tierra Blanca, Playa Vicente, Juan Rodríguez Clara, Hidalgotitlán; entre otros), lo cierto es que fortalece su presencia en municipios con larga tradición panista, como el área conurbada de Veracruz y el corredor industrial Córdoba-Orizaba, en la zona centro del Estado; confirmándose la tendencia que el voto panista avanza más rápidamente en la zonas urbanas de la entidad. En el caso del PRD, aunque triunfa en importantes zonas de la geografía veracruzana e incluso gana en un número mayor de municipios que el PAN, lo cierto es que en muchos de ellos le está disputando el voto rural al PRI. Algunas de las presidencias más importantes ganadas por el PRD fueron: Tuxpan, Papantla, en el norte del estado; mientras que en el sur obtiene triunfos en Coatzacoalcos, Minatitlán; entre otros. 
electorado al ganar en aproximadamente la mitad de los municipios. En este sentido, el PAN ganaría en 39 municipios y el PRD en $30 .^{5}$

Las elecciones de 2004 constituyen el descalabro más significativo del PRI en las elecciones para renovar ayuntamientos. Ese año el padrón electoral estaba integrado con cerca de 5.000.000 de electores (4.836.185), de los cuales votaron poco menos del 60\% (2.766.443). De las 116 alcaldías ganadas por el PRI en la elección previa, en las elecciones de este año perdería 46 de ellas, quedándose únicamente con 70. La oposición panista, por su parte, obtuvo el triunfo en 88 presidencias municipales y el PRD en 43.6

Entre esa elección y las de 2007, un súbito cambio operó entre los electores, ya que volvió el fervor priista en ellos. La participación ciudadana alcanzó casi el 60\%, pues de un total de 5.000.000 de electores registrados en el padrón electoral, acudieron a las urnas alrededor de 3.000.000 de veracruzanos (2.854.637). El PRI ganó en 155 municipios, volviendo casi a los niveles de 1994 cuando triunfó en 148. Mientras tanto, el PAN obtuvo triunfos en 31 alcaldías, pero el peor caso fue el PRD, pues solamente pudo ganar en 14. En ambos casos, un retroceso

5 Acción Nacional obtiene triunfos importantes en municipios como Pánuco y Tantoyuca, en el norte del Estado; mientras que en el centro de Veracruz afianza su presencia ganando las alcaldías del Puerto de Veracruz y Boca del Río. Finalmente, en la zona sur triunfa en Acayucan, Cosamaloapan, Jesús Carranza, entre otros municipios. Por el lado del PRD, sus más reconocidas victorias fueron la capital del Estado, Jalapa; vuelve a ganar en Papantla y, en la región sur, conserva municipios tan importantes como Coatzacoalcos, Agua Dulce; entre otros.

6 El PAN obtiene triunfos en Tuxpan, Tantoyuca, Papantla; entre otros municipios de la zona norte de la entidad. En la región central, amplía su influencia a Medellín y Alvarado, municipios colindantes con Boca del Río y el Puerto de Veracruz, donde existe una marcada tradición de voto hacia el PAN. El fenómeno expansivo del PAN, también ocurre en el corredor industrial Córdoba-Orizaba. En el sur, mantiene las alcaldías de Jesús Carranza e Hidalgotitlán; al tiempo en que se agregan San Juan Evangelista, Uxpanapa y Las Choapas; entre otras. El PRD, por su parte, aunque triunfa en varios municipios tanto en el norte, como en el centro y sur de la entidad; prácticamente es en esta última en donde encuentra la región más integrada. En efecto, será en esta zona en la que obtiene las alcaldías de Catemaco, Santiago Tuxtla; entre otros, aunque pierde lugares emblemáticos como la capital del estado (Jalapa) y Coatzacoalcos, municipios con larga tradición oposicionista de izquierda. 
significativo que implicó la pérdida de más de la mitad de los ayuntamientos ganados en la elección anterior. ${ }^{7}$

Finalmente, en la elección del 2010 vuelven a estabilizarse las cifras, por lo menos a los niveles del año 2004. La elección intermedia parece haber sido una pesadilla o una suerte de ficción que no se correspondía con los resultados previos que manifestaban una clara tendencia decreciente de la aceptación ciudadana por el PRI. En el año 2010 poco más de 5.000.000 millones de ciudadanos estaban inscritos en el padrón electoral (5.311.938), de los cuales votaron casi el 60\% (3.149.030). El PRI, con sus aliados, triunfó en 83 municipios, mientras que el PAN lo hizo en 89 municipios y el PRD en 36.

Si se observan los datos en función de las características principales de los municipios ganados por partido o coalición, sin duda el PRI se lleva los más importantes en el mayor número de ellos. En efecto, refrendó sus triunfos en el significativo Puerto de Veracruz, en la capital del estado, Xalapa, ${ }^{8}$ así como en el otrora corredor blanquiazul, en los municipios de Córdoba y Orizaba. También conquista las alcaldías de Pánuco, Papantla y Poza Rica, en el norte del estado. Mientras que en el sur obtiene las presidencias de San Andrés Tuxtla, Coatzacoalcos y Minatitlán, por mencionar algunas de las más importantes. En particular, el triunfo de Carolina Gudiño, candidata del PRI a la alcaldía de Veracruz, ocurrió en un contexto de una muy cerrada disputa con el PAN y dirimiéndose el conflicto poselectoral en los tribunales.

7 El PAN, por ejemplo, en 2007 sólo pudo conservar el municipio de Alvarado, sobre un corredor de gobiernos municipales panistas que incluye el Puerto de Veracruz, Boca del Río y Medellín. Algo parecido ocurre en el resto de las regiones en que la oposición panista venía consolidando su presencia. El PRD, queda reducido a su mínima expresión, puesto que únicamente obtendrá triunfos en ciertos municipios indígenas y en algunos otros poblados cuya característica principal es el aislamiento y la pobreza.

8 En este municipio, la capital del estado de Veracruz, cobra especial relevancia el hecho de que el PRI designó como su candidata a una comunicadora de la televisión estatal y diputada federal por el distrito de Xalapa, Elizabeth Morales, quien en los últimos años ha mantenido un programa de apoyo a sectores vulnerables de la población. 
CAMBIOS, CONTINUIDADES Y REACOMODOS...

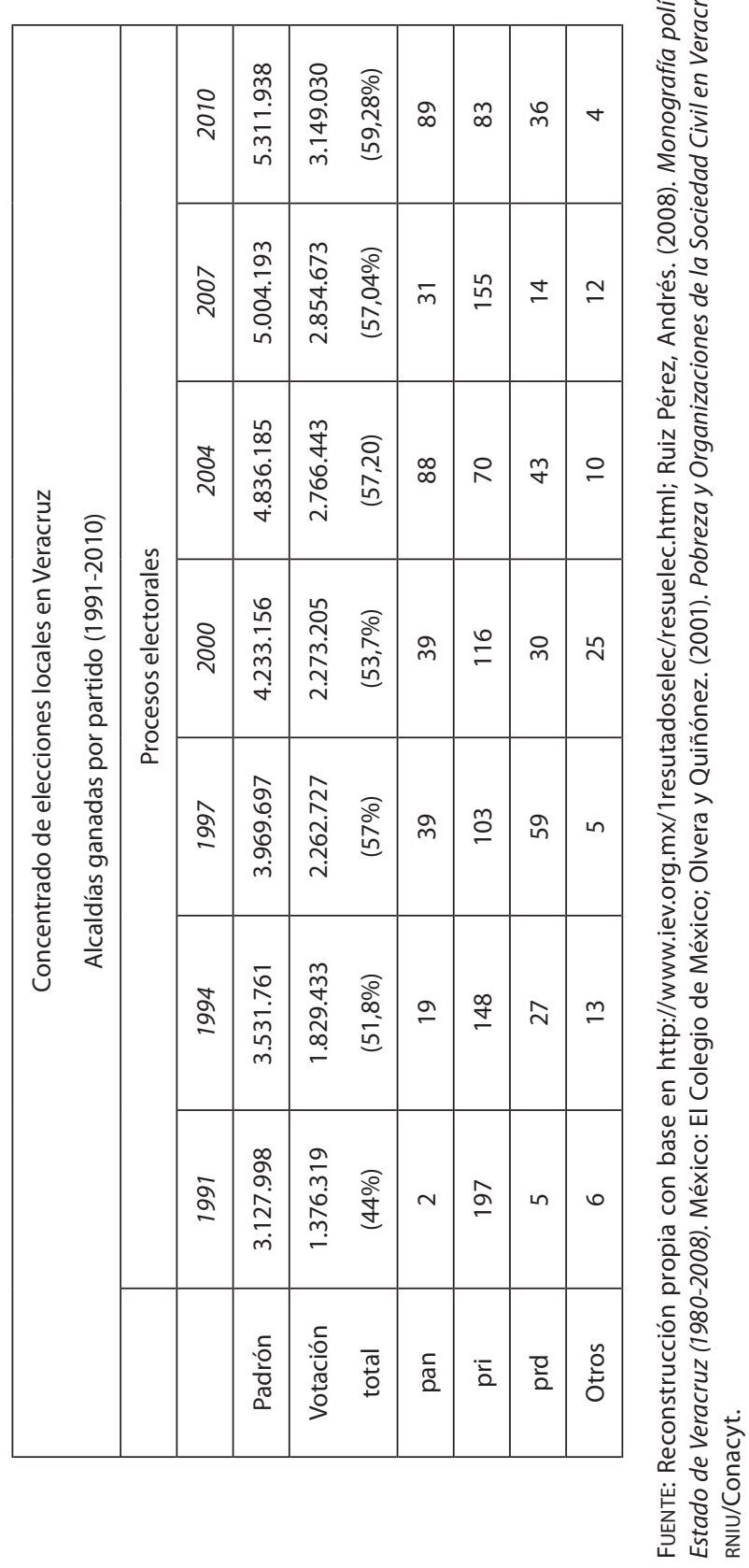


El PAN pierde los municipios conurbados de Boca del Río, Medellín y Alvarado. Sin embargo, obtiene triunfos en ciudades medias como Martínez de la Torre o Tantoyuca; al tiempo en que refrenda triunfos en plazas que podrían considerarse atípicas para el panismo debido a su carácter rural y a su predominante población indígena, como Chinameca, Oteapan y Cosoleacaque, y en el municipio de Pajapan sostuvo una cerrada disputa con la alianza formada por el PRD, Convergencia y el PT, aunque estos últimos se llevaron el triunfo con una diferencia de poco más de 100 sufragios. Si hubiera ganado el PAN en Pajapan, esta habría sido la tercera administración panista consecutiva. También gana en municipios en los que aún no ha gobernado, como el caso de Santiago Tuxtla, entre otros. En su conjunto, y por la cantidad de ciudadanos que viven en los municipios ganados, el PAN será la segunda fuerza política en Veracruz. Por último, la alianza formada por el PRD y otros partidos obtendrán triunfos en pequeños poblados, la mayoría de ellos todavía pueden ser considerados como rurales, pero no por ello menos importantes. En este sentido, se destacan los triunfos en Cosamaloapan, Gutiérrez Zamora, Isla, Playa Vicente, Ciudad Mendoza y Banderilla.

Así, el mapa de la representación política a escala municipal se observa con una renovada pluralidad, la misma que se había interrumpido en las elecciones intermedias celebradas en el año 2007 y en la que se especuló mucho en la prensa sobre los operativos de compra y coacción del voto para favorecer a los candidatos del PRI, aunque debe reconocerse que esta ya no es una característica que distinga únicamente a ese partido político, más bien se trata de una práctica que todos los actores políticos formales están dispuestos a usar en su lucha por el poder.

\section{SANTIAGO TUXTLA.}

\section{CARACTERÍSTICAS GENERALES DEL MUNICIPIO}

Santiago Tuxtla es un municipio ubicado en la parte suroriental del estado de Veracruz y pertenece a un conjunto de localidades que tienen como eje 
principal la producción agrícola y ganadera. Sus recursos naturales, en particular la disposición de agua y las extensas llanuras de la región, hacen propicia la práctica de la agricultura y la ganadería e incluso puede catalogarse como un espacio con alto potencial en esos sectores económicos. Sin embargo, lo que predomina es un modelo de producción agrícola basado en el monocultivo (caña de azúcar y algunos productos básicos como el maíz y el frijol). La producción pecuaria igualmente sigue modelos tradicionales que implican un uso extensivo del suelo, aunque hay experiencias novedosas de un uso intensivo de la tierra y la introducción de ganado de doble propósito (producción de carne y leche al mismo tiempo). En los años de bonanza este modelo fue impulsado por el Estado y ofreció diferentes tipos de estímulos (acceso al crédito e insumos diversos) a la producción con un fin más bien político que económico. Al correr de los años, la estrategia seguida transformó el paisaje rural, convirtiendo la complejidad de los sistemas selváticos en praderas monofuncionales.

Aunque las clasificaciones pueden diferir unas de otras, a menudo esta zona tiende a reconocerse como parte integrante de la región de los tuxtlas. En efecto, Santiago Tuxtla colinda al norte con los municipios de Saltabarranca y Ángel R. Cabada, al sur con Ciudad Isla y San Andrés Tuxtla, al oriente con el mismo municipio y al poniente con el legendario municipio de Tlacotalpan. Todos ellos comparten, exceptuando una que otra particularidad, como ejes predominantes la producción agrícola y pecuaria. En algunos de ellos predomina un esquema de cultivo de plantación ligado a procesos agroindustriales, como en el caso de la caña de azúcar o la producción de piña, por ejemplo; no obstante, en todos ellos está presente la producción ganadera y el cultivo del maíz.

De acuerdo con los últimos datos publicados por INEGI, del total de la superficie sembrada en 2009 (10, 162 has), el 83,64\% se dedicó a la siembra y cosecha de maíz (8500 has), con rendimiento de tres toneladas por ha. Otros cultivos importantes son la caña de azúcar y el frijol. ${ }^{9}$

9 INEGI. Banco de información sociodemográfica y económica. 2010. 
Por el lado de la producción pecuaria destaca sobre todo la producción de ganado bovino y porcino. En el primer caso, si bien se trata de ganado de engorde en grandes extensiones de tierra, también se desarrolla la producción de ganado de doble propósito, es decir, para obtener beneficios de la carne y la leche. El resto de los sectores tiene un aporte marginal, frente a lo que representan en términos del valor que tienen los principales productos ya mencionados. Por ejemplo, en el 2009 el valor total de la producción de carne en el municipio fue de $\$ 83.357 .000$ y el valor de la producción de carne en canal de bovino y porcino ascendió a $\$ 75.482 .000$. Es decir, nada más estos dos productos representan casi el $90 \%(90,55 \%)$ del valor total de la producción pecuaria del municipio. ${ }^{10}$

Ahora bien, en términos de la dinámica de la población, los datos de INEGI indican que el crecimiento prácticamente se ha mantenido estable durante un largo periodo e incluso no ha significado una movilidad intramunicipal que haya modificado el patrón de asentamientos que se ha experimentado en el municipio durante los últimos quince años, pues las pocas áreas urbanas con las que cuenta manifiestan un crecimiento de poca importancia en el periodo mencionado. De hecho, se calcula que el índice de crecimiento poblacional en algunos años del periodo se ha mantenido incluso inferior al $1 \%$.

No obstante, un dato interesante es que sí parece estar cambiando la relación entre la población total de hombres frente a la de las mujeres. En 1995, por ejemplo, existían 27.132 hombres y 27.390, es decir, había un cierto equilibrio entre ambos. Del año 2000 a la fecha, la distribución ha cambiado y cada vez son menos hombres que mujeres. Desde luego esto puede deberse a muchas razones, pero pensamos que una de mucho peso es el de la migración, ya que puede ser la causa de que cada vez sea mayor la brecha entre hombres y mujeres en el municipio. Frente a condiciones económicas adversas, uno de los caminos es justamente la movilidad de la población a fin de paliar dichas condiciones y buscar

10 INEGI. Banco de información sociodemográfica y económica. 2010. 
opciones fuera de su contexto inmediato, dada la crisis que experimentan los sectores productivos de la región.

Por otra parte, si uno compara la relación entre la población urbana y rural, lo primero que observa es que prácticamente se han mantenido inalterables los equilibrios entre ambas, de modo que poco menos del $40 \%$ de la población se asientan o tiene su residencia en una de las dos principales áreas urbanas con que cuenta el municipio (la propia cabecera municipal y Tres Zapotes), mientras que el resto de la población se disgrega en un conjunto muy disperso de localidades rurales, semirrurales o semiurbanas.

De acuerdo con estimaciones del Consejo Nacional de Población y del Consejo Nacional de Evaluación, Santiago Tuxtla posee un alto grado de marginalidad, tomando en cuenta los rezagos sociales existentes en términos de saludos, educación y vivienda. Por ejemplo, los datos sobre la escolaridad promedio en el municipio son más que reveladores, pues un porcentaje alto de la población apenas y alcanza a cubrir los primeros seis años de instrucción. En efecto, para el año 2000 el conAPO calculaba que un $56,65 \%$ de la población mayor de quince años apenas había terminado la primaria. Si a esto agregamos que para el mismo año se calculaba que la población analfabeta alcanzaba un porcentaje de 27,45, podemos entender algunas razones que explican las condiciones socioeconómicas adversas que una buena cantidad de habitantes del municipio padecen.

Ahora bien, por el lado de los ingresos tenemos que una porción de la población en edad de trabajar apenas sobrevive con dos salarios mínimos diarios. Según el Sistema de Administración Tributaria, en el año 2012 el municipio de Santiago Tuxtla se encuentra clasificado dentro de la zona C, con la que determina el nivel del salario mínimo vigente. En este sentido, la tasa del salario mínimo en Santiago Tuxtla es de casi 60 pesos $(59,08)$, y si tomamos en cuenta los datos de INEGI, así como los del conAPO, que señalan que un porcentaje por arriba del $70 \%$ de la fuerza laboral en la zona puede llegar a ganar hasta dos salarios mínimos, estamos hablando de un conjunto de familias que sobreviven 
en situaciones extremadamente precarias. Es decir, poco más de 40.000 personas viven en condiciones de vulnerabilidad social por lo insuficiente de sus ingresos, cuyo monto no rebasa los 3600 pesos al mes.

\section{ELECCIONES Y ALTERNANCIA EN SANTIAGO TUXTLA: CAMBIOS Y CONTINUIDADES EN LAS REDES DE CONTROL POLÍTICO}

Para muchos actores de la política local, Ángel Carvajal Bernal fue uno de los personajes relevantes que, pese a nunca haber sido alcalde, se reconoce como uno de los políticos que llegó a definir las candidaturas e incluso a imponer a los alcaldes hasta los primeros años de la década del setenta del siglo pasado. Es posible que solo sea un mito el poder atribuido a don Ángel Carvajal, pero lo cierto es que dicha percepción no está alejada de la forma tan personal como aún hoy se maneja la política en México. Como a Porfirio Díaz, a don Ángel Carvajal lo desgastaron los años, la lejanía de la tierra natal y las malas decisiones. Una nueva generación de políticos emergió de sus cenizas.

En los primeros años de la década del setenta ocurre un conflicto por la falta de consenso en la designación del candidato oficial a la presidencia municipal. Una nueva camada de políticos jóvenes comienza a disputar los espacios y exige ser reconocida en la distribución del poder local. Cansados de las imposiciones, los políticos de la nueva generación impugnan el proceso, pues la designación oficial recaía en uno de los miembros de la familia Díaz, que por muchos años se había beneficiado del poder municipal. La falta de acuerdo para procesar el conflicto entre las partes locales, originó que un personaje foráneo mediara a fin de superar los desacuerdos. Así, llega a la alcaldía Ibérico Montesano Carbonell, quien formalmente gobernaría el municipio en el periodo 1973 a 1976.

...encabezadas por un grupo de 30 personas donde empiezan a preguntarse por qué hemos vivido en una especie de oscurantismo dentro de la 
representación política y hemos dejado que durante 20 años solamente existan los "Díaz" dentro del gobierno; entre bromas decían tenemos 20 años de días y no hemos podido ver noches. ¿Por qué? Porque en aquellos tiempos se acostumbraba que personajes importantes, respetados, como don Ángel Carvajal, que había sido gobernador del estado y con cargos muy importantes [...] dieran la última palabra. Se acostumbraban los famosos cacicazgos, y había gente que ponía a los presidentes municipales y ponían a un Díaz y a otros Díaz y así fueron 20 años... ${ }^{11}$

Este nuevo grupo político se enfrentó y desplazó al viejo cacicazgo de Ángel Carvajal y como denominación adoptaron el nombre de Grupo Reformista Tuxtleco. Varios de quienes formaron este grupo político han llegado a ser alcaldes, entre ellos Nemesio Domínguez Domínguez quien es ahora uno de los de los personajes centrales en la vida política local.

Ante el signo de rebeldía todo el mundo empieza a protestar, a querer que eso cambie para poner a nuestras autoridades nosotros; ahí empieza un movimiento político y empiezan a tratar de tumbar a la figura grande para que el débil pueda sobreponerse. Y nos venden la idea a todos de que viene un redentor, que es el que tiene las relaciones públicas del mundo y tiene toda la fuerza y capacidad política, que se lleva con todos los gobernantes y con toda la gente política pudiente de México, de la capital, y que nos va a salvar de la pobreza y la marginación y nos vende a Ibérico Montesano Carbonell como candidato que empieza la lucha. El PRI no deja que entre como candidato y entonces se va con el PAN. Con esa revolución la gente se va sumando y el escándalo se hace más fuerte y después de platicar todos esos partidos [...] el PRI abre las puertas y lo nombra su candidato. Llega Ibérico Montezano con el aplauso de todo el pueblo en 1973-1976; él triunfa y toma posesión. ${ }^{12}$

11 Entrevista realizada el 10 de octubre de 2012.

12 Entrevista realizada el 10 de octubre de 2012. 
No obstante el respaldo popular que tuvo la candidatura de Ibérico Montesano luego de impulsar algunos proyectos culturales, ${ }^{13}$ así como cierta infraestructura de caminos en el municipio, el alcalde descarga la tarea de gobernar en el síndico y prácticamente se ausenta del municipio. En la práctica, el abandono del cargo por parte de Ibérico Montesano provoca conflictos y descontrol en la administración municipal. En consecuencia, se generan inconformidades entre la población y el Grupo Reformista se divide en el siguiente proceso electoral. “...la gente no confía, y ese grupo se divide en dos. Y entonces muchos se van con el antiguo PAN y otra parte con el PRI, la consecuencia es un Consejo Municipal, después del desfogue, viene el Consejo Municipal y lo preside Jorge Santos Azamar, que lo mandan de Alvarado..."14

Entonces, el municipio transita por un periodo de inestabilidad política, dada la falta de acuerdo entre las elites políticas locales que, antes de sentirse agraviadas o derrotadas por una de las fracciones en pugna, prefieren ceder espacios de poder a otros actores que, en teoría, puedan mantener o restablecer los equilibrios perdidos. El permanente conflicto que perdura durante los tres años del Consejo Municipal (1997-1979), incide e incrementa el descontento social ante la falta de obras y la inacción del gobierno en turno. Estas circunstancias originan que la ciudadanía tome a menudo las instalaciones del palacio municipal en señal de protesta con el fin de hacerse escuchar y de obligar a las autoridades locales a que respondan a sus demandas.

\begin{abstract}
Al final de los tres años no se ven obras ni realizaciones de ninguna especie y la gente otra vez empieza con las manifestaciones. Ahí entro en la historia de Santiago. Empiezan a candidatearme como una expresión nueva. Yo llego a Santiago a formar grupos culturales de música, danza, coros. Salgo de la Escuela Normal Veracruzana como maestro, soy estudiante de la
\end{abstract}

13 Por ejemplo, se construye el museo de sitio de Tres Zapotes.

14 Entrevista realizada el 10 de octubre de 2012. 
Facultad de Derecho, llego allá, empiezo a dar cátedra de Ciencias Sociales en la escuela secundaria y de bachilleres de Santiago, colaboro con la casa de la cultura; puras actividades culturales, nada de políticas. Esa era mi rama completamente. Entonces, empiezan a alborotarse, a decirme que quieren que sea candidato, yo era joven, sentí la aceptación de la gente y me meto. Yo tenía 27 años, me meto como una expresión ciudadana. Pero, del otro lado, se mete una gente que era poderosa, económicamente muy fuerte, ganadera, que era primo hermano de Gustavo Carvajal, quien era presidente del comité ejecutivo nacional del PRI y entonces yo veía el espanto muy grande, pero uno como joven se entrega al barco, con la ilusión de que va a ganar. Me metí con ellos a disputar. Yo vi en aquel tiempo al sistema que tenía que conservar el orden, tuve muchos momentos de presión para la retirada, sin embargo fui rascando, fui muy terco en ese aspecto para tratar de sacar mi candidatura. En ese tiempo se complicaron dos casos en Veracruz: Santiago Tuxtla y Córdoba. En Córdoba estaban enfrentados por la presidencia municipal, Juan Herrera Marín y Dante Delgado, y acá, Nemesio Domínguez y Gaudencio Sosa Carvajal. Entonces, eran dos intereses muy fuertes y era gobernador Agustín Acosta... Yo sentía que la inclinación del sistema en Santiago no era para mí, era para la otra persona [...] la cuestión es que se incendia todo esto. Se hace muy fuerte esta lucha, nos vamos hasta México, al Comité Ejecutivo Nacional a los dos últimos que faltábamos y le preguntan al presidente López Portillo la decisión que se iba a tomar porque el gobierno de acá apoyaba a uno y el de allá apoyaba a otro. Y dijo terminamos para que no se involucre a Gustavo, Nemesio se va para Santiago y Herrera Marín para Córdoba y ese día vine corriendo a tomar protesta aquí. ${ }^{15}$

\begin{abstract}
Ahora bien, en el plano de las elecciones propiamente locales existe una larga historia de hegemonía prí́sta, pero que no implica necesariamente una suerte de armonía al interior de los grupos políticos que
\end{abstract}

15 Entrevista realizada el 10 de octubre de 2012. 
mantienen o han mantenido el poder en el municipio. Sin embargo, ha sido claro, a juzgar por los resultados electorales que se presentaron hasta 1999, que el PRI había mantenido bajo su control el poder del ayuntamiento, pero las elecciones celebradas justamente en el año 2000 se convierten en el inicio de una sucesiva experiencia de derrotas del todopoderoso partido oficial. No es casual que el candidato ganador en la contienda de ese año haya sido un personaje que en dos ocasiones previas había triunfado bajo las siglas del PRI. En efecto, Gabriel Arnau había ganado las elecciones para el PRI en 1982, volvió a ganar en 1987 y nuevamente triunfa en las elecciones del año 2000, pero bajo una coalición formada por el PT y Convergencia. En este último proceso, la coalición obtuvo 5771 sufragios, mientras que el candidato del PRI obtendría únicamente 5131 votos. Lo que esto reflejaba era la intensificación de la lucha interna entre grupos de poder del PRI, de modo que si bien nos encontramos con el inicio de gobiernos de alternancia, no es menos cierto que se trata de las disputas que protagonizaban los viejos grupos hegemónicos del municipio.

Sin embargo, esto cambiará en la siguiente elección cuando genuinamente arribarán al poder no solo otros grupos del sistema de dominación local sino que, además, se rompe la hegemonía que ejercían los actores políticos de la cabecera municipal. No menos importante es que en dicha elección resulta ganadora una mujer, que no es de la cabecera municipal y con evidentes rasgos indígenas. Se trata de la primera alcaldesa en la historia política de las disputas por el control del ayuntamiento. En efecto, participará en las elecciones de 2004 como candidata por la Coalición Unidos por Veracruz, ${ }^{16}$ se trata de Yazmín Copete, dirigente local del PRD, originaria de la comunidad de Tres Zapotes y vinculada sentimentalmente con Arturo Hérvis Reyes, dirigente estatal de ese partido. ${ }^{17}$ Así,

16 Esta Coalición incluía al Partido del Trabajo y a Convergencia.

17 Para uno de nuestros informantes, Yazmín Copete ganó la elección porque existió una negociación política entre el dirigente estatal del PRD, Arturo Hérvis, con el entonces candidato del PRI al gobierno del Estado de Veracruz, Fidel Herrera Bel- 
la candidata ganadora obtendría 9901 votos, contra 5757 del candidato de la alianza PRI-Verde Ecologista.

Aun cuando es en estas últimas elecciones donde se configura realmente el fenómeno de la alternancia en el poder local, lo cierto es que la nueva administración de corte perredista atravesó por un sinfín de problemas derivados de sus propias incapacidades, así como por los conflictos generados por grupos que pretendieron ganar posiciones dentro del propio ayuntamiento, los cuales convirtieron una gestión con altas expectativas en un circo romano. Además de ello, la propia alcaldesa decidió a la mitad de su gestión, al más viejo estilo priista, lanzarse a la aventura de conquistar la candidatura a la diputación federal por su partido (PRD), pero fracasó estrepitosamente en el intento e incluso fue señala en la prensa de usar los recursos públicos del ayuntamiento para respaldar su campaña.

Después de las elecciones de 2004, el PRI volverá al poder tras ganar nuevamente la alcaldía en los comicios de 2007. En efecto, mediante una alianza con el Partido Verde Ecologista y el PANAL, ${ }^{18}$ el PRI obtendrá el triunfo con 8769 sufragios, mientras que su más cercano competidor del PRD únicamente conseguiría 6722 votos.

Finalmente, en las elecciones de 2010 nuevamente el PRI vuelve a perder la alcaldía. En esta ocasión ganó un candidato del PAN, Raúl Sosa González, quien sin embargo había solicitado ser registrado como candidato de la Alianza PRD, PT, Convergencia. Bajo esta lógica, los dirigentes de la alianza acordaron como método aplicar una encuesta a fin de seleccionar al candidato que mayores simpatías despertara entre la ciudadanía. Sin embargo, los resultados no favorecieron a Raúl Sosa, quien desconoció los mismos y terminó siendo candidato del PAN. Así, estas

trán. El acuerdo era dejar ganar al PRD en Santiago Tuxtla y dejar el camino libre al PRI en otros municipios y regiones del estado.

18 Partido Nueva Alianza, fundado en 2005 y respaldado por la lideresa del Sindicato Nacional de Trabajadores de la Educación, Elba Esther Gordillo Morales. En su corta existencia, el partido se ha caracterizado por realizar alianzas pragmáticas en coyunturas electores, ligándose principalmente a candidatos del PRI y el PAN. 
son las elecciones locales más disputadas de los últimos tiempos en el municipio, ya que prácticamente los resultados están divididos casi en tres tercios. En efecto, el PAN y sus aliados alcanzarán una suma de 9819 votos, mientras que el PRI y sus coaligados conseguirán casi 9000 sufragios (8962) y, por último, la alianza formada por el PRD, PT y Convergencia se adjudicarán 7078 votos para su causa.

Un asunto que no debe perderse de vista es que en estas elecciones el PRI impone como su candidata a María del Consuelo Rodríguez Robles, esposa del exalcalde, dirigente político y figura central en la determinación de las candidaturas del PRI en ese ámbito, Nemesio Domínguez Domínguez. No es menos importante señalar también que esta sería la segunda ocasión que la señora Rodríguez Robles ocuparía el cargo de alcaldesa, si hubiese ganado. De acuerdo con uno de nuestros informantes, la ciudadanía santiagueña está cansada de políticos que solo tienen como único fin la conquista del poder por el poder mismo.

El pueblo de Santiago es un pueblo que se cansa de tener mucho tiempo a un mismo político; se cansó de don Ángel, se cansó de Gabriel. Se cansó de Nemesio y la gente de Santiago quiere cosas nuevas, le da la oportunidad a una persona que ni vivía en Santiago, ahorita con el PAN. Llega ajeno y el pueblo le ve más posibilidad de enfrentar a Nemesio y le dan el voto a él. Y gana la alcaldía y se la gana a Nemesio y a Gabriel Arnau, tres veces presidente municipal. Nemesio, también con varias presidencias municipales director del DIF estatal, diputado federal; con toda la trayectoria que puedes imaginar, alguien que ni vivía en Santiago. ¿Qué pasa? El pueblo dice ya basta de lo mismo y le dan el voto a alguien que llegó y que ni siquiera hizo cierre de campaña, fue un voto de castigo contra la misma gente del poder. ${ }^{19}$

19 Entrevista realizada el 29 de febrero 2012. 
Sin embargo, para algunos de los actores políticos con presencia en el municipio, más allá del problema que significa la definición de candidaturas mediante procedimientos no democráticos, sino a la pertenencia de redes clientelares y a la disponibilidad de recursos para apuntalar campañas políticas, subyace el asunto de la compra y venta de votos. Según este punto de vista, ahora las elecciones se ganan mediante la compra abierta de votos, ese es el elemento que define o caracteriza la real politic. Es decir, hay un mercado de compra de votos y la gente vende el sufragio al mejor postor. Entonces, si la vía para ganar elecciones es la disponibilidad de recursos, ellos pueden obtenerse al menos por tres vías: a través de las aportaciones de agentes privados, a través de inyección de capital cuya procedencia se ignora y al controlar los hilos de la política social y de asistencia a sectores productivos.

\section{COMENTARIOS FINALES}

Si bien no es una condición única que la política social y de combate a la pobreza sirven como instrumentos para ganar elecciones, sí constituyen una suerte de ariete a través del cual pueden apuntalarse carreras políticas. En sucesivas campañas políticas locales, la denuncia más frecuente es el uso clientelar de los apoyos para los ciudadanos en situaciones de vulnerabilidad social. Sin embargo, esto no siempre parece seguir la misma norma. En ocasiones la ciudadanía responde contra la lógica clientelar eligiendo a candidatos que incluso aparecen prácticamente de la nada. Desde luego, eso no garantiza que se pueda tener un buen gobierno, pero al menos ofrece la posibilidad de no elegir a quienes sí se han percibido como dirigentes políticos corruptos o incapaces.

Finalmente, la ciudadanía queda atrapada en un proceso de elección de representantes que sólo le ofrece otorgar premios o castigos de manera posfáctica y, peor aún, únicamente puede elegir dentro de ofertas mediocres al menos peor de quienes aspiran a ser sus representantes. Sin embargo, debe reconocerse cierto aprendizaje social que permite 
tasar de distinta manera a los actores políticos que pretenden representar a la ciudadanía. En efecto, la compleja racionalidad manifestada en la manera en la que se ejerce el voto proporciona la posibilidad de que los ciudadanos puedan actuar a favor o en contra de quienes los gobiernan. Así, lo que observamos, por una parte, es que la vida cotidiana de las personas corre paralela a las prácticas políticas de sus representantes. Sin rubor alguno, los representantes políticos deciden por sobre cualquier tipo de norma democrática mínima. Por otra parte, la experiencia nos muestra un bajo nivel institucional de muy variadas formas de estructuras estatales cuyos márgenes de autonomía están siendo vulneradas sistemáticamente, tanto por la intervención ilegal o indebida de quienes tienen el suficiente poder para imponerse $y$, también, porque quienes integran las instituciones han claudicado en sus afanes por ampliar los márgenes de libertad y soberanía para un mejor desempeño de sus funciones sustantivas.

Nada de lo que hasta aquí se ha expuesto puede entenderse como explicación única de la racionalidad que opera en los electores y los actores políticos en contexto electorales, porque hay ciertos elementos del juego democrático que ofrecen dificultades (la secrecía del voto o el grado de conciencia de los votantes, por ejemplo) que no permiten asegurar de antemano los triunfos. Sin embargo, sobre estas condiciones subyacen algunos de esos elementos que nos pueden ayudar a encontrar explicaciones quizá no del todo convincentes pero por lo menos más plausibles de las dificultades propias de nuestra tierna democracia.

\section{BIBLIOGRAFÍA}

Amaral, Samuel, \& Stokens, Susan C. (comps.). (2005). Democracia local. Clientelismo, capital social e innovación política en Argentina. Eduntref, Buenos Aires.

Auyero, Javier, et al. (comp.). (1997). “¿Favores por votos?” Estudios sobre clientelismo político contemporáneo. Losada, Argentina. 
Auyero, Javier. (2001). La política de los pobres. Las prácticas clientelistas del peronismo. Manantial, Argentina.

. (junio 2002). "Clientelismo político en Argentina: doble vida y negación colectiva” en revista Perfiles Latinoamericanos No. 20. Pp. 33-52. México.

Bassols R., Mario y Socorro Arzaluz. (Julio-diciembre 1996). "Gobiernos municipales y alternancia política en ciudades mexicanas" en revista Frontera norte vol. 8 núm. 66. Pp. 103-124. México.

Bey, Marguerite y Hélène Combes. (Mayo-agosto 2011). "El intercambio en política" en revista Desacatos No. 36. Pp. 7-10. México.

Bowman, Margaret y Hampton, William. (comps.). (1989). Democracias locales, un estudio comparativo. FCE, México.

Cansino, César. (Julio-agosto 2006). "Construir la democracia" en revista Metapolítica No. 48. Pp. 25-30. México.

Cabrero, Enrique. (coord.). (2003). Políticas públicas municipales: una agenda en construcción. CIDE/ Miguel Ángel Porrúa, México.

Combes, Hélène. (Mayo-agosto 2011). “¿Dónde estamos con el estudio del clientelismo?" en revista Desacatos No. 36. Pp. 13-32.

Gallardo L., Rigoberto. (2009). Actores sociales colectivos y construcción ciudadana a nivel municipal. Plaza y Valdés, México.

González A. José A. (1997). El clientelismo político, perspectiva socioantropológica. Anthropos, México.

Lomnitz, Claudio. (1995). Las salidas del laberinto: cultura e ideología en el espacio nacional mexicano. Joaquín Mortiz, México.

. (2000). Vicios públicos, virtudes privadas: La corrupción en México. Miguel Ángel Porrúa/ciesas, México.

López M., Adriana. (1986). La lucha por los ayuntamientos, una utopía viable. Siglo xxi, México.

Massolo, Alejandra. (Octubre-diciembre 1994). "Las políticas del barrio" en Revista Mexicana de Sociología. No. 4. Pp. 165-183. México.

Olvera R., Alberto, et al. (coord.). (2012). Veracruz en crisis. Poderes, elecciones y medios de comunicación. Vol. III. Universidad Veracruzana, México. 
. (2012). Veracruz en crisis. La sociedad civil realmente existente: corporativismo sindical y campesino, movimientos indígenas y actores civiles. Vol. IV. Universidad Veracruzana, México.

Olvera, Alberto y Quiñónez, Efraín. (2001). Pobreza y organizaciones de la sociedad civil en Veracruz. En: Patiño, Elsa y Jaime Castillo (coords.). Pobreza y organizaciones de la sociedad civil en México. BUAP/RNIU/ CONACyt, México.

Padua, Jorge y Vanneph, Alain. (1988). Poder local, poder regional. Colmex/ Cemca, México.

Panfichi, Aldo (coord.). (2002). Sociedad civil, esfera pública y democratización en América Latina: Andes y Cono Sur. FCE, México.

Recondo, David. (2007). La política del gatopardo. Multiculturalismo y democracia en Oaxaca. La casa chata, México.

Vommaro G. y Julieta Quirós. (2011). "Usted vino por su propia decisión”: Repensar el clientelismo en clave etnográfica en revista Desacatos, pp. 65-84. México.

\section{PÁGINAS WEB}

Cambio Digital. Santiago Tuxtla, olvidada por gobierno del estado: Raúl Sosa.

Recuperado 24 de febrero de 2012 en http://www.cambiodigital.com. $\mathrm{mx} / \mathrm{mosno} \cdot \mathrm{php}$ ?nota $=56720 \&$ seccion $=$ Principal

Diario de Eyipantla. Candidata del PRI a la alcaldía de Santiago Tuxtla recorre colonias. Recuperado 27 de febrero de 2012 en http://www.diarioeyipantla.com/candidata-del-pri-a-la-alcaldia-de-santiago-tuxtla-recorre-colonias/

Diario de Eyipantla. DIF de Santiago Tuxtla apoya al adulto mayor. Recuperado 24 de febrero de 2012 en http://www.diarioeyipantla.com/dif-de-santiago-tuxtla-apoya-a-adulto-mayor/

Diario de Eyipantla. Gana la planilla azul; Dolores Vichi, nuevo Comisariado Ejidal de Santiago Tuxtla. Recuperado 24 de febrero de 2012 en http:// 
www.diarioeyipantla.com/gana-la-planilla-azul-dolores-vichi-nuevocomisariado-ejidal-de-santiago-tuxtla/Josabet

Diario de Eyipantla. Raúl Sosa, preside entrega de apoyos de PROCAMPO. Recuperado 22 de febrero de 2012 en http://www.diarioeyipantla.com/ raul-sosa-preside-entrega-de-apoyos-de-procampo/

Diario de Eyipantla. Santiago Tuxtla es pilar cultural de Los Tuxtlas. Recuperado 24 de febrero de 20123 en http://www.diarioeyipantla.com/santiago-tuxtla-es-pilar-cultural-de-los-tuxtlas/

Diario de Eyipantla. "Unidos por el Desarrollo de Santiago Tuxtla"; Raúl Sosa. Recuperado 22 de febrero de 2012 en http://www.diarioeyipantla. com/\%E2\%80\%9Cunidos-por-el-desarrollo-de-santiago-tuxtla \%E2\%80\%9D-raul-sosa/

Diario de Eyipantla. Uscanga Escobar se compromete a apoyar al campo y al turismo. Recuperado 24 de febrero de 2012 en http://www.diarioeyipantla.com/uscanga-escobar-se-compromete-a-apoyar-al-campo-y-alturismo/

Diario La Política. Acondicionan espacios deportivos en Santiago Tuxtla. Recuperado 24 de febrero de $2012 \mathrm{en} \mathrm{http://www.lapolitica.com.mx/?p=65435}$ Diario Marcha. Queman despensas del PRI en San Andrés Tuxtla para favorecer a Jorge Uscanga. Recuperado 27 de febrero de 2012 en http://www.marcha.com.mx/resumen.php?id=3975

El Universal. Concentra 29\% de municipios operación narco ven en EU. Recuperado 28 de octubre de 2012 en http://www.eluniversal.com.mx/primera/40592.html

El Universal. Municipios hasta el tope de deudas. Recuperado 26 de septiembre de 2012 en http://www.eluniversal.com.mx/estados/87898.html

Tuxtlas Blogspot. La contingencia ha pasado, el campo de Santiago Tuxtla sigue de pie gracias a Fidel Herrera: Josabet Cadena. Recuperado 22 de febrero de 2012 en http://enlostuxtlas.blogspot.com/2010/11/la-contingenciaha-pasado-el-campo-de.html

Tuxtlas Blogspot. Los virtuales ganadores de las elecciones a las alcaldías y diputaciones por el distrito XXIV y XXV. Recuperado 27 de febrero de 
2012 http://enlostuxtlas.blogspot.com/2010/07/los-virtuales-ganadores-de-las.html

Tuxtlas blogspot. El ayuntamiento de Santiago Tuxtla brinda facilidades a programas de Oportunidades. Recuperado 24 de febrero de 2012 en http:// enlostuxtlas.blogspot.com/2011/01/el-ayuntamiento-de-santiagotuxtla.html

Tuxtlas blogspot. Santiago Tuxtla se convierte en la sede de "PROCAMPO para Vivir Mejor". Recuperado 22 de febrero de 2012 en http://enlostuxtlas. blogspot.com/2011/08/santiago-tuxtla-se-convierte-en-la-sede.html

Informantes en Red. En suspenso elección de Santiago Tuxtla. Recuperado 27 de Febrero de 2012 en http://www.informantesenred.com/en-suspensoeleccion-en-santiago-tuxtla/

Noticiero Veracruz. El senador Juan Bueno Torio estuvo en Santiago Tuxtla, con su amigo Raúl Sosa. Recuperado 24 de febrero de 2012 en http://www. noticieroveracruz.com/10149_el-senador-juan-bueno-torio-estuvoensantiago-tuxtla-con-su-amigo-ral-sosa-.html

Noticiero Veracruz. Visita Yunes Linares Los Tuxtlas. Recuperado 24 de febrero de 2012 en http://www.noticieroveracruz.com/9282_visita-yunes-linares-los-tuxtlas.html

Política Los Tuxtlas. Confirman a Gabelo como candidato de la coalición en Santiago Tuxtla. Recuperado 27 de febrero de 2012 en http://www.politicalostuxtlas.com/1659_confirman-a-gabelo-como-candidato-de-lacoalicion-en-santiago-tuxtla-.html

Política Los Tuxtlas. Entrega SEDARPA Erick Lagos, Nemesio y Josabet 10 tractores en Santiago Tuxtla. Recuperado 24 de febrero de 2012 en http:// www.politicalostuxtlas.com/184_entrega-sedarpa-erick-lagos-nemesio-y-josabet-0-tractores-en-santiago-tuxtla.html

Política Los Tuxtlas. Jacinto Campos Ortiz, nuevo dirigente de la CNC en Santiago Tuxtla. Recuperado 24 de febrero de 2012 en http://www.politicalostuxtlas.com/128_jacinto-campos-ortiz-nuevo-dirigente-de-la-cncen-santiago-tuxtla-.html 
Política Los Tuxtlas. La comisión municipal electoral es responsable de los resultados. Recuperado 27 de febrero en http://www.politicalostuxtlas. com/27_la-comision-municipal-electoral-es-responsable-de-los-resultados-josabet.html

Política Los Tuxtlas. Cumple expectativas Tianguis Agropecuario en la colonial. Recuperado 24 de febrero de 2012 en http://www.politicalostuxtlas.com/746_cumple-expectativas-tianguis-agropecuario-en-la-colonial-.html

Sucesos Los Tuxtlas. En Santiago Tuxtla, productores de maíz recibieron el pago de indemnización por las inundaciones. Recuperado 22 de febrero de 2012 en http://www.sucesoslostuxtlas.com/en-santiago-tuxtla-productoresde-maiz-recibieron-el-pago-de-indemnizacion-por-las-inundaciones-2/

Vera News. "Adelante" entregó apoyos a Catemaco, Santiago Tuxtla, Lerdo de Tejada, Isla, Rodríguez Clara y Carlos A. Carrillo. Recuperado 24 de febrero de 2012 en http://www.veraznews.com/index.php?option=com_ content $\&$ view $=$ article $\&$ id $=4402$ :adelante-entrego-apoyos-a-catemacosantiago-tuxtla-lerdo-de-tejada-isla-rodriguez-clara-y-carlos-a-carrill o\&catid $=51$ :politica\&Itemid $=72$

\section{OTRAS PUBLICACIONES}

Aвdo I., G., Benítez P., P., \& Domínguez C., F. (2001). Autodiagnósticos comunitarios situacionales de las mujeres del municipio de Santiago Tuxtla, Veracruz. Xalapa, Veracruz, México: CESEM.

Movimiento Ciudadano Municipalista de los Tuxtlas. (2010). Agenda Ciudadana Municipalista de los Tuxtlas. Xalapa, Veracruz, México: CESEM.

Abdo I., G., Benítez P., P., \& Domínguez C., F. (2001). Autodiagnósticos comunitarios situacionales de las mujeres del municipio de Santiago Tuxtla, Veracruz. Cesem, Xalapa, Veracruz, México. 
Movimiento Ciudadano Municipalista de los Tuxtlas. (2010). Agenda Ciudadana Municipalista de los Tuxtlas. Cesem, Xalapa, Veracruz, México.

PROCAMPo. Padrón de productores apoyados. Recuperado en http://www. tiempofertil.gob.mx/TiempoFertil/comunes/PROGPRO/PROCAMPOPV04/prPV04300143.html

Subsidios al Campo en México. Programas aplicados a Santiago Tuxtla 19942009. Recuperado 22 de febrero de 2012 en http://www.subsidiosalcampo.org.mx/mexico/estados/veracruz/santiagotuxtla

SEFIPLAN. (2011). Santiago Tuxtla. Sistemas de información municipal: cuadernillos municipales. Gobierno del Estado de Veracruz. 


\title{
ACTORES SOCIALES Y PROCESOS DE DEMOCRATIZACIÓN EN LA REGIÓN DE HUATUSCO, VERACRUZ
}

\author{
Manuel Hernández Pérez
}

\section{INTRODUCCIÓN}

LA CAFETICULTURA ES UNA ACTIVIDAD FUNDAMENTAL en la vida económica y social de la región de Huatusco. Alrededor de dicha producción se han estructurado las relaciones económicas y sociales entre los diferentes actores que se ven involucrados en la cadena produccióntransformación-comercialización del café. Dicha región está compuesta por diez municipios, ${ }^{1} 111$ localidades, con aproximadamente 12.593 productores, 32.906 hectáreas y 18.824 predios. Lo que coloca a la región como una de las más productivas en el estado de Veracruz. ${ }^{2}$ Actualmente, en la región de Huatusco se producen de 300.000 a 500.000 quintales de café por cosecha. ${ }^{3}$

La región es la principal productora de café orgánico del estado de Veracruz. Tan solo la Unión Regional de Pequeños Productores de Café de Huatusco cosechó en el ciclo 2010-2011 cerca de 8000 quintales, que

Facultad de Sociología del Sistema de Enseñanza Abierta de la Universidad Veracruzana (Cuerpo Académico Estudios Sociales e Interdisciplinariedad) región Córdoba-Orizaba.Correo electrónico: mhptotus@yahoo.com.mx

1 Zentla, Comapa, Tlacotepec de Mejía, Tenampa, Totutla, Sochiapa, Huatusco, Tlaltetela, Ixhuatlán del Café y Tomatlán.

2 Por poner el ejemplo de la región cafetalera de Córdoba que cuenta con 15 municipios, 180 localidades, 12.412 productores, 23.195 hectáreas y 16.613 predios, pero que produce menos café que la región de Huatusco.

3 Hernández, Manuel. (2010). Actores sociales, identidades colectivas y participación política en la región cafetalera de Huatusco 1900-2008. Tesis de doctorado. IIH-S de la Universidad Veracruzana, p. 185. 
se exportarán a Estados Unidos y a países de Europa; Redcafés ocupa el segundo lugar.

La importancia de la producción de café orgánico en esta región es central para la conservación de la biodiversidad. ${ }^{4}$ Además es una alternativa para los productores que pueden obtener mejores ganancias ante la crisis del aromático, pues el café orgánico en el mercado internacional se cotiza mejor que el café convencional.

En este trabajo se hace un análisis de la Unión Regional de Pequeños Productores de Café de Huatusco y de Redcafés, de sus estrategias para enfrentar la crisis del café y sobre todo de sus proyectos de producción de café orgánico, con la finalidad de rescatar dichas experiencias para que puedan ser replicadas en otros lugares, ya que es una alternativa ante el acaparamiento que realizan las trasnacionales en la región.

\section{CONTEXTO SOCIOECONÓMICO:}

\section{LA URPPC DE HUATUSCO Y REDCAFÉS}

Las luchas iniciadas en las zonas cafetaleras a principios de los años ochenta originaron la Unión Regional de Pequeños Productores de Café, la cual cuenta con más 2000 socios. La Unión tiene 52 grupos y presencia en los municipios de Zentla, Comapa, Tenampa, Sochiapa, Tlaltetela, Totutla, Huatusco, Tomatlán e Ixhuatlán del Café. ${ }^{5}$

4 Hay trabajos que nos plantean la importancia de la flora y fauna que existen en los cafetales. Cuando se alteran estos ecosistemas también se modifican los patrones reproductivos de plantas y animales. Para el caso del café, las modificaciones en el clima pueden afectar la floración de los cafetos y ciertas aves que son propias de estos ecosistemas mueren o emigran ante los cambios bruscos en el clima o por la reconversión de cultivos. Ver: De Haro Guijarro, Sergio. (2006). Efectos del manejo del cafetal sobre las aves en el centro del estado de Veracruz. Tesis de maestría en Ciencias. México: Instituto de Ecología A.C., Xalapa; y Villers, Lourdes, Arizpe, Nancy; Orellana, Roger et al. (2009). "Impactos da mudança climática na floracao e desenvolvimento do fruto do café em Veracruz, México”. INCI vol. 34, no. 5, p. 322-329.

5 Bartra, Armando. (2003). “Sociedad de Solidaridad Social (sss) Unión Regional de Pequeños Productores de Café, Agropecuaria, Forestal, Agroindustrial de la zona de Huatusco, estado de Veracruz". El Profe. Vida y lucha de Manuel Sedas. Xalapa. 
Las luchas por el precio del café y por apoyos que el Instituto ofrecía a cambio de cosecha, que se dieron durante la década de los ochenta del siglo xx, fueron muy importantes para la apropiación de ciertos procesos productivos dentro de la cafeticultura en la región de Huatusco, y allí la Unión Regional de Pequeños Propietarios de Huatusco tuvo un papel central. ${ }^{6}$ Pero no solo estaba la cuestión de los precios del café, sino también los problemas con la burocracia del Inmecafé, que no daba una atención respetuosa hacia los productores, lo cual generaba mucho malestar.

El Inmecafé comenzó a tener problemas de liquidez, por ello no pudo enfrentar los compromisos contraídos con los miles de productores de café en los doce estados productores. Entonces el líder nato de la Unión Regional, el profesor Manuel Sedas Rincón, decide organizar una protesta con los productores de la región de Huatusco para exigir el pago de los adeudos que tenía con ellos el Instituto. Este movimiento se extenderá a otras regiones cafetaleras del país.

Lo que sucedió a inicios de los ochenta se siguió repitiendo año a año y cada vez se realizaban las movilizaciones. De estas luchas algunas se ganaron y otras se perdieron pues el Inmecafé ya no era viable y además el gobierno, con sus políticas neoliberales, tenía en la mira desaparecerlo. Así se llegó hasta las movilizaciones para la cosecha 86-87 que duró 62 días. En esos tiempos se perfilaba la candidatura de Carlos Salinas de Gortari a la presidencia de la República. ${ }^{7}$

Carlos Salinas planteó a los cafeticultores que Inmecafé ya no era viable y que se cerraría, pero que los beneficios e infraestructura podían pasar a la iniciativa privada o al sector social. La Unión Regional (en

6 Entrevista con Angelino Espinosa Mata, presidente del Comité Ejecutivo de la Unión Regional de Pequeños Productores de Café de Huatusco, realizada el 15 de octubre de 2010.

7 Hernández Pérez, Manuel. (2010). Actores sociales, identidades colectivas y participación política en la región cafetalera de Huatusco, Veracruz: 1900-2008. Tesis de doctorado en Historia y Estudios Regionales. México: Instituto de Investigaciones Histórico-sociales de la Universidad Veracruzana. 
aquel entonces UnCAFAeCSA, ${ }^{8}$ ligada a la Central Independiente de Obreros Agrícolas y Campesinos, CIOAC) solicitó quedarse con el beneficio Cruxtitla, junto con la Unión de Ejidos Adalberto Tejeda de la Confederación Nacional Campesina (CNC). Mientras se resolvía ese asunto, los directivos de UNCAFAECSA buscaron la manera de comprar café a sus agremiados y a quien quisiera venderles; para ello se valieron de las instalaciones del Beneficio Fortuna que está a un costado del Cruxtitla, a través de maquila participativa. Cabe mencionar que muchos empleados de Inmecafé comenzaron a comprar café por su cuenta para otras empresas aprovechando que los productores los conocían y ante el cierre del beneficio del Instituto tenían temor de que su cosecha no fuera comprada.

La Unión Regional adquirió el beneficio Cruxtitla el 11 de octubre de 1989 y tuvo un precio de 1.300.000.000 de viejos pesos. Durante la cosecha 89-90 la organización se hizo cargo de la maquila del café y para la siguiente cosecha se le dio un contrato de compra del beneficio. La obtención del beneficio fue resultado de una lucha cuyo objetivo era apropiarse de una parte de la cadena de producción-comercialización de la cafeticultura; su adquisición fue también un logro simbólico para los miembros de la organización. El contrato de compra se firmó en 1992 en el beneficio de Puerto Rico en el municipio de Coatepec y el recurso fue aportado por la Secretaría de Desarrollo Social cuyo secretario era en ese entonces Luis Donaldo Colosio, y en ese preciso momento fue entregado el cheque a don Manuel Sedas. Y aunque la Unión de Ejidos Adalberto Tejeda estaba en un inicio en este proyecto, no entregó buenas cuentas durante las cosechas que trabajaron juntos, y por ello ya no participó en la adquisición final del beneficio Cruxtitla.

8 La uncafaecsa son las siglas de Unión Nacional de Crédito Agropecuario, Forestal y Agroindustrias de Ejidatarios, Comuneros y Pequeños Propietarios Minifundistas, organismo creado por la Central Independiente de Obreros Agrícolas y Campesinos (CIOAC), producto de un acuerdo del iv Congreso Nacional realizado en 1980. Funcionaba como una organización auxiliar de crédito autorizada por la Comisión Nacional Bancaria. 


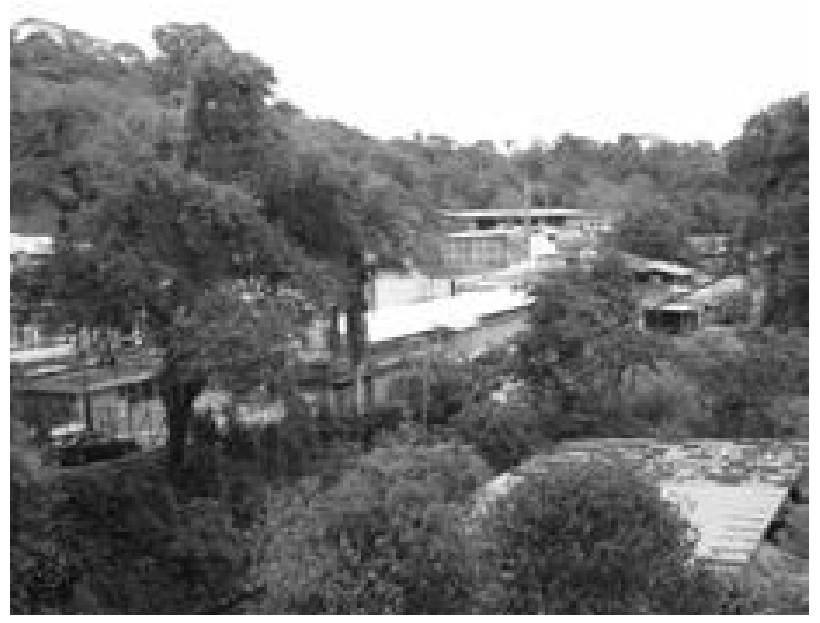

Beneficio Cruxtitla de la Unión Regional de Pequeños Productores de Café de Huatusco

El proceso por el cual han pasado los productores de la Unión Regional de Pequeños Productores de Café de Huatusco evidencia que la reestructuración de la economía impacta de forma diferenciada en los espacios locales y que muchos actores responden con la construcción de estrategias para enfrentar dichos procesos y mejorar su calidad de vida.

\section{LA UNIÓN REGIONAL Y SU PROYECTO DE CAFÉ ORGÁNICO}

El proyecto de café orgánico que tiene la Unión Regional de Pequeños Productores de Huatusco inicia en 1994 como un intento por educar a los agremiados en la protección del medio ambiente, que como ya anotábamos párrafos arriba suman más de 2000. De ellos, solo 464 están certificados actualmente en la producción de café orgánico, pero otro número significativo está en proceso de certificación, lo cual es importante porque ello quiere decir que el proyecto está siendo acogido por más productores. ${ }^{9}$

9 Entrevista con José González, tesorero de la Unión Regional de Pequeños Productores de Café, realizada el 15 de octubre de 2010. 
Dichos productores son de los diferentes municipios de la región cafetalera de Huatusco, excepto Comapa. El procedimiento para que los productores que cultivan su café convencionalmente puedan ingresar como productores orgánicos, depende del historial del manejo de sus fincas. Si los productores ya tienen algún tiempo sin usar agroquímicos el tiempo se acorta, pero el proceso es más complejo, pues se tiene que pasar por un proceso de aprendizaje largo. Dentro de este proceso tienen que elaborar su composta para no tener que comprarla.

El impacto de este tipo de producción es más en la conciencia de cada productor, no importa tanto la idea de obtener ganancias, sino de que se está protegiendo al medio ambiente. Cuando el productor está convencido del cuidado del medio ambiente se le dan nuevas alternativas para mejorar la producción con productos orgánicos y por consiguiente el certificarse les beneficiará en lo económico, pues podrán acceder a otros mercados fuera del convencional.

El impacto va en dos sentidos, el ecológico y el económico pero para llegar a eso se pasa por varias etapas, principalmente es entender la filosofía del manejo y producción orgánica, la relación tierra-hombre, aquí nos pasó lo siguiente, el productor confundía lo orgánico con lo económico, cuando bajan las ganancias ya no les es atractivo y desertan. Lo orgánico no quiere decir que se deban abandonar las fincas, sin fertilizarlas, sino que se debe llevar todo un proceso. Muchos al ver que repunta el mercado del café, le aplican agroquímicos para producir más. Allí existe una confusión. Lo orgánico lleva un sistema de manejo, lleva un plan. El impacto va en relación con la recuperación de los suelos, la reforestación y también un impacto en el precio. Pero la producción orgánica requiere mucha inversión en mano de obra. También el impacto está en que si estamos organizados tendremos la capacidad de exportar, pero si somos un pequeño grupo no lo podremos comercializar aunque tengamos la certificación como productor orgánico. Porque al venderlo dentro del mercado convencional lo pagaran igual que el café convencional. Se certifica como orgánico pero lo venden como conven- 
cional. Como organización tenemos esa fortaleza, somos pequeños productores pero tenemos volumen para exportar. ${ }^{10}$

El principal comprador de la Unión Regional es Green Mountain en los Estados Unidos, pero también se comercializa en Holanda, Inglaterra y recientemente en Francia. La cantidad de café que se vendió en la cosecha 2008/2009 fue de 4000 quintales y para la cosecha 2010/2011 será de 6800 quintales con 464 productores, en 930 hectáreas. ${ }^{11}$

La Unión Regional es la organización pionera de producción de café orgánico en Veracruz. Desde 1995 inició con los programas de certificación y logró la primera certificación en la cosecha 97-98 y de allí en adelante ha sido consecutiva la certificación.

Los productores que aglutina la organización son pequeños, pues así lo establecen los estatutos; tienen desde media hectárea hasta cinco, el promedio serían dos hectáreas, aunque existen algunos que llegan a tener hasta diez hectáreas.

El programa de café orgánico de la Unión Regional lleva todo un proceso, un plan de trabajo: se inicia antes de la cosecha, se hace una inspección, se verifica a todos los productores, sus parcelas, en relación con el año anterior, si cumplieron con las recomendaciones se les certifica, de lo contrario se quedan en transición. Después de eso, se da la inspección externa, la separación del producto desde el campo, acopio, transporte, beneficiado y almacén; tienen que ir por separado y el otro factor es la trazabilidad ${ }^{12}$ del producto, Se ve por centro de acopio cuántos productores completan una tonelada, después cuánto entra al beneficio, cuánto entra al proceso, cuánto sale de pergamino, cuánto va al

10 Entrevista con el ingeniero René Ixtla Herrera, encargado del programa de café orgánico de la Unión Regional de Pequeños Productores de Café de Huatusco, realizada el 15 de octubre de 2010.

11 Green Montain es uno de los tostadores de cafés orgánicos en los Estados Unidos.

12 La trazabilidad o rastreabilidad es la capacidad de identificar un producto y proveer información acerca de su origen y su proceso de elaboración. Se compone de un rastreo y un seguimiento. 
almacén, cuánto sale a maquila y cuánto sale de producto. Esos pasos componen la trazabilidad del producto. Para este proceso, la Unión Regional cuenta con un beneficio que es especialmente para el beneficiado húmedo y que se ubica en la comunidad de Sabanas, que se llama Solidaridad Cafetalera y que procesa exclusivamente café orgánico. Ya en el beneficiado seco el procesamiento es mixto, se beneficia el convencional y se beneficia el café orgánico. Pero cuando se va a procesar café orgánico para un cliente se detiene la maquinaria y se realiza un purgado del equipo para procesar el café orgánico; las labores de limpieza y purgado se realizan dependiendo de cuándo lo solicitan los clientes.

En relación con el tratamiento de agua que se utiliza en los beneficios la Unión Regional, se debe garantizar que el agua que se utiliza para el despulpe esté libre de coliformes, de metales pesados. Para ello se realiza un análisis: es agua que no debe estar contaminada, tanto la que se ocupa en el café convencional como en el orgánico. Pero en la actualidad el consumo de agua es mínimo, antes se utilizaba más de un litro por kilo de cereza, hoy se utilizan 900 mililitros por kilo de cereza. Los sifones ${ }^{13}$ que se utilizan son en seco, antes era con agua, hoy es mixto. La misma certificadora y las normas de la Comisión Nacional del Agua (CNA) exigen no arrojar esas aguas a los ríos sin ser tratadas. En los beneficios de la Unión Regional se tienen análisis de las aguas que salen tratadas y están en mejores condiciones de pureza que antes de haberse utilizado en los procesos de beneficiado.

El impacto que se tiene en conservación del agua de los ríos de la zona de Huatusco es fundamental, ya que hoy en día no se tiene mucho cuidado sobre los desechos que se arrojan en dichos afluentes. Además, la Unión Regional tiene un proyecto que consiste en procesar los aguamieles del café que salen del beneficio húmedo, pues están muy concentrados debido a que la cantidad de agua que se utiliza es mínima y de

13 Contenedor donde se realiza la separación del café cereza bueno del vano y de la basura. 
allí obtener etanol. Ya se realizó una prueba piloto con asesores y existen las condiciones para ello. De hecho, la Unión Regional es la única organización que realiza estos procesos de control de las aguas que se utilizan en el beneficiado del café en la región de Huatusco.

La prohibición por parte de la CNA de que sigan operando los centros de despulpe que los productores tenían en sus casas porque no trataban las aguas, fue un duro golpe que afectó al mediano y al pequeño cafeticultor. Dichos centros contaban con una despulpadora y un pequeño asoleadero. Dichas políticas limitan al productor porque ya no se le puede dar un valor agregado al producto y lo tienen que entregar cereza y porque se podía vender un poco en cereza y otro tanto procesarlo pergamino para ganar un poco más. Pero con la crisis de los precios del aromático ya no convenía secarlo porque se invertía mucho y se ganaba poco. Muchos productores quieren reactivar sus beneficios, pero ahora se les presentan dificultades, no solo en relación con el tratamiento de aguas residuales, sino también porque esa agua no puede ser tomada de redes que se han instalado para consumo humano sino que tienen que obtener una concesión, lo cual es muy difícil. Así, de ser pergamineros ahora solo pueden ser cereceros, lo que les impide abrir sus opciones de procesamiento y comercialización.

\section{REDCAFÉS COMO PROYECTO ALTERNATIVO}

La Red Nacional de Organizaciones Cafetaleras A.c. (Redcafés) surge en el año 2002 ante la necesidad de los pequeños productores de enfrentar la crisis y la tendencia a la baja de los precios del café. Está integrada por más de 1626 pequeños productores con origen diverso de 101 comunidades de 22 municipios de las regiones cafetaleras de Chiapas, Oaxaca, Veracruz y Guerrero. Cuenta con un patrimonio de 2.000 .000 de pesos. Tiene un ingreso de 48,6 millones de pesos por cosecha y tiene una línea de préstamos por 2.000.000 de dólares en México y el extranjero y una mejoría de ingreso de 1727 familias de 5,7 dólares al día, 2,7 veces la canasta básica. 
Son aproximadamente 3000 hectáreas con manejo orgánico en el trópico mexicano. ${ }^{14} \mathrm{Y}$ se realizan todas sus actividades comerciales y transacciones al extranjero a través de la figura de Café y Desarrollo s.A. de c.v.

Redcafés es una empresa del sector social, cuyo modelo organizacional es justamente el de una "Red" que agrupa y cobija a organizaciones productoras de café, mediante el uso eficiente de infraestructura y capacidad humanas, basando sus acciones en la planeación y ejecución participativa de: productores, técnicos, campesinos, facilitadores, asesores e instituciones; con la principal estrategia de realizar solo producción ecológica certificada, orientada al Comercio Justo. ${ }^{15}$

Esta red es el ejemplo de cómo los productores se pueden organizar de forma independiente frente al control corporativo del Estado y de la lógica del simple lucro de las trasnacionales del café y tener éxito. Ante los retos de la peor crisis del aromático se da una respuesta desde las bases sociales para buscar soluciones. El año 2002 fue cuando los precios estuvieron más bajos, pues por 100 libras de café se pagaban 48 dólares.

Ya para 2005, las cinco organizaciones que iniciaron este proyecto tenían la certificación orgánica de su producción y de manera colectiva se obtuvo la certificación social por el comercio justo. Para el año 2007 se da el inicio de las exportaciones directas en el mercado justo. Actualmente se vende café a los siguientes clientes: Coop Coffee Inc. (Georgia, USA), Elan Organic Coffe Inc. (San Diego, California, USA), Sustainable Harvest (Portland, USA), Eza GMBH (Kôstendorf, Austria) y CMC Malongo (Carros, Francia). Y para el 2008 se comercializa el primer lote de café con tres sellos: orgánico + comercio justo + sombra; es decir, los productores de Redcafés no solo obtienen un mejor precio por su producto sino que son reconocidos como productores sustentables.

14 Entrevista con Doris Elvira Camacho Bringas, encargada del Departamento de Créditos de Café y Desarrollo S.A. de C.V., realizada el 26 de agosto de 2011.

15 Café y Desarrollo, S.A. de C.V., Documento interno de Redcafés. 
El esquema organizativo de la red pretende hacer más horizontal la toma de decisiones y que sean los propios grupos en las comunidades quienes decidan cómo participarán en la red y qué destino tendrá su producción.

En relación con los grupos que analizaremos en este estudio solo están contemplados cinco: Catuai Amarillo S de SS (18 productores); Cafeteros de la Noria Soc. Coop. De R. L. de C.V. (20 productores) y Cafetos de Nería Sociedad Cooperativa (133 productores) de la comunidad de San José Nería, ambos grupos pertenecen al municipio de Chocamán, la Coordinadora de PzCev S.C. de R. L. de C.V. de Sabanas, Huatusco (118 productores) y la UPM de Ocozaca S de S.S. (17 productores) en el municipio de Ixhuatlán del Café.

Se debe mencionar que el total de grupos con los que cuenta la red en los estados de Chiapas, Oaxaca, Guerrero y Veracruz son hasta el momento quince. También es bueno mencionar que las oficinas centrales de Redcafés están en la población de Chocamán, Veracruz, y que desde allí se coordinan los esfuerzos de los demás grupos en las cuatro entidades.

En el cuadro siguiente aparecen los otros grupos de productores en los cuatro estados, con los cuales nuestros grupos de estudio comparten no solo el esquema organizativo, sino también una filosofía acerca de la producción sustentable en el campo.

En relación con el grupo de Catuai Amarillo de Chocamán, se puede decir que es uno de los iniciadores y fundadores de la red, y aunque solo cuenta con pocos productores es uno de los grupos más dinámicos y que ha sido punta de lanza en la región para impulsar la producción de café orgánico dentro de un lógica de sustentabilidad.

\section{EL CASO DE LOS PRODUCTORES DE LA UNIÓN DE PRODUCTORES DE LA MONTAÑA DE OCOZACA}

El proceso de constitución de la Unión de Productores de la Montaña de Ocozaca de la comunidad de Zacamitla, del municipio de Ixthuatlan 
del Café, es muy complicado y en ocasiones difícil de afrontar, ya que han pasado por momentos que han ido probando su trabajo y también el corazón del mismo grupo, que es la capacitación como método para lograr una organización exitosa.

La organización inició sus actividades en el año 2000, después de que se agudizaran los problemas con los precios del café y de que las organizaciones tradicionales en la zona no respondieran a los intereses de los productores. Los productores de café responden a la crisis construyendo estrategias que les ayudan a enfrentar tal situación. El ingeniero Felipe Melchor, asesor e impulsor de la Unión de Productores de Ocozaca lo plantea así:

...en 2000 la crisis del café se debía a la especulación en la bolsa de New York y se basaba en las existencias del producto a nivel internacional; además es un mecanismo para que los ricos sigan volviéndose más ricos, ellos tienen el dinero y nosotros el producto. Para esas épocas se vivía una fuerte crisis del café, el precio estaba a un peso con sesenta centavos y pagabas la mitad al cortador, además de los insumos para hacer producir las fincas era muy alto, las fincas se vinieron abajo, el interés de los productores hacia el campo se perdió y se comenzó a presentar el fenómeno de la migración. En esta zona no había habido tanta migración, era triste ver a tanta gente migrar por la crisis. (2012)

Es decir, la organización responde a una situación real y que busca resolver un problema que los campesinos productores de café enfrentan. En este proyecto no participan todos los productores, solo aquellos que logran vencer el miedo y que consideran que hay mayores posibilidades de éxito en la búsqueda de nuevos esquemas organizativos en lugar de quedarse estancados sin construir una respuesta a tales problemas.

La historia de la Unión de Productores de Ocozaca es el ejemplo vivo de que cuando se conjuntan voluntades se pueden lograr muchas cosas. De no tener prácticamente nada, solo algunas fincas de café, pasan a adquirir un beneficio de café, a bajar apoyos para mejorar sus 
cafetales, vehículos y la construcción de la primera etapa de lo que será una escuela campesina en la que se busca impulsar la capacitación entre productores en conjunción con los conocimientos científico-técnicos de los distintos centros educativos de la región y de otras partes del mundo.

Como en muchos proyectos, en un inicio fueron muchos los que respondieron a la convocatoria para formar un grupo de productores que trabajara con nuevos métodos y con una nueva ética; así lo plantea el ingeniero Melchor:

Iniciamos una promoción fuerte, como con 65 gentes, eran de las comunidades de Ocotitlán, Zacamitla, Ixhuatlán del Café, Ixcatla, Opatla y el Crucero de Zapata. Entonces se junta este grupo de 65 productores y se planteó que se formara una figura jurídica y que se le pusiera nombre y surgió el de Ocozaca que son las contracciones de Ocotitlán y Zacamitla y se comenzó con una capacitación intensiva cada jueves, durante todo el día y que duró dos años y que buscaba una visión distinta de cómo organizarse y una nueva ética en el trabajo. (2012)

Con pocos recursos pero con muchos deseos de impulsar un nuevo tipo de organización, estos campesinos iniciaron el difícil camino de la autogestión, que no es otra cosa que utilizar de lo poco que disponen para impulsar su proyecto. La cuestión de la ética es el centro de este nuevo tipo de trabajo organizativo, porque por experiencia en México la mayoría de los proyectos productivos fracasan a causa de casos de corrupción o de corporativismo de las centrales campesinas tradicionales o por los partidos políticos. Haber logrado arraigar un proyecto dentro de comunidades tradicionalmente corporativizadas es un logro de reconocer por sí mismo. Pero no solo eso, sino que han pasado a un segundo plano y, además de lograr cierto éxito productivo, también buscan socializar y dar a conocer el proyecto a través de una escuela campesina, donde los campesinos capaciten a los demás campesinos. A continuación, así lo expresan los propios integrantes de la directiva del proyecto. 
La idea de crear una escuela campesina es porque el entender del campesino con campesino es mejor y porque la cuestión técnica está muy corrupta, se forman organizaciones y al final el técnico es el que se adueña de la organización [...]. Las cuestiones técnicas no están ayudando a resolver los problemas en el campo, por ello hay que capacitarse. Ingeniero no es el que tiene título colgado en su casa, ingeniero es el que tiene el ingenio para resolver los problemas y les digo que los campesinos pueden ser más ingenieros que los que tienen título. Los compañeros me han sorprendido por muchas habilidades que han desarrollado a partir de la valorización de su persona. (2012)

Así, podemos constatar que la acción colectiva se dispara a partir de que los individuos toman conciencia de su capacidad para actuar y de la necesidad de agruparse para tener más fuerza e impacto en la comunidad y después en la sociedad local. La experiencia de los productores del proyecto de Ocozaca es un ejemplo de cómo están surgiendo infinidad de acciones colectivas con la finalidad bien marcada de impactar en la calidad de vida de sus integrantes, no solo quedar en las buenas intenciones, porque eso ya lo habían vivido durante mucho tiempo atrás cuando el régimen autoritario del PRI imperaba en México. En el mundo cafetalero surge una serie de acciones intermitentes y quizás sea la señal de que la sociedad ha reconocido que no necesita amos o señores para organizarse y alcanzar sus sueños.

\section{ANÁLISIS Y REFLEXIÓN SOBRE LA ACCIÓN COLECTIVA EN LA REGIÓN DE HUATUSCO}

En el libro coordinado por Boaventura de Sousa Santos, Producir para vivir, ${ }^{16}$ podemos constatar que infinidad de proyectos a lo largo y ancho

16 De Sousa Santos, Boaventura (coord.). (2011). Producir para vivir. Los caminos de la producción no capitalista. México: Fondo de Cultura Económica. 
del planeta son exitosos y que existe la posibilidad de construir nuevos horizontes con el capital humano y material con el que se cuenta en las comunidades pobres de nuestros países. En nuestro caso tenemos dos proyectos que hasta el momento podemos decir que han sabido sortear las dificultades que implica la feroz competencia en el sector agroindustrial del café: la Unión Regional de Pequeños Productores de Café de Huatusco y Redcafés.

Estos dos actores ${ }^{17}$ de la región de Huatusco (históricamente cafetalera) han generado una identidad en torno a sus "comunidades" productoras de café, le han dado un valor agregado a su producto y han enfrentado con cierto éxito el voraz control del mercado por parte de las trasnacionales. Pero no podemos ver este fenómeno de forma lineal. Estos actores se apropian de los procesos de mercantilización de la vida productiva, Norman Long lo plantea de la siguiente manera:

La mercantilización es manejada, definida o impugnada por las acciones de los actores específicos. No es un proceso hueco que se rige bajo sus propias 'leyes de movimiento', ni se puede reducir a una noción abstracta de las 'fuerzas del mercado' que empobrecen a la gente o la impulsan hacia determinada acción económica lucrativa. Más bien los procesos de mercantilización toman formas específicas a través de las acciones de una serie heterogénea de actores sociales eslabonados y se componen de constelaciones específicas de intereses, valores y recursos. La mercantilización no tiene una trayectoria dada o necesaria, excepto aquella que es negociada por los grupos involucrados y como un proceso que nunca es 'completo'. Constituye una etiqueta que aplicamos a procesos en marcha,

17 El actor social ocupa siempre una o varias posiciones en la estructura social, no se le concibe sino en interacción permanente con otros actores sociales. Está dotado de alguna forma de poder, comporta siempre una identidad o imagen de sí mismo en relación con otros; por lo general posee un proyecto (de vida cotidiana o de sociedad) que fija objetivos y define los medios para lograrlos y, por último, se encuentra en permanente proceso de socialización. 
los cuales implican luchas y negociaciones discursivas y sociales sobre el sustento, sobre valores económicos y sobre imágenes del 'mercado'.18

Los procesos en que se ven involucrados nuestros dos actores en la región de Huatusco están determinados por una serie de negociaciones y de relaciones de poder que les llevan a elegir esta ruta de la producción sustentable. A partir de las luchas que han entablado la Unión Regional y Redcafés han ido construyendo una identidad y otros grupos de la región (otras organizaciones del Consejo Regional del Café) los reconocen como actores claves, con proyectos alternativos exitosos hasta el momento. Tanto la Unión Regional como Redcafés han construido sus identidades políticas ${ }^{19}$ a través de la interacción que han mantenido con los demás actores de la región y con los procesos del mercado mundial del café. También han construido nuevas formas en la toma de decisiones desde posturas más horizontales, en la democratización de los procesos productivos, al incorporar nuevos mecanismos de distribución de la riqueza. En la región de Huatusco, en donde históricamente han imperado el caciquismo y el corporativismo estatal, estas nuevas formas de organización son vistas como novedosas y cada día convocan a más productores que ven en ellas la oportunidad de cambiar sus vidas y comunidades. Impulsar estas iniciativas no ha sido fácil, como lo comenta un asesor de Redcafés:

18 Long, Norman. (1998). “Cambio rural, neoliberalismo y mercantilización”. En Zendejas, Sergio \& de Vries, Pieter (coords.), Las disputas por el México rural. México: Colegio de Michoacán, pp. 58-59.

19 Según Gilberto Giménez, las identidades políticas son: "Identidades colectivas orientadas a la participación directa en el ejercicio del poder o a la intervención sobre los poderes públicos en términos de influencia y de presión. Y las identidades colectivas, a su vez, son el conjunto relativamente estable de rasgos distintivos por los que se reconocen y/o son reconocidos grupos o conjuntos de individuos que comparten representaciones socialmente construidas (creencias, valores, símbolos...) referentes a un campo específico del espacio social y, en consecuencia orientaciones comunes a la acción" (Giménez, G. (1996). Cultura política e identidad, México: unam, p. 12). 
...por la naturaleza de los productores que en su mayoría son pequeños, en México más del 90\% de los productores de café tienen menos de 5 hectáreas y alrededor del $60 \%$ tienen terrenos menores a una hectárea, aunque nos encontramos con contrastes porque hay productores que tienen 200, 300 plantitas hasta una finca que está en Puebla que tiene 1500 hectáreas. Nuestro país es un país de contrastes, de desigualdades, pero la mayoría son pequeños productores y muchos de ellos son indígenas, dentro de la cafeticultura en México participan 30 grupos indígenas, porque el café está en las montañas en condiciones difíciles y en ocasiones incongruentes porque en las montañas está la biodiversidad, los recursos naturales, está el agua, la riqueza. Pero por el otro lado está la pobreza y la marginación. El café es uno de los cultivos que más se han adaptado a estas condiciones de la montaña, de las sierras y la forma de enfrentar esto es la organización de los productores, pero sobre todo organizaciones que sean democráticas, autogestivas. En nuestro estado los productores es muy difícil que se organicen, porque impera más la organización de tipo político, para manipular, para controlar, pero no para que las organizaciones vayan avanzando en estos procesos. No ha sido fácil que los cafés diferenciados, como el café orgánico y el comercio justo que implica criterios sociales, crezcan en Veracruz; ha sido muy complicado y son pocas las organizaciones que están trabajando en esto. ${ }^{20}$

Si tomamos en cuenta la historia del corporativismo en México comprenderemos lo que nos plantea la cita anterior, lograr construir nuevas relaciones, fincadas en otro tipo de lógica es muy difícil en el campo veracruzano. Todo este entramado de relaciones y concepciones de su entorno sociocultural va generando una cultura política ${ }^{21}$ propia de

20 Entrevista con Esteban Escamilla Prado, investigador del Centro Regional Universitario Oriente de la Universidad Autónoma Chapingo-Huatusco y asesor de Redcafés, realizada el 9 de octubre de 2011.

21 Para Giménez, la cultura política es un "conjunto de conocimientos, creencias, valores y actitudes que permiten a los individuos dar sentido a la experiencia rutinaria 
estas organizaciones, que las lleva a tener una muy particular forma de participación política. Y aunque ni la Unión Regional ni Redcafés están directamente afiliadas a partidos políticos, los productores de forma particular sí lo están, pero aquí lo importante es la imagen y el discurso que estos actores crean sobre las relaciones que el estado tiene hacia ellas a partir de ciertas políticas públicas hacia el sector cafetalero. La Unión Regional y Redcafés tienen una participación política, ${ }^{22}$ si no partidaria de forma directa, sí en relación con el imaginario colectivo que construyen sobre su propia realidad y quienes los gobiernan.

\section{CONCLUSIONES}

Los actores sociales enfrentan los retos, las transformaciones y la reestructuración económica que genera el libre mercado -con un discurso sobre la modernización de la economía-, así como los nuevos paradigmas de sustentabilidad y los cambios en ciencia y tecnología agrícola. Los diferentes actores del campo enfrentan esos cambios, a veces con muchas desventajas y otras con instrumentos que les ayudan a sobrellevarlos en mejores condiciones. Es lo que se llama "reinvención del capital social". ${ }^{23}$

Este el caso de la Unión Regional de Pequeños Productores de Café de Huatusco y de Redcafés A.c. Ambos grupos han construido estrategias para enfrentar la crisis y se han dado a la tarea de crear conciencia y toda una filosofía de protección del medio ambiente en la región, cuya punta

de sus relaciones con el poder que los gobierna, así como también con los grupos que le sirven como referencias identitarias" (Giménez, 1996, p. 4).

22 Por participación política se entienden aquellas actividades relacionadas con el acto de votar, la militancia o simpatía por partidos políticos, la participación en protestas y manifestaciones, la discusión de problemas políticos, el apoyo dado a candidatos en campaña, la presión ejercida sobre dirigentes sociales y políticos, la difusión de ideas e información política (Bobbio, Norberto et al. (2002). Diccionario de política. México: Siglo xxI).

23 Long, Norman. (2007). Sociología del desarrollo: una perspectiva centrada en el actor. México: Ciesas-Colegio de San Luis, pp. 253-254. 
de lanza es la producción de café orgánico. Dicha tarea tiene dos objetivos fundamentales: la protección del medio ambiente y un beneficio económico para los productores que deciden participar en dichos proyectos.

Si partimos de la idea centrada en el actor, debemos reformular la concepción de desarrollo rural, intervención estatal, mercantilización de las relaciones de producción y la de la generación del conocimiento agrícola. Las relaciones establecidas gracias a las políticas estatales hacia ciertos sectores del campo (en nuestro caso el café) deben ser analizadas detenidamente. Los planificadores y los burócratas "conceptualizan, manejan y se convierten en agentes de la creación y reproducción de estos dinámicos y a menudo volátiles vínculos de mercado, lazos comunitarios o relaciones gubernamentales". ${ }^{24}$

La historia de la Unión Regional y de Redcafés es un ejemplo de estos procesos, pues han tenido que enfrentar los cambios y transformaciones que el sector cafetalero ha sufrido en los últimos 30 años, desde la crisis y desaparición de Inmecafé, hasta las políticas más recientes que el gobierno ha implementado para que el aromático mexicano esté regido por el libre mercado, cuyos representantes más claros son las trasnacionales del café.

Rescatar la historia de estos procesos de democratización es una exigencia y un reto para la sociología, pues de lo contrario no contaremos con la información necesaria para en el futuro próximo poder tomar decisiones que mejoren la situación de los productores del campo, que en nuestro caso concreto serían los cafeticultores de la región de Huatusco.

\section{BIBLIOGRAFÍA}

Bartra, Armando (2003). Sociedad de Solidaridad Social (sss) Unión Regional de Pequeños Productores de Café, Agropecuaria, Forestal, Agroin-

24 Long, Norman. (1996). “Globalización y localización. Nuevos retos para la investigación rural”. En La sociedad rural mexicana ante el nuevo milenio. México: INAHUNAM-P y v, p. 66. 
dustrial de la zona de Huatusco, estado de Veracruz. En: El Profe. Vida y lucha de Manuel Sedas. Graphos, Xalapa.

Boвbio, Norberto et al. (2002). Diccionario de política. Siglo xxi, México.

Redcafés. (s.F.). Café y desarrollo, S.A. de C.V. Documento interno de Redcafés.

De Haro Guijarro, Sergio. (2006). Efectos del manejo del cafetal sobre las aves en el centro del estado de Veracruz, México. Tesis de maestría en Ciencias. Instituto de Ecología A.C., Xalapa.

De Sousa Santos, Boaventura (coord.). (2011). Producir para vivir. Los caminos de la producción no capitalista. Fondo de Cultura Económica, México.

Giménez, Gilberto. (1996). Cultura, política e identidad. unam, México.

Hernández Pérez, Manuel. (2010). Actores sociales, identidades colectivas y participación política en la región cafetalera de Huatusco, Veracruz: 1900-2008. Tesis de doctorado en Historia y Estudios Regionales. México: Instituto de Investigaciones Histórico-sociales de la Universidad Veracruzana.

LoNG, Norman. (1996). Globalización y localización. Nuevos retos para la investigación rural. En: La sociedad rural mexicana ante el nuevo milenio. Inah-unam, México.

Sociología del desarrollo: una perspectiva centrada en el actor. CIESAS-Colegio de San Luis, 2007, México.

. (1998). Cambio rural, neoliberalismo y mercantilización. En: Sergio Zendejas \& Pieter de Vries (coords.), Las disputas por el México rural. Colegio de Michoacán, México.

Villers, Lourdes et al. (2009). Impactos da mudança climática na floraçao e desenvolvimento do fruto do café em Veracruz, México. INCI, 34(5), 322-329.

\section{ENTREVISTAS}

Angelino Espinosa Mata, presidente del Comité Ejecutivo de la Unión Regional de Pequeños Productores de Café de Huatusco. 15 de octubre de 2010. 
Doris Elvira Camacho Bringas, encargada del Departamento de Créditos de Café y Desarrollo S.A. de C.V. 26 de agosto de 2011.

Esteban Escamilla Prado, investigador del Centro Regional Universitario Oriente de la Universidad Autónoma Chapingo-Huatusco y asesor de Redcafés. 9 de octubre de 2011.

Felipe Melchor, asesor e impulsor de la Unión de Productores de Ocozaca. S.f. José González, tesorero de la Unión Regional de Pequeños Productores de Café. 15 de octubre de 2010.

Productores de la Unión de Productores de la montaña de Ocozaca de la comunidad de Zacanitla, Ixthuatlán del Café. 27 de octubre de 2012.

René Ixtla Herrera, encargado del programa de café orgánico de la Unión Regional de Pequeños Productores de Café de Huatusco. 15 de octubre de 2010. 

SEGUNDA PARTE:

ELITES POLITICAS 



\section{LA PARTICIPACIÓN ELECTORAL COMO FORMA DE ACCIÓN COLECTIVA EN EL ÁMBITO LOCAL EN COLOMBIA}

YANN BASSET ${ }^{*}$

\section{INTRODUCCIÓN}

El ANÁlisis ELECTORAL y la sociología de los movimientos sociales son dos perspectivas que pocas veces se cruzan, más aún en Colombia donde la política suele ser vista por los activistas sociales como un ámbito separado, reservado a unos actores específicos preocupados por sus propios intereses y mirados con cierto recelo. A su vez, muchos políticos suelen considerar con desconfianza el ámbito de los movimientos sociales, como fuente de presiones indebidas que limitan su margen de acción y, por lo tanto, su poder. El conflicto armado lancinante que sufre el país contribuye a agravar el divorcio entre estas dos esferas.

Ahora bien, el objetivo del grupo de trabajo cuyas contribuciones se reúnen en este libro fue precisamente estudiar a estos dos tipos de actores, elites políticas y miembros de movimientos sociales, en sus interacciones y en espacios donde sus relaciones parecen menos susceptibles de presentarse en condiciones óptimas. En este artículo retomaremos en forma comparativa reflexiones que se desprenden de los terrenos estudiados por el grupo en escenarios locales colombianos. Estos terrenos tienen en común un carácter periférico con respecto a las diná-

Doctor en Ciencia Política de la Universidad de París III Sorbonne Nouvelle, profesor de Ciencia Política en la Universidad del Rosario, investigador del Centro de Estudios Políticos e Internacionales (CEPI), director del Observatorio de Procesos Electorales (OPE). 
micas políticas, sociales, económicas y culturales centrales del país. Sufren los efectos de una gran distancia con respecto al Estado y sus instituciones, y son gravemente afectados por la violencia que azota el país, así como por la pobreza y la carencia de servicios esenciales. Sin embargo, las anteriores contribuciones mostraron que este contexto adverso no impide el emprendimiento de importantes acciones colectivas de diversas índoles. ${ }^{1}$ Lo que quisiéramos mostrar ahora es que estas acciones colectivas, lejos de permanecer aisladas de la escena política institucional, se interrelacionan con ella, aun con muchas dificultades y malentendidos. Con esto quisiéramos ilustrar, a través de unos ejemplos, el interés del estudio de la participación electoral en el ámbito local, como una excelente herramienta para descubrir de qué forma se establecen estas relaciones. A su vez, nos permite entender mejor algunos aspectos de los procesos de acción colectiva estudiados que no siempre aparecen con claridad al escuchar el discurso de los miembros comprometidos en ellas.

Empezaremos con algunas consideraciones teóricas a manera de marco de análisis que nos permitirán sentar aspectos relevantes del estudio de la participación electoral en relación con la acción colectiva. En un segundo momento, esbozaremos en forma general las dinámicas de participación electoral en Colombia, antes de interesarnos en forma comparativa a la misma en los distintos terrenos colombianos explorados en este libro. Finalmente, propondremos algunas interpretaciones al respecto que permitan ajorar luces sobre las condiciones mediante las cuales la participación electoral puede ser un buen indicador para ayudar a caracterizar formas de acción colectiva.

1 En este trabajo entendemos por acción colectiva la acción voluntaria, coordinada y consciente de dos o más actores sociales en función de un objetivo compartido. Esta definición formal distingue el ámbito de la acción colectiva (de la cual los movimientos sociales son una forma destacada por su organización y durabilidad) de los tipos de interacciones con formas de coordinación no conscientes y espontáneas, por ejemplo, el mercado tal como está analizado en la teoría neoclásica. 


\section{LOS DETERMINANTES INDIVIDUALES Y COLECTIVOS DE LA PARTICIPACIÓN ELECTORAL}

La sociología electoral ha propuesto varias explicaciones a la participación electoral. No pretendemos acá reseñarlas con exhaustividad, ni aportar nuevas hipótesis al respecto, pero quisiéramos observar que tales explicaciones pueden agruparse en dos grandes grupos: unas hacen hincapié sobre incentivos individuales, mientras otras privilegian incentivos colectivos. Estas últimas nos acercan de manera interesante al ámbito de la acción colectiva y serán privilegiadas acá.

Las primeras explicaciones son tal vez las que nos llegan a la mente con mayor facilidad, porque corresponden a la manera misma como el sufragio ha sido concebido por la ideología liberal-republicana que acompañó la constitución de los regímenes representativos modernos. El derecho al voto era personal y los ciudadanos eran invitados a pronunciarse en las elecciones libremente, es decir, en función de sus propias opiniones, sin interferencias ajenas. Es por esta razón que la Revolución francesa insistió tanto en la prohibición de los cuerpos intermediarios, que vendrían a interponerse entre los ciudadanos y el Estado, y que excluyó de paso del derecho de sufragio a todos los que no eran considerados aptos para expresar una opinión libre, como las mujeres, los analfabetos o los trabajadores dependientes. ${ }^{2}$ Más tarde, a partir del final del siglo xIx, el voto secreto obedeció a la misma lógica de exaltación de la autonomía del ciudadano. Se trataba de reafirmar la dimensión eminentemente personal del sufragio, resultado de una decisión individual, informada y no influenciada por terceros.

A partir de la segunda mitad del siglo xx, la escuela de la elección racional se esforzó por teorizar estas premisas en claves científicas, par-

2 Al respecto se pueden consultar los desarrollos de Pierre Rosanvallon en el caso francés (Rosanvallon, 2001). 
tiendo de los trabajos seminales de Anthony Downs (1957). La idea básica de este tipo de análisis es que la decisión de participar en una elección como votante es el resultado de un cálculo de los beneficios esperados por la elección del candidato que se apoya.

En esta línea, se enfatizó la importancia del voto programático y de los temas destacados en las campañas (issues) en el comportamiento electoral (Nie, Verba y Petrovik, 1976). Por otra parte, la perspectiva de la elección racional también puede dar cuenta de un fenómeno fundamental para nuestros terrenos y para América Latina en general: el clientelismo electoral. Ahí, el voto es el resultado de una transacción que permite "comprar" un bien o el acceso a un servicio proporcionado por el político candidato (Kitschelt y Wilkinson, 2007).

Si en el caso del clientelismo estamos lejos del modelo de virtud promovido por el civismo republicano, existe en el fondo una sutil continuidad entre los dos que radica fundamentalmente en una visión utilitarista del voto como resultado de un cálculo de maximización de intereses, aun cuando ciertas versiones de republicanismo inspiradas en Rousseau insisten en la idea de que el cálculo debe tener por objeto el interés general.

Aunque la escuela de la elección racional sigue influenciando muchos trabajos de análisis electoral hoy, sus postulados han sido objeto de críticas permanentes desde la sociología electoral que, desde su fundación al principio del siglo $\mathrm{xx}$, tendió más bien a enfatizar el papel de incentivos colectivos de varias índoles. En el origen de esta perspectiva yace la constatación empírica de que, al contrario de lo que supone la idea normativa defendida por la ideología republicana-liberal, el voto puede ser analizado como una acción colectiva en la medida en que supone la coordinación de muchas acciones individuales en función de un objetivo compartido.

Esta constatación es tan antigua como el derecho de sufragio y ya había sido relevada de manera muy ilustrativa por Alexis de Tocqueville en un pasaje famoso de sus memorias donde describe la manera como se 
desarrollaron las primeras elecciones al sufragio universal en un pequeño pueblo francés en $1848 .^{3}$

Este aspecto colectivo de las elecciones no deja de apreciarse en los resultados del proceso. Dando nacimiento a la sociología electoral al principio del siglo xx, André Siegfried ponía en evidencia la existencia de patrones territoriales consistentes en la distribución geográfica de los votos que daban cuenta de esta dimensión (Siegfried, 1913). Detrás de estos resultados electorales en forma de grandes bloques relativamente homogéneos reconocemos la existencia de las identidades colectivas que focalizan la atención de los analistas de los movimientos sociales. Como lo subrayó Daniel Gaxie: "El voto es una experiencia colectiva que revela y reactiva la pertenencia a grupos sociales al mismo tiempo

3 “La población siempre había sido benévola conmigo, pero esta vez la encontré afectuosa, y nunca me vi rodeado de más respeto que ahora, cuando la igualdad brutal estaba fijada en pasquines por todas las paredes. Teníamos que ir a votar juntos al pueblo de Saint-Pierre, a una legua de distancia de nuestro lugar. La mañana de la elección, ante la iglesia se reunieron todos los electores, es decir, toda la población masculina mayor de veinte años. Todos aquellos hombres se alinearon de dos en dos, por orden alfabético. Yo quise colocarme en el puesto que me correspondía por mi apellido, porque sabía que, en los países y en los tiempos democráticos, hay que hacerse poner a la cabeza del pueblo, y no ponerse uno mismo. Al final de la larga fila, venían, en caballos de albardas o en carros, los débiles o los enfermos que habían querido seguirnos. No quedaban en el lugar más que los niños y las mujeres. En total, éramos ciento setenta. Al llegar a lo alto de la colina que domina Tocqueville, nos detuvimos un momento. Me dijeron que querían que yo hablase. Me subí, pues, al declive de una zanja, formaron un círculo a mi alrededor y dije algunas palabras que la ocasión me dictó. Recordé a aquellas buenas gentes la gravedad y la importancia del acto que iban a realizar, les recomendé que no se dejasen acercar ni apartar por individuos que, a nuestra llegada al pueblo, podrían tratar de engañarles, sino que caminasen sin separarse y que se mantuviesen juntos, cada uno en su sitio, hasta que se hubiese votado. 'que nadie -dije- entre en una casa para comer algo o para secarse (era un día de lluvia), antes de haber cumplido con su deber'. Gritaron que así lo harían y así lo hicieron. Todos los votos fueron entregados al mismo tiempo y tengo motivos para pensar que casi todos fueron para el mismo candidato" (Tocqueville, 1848, pp. 145-146). Con esta descripción, estamos muy lejos del ideal del elector racional y autónomo. Se podrá objetar que la escena corresponde a una comunidad tradicional todavía poco acostumbrada a la mecánica electoral, sin embargo, una observación somera de los rituales electorales contemporáneos que se realizan sobre el terreno, desde el principio de la campaña hasta el día de los comicios, no puede obviar todos los detalles que traicionan la naturaleza eminentemente colectiva del acto electoral. 
que depende de esta pertenencia y de la posición de los grupos en el sistema de clivajes entre los grupos” (Gaxie, 1985, p. 22, traducción nuestra).

La naturaleza de estos grupos y, por ende, el tipo de incentivos colectivos susceptibles de favorecer su participación electoral siguen siendo objeto de controversias. Con el paradigma de Columbia, Lazarsfeld enfatizaba el papel de la socialización a través de redes concretas y diversas de los electores para explicar sus comportamientos electorales (Lazarsfeld, 1944). Ese enfoque cuestionaba el papel de la propaganda y el marketing electoral en una época en que se les consideraba como fundamentales. Más tarde, un grupo de estudiosos mostró la importancia de identidades políticas más abstractas que se refieren a los partidos políticos en el caso de Estados Unidos (Campbell et al., 1960). Hoy, los estudios tienden a mostrar en varios países que dichas identidades se hacen más fluidas y cambiantes de una elección a otra, pero no por eso pierden su importancia.

Incluso se ha mostrado que el clientelismo, que parece conformarse tan naturalmente al modelo de análisis tipo "elección racional" en la medida en que acerca el voto a un intercambio de naturaleza económica, no se realiza en forma aislada con respecto a estas identidades colectivas. Los estudios empíricos más destacados del fenómeno muestran, al contrario, que el clientelismo se desarrolla en el marco de un ritual que tiene precisamente como objeto poner a distancia su ruda naturaleza de intercambio utilitario para darle otra significación de pertenencia a una red de solidaridad sustentada en una identidad colectiva. Así, Javier Auyero mostró en el caso de las redes clientelistas del partido peronista argentino que lo importante no era lo que se daba en esta relación sino la manera como se daba, que repetía siempre la puesta en escena del pacto de lealtad entre el peronismo y el pueblo (Auyero, 2001). En este sentido, contrariamente a lo que supone un análisis estándar con enfoque de "elección racional", las observaciones empíricas muestran que los clientes no necesariamente entregan el voto al 
político que más ofrece. Este intercambio se inscribe en muchos casos en una relación de confianza que se sustenta en una tradición política compartida. Dicho de otra manera, el clientelismo es también una acción colectiva y no un proceso de coordinación espontáneo como el mercado de las teorías económicas neoclásicas.

Así, si bien el gesto de votar es individual, el hecho más general de participar en una elección que supone la tarea no solamente de informarse sino también de discutir con otros, eventualmente asistir a reuniones públicas, armar, activar o integrar una red de clientes, o incluso participar activamente en una campaña, implica un proceso consciente de coordinación con terceros para lograr un objetivo. En otras palabras, tiene que ser analizado como acción colectiva. Mejor aún, podríamos decir que una elección funciona como un nudo de varios procesos de acciones colectivas que se nutren las unas de las otras.

Si miramos las elecciones de esta manera podemos considerar la participación electoral como un barómetro que mide el éxito de este proceso de acciones colectivas imbricadas. Una gran cantidad y amplitud de acciones colectivas emprendidas en ocasión de una elección debería movilizar una mayor cantidad de ciudadanos y resultar en una participación alta. A su vez, podemos observar en la línea de los conocidos trabajos de Putnam que la acción colectiva tiende a reproducirse a través de la construcción de capital social, es decir de "normas de reciprocidad y redes de compromiso cívico” (Putnam, 1993, p. 167, traducción nuestra). Si es así, una alta participación electoral puede indicarnos la existencia de un importante capital social en la comunidad considerada. Este capital social es un activo incremental que facilita la movilización colectiva, y que es alimentado por las experiencias de movilizaciones pasadas. ${ }^{4}$

4 Sobre la utilización del concepto de capital social con relación a la participación electoral, se pueden consultar las reflexiones y el trabajo empírico de Condon (2009). 
Por otra parte, como lo señala Putnam, el capital social no varía solamente en intensidad, sino también en alcance: "Redes horizontales densas pero segregadas sostienen la cooperación dentro de cada grupo, pero redes de compromiso cívico que atraviesan clivajes sociales nutren una cooperación más amplia" (Putnam, op. cit., p. 175, traducción nuestra). De esta manera, un intenso capital social comunitario puede nutrir una alta participación en elecciones locales, pero baja en elecciones nacionales.

En las siguientes secciones mostraremos cómo esta perspectiva puede aplicarse a nuestros terrenos comparando los indicadores de participación electoral de nuestros terrenos de estudios entre ellos y con respecto a los niveles nacionales desde dos perspectivas: primero, utilizando el porcentaje general de participación como variable indicadora de la intensidad del capital social en el terreno estudiado, y segundo, utilizando la variación entre distintos tipos de elección como variable indicando el alcance del capital social en cuestión. Confrontando estos resultados con lo que conocemos de las modalidades de acción colectiva en estos terrenos, podremos sacar conclusiones importantes para el conjunto de nuestros trabajos.

\section{LA PARTICIPACIÓN ELECTORAL EN COLOMBIA: UN TERRITORIO DESARTICULADO}

La comparación de las tasas de participación electoral en Colombia y otros países de América Latina suele mostrar un panorama poco alentador para la primera, sin importar el tipo de elección. Como ejemplo podemos señalar que las elecciones presidenciales del año 2010 registraron una tasa de participación de 49,9\% en la primera vuelta para Colombia, mientras que la de las elecciones federales de 2012 en México fue de $63,14 \% .{ }^{5}$ Las comparaciones tienen que ser tomadas con cuidado pues

5 Cifras obtenidas, respectivamente, por la Registraduría Nacional de Estado Civil de Colombia y por el Instituto Federal Electoral de México. 
las diferentes legislaciones inciden directamente sobre estos porcentajes. Entre otras cosas, el voto es obligatorio en México aunque la abstención no es sancionada, mientras es facultativo en Colombia. No obstante, no hay duda acerca del carácter llamativamente bajo de la participación electoral en general en Colombia. Pocos son los estudios que intentaron explicar este fenómeno todavía mal comprendido, del cual los modelos estadísticos convencionales no permiten dar cuenta. ${ }^{6}$ Se apunta en general hacia dos elementos: por una parte, la violencia de los grupos armados que, como lo veremos, tienen efectivamente un impacto, pero en una parte limitada del territorio; y por otra, las dinámicas históricas específicas del país.

En cuanto a esto, cabe mencionar que Colombia no fue siempre un país abstencionista, al contrario. Existen tres períodos bien distintos al respecto: de 1930 a 1958, la participación fue importante y creciente en un contexto de fuerte movilización social y política que desembocaría en la casi guerra civil conocida como la Violencia desde 1948. A partir de 1958, el pacto del Frente Nacional pone fin a la violencia partidista y se traduce en una desmovilización política general que se nota no solo en el nivel de violencia, sino también en las urnas. La participación cae poco a poco hacia niveles bajos en la medida en que la alianza entre los dos principales partidos le restó competitividad a las elecciones. El fin de este sistema en 1974 se traduce en un efímero auge de la participación electoral en los años setenta, antes de que la tendencia vuelva a bajar hacia 1994. Desde esta fecha, la participación se estabilizó en el bajo nivel actual. ${ }^{7}$ Así, el descenso en la participación y su posterior estabilización a nivel bajo se debería a una despolitización programada a partir del Frente Nacional, que si bien tuvo el efecto buscado de poner fin a la violencia política de los años 1948-1958, se prolongó hacia una actitud apática y escéptica frente al sistema político. Por otra parte, a

\footnotetext{
6 Véanse al respecto las consideraciones de Losada, Giraldo y Muñoz, 2004.

7 Este resumen sintético puede ser ampliado a partir de las lecturas de Weiss, 1968, Gutiérrez, 2007, y Losada, Giraldo y Muñoz, 2004.
} 
partir de los años setenta, este contexto favoreció la aparición de una nueva generación de políticos de la mano con el clientelismo y, eventualmente, la corrupción o las alianzas locales con actores armados. Esto habría contribuido al alejamiento de muchos colombianos con respecto a la política (Gutiérrez, 2007). De cualquier forma, conviene observar que la participación electoral no es un fenómeno homogéneo. Un análisis geográfico nos permite entender por qué las explicaciones simples no bastan, y por qué los modelos estadísticos no arrojan resultados claros al nivel nacional.

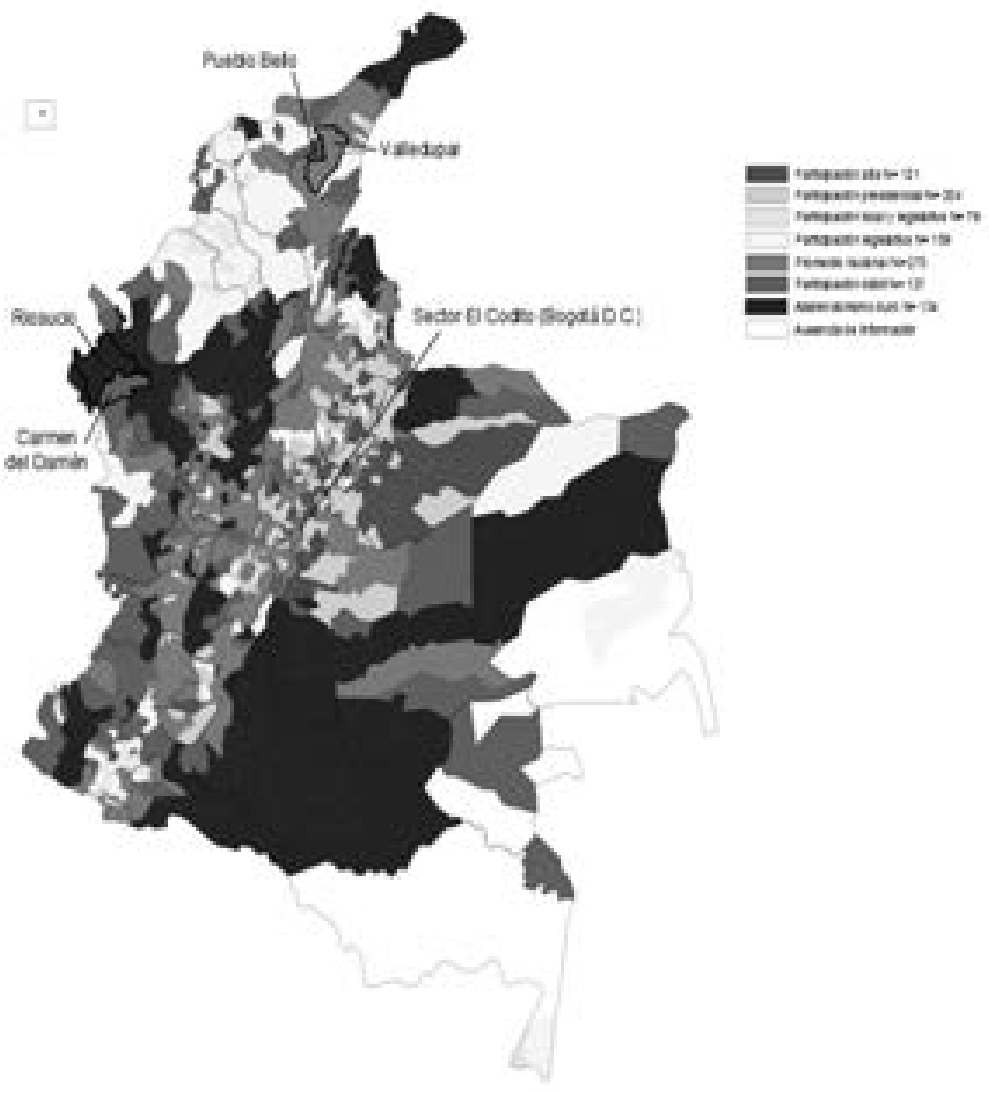

Mapa 1. Mapa sintético de la participación electoral en Colombia 
El mapa 1 es un mapa sintético que nos permite hacer un resumen de la participación electoral de las dos últimas elecciones presidenciales, legislativas y locales a nivel de municipios. Se obtuvo mediante una técnica estadística denominada Clasificación Ascendente Jerárquica (CAJ), que permite agrupar los municipios del país en función de un comportamiento afín de las seis variables consideradas aquí (es decir, la tasa de participación en cada una de las seis elecciones consideradas). ${ }^{8}$ El resultado se lee intuitivamente a través del nombre que le pusimos a las siete

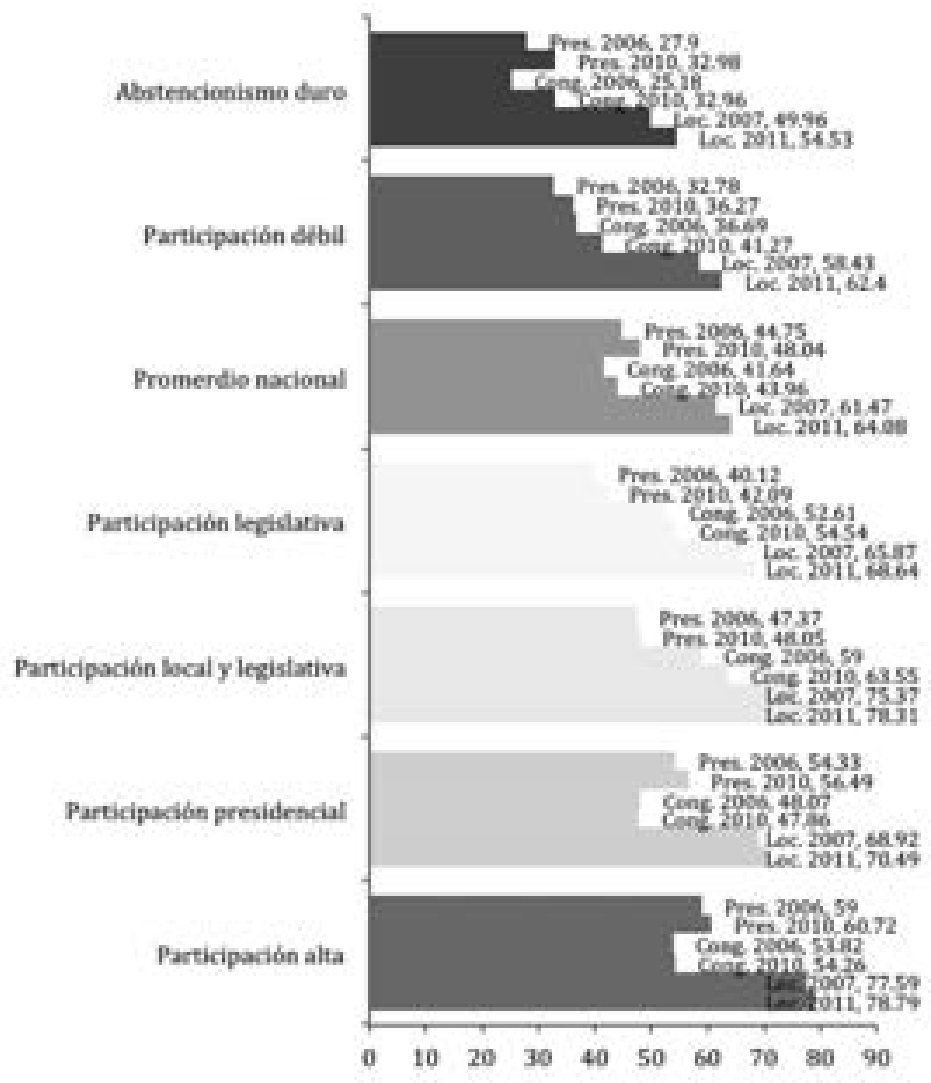

8 Este mapa ha sido realizado con el software Philcarto puesto a disposición en internet por su creador, Philippe Waniez (http://philcarto.free.fr). 
categorías representadas en leyenda, y con la ayuda del gráfico de leyenda que acompaña el mapa. En el gráfico representamos las tasas de participación promedio de los municipios que pertenecen a cada categoría, para cada elección. Podemos apreciar así la existencia de comportamientos muy diferenciados en distintas regiones del país desde el punto de vista de la participación electoral.

Este mapa nos permite ir más allá de las tasas nacionales para entender la diversidad de los comportamientos al nivel territorial. Constatamos entonces que, a pesar del abstencionismo general, existen unos 120 municipios (en verde oscuro), sobre los 1124 que cuenta Colombia, que tienen tasas de participación nada despreciable, en particular para elecciones presidenciales (alrededor de 60\%) y sobre todo locales (alrededor de 80\%). Esta misma zona de alta participación se completa con unos 200 municipios (verde) con participación no tan importante, pero que sigue por encima de la participación nacional por unos cinco puntos en promedio. En este segundo grupo de municipios la participación no es tan intensa al nivel local (unos ocho puntos menos que en la categoría anterior), aunque sigue bastante alta con respecto a los estándares nacionales. También baja significativamente en cuanto a las elecciones legislativas. En cambio, la participación en las elecciones presidenciales se ubica apenas cuatro puntos por debajo de los municipios de la categoría anterior. Como podemos ver en el mapa, estas dos primeras categorías agrupan municipios del centro del país, ubicados en particular sobre la cordillera oriental, sobre todo en los departamentos de Boyacá, Casanare, Cundinamarca y Santander. La proximidad geográfica de la capital del país favorece ahí una fuerte integración de la población en las dinámicas políticas, económicas y sociales nacionales, lo que explica esta fuerte participación. Por otra parte, la presencia de los actores armados en esta región no se hace sentir de forma tan apremiante como en otras. Finalmente, la misma geografía montañosa tuvo como consecuencia una arquitectura administrativa en forma de municipios poco extensos, organizados alrededor de pueblos pequeños o 
medianos, lo que favorece la existencia de una vida local dinámica. Por lo tanto, retomando la explicación sugerida en la primera parte, podemos considerar que la participación electoral se asienta ahí en intensas redes de capital social. Esto es la clave de la alta participación en las elecciones locales en particular.

Siguen en verde-amarillo y amarillo dos categorías interesantes porque se destacan por un comportamiento de participación electoral intermedia, pero con un pico para las elecciones legislativas que lleva la participación incluso a niveles superiores en el caso de las dos categorías de municipios más participativos. A la inversa, la elección presidencial moviliza ahí menos electores que en el promedio nacional. Así, los municipios que pertenecen a estas categorías tienen la particularidad de movilizar más electores para las legislativas que para las presidenciales, comportamiento inverso a las cifras nacionales. La primera de estas dos categorías agrupa unos 80 municipios (verde-amarillo) que siguen demostrando una excelente participación en elecciones locales, la cual se ubica casi al nivel de los municipios de la categoría de mayor participación. Sin embargo, se diferencian de estos por una participación presidencial débil que se ubica por debajo del promedio nacional y, en cambio, por tener los récords de participación nacional en las elecciones legislativas (de 15 a 20 puntos por encima de la participación nacional). Estos municipios, generalmente pequeños, se ubican en su mayoría en dos regiones distintas: en el interior de la costa Caribe y en la parte alta del departamento de Nariño, en el sur del país. Los 159 municipios de la categoría siguiente (amarillo) tienen un comportamiento electoral parecido a la categoría anterior en cuanto a la diferencia entre tipos de elecciones, pero con una participación de diez puntos menos para todas. En este caso, la gran mayoría se ubican en la costa Caribe. Así, estas dos zonas tienen un comportamiento atípico y contraintuitivo. El hecho de participar más en las elecciones legislativas que en la presidencial va en contra de lo que suele ocurrir en los regímenes presidenciales, donde la elección del primer mandatario suele ser el momento estelar de la vida 
política por la importancia del puesto y, por lo tanto, la elección más concurrida, por lo menos en cuanto a elecciones nacionales. Por otra parte, la personalización de las campañas que se deriva del escrutinio presidencial es más adecuada para generar la adhesión popular que los escrutinios de lista del Congreso.

La explicación tiene que ser encontrada en las modalidades del clientelismo colombiano. Es durante las elecciones legislativas que el clientelismo se nota con mayor fuerza. Desde el año 2003, los congresistas colombianos son electos con escrutinio de lista, pero con voto preferente, lo que personaliza considerablemente la elección. Sin embargo, los candidatos al Congreso no gozan ni de la notoriedad local "de proximidad" de un candidato a la Alcaldía o al Concejo, ni de la imagen nacional de los presidenciables. En este contexto, el clientelismo se ha vuelto la modalidad "normal" para ganar elecciones legislativas en buena parte del país. En las elecciones presidenciales el clientelismo tiene una importancia mucho más difusa, mientras al nivel local es temperado por las relaciones personales que se inscriben en redes de diversas índoles. ${ }^{9}$ Podemos concluir, por lo tanto, que los municipios de las dos categorías que nos ocupan corresponden a las áreas de mayor implantación de esta modalidad. Existen todavía redes con capital social fuerte, pero relativamente segregados en el espacio, esto explica la ubicación de estos municipios en regiones alejadas de la capital y con fuertes identidades provinciales.

Pasaremos rápidamente sobre la categoría que denominamos "promedio nacional" (naranja) que, como indica su nombre, corresponde a unos 273 municipios cuya participación electoral es conforme a lo que muestran las cifras nacionales. Observemos simplemente que esta categoría, además de agrupar el mayor número de municipios,

9 El clientelismo no está totalmente ausente de las elecciones presidenciales. Se canaliza, en este caso, a través de programas oficiales de transferencias condicionadas como "Familias en Acción". Sin embargo, su impacto parece mucho más limitado (ver al respecto Basset y Guerrero, 2011). Para un panorama más general del clientelismo en Colombia (Gutiérrez, 2007). 
tiene un peso muy importante también en la medida en que muchas ciudades importantes pertenecen a ella, en particular, Bogotá, Medellín, Cúcuta, Bucaramanga, Pereira, Ibagué o Manizales. De este modo, estamos hablando del comportamiento electoral "estándar" de la Colombia urbana, que tiene un peso fuerte en los resultados finales.

Finalmente, las dos últimas categorías agrupan los municipios que registran la mayor abstención electoral. Los municipios en rojo claro alcanzan a tener una participación significativa a nivel local, aunque por debajo de los niveles nacionales. En cambio, las elecciones nacionales movilizan muy poco, en particular la presidencial que atrae solamente el tercio de los electores. Las legislativas alcanzan a movilizar un poco más, como en las categorías anteriores, probablemente por la misma razón. Sin embargo, en este caso, aún el uso del clientelismo no alcanza a llevar a las urnas más de un $40 \%$ de los electores, lo que nos ubica por debajo del nivel nacional. En el caso de la última categoría (rojo oscuro) tenemos unos 130 municipios en los cuales este recurso ni siquiera parece capaz de sacar de la apatía a los electores. Ahí el nivel de participación es igual de bajo para presidenciales como para legislativas (menos del tercio del electorado), y las locales a duras penas logran la participación de la mitad de los electores. Sin sorpresa, una simple mirada al mapa nos confirma las premisas mencionadas en la primera parte a propósito de las explicaciones de la participación. Los municipios de estas dos categorías corresponden a las zonas más periféricas del país, alejadas de las grandes dinámicas económicas y sociales y, además, las más afectadas por la presencia de actores armados. ${ }^{10}$ La categoría roja oscura corresponde a las zonas que han sido históricamente bastión de las guerrillas. Así, en estas zonas encontraremos comunidades que disponen de un capital social limitado, y sobre todo, muy segregado. Los efectos de desestructuración social de la violencia se notan acá con mucha fuerza.

10 Los mapas de riesgo por violencia política de la Misión de Observación Electoral confirman esta relación (MOE, 2011). 


\section{LA PARTICIPACIÓN EN LOS TERRENOS DE ESTUDIO}

Teniendo claro el panorama anterior podemos empezar a ubicar nuestros terrenos de estudio en el panorama nacional de la participación electoral. ${ }^{11}$ En el mapa ya citado hemos ubicado los municipios que corresponden a los terrenos de estudio. La primera constatación que se impone es que todos se ubican en zonas de participación débil o de abstencionismo duro. Esto no puede sorprendernos. Nuestro estudio se centró en acciones colectivas que se realizan en condiciones particularmente adversas por el contexto de violencia, desplazamiento, pobreza, abandono estatal, etc. A primera vista, esto parece confirmar nuestra hipótesis: estas zonas adversas a los procesos de acción colectiva son también adversas a la participación electoral, conforme a nuestra caracterización de la elección como un nudo de acción colectiva. La única excepción es el caso del sector El Codito, que se ubica en la categoría "promedio nacional"; no obstante, la pertenencia del sector a esta categoría resulta de la clasificación del Distrito Capital en su conjunto, de nuevo, en dicha categoría. En este caso conviene, por lo tanto, observar los resultados electorales a un nivel más fino, pues la participación de Bogotá no es necesariamente buen indicador de la participación electoral del barrio. Para poder hacer una observación más detallada hemos intentado acercarnos lo más posible al cálculo de la participación electoral de los grupos que nos interesan. Hemos seleccionado los centros de votación que reciben los votos de la población involucrada en los procesos de acción colectiva estudiados, con el fin de tener una idea del nivel de su participación electoral. No sobra decir que este ejercicio tiene que ser tomado con mucha cautela. No todas las personas que

11 No hemos podido integrar las comunidades afrodescendientes que trabaja Armando Durán en nuestro estudio debido a su dispersión geográfica. En cambio, hemos integrado el caso del sector El Codito, un barrio periférico de Bogotá sobre el cual nuestro grupo de investigación ha realizado varios trabajos. Aunque no se pudo integrar un artículo sobre este caso en este libro, el lector se podrá remitir a: Mendoza y Guevara, 2012. 
votan en esos puestos son miembros o se sienten representadas por las organizaciones estudiadas, ni todas las personas pertinentes para nuestro estudio votan en los puestos que hemos tomado en cuenta. Sin embargo, confiamos que la selección de los puestos nos da un resultado que corresponde a una aproximación razonable del comportamiento electoral de la población estudiada en el caso de El Codito (el puesto de votación tomado en cuenta es el único ubicado en el sector), y del pueblo arhuaco (las cifras corresponden a la suma de los tres puestos de votación que se ubican dentro del resguardo indígena).

CUADRO 1. La participación electoral en los terrenos de estudio

\begin{tabular}{|l|c|c|c|}
\hline Tasa de participación & Locales 2011 & $\begin{array}{c}\text { Presidencial 2010 } \\
\text { (1ravta.) }\end{array}$ & Legislativas 2010 \\
\hline Nacional & 57,3 & 49,3 & 44,24 \\
\hline Municipal & & & \\
\hline Pueblo Bello & 56,14 & 29,32 & 36,03 \\
\hline Riosucio & 54,23 & 20,83 & 31,12 \\
\hline Carmen de Darién & 67,47 & 24,21 & 33,97 \\
\hline Tumaco & 55,51 & 34,56 & 43,05 \\
\hline Buenaventura & 55,26 & 35,48 & 39,16 \\
\hline Local & & & \\
\hline Sector El Codito & 59,11 & 68,07 & 46,33 \\
\hline Pueblo arhuaco & 38,18 & 11,24 & 22,45 \\
\hline
\end{tabular}

El cuadro 1 confirma que el sector de El Codito es realmente una excepción dentro de los terrenos que estudiamos. Se trata del único de nuestros terrenos cuyas tasas de participación se ubicaron por encima de las tasas nacionales en las últimas tres elecciones. Estas cifras aproximan incluso el sector a la categoría de "participación presidencial" del mapa sintético más que a la de "promedio nacional" en la cual se ubica el dis- 
trito capital en su conjunto. Así, El Codito tiene tasas de participación electoral llamativamente altas, incluso en el contexto bogotano. Esta constatación no infirma nuestra hipótesis sobre el vínculo entre participación electoral e intensidad de los procesos de acción colectiva. Los estudios realizados por la Universidad del Rosario ponen de relieve la importancia de las estructuras de participación en la zona. ${ }^{12}$ Esto se debe en parte a la historia de El Codito, atravesada por luchas colectivas para obtener la legalización del sector. Así, las Juntas de Acción Comunales (JAC), ${ }^{13}$ o los comedores y jardines comunitarios se benefician de un importante reconocimiento. Por otra parte, la proximidad física con las instituciones distritales y nacionales ha favorecido la organización periódica de una gran cantidad de espacios de participación ciudadana promovidos por las instituciones públicas. Esto nos habla de la existencia de un capital social particularmente denso en el caso de El Codito, a pesar de los problemas de inseguridad y carencias diversas que sufre la zona. Las consecuencias sobre la participación electoral son evidentes, en particular a nivel local. Hay que añadir a esto el hecho de que el sector acoge a una población migrante originaria en particular de Boyacá, el norte de Cundinamarca o Santander, departamentos que, como nos indica el mapa, gozan de la mayor tradición de participación electoral del país. Muchos habitantes, en particular los de mayor edad, importaron la tradición política de sus pueblos de origen, donde el bipartidismo conservador/liberal solía tener raíces profundas. Parte de la generación siguiente se identificó con la izquierda, que estuvo muy activa en las luchas por la legalización del sector. Finalmente, las últimas en llegar fueron las iglesias cristianas, que empezaron a prosperar en el sector y

12 Nos apoyamos aquí en particular sobre el estudio ya citado de Mendoza y Guevara (2012) a partir de una encuesta realizada por la Universidad en el sector.

13 Las Juntas de Acción Comunal son organizaciones civiles reconocidas por las instituciones estatales que se encargan de diversos problemas de interés local. Fueron promovidas a partir del Frente Nacional como un mecanismo de interlocución entre el Estado y la sociedad civil. 
promueven la participación electoral con el Movimiento Independiente de Renovación Absoluta (MIRA), vinculado orgánicamente a ellas.

El clientelismo político también está muy presente en el sector. La encuesta realizada por la Universidad evidencia su importancia, y nuestras propias observaciones durante la jornada electoral del 30 de octubre de $2011,{ }^{14}$ la confirman, incluso bajo sus formas más burdas de compra de votos el mismo día de la elección. No obstante, este fenómeno no explica por sí solo la importancia de la participación electoral en El Codito. Desde este punto de vista, llama la atención la relativa debilidad de la participación en las elecciones legislativas, que son las más susceptibles de movilizar este tipo de práctica. En cambio, el tipo de elección que más suscita participación en el sector son las presidenciales, con un porcentaje realmente llamativo de $68 \%$, es decir, veinte puntos más que la participación nacional.

Así, contrariamente a lo que podríamos imaginar, la fuerte inscripción de la población en redes de acción colectiva locales no limita su participación electoral al ámbito local. Este resultado es llamativo porque, como lo señala la encuesta aludida anteriormente, la población del sector tiene una actitud bastante escéptica, cuando no francamente hostil con respecto a la política. Esta paradoja se puede entender de dos maneras no excluyentes. Por una parte, la población de El Codito parece interesarse por la política mucho más de lo que está dispuesta a admitir, en un contexto en que denigrar de la política es de buen tono. Por otra parte, esta desvalorización de la política puede obedecer precisamente al hecho de que se espera demasiado de ella, lo que genera frustración relativa. La propensión a la participación que se evidencia en el sector, y que las instituciones estatales alimentan, puede generar la ilusión de que se pueden arreglar rápida y fácilmente la mayoría de los problemas, lo que la realidad suele desmentir con crueldad.

14 Este escrutinio corresponde a las elecciones locales, en las cuales se eligieron en todo el país los gobernadores de departamentos, las Asambleas Departamentales, los alcaldes, los concejales y, en el caso de Bogotá, las Juntas Administradoras Locales (JAL). 
En el caso de El Codito el diagnóstico es mitigado. Por un lado, el sector evidencia una gran densidad de organizaciones sociales que soportan un capital social propicio para la participación, tanto en el ámbito local como electoral. No obstante, por otra parte, buena parte de la población siente que todas estas acciones colectivas no ayudan mucho a la resolución de los problemas de inseguridad y falta de oportunidad de desarrollo que afectan el barrio. La acción colectiva en el ámbito social tiene un impacto limitado, y la del ámbito electoral tampoco ha tenido gran efecto en este aspecto. La organización Asocerros, que busca agrupar a todas las JAC del sector, intentó sin éxito promover una candidatura a la Junta Administradora Local (JAL) de Usaquén, con la idea de que El Codito tenía el potencial electoral suficiente para tener su propio edil en la JAL. ${ }^{15}$ Pero mirándolo bien, este fracaso no es tan sorprendente. En un contexto de alta participación político-electoral es muy difícil que todas las organizaciones del sector se pongan de acuerdo para apoyar a una candidatura única. En realidad, el éxito de los procesos de acción colectiva es tal que obstaculiza su traslado automático al ámbito electoral en forma de proyecto único. El dar libre curso a los conflictos y desacuerdos es lo propio del ámbito político y, por lo tanto, esta bifurcación entre acción colectiva social local, por una parte, y electoral, por la otra, es algo esperable. Finalmente, el problema que se plantea en el caso de El Codito es el de la relación entre el activismo social y electoral. Ambos campos son el lugar de acciones colectivas bastante intensas que, por este mismo hecho, no pueden compatibilizarse fácilmente. Parece existir aquí un problema de escala que se hace más claro en el caso de los consejos comunitarios del Chocó.

En el caso del Chocó nos encontramos en un cuadro mucho más esperado de baja participación electoral. Los consejos comunitarios federados en Ascoba se encuentran ubicados sobre el territorio del

15 El Distrito Capital de Bogotá está dividido en 20 localidades en las cuales se eligen las Juntas Administradoras Locales, que funcionan como un Concejo descentralizado y proponen una terna al alcalde mayor para elegir el alcalde de cada localidad. 
municipio de Riosucio, que se clasifica en la categoría de "abstencionismo duro", y el de Carmen del Darién, que se ubica en la categoría de "participación débil". Como lo menciona el artículo de Juan Carlos Guerrero incluido en este libro, este terreno se caracteriza por la presencia de actores armados que provocaron unas olas de desplazamiento de población y asesinatos. Como es obvio, este contexto resulta particularmente adverso a los procesos de acción colectiva pues cualquier actor que pretenda movilizarse es susceptible de ser señalado por los grupos armados como un activista cómplice de los grupos rivales. Sin embargo, gracias a la acción de la Iglesia católica, en particular, y de muchas organizaciones no gubernamentales internacionales, se hizo un gran esfuerzo para organizar la comunidad a través de las comunidades de paz, primero, y más recientemente, a través de los consejos comunitarios. La organización Ascoba, que federa los consejos comunitarios de la región, hereda de la experiencia de estas formas de resistencia a la violencia y despojos masivos de tierra que han azotado la zona, y reivindica la representación de unas 18.000 personas.

Al principio, este fenómeno de organización comunitaria se desarrolló al margen de la institucionalidad pública, en parte por la precariedad de la misma en esta región muy lejana de los centros de poder administrativos del país, en parte por la misma reticencia de las comunidades animadas por una idea de neutralidad frente a los actores armados y que tendían a identificar al Estado como uno más de ellos. Así, si los consejos comunitarios son el fruto de la constitución de un importante capital social acumulado para la población, este se constituyó al margen de las instituciones, razón por la cual no se trasladó al ámbito electoral. La violencia y los desplazamientos masivos de población volvieron materialmente muy difícil la participación en las urnas y, por otra parte, los actores armados utilizaron el contexto de violencia para capturar una buena parte de las instituciones locales.

Este contexto explica suficientemente la escasa participación electoral en la región. Riosucio en particular puede ser uno de los munici- 
pios más abstencionistas del país, con apenas un $20 \%$ de la población participando en elecciones presidenciales, un $30 \%$ en las legislativas y un poco más de la mitad en las locales. El alejamiento con respecto a las elecciones nacionales es llamativo. Ni siquiera el clientelismo, activo en Riosucio en la medida en que representa un potencial electoral nada despreciable, logra atraer a los electores en proporciones razonables.

No obstante, lo interesante del caso del Bajo Atrato es el contraste entre Riosucio y Carmen del Darién. En este último municipio la participación es apenas más importante que en Riosucio para las elecciones nacionales. En cambio, alcanza un nivel excepcional de 67\% en las locales, unos diez puntos por encima de la participación nacional. El caso parece mostrar que el divorcio entre la acción colectiva en el ámbito social y el político podría llegar a su fin. Las elecciones locales de 2011 fueron efectivamente la ocasión de una campaña exitosa que permitió por primera vez la elección a la alcaldía de Carmen del Darién de una persona comprometida con las acciones de Ascoba. Esto ha sido posible debido al número limitado de electores (menos de 5000 inscritos en 2011), entre los cuales dominan los que viven en las zonas rurales del municipio, donde se ubican los consejos comunitarios. Esta configuración hizo que Ascoba pudiera pesar en estas elecciones y movilizar a sus miembros exitosamente a favor de un candidato. A la inversa, tal proceso no se ha visto en Riosucio donde existen más de 10.000 electores inscritos, la mayoría en el casco urbano.

Así, el caso de las comunidades del Bajo Atrato nos muestra cómo en las condiciones más adversas un proceso de acción colectiva exitoso empieza a trasladarse en la arena política. En la medida en que la administración de Carmen del Darién logre efectivamente trabajar de la mano con Ascoba, podríamos asistir a un importante proceso de empoderamiento cruzado. Por un lado, Ascoba puede obtener un reconocimiento inédito de las autoridades locales que le permita emprender con su apoyo programas de desarrollo a favor de las comunidades afiliadas; y por otra, las instituciones municipales obtendrían una legitimidad 
social que les hace mucha falta en la región. En este contexto, Carmen de Darién se ha vuelto un laboratorio para superar la desconfianza entre las comunidades y las instituciones públicas en la zona que tendremos que observar con mucho cuidado, y que podría volverse un ejemplo para las comunidades de los municipios vecinos. En resumen, las comunidades del Chocó nos muestran un caso llamativo de presencia de un capital social intenso, pero tan segregado que su traslado a la esfera electoral resulta difícil y solo se puede efectuar en el nivel más local.

El caso del pueblo arhuaco de la Sierra Nevada de Santa Marta nos ofrece una clara excepción desde el punto de vista de la relación entre las acciones colectivas en el ámbito social y electoral. La existencia de un capital social importante en este caso es particularmente evidente, y se asienta sobre las formas comunitarias tradicionales que caracterizan la organización del pueblo arhuaco. En efecto, como lo muestra el texto de Ángela Santamaría, Mónica Acosta y Yeshica Serrano incluido en este volumen, los arhuacos son reconocidos como el pueblo indígena que ha preservado mejor su herencia cultural y sus formas de organización comunitarias. Esto le ha permitido resistir no sin dificultad la violencia de los grupos armados y la presión de los terratenientes de la región sobre su territorio. No obstante, en este caso el importante capital social que existe entre el pueblo arhuaco no se ha traducido en el ámbito electoral.

En 1997, Pueblo Bello fue elevado al estatuto de municipio y separado de Valledupar, capital del departamento de César. Este cambio administrativo fue resistido por el pueblo arhuaco, cuyo resguardo se encontraba, de ahí en adelante, en su mayor parte en el nuevo municipio. Para los arhuacos la creación de Pueblo Bello resultaba inconveniente porque dividía su población entre el nuevo municipio y Valledupar, y porque se habían acostumbrado a tratar con la elite política de la capital departamental. Con la nueva situación, tendrían que interactuar con la nueva municipalidad que, según temían, sería dominada por los terratenientes de la región con los cuales estaban en conflicto. De esta manera, el 
Cabildo Gobernador ${ }^{16}$ de la época decidió que el pueblo arhuaco se mantendría al margen del juego electoral como forma de protesta en contra de la creación del nuevo municipio. De este modo, las bajas tasas de participación electoral que registra Pueblo Bello, que pertenece a la categoría de "participación débil", no tiene que ser interpretada como consecuencia de una apatía de la población, sino como el resultado del rechazo de una parte de ella, el pueblo arhuaco, que representa la mayoría de la misma.

Sin embargo, este rechazo no es absoluto. La aproximación al voto del pueblo arhuaco, que presentamos en el cuadro 1, nos muestra que aunque muy limitada, existe una participación electoral en todo tipo de elecciones. Está alimentada por una minoría que resiste la decisión de no participación porque considera que el pueblo arhuaco tiene que hacer oír su voz en las instituciones públicas, e incluso que potencialmente podría tener el peso suficiente para controlar la alcaldía de Pueblo Bello. Por otra parte, aunque firmemente resistido y combatido por la comunidad, el clientelismo permea la comunidad como los arhuacos mismos lo reconocen, ${ }^{17}$ lo que explica, por ejemplo, que el voto llegue a $22 \%$ de participación para las elecciones legislativas.

Las elecciones locales de 2011 parecieron representar un giro en la actitud del pueblo arhuaco con respecto a la política formal. En esta ocasión, los que buscaban revertir la prohibición que pesa sobre la participación electoral intentaron organizarse para demostrar su importancia. Se constituyeron dos candidaturas para integrar el Concejo de Pueblo Bello, por una parte, la de Seiningumu Torres, indígena politólogo de la Universidad Nacional que se presentó sobre la lista del Partido Liberal; y, por otra parte, un grupo de jóvenes que conformó una lista con el aval del partido Autoridades Indígenas de Colombia (AICO). Por otra parte, se intentaron unos acercamientos con la candidata libe-

16 El Cabildo Gobernador es la máxima autoridad política, designada por los mamos (autoridades espirituales del pueblo arhuaco).

17 Para un estudio más detallado del comportamiento electoral del pueblo arhuaco, nos permitimos remitir a: Basset, 2012. 
ral a la alcaldía Nayarith Hernández Villazón. No obstante, estas tentativas de incursión en el terreno político no tuvieron el apoyo suficiente. En el municipio, la participación fue de 56\%, mientras que alcanzó apenas 38\% entre los arhuacos. Así, la inercia del abstencionismo tradicionalmente promovido en el seno del pueblo arhuaco hizo que las candidaturas arhuacas no resultaran en curules en el Concejo. ${ }^{18}$ Por su parte, Nayarith Hernández perdió la Alcaldía por un estrecho margen frente a Javier Landazabal, que ya había sido alcalde durante la década pasada.

Aun siendo una clara excepción (la abstención como forma de acción colectiva no es tan frecuente y su impacto, por definición, es imposible de evaluar en forma cuantitativa), el caso del pueblo arhuaco nos recuerda que el vínculo entre las acciones colectivas que se dan en el ámbito social y el ámbito político-electoral no es automático. Para que se concrete, se tiene que superar en muchos casos la desconfianza hacia la arena político-electoral, en la cual intervienen una serie de profesionales considerados con recelo por la comunidad. Por lo tanto, es difícil llegar a un consenso en el seno de las organizaciones. Por otra parte, existen condiciones técnicas, en particular de umbral. Si los miembros de la red de acción colectiva no son suficientemente numerosos (como en el caso de Riosucio), no podrán pesar de manera determinante sobre los escrutinios para llegar a controlar cargos de elección popular en el ámbito local. En cambio, si son demasiado numerosos y diversos (como en el caso Asocerros en El Codito), difícilmente lograrán ponerse de acuerdo para una acción colectiva en las elecciones.

18 En el caso de Seiningumu Torres, la elección fue frustrada por la desaparición del conteo final de unos cien votos que aparecen registrados en el formulario de mesa E14. El incidente generó una marcha de protesta del pueblo arhuaco hacia el casco urbano de Pueblo Bello. Las elecciones fueron plagadas de incidentes como este en todo el país. La Misión de Observación Electoral contó 52 asonadas o disturbios postelectorales en todo el país (ver: http://wwww.moe.org.co/observación-electoral/ elecciones-2011/327-directores-de-partidos-y-movimientos-politicos-deben-investigar-y-sancionar-a-causantes-de-asonadas-moe.html). Esto demuestra la efervescencia que suele acompañar las elecciones, en particular locales, así como la precariedad de la organización electoral. 


\section{A MODO DE CONCLUSIÓN: LAS ELECCIONES COMO NUDOS DE ACCIONES COLECTIVAS}

En todos los terrenos que hemos estudiado, la participación en elecciones es una tentación hacia la cual las organizaciones sociales exitosas nacidas de procesos de acción colectiva se vuelcan casi naturalmente. Entre los diferentes cargos que estaban en juego durante las elecciones locales de 2011, la Registraduría Nacional del Estado Civil contó un poco más de 100.000 candidatos para todo el país. Reportado a los 30.000 .000 de electores registrados, esto significa que un elector colombiano de cada 300 era candidato a algo en esta ocasión, proporción que desde luego aumenta considerablemente en los pueblos pequeños. Esta relación significa que en esta ocasión la probabilidad de estar vinculado a través de una relación familiar, profesional o de amistad con uno o más candidatos fue muy alta. Por lo tanto, las elecciones están profundamente insertadas en la vida social, y no hay nada de sorprendente en que la misma población que participa en movilizaciones colectivas en la esfera social encuentre una continuidad lógica de la misma en el ámbito electoral.

Para muchas de las organizaciones o redes que hemos estudiado, el acceso a un puesto electivo significa el logro de una influencia en las instituciones que puede llegar a ser crucial para los objetivos comunes; y, más allá, un reconocimiento que les otorgue un estatuto de interlocutor con las elites políticas tradicionales.

El paso de la esfera social a la política-electoral, por lo tanto, no tiene nada excepcional y merece toda la atención de la academia. Sin embargo, tampoco se trata de un proceso fácil y automático. Los grupos de acción colectiva podrán tener éxito en el ámbito electoral en función de la intensidad de los vínculos que pueden suscitar, pero también en la medida en que sean capaces de focalizarse sobre puestos al alcance de su capacidad electoral. Los casos estudiados revelan la importancia para el análisis del tipo de capital social disponible para la comunidad: en el caso de un capital social intenso pero segregado como en el bajo 
Atrato o la Sierra Nevada la participación electoral apenas puede aspirar a cargos locales, y solo en la medida en que se ubique en circunscripciones pequeñas como Carmen de Darién. En el caso de un capital social más difuso pero de mayor alcance, como en El Codito, la estrategia más adecuada parece ser la diversificación. Así, el análisis tiene que concentrarse no solo en la intensidad de la acción colectiva en el ámbito social, sino también en su alcance, que tendrá consecuencias distintas en el ámbito electoral. Acá existe un complejo juego de escalas que comanda estrategias distintas y que conviene analizar caso por caso.

Finalmente, este artículo no toca el tema del resultado a medio o largo plazo para las comunidades de su incursión en la política electoral, más allá de la eventual elección de un candidato. Existe acá todo un campo que merecen estudios específicos en forma comparativa, que el grupo de trabajo reunido para este libro espera poder realizar en el futuro.

\section{BIBLIOGRAFÍA}

Auyero, Javier. (2001). La política de los pobres. Manantial, Buenos Aires.

BAsset, Yann. (2012). El pueblo arhuaco en las dinámicas electorales colombianas. En: Ana Catalina Rodríguez Moreno et al., Escuela intercultural de diplomacia indígena. Universidad del Rosario, Bogotá.

Basset, Yann \& Guerrero, Juan Carlos. (2011). Pauvreté et clientélisme électoral en Colombie. CERISCOPE Frontières. Disponible en: http://ceriscopesciences-po.fr/node/246

Campbell, Angus; Converse, Philip; Miller, Warren; \& Stokes, Donald. (1960). The American Voter. The University of Chicago Press, Chicago.

Condon, Meghan. (2009). The effect of Social Capital on voter Turnout. University of Wisconsin.

Downs, Anthony. (1957). An economic theory of democracy. New York: Harper.

Gaxie, Daniel. (1985). Explication du vote. Presses de la Fondation Nationale des Sciences Politiques, Paris. 
Gutiérrez Sanín, Francisco. (2007). ¿Lo que el viento se llevó? Los partidos políticos y la democracia en Colombia. 1958-2002. Norma, Bogotá.

Kitschet, Herbert, \& Wilkinson, Steven I. (2007). Patrons, clients, and policies: Patterns of democratic accountability and political competition. Cambridge University Press, New York.

Lazarsfeld, Paul. (1944). The people's choice. Duell, Sloan and Pearce, New York.

Losada, Rodrigo, Giraldo, Fernando, \& Muñoz, Patricia. (2004). Atlas sobre las elecciones presidenciales de Colombia. Pontificia Universidad Javeriana, Bogotá.

Mendoza Molina, Mónica, \& Guevara Salamanca, Juan David. (2012). Retos $y$ avances del desarrollo local. Caso El Codito. Universidad del Rosario, Bogotá.

Misión de Observación Electoral. (2011). Mapas y factores de riesgo electoral. Elecciones de autoridades locales. Colombia 2011. MoE, Bogotá.

Nie, Norman H., Verba, Sidney, \& Petrovik, John. (1976). The changing american voter. Harvard University Press, Cambridge.

Putnam, Robert. (1993). Making democracy work. Princeton University Press, Princeton

Rosanvallon, Pierre. (2001). Le sacre du citoyen. Histoire du suffrage universel en France. Folio, Paris.

Siegrried, André. (1913). Tableau politique de la France de l'ouest sous la troisième république. A. Colin, Paris.

Tocqueville, Alexis de. (1984). Recuerdos de la Revolución de 1848. Editora Nacional, Madrid. 


\title{
VALORES Y LÍMITES A LA DEMOCRACIA EN VERACRUZ
}

\author{
Leopoldo Alafita MÉndez
}

\section{INTRODUCCIÓN}

\begin{abstract}
Al proponernos reflexionar sobre la temática de la cuestión civil, de los valores y de las responsabilidades ciudadanas en la democracia, indagamos sobre la manera en la que los ciudadanos perciben distintos temas relacionados con las instituciones de la esfera pública. Estos consisten en todos los elementos que en la historia contemporánea han incidido en la formación de la cultura política y de los valores sociales fundamentales para la convivencia, pero, sin duda, también en la manera de actuar en los procesos generales regionales de democratización en esta región del golfo de México.

Nos interesa destacar también la importancia de la percepción de los ciudadanos acerca de los aspectos subjetivos, personales y sociales que interactúan en las relaciones políticas de los habitantes del Estado. De manera más amplia, abundamos en esta primera parte de una relación de un objeto mayor que es establecer la relación entre percepción y comportamiento político en el marco de una sociedad autoritaria-corporativa.
\end{abstract}

La investigación tiene una base sustentada en sondeos sobre la opinión y percepción que los habitantes de la entidad tienen de sí mismos y de las instituciones gubernamentales. Después de una década de seguimiento, en el resultado más general es posible ver la consistencia de los

Investigador del Instituto de Investigaciones Histórico-Sociales de la Universidad Veracruzana. 
parámetros y el movimiento entre valores de la civilidad y las dificultades que enfrentan los procesos de la democracia. Dicha investigación la hemos realizado con el apoyo del Laboratorio de Investigación de Estudios Estadísticos de la Universidad Veracruzana.

En el carácter de una sociedad se expresan en gran medida contenidos que los individuos han construido como resumen de su expresión cultural, la manera en la que han desarrollado sus valores y las relaciones que les son inherentes. El enfoque que se privilegia trata sobre cómo los ciudadanos viven esa relación interna entre distintos sectores de la sociedad y su relación con el Estado, el sentido registrado de manera expresa en la propia sociedad, donde la identidad no es una cuestión privada y se vive ahí afuera, en la comunidad, en una relación dinámica aunque no siempre de manera consciente.

Se pone acento en la forma de percibir a las instituciones, la legalidad, el reconocimiento del otro, la seguridad y la tolerancia. Todas ellas, partes fundamentales de la relación entre individuos y de éstos con las instituciones. La función pública representada y valorada en distintos niveles de operación de las instituciones gubernamentales, pero esa mirada, para nada simple, sino al contrario, rebuscada, revela mixturas que son complejas donde se relacionan gobiernos, instituciones y sociedad en distintos momentos de su desarrollo en los que se han impuesto determinadas políticas. La identidad cultural también va de la mano de la política, la influye y reproduce. En una sociedad multicultural se debe respetar, incluso alentar, la diferencia cultural. ${ }^{1}$ Todo esto, claro está, forma parte de una tradición europea liberal, pero inevitablemente suscita un problema para otra tradición política liberal dominante en América, basada en el principio de que todos los ciudadanos son iguales, lo mismo ante la ley, como dice Charles Taylor, quien intenta hallar alguna base para conciliar estas dos tradiciones liberales, pero se trata

1 Véase: Alafita Méndez, Leopoldo. (2012). “Tolerancia y democracia los valores políticos en Veracruz”. En Aguilar Sánchez, Martín (coord.), La difícil construcción de la democracia en Veracruz. México, Editorial Universidad Veracruzana. 
de una tarea imposible no solo porque la política cultural requiera, en realidad, una discriminación positiva, aunque este problema exista, sino porque exige conformidad. ${ }^{2}$

\section{EL PASADO RECIENTE}

El establecimiento de las instituciones constituidas en el primer tercio del siglo pasado ha resultado de tal manera influyente en el devenir del carácter de la sociedad presente, que expresa tendencias substanciales del sentido y la forma en que se erigieron algunos sectores sociales de gran peso político.

La Revolución mexicana ha sido determinante para la articulación de los distintos sectores sociales, los diferentes niveles de gobierno y las entidades federativas. En ese proceso, en algunos aspectos todavía vigentes, se influencian acciones de individuos o de grupos dominantemente corporativos, trazando conductas y costumbres de larga data. Se trata de la cultura que se mantuvo unificada por un sistema que logró imponerse en la diversidad, frente a los distintos.

Por supuesto, en el establecimiento de esa institucionalidad dominan los entramados que se impusieron a partir de momentos en los que se definen sentidos históricos, sociales, pactos, y se construye el Estado. Se procura el ejercicio de la administración pública que dispone lógica, reglas sociales, en momentos en que se construía la organización social. De ahí surgen los regímenes tan heterogéneos, como resultó a fin de cuentas, en nuestro país, el proceso de la Revolución mexicana. ${ }^{3}$

2 Kuper, Adam. (2001). Cultura: la versión de los antropólogos. Barcelona: Paidós, pp. 271-272.

3 Véanse al respecto los textos ya clásicos: El laberinto de la soledad de Octavio Paz, La formación del poder político en México de Arnaldo Córdoba, La crisis Obregón-Calles y el Estado Mexicano de Rafael Loyola, El Estado y la política obrera del cardenismo de Arturo Anguiano, "Los artífices del cardenismo" en Historia de la Revolución mexicana de El Colegio de México, La consolidación del nuevo orden institucional en México (1929-1940), América Latina: historia de medio siglo. Ver también: De la Garza 
El propio carácter de la construcción social del país hace categóricos algunos aspectos e inciertos otros. Se privilegian o se acentúan prácticas parciales de políticas públicas en las que se dejan al margen aspectos muy importantes de la vida social que aún excluyen sectores sociales completos, los que resultan ser los más numerosos de la población. Es ahí donde se hace presente la fuerza de la gestión política que privilegia su posición para concentrar la atención de las esferas gubernamentales como la imposición en extenso del poder político de los vencedores y privilegiados, instrumentando con lo disponible, acciones de gobierno cobijadas siempre por una ideología que dio forma y contenido a más de medio siglo de vida social en el país.

La reproducción del poder político que se heredaba se apoyó siempre en las propias bases sociales: lo que conduce a la formación de la familia revolucionaria asegurando su reproducción y consolidación. Esta familia teje vínculos, redes y acuerdos entre sectores sociales cuya organización matiza formas de dominio. Los actores que operan la política adquieren presencia en cada espacio de administración. Se reconoció al superior en la jerarquía política, impone signos que son sesgos, definen estilos de cada administración pública que demarca derechos sociales de privilegio para sus clientes, exige flexibilidad y negociación política, fidelidad a cambio de privilegios normalmente sujetos a chantajes que subordinaron.

Nuestro interés radica en conocer cuáles son los límites del desarrollo ciudadano y del proceso histórico y cultural democrático. En dicho proceso se establece una lógica de la construcción contemporánea de políticas gubernamentales "públicas” dirigidas a las masas de manera selectiva y sectorial, para señalar el modus operandi. Así, algunos programas destacan formas de ejecución política en donde lo aparentemente público se convierte en acento de operación gubernamental que solo pri-

Toledo, Enrique. (1998). Ascenso y crisis del estado social autoritario. México: El Colegio de México, pp. 37-95. 
vilegia sectores de trabajadores. En nuestro país, los gobiernos, al atender solamente los intereses de los sindicatos y agrupaciones gremiales otorgarles privilegios especiales, no generan políticas públicas para todos, más bien toman medidas que apenas superan lo privado, distinguen y separan, y dejan a las grandes mayorías relegadas a la exclusión social.

La administración pública en el país, en su construcción histórica, determinó acentuar el beneficio negociado a los trabajadores de ramas económicas dinámicas que jugaban papeles estratégicos respecto al desarrollo, tales como petróleo, minería, transportes ferroviarios, educación o salud. Estos sectores adquirieron significado por su participación en el crecimiento económico y desarrollo social, lo que permitió que esa relación productiva fructificara al mismo tiempo en rédito político inmejorable para un proyecto social de la Revolución en la que no cabían todos. El sustento de un proceso que parece que atraía tanto se fundó en un sistema de privilegios. Ese sistema se hizo viable por la relación Estado-mercado que se logró en el país bajo el manto protector que justifica y legitima regímenes y acuerdos. El nacionalismo mexicano no solo no estorbó ese modelo, sino que fue un modelo de mercado, además de una ideología de Estado. En ese modelo los agentes del mercado empresarial interno no se opusieron ni siquiera en momentos álgidos donde operó claramente la figura nacionalista, como fue en la expropiación petrolera. En el lado sociopolítico, los gobiernos del régimen revolucionario son coherentes con ese proyecto social que promueve el pacto social de la Revolución en México. Estos sectores, importantes económica y socialmente, son a la vez aquéllos en los que aparece también la lógica de la renta política. Ahí, con los sindicatos y los trabajadores, se enfatiza la atención de esa función política social imprescindible para la Revolución mexicana, que primero pacificara, después unificara, y más tarde permitiera reproducir y mantener la vigencia del régimen político que de ahí derivó.

En México la sociedad también es resultado de la conquista de las masas de trabajadores por parte de un Estado populista que promovió 
su organización y les otorgó un papel que les permitió reproducirse en los límites de la estipulación, que a pesar de ser acciones contrarias situó a los dirigentes de su lado a través de estímulos monetarios, cargos públicos, funciones laborales y la separación de la función original de representar los intereses gremiales.

Sin embargo, no fue un proceso maquiavélico imaginado y dirigido por el Estado. El papel de los trabajadores fue a momentos protagónico, en una interacción en la que obreros y campesinos fueron actores fundamentales de las historias regionales, se hicieron predominantes a la hora de la firma de los contratos de trabajo, en esas prácticas empoderan líderes, políticas del gobierno y al partido, es parte sustantiva del pacto político, donde se asignan roles a mediadores del conflicto que administran privilegios como la clave del proceso histórico-político nacional.

\section{LOS SUSTENTOS POLÍTICO-SOCIALES DEL MODELO DE LA REVOLUCIÓN}

En México, las actividades económicas que predominaron en ese periodo fueron determinantes para establecer rasgos sociales y formas de organización social y política que han influido en el carácter y los valores de sus habitantes. Dadas las condiciones geográficas, de suelos y subsuelos del territorio de la entidad, se establecieron las condiciones propicias para favorecer la relación con el mercado. Las materias primas que se hallaron en el territorio produjeron la coronación de múltiples especulaciones colonizadoras, en consonancia con el propio desarrollo del mercado mundial. Suelo, clima y flora aportaron el sustrato productivo e integraron lo que ya se había perfilado como paisaje cultural y que fue aderezado por distintos movimientos de población regional y nacional.

Las comunidades así establecidas tampoco se dieron a sí mismas tareas para su desarrollo independiente, no demandaron a la imaginación creativa el desarrollo tecnológico. Estas poblaciones no se vieron forzadas a preocuparse en preparar el futuro. Tampoco el sistema de 
educación los enfrentó a retos tales para el establecimiento permanente o para trascender los límites que imponía una sociedad que vivía sobre todo de lo que tomaba de la naturaleza y después vendía afuera de sus fronteras. En todo caso, las herramientas para llevar a cabo las tareas productivas de cada rama señalada, como ejemplo, se traían a la región procedente de países cuyos empresarios dirigían las actividades en cuestión.

Otro punto que nos viene de lejos y que ha influido de manera desventajosa en el ánimo de varias generaciones de mexicanos sin distingo de procedencia social, se refiere a una suerte de dependencia, lo externo, lo extranjero. Esto revela una falla en la valoración de sí mismos, de los individuos, pero también de la calidad de lo nacional, como una suerte que no se supera sino de manera tardía cuando las brechas del desarrollo marcan siempre atraso y que a fin de cuentas se acepta como una condición de humildad personal y social. En el contexto descrito se sitúa una sociedad que se organiza a partir de un rompimiento social revolucionario, que reorganiza a la sociedad hacia una participación muy amplia en lo político, incorporando sectores numerosos de cada región. De los años veinte a los sesenta se desarrollan amplios movimientos sociales esencialmente autónomos donde el Estado, con un discurso cercano a sus intereses, operó poniendo límites, como un Estado social autoritario.

El proyecto económico de la Revolución contempló un carácter incluyente favorecido por los recursos naturales de la nación, ramas económicas importantes como el petróleo y la electricidad, y su importancia en el mercado internacional permitió desarrollos regionales entre los que se destaca la zona del golfo de México. Economía y régimen político se acompañaron en un proyecto que perdió dinamismo durante los años sesenta del siglo xx. En ese pasado cercano, Veracruz tiene su versión local, pero este no modifica el patrón económico; en este tipo de desarrollo prevaleció el Estado interventor, conciliador y organizador, representado por agentes que concilian o acatan en disci- 
plina, aparatos de justicia subordinados en los que prevalecen los intereses dominantes o que actúan en el mejor de los casos con un sentido que siempre respondió a los intereses dominantes.

Los regímenes revolucionarios tuvieron que enfrentar distintas realidades en las regiones. En el golfo, por ejemplo, se dio un fuerte impulso a la organización de los trabajadores de sectores ferroviarios, petroleros, magisteriales, textileros y de oficios predominantemente urbanos y la importante reforma agraria. Pero en ese modelo de reorganización social, el papel del Estado fue protagónico y paternalista. El papel de los trabajadores se hizo central en un periodo dilatado de la Revolución, aunque el rol trascendente lo jugaron sus dirigentes, al mismo tiempo fue a través de esa posición indiscutible de los líderes, que pronto ocuparían un papel relevante en la estructura de la administración política.

Los procesos locales fueron perdiendo espacios mediante la institucionalización del Estado revolucionario, lo que posibilitó, entre otras cosas, la especialización de una burocracia profesional, la creación del Partido Nacional Revolucionario (PNR) y el impulso de organizaciones nacionales de trabajadores y campesinos ligados al partido estatal y a la Presidencia. Conforme el proceso anterior se fue desarrollando, aparecieron los mecanismos de control impuestos por caciques militares y los movimientos y organizaciones populares independientes. Ese fue un periodo en el que se avanzó de manera ininterrumpida en torno a la centralización de sistema político a partir del movimiento revolucionario. Más de una década de gobiernos estrechamente ligados a los principios sociales originales de los movimientos de los asalariados se sucedieron, sobre todo en el estado de Veracruz.

\section{ORGANIZACIÓN POLÍTICA CORPORATIVA Y LOS LÍMITES CIVILES}

El proceso de formación y consolidación del sistema político en el Veracruz postrevolucionario está íntimamente ligado a la suerte de otros 
grupos sociales organizados de la entidad: sindicatos diversos, ligas campesinas, asociaciones de propietarios, logias, asociaciones profesionales, comerciantes, ganaderos o transportistas, cuyos líderes surgieron de las propias bases participantes. Así, tenemos que los protagonistas principales en la formación de la clase política de la entidad y las regiones del estado de Veracruz provienen de las dirigencias de sectores de trabajadores organizados y otras organizaciones sociales. Los vínculos entre ellos parten de las demandas de los propios trabajadores y, de manera interactiva, de respuestas gubernamentales en las que prácticamente se cede a las dirigencias sindicales la administración de los contratos de trabajo y el importante poder que supone el manejo del ingreso laboral en el monopolio del ingreso al trabajo por rama de servicios o del sector industrial.

En el monopolio del acceso al trabajo y el control de los ascensos y la permanencia laboral, además de la cláusula de exclusión, se garantizó disciplina y colaboración. Se aseguró, aunque no fue así siempre, que no habría sobresaltos para la burocracia sindical ni para la paz revolucionaria. De esa manera se comprometieron intereses específicos en proyectos y acciones intersindicales, y de carácter político electoral. Por otro lado, la posibilidad de las elites para acceder y mantenerse en el poder fue, en buena medida, mediada por la capacidad de responder a sus agremiados, así fuera parcialmente, las demandas e intereses de las bases sociales, y para ello debían ser duchos en su gestión, lo cual estuvo siempre determinado por la buena relación que se mantuviera con los distintos gobiernos que manejaban los dineros y las concesiones.

Esa articulación se cristalizó en tres espacios: el local, el regional y el federal, lo que dio contenido político-social a los diferentes niveles de gobierno. En el estado de Veracruz, a medida que avanzaban las políticas centralistas también había disminuido la autonomía regional que se presentaba como consecuencia de la visión necesariamente centralista de la Revolución. Todo poder emergente, este es el caso mexicano hacia los años treinta, procura que las estructuras sociales a su cargo, en los 
límites del espacio y el ejercicio del poder, se correspondan con los principios y programas que se van estableciendo conforme son capaces de organizar y dar gobierno a la sociedad que se domina; por ello les tocó resolver el ejercicio de enlace entre poderes centrales, regionales y los grupos sociales organizados.

Cuando se presenta el proceso de institucionalización del Estado nacional lo primero es reconocer que la gran preocupación se localiza en cerrar espacios a quien se sale o intenta salir del control. El poder revolucionario entra en un ejercicio político donde muy pronto va a predominar la negociación por encima de las instituciones. Estos comportamientos definen el sistema autoritario-populista.

El proceso político que se vivió en el país y en Veracruz no fue un proceso uniforme. Se fundó en un partido que dominó la escena durante todas esas décadas y en que el gobierno federal institucionalizó una nueva centralización, con nuevas dinámicas, proyectos y resultados distintos a lo largo del país. Todo esto, detrás de la aparente armonía que presentó el sistema de dominio del partido oficial como el mexicano, sumamente relevante sobre todo si lo comparamos con el resto de los procesos sociales latinoamericanos, que generalmente se encontraron en una dinámica de enfrentamientos y de imposiciones basadas en relaciones de fuerza y represiones militares.

En la revolución que comentamos, generalmente estuvieron en las cúpulas del poder las elites políticas, militares y empresariales, pero también los dirigentes sindicales y de los grupos sociales locales más activos, cada uno tras la búsqueda de sus propios intereses. Al concluir el gobierno cardenista, la vida de las instituciones que resguardaban las burocracias políticas se había impuesto a través de personalismos regionales, así la dirección de la sociedad se había consolidado en las burocracias políticas, sindicales y los grupos económicos regionales.

En un estudio [...] sobre épocas más recientes, Enrique de la Garza especifica la relación entre sindicatos y las elites gubernamentales cuya colabora- 
ción posibilitó un proceso de industrialización acelerado después de los años 40 y hasta la década de los 60 , lo que significó demérito para las condiciones laborales y salariales. Ese afán de colaboración de las organizaciones sindicales fue compensado con el ingreso a un sistema de privilegios al ingresar a la clase política veracruzana, de modo que no sólo se favoreció de manera limitada la industrialización, también se colaboró en el desarrollo de la estructura política, estableciendo un intercambio entre beneficios a los trabajadores a cambio del apoyo a las políticas públicas y al sistema electoral. Los líderes se constituyeron en dirigentes partidarios, recibiendo puestos de elección popular y de la administración gubernamental, pero ya estaba creado un sistema de disciplina que aseguraba el funcionamiento de excluir a los disidentes, lo que constituyó un sistema político de privilegios, autoritario y con exclusión. ${ }^{4}$

\section{EL DESARROLLO DE LA CIVILIDAD EN EL ESTADO}

Dadas las condiciones del contexto al que nos referimos, el desarrollo de la civilidad en la entidad está íntimamente ligado a las condiciones sociales de un Estado paternalista, que reparte a sus hijos, a quienes considera siempre como menores, y les indica el camino. El destino civil estaba resuelto, no tenían que preocuparse ni dilucidar rumbos; el sistema, el partido y los gobiernos lo hacen en su nombre, así interpretaban su tarea. Pero el modelo se agotó, el grado de desarrollo social que se alcanzó en décadas fue escaso para unos. Para las mayorías marginadas del pacto social no hubo respuestas, no alcanzaba, las contradicciones afloraron, el Estado de bienestar se mostró insuficiente, entró en crisis, y varios sectores sociales produjeron movimientos de inconformidad. Así, múltiples movimientos sociales se unieron en distintos

4 Ver: De la Garza Toledo, Enrique. (2003). "La crisis de los modelos sindicales en México y sus opciones”. En La situación del trabajo en México. México: UAM-Plaza y Valdés; (2004). "Del corporativismo y neocorporativismo al postcorporativismo". En Alternativas sindicales en América Latina. Medellín: Escuela Nacional Sindical. 
momentos: los ferrocarrileros, los médicos, magisteriales, estudiantes universitarios, las oposiciones político-electorales y movimientos campesinos, entre otros. Todos se expresaron, forzando en el largo plazo la liberalización del aparato político y la democracia.

Pero también, apuntalados desde diferentes frentes sociales: organismos políticos, sociales, empresariales, movimientos ciudadanos, etc., lograron reformas legales constitucionales y generaron modificaciones al sistema de partido único, creando un sistema de partidos y un sistema electoral moderno con gran inversión en recursos públicos, pero estableciendo un sistema de competencia electoral que ha permitido expresar una parte de la pluralidad social del México actual. Aunque, a pesar de todo, no se ha logrado terminar con las prácticas desleales de las contiendas políticas en las que los protagonistas son los partidos políticos o, en todo caso, los candidatos que protagonizan en cada proceso electivo.

El marco legal electoral puede considerarse, en general, bien dotado legalmente para elegir en civilidad a gobernantes y representantes. Sin embargo, cada proceso electoral es motivo de infinidad de impugnaciones debido a los ilícitos de los competidores, de acciones fuera de la ley por parte de gobernantes que reproducen complicidades que deterioran la frágil democracia. Pero los grandes desacuerdos políticos nacionales y los grandes escándalos que han dividido al país no solo se han expresado por las competencias entre partidos políticos, también se manifiestan en las contiendas internas de los propios partidos políticos, que han demostrado que pueden ser más virulentas cuando son internas que aquellas que son producto de supuestas diferencias ideológicas.

Pero más allá de lo electoral, mejorar la convivencia social en el estado es una tarea que debe de abordarse en un sinfín de frentes. Si atendemos a la realidad social, son múltiples los rezagos que se confrontan en materia ciudadana. Es cierto que los poderosos atropellan a los débiles; los empresarios favorecidos se benefician al margen de la ley, entregando la parte del paquete que corresponde a los que permiten 
esos privilegios corruptos. Los funcionarios cierran el círculo perverso de la corrupción, con una procuración de justicia simulada. La contraparte es la subordinación cuando no sometimiento de los sectores sociales más amplios.

Los problemas y los temas sociales en torno a lo que los veracruzanos deben organizarse son tantos que están registrados en las agendas de los asuntos de carácter público. Es cuando el poder político establece reglas que modelan conductas en tanto aparato de Estado, y las formas de operar de sus agentes políticos las siguen de manera tan rígida que influyen en el perfil de la cultura política de la sociedad. Entonces la regla es la "representación" que tienen de la sociedad, la del partido, quien el cual vela por el interés de la sociedad; es el representante, la cámara, los dirigentes que también pertenecen al partido. Los ciudadanos y el pueblo solo se hacen presentes si se les llama para apoyar cuando el representante lo solicita, mientras los intereses de todos están frecuentemente bajo la gestión del diputado, del dirigente o del partido. Cuando la gestión es independiente se atora, o si es de adversarios políticos no avanza. Cuando del tema de la participación ciudadana se trata, fruncen la cara; eso pertenece a modelos políticos ajenos: "aquí la Revolución ya triunfó”. Mucho menos se aceptan los temas de los movimientos sociales. Con todo ello deben lidiar los dirigentes del partido, los ciudadanos de México no deben preocuparse de lo público, sus preocupaciones deben ser las de la vida privada, estos temas sí que les pertenecen. Y en ese escenario, desde las últimas cuatro décadas por lo menos, aparecieron los medios de comunicación, particularmente los televisivos, cada vez más poderosos, con los cuales se cierra la pinza del poder. Se administra la información y se procura definir la opinión. A pesar de todo esto, el movimiento electoral antipriísta e independiente es el más numeroso del país.

Un proceso social como el de México, que se vive en esa lógica, propició que sectores importantes de la población abandonaran, o por lo menos dejaran de pensar a los asuntos públicos como suyos, por 
comodidad o porque amplios sectores dudan sobre los asuntos sociales que les corresponde de ocuparse. Por ello han abandonado o eludido el fondo auténtico de la representación social, que pasó a ser asunto solo de los partidos y del gobierno. Han rehuido a la defensa independiente de sus intereses, la revolución organizada y pervertida, y luego los tiempos neoliberales los han dejado desamparados en medio de sus propios problemas y demandas, con alternativas casi únicas para acciones individuales o locales de migración, comercio informal o actividades ilegales. De esa manera abandonan la cuestión pública. Al hacerlo dejan espacios libres para la acción de la representación del actual sistema de partidos que velan por lo suyo, donde dominan los que actúan con sus aparatos electorales en una gestión deformada por los intereses de grupo que actúan en todo momento con la mirada puesta en el beneficio de ellos mismos.

Promover el diálogo entre los que no han experimentado la democracia es un primer paso hacia el desarrollo de un modelo incluyente en el que imperen en la función pública criterios de servicio social, donde los criterios de los privados no excedan los límites del derecho. Este asunto es hoy de distintas formas ajeno a los ciudadanos que miran atropellos cotidianos en los que, excediendo sus derechos y propiedades, abusan de civiles urbanos o rurales apropiándose de espacios y bienes públicos y hasta de áreas protegidas porque cuentan con la complicidad de la autoridad, o, de otra manera, el abuso análogo de la propia autoridad.

\section{LOS VERACRUZANOS: EL CARÁCTER DEL CIUDADANO Y LA DEMOCRACIA}

El movimiento económico y social de inicios del siglo xx y hasta los años cuarenta permitió que el desarrollo industrial en Veracruz ocupara un sitio privilegiado en el concierto nacional. Hoy solo queda el peso corporativo de la membresía. Veracruz ocupa el tercer lugar en número de habitantes en el país. Su población supera los 7.500.000 habi- 
tantes, es la tercera cifra luego del estado de México y del Distrito Federal con poco más de 15.000.000 el primero y el segundo con cerca de 9.000.000, según el censo del INEGI. Estas tres entidades suman el 28,2\% del total de la población nacional, población que sumada es más que la que tienen un número importantes de naciones en mundo. Por ello es que para las elecciones nacionales quien tenga resuelto el apoyo político aquí decide su peso político electoral. Pero, sin duda, ninguna de las fuerzas políticas está a salvo de la incertidumbre.

La diversidad cultural y política es muy amplia, se da de manera tan diversa y contradictoria, que afirmar que en política existe una gran manipulación es solo conocer de manera somera a los habitantes del Estado. Los comportamientos políticos a los que nos referimos antes se pueden documentar de manera abierta con datos disponibles de ya casi veinte años de estadísticas electorales en los que es posible documentar estos comportamientos de los electores que, si bien se expresan como fuerzas electorales, también son expresiones políticas individuales, sectoriales, regionales, etcétera.

En nuestro estudio es posible observar lo complejo que resultan ser los habitantes de esta entidad, acerca de las disparidades como se expresan estas percepciones y valoraciones políticas. La confianza en las instituciones, en la clase política, es reveladora de los porcentajes de participación en las jornadas electivas y también lo es relacionar la opinión sobre la otredad social, lo que tiene mucho que ver con la confianza que inspiran los vecinos y los que tienen ideas distintas.

En cuanto a la tolerancia y la convivencia, la sensibilidad también tiene que ver con desarrollo social y niveles de educación, pero cuando los resultados se pueden comparar en algunos niveles municipales se crea un instrumento muy útil. Hace falta relacionar estos resultados con el tipo de político característico de distintas tipologías resultantes. Por ejemplo, resulta interesante conocer en qué municipios o regiones se localizan rasgos que denotan autoritarismo o falta de confianza en el ciudadano, lo que puede influir en posiciones conformistas lejanas a los 
requisitos para el desarrollo cívico y de actitudes de exigencia de rendición de cuentas. De esa información se derivan apreciaciones de formas para ejercitar el poder y las relaciones sociales entre sus habitantes. Los resultados nos muestran una sociedad particularmente autoritaria, de grandes mayorías subordinadas, donde la simulación ha dominado los escenarios gubernamentales marcados por las acciones fuera de la ley, con límites a las libertades sociales, particularmente la libertad de expresión, y demás características constitutivas de formas de gobierno que a su vez son partes constitutivas de una forma de Estado.

Existen ámbitos locales con respecto al nivel federal, pero también otro nivel de localidad, que es lo interior con respecto a la capital del estado, o de lo que son capitales regionales en el norte, sur y centro interior del mismo. Esto supone localidades o provincias interiores donde los medios de comunicación modernos tienen controles centralizados y, por lo tanto, la prensa es prácticamente inexistente. Las condiciones no son propicias para contrarrestar el atraso político y social que los hace presa, con mayor dificultad, de acciones clientelares.

Es posible ubicar cada elemento resultante de tales estudios en un espacio determinado; por ejemplo, si es el caso de una característica que se refiere en general al estado, o si en cambio pertenece solo como propiedad característica de un sector marginal, de un municipio o grupo de municipios, si solo corresponde a un género o grupo de edad. Los avances que se han logrado son indicativos al mismo proceso, solo que son expresiones de problemas particulares: si las autoridades tuvieran la voluntad, estos estudios ayudarían a orientar políticas hacia el desarrollo social y ciudadano.

Ser ciudadano es una construcción en la que intervienen elementos de distinta naturaleza; su progresión constituye un complejo social de oportunidades y beneficios, de compromisos plenamente consagrados, respetados por el Estado, pues con esa entidad es que opera el pacto social que exige, sin negociación, un Estado de derecho que garantice a todos el apoyo de la función pública, que vigile y haga cumplir el derecho de todos. Ese es el único Estado de derecho. 
El condicionamiento del avance civil de ese Estado de derecho, que debe poner en primer término el razonamiento colectivo y la expansión de oportunidades para la población en la entidad y el país, es lo público. Debe tener una confrontación amplia y permanente. El derecho de los particulares no se puede privilegiar utilizando a las autoridades para atropellar a los demás. La función pública no se debe reducir al beneficio de un sujeto privado o a un grupo de individuos, esa acción pervierte la función pública del Estado democrático. Promover el interés colectivo ayudará a resolver el carácter abstracto del señalamiento "de lo público" y el discernimiento de la razón de los intereses ciudadanos.

El desarrollo del carácter civil de los veracruzanos se ha dado a través de las transformaciones sociales que se producen a pesar de los grupos de poder o de los sistemas de educación, cuyo desarrollo ha sido delimitado y establecido históricamente al margen de la ley.

Las acciones de los gobiernos de la Revolución que buscaron la articulación de la sociedad mexicana pueden justificar, en algún sentido, a un Estado rector de la misma, que administra recursos y demandas sociales, concede canonjías y derechos, pero que al ser administradas desde el poder, de manera selectiva y regional, con énfasis sectoriales, sus acciones corporativas, clientelares, populistas, establecieron la subordinación, ausencia de derecho e inhibición de una participación civil.

La acción del Estado que actúa para pacificar tiene sentido como política, se puede aceptar sobre todo en las condiciones en las que se imponían durante la Revolución. Dichas políticas tal vez fueron necesarias, así como fueron adecuadas muchas directrices gubernamentales que buscaron la unificación de los trabajadores. Por ejemplo, en distintos momentos se impulsó la organización sindical, cosa que en la propia lógica revolucionaria del momento fue totalmente aceptada. Pero tal acción, al mismo tiempo, subordinó al movimiento sindical al discurso y políticas oficiales.

Institucionalizar la negociación para dirimir las pugnas por el poder político, desarrolló un sistema de control de los avatares a través 
de las décadas, construyó un sistema político incierto mediante el sistema de partido dominante que dirigió al país logrando imponerse. Pero más que partido político fue, por muchas décadas, una especie de secretaría de Estado en comunicación directa con el presidente o los gobernadores, atentos a las indicaciones que en momentos electorales centraban la atención de toda acción de relevo gubernamental. Quienes ejecutaron esas políticas fueron dirigentes y cuadros de gran influencia, de poder nacional y local, con controles territoriales y hasta por rama económica o región. Ese mismo sistema político impidió la modernidad política, el desarrollo ciudadano y el desarrollo civil. Las formas sexenales de gobierno, que impusieron grupos particulares de poder, lograron cambiar el sentido de la lógica del Estado que se representaba modificando el sentido de lo público en tanto interés general. En estos términos transcurrió una vida social que se abstrae del pensamiento que hacía vigente al ciudadano moderno responsable de su vida social. Hoy en día, en el estado de Veracruz, como resultado de un abandono constante de la responsabilidad social pública, esta se encuentra secuestrada por una representación que dialoga a sus espaldas.

El propio carácter de la integración geográfica de la entidad político-social también estableció algunos condicionantes agregados por la distribución espacial de su población a lo largo de 700 kilómetros de litoral, hasta hace solo pocas décadas permanecían incomunicadas entre sí. Durante gran parte de ese siglo $\mathrm{xx}$, la falta de comunicaciones mantuvo dispersa la población en el golfo. Costas y montañas no fueron fácilmente franqueables ni importantes localidades hasta hace poco fueron conectadas a redes carreteras, pero su vida social conoció escasamente los sistemas de medios informativos; las señales televisivas son tan recientes que sorprende.

Para el desarrollo cívico se requiere información libre, ideas, saberes diversos, confrontación de conocimientos y diálogo. El aislamiento explica uno de los elementos que influyen en el bajo perfil de la sociedad civil. 
Las estructuras sociales y políticas, a pesar de la modernidad, permanecen amarradas al pasado, actúan como condición e influencia, al mismo tiempo que condensan una acción preservadora de costumbres y formas de actuación social, imponiendo límites que afectan la expansión de la diversidad, la pluralidad cultural y la diversidad política. ${ }^{5}$

El carácter cultural de los distintos mundos indígenas del estado, las condiciones rurales o industriales y las formas en las que se relacionaron con los mercados locales y externos, influyeron para aislar intereses a veces aparentemente antagónicos. Sin embargo, al paso de las décadas, se nota que estos intereses y valores no son insuperables, que cuando se pierde centralidad social de sectores o figuras sociales, incluso las identidades se alteran y las posibilidades de desarrollo civil renacen, y una nueva posibilidad de acuerdos sociales surge con ciudadanos herederos de una sociedad que está construyéndose.

Por supuesto que a lo largo del territorio del estado, en su historia reciente, encontramos multitud de expresiones ciudadanas de sus habitantes en todos sus rincones y en las poblaciones más remotas. Cuando ese tipo de acciones trascendieron, los agentes gubernamentales les introducían en la operación del sistema político, lo que puso en un plano secundario la representación de sus intereses.

5 Hubo una vigorosa ola asociacionista en los últimos lustros. Junto a las organizaciones tradicionales -obreras, agrarias, empresariales-, aparecieron importantes formaciones en defensa de los derechos humanos, el medio ambiente y los recursos naturales, el voto y la transparencia, feministas, gais, de colonos y vecinos, y súmele usted que presagiaban un robustecimiento de la sociedad organizada. Pero los adjetivos colocados en el párrafo anterior no creo que sean caprichosos: sigue siendo epidérmica, porque sólo una minoría de los ciudadanos participa de manera sistemática en la "cosa pública" o siquiera se interesa por algún tema de la misma; más bien, la inmensa mayoría se recluye en sus asuntos, construye fortalezas para su vida privada, y deja a otros participar en los temas que supuestamente son de todos. Es desigual, porque mientras algunos "sectores" se encuentran muy bien organizados, otros carecen por completo de voz. 


\section{PERCEPCIÓN CIUDADANA}

\section{Y PERFIL DE LA CULTURA POLÍTICA}

Legitimación y confianza son dos aspectos de lo político-social cuya comprensión puede otorgar herramientas a los ciudadanos en sus acciones sociales. De hecho, la confianza en lo social tiene una relación determinante en el afán de la construcción de sus proyectos personales. Las empresas individuales o sociales a las que los habitantes del estado se enfrentan de manera cotidiana requieren de confianza para poder desarrollarse. El sustento familiar o personal de los veracruzanos depende de la certeza y la seguridad con la que se desempeñan en su actividad productiva, así como de la administración social, sea cual sea el proyecto.

Es posible constatar que los veracruzanos de distintos puntos de la geografía del estado expresan frustración en su acción proveedora familiar y empresarial. La falta de confianza y seguridad han impactado de manera negativa en la vida económica, social, familiar y emocional a los habitantes del estado, por lo cual resulta pertinente relacionar distintos elementos de la realidad social, aunque demos cuenta de solo particularidades como resultado.

Como se puede apreciar en el estudio citado, la confianza en el estado de Veracruz, solo comparando enero de 2008 y agosto de 2011, revela un deterioro que se constata con la encuesta que comentamos, así como por el programa de entrevistas personalizadas con ciudadanos, que se vienen realizando en un programa permanente en el estado. Lo que se resalta en dichas encuestas es el incremento de quienes no confían o de quienes han retirado la confianza al gobierno y expresan con toda certeza su posición.

Un punto que consideramos de carácter general en nuestro estudio es la economía. Este tema, que afecta a todos los mexicanos, es algo que en las últimas décadas del siglo xx se revelaba como el asunto más importante a resolver, puesto que está relacionado con empleo, salarios, oportunidades de realización y sobrevivencia. El segundo punto recaía 
en el tema de la seguridad pública, pero recientemente esta se ha convertido en la demanda de mayor prioridad, desplazando también otras demandas tan urgentes como la salud. Para los veracruzanos el tema de la seguridad no era prioritario durante el 2004 ni el 2008, sin embargo en el 2011 pasó a ser el tema central. La seguridad se ha venido convirtiendo en el problema de México, así lo demuestra la encuesta GEA-ISA ${ }^{6}$ donde la cuestión de la seguridad es considerada como el principal problema que aqueja a los habitantes del país.

\section{CÓMO SE PERCIBE LA ECONOMÍA Y EL DESARROLLO SOCIAL}

¿Cuál es la mirada del ciudadano respecto al desarrollo social y a la economía del país, considerando su funcionamiento desde la última década del siglo pasado y lo que va del presente siglo?

La respuesta promedio obtenida nos ubica en una evaluación reprobatoria de 5,5; sin embargo, para el año 2008 la situación en Veracruz mejoró en 7 décimas, esto obedece al reforzamiento que se realizó a través de una extraordinaria campaña gubernamental de medios y de publicidad que se vivió en el estado de Veracruz. No obstante, en el año 2011 se redujo nuevamente.

La opinión de los entrevistados nos permitió distinguir ciudadanos de distintas condiciones sociales, regiones, edad, sexo, filiación política, escolaridad y religión, que portan una percepción de cautela y razonamiento que no conduce a la expresión pública ni a la participación abierta. Encontramos que los sectores en los que se concentraron las respuestas más positivas fueron los más jóvenes, quienes también se ubican como los más críticos de la situación económica de ese momento. No obstante, es notable la posición de crítica de las mujeres que muestran mayor desacuerdo.

6 Encuesta Nacional GEA-ISA, grupo de economistas asociados. Estudio realizado en el mes de agosto de 2011. 


\begin{tabular}{|c|c|c|c|c|c|}
\hline \multirow{13}{*}{ 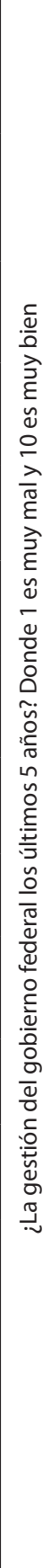 } & $\begin{array}{l}\frac{0}{\bar{z}} \\
\text { है } \\
\frac{0}{2}\end{array}$ & 울 & $\begin{array}{l}\text { mે } \\
\text { in }\end{array}$ & $\begin{array}{l}8 \\
\text { in }\end{array}$ & 고 \\
\hline & $\frac{d}{D}$ & $\begin{array}{l}8 \\
8 \\
8\end{array}$ & $\begin{array}{l}8 \\
8 \\
8\end{array}$ & $\begin{array}{l}8 \\
8 \\
8\end{array}$ & $\begin{array}{l}8 \\
8 \\
8\end{array}$ \\
\hline & 인 & $\begin{array}{l}\text { ஷ } \\
\infty\end{array}$ & 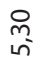 & $\stackrel{\text { N }}{m}$ & $\begin{array}{l}\stackrel{\bigcirc}{\infty} \\
\stackrel{+}{*}\end{array}$ \\
\hline & $a$ & $\begin{array}{l}\stackrel{0}{0} \\
0 \\
0\end{array}$ & 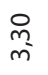 & $\stackrel{\text { @ }}{\text { m }}$ & $\begin{array}{l}\stackrel{\wp}{n} \\
\sim\end{array}$ \\
\hline & $\infty$ & $\begin{array}{l}\stackrel{Q}{0} \\
\stackrel{\sim}{\sim}\end{array}$ & 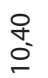 & $\begin{array}{l}\text { m. } \\
\text {. }\end{array}$ & \begin{tabular}{l}
$\stackrel{+}{+}$ \\
0 \\
\hdashline
\end{tabular} \\
\hline & $\wedge$ & $\stackrel{\text { 울 }}{=}$ & 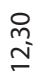 & $\begin{array}{l}\stackrel{R}{m} \\
\stackrel{n}{r}\end{array}$ & $\begin{array}{l}\underset{m}{m} \\
\stackrel{n}{n}\end{array}$ \\
\hline & 0 & $\begin{array}{l}\infty \\
\infty \\
\sigma\end{array}$ & 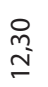 & 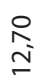 & \begin{tabular}{l}
$\underset{丶}{0}$ \\
\hdashline
\end{tabular} \\
\hline & in & $\begin{array}{l}8 \\
\text { : }\end{array}$ & $\underset{\sim}{\stackrel{ }{N}}$ & $\stackrel{8}{\circ}$ & $\frac{8}{i}$ \\
\hline & $\nabla$ & $\begin{array}{l}\stackrel{m}{\text { f }} \\
\text {. }\end{array}$ & $\begin{array}{l}\stackrel{\circ}{n} \\
\infty\end{array}$ & $\begin{array}{l}\text { in } \\
\text { ñ }\end{array}$ & $\underset{\infty}{\stackrel{\infty}{\infty}}$ \\
\hline & $m$ & $\stackrel{\text { ్ }}{N}$ & 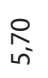 & 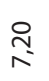 & $\begin{array}{l}8 \\
\text { \& }\end{array}$ \\
\hline & $\sim$ & $\stackrel{q}{q}$ & $\begin{array}{l}\stackrel{P}{\leftarrow} \\
\stackrel{+}{*}\end{array}$ & $\stackrel{\text { ㄱ }}{\sim}$ & શ્ \\
\hline & - & 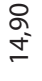 & $\begin{array}{l}0 \\
\text { in } \\
0\end{array}$ & $\begin{array}{l}\stackrel{+}{+} \\
\underset{ \pm}{*}\end{array}$ & $\begin{array}{c}\stackrel{P}{1} \\
\stackrel{m}{r}\end{array}$ \\
\hline & 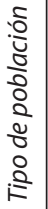 & 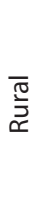 & 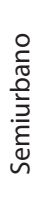 & 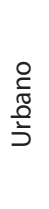 & 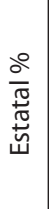 \\
\hline
\end{tabular}

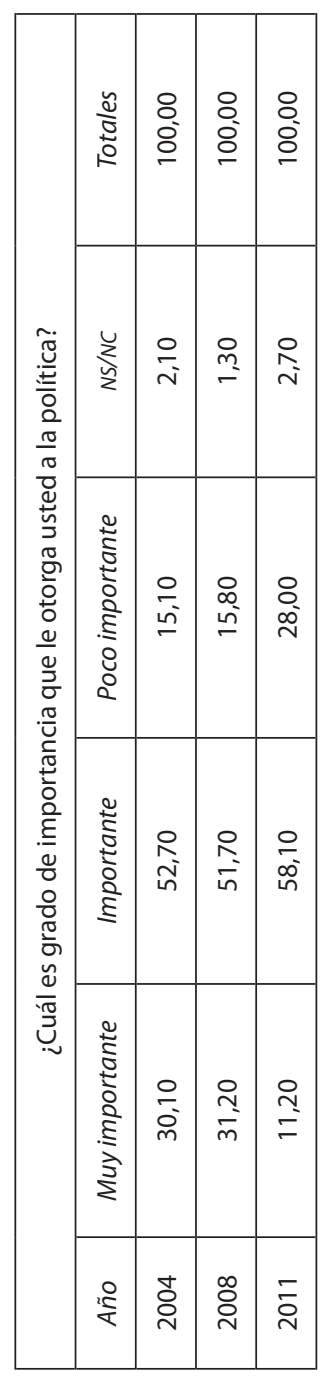


Consideramos que, en términos de política, se consiguió la centralidad luego de distintas reformas políticas y la creación del IFE, una acción de todo el sistema electoral y político donde se involucraron los distintos sectores sociales y los grupos más diversos, con lo cual se creó un clima de confianza en la figura sociopolítica de la transición a la democracia. Esta situación realmente trajo un gran protagonismo a los representantes y funcionarios de los poderes de la Unión, además del activismo de los dirigentes de los partidos políticos.

La última década del siglo xx había colocado altos los bonos del sistema de la administración electoral y el sistema de partidos en México con aceptación de poco más del 70\% de la población. Sin embargo, a poco de iniciado este siglo, la cuestión cambió, no obstante ese clima nacional, y no hubo grandes rupturas políticas en la entidad. Pero no se puede dejar de reconocer el avance de la pluralidad política y la pérdida del control absoluto del PRI.

El estudio del año 2008 en la percepción de los veracruzanos revela que la política era considerada como un bien social con valoraciones de alrededor de 8 puntos de 10. En esos momentos la política era considerada como una premisa de primer orden de la agenda nacional. Para la versión del estudio que comparamos, la evaluación se transforma en un interés social de menor rango; a la vez, la política, en la percepción de 2011, sufre una pérdida de centralidad comparativa.

La consideración capital de parte de los ciudadanos mexicanos, por lo menos en el tiempo corto que referimos, así se expresa. A partir de esa visión, y aun reconociendo la preponderancia de la violencia en la sociedad, no es posible desentenderse de otras varias tareas sociales, sobre todo cuando se ve cómo en Veracruz se pierden espacios de desarrollo político-civil con el consiguiente detrimento del uso de espacios sociales y públicos medianamente ganados en la construcción de democracia. En diversas entrevistas se expresan ideas en torno a que existen políticas y tareas sociales impostergables, en las plazas públicas de las ciudades del estado pero también en el diálogo ciudadano en redes y en 
círculos sociales. Además, se consideran varias perspectivas para encontrar salida a la violencia que se padece.

Recientemente, en el estado de Veracruz la visión medianamente optimista que sus habitantes expresaban sobre los asuntos de la política del estado y del país fortalecía al sistema político, no se vislumbraba una descalificación; al contrario, se confiaba moderadamente en la construcción de una transición democrática. La inercia que se propagó desde los organismos políticos, sociales y académicos con la liberalización política en el país todavía se alcanzaba a percibir al inicio del segundo lustro del presente siglo. Pero a partir de ahí, coincidentemente al perder el control político del Ejecutivo federal, el priísmo cedió la puntilla del sistema de partido único y la alternancia incontrolada. La aparición de escenarios de elevada competencia electoral, producto de poderes políticos reales emanados desde el interior del PRI o desde grupos emergentes de la oposición, provocó en los círculos más poderosos de la clase política histórica la idea de la restauración del sistema autoritario anterior. ${ }^{7}$

Lo que se había estropeado tenía grandes significados: no fue solamente perder una elección, fueron fracasos hilvanados en todo el país. Pero el extravío fue más profundo, pues quedaron sin gestión directa enormes privilegios; la confusión les aturdió, pero algunos personajes, desde la elección de 1997, ya planteaban la restauración del poder del PRI. Esta situación va a fortalecer una férrea posición de contrarreforma que da al traste con la supuesta transición democrática. Se impone un sesgo, que se bifurcará en franca perversión política: se trata de ese periodo que constituyó la elección de gobernador en el año 2010 en el estado y que implicó varios años de acciones correlacionadas.

7 El texto La balcanización del poder, de Jorge Alcocer V., corolario de la primera alternancia, condujo a la ineficacia de los instrumentos para la rendición de cuentas de los gobiernos estatales y municipales, y también los debilitó en el ámbito federal, en los poderes y organismos autónomos. 
Esa idea de prestigio democrático que se tuvo dentro del país, e incluso en el extranjero, se empañó como por arte de magia. Los datos que se citan arriba de la encuesta de Gea se significan en esta consideración. Nuevamente se pone de relieve la importancia de cuestionar la idea de que el progreso democrático es algo totalmente incierto, nebuloso, que la construcción de futuro ciudadano con valores y ética es algo que depende de la corresponsabilidad de todos los actores sociales, y que ahí donde el ciudadano consciente y participativo se aleja de las responsabilidades públicas queda un vacío que ocupan de manera inmediata las fuerzas que permanecían encubiertas por los aparatos de poder político y de la seguridad pública de las entidades y municipios.

Si los eventos sociales o naturales fueran objeto de permanente progreso, para desarrollarse solo se necesitaría ir al encuentro de la solución. Para corregir algún proceso entonces bastaría con esperar; se justificarían, por lo tanto, las actitudes que aguardan el paso del tiempo para su maduración y respuesta del devenir; solo se precisaría paciencia. Entonces se excusarían la contemplación o la inactividad.

Si la educación, la ciencia o la tecnología son cuestionadas desde posiciones encontradas, para saber sobre la manera en que en conjunto han contribuido en el desarrollo humano y para mejorar la convivencia, las respuestas no siempre satisfacen el interés de todos los grupos sociales. Se espera casi siempre que la educación, los medios, la tecnología y la civilización influyan moral y éticamente sobre los hombres para que tengan un mejor comportamiento, una mejor urbanidad, en suma, más respeto entre los individuos.

Una confirmación de esta reflexión la argumenta Rabotniko N. al señalar que:

La ciencia en la modernidad pasó de un periodo absolutista hegemónico, a un periodo relativista, donde se reconocen los límites de la misma ciencia en cuanto al carácter aproximado que resultan todas las explicaciones teóricas. Sin embargo, esta tendencia trajo grandes con- 
secuencias que implicaron un diálogo abierto con todos los saberes, incluyendo los provenientes del mundo oriental. Una idea que viene de educadores como Pasillas y Salmerón es que no sólo se han perdido valores por modificaciones de paradigmas en la historia contemporánea que genera referentes en éticas distintas, sino que se han perdido saberes que comunidades de mexicanos tuvieron y se olvidan sin cuestionamiento alguno, y que la reflexión de quienes conducen las políticas educativas ha dejado sin valorar el papel de los sistemas de valores. Con todo, los ciudadanos en algunas ciudades tienen relaciones y comportamientos distintos. El mundo rural y urbano son diferentes, los ciudadanos de la capital del país tienen comportamientos diferentes y empatías sociales y políticas que son acentuados en referencia a sus propios contextos pero sin duda en todos los casos es pertinente propiciar el ejercicio de la reflexión. ${ }^{8}$

\section{LOS VALORES SOCIALES ENTRE LOS CIUDADANOS DEL ESTADO}

Si estamos de acuerdo en que los valores de la democracia como la ética, la confianza, el reconocimiento de la otredad y, por extensión, la tolerancia, buscan implantar razonamientos encaminados a mejorar el entendimiento entre individuos o grupos sociales, en pos de una convivencia civilizada, entonces debe darse a través de la conquista de espacios públicos, el reclamo de la correcta aplicación de las funciones públicas y la exigencia en la rendición de cuentas de la administración de los bienes públicos. Estos son primordialmente los escenarios para propugnar por la democracia: no hasta que se conceda por medio de una extraordinaria reforma, sino por el ejercicio libre, por decisión pro-

8 Salmerón Castro, Ana María. (2009). “Educación cívica ¿para qué?”. Revista Internacional de Psicología y Educación vol. 11, no. 1, pp. 5-11; Pasillas Valdez, Miguel Ángel. (1999-2000). “Pedagogía, valores universales y contextualización”. Revista Colección Pedagógica Universitaria no. 32-33, pp. 15-31. 
pia de los ciudadanos que toman en sus manos las responsabilidades que les corresponden. ${ }^{9}$

Estaremos también ante una oportunidad de escenarios que permitan la discusión de ideas que aborden nuevos espacios posibles y cotidianos para el desarrollo democrático y de crecimiento de los ciudadanos en tanto sujetos activos para la democracia. Construir espacios sociales cada vez más incluyentes en los que no se impongan las mayorías, sobre todo cuando son construidas de manera artificial, manipulada, con fraudes o chantajes a los más necesitados. La inclusión social apela a armonizar a los diferentes con la razón que abarque a todos, el diálogo, en donde se mande y ordenen las cosas en el beneficio de lo colectivo impuesto sobre la lógica de lo individual. Silva Herzog dice

mientras la izquierda propone una república amorosa, la derecha propone una política maternal. [...] Asociar el gobierno con la paternidad (o la maternidad) es una de las ideas más antiguas y una de las nociones primordiales de la política: el gobernante como un padre protector que, con severidad (o dulzura), nos hace ver lo que por nuestra inmadurez no alcanzamos a entender. El paternalismo [...] nos cree incapaces de decidir y está convencido de que nos podemos hacer mucho daño si nos dejan libres. Cuando el patriarca nos castiga es, siempre en nuestro nombre y para nuestro propio bien. ${ }^{10}$

9 En la consideración de Cano Cabildo, el concepto arendtiano de libertad política es posible por la conjunción que hace compatible el sentido positivo de libertad con la idea griega de la política, desde donde nace un concepto que mira posible y viable que invita a la participación pública. Considera que la libertad política ya no será concebida como un efecto necesario de la liberación, el hombre ya no debe esperar a que estén dadas las libertades negativas, para que sea posible la participación pública, porque será el ejercicio de la libertad positiva que pueda crear espacios políticos. En el pensamiento de Arendt no se requiere esperar a que las formas de gobierno sean honestas o a que la cultura política sea democrática para interesarnos en lo público.

10 Silva-Herzog Márquez, Jesús. (13 de febrero de 2012). “Maternalismo”. Grupo Reforma, El Blog de Jesús Silva-Herzog Márquez. Disponible en: http://blogjesussilvaherzogm.typepad.com/el_blog_de_jess_silva_her/2012/02/maternalismo.html. 
Este razonamiento puede también ser útil en la comprensión de aspectos tan importantes como los que no acaban de convencer a las nuevas generaciones y que tienen que ver con el hacerse cargo de los destinos de su propia sociedad, lo que supone, por lo tanto, transformar a la política. La crisis de las utopías y los desencantos va más lejos, pero no se puede suponer que el desencanto ahí se agota, más bien se extiende a sectores de todas las edades y género, así como de todas las condiciones sociales. Por lo tanto, no es un asunto particular de un sector social, no debe dejarse de lado el análisis de las oportunidades sociales, y su gestión puede ser parte de la superación del desencanto.

Los ciudadanos del estado de Veracruz tienen algunas ideas y percepciones acerca de la política, de sus responsabilidades públicas y sobre su participación social; cómo conciben a la autoridad es revelador del carácter y las formas en las que se administra desde los gobiernos a la sociedad. No se desconfía de la autoridad de manera incomprensible, la percepción está relacionada con la actuación de los políticos administradores y ejecutores de las acciones gubernamentales. Es la otra cara de la misma moneda. La manera en la que quienes tienen ventaja social y se sirven de las instituciones, con o sin la autoridad política, ha generado desacuerdos y contradicciones que parecen insuperables en el corto tiempo.

Los valores sociales que son fundamentales para la convivencia social tienen que ver con el respeto que se puede establecer entre los distintos miembros de la comunidad. Cuando existen, la ética y la solidaridad cohesionan y fortalecen, pero no podrán existir si se abusa, si se atropella, si solo se privilegia a los que comparten o apuntalan el predominio. Resolver las contradicciones que se expresan en los niveles de desconfianza implica distintos niveles de atención, que sin la profundización de la democracia con ciudadanos ausentes o sin movimientos sociales vigorosos, no se pueden visualizar.

Para hacernos una idea acerca de cómo percibe su comportamiento político el veracruzano, indagamos si es correcto para la toma 
de decisiones atenerse a la opinión de los expertos o de los líderes que los representan, hipótesis válida para el trabajo o la circunstancia política. De lo anterior resultó que 4 de cada 10 habitantes con derechos políticos o laborales respondió que se supedita a este tipo de explicaciones o señalamientos para hacerse su propio punto de vista. Esto se deriva de que no se considera con solvencia plena como ciudadano, tiene una opinión personal deficiente que no le permite la toma de decisiones o su imagen de sujeto político es devaluada, por lo tanto, dependiente de quienes están en condiciones de saber dirigir mensajes indicativos o información sobre asuntos de la vida política. ${ }^{11}$

Por lo que se ve, parece que para un importante sector de los habitantes del estado es normal el papel que juegan los políticos. "Si se están aprovechando de su puesto para hacerse ricos como todos los que han pasado por ahí lo han hecho, cualquiera que llegue va a hacer lo mismo. Todos los que fueron presidentes tienen ranchos, casas y mucho dinero. Y los principales están bien porque han estado cerca de donde se reparte. Eso no va a cambiar". ${ }^{12}$ Que un ciudadano tenga la expectativa de que sus esperanzas de vida sean encauzadas por un líder debido a que se consideran como en una especie de incapacidad social, sitúa a una sociedad en franca fragilidad social.

Otros elementos de nuestro estudio nos permiten conocer particularidades adicionales que se han desvelado en una relación entre resultados estadísticos y entrevistas personales en los municipios escogidos para profundizar la encuesta. Con el complemento de ese panorama social, los mayores porcentajes de quienes no reconocen o aceptan ser dirigidos en su opinión, se encuentran entre los ciudadanos que habitan los municipios de menor marginación social. Esto nos permite ubicar

11 Esta es una opinión de respuesta complementaria resultado del cruce de información entre la encuesta 2011 y el programa de entrevistas realizado durante el año 2012.

12 Programa de entrevistas a ciudadanos de los municipios que fueron fuente de la encuesta de valores sociales y cultura política, programa 2012. 
regionalmente cuáles son las zonas que requieren mayor atención de parte de necesarios programas de educación cívica.

La visión que se desprende de los datos de nuestros estudios de percepción, encuestas y entrevistas, es de cierta incompetencia civil cuando se trasciende a los ámbitos privados, considerando la perspectiva habermasiana que sostiene que la democracia tiene que pasar por abordar considerablemente la esfera pública, en donde el razonamiento en la comunicación entre los individuos considere de manera destacada el interés público. Lo anterior complementa la idea de Arendt, quien propone que al interior de las colectividades es donde surge la política.

En otra indagación se buscó saber si el ciudadano está en condición de emitir un juicio de carácter social o si tendría que esperar a tener una opinión de aquellos a los que respeta. El porcentaje de quienes esperan ser dirigidos se convierte en casi 55,3\% de la población. De los ciudadanos del estado, 6 de cada 10 asisten a las urnas en los procesos electorales. De manera coherente, 5,8 de 10 piensan que los ciudadanos no tienen manera de influir en las decisiones gubernamentales. Los que más apoyan esta idea son los más jóvenes y las mujeres. Un alto porcentaje de los veracruzanos que se tiene en baja estima política, a pesar de pensar que no pueden influir en las decisiones de los gobernantes, asiste a las urnas a depositar su sufragio en las jornadas electorales.

El 45\% de los veracruzanos considera que lo mejor que puede suceder es que cada quien se interese solo en sus propios asuntos sin importar lo que hagan los otros. El 50\% estaría en disposición de interesarse en una perspectiva colectiva, de la cual se desprende una franja de diez puntos de certera radicalidad proclive a la participación social en la que tiene sentido el concepto de lo público. El 36,2\% de los ciudadanos del estado declararon haber tenido una participación de carácter comunitaria, el 62,3\% expresaron que rara vez o nunca han tenido esa experiencia, el grupo de edad con menos experiencia de participación colectiva es entre 18 y 25 años. 


\begin{tabular}{|c|c|c|c|c|c|c|}
\hline \multicolumn{7}{|c|}{ ¿Asiste a reuniones de asociaciones o comunidades para resolver problemas } \\
de su barrio o comunidad? & $\begin{array}{c}\text { Algunas } \\
\text { veces }\end{array}$ & Rara vez & Nunca & NS/NC & Total\% \\
\hline Año & Frecuentemente & 24,90 & 23,30 & 42,50 & 2,90 & 100,00 \\
\hline 2004 & 6,40 & 26,70 & 15,40 & 43,30 & 3,90 & 100,00 \\
\hline 2008 & 10,70 & 26,70 & 26,60 & 35,70 & 1,50 & 100,00 \\
\hline 2011 & 9,50 & & & & &
\end{tabular}

En otros ámbitos de la vida social de los veracruzanos, la participación de los ciudadanos es marginal y es ahí donde los estos no han sido capaces de desempeñar las responsabilidades públicas.

En la medición que realizamos en el año 2008, 6,5 de cada 10 ciudadanos del estado consideraba que vivíamos en una sociedad en democracia, al mismo tiempo consideraban que la democracia en el país era de menor calidad a la practicada en el estado. La anterior consideración se expresó cuando aún se hallaba fresca la fractura social que se generó con la elección presidencial del año 2006, y en una situación según la cual la mayoría de los electores en el estado de Veracruz que acudieron a las urnas votaron por el candidato que resultó perdedor. Sin embargo, es muy clara la percepción de los veracruzanos al decir que, comparadas con ese momento, las cosas funcionaban mejor en el país en los últimos años del siglo xx.

Lo que se revela en nuestros estudios demoscópicos y en las entrevistas personales realizadas después del levantamiento, es que las necesidades de deliberación entre los ciudadanos deben ser promovidas desde distintos espacios públicos. Sobre todo desde la educación pública, que debería ser considerada como una demanda nacional, con el fin de revertir la escasa asistencia de grupos sociales en acciones de participación y desarrollo de la civilidad. En ese ámbito, la preservación y respeto de los bienes y de los espacios públicos es una arena de suma importancia cuya vigilancia compete a todos, educa y hace más digna la 
vida en sociedad. Las experiencias exitosas pueden ser un punto de consideración en la esfera social y al abordarla se estará fomentando un ciudadano celoso al que los gobernantes con otros intereses no podrán hacer a un lado de manera impune. ${ }^{13}$

El reconocimiento de las distintas vertientes que originan a las sociedades que son el centro de nuestras consideraciones, nos indica que el punto de partida para establecer las razones estructurales de la baja intensidad ciudadana no puede dejar de considerar el peso del colonialismo con sus determinantes culturales de distinta factura histórica, situación que apela a la investigación del pasado desde el interés del presente.

En el perfil ciudadano y de los actuales cuerpos sociales reconocemos formaciones sociales diferenciadas. En esas construcciones es en donde históricamente y en el presente se hace la diferencia de cómo se vive la cultura y los conceptos de la democracia, la moral, la ética social, la tolerancia, la seguridad, la salud y la educación. El profesor Francisco Zapata insistía en algo que ya señalaba Touraine, él había establecido que la democracia es un régimen político cuyo funcionamiento es mediado por los tipos de articulación entre sociedad, sistema político y Estado, y opina que dichos tipos de articulación constituyen el trasfondo en el que se desarrolla lo específico de esta forma de representación. ${ }^{14}$

Los valores de la democracia son adoptados y reconocidos, en lo general, por los veracruzanos. Así se demostró en la encuesta levantada en el año 2008, donde los promedios adquieren un valor de 7,2 en rela-

13 Hahn Lüchmann, Ligia Helena, Participación y representación: algunas reflexiones sobre las experiencias participativas en Brasil, pp. 213-246; Velásquez C., Fabio E., Participación ciudadana y control social institucionalizado en Colombia, pp. 345376. En: Izunsa Vera, Ernesto y Gurza Lavalle, Adrián (coords.). (2010). La innovación democrática en América Latina. Tramas y nudos de la representación, la participación y el control social. México: Ciesas-Publicaciones de La Casa Chata, p. 447.

14 Zapata, Francisco. (2000). Democracia en América Latina. México: Flacso/Fondo de Cultura Económica. "En América Latina se pueden distinguir dos tipos básicos de articulación corporativa [...] que definen el desarrollo de la ciudadanía, la formación de los partidos políticos y los procesos electorales [...] que varían según los procesos históricos de la sociedad de que se trate". 
ción de 10. Otras estimaciones que complementan una percepción en ese momento alcanzan altas puntuaciones. Tal es el caso del trabajo, que en la misma referencia se valora en 9,7 puntos, una sobresaliente apreciación social que se ve un poco menguada en los sectores de mayor marginación. Esta situación refleja sin duda una menor estimación debido a las condiciones de precariedad de los trabajos que conocen los ciudadanos pertenecientes a estos sectores.

La valoración que en 2008 los habitantes del estado hicieron de la familia es de 90,9, consideración que la situó como una de las instituciones más sólidas de la sociedad veracruzana. Pero muy pronto la profundización de la crisis económica del país, así como la crisis de los valores políticos en el estado, situaron a la familia en fuertes confrontaciones, lo que se ha agravado por falta de oportunidades para los jóvenes, al cuestionar los valores como se demuestra en el estudio de 2011 los deteriora. Nuevamente una menor apreciación se percibe en los ciudadanos de sectores de jóvenes más pobres. Es de destacarse que la valoración que se puede colegir es sostenida entre todos los grupos de edades, igual entre los de 18 años que entre aquellos que tienen más de 65 años.

Para los veracruzanos, la escuela es un centro primordial que sintetiza valores sociales, de progreso, ascenso social, educación, de saber, de preparación para etapas superiores de escolaridad y de superación y mejoramiento social. ${ }^{15}$ Esos, y seguramente otros elementos más, significan la educación para los mexicanos, pero fundamentalmente la educación pública. Sin embargo, en épocas recientes la educación pública ha sido sumamente cuestionada por sus resultados. En evaluaciones internacionales, estos hechos han sido objeto de comentarios de distintos niveles, ámbitos y enfoques, en cuyos argumentos se trata de encontrar las razones por las que los rendimientos de tan extraordinarios recursos públicos que en ella se invierten no tienen los beneficios esperados. La importancia social de la escuela sufrió un impacto que debe

15 Programa de entrevistas personalizadas (Alafita Méndez, Leopoldo, 2004-2011). 
alertar a la sociedad del estado: en opinión de los ciudadanos, su valoración social descendió de 96 puntos a 70, seguramente por la crisis económica, el desempleo y la inseguridad, temas que corresponden a la responsabilidad gubernamental.

En distintos foros y medios televisivos se ha insistido en que uno de los diversos elementos que intervienen en forma negativa con los bajos resultados de la educación pública, se ubica en las determinaciones que surgen del carácter corporativo del sindicato, de la relación sesgada del objeto del trabajo educativo y su vínculo político partidario con el PRI. Pero su participación no se agota en esa relación distinta de papel social que debe jugar el magisterio mexicano, en medio del pacto social entre profesores y Estado de la revolución. Para mantener un sistema educativo universal se otorgó doble y hasta triple plaza a un considerable número de trabajadores de distintos niveles, con lo cual, de manera privilegiada, se aumentan los ingresos de los trabajadores y todo se resuelve de manera privada en la gestión ya no por la acción sindical sino por la gestión individual de los trabajadores ante los dirigentes en cuestión.

De manera complementaria, el lugar de trabajo constituye otro elemento más que maneja a discreción el sindicato para complementar las prácticas corporativas en el sector educativo. A la obtención de la plaza se le agrega no solo la permanencia en el trabajo, sino también el ascenso escalafonario y, con esto, también el lugar de labor y de consumo de servicios como otro mecanismo de poder para la venta de favores y el mantenimiento de la atención de los clientes del sindicato. Lo anterior se ilustra con el movimiento magisterial que estalló en su primera etapa entre agosto y septiembre de 2008 y por segunda ocasión en noviembre de 2009, en el estado de Morelos, en donde fue destacado el apoyo social de las comunidades. Su demanda central era la defensa del derecho de heredar la plaza y el lugar de trabajo a los descendientes. Lo que se argumentaba constituía una conquista sindical revolucionaria. Esto por supuesto ocasiona una pérdida de interés sustantiva de calidad 
educativa, ya que esta no es en modo alguno motivo de premios al buen desempeño de la calidad de la educación.

En ese contexto nacional, los veracruzanos expresan sus puntos de vista sobre la escuela, pues escuela y educación no son significados idénticos. En Veracruz, por el contrario, tienden a ser diferentes si estamos de acuerdo en que la escuela es un espacio en el que se integran alumnos y profesores con intereses específicos; que maestro y sindicato, a pesar de las determinaciones que se han descrito antes, son dos niveles en los que las responsabilidades de cara a la calidad de la enseñanza son muy diferentes pero están muy entrelazadas. Por estas razones tal vez no debería causar extrañeza la valoración que de la escuela hacían los veracruzanos apenas en el 2008, ya que se expresaban valores de alta consideración: 9,6 de una escala de 10 es muy revelador en una entidad que es muy orgullosa de escuelas y educadores de carácter histórico. Es notorio que los ciudadanos que pertenecen a sectores menos marginados son los que ponderaban con menos entusiasmo el papel social de la escuela.

En cuanto a la percepción ciudadana y a la cultura política, se puede demostrar que los ciudadanos abrazan el sistema democrático. Sin embargo, un porcentaje que ronda la media y poco más, en ese mismo 2008 consideraba que los gobernantes surgidos de la democracia deben imperar, pero que ni resuelven los asuntos económicos, ni saben gobernar, además de que en este sistema se presentan muchos desacuerdos.

Sobre la religión, los veracruzanos están expresando un proceso que seguramente es de gran importancia para observadores del tema y otros interesados. Ven muy claro un proceso de pérdida de centralidad de este aspecto en la vida social del estado. De un promedio estatal que se establece en 6,9 puntos, la diferencia entre el grupo de mayor edad y los más jóvenes va de 7,2 a 5,5\%, así como de género femenino a masculino desciende de 6,8 a 5,9 \%. Es claro que los valores religiosos disminuyen en hombres y jóvenes, y entre los sectores de veracruzanos de más altos ingresos. 
SOBRE LA CULTURA Y LOS VALORES CÍVICOS:

LA CONFIANZA. CÓMO SE PERCIBE A LOS GOBIERNOS Y A LAS INSTITUCIONES

En este apartado se indaga la percepción de los ciudadanos de la entidad sobre los distintos niveles de gobierno. Cómo se representa en su imaginario social el comportamiento político. De esta valoración a las instituciones gubernamentales depende la confianza en los políticos que gobiernan, y la percepción que se tiene de la legitimidad de la representación social. El aparato judicial en el estado de Veracruz ha sufrido también pérdida de confianza por parte de los ciudadanos. Una de las razones importantes que determinan esa situación corresponde a la falta de autonomía de ese poder público. El manejo político subordinado al Ejecutivo impide su desarrollo institucional y en muchas ocasiones el ejercicio de la justicia es fuera del marco del Estado de derecho.

\begin{tabular}{|c|c|c|c|c|c|c|}
\hline \multicolumn{7}{|c|}{$\begin{array}{l}\text { ¿Cómo valora las siguientes posibilidades de gobierno?: ¿Tener un sistema político } \\
\qquad \text { democrático? }\end{array}$} \\
\hline Año & Muy bueno & Bueno & Malo & $\begin{array}{l}\text { Muy } \\
\text { malo }\end{array}$ & $N S / N C$ & Total \% \\
\hline 2004 & 28,10 & 43,80 & 17,50 & 5,30 & 5,30 & 100,00 \\
\hline 2008 & 29,70 & 53,20 & 5,40 & 1,50 & 10,20 & 100,00 \\
\hline 2011 & 28,40 & 51,00 & 11,10 & 4,50 & 5,10 & 100,00 \\
\hline
\end{tabular}

Al parecer de los veracruzanos, en el estado la democracia se halla lejana, ni siquiera se consolida la democracia procedimental. El perfil de la sociedad civil es de baja intensidad y la insatisfacción es generalizada, lo que provoca un profundo sentido de desencanto. Tal desconfianza es hacia las instituciones gubernamentales y hacia los organismos autónomos, se extiende incluso hasta los conciudadanos y a la valoración de sí mismo. 
La información recabada es sumamente amplia y aspiramos a que sea del interés general, pero se pretende al mismo tiempo, y no es un asunto secundario, que el trabajo sea útil para poder contribuir a promover el diálogo entre los ciudadanos para el desarrollo de la civilidad participativa. El decrecimiento de los que confiaban en la existencia de la democracia en el estado de Veracruz pasó de más de $64 \%$ a solo $43 \%$, y los que niegan su existencia crecieron de $31 \%$ a $53 \%$.

\begin{tabular}{|c|c|c|c|c|c|c|}
\hline \multicolumn{7}{|c|}{ ¿Existe la democracia en México? } \\
\hline Año & $\begin{array}{l}\text { Totalmente } \\
\text { de acuerdo }\end{array}$ & $\begin{array}{c}\text { De } \\
\text { acuerdo }\end{array}$ & $\begin{array}{l}\text { En desa- } \\
\text { cuerdo }\end{array}$ & $\begin{array}{c}\text { Totalmente en } \\
\text { desacuerdo }\end{array}$ & $N S / N C$ & Totales $\%$ \\
\hline 2004 & 6,00 & 41,70 & 37,90 & 9,40 & 5,00 & 100,00 \\
\hline 2008 & 7,60 & 51,20 & 30,00 & 6,20 & 5,00 & 100,00 \\
\hline 2011 & 3,50 & 6,40 & 37,50 & 37,90 & 14,70 & 100,00 \\
\hline \multicolumn{7}{|c|}{ ¿La democracia puede causar desórdenes? } \\
\hline Año & $\begin{array}{l}\text { Totalmente } \\
\text { de acuerdo }\end{array}$ & $\begin{array}{c}\text { De } \\
\text { acuerdo }\end{array}$ & $\begin{array}{l}\text { En desa- } \\
\text { cuerdo }\end{array}$ & $\begin{array}{c}\text { Totalmente en } \\
\text { desacuerdo }\end{array}$ & $N S / N C$ & Totales \% \\
\hline 2004 & 11,10 & 28,80 & 40,20 & 13,50 & 6,40 & 100,00 \\
\hline 2008 & 10,20 & 47,70 & 28,30 & 6,80 & 7,00 & 100,00 \\
\hline 2011 & 11,30 & 39,30 & 32,80 & 12,30 & 4,30 & 100,00 \\
\hline \multicolumn{7}{|c|}{ ¿Existe la democracia en Veracruz? } \\
\hline Año & $\begin{array}{l}\text { Totalmente } \\
\text { de acuerdo }\end{array}$ & $\begin{array}{c}\text { De } \\
\text { acuerdo }\end{array}$ & $\begin{array}{l}\text { En desa- } \\
\text { cuerdo }\end{array}$ & $\begin{array}{c}\text { Totalmente en } \\
\text { desacuerdo }\end{array}$ & $N S / N C$ & Totales \% \\
\hline 2004 & 4,60 & 40,70 & 36,40 & 13,60 & 4,70 & 100,00 \\
\hline 2008 & 9,00 & 55,20 & 25,00 & 6,70 & 4,10 & 100,00 \\
\hline 2011 & 4,50 & 37,60 & 40,40 & 14,00 & 3,50 & 100,00 \\
\hline \multicolumn{7}{|c|}{ ¿El gobierno de Veracruz es de confianza? } \\
\hline Año & $\begin{array}{l}\text { Totalmente } \\
\text { de acuerdo }\end{array}$ & $\begin{array}{c}\text { De } \\
\text { acuerdo }\end{array}$ & $\begin{array}{l}\text { En desa- } \\
\text { cuerdo }\end{array}$ & $\begin{array}{c}\text { Totalmente en } \\
\text { desacuerdo }\end{array}$ & $N S / N C$ & Totales \% \\
\hline 2004 & 4,40 & 35,40 & 41,00 & 13,90 & 5,30 & 100,00 \\
\hline 2008 & 12,80 & 55,50 & 23,50 & 4,70 & 3,50 & 100,00 \\
\hline
\end{tabular}


Frecuentemente es más deseable abstenerse de emitir un juicio acerca de lo que pasa, hasta que uno tenga la oportunidad de escuchar la opinión de aquellos que respetamos

\begin{tabular}{|c|c|c|c|c|c|c|}
\hline Años & $\begin{array}{c}\text { Totalmente } \\
\text { de acuerdo }\end{array}$ & $\begin{array}{c}\text { De } \\
\text { acuerdo }\end{array}$ & $\begin{array}{c}\text { En } \\
\text { desacuerdo }\end{array}$ & $\begin{array}{c}\text { Totalmente en } \\
\text { desacuerdo }\end{array}$ & NS/ NC & Totales \% \\
\hline 2004 & 14,90 & 42,70 & 26,20 & 7,00 & 9,20 & 100,00 \\
\hline 2008 & 11,20 & 60,70 & 17,00 & 3,00 & 8,10 & 100,00 \\
\hline 2011 & 12,90 & 42,40 & 27,70 & 9,30 & 7,70 & 100,00 \\
\hline
\end{tabular}

¿En México se respetan los derechos humanos?

\begin{tabular}{|c|c|c|c|c|c|c|}
\hline Año & $\begin{array}{c}\text { Totalmente } \\
\text { de acuerdo }\end{array}$ & $\begin{array}{c}\text { De } \\
\text { acuerdo }\end{array}$ & $\begin{array}{c}\text { En } \\
\text { desacuerdo }\end{array}$ & $\begin{array}{c}\text { Totalmente en } \\
\text { desacuerdo }\end{array}$ & NS/NC & Totales \\
\hline 2004 & 3,70 & 27,40 & 47,90 & 16,80 & 4,20 & 100,00 \\
\hline 2008 & 3,30 & 31,70 & 51,40 & 10,50 & 3,10 & 100,00 \\
\hline 2011 & 6,40 & 37,50 & 37,90 & 14,70 & 3,50 & 100,00 \\
\hline
\end{tabular}

La confianza en el gobierno de México es algo que se ha medido en varios momentos. Ahora solo confirmamos la tendencia negativa que se redujo en la visión de los veracruzanos, de $48 \%$ a $31 \%$, y la desconfianza se incrementó de $48 \%$ a $77 \%$. Mientras que 35\% de los mexicanos estaban convencidos de que en nuestro país se respetaban los derechos humanos, tal idea se ha visto reducida a solo el $31 \%$. Los convencidos de lo contrario, que sumaban $62 \%$, ahora representan el $78 \%$.

\begin{tabular}{|c|c|c|c|c|c|c|}
\hline \multicolumn{7}{|c|}{ ¿Ha disminuido la corrupción en México? } \\
\hline $\begin{array}{c}\text { Tipo de } \\
\text { población }\end{array}$ & $\begin{array}{c}\text { Muyde } \\
\text { acuerdo }\end{array}$ & De & Ecuerdo & Totalmente en \\
desacuerdo & desacuerdo & NS/NC & Total \% \\
\hline Rural & 0,90 & 26,00 & 42,10 & 28,00 & 3,00 & 100,00 \\
\hline Semiur- & 0,00 & 19,40 & 46,00 & 31,30 & 3,30 & 100,00 \\
\hline bano & 4,30 & 14,20 & 40,90 & 38,60 & 2,00 & 100,00 \\
\hline Urbano & 2,70 & 17,70 & 42,10 & 35,00 & 2,50 & 100,00 \\
\hline
\end{tabular}


La percepción de los ciudadanos del estado sobre la corrupción es que esta creció de manera significativa. La columna de los que opinan más radicalmente sobre la existencia de la corrupción es de $77 \%$.

A finales de 2007 y principios de 2008, los veracruzanos que pensaban que el gobierno de Veracruz era digno de confianza representaban el $68 \%$, porcentaje que disminuyó drásticamente a solo el $38 \%$. Quienes desconfían del gobierno de Veracruz pasaron a ser poco más de 59\%. En estos datos se muestra cómo se invirtieron los niveles de confianza.

Para los veracruzanos, la importancia de la familia se ha visto menoscabada en el informe comparativo que estamos ofreciendo al público: desciende de 98 a 85 puntos cuando se habla de trastocar los valores sociales, que generalmente se expresan de manera subjetiva.

La consideración que los ciudadanos veracruzanos otorgaban alto valor a la política, se redujo de 31 a 11 puntos, no obstante del cuadro anterior podemos ver que se sigue apreciando la importancia de esta. En relación con otras variables, la marginación de los ciudadanos en política no los hace abandonar esta vía. Por otro lado, es notable el crecimiento de rechazo a la política real creció de $15 \%$ a $28 \%$.

La importancia social de la escuela sufrió un impacto que debe alertar a la sociedad del estado. Su valoración social, en opinión de los ciudadanos, descendió de 96 puntos a 70, seguramente por la crisis económica, el desempleo y la inseguridad, temas que corresponden a la responsabilidad gubernamental.

El gran interés por la política, de parte de los ciudadanos, se redujo de 10 a 4 puntos, el interés ponderado varió de 28 a 25 puntos. Los que expresaron poco interés crecieron de $42 \%$ a $49 \%$ y los que mostraron rechazo crecieron de $19 \%$ a $20 \%$.

Sobre la restricción de la libertad de expresión se opina casi en los mismos términos. La tolerancia democrática mejoró de manera escasa. La convicción más radical por la libertad de expresión es el cambio más importante. 
ALAFITA MÉNDEZ

\begin{tabular}{|c|c|c|c|c|c|c|}
\hline \multicolumn{7}{|c|}{$\begin{array}{r}\text { ¿Qué grado de importancia tiene para usted cad } \\
\text { ciudadanos? }\end{array}$} \\
\hline \multicolumn{7}{|c|}{ Libertad de expresión } \\
\hline Año & $\begin{array}{l}\text { Muy } \\
\text { importante }\end{array}$ & Importante & $\begin{array}{l}\text { Algo impor- } \\
\text { tante }\end{array}$ & $\begin{array}{l}\text { No es } \\
\text { importante }\end{array}$ & $N S / N C$ & Total \\
\hline 2004 & 67,50 & 26,10 & 2,60 & 1,00 & 2,80 & 100,00 \\
\hline 2008 & 65,70 & 28,00 & 2,70 & 0,50 & 3,10 & 100,00 \\
\hline 2011 & 58,00 & 35,40 & 5,60 & 0,10 & 0,90 & 100,00 \\
\hline
\end{tabular}

\begin{tabular}{|c|c|c|c|c|c|c|}
\hline \multicolumn{7}{|c|}{$\begin{array}{l}\text { Aunque la libertad de expresión es una meta valiosa, desgraciadamente es necesa- } \\
\text { rio restringir la libertad de ciertos partidos políticos }\end{array}$} \\
\hline Año & $\begin{array}{l}\text { Totalmente } \\
\text { de acuerdo }\end{array}$ & $\begin{array}{l}\text { De } \\
\text { acuerdo }\end{array}$ & $\begin{array}{l}\text { En } \\
\text { desacuerdo }\end{array}$ & $\begin{array}{c}\text { Totalmente en } \\
\text { desacuerdo }\end{array}$ & $N S / N C$ & Totales \\
\hline 2004 & 19,60 & 45,00 & 25,00 & 4,80 & 5,60 & 100,00 \\
\hline 2008 & 11,40 & 52,80 & 22,80 & 4,10 & 8,90 & 100,00 \\
\hline 2011 & 12,10 & 49,50 & 24,40 & 8,10 & 5,90 & 100,00 \\
\hline
\end{tabular}

En cuanto al muy actual tema de las coaliciones o alianzas, los opositores más radicales subieron $2,5 \%$. Los moderados que se oponen se redujeron de $35 \%$ a casi $32 \%$, lo que indica que se gana en tolerancia. Los que sostienen una idea a favor de la coalición se mantienen. Lo novedoso recae en los más convencidos de la importancia de los acuerdos políticos, pues se elevó en más de cinco puntos.

El siguiente cuadro muestra cómo los electores transitaron de la identidad partidaria a la preferencia por los candidatos. Algo que se documenta es el incremento del porcentaje de ciudadanos que votan de manera libre por cualquier partido político. Al mismo tiempo es notable que la identidad partidaria disminuyó en años recientes, mientras que en el 'no 2004 un 52,60\% de los habitantes de la entidad se declararon sin simpatía hacia un partido político. Se observa que para el 2011 
la cifra cambió a 59,60\%, lo que revela la pérdida por el peso porcentual del corporativismo.

\begin{tabular}{|c|c|c|c|c|c|}
\hline \multicolumn{7}{|c|}{ En las jornadas electorales usted: } \\
\hline & $\begin{array}{c}\text { 2: Depende del } \\
\text { 1: Siempre vota } \\
\text { candidato para } \\
\text { por el mismo } \\
\text { vano }\end{array}$ & $\begin{array}{c}\text { 3: Votar por ese } \\
\text { partido } \\
\text { rente partido }\end{array}$ & cada elección & NS/NC & Total\% \\
\hline 2004 & 20,90 & 59,30 & 9,50 & 10,30 & 100,00 \\
\hline 2008 & 24,80 & 58,80 & 9,10 & 7,30 & 100,00 \\
\hline 2011 & 20,70 & 54,50 & 15,60 & 9,20 & 100,00 \\
\hline
\end{tabular}

\begin{tabular}{|c|c|c|c|c|}
\hline \multicolumn{5}{|c|}{ ¿Simpatiza usted con algún partido político? } \\
\hline Año & Si & No & NS/NC & Total \% \\
\hline 2004 & 36,40 & 52,60 & 11,00 & 100,00 \\
\hline 2008 & 41,80 & 44,70 & 13,50 & 100,00 \\
\hline 2011 & 28,10 & 59,90 & 12,00 & 100,00 \\
\hline
\end{tabular}

Si recordamos que los habitantes del estado tienen la percepción de que la corrupción creció, el desagregado nos revela que la dependencia que se lleva los mayores señalamientos es la Policía de Tránsito con más del $35 \%$, un porcentaje verdaderamente elevado si se toma en cuenta que la gran mayoría de la población no tiene auto. Las siguientes dependencias consideradas como más corruptas en el estado son el Municipio y la Policía.

La confianza en el Ejército se ha visto considerablemente menguada, la extraordinaria exposición a la que han sido expuestas las Fuerzas Armadas del país ha hecho mella en su consideración social. Ese debe ser un punto de exhibición para los diálogos sociales que se 
requieren promover. El porcentaje de ciudadanos que declara de manera enfática total desconfianza creció casi 10\% de 2008 a 2011.

Las policías estatales redujeron su suma positiva de $42 \%$ a $22 \%$. Las sumas negativas pasaron de $45 \%$ a $75 \%$, por lo que los policías del estado son reprobados de manera contundente por parte de los habitantes.

Los diputados son altamente cuestionados. En ello seguramente influye que no se perciben como parte de un poder con autonomía, lo que conduce a plantearse el papel que juegan el sistema de partidos en el estado y el tema de la crisis de la democracia representativa. La suma negativa de los diputados creció de $66 \%$ a $79 \%$ de desconfianza, y una Cámara de representantes que tiene casi $80 \%$ de desaprobación, lo que indica claramente una profunda crisis de representación.

Los organismos electorales locales crecieron en desconfianza de $23,6 \%$ a $46,9 \%$ de su suma negativa de 2008 a 2011. Parece que la elección del 2010 y el papel de los consejeros tienen repercusiones que finalmente se cuantifican. La confianza plena en los organismos electorales locales se redujo de 31,4\% en el 2008 a 9,7\% en el 2011.

Observamos finalmente que la mengua de la simpatía partidaria es una realidad que se constata a solo 30 meses de los resultados que comparamos. Este punto particular requiere de mayor desglose y cruce de información.

En la investigación social no resulta infrecuente hallar posiciones de desinterés, cuando no de franca oposición, a considerar el pasado para ayudar a la comprensión del presente. Si bien para algunos existe duda sobre la importancia de revisar el proceso que da cuenta de la manera como se construyen determinantes sociales, esta reflexión sirve para ese diálogo académico que enmarca prácticas de organismos electorales subordinados, ejercicios de poder desde posiciones gubernamentales que en complicidad con empresas de la comunicación, restaron el ejercicio del derecho constitucional de elegir en libertad. 
VALORES Y LÍMITES A LA DEMOCRACIA EN VERACRUZ

\begin{tabular}{|c|c|c|c|c|c|c|c|}
\hline \multicolumn{8}{|c|}{ ¿Qué tanta confianza le merecen cada una de las instituciones o grupos siguientes? } \\
\hline \multirow{4}{*}{ La familia } & Año & $\begin{array}{c}\text { Mucha } \\
\text { confianza }\end{array}$ & Confianza & $\begin{array}{c}\text { Poca } \\
\text { confianza }\end{array}$ & $\begin{array}{l}\text { Nada de } \\
\text { confianza }\end{array}$ & $\begin{array}{l}\text { NS/ } \\
\text { NC }\end{array}$ & Total \% \\
\hline & 2004 & 82,10 & 12,80 & 2,80 & 1,30 & 1,00 & 100,00 \\
\hline & 2008 & 90,90 & 5,70 & 2,20 & 0,40 & 0,80 & 100,00 \\
\hline & 2011 & 66,30 & 26,80 & 4,90 & 1,60 & 0,40 & 100,00 \\
\hline \multirow{4}{*}{ La escuela } & Año & $\begin{array}{c}\text { Mucha } \\
\text { confianza }\end{array}$ & Confianza & $\begin{array}{c}\text { Poca } \\
\text { confianza }\end{array}$ & $\begin{array}{l}\text { Nada de } \\
\text { confianza }\end{array}$ & $\begin{array}{l}\text { NS/ } \\
\text { NC }\end{array}$ & Total\% \\
\hline & 2004 & 35,00 & 43,60 & 14,90 & 4,40 & 2,10 & 100,00 \\
\hline & 2008 & 47,40 & 34,50 & 12,60 & 4,20 & 1,30 & 100,00 \\
\hline & 2011 & 13,70 & 51,60 & 27,00 & 6,60 & 1,10 & 100,00 \\
\hline \multirow{4}{*}{ La Iglesia } & Año & $\begin{array}{c}\text { Mucha } \\
\text { confianza }\end{array}$ & Confianza & $\begin{array}{c}\text { Poca } \\
\text { confianza }\end{array}$ & $\begin{array}{l}\text { Nada de } \\
\text { confianza }\end{array}$ & $\begin{array}{l}\text { NS/ } \\
\text { NC }\end{array}$ & Total \% \\
\hline & 2004 & 40,70 & 35,60 & 17,30 & 5,50 & 0,90 & 100,00 \\
\hline & 2008 & 50,50 & 30,40 & 14,40 & 4,00 & 0,70 & 100,00 \\
\hline & 2011 & 29,90 & 44,80 & 19,10 & 5,80 & 0,50 & 100,00 \\
\hline \multirow{4}{*}{ Los jueces } & Año & $\begin{array}{c}\text { Mucha } \\
\text { confianza }\end{array}$ & Confianza & $\begin{array}{c}\text { Poca } \\
\text { confianza }\end{array}$ & $\begin{array}{l}\text { Nada de } \\
\text { confianza }\end{array}$ & $\begin{array}{l}\text { NS/ } \\
\text { NC }\end{array}$ & Total \% \\
\hline & 2004 & 8,40 & 35,00 & 35,20 & 17,70 & 3,70 & 100,00 \\
\hline & 2008 & 13,20 & 31,20 & 37,80 & 15,00 & 2,80 & 100,00 \\
\hline & 2011 & 4,20 & 24,00 & 47,10 & 22,50 & 2,30 & 100,00 \\
\hline \multirow{4}{*}{$\begin{array}{c}\text { El } \\
\text { Ejército }\end{array}$} & Año & $\begin{array}{c}\text { Mucha } \\
\text { confianza }\end{array}$ & Confianza & $\begin{array}{c}\text { Poca } \\
\text { confianza }\end{array}$ & $\begin{array}{l}\text { Nada de } \\
\text { confianza }\end{array}$ & $\begin{array}{l}\text { NS/ } \\
\text { NC }\end{array}$ & Total \% \\
\hline & 2004 & 23,30 & 46,20 & 22,80 & 6,00 & 1,70 & 100,00 \\
\hline & 2008 & 35,10 & 37,00 & 22,50 & 3,90 & 1,50 & 100,00 \\
\hline & 2011 & 15,00 & 39,30 & 32,30 & 12,80 & 0,50 & 100,00 \\
\hline
\end{tabular}


ALAFITA MÉNDEZ

\begin{tabular}{|c|c|c|c|c|c|c|c|}
\hline \multirow{4}{*}{ La Policía } & Año & $\begin{array}{c}\text { Mucha } \\
\text { confianza }\end{array}$ & Confianza & $\begin{array}{c}\text { Poca } \\
\text { confianza }\end{array}$ & $\begin{array}{l}\text { Nada de } \\
\text { confianza }\end{array}$ & $\begin{array}{l}\text { NS/ } \\
\text { NC }\end{array}$ & Total \% \\
\hline & 2004 & 11,50 & 34,00 & 33,10 & 19,80 & 1,60 & 100,00 \\
\hline & 2008 & 13,50 & 29,10 & 37,50 & 19,00 & 0,90 & 100,00 \\
\hline & 2011 & 3,72 & 19,16 & 46,96 & 29,43 & 0,73 & 100,00 \\
\hline \multirow{4}{*}{$\begin{array}{c}\text { Los } \\
\text { diputados }\end{array}$} & Año & $\begin{array}{c}\text { Mucha } \\
\text { confianza }\end{array}$ & Confianza & $\begin{array}{c}\text { Poca con- } \\
\text { fianza }\end{array}$ & $\begin{array}{l}\text { Nada de } \\
\text { confianza }\end{array}$ & $\begin{array}{l}\text { NS/ } \\
\text { NC }\end{array}$ & Total \% \\
\hline & 2004 & 4,20 & 25,80 & 34,10 & 32,70 & 3,20 & 100,00 \\
\hline & 2008 & 7,40 & 23,80 & 36,10 & 30,10 & 2,60 & 100,00 \\
\hline & 2011 & 2,70 & 16,20 & 45,70 & 33,20 & 2,20 & 100,00 \\
\hline
\end{tabular}

En el estado de Veracruz, y en general en el país, observamos que se califica en algunos aspectos como "modernos" a los gobiernos, clase política, empresarios de la comunicación, corporaciones sindicales y organismos patronales de diversas ramas de la producción y el comercio o los servicios; estos lograron imponer a un candidato del PRI que nunca dejó de ejercer el poder.

Díganos qué tan de acuerdo o en desacuerdo está usted con las siguientes afirmaciones: El voto influye de manera importante en las condiciones de vida de la población

\begin{tabular}{|c|c|c|c|c|c|c|}
\hline Año & $\begin{array}{c}\text { Muy de } \\
\text { acuerdo }\end{array}$ & $\begin{array}{c}\text { De } \\
\text { acuerdo }\end{array}$ & $\begin{array}{c}\text { En desa- } \\
\text { cuerdo }\end{array}$ & $\begin{array}{c}\text { T.en de- } \\
\text { sacuerdo }\end{array}$ & NS/NC & Total \% \\
\hline 2004 & 23,30 & 45,90 & 21,30 & 5,20 & 4,30 & 100,00 \\
\hline 2008 & 19,00 & 58,10 & 15,90 & 1,60 & 5,40 & 100,00 \\
\hline 2011 & 18,40 & 54,40 & 20,40 & 4,00 & 2,80 & 100,00 \\
\hline
\end{tabular}


VALORES Y LÍMITES A LA DEMOCRACIA EN VERACRUZ

\begin{tabular}{|c|c|c|c|c|c|c|}
\hline \multicolumn{6}{|c|}{ ¿Qué nivel de confianza le merecen las autoridades que organizan las elecciones? } \\
\hline Año & Mucha & Alguna & Poca & Ninguna & NS/NC & Total \% \\
\hline 2004 & 16,00 & 46,70 & 27,90 & 7,60 & 1,80 & 100,00 \\
\hline 2008 & 31,40 & 29,20 & 18,70 & 4,90 & 15,80 & 100,00 \\
\hline 2011 & 9,70 & 28,10 & 33,90 & 13,00 & 15,30 & 100,00 \\
\hline
\end{tabular}

La elección del pasado julio de 2010 no solo confirmó el régimen priísta, sino que avaló el sistema corporativo y las políticas con las que garantiza el sistema de privilegios al cancelar la construcción de instituciones democráticas sin las que el estado sería omiso en la obligación constitucional para el desarrollo de la vida democrática en el país. Como señala Amartya Sen, las libertades de los individuos dependen de la superación de la precariedad. Si una persona no logra vestirse, tener medicina básica para recuperar su salud, agua, techo que le proteja, no está en camino del ejercicio de la libertad. Solo cuando el desarrollo humano hace posible tales bienes es posible acceder a las libertades, los derechos y la democracia. El desarrollo humano le entrega potestad material a la persona para que se presente en el espacio público portando un relativo margen de autonomía frente a sus pares, sobre todo si es que eventualmente estos pretendieran conculcar sus respectivos derechos, someter arbitrariamente su voluntad o inducir su participación política. ${ }^{16}$

\section{BIBLIOGRAFÍA}

Alafita Méndez, Leopoldo. (2012). Tolerancia y democracia los valores políticos en Veracruz. En: Martín Aguilar Sánchez (coord.), La difícil construcción de la democracia en Veracruz. Editorial Universidad Veracruzana, México.

16 Ver: Kumar Sen, Amartya. (2000). Desarrollo y Libertad. Madrid: Planeta. 
Anguiano, Arturo. (1978). Los artífices del cardenismo. En: Historia de la revolución mexicana. El Colegio de México, México. . (1985). La consolidación del nuevo orden institucional en México (1929-1940). América Latina: historia de medio siglo. Siglo XXI, UnAm, México.

BEAs, Diego. (29 de febrero de 2012). Vientos de cambio que incorporan nuevos elementos tecnológicos que influyen sobre sociedades locales. Diario Reforma.

Córdoba, Arnaldo et al. (1980). La crisis Obregón-Calles y el Estado mexicano. Siglo xxi, México.

De la Garza Toledo, Enrique. (1998). Ascenso y crisis del estado social autoritario, El Colegio de México, México.

. (2003). La crisis de los modelos sindicales en México y sus opciones. En: La situación del trabajo en México. uAM-Plaza y Valdés, México. . (2004). Del corporativismo y neocorporativismo al postcorporativismo. En: Alternativas sindicales en América Latina. Escuela Nacional Sindical, Colombia.

Granados Chapa, Miguel Ángel. (Octubre 9 de 2011). Plaza pública: tragedia y ridículo en Veracruz. Reforma.

Grupo de Economistas Asociados, GeA-ISA. (Agosto de 2011). Encuesta Nacional. s.e., México.

Hahn LÜChmann, Ligia Helena. (2010). Participación y representación: algunas reflexiones sobre las experiencias participativas en Brasil (213-246). En: Ernesto Izunsa Vera y Adrián Gurza Lavalle (coords.), La innovación democrática en América Latina. Tramas y nudos de la representación, la participación y el control social. Ciesas-Publicaciones de La Casa Chata, México.

Kumar Sen, Amartya. (2000). Desarrollo y libertad. Planeta, Madrid.

Kuper, Adam. (2001). Cultura: la versión de los antropólogos. Paidós, Barcelona:

Loyola, Rafael. (1980). El Estado y la política obrera del cardenismo. Era, México. 
Pasillas Valdez, Miguel Ángel. (1999-2000). Pedagogía, valores universales y contextualización. Revista Colección Pedagógica Universitaria, 32-33, $15-31$.

Paz, Octavio. (1978). El laberinto de la soledad. La formación del poder político en México. Era, México.

Programa de Entrevistas a Ciudadanos de los Municipios de VeraCRUZ. (2012). Encuesta de valores sociales y cultura política programa 2012. IIH-S/UV, Xalapa, Veracruz.

Rabotn. (1987). Desencanto e individualismo. En Estudios Filosofía-historialetras. Biblioteca iтam, México.

Salmerón Castro, Ana María. (2009). Educación cívica ¿para qué? Revista Internacional de Psicología y Educación, 11(1), 5-11.

Secretaría de la Defensa Nacional. (9 de febrero de 2012). Comunicado. S.l. S.e.

Silva-Herzog Márquez, Jesús. (2012). Maternalismo. Grupo Reforma, El Blog de Jesús Silva-Herzog Márquez. Disponible en: http://blogjesussilvaherzogm.typepad.com/el_blog_de_jess_silva_her/2012/02/maternalismo.html.

Velásquez C., Fabio E. (2010). Participación ciudadana y control social institucionalizado en Colombia. En Ernesto Izunsa Vera y Adrián Gurza Lavalle (coords.), La innovación democrática en América Latina. Tramas y nudos de la representación, la participación y el control social. Ciesas-Publicaciones de La Casa Chata, México.

Zapata, Francisco. (2000). Democracia en América Latina. Flacso/Fondo de Cultura Económica, México.

Zigmunt, Bauman. (1994). From Pilgrim to Tourist or a Short History of Identity. En: Stuart Hall \& Paul du Gay (comps.), Questions of Cultural Identity. Londres: Sage. 



\title{
ELITES POLÍTICAS EN HIDALGO: UNA INTERPRETACIÓN DESDE LA PERSPECTIVA DE REDES SOCIALES
}

\author{
Daniel Carrasco Brihuega
}

\section{INTRODUCCIÓN}

EL OBJETIVO DE ESTE TRABAJO es utilizar la perspectiva de redes sociales para explicar el fenómeno de las elites políticas y el acceso al poder político en un contexto de cambio político ${ }^{1}$ en el Estado de Hidalgo, México. Para ello iniciaremos con la descripción breve del contexto sociopolítico de la entidad, para dar cuenta de la existencia de un proceso de cambio político. Posteriormente, presentaremos las variables que intervienen en la explicación; en tercer lugar el objetivo será identificar las redes que buscan el acceso al poder político y conocer los tipos de relación existentes entre ellas, así como los recursos que se intercambian. Finalmente, en la última parte intentaremos responder a algunas preguntas centrales sobre el alcance explicativo de la perspectiva de redes sociales con respecto al fenómeno estudiado.

Lejos de ser un estudio típico sobre las elites políticas y la circulación de sus miembros en un contexto local, lo que se pretende en este

Universidad de Guanajuato-Campus León.

1 Según Cansino existen dos perspectivas metodológicas para estudiar los procesos de cambio político: a) una que centra su atención en las estructuras políticas; y b) otra que lo hace en el comportamiento de los actores. Es esta última perspectiva la más próxima a la de redes sociales. Su principal característica consiste en atribuir un lugar preponderante a la acción de los actores políticos (partidos políticos, grupos de interés, movimientos sociales, representantes del poder, protagonistas de cambio o a la configuración de las relaciones políticas a partir de dichos actores y de su acción, estrategias, cálculos y decisiones). Sin excluir los condicionamientos de tipo cultural, económico e internacional. 
trabajo es hacer intervenir metodológicamente la perspectiva de redes sociales para poder entender la dinámica política en un contexto local. Putnam ${ }^{2}$ analiza a las redes sociales a través del intercambio de capital social entre los individuos o miembros que las componen; se refiere con ello a la conexión entre individuos y a las normas de reciprocidad que existen entre las propias redes. La construcción de redes se crea a través de ese intercambio de capital, el cual resulta a su vez un proceso de interacción e interdependencia (Putnam, 2000).

La noción de red en el poder político se puede centrar en el acceso o acumulación de poder político (puestos de elección popular y de alta función pública). Por tanto, al análisis de la posesión de recursos, de los códigos de entendimiento entre las redes y la dependencia e interacción de los actores políticos durante un periodo de tiempo determinado. Así mismo, al intercambio dinámico de recursos que se genera entre los actores (personas o individuos y empresas) y las instituciones (partidos políticos, instituciones gubernamentales, organizaciones, etc.). En este sentido, el concepto de capital social utilizado por Putnam resulta útil ya que puede relacionarse con la idea de red de poder político o rede de política.

De esta manera, el objetivo del presente capítulo es identificar las redes que intervienen en la dinámica del poder político en el estado de Hidalgo, México. También, explicar la capacidad política entre los partidos políticos y su relación con los electores, conocer las redes de relaciones entre los distintos actores que intervienen y analizar su forma de actuar dentro de la arena política estatal.

\section{EL CONTEXTO LOCAL}

En la mayoría de los estados de México la competencia electoral es cada vez más evidente. Por lo tanto, la oferta política de los partidos ha

2 Putnam, R. D. (s.f.). Bowling Alone. The collapse and revival of America community. New York: Simon and Schuster. 
entrado en una dinámica de verdadera competencia, lo cual refleja un proceso de liberalización del régimen autoritario a nivel estatal. ${ }^{3}$ Este proceso establece, por un lado, la adopción de un régimen con rasgos más democráticos y, por otro, el establecimiento de un sistema multipartidista y más competitivo. Los resultados de los procesos electorales atestiguan que Hidalgo experimenta un proceso de cambio que se refiere a la valoración y a la percepción ciudadana de las instituciones, de los partidos y por lo tanto de la democracia local.

En los últimos veinte años, el estado de Hidalgo ha experimentado cambios significativos, transformaciones que reflejan en cierta medida la necesidad de analizar con mayor precisión la relación entre el conjunto de actores políticos ya establecidos y los nuevos o emergentes así como el liderazgo que conlleva cada uno de ellos. Explicar este "reciente" proceso de competencia política únicamente a través de los resultados electorales sería limitarse a un solo factor explicativo, en donde el argumento central gira en torno a la emergencia de dos nuevas fuerzas políticas, y una nueva dinámica competencia por el poder político estatal.

Las transformaciones políticas en Hidalgo son resultado de la búsqueda del poder político. Estos cambios se descifran en parte a través de la competencia entre las redes que buscan ocupar los principales espacios de poder político (gobierno estatal y presidencias municipales, diputaciones y senadurías). Estas redes fueron generadas por la red central (gobierno estatal y PRI), y a partir de un nuevo esquema de distribución e intercambio de recursos tanto formales como informales. ${ }^{4}$

Es decir, la red central o inicial, por sí misma, estimula su propia competencia desde el interior generando otras redes opositoras que buscan su autonomía y en ocasiones rebasan en términos de capacidad

3 Se refiere a la noción de liberalización a través de la competencia política entre partidos políticos (Cansino, 2008, p. 138).

4 Los recursos formales se refieren a los puestos de elección popular y a los de dirección política dentro de la función pública, distinguiéndose de los recursos informales que se refieren a los recursos financieros, materiales los cuales son distribuidos e intercambiados esencialmente en los procesos electorales. 
política a la red matriz que las generó, restándole así centralidad. Es evidente entonces la aparición de nuevos actores que posteriormente se consolidan como nuevos líderes. ${ }^{5}$ Pero también existen otras redes que intervienen en este proceso de intercambio dinámico y de competencia, provenientes de otros contextos e instituciones. En ocasiones son redes exógenas al contexto local hidalguense, tales como el gobierno federal, la iniciativa privada o los comités ejecutivos nacionales de los propios partidos políticos, que inciden en la conformación de la red de acceso al poder político estatal.

\section{VARIABLES QUE INTERVIENEN}

La red de acceso al poder político en Hidalgo está conformada por una serie de relaciones entre las redes que están en la búsqueda del poder político gubernamental. Las variables que se utilizan en este estudio son, por un lado, las variables independientes tales como: redes internas, político-partidistas, ejidatarios, sindicales de iniciativa privada, redes exógenas el contexto político local y nacional y el intercambio de recursos, formales e informales. Y la variable dependiente constituida esencialmente por la gubernatura del estado, las presidencias municipales, las diputaciones federales y las senadurías.

\section{REDES Y DINÁMICA POLÍTICA LOCAL}

Las redes políticas en Hidalgo están formadas por nodos que representan relaciones establecidas por dos o más personas. Las redes varían de forma considerable y dependen de la cantidad de actores y del número y tipo de conexiones que hay entre ellas; las redes tienen metas claras y cuentan con lazos fuertes y débiles. La política local puede estar for-

5 Los liderazgos políticos son parte fundamental de los cambios sociales y políticos (véase: Blondel, J. \& Cansino, C. (1998). Political leadership in changing societies. México: Серсом. 
mada por varias redes y subredes que resultan de la combinación de intersecciones y/o uniones de grupos de individuos.

Según White, " "la teoría de las redes sociales se basa en la interdependencia entre redes sociales y corrientes de actividad humana”. Son conexiones que representan relaciones formales, informales, sistémicas y organizacionales. El tipo de vínculos que se establecen en la red se traduce en un esquema que muestra el flujo de la información y el tipo o patrón de las relaciones. De esta manera, la determinación de la influencia que una red puede ejercer depende de su centralidad, es evaluada por su participación en diversos grupos a lo largo del tiempo y por sus relaciones con otros actores o individuos. Un individuo que participa en varios grupos tiene más influencia debido a que puede movilizar, emitir y recibir más recursos.

No todos los miembros de una red tienen acceso al centro del poder, por lo tanto no todos tienen la misma influencia. Si un actor político se encuentra en la intersección de varios grupos, su influencia puede ser considerable debido a que se trata, en cierta manera, de un actor central interconectado con diversos intereses y grupos. Se puede determinar el número de grupos o subgrupos a los cuales un individuo pertenece y asignarle un valor, de tal suerte que también se puede determinar el centro de una red. Como en el sistema político mexicano, en donde al presidente se le puede considerar el nodo central de la red la cual está formada por una configuración de grupos o subredes en permanente competencia. En este estudio el gobernador resulta la parte esencial de la red de la política hidalguense y contemplamos a redes dependientes y/o subredes de la red central que están en competencia.

6 Ver: White, Douglas R. (1994). "Enfoque de redes para el estudio de comunidades urbanas”. Estudios Demográficos y Urbanos vol. 9, no. 2, pp. 303-326; Schmidt, S. (1999). "La red de poder mexicana. Estabilidad política y gobernabilidad". Instituciones y desarrollo 3. 


\section{LAS REDES}

\section{LA RED HUICHAPAN}

La red Huichapan se genera a partir de la llegada de Javier Rojo Gómez a la gubernatura del estado de Hidalgo, en 1937. La génesis de la red se da a partir del parentesco y, después, de las lealtades que se fueron formando a partir del poder político con que el grupo Huichapan contaba y que el propio Rojo Gómez articuló en la estructura del poder Ejecutivo Federal y con "poderes" estatales.

Rojo Gómez ejerció el poder con una gran capacidad de intermediación hacia el centro y hacia los liderazgos locales: primero, tejiendo una fuerte e intrincada red de relaciones y de arreglos con caciques rurales, con exjefes revolucionarios y demás grupos de poder, prácticamente en todos los municipios y regiones del Hidalgo. Pero, sobre todo, manejó hábilmente los vínculos y contactos con el centro: poco antes de la llegada del presidente Lázaro Cárdenas al poder, Rojo Gómez se desvinculó del grupo político que apoyaba la candidatura de Manuel Pérez Treviño del Partido Nacional Revolucionario (poco después llamado Partido Revolucionario Institucional) y se sumó a la de Cárdenas y, cuando este terminaba su mandato, se agregó al "bloque de gobernadores” que apoyó la sucesión a favor de Manuel Ávila Camacho. Estableció compromisos que consolidarían su poder en la entidad y lo transformarían en patriarca de la "familia revolucionaria" hidalguense.

Con el apoyo del gobierno federal, desde el gabinete de Ávila Camacho ${ }^{8}$ y en otras posiciones centrales, ${ }^{9}$ fue que Rojo Gómez impuso

7 Vargas González, P. (2003). Hidalgo, elecciones y reforma política 1979-2000. México: Cámara de Diputados Lvin Legislatura, Universidad Autónoma del Estado de Hidalgo, p. 51.

8 En 1940 deja la gubernatura de Hidalgo, por un llamado del presidente Ávila Camacho a la Regencia del Departamento del Distrito Federal (actualmente jefatura del gobierno del Distrito Federal, Ciudad de México).

9 Además de regente del DDF fue embajador en Japón, secretario general de la Confederación Nacional Campesina y gobernador del estado de Quintana Roo. 
a familiares y colaboradores en puestos estratégicos de la política local: Otilio Villegas toma la gubernatura interina cuando Rojo Gómez es llamado a la regencia del DDF, quien era un colaborador incondicional y al terminar el periodo constitucional, que originalmente era de Rojo Gómez, promueve la candidatura e inevitable ascenso al poder estatal de José Lugo Guerrero, cuñado de Rojo Gómez. De esta manera, la familia Rojo Lugo manejará la política de Hidalgo colocando a cercanos colaboradores en los Congresos local y federal; envían, por ejemplo, como diputados federales a Adolfo Lugo Guerrero, hermano del entonces gobernador, y a Raúl Lozano Ramírez, que jugará un papel importante para Grupo Huichapan en la desaparición de poderes en el estado en 1975. Dicho control de la política estatal por parte de la familia real, como se le conoce también a la de los Rojo Lugo, se encuentra supeditado, a través de los años, a las decisiones del presidente de la República en turno.

Fueron precisamente los presidentes de México quienes en circunstancias determinadas apoyaron o negaron, como también sucedió, ${ }^{10}$ el apoyo a las personas integrantes del Grupo Huichapan.

Los personajes que toman la gubernatura del estado, a su vez, promueven a familiares y amigos para ocupar cargos estratégicos dentro de la administración pública, pero siempre con el consentimiento de las cabezas de la red como sucedió con el gobernador Vicente Aguirre (1945-1951) quien, en el periodo de Rojo Gómez, fue impuesto como diputado federal y aquel por este. En este periodo gubernamental, Aguirre colabora con el mismo Rojo Gómez y José Lugo para ubicar al secretario particular de Rojo, Alfonso Corona del Rosal, como senador de la República y al hermano de Lugo, Adolfo Lugo Guerrero, como diputado federal.

10 Tanto el presidente Miguel Alemán como José López Portillo, en su momento, no dejan llegar a la gubernatura a los candidatos de la familia Rojo Lugo y se inclinan por personajes neutrales como Quintín Rueda y Guillermo Rossell, respectivamente. 
Cuando Aguirre termina su mandato, el Grupo Huichapan se enfrenta a la negativa del presidente de México, Miguel Alemán, de poner como gobernador al entonces senador Corona del Rosal, y trata de romper la inercia política del grupo hidalguense colocando a Quintín Rueda Villagrán. Las razones por las que el presidente Alemán no concedió espacio a la red Grupo Huichapan son en virtud de que este había competido por la candidatura presidencial contra el propio Rojo Gómez. No obstante, el grupo pierde espacio y el presidente no deja crecerlo, los Rojo Lugo logran colocar en el Congreso de la Unión a Carlos Ramírez Guerrero, hijo de Cecilio Ramírez, amigo de Javier Rojo y José Lugo, ${ }^{11}$ quien más tarde también será gobernador del estado.

El Grupo Huichapan desaparece en gran medida de la escena política estatal y nacional, pero no significa que pierdan poder y capital político en el estado: al terminar su mandato Rueda Villagrán, la familia real regresa al poder imponiendo al incondicional Alfonso Corona del Rosal, el mismo que poco más tarde y sin terminar el periodo correspondiente es llamado por el presidente Adolfo López Mateos para ocupar la presidencia nacional del PRI. ${ }^{12}$

En este periodo, el grupo coloca a Carlos Ramírez Guerrero como senador; al tercer hermano Lugo Guerrero, Fernando, como diputado federal y también al hijo de Javier Rojo Gómez, Jorge Rojo Lugo, quien será el "heredero" del Grupo Huichapan. Alfonso Corona, a la llegada del presidente Gustavo Díaz Ordaz, es designado regente del Departamento del Distrito Federal, e intercede ante él para que el ya citado Carlos Ramírez llegue a ser gobernador estatal en 1963, quien coloca a los hijos de José Lugo Guerrero, José y Humberto Lugo Gil, como diputados del Congreso Local.

11 Los tres fueron diputados federales en la década de los años veinte. Rojo Lugo y Lugo Guerrero, que ya se conocían, por ser cuñados, hicieron amistad con Cecilio Ramírez y, después, con su hijo Ramírez Guerrero.

12 "En 1958, el general Alfonso Corona del Rosa, que apenas cumplía año y medio en la gubernatura, prefirió venir a ser presidente del CEN Comité Ejecutivo Nacional del PRI durante el sexenio de López Mateos”. Ver: Granados Chapa, Miguel Ángel. (1999). Constancia hidalguense. México: Grijalbo, p. 284. 


\section{LA RED SÁNCHEZ VITE}

Cuando Ramírez Guerrero termina su mandato, en 1969, llega a ser gobernador Manuel Sánchez Vite, quien no tiene nada que ver con el grupo Huichapan e incluso se consolida como cabeza de un grupo alterno, perteneciente a la red del PRI, pero en contraste con la familia real.

Manuel Sánchez Vite era un exdirigente magisterial del Sindicato Nacional de los Trabajadores de la Educación y considerado cacique del estado de Hidalgo y quiso prolongar su influencia al designar a su sucesor sin el aval presidencial de Luis Echeverría, imponiendo a Otoniel Miranda: "Sánchez Vite no hizo faenas extraordinarias para llegar a cacique; heredó los restos del cacicazgo de los Austria en la Huasteca y de los latifundistas de la sierra, así como de los explotadores de indios en el Valle del Mezquital y de los restos de la aristocracia pulquera. Pero aunque no se había revelado hasta ahora. Como cacique hidalguense, venía obrando de igual manera desde antes; como estaba de acuerdo con los jefes del PRI-gobierno, todo se le dispensaba, se le justificaba o se le disfrazaba". ${ }^{13}$

Lo que siguió fue la molestia del Grupo Huichapan y, con el apoyo certero del presidente Echeverría y por sus propias instrucciones, el Congreso de la Unión decretó la desaparición de poderes a tan solo 29 días de que Miranda hubiera tomado posesión del cargo como gobernador. Era un momento, el de la sucesión, en el cual Sánchez Vite quiso imponer su voluntad saltando la designación de la familia real y, desde luego, del presidente de la República; su infortunio comenzó cuando se decidió a obrar con independencia de la estructura cacical centralizadora. Ahora los representantes de los caciques lo presentaban como el hombre más cruel, más irresponsable y violador de las leyes que haya

13 "En 1958, el general Alfonso Corona del Rosa, que apenas cumplía año y medio en la gubernatura, prefirió venir a ser presidente del CEN Comité Ejecutivo Nacional del PRI durante el sexenio de López Mateos”, Granados Chapa, Miguel Ángel. Constancia Hidalguense. Grijalbo 1999. México. p. 284. 
habido nunca. Y eso que había sido dirigente del SNTE, alto funcionario del ministerio de educación pública, gobernador y jerarca aparente del PRI: “[Manuel Sánchez Vite] tuvo las agallas y, presuntamente, la habilidad para imponer como su candidato al doctor Otoniel Miranda, pero el presidente Echeverría y el secretario de Gobernación, Mario Moya Palencia, le enseñaron poco después quién manda de verdad en esos casos, derrocando al gobernador impuesto en menos de un mes después de su toma de posesión".

La desaparición de poderes se da producto de una manifestación de sectores populares maquinada por los Rojo Lugo, con el apoyo del centro:

Hace 31 años libraban una batalla política el presidente Echeverría y su compadre el gobernador Manuel Sánchez Vite, quien osó y parecía haber conseguido imponer un sucesor al margen de la voluntad presidencial. Pero a los 28 días de la asunción al poder de su valido el doctor Otoniel Miranda, una rebelión campesina artificiosamente organizada desde Los Pinos, como parte de una andanada contra Sánchez Vite y su causahabiente, dio pie a que se declarara que había llegado la hora de sustituir a Miranda porque los poderes habían desaparecido. Fue nombrado en su lugar Raúl Lozano Ramírez, antiguo secretario particular de Javier Rojo Gómez, quien organizó la elección del hijo de éste, Jorge Rojo Lugo, quien haría más tarde secretario de gobierno a Murillo Karam. ${ }^{14}$

Sánchez Vite pudo conservar cierto poder político dentro de la red local y nacional, siempre y cuando se ajustara a las decisiones del centro; pero una vez desaparecidos los poderes, el antiguo gobernador vio truncada su carrera política: "Por la descripción que de él hacen y por los cargos que le lanzan, Otoniel Miranda más bien aparece como un Pinochet de

14 Granados Chapa, Miguel Ángel. (1 de noviembre de 2006). "Plaza Pública”. Diario La Jornada. 
tercera, entronizado en un gobierno de quinta. Sánchez Vite ya no podrá señalar al hombre de Bucareli como causante de su desgracia: se la ha buscado él mismo; tal vez no afirme que la historia del PRI se divide en un antes y un después de Jesús, sino en un antes y un después de que logró imponer su candidato y se plantó ante sus dirigentes, desafiante. La desgracia del cacique nace de enfrentarse a caciques mayores" ${ }^{15}$

Echeverría coloca como gobernador interino a otro prominente miembro del grupo Huichapan, Raúl Lozano Ramírez, quien prepara el camino para que el heredero del Grupo Huichapan, hijo de Javier Rojo Gómez, Jorge Rojo Lugo, asuma la gubernatura del estado y la cabeza de la familia. A partir de la llegada de Rojo Lugo empieza una renovación de integrantes del Grupo Huichapan, personajes que más tarde serán trascendentes en la política estatal empiezan a colocarse en la esfera gubernamental. Rojo Lugo posiciona a su primo hermano, Humberto Lugo Gil, en la senaduría y a Jesús Murillo Karam en una diputación federal; cuando llega a la presidencia de la República José López Portillo, en 1976, Rojo Lugo logra que su primo Lugo Gil repita en el Senado de la República, y, más tarde, el gobernador es quitado de su puesto para ocupar la secretaría de la Reforma Agraria del gabinete federal pero tres años después prescinde de sus servicios y es enviado de vuelta a Hidalgo a terminar su gestión y Rojo Lugo designa a Jesús Murillo como secretario de Gobierno, posición fundamental en el gabinete estatal.

Para la renovación de la gubernatura, López Portillo, enterado de la actuación de la familia Rojo Lugo, decide poner en el gobierno estatal a Guillermo Rossell de la Lama tratando de terminar con el cacicazgo de Hidalgo que imperaba desde hacía más de cincuenta años. Sin embargo, con el arribo de Miguel de la Madrid a la presidencia de México, y debido a que fue compañero de escuela de los Rojo y los Lugo en una escuela de la capital de país, les concede las senadurías a Jesús Murillo y a Adolfo Lugo Verduzco, sobrino del exgobernante José Lugo

15 Manuel Moreno Sánchez, Revista Siempre!, 1975. 
Guerrero y de Javier Rojo Gómez, y primo hermano del heredero Jorge Rojo Lugo.

En este momento surgen dos candidaturas al gobierno del estado, los primos hermanos Adolfo y Humberto Lugo, pero el "fiel de la balanza”, Miguel de la Madrid, se inclina por Adolfo, a quien antes lo había colocado en la presidencia nacional del PRI. El premio de consolación para Humberto Lugo fue nuevamente una senaduría; también es promovido senador, al que se le llamó el “delfín” de Rojo Lugo, Jesús Murillo Karam.

\section{LA RED MURILLO}

Jesús Murillo llega a la gubernatura en 1992 y Jorge Rojo impone funcionarios en el gabinete estatal: su hijo, José Antonio Rojo, es nombrado secretario de Desarrollo Social y a medio sexenio es colocado en la Cámara de Diputados federal, el mismo que ocupó la dirigencia estatal del PRI, Jorge Rojo, hermano de José Antonio, es actualmente el dirigente del partido a nivel estatal.

Cuando se acercaba en 1998 la designación del candidato del PRI a la gubernatura, Murillo se inclina por un colaborador suyo, Manuel Ángel Núñez Soto. Sin embargo, el apoyo popular lo tiene el senador José Guadarrama, a quien se le atribuía fama de cacique local del municipio de Jacala y cercanía con los ejidatarios, y es la primera vez que la designación del candidato se da en votación abierta a los electores; la elección es claramente ganada por Guadarrama, pero el gobernador Murillo altera la elección interna y la gana Núñez Soto, provocando un conflicto estatal que hace peligrar la estabilidad política estatal. De tal suerte, el presidente de México Ernesto Zedillo decide retirar de la gubernatura a Murillo y lo asigna a una subsecretaría federal y manda como gobernador interino al hijo de José Lugo Guerrero, Humberto Lugo Gil, quien tantas veces había buscado la gubernatura estatal. Por menos de un año desempeñó el cargo, y en 1999 pasó la batuta a Manuel Núñez Soto. 


\section{LA RED UNIVERSIDAD}

El Grupo Universidad nace de la relación entre la Universidad Autónoma de Hidalgo y el PRI. Se le llama así a la red que se formó bajo el nombre de Federación de Estudiantes Universitarios de Hidalgo en el año de 1966 que, buscaba la vinculación de los estudiantes de la UAH y sus escuelas incorporadas, con las instituciones educativas estatales y nacionales. $\mathrm{Si}$ bien es cierto que ninguno de los integrantes de esta red han accedido, hasta el momento, a la gubernatura del estado de Hidalgo, muchos de ellos han ocupado puestos políticos clave en la política estatal: desde alcaldías y diputaciones locales, hasta puestos legislativos federales y cargos en distintas administraciones del Gobierno del estado.

La FEUH sirvió por varios años como trampolín político en la escena estatal: el ejemplo más notorio es el de su exdirigente Gerardo Sosa Castelán, que fue su presidente, secretario general de la propia $\mathrm{UAH}$, rector de la misma, diputado federal y hoy nuevamente diputado federal de la Lx legislatura y anteriormente presidente del Comité Directivo Estatal del PRI en Hidalgo. Otros presidentes de la FEUH que llegaron a ocupar cargos públicos son: Aurelio Marín Huasso, secretario de Gobierno de la administración estatal del gobernador Manuel Núñez Soto (1999-2005); Francisco Olvera Ruiz, actual gobernador de Hidalgo y secretario de Gobierno de la administración del gobernador Miguel Osorio Chong (2005-2011), además del propio Sosa Castelán que ha buscado en dos ocasiones, sin conseguirlo, la candidatura del PRI al gobierno del estado.

A Sosa Castelán se le identifica como el dirigente formal de la agrupación. Arturo Herrera Cabañas lo definió a él y a Grupo Universidad así: personaje hábil que ha llegado a convertir la FEUH en el núcleo de un grupo de poder que extiende sus brazos por distintos ámbitos.

El grado de permeabilidad de Sosa quedó de manifiesto cuando, en la administración del gobernador del estado Jorge Rojo Lugo, se crea el Sindicato Único de Trabajadores al Servicio de los Poderes del 
Estado de Hidalgo y es nombrado Sosa como su primer secretario general. Sosa Castelán tejió una red de intereses políticos que lo convirtió, con el paso de los años, en jefe nato del Grupo Universidad, una camarilla de líderes estudiantiles y académicos que escalaron posiciones de gobierno hasta quedar incrustados en diferentes cargos de la administración estatal y con posiciones en diferentes legislaturas del Congreso local.

Cuando Gerardo Sosa fue secretario general de la UAH, el propio rector Menes reconocía que él se ocupaba de lo académico, mientras que aquel se encargaba de lo político. Así, la FEUH fue ganando terreno y logró que estos representantes, de manera automática, formaran parte del honorable Consejo Universitario, órgano de control y dirección institucional de más alto rango.

En las elecciones para gobernador de Hidalgo del 2005, Gerardo Sosa contendió como precandidato por el PRI, como también lo intentó en 1998, pero fue marginado del proceso de selección del candidato priista y por tanto de la sucesión ya que el candidato resultó ser el hoy mandatario estatal, Miguel Osorio. Sosa ocupó, a cambio, la dirigencia estatal del partido para después ser candidato por la vía plurinominal a la cámara de diputados y fue elegido presidente de la Comisión de Diputados del Estado de Hidalgo y ejerce como miembro de la comisión de ciencia y tecnología, educación pública y servicios educativos, vigilancia de la auditoria federal de la federación y en la comisión especial prospectiva para la definición del futuro de México.

\section{CUESTIONES CENTRALES}

¿Cómo se creó la red? ¿Cuáles fueron las condiciones del contexto? ¿Existen redes en el mismo contexto que no lograron consolidarse? Evidentemente existen redes que no logran consolidarse y esto depende de las metas de ellas mismas, es decir las redes que no han logrado obtener el poder político. 
La red se crea a través de la relación entre los distintos grupos de poder estatal. ${ }^{16}$ Sin embargo, existe una red central que originó la creación de las subredes o de las otras redes: la red Huichapan, la red Sánchez Vite, la red Murillo, la red Universidad, la red Guadarrama y la red PAN.

Originalmente, la relación tripartita entre la red Huichapan, el gobierno del estado de Hidalgo y el PRI, conforman la red de poder político y tienen como objetivo alcanzar y mantener su espacio de poder en el ámbito político, ganando las elecciones municipales, de diputados y la del gobernador para, de esta manera, conservar en el gobierno a sus grupos. Esto duró mucho tiempo, es decir que permaneció un esquema de nula competencia política. La red se transformó muy poco en un periodo largo de tiempo los gobernadores de (1937-199) fueron dependientes de esta red Huichapan-gobierno del estado y PRI.

Los recursos utilizados fueron durante muchos años los principales recursos generadores de los códigos de entendimiento de la política local. Por un lado, los recursos formales y por otro lado los recursos informales, los primeros referentes esencialmente a los puestos de dirección política dentro de la estructura gubernamental estatal y los puestos de elección popular. En lo que concierne a los recursos informales podemos identificar los recursos financieros y materiales suministrados e intercambiados durante los procesos electorales, estos recursos identifican el tipo de relación clientelar que aún existe en la región.

El contexto político hidalguense se caracterizó durante mucho tiempo por una hegemonía del PRI (reflejo de la competencia política nacional). Desde la revolución era el PRI que conducía la vida política en Hidalgo, presidencias municipales, diputados locales y federales y gobernador fueron priistas, lo que muestra una nula competencia polí-

16 Inicialmente los grupos de poder se pueden identificar con los grupos políticos productos de sistema político nacional y local, es decir grupos dependientes del Comité Ejecutivo Nacional del PRI CEN, y del propio gobierno estatal junto con la dirigencia del Comité Ejecutivo Estatal del PRI. A partir de esto tenemos tres redes generadoras de la red política en Hidalgo, PRI nacional y estatal y gobierno del estado de Hidalgo. 
tico-partidista y un desarrollo democrático local incipiente. Las condiciones en las que la red actual se construye son condiciones marcadas por nuevos actores que generan una verdadera competencia política. Con todavía un predominio del PRI, los factores son de índole local, aunque no se puede excluir los factores externos nacionales provenientes, directamente del CEN del PRI y de la presidencia de la República. Así mismo, un rasgo característico en la dinámica de esta red política es sin duda la presencia significativa de nuevas redes caracterizadas por liderazgos personales relacionadas estrechamente con instituciones y organizaciones sociales y de la iniciativa privada. En los últimos años aparecen algunos liderazgos claves dentro del estado, Jesús Murillo Karam, Gerardo Sosa Castelán y José Guadarrama. El primero de ellos exgobernador, dos veces senador y actual secretario general del CEN del PRI, el segundo de ellos actual diputado federal y exrector de la universidad estatal; y por último José Guadarrama, actual senador por el PRD.

Hay redes de poder político que aún no logran el acceso al poder y que forman parte de la gran red hidalguense, es el caso de la red Universidad (identificada con Gerardo Sosa), la cual no ha logrado aún obtener el poder político. Los recursos utilizados por esta red son funciones y puestos dentro de la universidad estatal, así como la asistencia social que se desprende de la fundación hidalguense a las comunidades más necesitadas. Por otro lado está la red de José Guadarrama, formada por este líder actualmente, expriísta, que ha tenido una influencia significativa en las regiones rurales y en comunidades marginadas. El profesor normalista de Jacala cuenta con una red de apoyo significativo ganando la última elección de mayoría del senado al exgobernador Murillo. Las 22 de las 84 presidencias municipales ganadas por el PRD en las elecciones de noviembre del 2005 se le atribuyen a su gran capacidad de operación política y al efecto AMLO en el estado de Hidalgo.

Es así como la red se transforma inicialmente con la creación de la red Huichapan y la del gobierno estatal junto con el PRI. Con el paso del tiempo se van creando primero la red Murillo, posteriormente la red 
Universidad y finalmente la red Guadarrama. Entorno a ellas se explica la competencia por el poder político en Hidalgo.

\section{¿CÓMO SE DISTRIBUYE EL PODER AL INTERIOR DE LA RED?, ¿QUIÉN DECIDE LA ENTRADA Y LA SALIDA DE LOS RECURSOS DE ALGUNOS MIEMBROS? Y, ¿CUÁLES SON LOS RECURSOS QUE MONOPOLIZA O UTILIZA LA RED?}

Se puede observar cómo la red de acceso al poder político en Hidalgo distribuye de dos formas el poder: el poder formal y el informal. El poder formal se refiere al hecho de transmitir recursos institucionales como las propias candidaturas a puestos de elección popular diputaciones, presidencias municipales emitidas de forma institucional, formalmente por el partido político en el poder, pero tradicionalmente por los liderazgos personales. Por otro lado, están los puestos en el gabinete de distintos niveles del mismo gobierno estatal.

En cuanto a los recursos informales, estos recursos se desprenden de los institucionales así como de la iniciativa privada. Están dirigidos a los líderes de los grupos políticos y se utilizan como elementos de persuasión o incentivos para la participación, permanencia y activación de la propia red. Estos recursos informales se refieren a los incentivos materiales de construcción, por ejemplo, y financieros y son utilizados para desplegar apoyos a candidaturas; son recursos que gestionan los propios líderes de los grupos y son distribuidos de forma "estratégica" con el objetivo de incrementar el alcance y la efectividad de la red. El manejo y la gestión de estos dos tipos de recursos, es decir la entrada y la salida, son finalmente controlados por el gobierno estatal y el PRI; es el gobernador quien finalmente decide la repartición de estos dos tipos de recursos a las otras redes de apoyo. Actualmente, la distribución de los recursos no solo depende del gobierno estatal sino que hay recursos provenientes de otros partidos, su financiamiento externo, así como de la iniciativa privada por sí misma. 
Así, los recursos que utiliza la red son, por un lado, institucionales formales, reflejados en la designación de las candidaturas a diputaciones locales y federales y presidencias municipales, como a los puestos del gabinete. Por otro lado, los recursos informales que se ven reflejados en lo material y financiero son más bien utilizados para el apoyo de las propias campañas políticas.

No existe un verdadero monopolio de los recursos. Durante mucho tiempo se concentró en la capacidad de decisión del gobernador, en los principales operadores de las redes y en los nodos de apoyo. El PRI, las presidencias municipales y los principales líderes de los grupos de apoyo eran quienes distribuían los recursos.

Existen también recursos que ingresan a la red de acceso al poder político provenientes del sector privado, del Consejo Coordinador Empresarial y de grupos de empresarios, fundamentalmente el club de fútbol de Pachuca, constructores, así como de ejidatarios y de grandes gremios como el SNTE.

La red de poder político en Hidalgo intercambia capital político y apoyo electoral y movilidad social en términos del voto y/o aceptación; es decir, un sistema clientelar de apoyo al grupo gobernante, al partido político y a las redes que buscan el acceso al poder.

\section{¿CÓMO EVOLUCIONA EN SUS METAS}

\section{Y EN SU FORMA DE ORGANIZACIÓN?}

La red funcionó de manera vertical y autoritaria, poco abierta. El acceso estaba determinada en buena medida por los mismos grupos que han intervenido y participado, es decir, la red hoy cuenta con redes distintas que dinamizan el intercambio de recursos y que compiten por el poder. Las cuatro últimas redes (Murillo, Universidad, Guadarrama y PAN) son de reciente creación, (1999-2007), lo cual es reflejo del nivel de desarrollo político del estado, del nivel de democratización. Es decir, las redes han sido parte fundamental del cambio político y por tanto de la 
competencia por el poder. Pero este funcionamiento ha sufrido serias transformaciones, ha evolucionado en los últimos años. Si la entrada y la salida de los recursos se observa en los procesos electorales, y en las campañas el despliegue de recursos, podemos comprender el momento de transformación en donde la oposición con propios recursos del mismo tipo, formales e informales, empieza a generar competencia, es decir, crea una red en competencia por la obtención del poder político. Obviamente la red del poder político se ha modificado y ahora existen nuevas redes de apoyo, así como redes de competencia; en ese sentido, tanto la red, los recursos y su distribución son distintos y se han modificado a través de los últimos años.

Podemos delimitar claramente la red en el tiempo, en el espacio social (quién pertenece y quién no), ¿cómo se participa en la red y cómo se recluta a los participantes?, ¿podemos definir claramente sus objetivos de la red? La delimitación de las redes de poder político en Hidalgo se puede hacer en el tiempo y en el espacio territorial. En la actualidad existen cinco grandes redes que buscan el poder político y la red central que intenta mantenerlo.

Este esquema permaneció por más de cuarenta años hasta que la selección del candidato a la gubernatura dejó de estar al alcance de la red Huichapan. En 1992 las dos redes dejan de ser las principales operadoras y se incorpora una nueva red: Murillo, quien a través de su liderazgo político, vínculos y experiencia partidista logra ir en contra de los propios candidatos propuestos por el grupo Huichapan y gana la candidatura del PRI al gobierno del estado de Hidalgo. Es entonces que una nueva red emerge y se consolida con la presencia de tres gobernadores que se desprenden, del liderazgo del propio Murillo (1993-1999), Manuel Ángel Núñez Soto (1999-2005), Miguel Osorio Chong (2005-2011) estos dos últimos fueron miembros del gabinete del gobierno de Murillo, MANS, militante priista, representante del Banco de Comercio Exterior (BANCOMEXT) en Canadá y cercano al grupo de especialistas financieros, Miguel Ángel Gurría, actual de presidente de la ocDE, y de Jaime Serra 
Puche, negociador del TLC y miembro del gabinete del presidente Salinas, y cercano a Herminio Blanco, sucesor de Serra en el puesto de secretario de comercio y fomento industrial del gobierno de Zedillo. Todos ellos formaron parte del equipo negociador del TLC con Estados Unidos y Canadá. Manuel Ángel Núñez Soto es secretario de desarrollo económico del gobierno de Murillo, es elegido diputado federal por el distrito de Pachuca y finalmente designado candidato del PRI a la gubernatura.

Por su parte, durante el gobierno de Murillo, Miguel Ángel Osorio es secretario de acción electoral del PRI y en ese mismo periodo alcanza la presidencia estatal de su partido, posteriormente fue uno de los coordinadores de la campaña política de Manuel Ángel Núñez Soto y cuando este asume el gobierno estatal lo nombra subsecretario de gobierno y después titular de esta secretaría.

Con estos dos movimientos, la red Murillo se establece como una red capaz de alcanzar el poder gubernamental y de vencer las candidaturas, tanto de la red Huichapan como de la UAEH y la de Guadarrama (esta última desprendida de la red Murillo), pues fue el secretario de gobierno y antes había sido ya senador por el PRI y secretario de acción política y encargado de la elección de Labastida en el año 2000.

La red UAEH inicia cuando Murillo deja el gobierno y el líder de la universidad y expresidente de la federación de estudiantes se postula como posible candidato del PRI a la gubernatura. Sin embargo, su objetivo no es alcanzado y no cuenta con los recursos suficientes para poder convencer que él sea el candidato por el PRI. De igual manera sucedió con la red Huichapan que contaba con su propio candidato José Antonio Rojo.

\section{¿LA RED EXISTE, ESTÁ ACTIVA DE FORMA PERMANENTE O ES TEMPORAL/EFÍMERA?}

Es evidente la existencia de la red de poder político en Hidalgo que, a su vez, se compone por un conjunto de redes. Actualmente es una red que en, términos de operación, funciona a un bajo porcentaje de efec- 
tividad, es decir, la actividad de las redes políticas en Hidalgo llega a su máxima capacidad operativa y de funcionamiento, esto es de transmisión e intercambio de recursos, en los momentos electorales, precampañas y campañas políticas. Es pues durante los tiempos electorales cuando la red se muestra más activa y el flujo o intercambio de recursos llega a su máxima funcionalidad. Es una red que por su naturaleza podríamos decir que es dependiente de los tiempos electorales, tanto federales como locales. Por lo tanto, al observar los distintos resultados electorales se puede ver qué red opera con mayor intensidad y efectividad, esto con el número de presidencias municipales ganadas.

\section{¿CUÁL ES EL NIVEL DE FORMALIZACIÓN O DE JURIDIZACIÓN DE LA RED?}

La red no se encuentra normativizada en términos estricto, aunque su funcionamiento depende de un marco de competencia electoral. La activación de los recursos se juega en relación al ritmo electoral, por lo tanto podría ser formalizada con base en la legislación electoral de Hidalgo.

¿Cómo es percibida la red a partir de las fuentes de su financiamiento y a partir de sus objetivos y/o metas? Con respecto de las fuentes de financiamiento de las redes podemos decir que las redes se financian vía las propias instituciones y actores adheridos a ellas. En el caso del gobierno-PRI como red central sus recursos provienen del CEN COMITÉ que establezca la legislación electoral.

Pero también existen medios de financiamientos privados, es decir empresas privadas que acompañan a las distintas redes. Es difícil mencionar con precisión a las empresas participantes en el financiamiento pero lo que sí es cierto es que, por ejemplo, el cCE de Hidalgo ha jugado un rol importante en la red Murillo así como el club de fútbol Pachuca, que sin duda intensificó la actividad económica de la capital del estado. Para diagnosticar la preferencia ciudadana tanto del candidato del PRI 
como del posible gobernador en 2005, las empresas encuestadoras fueron contratadas por el CCE, ello es muestra de la cercanía del presidente del CCE con el actual gobernador Osorio. ${ }^{17}$

\section{¿LA RED SE DIFERENCIA DE LAS REDES CLIENTELARES EN SU FORMA DE OPERAR?}

El sistema de intercambio de recursos entre las redes no se diferencia mucho de un sistema clientelar, entendiendo a este como el intercambio claramente clientelar entre los consensos electorales de los individuos y los recursos que cada red posee y pone a disposición de sus miembros.

¿Cómo un individuo entra a la red? ¿Las condiciones del contexto parecen ofrecer una explicación suficiente? Las condiciones del contexto no parecen ser suficientes para explicar cómo un individuo tiene acceso a la red. En términos proporcionales, el incentivo para poder ser miembro activo a la red proviene de la posibilidad de ocupar un puesto importante dentro de ella. En el caso de la red Murillo, una minoría tiene acceso a los puestos del gobierno estatal. En los tres últimos sexenios ha habido en realidad poca rotación en los puestos medios y bajos; lo que sí es cambiante es la ocupación de los puestos altos: direcciones generales, subsecretarios y secretarios del gobierno estatal, son ellos quienes entran a la red en un contexto de participación política electoral y como miembros con responsabilidades directas. Por ejemplo: el actual secretario de gobierno del gobierno estatal, fue el coordinador de campaña del gobernador Osorio, el encargado de comunicación e imagen de la campaña fue coordinador de asesores y actualmente funge como contralor del gobierno estatal. No resulta sencillo evidenciar el acceso a las redes al menos para el grueso de los miembros de las redes.

¿La participación en la red es capaz de generar un sentimiento de pertenencia a una comunidad o grupo? La participación en la red es

17 Ver: Milenio Hidalgo, febrero 17 de 2005. 
capaz de generar un sentimiento de pertenencia a una comunidad o un grupo en busca del poder político local, esto le permite identificarse a un grupo y crear subredes de apoyo y consolidar su permanencia dentro de la red. Ese sentimiento de pertenencia a la red es una protección simbólica que genera una red de amistad y de trabajo dentro de las propias organizaciones, tales como el PRI, administración pública estatal, universidad y los propios partidos políticos.

Hemos observado que la participación en la red central induce a la participación de otras redes y genera posibilidades de crear otras redes, es decir favorece la ceración y vinculación de otras redes. Sin duda, es uno de los modos de socialización.

\section{CONCLUSIONES}

La perspectiva de redes sociales nos permite explicar la dinámica del poder político local a través de los tipos de relaciones que se generan entre grupos líderes y las propias redes. Asimismo, muestra el tipo de socialización en el estado de Hidalgo y refleja parte de la cultura política local y de los códigos de entendimiento entre los principales actores. Realizar un estudio como este nos ayuda a entender cómo se da la competencia política en un contexto de cambio y transformación política local.

En Hidalgo es evidente una tendencia a la multiplicación de las redes. Se puede decir que a mayor nivel de democratización, mayor interacción entre las redes sociales en búsqueda del poder político. Las redes resultan generadoras de espacios de competencia política y de mayor número de recursos que se orientan al intercambio. El análisis de la red de acceso al poder político en Hidalgo, a través de la interpretación de las redes sociales, facilita el entendimiento de los arreglos políticos, la construcción de coaliciones y la forma en que los grupos y los liderazgos interactúan entre ellos y el electorado.

La red de poder político en Hidalgo intercambia, por un lado, capital político y apoyo electoral y movilidad social en términos del voto y/o 
aceptación, es decir un sistema clientelar de apoyo, al partido político, y a las redes que buscan el acceso al poder. Con el desarrollo de las cuatro últimas redes (Murillo, Universidad, Guadarrama y PAN) se puede ver reflejado otro nivel de competencia político-electoral, un cambio en el nivel de desarrollo político del estado, lo cual coincide con el escenario político nacional y por lo tanto no resultan ajenas a él.

\section{BIBLIOGRAFÍA}

Adler Lomnitz, Larissa, \& Gorbach, Frida. (1998). Entre la continuidad y el cambio: el ritual de la sucesión presidencial. Revista Mexicana de Sociología, 60(3), 61-83.

Blondel, J., \& Cansino, C. (eds.). (1998). Political leadership in changing societies. СЕРСОМ, México.

Cansino, C. (2000). La transición mexicana, 1977-2000. Серсом, México.

GARCía LóPEz, Fabián. (2006). Los recursos para acceder a la candidatura del PRI al gobierno del estado de Hidalgo. Tesis de licenciatura UAEH. UAEH, México.

Gil Mendieta, Jorge et al. (1997). A Dynamic Analysis of the Mexican Network of Power. Sunbelt 17, San Diego, CA.

GIL, J.,\& Schmidt, S. (1999). La red política en México: modelación y análisis por medio de la teoría de grafos. unam-IImass, México.

Granado Chapa, M. (1999). Constancia hidalguense. Grijalbo, 1999, México.

Herrera Cabañas, Arturo. (1987). Política y gobierno en Hidalgo. Fundación Arturo Herra Cabañas, México.

Linz, J., \& y Stepan, A. (eds.). (1978). Crisis, breakdown and reequilibratio. John Hopkins, Baltimore.

Sснмidt, S., \& Gil, J. (1991a). La red de poder mexicana: el caso de Miguel Alemán. Revista Mexicana de Sociología, 3, 103-117. . (1991b). La carrera por la presidencia de México. Review of Latin American Studies, 3(2), 197-233.

. (1994). La red de poder en México. Revista Este País, 44. 


\title{
ELITES POLÍTICAS, REDES DE PODER Y CAMPO POLÍTICO ANTE LOS RETOS DE LA DEMOCRACIA EN MÉXICO: EL CASO VERACRUZANO (1981-2012)
}

\author{
MaLiK TAHAR-CHAOUCH ${ }^{*}$
}

\section{INTRODUCCIÓN}

El RÉGimen postrevolucionario mexicano se fundamentó en el hiperpresidencialismo, el corporativismo y la dictadura del partido hegemónico. Ese régimen mantuvo la legalidad constitucional y no renunció nunca a la simulación electoral: el Partido Revolucionario Institucional (PRI) tenía la victoria asegurada de antemano. Por lo tanto, la transición mexicana a la democracia implicó la pluralización del sistema de partidos, mayores garantías en los procesos electorales y acuerdos entre partidos para alcanzarlas. Por esta razón, Mauricio Merino la define como "una transición votada" donde el voto diferenciado de los ciudadanos abrió brechas en el régimen sin desembocar en una redefinición profunda de sus instituciones (Merino, 2003).

Por un lado, se trató principalmente de una transición impulsada por los pactos entre elites políticas y desde el interior del régimen, lo que limitó sus alcances. Por lo mismo, la realidad del cambio democrático depende en gran parte de la calidad de la representación política y de la renovación de las mismas elites para generar una oferta política diferenciada. Obviamente, la participación limitada de la ciudadanía en el proceso de transición favoreció dinámicas viciadas a nivel de esas elites. La sentencia según la cual "todos son uno” pone en evidencia su uniformi-

* Instituto de Investigaciones Histórico-Sociales de la Universidad Veracruzana. 
zación y los espejismos de la pluralización partidista. Se observan, al mismo tiempo, las tendencias "partidocráticas” de la democracia mexicana, en la cual los partidos desarticulados de las demandas ciudadanas tienen el monopolio de la acción política legítima, y la debilidad de las estructuras partidistas rebasadas por las redes políticas y sus intereses oligárquicos que tienden a la homogenización.

El carácter autorreferencial del campo político, sus derivas oligárquicas y la percepción ciudadana de que ya no existe una oferta política diferenciada ante la fatalidad de la realidad económica es un problema de todas las democracias modernas. En el caso mexicano, esos aspectos están acentuados por las herencias autoritarias del régimen. En el plano estricto de las dinámicas de las elites políticas esas herencias se observan en la reproducción del personal político, de las redes de poder y de las prácticas y lógicas sistémicas, a pesar del cambio político a nivel federal y de las alternancias en muchos Estados de la República.

El contexto veracruzano es muy distinto debido al hecho de que este estado no experimentó nunca un cambio político. El PRI perdió elecciones locales y federales, lo que da cuenta del impacto de la pluralización partidista en el Estado, pero se mantuvo sin ninguna discontinuidad en el gobierno estatal. A nivel federal, la pregunta versa sobre las continuidades en medio del cambio; a nivel veracruzano, la pregunta consiste más bien en explicar por qué no se dio tal cambio, si bien no todo fue continuidad.

Hasta cierto punto el contexto veracruzano permite tomar el problema nacional a contrapié, esclareciéndolo desde otro punto de vista. En vez de abordar la transición mexicana como un proceso homogéneo, se busca explicar sus límites desde las asimetrías de los contextos regionales y locales aprendidos en su singularidad no como "casos aparte" sino como partes constitutivas del proceso nacional con el cual interactúan. De hecho, nada está fijo: el PRI ya regresó a la presidencia de la República; en el futuro el estado de Veracruz puede ser ganado por la oposición. En este sentido, hay que preguntarse si el caso veracruzano 
es un contraejemplo del proceso nacional o el espejo invertido de sus propios límites. Para ello hay que analizar detenidamente los factores de reproducción de la hegemonía del PRI a nivel estatal. Al respecto, existen explicaciones macrosociales como la pobreza y la cultura clientelista, pero tal cultura rebasa los sectores populares y todos los partidos recurren a tácticas clientelistas. Además, esos factores existen también a nivel nacional. Esas explicaciones pueden proporcionar respuestas, ya que el PRI sale de todas formas beneficiado por esos factores y porque estos implican ciertamente configuraciones específicas en Veracruz. Aun así, son siempre muy discutibles y, en todo caso, insuficientes. Hace falta un análisis de las propias dinámicas de las elites políticas y de cómo pueden favorecer la hegemonía del PRI en el contexto estatal, siendo incluso determinantes en los procesos electorales.

Esto implica tres niveles de análisis: el de los modos de reclutamiento, de la composición, de las trayectorias y de la tipología del personal político; el de las redes de poder y de cómo se reconfiguran más allá de las características individuales de los agentes políticos; y el del campo político, de sus génesis y de su estructura, de sus lógicas y de sus pugnas internas y de cómo involucran y determinan las dinámicas de las redes de poder. ${ }^{1}$ Es así como se puede dar cuenta de las continuidades y discontinuidades al interior de las elites políticas estatales, así como de los factores internos de reproducción de la hegemonía del PRI. Lo anterior abre la puerta a un análisis comparado a nivel nacional para ubicar los factores de continuidad dentro del cambio, desde los escenarios donde ocurrió el cambio político, a pesar de las continuidades, y los escenarios donde predominó la continuidad, a pesar de los elementos de cambio.

Este artículo presenta algunos avances en este sentido para el estado de Veracruz, sin perder de vista el contexto nacional y sus inte-

1 Sobre la noción de campo político se pueden consultar los trabajos de Bourdieu (2000) y Offerlé (2005) en Francia. 
racciones con el contexto regional, en los tres planos analíticos definidos: personal político, redes de poder y campo político.

\section{EL PERSONAL POLÍTICO}

El más completo estudio de las elites políticas mexicanas en el periodo postrevolucionario, Reclutamiento político en México, 1884-1991 de Roderic Camp (1996), pone énfasis en las camarillas como dispositivo de reclutamiento, cooptación y socialización del personal político, así como elemento central de la reproducción de la hegemonía del PRI durante ese periodo y del propio sistema político. La camarilla designa a "un grupo personal que se fundamenta en gran medida en las lealtades políticas entre seguidores y líderes” (Camp, 1992, 32); “es un grupo de individuos que tienen intereses políticos comunes y confían el uno en el otro para mejorar sus posibilidades dentro de la dirigencia política" $(2000,159)$.

Roderic Camp enuncia varias de sus características: están conformadas por parentescos familiares y redes de amistades construidas en diversos espacios, entre los cuales el ámbito educacional se destaca; si bien la ideología y el mérito profesional pueden tener un papel en ellas, lo que predomina son la lealtad al líder y los lazos y cualidades personales por encima de consideraciones ideológicas y de competencias. No obstante, las camarillas no son excluyentes las unas de las otras y tienden más bien a superponerse y jerarquizarse, por lo que un mismo político puede tener lealtades divididas y no suele permanecer toda su carrera política a una misma camarilla, ya que las traiciones son frecuentes, cuando el líder de una camarilla pierde posiciones o porque el seguidor ya ve cerradas su posibilidades de promoción en ella (Camp, 2000, 160).

Este fenómeno de amistades, lealtades y compromisos ha sido también muy bien descrito para el estado de México (Hernández Rodríguez, 1998). Aunque pueda parecer asemejarse a otras formas de “amistad" y "padrinaje” político en otros contextos, tiene una originali- 
dad irreductible, quizás no exclusivamente mexicana, pero distinta de esas formas y supremamente determinante en la vida política mexicana.

Durante el periodo postrevolucionario, los principales espacios de reclutamiento político eran las universidades, en particular las facultades de Derecho, y la administración federal en torno a la figura del presidente. Una de las características más originales de las elites políticas mexicanas fue también su relativa disyunción con las elites económicas (Smith, 1979; Adler-Lomnitz y Pérez Lizaur, 1993). Con la pluralización partidaria y el cambio político, los partidos y las administraciones estatales recobraron más importancia. Al mismo tiempo, la mutación del modelo gubernamental corporativista hacia políticas neoliberales y la tecnocratización de las elites políticas las acercaron a las elites económicas. ${ }^{2}$

Aun así, el modelo de las camarillas no ha dejado de predominar en el sistema político mexicano, al interior de todos los partidos y de forma transversal a ellos. ${ }^{3}$ Ese modelo radicaliza la uniformización oligárquica de las elites políticas en las democracias modernas, en detrimento de sus funciones de representación política y limitando el impacto de la pluralización partidista y de la competitividad electoral. Mientras la oligarquización implica una cierta homogeneización de los programas políticos y poca movilidad social dentro de las elites en las democracias modernas, en México incluso más que la limitada movilidad social importa la camarilla como "familia política".

A principios de los años ochenta esas mutaciones coincidieron a nivel federal y en el estado de Veracruz. El gobierno del primer gobernador tecnócrata de Veracruz, Agustín Acosta Lagunes (1981-1986), el cual no tenía ningún arraigo en la entidad y fue promocionado por las redes políticas federales que preparaban la próxima elección presiden-

2 Sobre la tecnocratización de las elites mexicanas se puede consultar: Suárez Farias, 1991 y Lindau, 1992.

3 Martínez González (2005) analiza el fenómeno en el PRD y muestra cómo los grupos en pugna dentro del partido se constituyen menos por ideología que por intereses y pragmatismos. 
cial, y el gobierno nacional de Miguel de la Madrid (1982-1988) tenían una orientación similar basada en el proyecto de "modernización económica” del país. Si bien esa tecnocratización fue lenta, incompleta y diferencial en el caso veracruzano (Portillo Villanueva, 2000, 70), impactó en la conformación del personal dirigente del estado, donde se reclutaron tecnócratas y empresarios.

La modernización involucró también a los cacicazgos que la impulsaron en el ámbito de la agricultura y de la ganadería, asumiendo un papel sociopolítico de mediación entre el gobierno y grupos de sus zonas sociales (Portillo Villanueva, 57). Por lo tanto, empezó a aparecer una brecha entre cacicazgos "tradicionales" y "modernos". Uno de los principales caciques "modernos” fue entonces Cirilo Vásquez en el sur del estado, quien fue acusado de participar en el tráfico de drogas y en 1986 logró tener el control político de casi veinte municipios de la región (Aguilar Sánchez, 2009, 81).

Ese periodo incrementó la corrupción, la violencia y la impunidad. La tentativa de mutación sociopolítica fue considerada como un fracaso. Esta tentativa fue sentenciada con la famosa expresión según la cual Acosta Laguna daba "un trato político a los problemas económicos y, económico, a los políticos”, dejando de lado las actividades partidarias y la formación de cuadros (Portillo Villanueva, 57).

La llegada de Fernando Gutiérrez Barrios a la gubernatura en 1986 permitió a perfiles más tradicionales de la política local regresar al gobierno, en particular licenciados en Derecho formados en la Universidad Veracruzana (Uv) y en la Universidad Nacional Autónoma de México (UNAM). El nuevo gobernador buscó, al mismo tiempo, reforzar el control político perdido y restablecer el orden público, reclutando personal político con perfil policiaco y militar. Su gobierno se opuso a los nuevos caciques, arrestando a Cirilo Vásquez y apartándolo de la vida político local. Aún así, su gobierno se ubicó en la continuidad de la política de "modernización económica". Durante su gobierno, los empresarios veracruzanos ganaron espacios entre las elites políticas, 
entre otros la familia Chedraui. De hecho, la llegada de Gutiérrez Barrios a la gubernatura fue impulsada por el futuro presidente Salinas de Gortari, principal artesano de las políticas neoliberales en el país, del cual se volvió secretario de gobernación en 1988.

Con el nombramiento de Dante Delgado Ranaurro como gobernador sustituto en este mismo año, el fenómeno de regreso a las viejas lógicas de reclutamiento político se acentuó. Él se rodeó de gente de su confianza: amigos de la infancia y de la universidad y hasta su exchofer. Su política consistió a utilizar los programas sociales y tácticas corporativistas de concertación con los líderes sindicales y cooptación de los movimientos sociales para incrementar el control político del PRI, lo cual representó uno de los momentos de mayor corrupción del estado (Portillo Villanueva, 112-123).

En este sentido, los años ochenta fueron un importante momento de génesis de las dinámicas actuales de las elites políticas veracruzanas. Es cuando se impuso una tensión entre "políticos profesionales" y "tecnócratas". Sin embargo, esa tensión no debe esconder un hecho central: la "modernización" y las lógicas heredadas del sistema político se combinaron. El gobierno federal de Salinas de Gortari, quien no dejó de entrometerse en los asuntos internos del gobierno de Veracruz hasta "castigar" jurídicamente a Dante Delgado por su deslealtad al PRI, fue el apogeo de esa combinación.

Durante los años noventa, cuando la pluralización política iniciada en la década anterior a la par de la "modernización económica" empezó a dar frutos tangibles en las elecciones, esta se combinó a su vez con la preeminencia de las camarillas en los modos de reclutamiento del personal político. A pesar de las discontinuidades y divisiones dentro de las elites políticas, las camarillas y sus migraciones de un partido a otro favorecieron la reproducción a través de recomposiciones que rebasaron la competencia electoral entre partidos.

Es así como en la elección para la gubernatura del 2010, los tres candidatos provenían de una matriz común. Ante el candidato del PRI 
que ganó la elección, Javier Duarte Ochoa, el candidato de la izquierda fue Dante Delgado, es decir, un agente tradicional del sistema político veracruzano que había migrado hacia la izquierda con sus seguidores, creando el partido Convergencia (1998); y el del Partido de Acción Nacional (PAN) fue Miguel-Ángel Yunes Linares, quien había sido el muy represor secretario de gobierno del gobernador Patricio Chirinos Calero (1992-1998), también para el PRI, y se pasó al PAN durante el sexenio del presidente Felipe Calderón (2006-2012).

Los dos habían sido agentes de la camarilla nacional de Salinas de Gortari y el segundo pertenece a una familia política importante del estado de Veracruz, los Yunes, muy ligados al PRI. Viendo sus aspiraciones nacionales y para la gubernatura de Veracruz bloqueadas dentro del PRI, ambos optaron por la migración política hacia otros partidos (el primero creando la suya), donde pudieron impulsar sus candidaturas a la gubernatura de Veracruz y reubicarse en la escena nacional. Pues Dante Delgado fue senador y diputado federal, así como un aliado importante de Andrés Manuel López Obrador para las elecciones presidenciales de 2006 y 2012, lo que garantizó el apoyo del Partido de la Revolución Democrática (PRD) para su candidatura a la gubernatura en el 2004 y 2010. Por su parte, Miguel-Ángel Yunes alcanzó a ser el director nacional del Instituto de Seguridad y Servicios Sociales de los Trabajadores del Estado (ISSSTE) entre 2006 y 2010, antes de ser entronizado también por el PAN en la elección a gobernador del 2010.

A través de las trayectorias de Miguel-Ángel Yunes y Javier Duarte, las alianzas entre "políticos” y “tecnócratas" se muestran también claramente. El primero, producto de las facultades de derecho de la uv y de la UNAM, fue secretario del gobierno de un economista con enfoque tecnócrata, si bien este gobierno favoreció también el amiguismo. El segundo, licenciado en derecho pero sobre todo formado en economía y gestión pública, fue el secretario de finanzas y planeación del gobierno del muy político Fidel Herrera Beltrán (2004-2010), representativo del caudillismo priista más tradicional. Con Javier Duarte se impuso un 
gobierno de corte autoritario duro, con muy poca capacidad de mediación y una tendencia tecnócrata en medio de una grave crisis de seguridad pública del Estado.

En este mismo sentido, el más empresarial de todos los gobiernos del Estado, el de Miguel Alemán Velasco (1998-2004), contó con una fuerte colaboración de licenciados en derecho, representativos de los perfiles tradicionales de la política local. Ese gobernador provenía por parentesco directo de una de las familias y camarillas más importantes de la política mexicana del siglo xx, la de su padre y expresidente Miguel Alemán Vásquez (1946-1952), precisamente originada de Veracruz. Al mismo tiempo, pertenecía al mundo empresarial, y estuvo ligado con la más poderosa empresa mediática del país, Televisa, que acaba de apoyar incondicionalmente la elección del presidente actual, Enrique Peña Nieto, y el regreso del PRI a los Pinos en el 2012.

Las trayectorias de los actores políticos centrales de la vida política veracruzana indican una gran continuidad del personal político y de sus camarillas por encima de la pluralización partidista. Esto no significa que no haya cierta renovación en el reclutamiento, pero esta queda subordinada a la reproducción, a diferencia de otros estados donde, a pesar de las continuidades, las discontinuidades fueron más pronunciadas dentro del reclutamiento de las elites políticas antes de verse reflejadas en el voto de los ciudadanos y los cambios políticos.

Esa distinción concierne tanto a los actores individuales como a su tipología. A nivel nacional, hubo ciertas aperturas para los cuadros de movimientos sociales y al sector ciudadano, en particular en la izquierda e incluso en la derecha, si bien estas quedaron limitadas. En Veracruz, aún cuando los actores sociales pueden involucrarse en actividades partidarias, no suelen alcanzar las altas esferas políticas, tanto partidarias como legislativas y ejecutivas. Por otro lado, los espacios políticos conquistados por los empresarios regionales y la tecnocratización de las elites no desembocaron en grandes cambios dentro de la estructura tradicional de control político, ya que siguieron subordinados a sus agen- 
tes e incluso alzándose en las más altas esferas políticas quedaron dependientes de ellos.

\section{LAS REDES DE PODER}

La composición del personal político y sus modos de reclutamiento se insertan en dinámicas de redes y lógicas de campo político que constituyen una explicación más fundamental de su reproducción, pues las transferencias de agentes políticos de un partido a otro involucran camarillas e impactan en las recomposiciones partidarias y de las propias camarillas, modificando alianzas. En otras palabras, ese fenómeno es la parte más visible de las reconfiguraciones de las redes de poder político.

En este sentido, incluso cuando existe cierta renovación del personal político, esta no figura necesariamente profundas discontinuidades en las redes políticas. Es así como la incorporación de líderes sociales y elementos ciudadanos a las elites políticas, lejos de romper el predominio de las camarillas, suele insertarse en ellas. De la misma forma, la renovación del personal político, a través de la pluralización partidista, suele acompañarse de alianzas y reconfiguraciones anteriores o posteriores a los momentos de cambio político que lo moderan. Aún así, en muchos estados de la República y a nivel federal se puede ver una renovación bastante significativa de las redes de poder político, en particular a través de empresarios independientes, políticos vinculados con ellos y cuadros de movimientos sociales que introducen nuevas dinámicas en ellas.

En el caso de Veracruz los actores políticos emergentes son escasos. Existe poca renovación del personal político y del tipo de personal político. Sin embargo, a principios de los años ochenta se abrieron espacios a tecnócratas y empresarios, pero muy poco a actores sociales y ciudadanos. Esos elementos emergentes no suponen necesariamente una renovación en las redes de poder político. En el estado, más escasamente aún se logra entrar en política sin afilarse a una camarilla política 
"histórica". Los líderes sociales que ingresan en las elites políticas lo logran únicamente en condición de subordinados; de hecho, principalmente como agentes del viejo control corporativo. De lado empresarial, la tendencia es la misma. Familias empresariales importantes del Estado (Chedraui, Fernández, Alemán) se vincularon con camarillas políticas del PRI para poder ganar espacios políticos.

Esa dependencia del sector empresarial al sector político y gubernamental fue un dato histórico importante de la vida política postrevolucionaria en México. No obstante, en el norte del país se desarrolló una clase empresarial autónoma en pugna con el PRI. Esta clase empresarial se involucró en la política y tuvo un papel importante en el proceso que desembocó en el cambio político. Ese proceso inició con victorias en elecciones locales y estatales para culminar con la victoria del pan en la elección presidencial del 2000. En este sentido, hay que recordar que el primer Estado que pasó del lado de la oposición fue el estado norteño de Baja California con la victoria del panista Ernesto Ruffo Appel en las elecciones a gobernador de 1989.

En Veracruz incluso los actores emergentes independientes de las camarillas políticas "históricas", es decir, no reclutados por ellas, acaban siendo cooptados. El caso más sonado es el de Gerardo Buganza Salmerón. Ingeniero industrial por la Universidad Iberoamericana, donde cursó también la carrera de Administración de Empresas, Buganza no rompía con los dos perfiles predominantes dentro del campo político veracruzano: "políticos profesionales" y "tecnócratas". Tampoco estaba vinculado con ningún movimiento social, ni provenía estrictamente hablando del sector ciudadano. Aun así, se distinguía de otros empresarios por no estar vinculado con el PRI. Originario de Córdoba en la región del centro del estado, ejerció su profesión en empresas privadas y llegó a ser director general del Grupo Industrial cordobés ALZA, especializado en la producción de café y bebidas alimenticias.

En 1994, Buganza se afilió al PAN, donde empezó su carrera política, siguiendo así el ejemplo de empresarios vinculados con el PAN en 
otras partes del país. Diputado federal (1997) y senador (2000) de Veracruz, fue candidato del partido para la elección a gobernador del 2004. Su ascensión política rápida se ubicó en un contexto nacional de cambio político, donde se beneficiaba de su capital social de empresario, de la dinámica del partido ascendente entonces en busca de nuevos agentes políticos y, a partir del 2000, del apoyo de la nueva administración federal.

En la elección del 2004 estuvo a punto de ganar, pero perdió ante Fidel Herrera Beltrán por una mínima diferencia, inferior a un punto porcentual: Herrera obtuvo 34,6\% de la votación y él 33,7\% (Dante Delgado tuvo 28,2\%). El PAN alcanzó el mismo número de diputados locales en el congreso estatal que la coalición que apoyó a Fidel Herrera y ganó más municipios que el PRI: 88 en contra de 71 para el PRI o 81, si se incluyen los municipios ganados por el Partido Revolucionario Veracruzano que pertenecía a la coalición de Fidel Herrera en la elección estatal. En ese momento, el estado estuvo muy cercano de pasar a la oposición, cuando precisamente se alzó un candidato independiente de las camarillas políticas provenientes del PRI.

En la siguiente elección a gobernador, durante el sexenio de Felipe Calderón, el PAN apoyó a la candidatura de Miguel-Ángel Yunes, en detrimento de Buganza. Como consecuencia, este último renunció a su militancia dentro del partido y se convirtió luego en secretario de gobierno del gobernador Javier Duarte. De opositor electoralmente peligroso para el PRI, Buganza pasó entonces a ser el primer personaje político del nuevo gobierno priista. Las migraciones de Miguel-Ángel Yunes del PRI al PAN y de Buganza del PAN al gobierno priista, así como la opción tomada por el presidente de la República y el PAN (no sin fuertes divisiones internas ante la opción presidencial) de apoyar al expriísta en detrimento de su candidato "histórico", son reveladoras del funcionamiento pragmático de la política mexicana. En ella, la ideología suele tener un papel secundario y las estructuras partidistas se encuentran fácilmente rebasadas por las camarillas políticas. 
Esta situación da también cuenta de las interacciones entre los niveles regional y nacional. Por un lado, existe un fuerte impacto de lo nacional en las dinámicas regionales, como ya lo manifestó la intromisión directa de Salinas de Gortari en el estado o en este caso la opción presidencial de Felipe Calderón en contra de las preferencias panistas locales. Sin embargo, desde el final de la hegemonía priista y con el debilitamiento de la antes omnipotente figura presidencial (las tensiones entre Calderón y sectores del PAN han sido una constante en su sexenio), lo regional ha tomado un papel cada vez más central dentro del sistema político mexicano.

Es así como la opción de Miguel Ángel Yunes para el PAN o la de Dante Delgado para el PRD se imponen como un cálculo político regional de los partidos nacionales en contra de sus respectivos vínculos empresariales y sociales, ni siquiera siempre para su beneficio electoral, pero para tener "operadores" arraigados con clientelas políticas en los Estados. Las elites nacionales se apoyan en agentes regionales con clientelas afianzadas para tener nexos duraderos en los Estados y estos agentes se benefician de ese apoyo para consolidar sus posiciones locales e incluso mejor sus posiciones en el campo político nacional. Incluso cuando tienen un capital electoral, social o ciudadano, los individuos que no cuentan con el capital político de las camarillas suelen adaptarse a esas condiciones. En la racionalidad del sistema político mexicano, el compromiso político pesa incluso más que la eficiencia electoral.

\section{EL CAMPO POLÍTICO}

Esta realidad de la cultura política de las elites mexicanas remite a las lógicas del campo político, las cuales determinan, en última instancia, las reproducciones anteriores y rebasan los elementos observados de renovación. Pues, a pesar de las luchas internas, hasta entonces esas lógicas han predominado. 
Iniciando el proceso de "modernización económica" y permitiendo la liberalización del régimen bajo presiones externas e internas, el PRI no pudo evitar que se abrieran brechas en el sistema político. La renovación fue primero interna al PRI, donde surgieron nuevos actores y tipos de actores políticos con perfiles empresariales y tecnocráticos. Ese surgimiento impuso nuevas relaciones de fuerza y equilibrios dentro del partido, así como un modelo de gestión política que combinó el viejo modo de hacer política, basado en el predominio de las camarillas, con el estilo tecnocrático. Sin fusionarlos, ni eliminar las pugnas, esos estilos tendieron a aliarse y a integrarse mutuamente. Si bien no tuvo un desarrollo autónomo, la clase empresarial tradicionalmente subordinada al PRI ganó espacios y peso político dentro del partido, no tanto los actores sociales.

La mutación del PRI coincidió con el desarrollo de la oposición, al margen de los actores sociales y económicos dependientes del él, pues el cambio de modelo gubernamental y la propia liberalización del régimen político les abrió espacios. Actores económicos y sociales emergentes o de larga oposición, tanto de derecha como de izquierda, ingresaron entonces al campo político en posición de competitividad. Por voluntad de cambio político u oportunismo, expriístas se juntaron a ellos. Estos últimos llegaron incluso a liderar las nuevas fuerzas políticas, sobre todo en la izquierda.

El PRI fue desbordado por el PAN, fundado en 1939 y producto de una larga oposición de corte católico, donde se consolidaron grupos de empresarios independientes, así como políticos de clase media inspirados por su proyecto de autonomía (Loaeza, 1999). Del lado izquierdo, el PRD nació en 1989, después del supuesto fraude electoral de 1988, como resultado de convergencias entre una corriente democrática dentro del PRI, varios pequeños partidos de izquierda y movimientos y organizaciones sociales (Combes, 2011). Esto implicó por supuesto discontinuidades en la conformación del personal político y en las configuraciones de sus redes. Esas discontinuidades se reflejaron en la pluralización partidistas y los cambios políticos a niveles local, estatal y federal. 
Sin embargo, el imperio de las camarillas se impuso dentro de todos los partidos. Esta dinámica pudo favorecer las transferencias de personal político y las reconfiguraciones transpartidarias de las redes de poder. La elección de los candidatos de los partidos reflejan en muchos escenarios estatales esas segundas migraciones priistas hacia otros partidos. Inclusive cuando no se dio tal fenómeno, la reproducción del "modo de hacer política” bastó para homogeneizar las elites políticas, en particular en el plano de las prácticas.

Esto puede explicarse por las interdependencias de las elites en el proceso de "modernización económica", el control político que implica y los compromisos que supone. Si bien la "modernización” debilitó el modelo corporativo clásico, sus efectos sociales poco democráticos acentuaron el imperativo de control político, por lo que el corporativismo, lejos de desaparecer, mutó para adaptarse a esa "modernización" y a la pluralización partidista, participando de las reconfiguraciones de las redes de poder.

En esta perspectiva, la relación entre elites políticas y actores sociales sigue siendo principalmente instrumental o de exclusión: en el PRI y en los otros partidos. Los cuadros de movimientos sociales que habían ingresado en la izquierda con cierto impacto en el campo político acabaron siendo agentes "normales" de ese campo. El mismo proceso acercó los intereses de las elites políticas y económicas, poniendo el neocorporativismo al servicio de ese acercamiento. Por lo tanto, si antes el predominio de las elites políticas sobre las elites económicas y los agentes corporativos era claro, ahora la relación es más equilibrada y, en algunas ocasiones, invertida. En todo caso, esas elites son fundamentalmente interdependientes.

En síntesis, el cambio político, más que modificar las lógicas del campo y terminar con la cultura política y prácticas heredadas del régimen postrevolucionario, las propagó. Desde esta óptica, el regreso del PRI al gobierno federal en torno a una fórmula marcada por los viejos amiguismos políticos y una concepción empresarial del país, no consti- 
tuye una ruptura (entendida como una restauración) dentro de la democratización mexicana, sino la continuidad e incluso la huida hacia adelante de la transición fallida. El PRI no dejó nunca de ser una fuerza política preeminente en el país, tanto en los estados como en el Congreso, y su regreso al poder federal es bastante lógico en las condiciones vigentes de la política mexicana.

A nivel nacional, la tecnocratización de las elites y el control político de las camarillas se impusieron juntas por encima de la pluralización partidaria y de los intereses ciudadanos. En Veracruz, la diferencia radica principalmente en la mayor conservación del control político tradicional, lo que explica las pocas discontinuidades en la conformación del personal político y de las redes de poder. Esto no significa por supuesto que no haya habido elementos de cambio. Vimos que, en el 2004, el estado estuvo muy cerca de pasar a la oposición.

Desde esta óptica, a menudo la atención es puesta sobre el hecho de que las camarillas provenientes del PRI se apropiaron los partidos de oposición, reduciendo el panorama electoral de los votantes, como lo refleja la fuerte abstención. Este hecho tiene una explicación más fundamental. En el estado, a pesar de la política de "modernización económica" iniciada a principios de los años ochenta, vimos que la relación de fuerza entre "políticos profesionales" y “tecnócratas" estuvo muy favorable a los primeros y los empresarios quedaron dependientes de la clase política tradicional.

Después de un momento contextual de auge electoral para el PAN, ninguna camarilla constituida de forma autónoma pudo disputar el control político del Estado al PRI. La falta de capital político propio de los empresarios, la dependencia de los actores sociales en un contexto mucho más radicalmente corporativo y la debilidad de los movimientos sociales y ciudadanos organizados convergieron a favor de la hegemonía priista. Por lo tanto, ni el contexto ni las lógicas microsociales del campo político, los cuales se determinan mutuamente, condicionaron una hegemonía que tampoco fue absoluta, ni están garantizados en un futuro próximo. 
De todas formas, las victorias de la oposición en otros Estados desembocaron en la reproducción de las lógicas del campo político e incluso en reconfiguraciones posteriores que relativizaron los alcances de la renovación de las elites políticas. Por lo que, en todos los casos, el monopolio de la participación política por los partidos no benefició a la calidad de la representación política. Con o sin renovación dentro del personal político y de sus redes de poder, el reino oligárquico se impuso. La radicalidad mayor de la realidad veracruzana en términos de restricciones de libertades públicas y cierres de espacios políticos no debe esconder esa similitud. Por lo que, para Veracruz, la pregunta pertinente probablemente no consista en preguntarse por qué el PRI sigue hegemónico, sino que refleja esa hegemonía de los cambios políticos nacionales e incluso de un eventual cambio político a nivel estatal.

\section{CONCLUSIÓN}

Finalmente, los desarrollos de este artículo apuntan a cuestionar los alcances reales de la democratización mexicana. A pesar de la liberalización política, del cambio político e incluso de las batallas sociales y ciudadanas, las lógicas heredadas del sistema político mexicano, reflejadas en las dinámicas de las elites, parecen haberse adaptado a una mutación económica con pocas virtudes democráticas. El liberalismo económico y las lógicas del sistema político conspiraron mutuamente para incrementar sus potencialidades antidemocráticas.

Esto hace de México un caso extremo, debido a su propio contexto, de los límites y paradojas de las democracias modernas. Cuando la democracia se encuentra subordinada al imperio del liberalismo económico y reducida al modelo partidario que excluye y subordina otras formas de participación política, la asimilación de la representación política a una oligarquía sirve casi para calificar el tipo de régimen que se tiene ante los ojos. 
En este sentido, la postransición mexicana no puede pensarse estrictamente como una transición inacabada, ni en términos de consolidación democrática, como lo impone el modelo de análisis demasiado normativo e incluso ideológico que predominó en los años ochenta y noventa a propósito de los cambios políticos en América Latina y en otras regiones del mundo. Las preocupaciones generadas por los procesos democráticos y los cuestionamientos fundamentales hechos a esos procesos rebasan hasta la vieja dicotomía entre democracia directa y democracia representativa. Tampoco se agotan en el papel inmaculado y supuestamente decisivo que se atribuye a la "sociedad civil" en esos procesos.

Un nuevo paradigma tendrá probablemente que abrir nuevas vías analíticas y políticas para plantear otras preguntas y desarrollar visiones distintas sobre realidades que los modelos científicos y normativos actuales no logran siempre explicar y ante las cuales se encuentran sin otras perspectivas que reiteran las antiguas e inoperantes recetas políticas.

\section{BIBLIOGRAFÍA}

Adler-Lomnitz \& Pérez Lizaur. (1993). Una familia de la elite mexicana. Parentesco, clase y cultura, 1820-1980. Alianza Editorial, México.

Aguilar Sánchez, M. (2009). Movimientos sociales y democracia en México (1982-1998). Una perspectiva regional. uv y Porrúa, México.

Bourdieu, P. (2000). Propos sur le champ politique. Lyon: PUL.

CAMP, R. (1992). Los líderes políticos de México, su educación y reclutamiento. Fondo de Cultura Económica, México. . (1996). Reclutamiento político en México, 1884-1991. Siglo XXI, México. (2000). La política en México. Siglo xxi, México.

Combes, H. (2011). Faire parti. Trajectoires de gauche au Mexique. Karthala, Paris. 
Hernández Rodríguez, R. (1998). Amistades, compromisos y lealtades: líderes y grupos políticos en el estado de México, 1942-1993. El Colegio de México, México.

Lindau, J. (1992). Los tecnócratas y la elite gobernante mexicana. Mortiz, México.

Loaeza, S. (1999). El pan: la larga marcha, 1939-1994. Oposición leal y partido de protesta. Fondo de Cultura Económica, México.

Martínez González, V.H. (2005). Fisiones y fusiones, divorcios y reconciliaciones: la dirigencia del PRD, 1989-2004. Plaza y Valdés. México.

Merino, M. (2003). La transición votada, crítica a la interpretación del cambio política en México. Fondo de Cultura Económica, México.

OfFerlé, M. (2005). Les partis politiques. Broché, Paris.

Portillo Villanueva, A. (2000). Las elites políticas en Veracruz, 1981-1996. Mecanismos de reclutamiento, circulación y gobernabilidad. UV-Sociología, Xalapa.

Smith, P. (1979). Labyrinths of power. Political Recruitment in Twentieth-Century Mexico. Princeton University Press, Princeton.

Suárez Farias, F. (1991). Elite, tecnocracia y movilidad política en México. Universidad Autónoma Metropolitana, México. 

MAPAS

EL CONTEXTO GEOGRÁFICO 



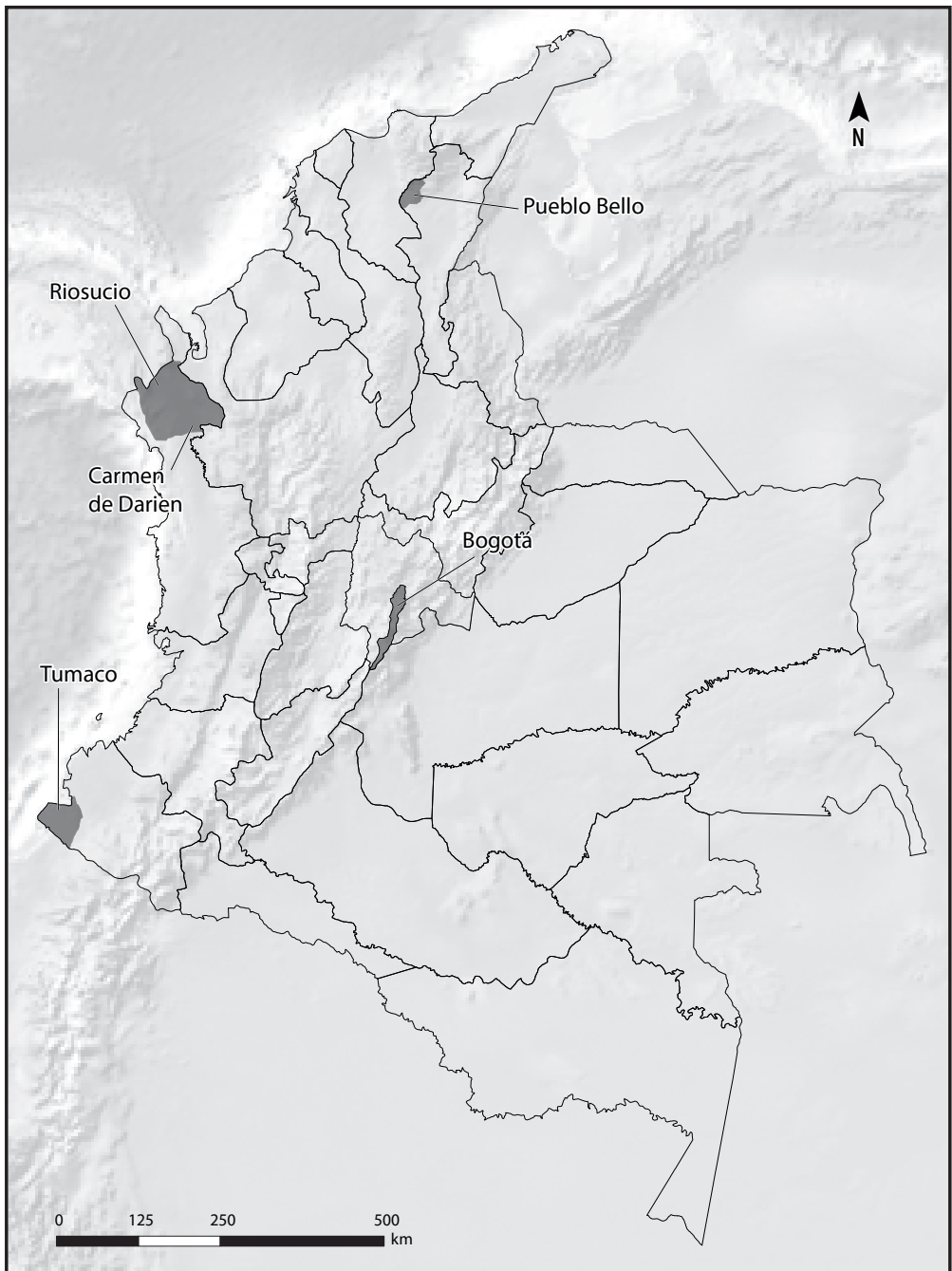




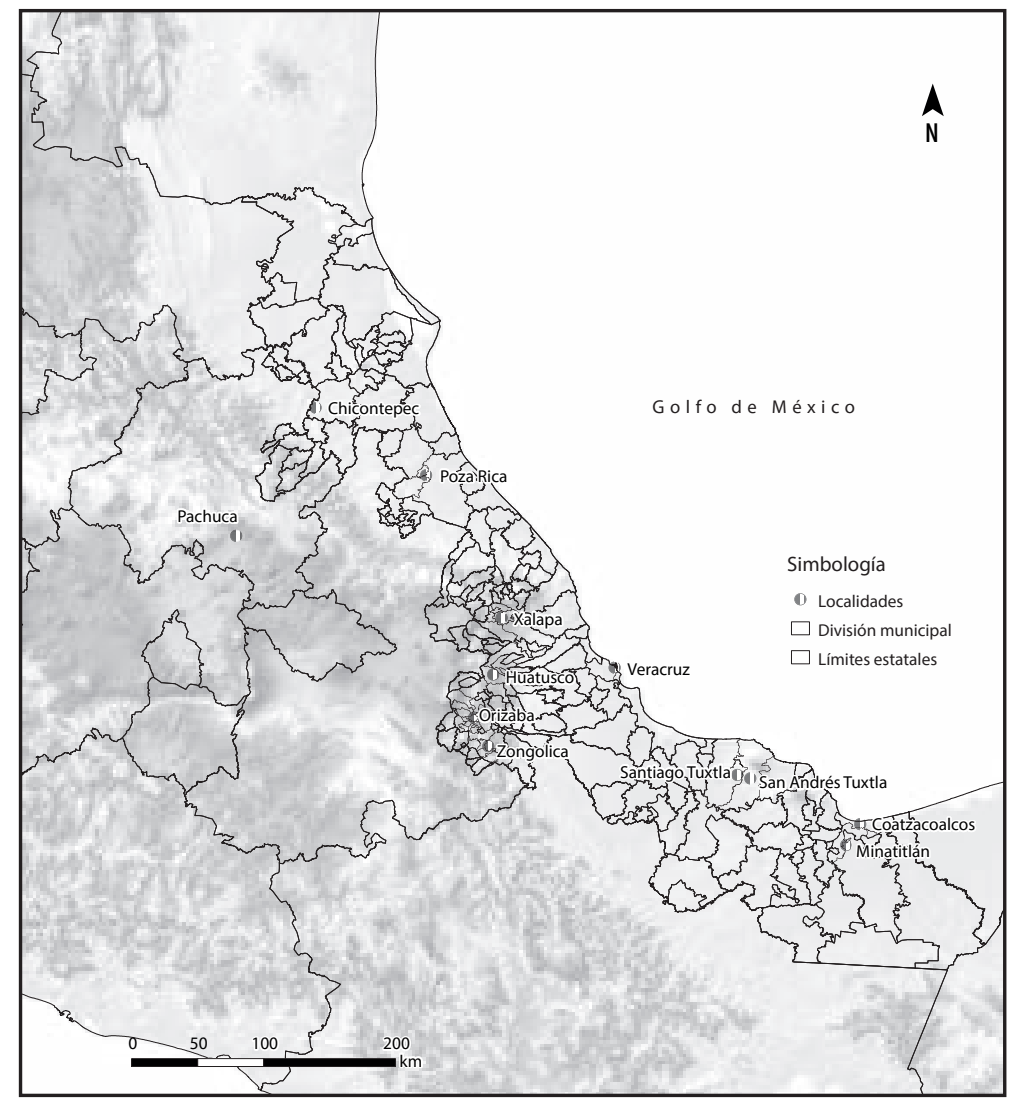




\title{
ÍNDICE
}

\author{
Introducción 7 \\ YANN BASSET y MaLik TAHAR-ChaOUCH
}

\section{PRIMERA PARTE. ACCIÓN COLECTIVA}

Entre mochilas, cestería y poporos: experiencias cruzadas entre las elites, la acción colectiva indígena y los procesos de democratización $\quad 23$

Mónica Acosta García, Norey Maku Quigua, Ángela Santamaría y Yeshica Serrano

Procesos de democratización en el bajo Atrato colombiano: una mirada desde los intersticios entre lo social y lo político 107 Karen Nathalia Cerón Steevens, Juan Carlos Guerrero Bernal, Pedro Rojas Oliveros, Luisa Trujillo Paredes

Acción colectiva en el Pacífico sur colombiano: experiencia del proceso de comunidades negras (PCN) 183

Armando Durán Durán

Transformaciones y tendencias de la acción colectiva en el estado de Veracruz 1997-2010 227

Martín Aguilar SánChez

Cambios, continuidades y reacomodos: conflicto político y alternancia en Santiago Tuxtla, Veracruz 251

EFRAÍN QUIÑóNEZ LEÓN 
Actores sociales y procesos de democratización en la región de

Huatusco, Veracruz 287

Manuel Hernández Pérez

\section{SEGUNDA PARTE. ELITES POLÍTICAS}

La participación electoral como forma de acción colectiva en el ámbito local en Colombia $\quad 311$

YANN BASSET

Valores y límites a la democracia en Veracruz 339

Leopoldo Alafita Méndez

Elites políticas en Hidalgo: una interpretación desde la perspectiva de redes sociales $\quad 387$

Daniel Carrasco Brihuega

Elites políticas, redes de poder y campo político ante los retos de la democracia en México: el caso veracruzano 411

Malik Tahar-Chaouch 

Siendo rectora de la Universidad Veracruzana

la doctora Sara Ladrón de Guevara,

Procesos democráticos en CONTEXTOS

DE VIOLENCIA: MÉxico y Colombia

de Yann Basset, Malik Tahar-Chaouch y Martín Aguilar Sánchez (coords.),

se terminó de imprimir en noviembre de 2014,

en los talleres de Master Copy S. A. de C. V.

Avenida Coyoacán núm. 1450,

col. Del Valle, del. Benito Juárez, CP 03220,

México, D. F., tel. (0155) 55242383.

La edición fue impresa en papel book cream de $60 \mathrm{~g}$.

En su composición se usaron tipos Minion Pro y Myriad Pro.

Cuidado de la edición: Martín Aguilar Sánchez.

Maquetación: Aída Pozos Villanueva y Guadalupe Marcelo Quiñones. 

